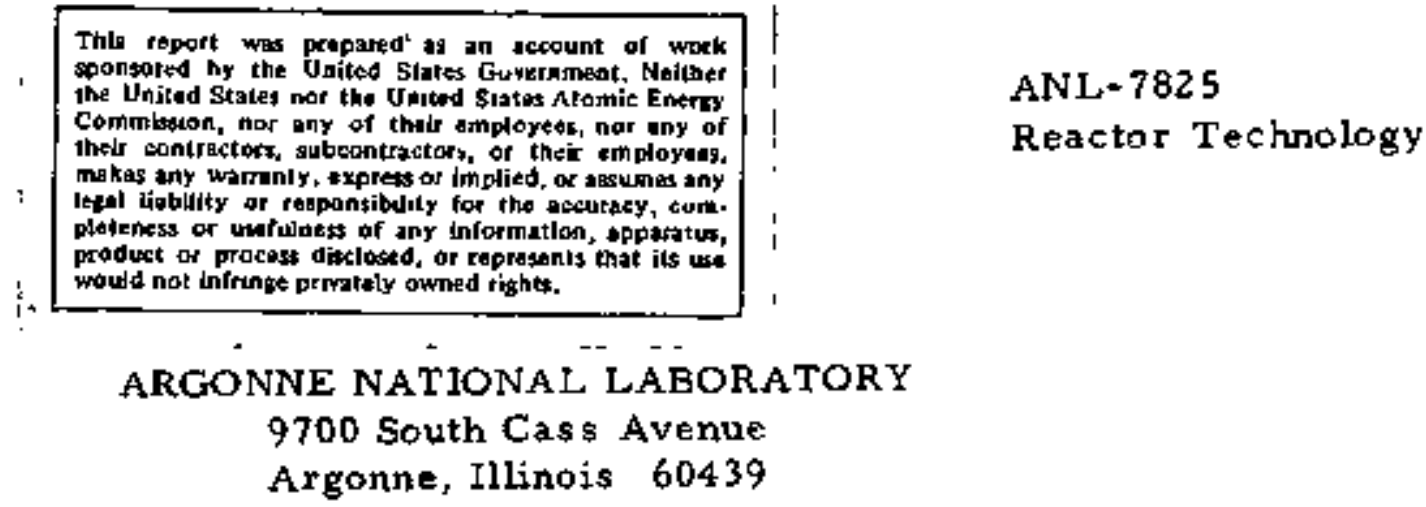

\title{
REACTOR DEVELOPMENT PROGRAM PROGRESS REPORT
}

April-May 1971

Robert B. Duffield, Laboratory Director Robert $V$. Laney, Associate Laboratory Director

\section{Program Area}

I EBR-II

II LMFBR Design Support

IiI Instrumentation and Control

IV Sodium Technology

V Fuels and Materials Development

VI Fuel Gycle

VII Reactor Physics

VIU Reactor Safety

IX Environmental Studies
Lead

Division

EBR-II M. Levenson

ETD

ETD

CEN

MSD

CEN

AP

RAS

CES
Division Director/

Program Manager

Report Coordinator: M. Weber

Issued: June 23, 1971 


\section{DISCLAIMER}

This report was prepared as an account of work sponsored by an agency of the United States Government. Neither the United States Government nor any agency Thereot, nor any of their employees, makes any warranty, express or implied, or assumes any legal liability or responsibility for the accuracy, completeness, or usefulness of any information, apparatus, product, or process disclosed, or represents that its use would not infringe privately owned rights. Reference herein to any specific commercial product, process, or service by trade name, trademark, manufacturer, or otherwise does not necessarily constitute or imply its endorsement, recommendation, or favoring by the United States Government or any agency thereof. The views and opinions of authors expressed herein do not necessarlly state or reflect those of the United States Government or any agency thereof. 


\section{DISCLAIMER}

Portions of this document may be illegible in electronic image products. Images are produced from the best available original document. 


\section{FOREWORD}

The Reactor Development Program Progress Report describes current activities, technical progress, and technical problems in the program at Argonne National Laboratory sponsored by the USAEC Division of Reactor Development and Technology. Not all projects are reported every month, but a running account of each project is maintained in the series of reports.

The last six reports in this series are:

$\begin{array}{ll}\text { October } 1970 & \text { ANL-7753 } \\ \text { November } 1970 & \text { ANL-7758 } \\ \text { December } 1970 & \text { ANL-7765 } \\ \text { January 1971 } & \text { ANL-7776 } \\ \text { February 1971 } & \text { ANL-7783 } \\ \text { March 1971 } & \text { ANL- 7798 }\end{array}$




\section{REACTOR DEVELOPMENT PROGRAM}

\section{Highlights of Project Activities for April-May 1971}

EBR - II

The reactor operated for $1467 \mathrm{MWd}$ in the two-month period ended May 15. The total accumulated operational total now is $43,788 \mathrm{MWd}$. Instrumented subassembly $X \times 0 Z$ was removed from the reactor, and instrumented subassembly XX03 was installed in the position (5F3) vacated by XX02. Subassembly XX02, which contains oxide fuel, had been in the reactor since April 1970. Subassembly XX03 is an experiment in which incore creep of Type 316 stainless steel will be measured directly by instrumentation.

Methods for determining silicon and boron in sodium have been developed and used for analyzing the EBR-II primary and secondary sodium. Initial analyses for silicon showed $0.9-1.6 \mathrm{ppm}$ in the primary sodium and 0.8-1.6 pprn in the secondary sodium. Initial analyses for boron showed less than $0.05 \mathrm{ppm}$ in both the primary and the secondary sodium.

The radioactive sodium chemistry loop (RSCL) has been installed on the primary system of EBR-II. The loop was designed and fabricated for prooftesting on-line devices for monitoring the quality of sodium coolant under operating conditjons typical of those of anticipated future liquidmetal-cooled fast breeders. The first experimental system, a module containing two oxygen meters, a hydrogen meter, and associated support equiprnent, is being installed in the loop.

A new type of capsule for measuring maximurn temperatures in a reactor is being test-irradiated in EBR-II. Measurement is bssed on increase of the internal volume of the sodium-filled stainless steel capsule.

The germanium-lithium argon-scanning system (GLASS) is now in preliminary on-line operation. Tests of the on-line digital subtract unit (ODSU) for the GLASS indicate that the circuit is not unduly affected by a spurious signal or by a strong interfering background. An alternative circuit that should eliminate the dead-time eifect inherent in the first circuit is being investigated.

\section{LMFBR DESIGN SUPPORT}

Heat Transfer and Fluid Flow

Detailed analytical studies of nonboiling transient heat transfer indicate that for transients considered reasonable for LMFBR accidents, the improverments in accuracy afforded by new engineering prediction methods are 
insufficient to warrant replacement of current quasi-steady-state prediction methods implicit in LMFBR Saiety Coder.

Fuels and Materials Development

Void formation has been studied in Type 304 stainless steel irradiated in EBR - II following cyclotron injection of helium and subsequent annealing. For a given injected helium content, structures containing a high dislocation density developed fewer voids. An experimental duplex superplastic alloy IN-744 showed little effect of fine grain size (per se) on void swelling, but in the ferritic phase containing a fine coherent precipitate, very low void swelling was observed, suggesting this may be a promising method to alleviate the problem.

Cyclic creep-fatigue studies on Type 304 stainless steel indicate that the addition of a tensile hold time in the cycle may change the mode of fatigue crack propagation from intragranular to intergranular.

Sensitivity analysis using the LIFE-I fuel-element code demonstrated that irradiation creep of fuel can significantly influence the pin-diameter change with burnup. Measurements of plutonium redistribution in mixedoxide fuel pins show that redistribution becomes negligible below $\sim 10 \mathrm{~kW} / \mathrm{ft}$ linear power, but is significant in the range $14-16 \mathrm{~kW} / \mathrm{ft}$.

Cladding samples from seven mixed-oxide fuel pins, irradiated at varying linear powers to varying burnups, were analyzed for oxygen content by Los Alamos Scientific Laboratory. The axygen level rose from S0$97 \mathrm{ppm}$ in the unirradiated condition to values in the range 420-3300 ppm when irradiated. Electron-microprobe studies at ANL indicated concentrations of oxygen, cesium, and molybdenum in the cladding up to 0.006 in. from the fuel-cladding interface, with higher concentrations in the grain boundaries. The mechanism by which cesium promotes this cladding oxidation is under investigation.

\section{REACTOR PHYSICS}

\section{The FTR Engineering Mockup Critical}

As part of the series of high-priority reactivity measurements made on the simulated FFT F reactor on ZPR-9, the isothermal temperature coefficient of the assembly in the temperature range between 25 and $32^{\circ} \mathrm{C}$ was found to be $-4.1 \pm 0.4 \mathrm{Ih} /{ }^{\circ} \mathrm{C}$. To compare techniques, the reactivity of subcritical configurations of this reactor was measured both by inversekinetics and by several noise-analysis methods. The results from one of the noise methods, employing cross-power spectral-density reactivity evaluations made at roll-off frequencies, did not agree with those from inverse-kinetics measurements; the second noise method, using correlation with amplitude measurements at low frequencies, agreed well. 
Reactivity Comparison of Plate- and Pin-Fueled Core Zones

Although fast power reactors generally use a rod-shaped fuel element, ANL fast critical facilities often use flat plates of fertile. fissile, coclant, and structural materials to avail themselves of the greaterassembly versatility thus attainable. The reactivity difference between the two systems is quite small and is calculable. Measurements made on two central zones of identical size and isotopic composition successively constructed in ZPR'-6 Assembly 7 verified the predicted increase in reactivity in zone fueled with $\frac{1}{4}-$ in. thick plates over the reactivity in the same zone fueledwith

\section{REACTOR SAFETY}

In the program for accident analysis and safety evaluation, the slugejection coolant-voiding model used in the SAS codes has been modified to account for vapor-bubble axial pressure gradients caused by friction and vapor acceleration due to vaporizalion and condensation. Results obtained with this new capability of the model indicate that vapor-pressure gradients aignificantly affect the consequences of a flow-coastdown accident. The gradients result in a fasterinsertion of voiding reactivity, and they inhibit coolant reentry into the core region and rewetting of the cladding.

In the fuel-dynamics gtudies in TREAT, hodoscope data from 11 TREAT transients (of the 17 observed by the hodoscope) have been scanned by the new ALICE flying-spot scanner; two are in a preliminary-evaluation stage in which accurate decoding of the data is attempted, five a re in various stages of processing in the main program, DIGLITES, in the CDC 3600 , and five have progressed to different degrees of analysis.

In the program to measure the high-temperature physical properties of reactor materials, experiments using matrix-isolation spectroscopy are providing data to improve the accuracy of the calculated thermodynamic properties of fuel vapor species and of their vapor pressures. It is important to determine, reasonably accurately, the total vapor pressure above the fuel and fission-product system, because preliminary studies of the effect of such vapor pressures on FFTF disassembly calculations indicate that they play an important role in determining the amount of energy released in the coastdown design-basis accident, particularly for mild excursions. Above $4000-5000^{\circ} \mathrm{K}$, we have estimated the partial pressure of the fuel species to be the most significant contributor to the total pressure. Because the experimental program does not provide data for dissociated or ionized species, the extent of dissociation and ionization have been calculated. The comptations indicate that thermal ionization is negligible up to at least $6000^{\circ} \mathrm{K}$; further, calculations of relative concentrations of $U$, UO, $\mathrm{UO}_{2}, \mathrm{UO}_{3}, \mathrm{O}$, and $\mathrm{O}_{2}$ indicate that the molecular species predominate when all species are in equilibrium with condensed fuel. 
In the coolant-dynamies program, additional data have been obtained on film thickness for transient voiding processes. Previous data for round tubes, taken under conditions in which the expulsion velocity for each run remained constant, showed the liquid fraction or film thickness to be independent of velocity. The new data, for conditions in which the liquid acceleration remained constant for each run, show that the liquid fraction or film thickness varies both with velocity and acceleration. These data were obtained with an annulus with and without wire wrap. Similar data are being analyzed from test assemblies of 7 pins, with and without wire wrap, and of 19 pins without wire wrap. Also, in the coolant-dynamics program, incipient-boiling superheat measurements were made in forced-convection sodium flow at pressures from 2 to $10 \mathrm{psiz}$ and at velocities up to $5.8 \mathrm{ft} /$ sec. Both a gas-detection nozzle and voltage taps indicated considerable entrained gas at $5.8 \mathrm{ft} / \mathrm{sec}$ velocity, and the system boiled at a low superheat. At low velocities, the entrained-gas concentration was less than can be measured reliably by the nozzle technique $\left(\alpha<10^{-1}\right)$, but the voltage taps indicated that individual bubbles entered the test section periodically. If the coolant was superheated when a bubble traversed the test section, boiling was initiated. Voltage-tap signals showed that the point of boiling inception varies from run to run, but that it frequently occurs at super heats substantially lower than the maximum superheat existing in the channel. The data show that the presence of inert gas in the cavities plays a significant role in determining the incipience point, and that the velocity has no significant effect on incipient superheat when no large gas bubbles are present. 
TABLE OF CONTENTS

$189 \mathrm{a} \mathrm{No}$.

Page

I. EXPERIMENTAL BREEDER REACTOR NO. II 1.1

A. Operations 1.1

02-075

$02-076$

1. Reactor Operations

1,1

2, Fuels and Examination Facility (FEF) 1.2

a. Fuel Assembly $\quad 1,2$

b. Fuel Handling and Transfer 1.2

c. Reactor Support 1.5

02-073 3, Fuel and Hardware Procurement. 1.5

a. Reclarnation of Vendor Fuel 1.5

02-053 4. Experimental Irradiation and Testing 1.6

a. Experimental Irradiations 1.6

b. Operational In-cell Handling and Examination Equipment

1.6

c. Experimental Support 1.10

B. Fuels and Materials Studies 1.13

02-051 1. Coolant Chemistry 1.13

a. Monitoring of Sodium-Coolant Quality 1.13

b. Radioactive Sodium Chemistry Loop 1.16

02-063' 2. Materials-Coolant Compatibility 1.20

a. Evaluation and Surveillance of EBR-II
Materials

b. Examination of Materials from EBR-II Surveillance Subassemblies 1.21

02-145 3. Metal Driver Fuel Development and Application

a. Advanced Fuel (Mark II) 1.21

b. Cladding Studiea 1.26

c. Surveillance Support 1,32

02-194 4. Surveillance and Failure Evaluation of Experimental Fuel Irradiations 1.32

a. Surveillance of Current Tests 1.32

C. Engineering 1.34

02-.068 1. Systems Engineering 1.34

a. Surveillance, Evaluation, and Studies of
Systems

02-045 2. Equipment--Fuel Related 1.35

a. Handling Sobas semblies Containing Failed Fuel 1.35

02-131 3. EBR-II In-core Instrument Test Facility 1.36

a. Design and Development of Facility 1.36 


\section{TABLE OF CONTENTS}

189 a No.

Page

D. Analysis and Testing

1.39

$02-144$

$02-148$

$02-151$

$02-530$

1. Reactor Analysis, Testing, and Methods

Development

a. Nuclear, Thermal, and Hydraulic

1.39

Surveillance

b. Improved Experimental-irradiation Capability

2. Operation with Failed Fuel

1.57

a. Failure Diagnostics and Procedures 1.57

b. Xenon-tag Technique 1.68

3. Characterization of Irradiation Environment 1.70

a. Radial Reaction-rate Traverses for ZPR-3 Assemblies $63 \mathrm{~B}$ and $63 \mathrm{C}$

b. Activation-rate Measurements in ZPR-3 Assembly 62 Mockup Experiments

c. Comparison of Calculated and Experimental Capture/Fission Ratios for EBR-II Loadings 1.76

d. Comparison of Neutronics Methods

1.79

4. Operation of Data Acquíition System (DAS) 1.80

a. Rod-drop Studies

1.80

b. Rod-drop Initiation Code

1.81

c. DAS Operation

1.81

d. RODCAL: Control-rod Calibration Code

e. Oscillator Studies

1.82

PUBLICATIONS

II. LMFBR DESIGN SUPPORT

$02-026$

A. Core Component Test Loop (CCTL)

2.1

1. Preparation of Mark-Il FFTF Fuel Assembly for Shipment

2. Preventive Maintenance and Modifications of the CCTL

1. LMFBR Flow Stability Studies

a. Preparation of Apparatus

b. Experiments with Superheat

2. Nonboiling Transient Heat Transfer $\quad 2.4$

a. Analysis of Heat-flux Transients 2.4

3. Liquid-metal Heat Transfer in Pin Bundles 2.5

a. Preparation of Apparatus

2.5 


\section{TABLE OF CONTENTS}

$189 \mathrm{a} \mathrm{No}$.

Page

4. Electron Bombardment Heater (EBH)

Development

2.5

a. Preparation of Single Pin 2.5

$02 \div 099$

C. Engineering Mechanics

2.6

1. Structure-fluid Dynamics

2.6

a. Near-field and Far-field Flow Noise

2.6

b. Mathematical Modeling of Flow-tnduced Vibration

2.7

c. Damping and Virtual Mass

2.7

d. Preparation of Crossflow Test Chamber

2.9

e. Tube-stop Impact

2.9

PUBLICATION

III. INSTRUMENTATION AND CONTROL

$02-024$

A. Instrumentation Development for Instrumented Subassembly

1. Fuel-pin Thermocouples

3.1

2. Coolant Thermocouples

3.1

$02-025$

B. FFTF Instrumentation Development

3.1

1. Permanent-magnet Probe-type Flowsensors

2. Eddy-current Probe-type Flowsensors

3.2

3. Magnetometer Probe-type Flowsensors

3.4

$02-138$

c. Neutron-detector Channel Development

3.5

1. Intermedrate- and Wide-range Systems

3.5

2. Out-of-core Detectors and Cables

3.5

$.02-096$

D. Advanced Technology Instrument Development

3.6

1. Boiling Detector

3.6

a. Acoustic Method

3.6

2. Flow Monitor

3.9

a. Two-thermocouple Method 3.9

3. Vibration Sensor

3.9

a. Out-of-ple Teets of Sodium-immersible Commercial Transducers

3.9 
A. Monitoring and Sampling Systems Development and Reactor Proof-test

2. Hydrogen Meter

3. Carbon Meter

4. Meter Modules for FFTF

a. Oxygen-Hydrogen Meter Module

b. Carbon-meter and Specimen-equilibration Module

5. Detection of Leaks in Steam Generators

a. Leak Detector for LMFBR Steam Generator 4,4

b. LMEC Leak-detection System

1. In-pile Stainless Steel Swelling and Mechanical Behavior

a. Effect of Helium an Void and Dislocation Loop Nucleation

b. Swelling of $\Pi \mathrm{N}-744$

c. Neutron Simulation Studies Using $4=\mathrm{MeV}$ Dynamitron

2. Creep, Fracture, and Fatigue Studies on Stainless Steel

a. Low-cycle Fatigue

3. Nondestructive Testing Research and

Development

a. Electromagnetic Field Studies

5.9

b. Neutron Radiography

B. Fuel Properties

a. Total Vapor Pressures and Carbon

$$
\text { Potentials in the Ternary U-C-Pu System }
$$

b. X-ray and Density Mea surements of Hypostoichiometric (U.Pu) Oxides 
TABLE OF CONTENTS

$189 \mathrm{a} \mathrm{No.}$

Page

$02-162$

3. Thermophysical Properties of Reactor Fuels

5.20

a. Oxygen Gradients, Total Vapor Pressures, and Oxygen Potentials in Reactor Fuels

b. Partial Pressures of Vapor Species in the U-Fu-O System and in the U-Pu-OSystem Containing Fission Products

c. U-Pu-O Phase Diagram

5.24

$02-175$

4. Physical and Chemical Studies--Molten Fuel, Cladding, and Coolant

a. Thermal Diffusivity of Reactor Materials: Liquid. $\mathrm{UO}_{2}$

c. Fuel Elements

$02-086$

$02-087$

$02-005$

1. Behavior of Reactor Materials

5.27

a. Migration of Major Fuel Constituents $\quad 5.27$

b. Fuel-Fission-product-Cladding Interactions

5.28

c. Experimental Studies of Swelling Mechanisms and Gas Release in Fuel Materials 5.31

2. Chemistry of Irradiated Fuel Materials

a. Postirradiation Studies of Reactor Fuels and Cladding

5.33

3. Oxide Fuel Studies 5.36

a. Fuel-swelling Studies - 5.36

D. Core Materials Applicationa 5.38

none

1. Core Design Technology

a. Empirical Assessment of Swelling and Creep Correlations.

5.38

PUBLICATIONS

5.42

VI. FUEL CYCLE

6.1

$02-173$

A. Molten Metal Decladding of LMFBR Fuels

6. 1

1. Engineering Development

6.1

$02-159$

B. LMFBR Reprocessing--Plutonium Isolation

6.2

1. Centrifugal Contactors for Plutonium Handing

2. Plutonium Valence Adjustment Kinetics

6.2

6.3

PUBLICATIONS

6.5 
A. ZPR Fast Critical Experiments 7,1

02-179 1. Fast Critical Facilities; Experiments and Evaluations - Illinois

a. Clean Critical Experiments

7.1

b. Mockup Critical Experiments

7.6

$02-181$

2. Fast Critical Facilities; Experiments and Evaluations - - Idaho

a. Clean Critical Experiments $\quad 7.12$

b. Doppler Experiments $\mathbf{7 . 1 4}$

02-015 3. Planning and Evaluation of FFTF Critical Assembly Experiments

a. Calculation of Kinetics Parameters for FTR-3, Loading 125

B. Support of ZPR Fast Gritical Experiments 7.18

1. Fast Critical Experiments: Theoretical Support--Idaho

a. Supplementary Analytical Evaluations of Integral Data

7.18

b. ZPR Heterogeneity Method Development 7.19

2. Fast Critical Experiments: Experimental

Support--Illinois"

a. Development of Techniques for Critical Experiments

3. Fast Critical Experiments; Experimental Support - -Idaho

a. Neutron Spectroscopy

a. Technical Administration and Quality Control

C. Acquisition of Nuclear Data $\quad 7.28$

$02-084$

1. Determination of Nuclear Constants

7.28

a. Total and Reaction Cross Sections 7.28

$02-082$

2. Cross-section Measurements

7.29

a. Spectrum-averaged Measurements

7.29

b. Low-mass Fission-product Yields

7.30

02-083. 3. Burnup Analysis and Fission Yields for Fast Reactors

a. Determination of Fast Fission Yields and Nonfission Nuclear Transformations in a 
189 a No.

Page

D. Fast Reactor Analysis and Computational Methods

$02-081$

1. Theoretical Reactor Physics

7.34

a. Cross-section Data Evaluation

7.34

b. Reactor Computations and Code Development

VIII. REACTOR SAFETY

8. 1

1. Initiating Accident Code Development

a. Incorporation of Slug-ejection Coolant Model into SASIA Code

2. Disassembly Accident Analysis. Including Computer Code Development and Sensitivity Studies

a. Sensitivity Studies

8.2

$02-114$

B. Coolant Dynamies

8.6

1. Sodium Superheat

8.6

a. Incipient-boiling Tests with EBR-II Sodium

8.6

b. Forced-convection Superheat Experiments with Annular Flow

2. Liquid-Vapor Dynamics

a. Liquid-film Thickness and Breakup $\quad \mathbf{8 . 8}$

a. Gas-release Experiments with $91-$ pin Array in Freon

b. Slow Gas Release in 19-pin Test Section in Water LoOP

c. Persistent-jet Gas-release Tests in Sodium

2. In-pile Studies

8.9

a. Planning and Design of Experiments

8.9 
1. Transient In-pile Tests with Ceramic Fuel

a. First Mark-II-loop Experiments (Ll and

L2) on Fuel-movement Failure of Unirradiated Fuel during a Los g-ot-flow Accident

b. Fir at Mark-II-loop Experiments (D) and D2) on Effects of Release of a Small Amount of Motten Fuel, Using Pins with Local High-enrichment Sections

2. Experimental Support

a. Cask Fabrication

b. Preparation of Last Six Mark-II Loops from EY 1970 Stocks

c. Preparation of Advanced Mark-II Loops for Use in Future Tests

3. Analytical Support

a. Automated Handling of Hodoscope Data

b. Analysis of Transient In-pile Experiments

4. Hot Laboratory Examinations

a. Examination of Pins after TREAT Tests

5. Idaho Loop Operations

E. High-temperature Physical Properties and

Equation-of-state of Reactor Materials

1. Theoretical Extrapolation of Measured Physical Propertie $B$ to Very High Temperatures

$02-164$

F. Fuel-Coolant Interactions

1. Out-of-pile Contacting Studies

a. Pressure Generation by Injection of Small Quantities of Sodium into $\mathrm{UO}_{2}$ and Stainless Steel

1. Core-debris Retention within the Reactor or Guard Vessel

a. Simulation Experiments to Verify Heattransfer Model for Pools with Internal Heat Generation 


\section{TABLE OF CONTENTS}

189a No.

b. Heat Transfer through $\mathrm{UO}_{2}$ Particle Beds in Sodium

c. Experiments on Heat Transfer through $\mathrm{UO}_{2}$ Particle Beds in Sodium

02.122

H. TREAT Operations

8.36

1. Operations

8. 36

a. Automatic Power Level Control System

8.37

02.126

I. Reactor System and Containment Structural Dynamic Response

1. Hydrodynamic Response of Primary Containment to High-energy Excursion

a. Parametric Studies of System Geometries and Excursion Magnitudes and Durations to Assist FFTF Accident Analysis

b. Transformation of Code Coordinates from Lagrangian to Eulexian Systems

PUBLICATIONS

IX. ENVIRONMENTAL STUDIES

$02-166$

A. Thermal-plume Dispersion Studies 9.1

1. Sinking-plume Experiment

9.1

$02+184$

B. Mass/Energy Balance of the Great Lakes

9.1

1. Thermal-discharge Effect on Stratification

9.1

PUBLICATION

9.3

PUBLICATIONS--General 
Ligting of Reportable

ANL Reactor Development Program Project?

in $189 \mathrm{a}$ Order

\begin{tabular}{|c|c|c|c|}
\hline $\begin{array}{l}189 . \\
\text { No. }\end{array}$ & $\begin{array}{l}\text { Reparted } \\
\text { This Month } \\
\text { in Section }\end{array}$ & $189 \mathrm{a}$ Title & $\begin{array}{l}\text { RDT } \\
\text { Branch }\end{array}$ \\
\hline $02-005$ & $v$ & Oxide Fuel Stadies & $\mathbf{R T}-\mathbf{F M}$ \\
\hline $02-009$ & & General Fast Reactor Physics & $\mathbf{R T}=\mathbf{P H}$ \\
\hline $02-010$ & VII & Fagt Critical Experiments; Theoretical Support--Idaho & $\mathbf{R T} \mathbf{T H}$ \\
\hline $02-011$ & VII & Fast Critical Experiments; Experimental Support--Idaho & $\mathbf{R} \mathbf{T} \cdot \mathbf{P H}$ \\
\hline $02-012$ & & Fast Critteal Experiments; Industrial Appointments & $\mathbf{R T}-\mathbf{P H}$ \\
\hline $02-013$ & VII & Fagt Critical Experimenta; Experimental Support--Illinois & $\mathbf{R T} \cdot \mathbf{P H}$ \\
\hline $02-015$ & VII & $\begin{array}{l}\text { Planning and Evaluation of FFTF Critical Assembly } \\
\text { Experiments }\end{array}$ & RT-PH \\
\hline $02-019$ & & Production of Materials for ZPR Experiments & RE-FE \\
\hline $02-020$ & VII & ZPR Materials Procurement & RE-FE \\
\hline $02-021$ & $I V$ & $\begin{array}{l}\text { Monitaring and Sampling Systema Development and } \\
\text { Reactor Proof-test }\end{array}$ & RT-CC \\
\hline $02-024$ & III & Instrumentation Development for lnstrumented Subassembly & PE-IC \\
\hline $02-025$ & III & FFTF lnatrumeatation Development & $P E-1 C$ \\
\hline $02-026$ & $\mathbf{L}$ & Core Component Test Loop (CCTL) & $\mathbf{R E} \cdot \mathbf{C D}$ \\
\hline $02-045$ & $\mathbf{I}$ & Equipment-- Fuel Related & $\mathbf{R E}=\mathbf{F H}$ \\
\hline $02-046$ & & New Subassemblies and Experimental Support & $R E \cdot C D$ \\
\hline $02-048$ & & Instrumented Subassemblies & $\mathbf{R E}=\mathrm{CD}$ \\
\hline $02-0 \$ 1$ & $I$ & Coolant Chemistry & $\mathbf{R T}-\mathbf{C C}$ \\
\hline $02-053$ & I & Experimental Irradiation and Testing & $\mathbf{R} \mathbf{T}-\mathrm{FM}$ \\
\hline $02-061$ & & Nuclear Instrument Test Facility & PE-IC \\
\hline $02-063$ & I & Materials-Coolant Compatibility & $\mathbf{R} T \mathbf{T} \mathbf{C}$ \\
\hline $02-068$ & I & Systems Engineering & PE-LS \\
\hline $02-073$ & I & Fuel and Hardware Procurement & RE-FE \\
\hline $02-075$ & $\mathbf{l}$ & Reactor Operations & PE.LS \\
\hline $02-076$ & 1 & Futs and Examination Facility $(F E F)$ & $\mathrm{AE}-\mathrm{EE}$ \\
\hline $02-081$ & VII & Theoretical Reactor Physics & $\mathbf{R T} \cdot \mathbf{P H}$ \\
\hline $02-092$ & VII & Croga-section Measurements & $\mathbf{R T}-\mathbf{P H}$ \\
\hline $02-083$ & VЦ & Burnup Analysis and Fission Ylelds for Fast Reactors & RT-FH \\
\hline $02-084$ & VII & Determination of Nuclear Constgnts & $\mathbf{R T}-\mathbf{F H}$ \\
\hline $02-085$ & VII & Reactor Code Center & $\mathbf{R} \mathbf{T}-\mathbf{P H}$ \\
\hline $02-086$ & 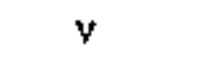 & Behavior of Rajactor Materials & $\mathbf{R T}-\mathbf{F} \mathbf{M}$ \\
\hline $02-087$ & $\mathrm{~V}$ & Chemigtry of Irradiated Fuel Materials & RT-FM \\
\hline $02-088$ & $\mathbf{v}$ & Thermodynamics of Carbide Fuel & $\mathbf{F T}-\mathbf{F M}$ \\
\hline $02-091$ & $\mathrm{v}$ & Creep, Fracture, and Fatngue Studies on Stainless Steel & RT-FM \\
\hline
\end{tabular}




\begin{tabular}{|c|c|c|c|}
\hline $\begin{array}{l}189 a \\
\text { No. }\end{array}$ & $\begin{array}{l}\text { Reported } \\
\text { This Month } \\
\text { in Section }\end{array}$ & 1892 Title & $\begin{array}{c}\text { RDT } \\
\text { Branch }\end{array}$ \\
\hline $02-092$ & $\mathrm{~V}$ & Nondestructive Testing Research and Development & RT-FM \\
\hline $02-094$ & $\mathrm{v}$ & High-temperature Properties of Ceramic Fuels & RT-FM \\
\hline 02.096 & UI & Advanced Technology listrument Development & RT-ST \\
\hline 02.097 & It & Heat Transfer and Fluid Flow & RT-ST \\
\hline $02-099$ & II & Enginetring Mechanics & $R T^{2}-5 T$ \\
\hline $02-112$ & VIII & Accident Analysis and Safety Evaluation & NS-FS \\
\hline $02-114$ & VIII & Cóolant Dynamics & NS-FS \\
\hline $02-115$ & & Core Structural Safety & NS-FS \\
\hline $02-116$ & VIய & Fuel-element Fallure Propagation & NS-FS \\
\hline $02-117$ & VसI & Futl Dynamies Studies in TREA $T$ & NS-FS \\
\hline $02-119$ & VIII & $\begin{array}{l}\text { High-temperature Physical Properties and Equation- of- Btate } \\
\text { of Reactor Materials }\end{array}$ & NS-FS \\
\hline $02-120$ & & Fast Reactor Safety Test Factlity Study & NŜ-FS \\
\hline $02-122$ & VIII & TREAT Operations & NS-RD \\
\hline $02=126$ & VLII & Reactor System and Containment Struetural Dynamic Response & NS-FS \\
\hline $02-131$ & I & EBR-II ln-core Instrument Test Facility & $P E-I C$ \\
\hline $02-133$ & & NDT Measurement of Effective Cold work in Cladding Tutes & RT-FM \\
\hline $02-134$ & & Fast Critical Experiments; Theoretical Support--Illinois & RT-PH \\
\hline $02-137$ & & Nonmetallic Impurity Interactions in Sodium-Metal Systems & $\mathbf{R} \mathbf{T}-\mathbf{C C}$ \\
\hline $02-138$ & III & Neutron-detector Channel Development & PE-IC \\
\hline $02-144$ & I & Reactor Analysis, Testing, and Methods Development & $R E-C D$ \\
\hline $02-145$ & I & Metal Drivex Fuel Development and Application & RE-FE \\
\hline $02-148$ & I & Operation with Failed Fuel & RE-CD \\
\hline $02-150$ & & Hot Fuel Examination Facilities & PE-FH \\
\hline $02-151$ & $\mathbf{I}$ & Characterization of lrradiation Environment & $R E-C D$ \\
\hline $02-156$ & & Sodium Impurity Analysis and Control & $\mathbf{R T}-\boldsymbol{C C}$ \\
\hline $02-157$ & & LMFBR Fuel Materials Preparation-- $\mathrm{J} / \mathrm{Pu}$ Nitrates to Oxides & RT-FR \\
\hline $02-158$ & & $\begin{array}{l}\text { LMFBR Fuel Fabrication-- Analys as and Continuous } \\
\text { Processing }\end{array}$ & RT-FR \\
\hline 02.159 & VI & LMFBR Reprocessing--Plutonium lsolation & RT-FR \\
\hline $02-162$ & $\checkmark$ & Thermophytical Ptoperties of Reactor Fuepls & $\mathbf{R} \mathbf{T}+\mathbf{F R}$ \\
\hline $02-164$ & VIII & Fuel-Coolant Interactions & NS-FS \\
\hline $02-165$ & VIr & Post-accident Heat Removal & NS-FS \\
\hline $02 \cdot 166$ & $1 \mathrm{x}$ & Thermal-plume Dispersion Studies & $\mathbf{P A}$ \\
\hline $02-173$ & VI & Molten Metal Decladdang of LMFBR Fuels & RT-FR \\
\hline $02-175$ & $v$ & $\begin{array}{l}\text { Physical and Chemical Studies--Molten Fuel, Cladding, and } \\
\text { Coolant }\end{array}$ & $R T-F R$ \\
\hline $02=178$ & & ZPR-6 and - 9 Operations and Maintenance & RT-PH \\
\hline
\end{tabular}




\begin{tabular}{|c|c|c|c|}
\hline $\begin{array}{l}389 a \\
\text { No. }\end{array}$ & $\begin{array}{l}\text { Reported } \\
\text { This Month } \\
\text { in Section }\end{array}$ & 189a Title & $\underset{\text { Branch }}{\text { RDT }}$ \\
\hline $02-179$ & Vil & $\begin{array}{l}\text { Fast Critical Facilities; Experiments and Evaluations-- } \\
\text { Illtaois }\end{array}$ & RT-PH \\
\hline $02-180$ & & ZPPR Operatione and Maintenance & RT-PH \\
\hline $02-181$ & VII & $\begin{array}{l}\text { Fast Critical Faciluties: Experiments and Evaluations-- } \\
\text { Idaho }\end{array}$ & $\mathbf{R T}-\mathbf{P H}$ \\
\hline $02-184$ & IX & Mass/Energy Balance of the Great Lakes & PA \\
\hline $02-185$ & & Lake Circulation Model Development & PA \\
\hline $02-194$ & $\mathbf{I}$ & $\begin{array}{l}\text { Surveillance and Failure Evaluation of Experimental Fuel } \\
\text { Irradiations }\end{array}$ & $\mathrm{RT}-\mathrm{FM}$ \\
\hline $02-195$ & & Scram-gystem Stody & PE- LLS \\
\hline $02-197$ & & TREAT Improvement Studies & PM-EB \\
\hline $02-200$ & & Gonceptual Design Study of FFTF Vestel Head-cavity System & RE- CD \\
\hline $02-509$ & & Sodium Chemistry and Radioactive Contaminant Behavior & $\mathbf{R} \mathbf{T}-\mathrm{CC}$ \\
\hline $02-526$ & $\mathbf{v}$ & ln-pile Stainlega Steel Swelling and Mechanieal Behavior & RT-FM \\
\hline $02-528$ & & Plant Dymanics and Control Analysis & PE-IC \\
\hline $02-530$ & 1 & Operation of Data Acquisition System (DAS) & $P E-I C$ \\
\hline
\end{tabular}

$x v i$ 


\section{EXPERIMENTAL BREEDER REACTOR NO. I}

\section{A. Operations}

1. Reactor Operations. G. E. Deegan (02-075: last reported: ANL-7798, p. 1)

In the period from March 16 through May 15, the reactor was oper ated for $1467 \mathrm{MWd}$ in Runs 48A-48E. The accumulated total of EBR-II operation now is $43,788 \mathrm{MWd}$.

During the loading changes for Run 48A, control-rod thimbles 2, 6, 7, and 8 were removed from the reactor grid and replaced as scheduled. Six suspect leakers, all experimental subassemblies containing encapsulated fuel elements, were removed from the reactor. The No. 8 control-rod drive was replaced by the oscillator drive. Operation of the oscillator and its associated interlocks was checked, and the reactor was started up on April 1 for a gamma-heating experiment using two special structural subassemblies.

While the reactor was critical at $50 \mathrm{~kW}$, a fire alarm was turned in by an operator in the basement of the reactor butlding. The primary purification cell was identified as the source of the smoke seen by the operator. The cell was entered, and a small, nonradioactive sodium fire was seen in the vicinity of the plugging loop. After the fire was extinguished, the plugging loop was removed, cleaned, and inspected. The leak had originated at a fin-to-tube connection in the sodium-to-air heat exchanger.

On April 2, the reactor was restarted, and the 4-hr gamma-heating irradiation at $62.5 \mathrm{MWt}$ was performed. After shutdown, the two gammaheating subassemblies were removed from the core, and the reactor was restarted for Run $48 \mathrm{~B}$. Oscillator experiments were conducted at power levels up to $40 \mathrm{MWt}$. Before the experiments could be performed at higher power, an increase in cover $\sim$ gas activity occurred, and the reactor was shut down. The previously removed six suspect leakers were returned to the core, and six additional auspects were removed.

Run 48C began on April 6 and continued until April 20, when another small activity increase, similar to the previous ones, occurred. A xenontag sample taken from the cover gas contained a small amount of tag. Analysis of the tag indicated Subassembly X058 as the most suspect leaker, and $X 07.3$ as the second most suspect. Subassembly X058 was removed, and the reactor was restarted for Run 48D, which continued from April 22 to May 3. Another similar increase in cover-gas activity was indicated on May 3, and reactor power was quickly lowered to $30 \mathrm{MWt}$. Subsequent analysis of cover-gas samples showed that the increase in activity had stopped and that the level of cover-gas activity at which shutdown is mandatory had not been reached. Reactor operation was continued, and an increase in power to $62.5 \mathrm{MWt}$, with holds at $5-\mathrm{MWt}$ increments, was initiated to further 
characterice the leak. Power was held at each 5-MWt increment for $4 \mathrm{hr}$ while gas samples were taken hourly and the fission-product-monitoring instruments were closely watched. At $60 \mathrm{MWt}$, another activity increase occurred, and the reactor was shut down.

It was decided to terminate Run 48 and to install instrumented subassembly XX03 in place of instrumented subassembly XXO2, After the primary tank had been cooled to $580^{\circ} \mathrm{F}$, and while XX02 was being prepared for removal, a change in programming required the short-tetm irradiation of Subassembly X108 (a HEDL central-melting test) before the insertion of $\mathrm{XX} 03$ into the reactor. Shutdown work was terminated, therefore, and the primary tank was reheated to $700^{\circ} \mathrm{F}$. Subassembly X 108 was transferred to the reactor, and $\mathrm{X} 073$ was removed as the most probable source of the in creases in cover-gas activity. Irradiation of X108 was completed in about $8 \mathrm{hr}$ and was terminated by a manual scram in accordance with the experimental procedure.

After $X 108$ had been removed from the reactor, the seal troughs of the large and small plugs were cleaned. Instrumented subassembly XX02 was then replaced by $\mathrm{XX03}$.

Besides the loading changes mentioned above and the changes in experimental-irxadiation subassemblies listed in Sect. I.A.4.a, the following noteworthy changes were made during the reporting perlod:

Before Run 48A, several outer-blanket subassemblies in Row 8 that were approaching the burnup limit were exchanged with outer-blanket subassemblies in Row 14. Before Run 48D, four subassemblies of impactbonded vendor fuel and one surveillance subassembly of Mark-II driver fuel were removed from the reactor. Before Run 49A, two surveillance subas semblies of Mark-If driver fuel were, installed for additional irradiation.

2. Fuels and Examination Facility (FEF). M. J. Feldman (02-076)

a. Fuel Assembly * D. L. Mitchell (Last reported: ANL-7798, p.2)

Thirteen Mark-LA subas semblies were assembled in the cold line during this reporting period. All were made up of centrifugally bonded vendor elements that had been heat-treated by ANL (see Sect. I.A.3.a).

Table I.1 summarizes the production activities for March 16 through May 15, 1971, and for fiscal year 1971.

b. Fuel Handling and Transfer. N. R. Grant, W, L. Sales, and K. DeCoria (Last reported: ANL-7798, p. 3)

Table I.Z summarizes the fuel-handling operations performed. 
TABLE 1.1. Froduction Sunmery for PEF Cold Line

\begin{tabular}{|c|c|c|}
\hline & $\begin{array}{l}3 / 16 / 71 \\
\text { chrough } \\
5 / 15 / 71\end{array}$ & $\begin{array}{c}\text { Total } \\
\text { for } \\
\text { FY } 1971 \\
\end{array}$ \\
\hline \multicolumn{3}{|l|}{ Subessenblies Fabricated with Mork-LA Fuel } \\
\hline $\begin{array}{l}\text { Wt th cold-line elenents } \\
\text { With vendor elementa }\end{array}$ & $\begin{array}{r}0 \\
13\end{array}$ & 93 \\
\hline \multicolumn{3}{|l|}{ Preirradiation Treatwent of Vendor Mark-IA Fuel } \\
\hline \multicolumn{3}{|c|}{ Heat-treating of as-fabricated elenents $\left(22,614^{a}\right)$} \\
\hline $\begin{array}{l}\text { Heat-treated, inapected, and eccepted } \\
\text { Heat-treated, inspected, and rejected }\end{array}$ & $\begin{array}{l}3,909 \\
1,091\end{array}$ & $\begin{array}{r}14,170 \\
4,129\end{array}$ \\
\hline \multicolumn{3}{|c|}{$\begin{array}{l}\text { Total Elements Avaliable for Subaesenbly Fabrtcation } \\
\text { as of } 5 / 15 / 71\end{array}$} \\
\hline \multicolumn{3}{|l|}{ cold-1ine fuel } \\
\hline $\begin{array}{l}\text { Kark IA } \\
\text { Fark II }\end{array}$ & \multicolumn{2}{|c|}{$\begin{array}{l}199 \\
189\end{array}$} \\
\hline \multicolumn{3}{|l|}{ Vendor fuel (Mark IA) } \\
\hline $\begin{array}{l}\text { Impact-bonded d } \\
\text { Beat-treated }\end{array}$ & & \\
\hline
\end{tabular}

These elements, cast and certrifugally bonded by the vendor, have been accepted by All verification inepection, but not yet approved for general use In the reactor. Thay are being heat-treated to reclain then. (See Sec. I.A.3.a.)

"The $f t_{g u r e s}$ in AlL-779B were incorrect. The "accept" elements after heat-treatment and Inspection ohould have been os followe: 4303 tot $1 / 16 / 71$ thtough $3 / 15 / 71$ and 10,261 for the Total for FI 1971 .

Foid aize in the oodfup bond to the principal cause for rejection. The bond in elements rejected for this reason are belris retested (see Sac. I.A.3.a); those elements rejected after this resvaluation may be reclained by lapact-bonding.

dImpact-bonding by AKL of $I 1,853$ unbonded vendor fuel eleoento was campleted in tracal year 1970 .

eIncludes elebents previously rejected for void alze, but found acceptable on teterating of the gadium bond. 


\begin{tabular}{lcc}
\hline & $3 / 16 / 71$ & Total \\
through & for \\
$5 / 15 / 71$ & Fr 1972 \\
\hline
\end{tabular}

Subergarbly Eandlipes

Subasenblies Received fron Reactor

Driver fuel (all types)

Experimental

Other (b1 anket)

Subasseablies Dtamantled for Survetllance,

Exanination, or shipuent to Experimenter

Driver fuel

Exper 1wental

Other (blanket)

Dr1ver-fuel zlemento to Survelllance

Humber fron Subassenblias

Subasanbliea Transferred to Reactor

Drtver fuel

Frod atr cell

From cold line

Experimental

From alr cell

From cold 11rea

$\begin{array}{rr}25 & 95 \\ 6 & 37 \\ 5 & 32\end{array}$

239

739

49

$32 \quad 1,527$

129

17

$14 \quad 82$

723

324

Fuel-d1loy and Hates Sh10nente

Gans to Burial Ground

Blanket Subassemblies to Bur1al Ground

419

$0 \quad 17$

Recoverable fuel Alloy to ICPP

Fuel elements $\mathrm{b}$

Subassembites ${ }^{b}$

Consolidation Ingoteb

Nonspectiftcation material

Skull oxide and glass ecrap

a cold-11ne subassmblies, after fabrication and final teote, are transferted elther to the reactor or to the apeciel-atater1als vaults for interin atorage unt11 needed for use in the reactor.

bigure outside parentheses is nuber of shipnente nude; tigure inatde in welght of alloy shipped. 
c. Reactor Support. J. P. Bacca and N. R. Grant (Last reported:

(1) Nondestructive Examination of High-fluence EBR-II Safety and Control-rod Thimbles (R, D. Phipps). Six thimbles with high fluence (1.4 $\times 10^{23}$ to $1.7 \times 10^{23} \mathrm{nvt}$ ) have been removed from EBR-II and sent to the FEF, where they are in various stages of examination. Three of these thimbles--safety-rod thimble(SRTh) 3A1 (peak fluence, $1.7 \times 10^{23} \mathrm{nvt}$ ), control-rod thimble (CRTh) 5A3 (peak fluence, $1.4 \times 10^{23}$ nvt), and CRTh 5Dl (peak fluence, $1.4 \times 10^{23}$ nvt)--were removed late in 1970 . Nondestructive examination of these three thimbles is essentially complete. The thimbles are being sectioned, and distribution of sectioned material from the thimbles to various laboratories for destructive examination has begun. The other three thimbles--CRTh 5D3 (peak fluence, $1.6 \times 10^{23} \mathrm{nvt}$ ), CRTh 5Al (peak fluence, $1.5 \times 10^{23} \mathrm{nvt}$ ), and CRTh 5F3 (peak fluence, $1.6 \times 10^{23}$. nvt)--were removed from the reactor during March 1971. Nondestructive examination of these thimbles is in progress.

Surveys of the flat-to-flat and corner-to-corner dimensions of the hexagonal tubes of SRTh $3 \mathrm{Al}$ and CRTh 5Dl show a considerable increase in these dimensions at the core region of each thimble. The nominal as-fabricated flat-to-flat dimension of the preirradiated thimbles was $2.290 \pm 0.005 \mathrm{in}$, and the nominal corner-to-corner dimension was 2.610 in. (no specified tolerance). The maximum postirradiation flat-to-flat dimension for SRTh $3 A 1$ was 2.381 in., 2 in. above the spacer buttons; the maximum corner-to-corner dimension was $2.697 \mathrm{in.}, 1$ in. above the spacer

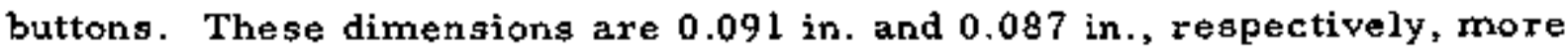
than the nominal as-fabricated dimensions. The maximum postir radiation dimensions of CRTh 5Dl were $2.357 \mathrm{in.} \mathrm{(flat-to-flat)} \mathrm{and} 2.668 \mathrm{in}$. (cornerto-corner); both maximum dimensions were about 1 in. above the spacer buttons. These dimensions are 0.067 and 0.058 in., respectively, more than the nominal as-fabricated dimensions.

3. Fuel and Hardware Procurement. M. Feldman (02-073)
a.
Reclamation of Vendor Fuel. ANL-7798, p.4)
D. L. Mitchell (Last reported:

During this reporting period, 5000 more centrifugally bonded vendor elements were heat-treated to reclaim them. Examination of the 5000 elements showed 3909 to be "accepts" and 1091 to be "rejects." The principal cause for Iejection was again the size of the voids in the sodium bond. The acceptable void size is based on Revision 6 of Specification FCF-1 (Product Spectfication for EBR-II Driver Fuel Elements).

Because a relatively high percentage $(-23 \%)$ of the elements heattreated to date have been rejected, the accuracy of the bond tester being used was checked by measuring void size in 2800 rejected elements (of the 4129 rejected in FY 1971) with a second bond tester. Of the 2800 elements 
retested, approximately $69 \%$ were found acceptable by the second tester. Destructive examination of selected elements verified the accuracy of that tester. Malfunctioning of the first tester apparently was caused by sporadic drifting of its electronic components.

The rest of the rejected elements also will be tested in the second bond tester. The rejected elements from this retesting will be reevaluated in a new type of bond tester currently being calibrated. This new tester has three separate eddy-current coils, rather than one as in the old type of bond tester, and can measure the larger void sizes that are acceptable under Revision 7 of FCF-1. Rejected elements from the new tester will be impact-bonded in an effort to reclaim them.

4. Experimental Irradiation and Testing. R. Neidner (02-053)

a. Experimental Irradiations (Last reported: ANL-7798, p. 4)

Table I.3 shows the atatus of experimental irradiations in EBR-II on May I5, after the end of Run 48E. Table I.4 lists all irradiated experimental-irradiation subassemblies now in the FEF for examination and reconstitution. Table I.5 lists the experimental-irradiation subassem blies transferred to and from the reactor during Run 48 . Of particular interest is the completion of the irradiation of instrumented subassembly XX02, which contains HEDL oxide-fuel elements. It was removed from the reactor at the end of Run 48 and replaced by XX03, the HEDL instru mented creep test.

b. Operational In-cell Handling and Examination Equipment . M. J. Feldman

(1) Examination Equipment. J. P. Bacca and G. M. Iverson (Last reported: ANL -7753 , p. 56)

(a) Scanning Electron Microscope (A. K. Chakraborty and R. Natesh). The scanning electron microscope (SEM) was received at the FEF and is being set up in one of the cold laboratories. It will be used initially for examining unirradiated materials. Ultimately, it will be installed in the Hot Fuel Examination Facilities (HFEF) for examining both irradiated and nonir radiated materials. The SEM is the Stereoscan Mark 2a instrument manufactured by Kent Cambridge Scientific, Inc. It is equipped with an electron-emitter gun of lanthanum hexaboride, which offers the following advantages: (1) an electron beam of very high intensity, (2) comparatively long life, and (3) a high signal-to-noise ratio. The SEM has a magntfication range of $20-100,000 \mathrm{X}$, a maximum resolution of $150 \AA$, and an operatingvoltage range of $1-30 \mathrm{kV}$. 


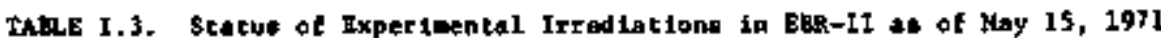
(Eun 4 g Completed)a

\begin{tabular}{|c|c|c|c|c|c|c|c|c|}
\hline \multicolumn{2}{|c|}{$\begin{array}{l}\text { Subarsembly No, } \\
\text { and (Posit } 1 \text { on) }\end{array}$} & \multirow{2}{*}{$\begin{array}{c}\begin{array}{c}\text { Date } \\
\text { Loaded }\end{array} \\
4 / 13 / 70\end{array}$} & \multicolumn{2}{|c|}{$\begin{array}{c}\text { Content and } \\
\text { (Mhenter of Cupeules) }\end{array}$} & \multirow{2}{*}{$\begin{array}{l}\text { Expert- } \\
\text { menter } \\
\text { hond }\end{array}$} & \multirow{2}{*}{ 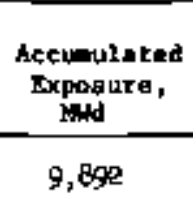 } & \multirow{2}{*}{ 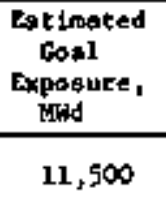 } & \multirow[t]{2}{*}{ Butrinup b } \\
\hline$x<025$ & $(5 F 3)$ & & $v_{0}-25$ wt $\mathrm{PuO}_{2}$ & $(36)$ & & & & \\
\hline$\times 003$ & (5F) & $5 / 12 / 71$ & Structurel & (1) & HEDL & 0 & 6,200 & 0 \\
\hline$x \cos A^{d}$ & $(\theta 02)$ & $9 / 14 / 70$ & $\mathrm{vO}_{\mathrm{c}}-2 \mathrm{O}$ wto $\mathrm{FuO}_{2}$ & (a) & $\mathbf{G E}$ & 3,109 & $13, \infty 00$ & $0.5+7.5+=8.0$ \\
\hline$\pi 004 A^{d}$ & $(\operatorname{sn} 7)$ & $9 / 15 / 70$ & $\mathrm{UO}_{2}-2 \mathrm{OD} \times \mathrm{t} \mathrm{PuO}_{2}$ & (2) & $G$ & 3,109 & $21, \infty \infty$ & $0.5+8.9 * 0.0$ \\
\hline$x 043 k^{c}$ & $(6 \mathrm{D})$ & $10 / 27 / 70$ & $\mathrm{UO}_{2}-25 \mathrm{wth} \mathrm{PO}_{2}$ & (37) & $a E$ & 2,947 & 3,100 & $1.2+6.20=7.4$ \\
\hline X055A & (7Es) & $3 / 16 / 71$ & $\left(v_{0} .85-P_{2} u_{15}\right) \mathrm{G}$ & (19) & UNEC & 1,467 & 15,000 & $0.3+4.8=5.1$ \\
\hline$x 056 A^{C}$ & $(6 \mathrm{~B} 2)$ & $10 / 27 / 70$ & $\mathrm{NO}_{-2}-25$ vtt $\mathrm{FrO}_{2}$ & (37) & GE & 2,947 & 3,100 & $1.2+6+3=7.5$ \\
\hline$x 0585$ & $(7 B 6)$ & $4 / 24 / 69$ & $v O_{2}-25$ sth $P Q_{2}$ & (37) & GE & 18,416 & 21,800 & 6.4 \\
\hline x06: & $\left(T^{3}\right)$ & $5 / 23 / 69$ & $\mathrm{WO}_{2}-25 \mathrm{rtw}_{\mathrm{NuO}}$ & (37) & $G E$ & 17,175 & 19,000 & 6.8 \\
\hline$x 065:$ & (7D5) & $4 / 22 / 71$ & Structural & (23) & ANL & 662 & 2,000 & $0.1+1+6=1.7$ \\
\hline XD6EA & (6B) & $2 / 23 / 71$ & Mrk IA & $(61)$ & ANL & 1,893 & 2,800 & $0.4+2.4 *=2.8$ \\
\hline xo6gh & $(6 \mathrm{p})$ & $4 / 22 / 71$ & $\mathrm{WO}_{2}-25 \mathrm{Nt} \mathrm{A \textrm {O } _ { 2 }}$ & (37) & FEDA & 662 & 16,000 & $0.1+2 . \operatorname{se}^{\mathrm{E}}=3 . \theta$ \\
\hline$x 0 \% 2 k$ & $(6 \mathrm{c}+)$ & $3 / 29 / 71$ & $\operatorname{mrk} I I$ & (37) & Nit & 1,467 & 5,800 & $0.6+6.6^{\mathrm{p}}=7.2$ \\
\hline$x 073^{x}$ & $(703)$ & $12 / 12 / 69$ & $\mathrm{HO}_{2}-25$ utt $\mathrm{PuO}_{2}$ & (37) & HEDL & 13,736 & 35,000 & 2.9 \\
\hline$x \cos d$ & $(7 / 2)$ & $3 / 27 / 70$ & $\mathrm{vO}_{2}-25$ wts $\mathrm{PuO}_{2}$ & (19) & WARD & $B, 661$ & 15,000 & 2.7 \\
\hline$x o r 8$ & $(6 \mathrm{~B} 3)$ & $2 / 24 / 71$ & $\begin{array}{l}\text { Mark IA } \\
\text { Mark IA }\end{array}$ & $(1)$ & ANL & 1,972 & 6,200 & $\begin{array}{l}0.4+4.2^{1}=4.6 \\
0.4\end{array}$ \\
\hline$x 079$ & (482) & $4 / 17 / 70$ & $\left(v_{0.85}-\mathrm{Pu}_{0.15}\right) c$ & $(19)$ & untc & 9,823 & $11,0 \infty 0$ & 5.0 \\
\hline$x 006$ & $\{6 \mathrm{E} 3)$ & $9 / 11 / 70$ & 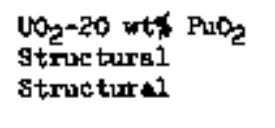 & $\left(\begin{array}{l}12 \\
1 \\
4\end{array}\right)$ & $\begin{array}{l}\text { MUDSC/ANL } \\
\mathrm{GE} \\
\mathrm{GE}\end{array}$ & 4,418 & 7,000 & $\begin{array}{l}1.6+11.0^{-}-12,6 \\
1.2+8.2^{=}=9+4 \\
1.2+1.0^{=}=2.2\end{array}$ \\
\hline$x 081^{4}$ & $(7 F 6)$ & $3 / 24 / 70$ & $v \mathrm{O}_{2}-25 \mathrm{PuD_{2 }}$ & (9) & $\mathrm{GE}$ & 7,160 & 19,000 & $2.2+6.7 t=8.9$ \\
\hline$x \operatorname{cosen}$ & $\{s+i)$ & $2 / 23 / 71$ & Mark IA & (61) & ANt & 1,972 & 3,500 & $0.3+2.8+3.1$ \\
\hline$x 083$ & (5E2) & $9 / 15 / 70$ & Mark Ih & (61) & ANC & 4,497 & 13,900 & 1.2 \\
\hline$x 0.54$ & $(5,2)$ & $2 / 24 / 71$ & 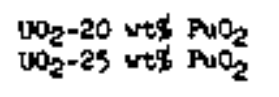 & $\begin{array}{l}(1) \\
(19)\end{array}$ & $\begin{array}{l}\text { ANL } \\
\text { ANI }\end{array}$ & 1,972 & Fallure & $\begin{array}{l}0.8+11.0 *=11.8 \\
0.8\end{array}$ \\
\hline$x 085^{h}$ & $(4 \mathbb{2})$ & $10 / 28 / 70$ & $\mathrm{WO}_{2}-25 \mathrm{xt}+\mathrm{PuO}_{\mathrm{2}}$ & (29) & AML & 1,480 & 10,000 & 0.6 \\
\hline$x 086$ & (SDL) & $\theta / 7 / 70$ & 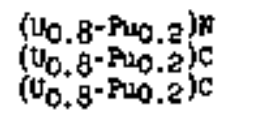 & $\left.\begin{array}{l}(10) \\
(5) \\
4\end{array}\right)$ & $\begin{array}{l}\text { EMI } \\
\text { LASL } \\
\text { WARB }\end{array}$ & 5,768 & 7,000 & $\begin{array}{l}2.9 \\
2.9 \\
2.6\end{array}$ \\
\hline Xoeta & $(\epsilon \in z)$ & $10 / 27 / 70$ & $\mathrm{tW}_{2}-25 \mathrm{vt} \mathrm{FuO}_{2}$ & $(61)$ & fEDL & 2,947 & 19,000 & $0.6+1.1^{e}=1.7$ \\
\hline$x 088^{d}$ & $(7 c 4)$ & $5 / 24 / 70$ & $\mathrm{WO}_{2}-25$ wt\$ $\mathrm{PuO}_{2}$ & $(19)$ & HARD & 7,160 & 14,500 & 1.8 \\
\hline$x 089$ & (2F1) & $9 / 25 / 70$ & structural & $(7)$ & HEDD & 4,497 & 7,800 & 1.9 \\
\hline$x 090$ & $(705)$ & $9 / 15 / 70$ & $\begin{array}{l}\text { Structural } \\
\text { structural } \\
\text { structural } \\
\text { Structural }\end{array}$ & $\left.\begin{array}{l}\left(\begin{array}{l}4 \\
2\end{array}\right) \\
1 \\
1\end{array}\right)$ & 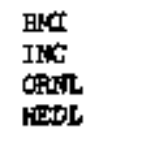 & $4,4,97$ & 6,300 & $\begin{array}{l}0.9 \\
0.9 \\
0.9 \\
0.9\end{array}$ \\
\hline
\end{tabular}


TABAE I, 3 (Cootd,)

\begin{tabular}{|c|c|c|c|c|c|c|c|c|}
\hline \multicolumn{2}{|c|}{$\begin{array}{l}\text { Subassecoly Ho. } \\
\text { and (Position) }\end{array}$} & \multirow{2}{*}{$\frac{\begin{array}{c}\text { Date } \\
\text { Landed }\end{array}}{9 / 11 / 70}$} & \multicolumn{2}{|l|}{$\begin{array}{c}\text { Gontant and } \\
\text { (Huber of Caputules) }\end{array}$} & \multirow{2}{*}{$\begin{array}{l}\text { Expert- } \\
\text { menter } \\
\text { HEDL }\end{array}$} & \multirow{2}{*}{ 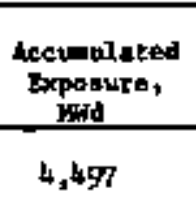 } & \multirow{2}{*}{ 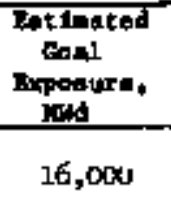 } & \multirow{2}{*}{$\frac{\text { Aurneng }}{i .7}$} \\
\hline$x 091$ & $(4+83)$ & & Structural & $(7)$ & & & & \\
\hline$x 093$ & $(6 \sqrt{4})$ & $10 / 27 / 70$ & $\mathrm{WO}_{2}-25 \mathrm{wt5} \mathrm{PuO}_{2}$ & (61) & KFODL1. & 2, की 7 & 16,000 & 1.0 \\
\hline$x \log 4^{d}$ & $\left(\mathrm{~TB}_{4}\right)$ & $11 / 16 / 70$ & $00_{2}-25$ wto PuOL & $(7)$ & COH & 584 & $8,6 \infty$ & 0.2 \\
\hline$x 095$ & $\{7 A 5)$ & $9 / 18 / 70$ & Structaral & $(1)$ & KRL & 4,476 & 11,000 & 0.9 \\
\hline$x \cos 7$ & $(5,2)$ & $3 / 18 / 71$ & $U D_{2}-25$ wts POO & (61) & HEDL & 1,467 & 24,000 & 0.7 \\
\hline$x 098$ & $(4 c 2)$ & $11 / 16 / 70$ & Strustural & $(19)$ & $G E$ & 2,972 & 8,000 & 0.7 \\
\hline$x 099$ & $(7 \% 5)$ & $11 / 16 / 70$ & Boron Carbide & (6) & OANL & $1,9 \pi$ & 20,000 & 0.4 \\
\hline$x 100$ & $(201)$ & 10/7/70 & Structurar & $(7)$ & ORa & 3,727 & 10,000 & 1.5 \\
\hline$x+02$ & $(\mathrm{~T} \mathbf{L})$ & $2 / 22 / 71$ & Structural Corrogion & $(1)$ & AKL & 2,972 & 20,000 & 0.3 \\
\hline$\times 106$ & $\{605)$ & $2 / 29 / 71$ & $100_{2}-20$ wts: $\mathrm{PuO}_{2}$ & $(7)$ & APIL & 1,972 & Faqluxt & $0.7+6.09-6.7$ \\
\hline $\operatorname{xog} t$ & (20n) & 5/ $6 / 71$ & $\begin{array}{l}\mathrm{tO}_{2}-25 \text { uth FuO } \\
\mathrm{HO}_{2}-25 \text { wt } \mathrm{FrO}\end{array}$ & $\left(\begin{array}{c}16 \\
3\end{array}\right)$ & $\begin{array}{l}\text { KEDL } \\
\text { HEDLL }\end{array}$ & 12 & 12 & $\begin{array}{l}\approx 0 \\
\approx 0+5.3^{2}=5.3\end{array}$ \\
\hline$x \geq 10$ & (7C5) & $2 / 22 / 71$ & Structural & $(7)$ & $\operatorname{In} \boldsymbol{x}$ & 2,972 & 7,500 & 0.4 \\
\hline$x+21$ & $(805)$ & $2 / 24 / 71$ & Ftasion Yierds & (4) & $\pi x$ & $1,9 T 2$ & 3,100 & 0.3 \\
\hline$x 112$ & $(6 \mathrm{~B} 2)$ & $5 / 12 / 71$ & 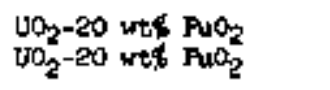 & $\begin{array}{l}19) \\
(19)\end{array}$ & $\begin{array}{l}\text { OFin } \\
\text { B\&H }\end{array}$ & 0 & 10,000 & 0 \\
\hline$x+23$ & $(6 \mathbf{n})$ & $4 / 22 / 71$ & 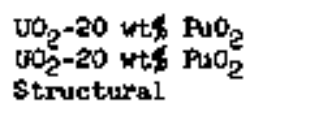 & $\left(\begin{array}{c}13 \\
5 \\
1\end{array}\right)$ & $\begin{array}{l}\text { AML } \\
\text { AML/ MIMISC } \\
\text { AML }\end{array}$ & 662 & 10,000 & $\begin{array}{l}0.2+3.7^{*}=3.9 \\
0.2+9.8^{0}=10.0 \\
0.1+2.4^{*}=2.5\end{array}$ \\
\hline$x+4$ & $\left(6 c_{3}\right)$ & $1 / 22 / 71$ & 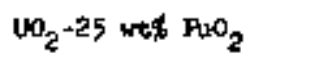 & (19) & $1 \mathrm{EOL} / \mathrm{ANL}$ & 662 & Faflure & $0.2+5.7^{*}-5.9$ \\
\hline$x 215$ & $(6 \mathrm{Dl})$ & $4 / 21 / 7$ & $\mathrm{HO}_{2}-25$ wts $\mathrm{FuO}_{2}$ & $(37)$ & WAFD & $6 \leqslant 2$ & 24,000 & 0.2 \\
\hline xn16 & $(673)$ & $4 / 22 / 71$ & 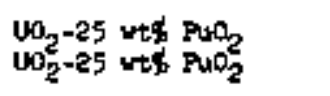 & $(14)$ & $\begin{array}{l}\text { HED/ARL } \\
\text { HOL/ARL }\end{array}$ & 662 & 5,000 & $\begin{array}{l}0.2+5.7=5.9 \\
0.2\end{array}$ \\
\hline xרב & $(\theta \mathrm{B} 2)$ & $2 / 2+/ 71$ & $\mathrm{WO}_{2}-25$ wh $\mathrm{PLO}_{2}$ & $(9)$ & $\mathbf{e x}$ & 1,893 & 30,000 & $0.4+4.9^{9}=5.3$ \\
\hline$x \geq 8$ & $(8 \log )$ & $2 / 24 / 71$ & $\mathrm{w}_{2}-25 w \mathrm{t}, \mathrm{PuO}$ & $(10)$ & WE & 1,893 & $30, \infty 00$ & $0.4+5.265 .6$ \\
\hline$x 120$ & $(723)$ & $5 / 6 / 71$ & $\begin{array}{l}\text { Boron carbide } \\
\text { Tantalum }\end{array}$ & $\left(\begin{array}{l}6 \\
1\end{array}\right)$ & HEDL, & 12 & 4,000 & 20 \\
\hline
\end{tabular}

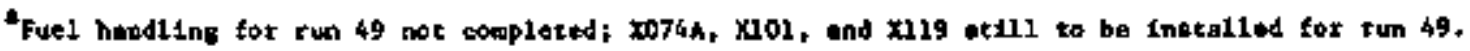

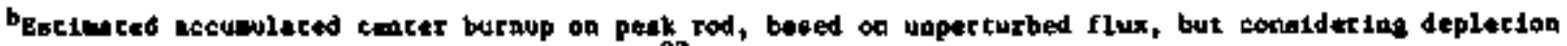
effecto (fuela, at. $x_{\text {; }}$ reafuela, nTt $\times 10^{-22}$ ).

ctemingted at and of rup $48 E$,

themoved to storage bakket for cunt $48 \mathrm{C}-48 \mathrm{E}$.

'Pravious exposure froe another subsectibly.

f Removed to etorage bopket fox rund till and $48 E$.

Benoved to akorage bogket for run $4 \mathrm{AE}$.

hasoved to etorage besket for runt $48 \mathrm{~A}-48 \mathrm{E}$.
} 


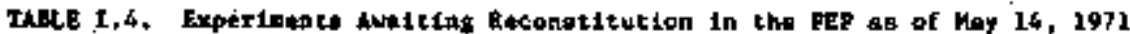

\begin{tabular}{|c|c|c|c|c|c|c|}
\hline 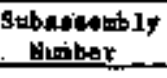 & Type & $\begin{array}{l}\text { Experi- } \\
\text { mithter }\end{array}$ & Cogresac & $\begin{array}{l}\text { Murion of } \\
\text { क्pasules }\end{array}$ & Burnute & Afrilsued bo \\
\hline 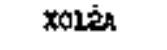 & Al9 & MI & $\mathrm{VO}_{2}-2 \mathrm{Wt} \times \mathrm{ArO}_{2}$ & 2 & 21.0 & roson \\
\hline$x 027$ & A19 & GE & $10_{2}-25 \times t \leqslant \mathrm{AOO}_{2}$ & 12 & 9.7 & -- \\
\hline$x 032$ & A19 & HEDL. & $\mathrm{NO}_{2}=25+4 \times \mathrm{PuO}_{2}$ & 2 & 5.4 & spare \\
\hline $\mathrm{xO}+\mathrm{kB}$ & E? & Keni & Concrol-rod Macl. & 7 & $3+5$ & xo4 35 \\
\hline$\dot{x} 0$;i & r37h & แต่ว & $\mathrm{WH}_{2}-25 \cdot \mathrm{tw} \mathrm{HaO}_{2}$ & . 37 & $3+2$ & $x 031 A$ \\
\hline$x 059$ & $835 \mathrm{~A}$ & EEDil & $\mathrm{UP}_{2}-29$ wtof $\mathrm{ArO}_{2}$ & 37 & 4.8 & $1059 A$ \\
\hline xogi i & \$19 & $G B$ & $\mathrm{UO}_{2}-25 \leqslant \mathrm{PrO}_{2}$ & 14 & 6.3 & -- \\
\hline$x 070$ & A19 & Ant & $\mathrm{NO}_{2}-20 \mathrm{w}+\mathrm{P} \mathrm{PuO}_{2}$ & 2 & 9.7 & $\mathbf{x} 080 \mathrm{~A}$ \\
\hline xo75 & 109 & $\ln 10$ & $\left(U_{0.85}-P_{0.15}\right) \mathrm{C}$ & 9 & 2.7 & --- \\
\hline
\end{tabular}

Tricluded untrradigtë̀ replacesents, 11 ayaliabla at EBR-II.

bigrinated actumblated centez butrup on geale rod, baen on unperturbed flux,

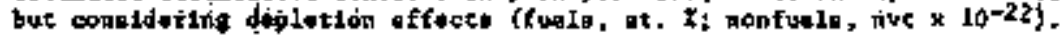

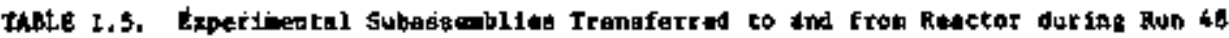

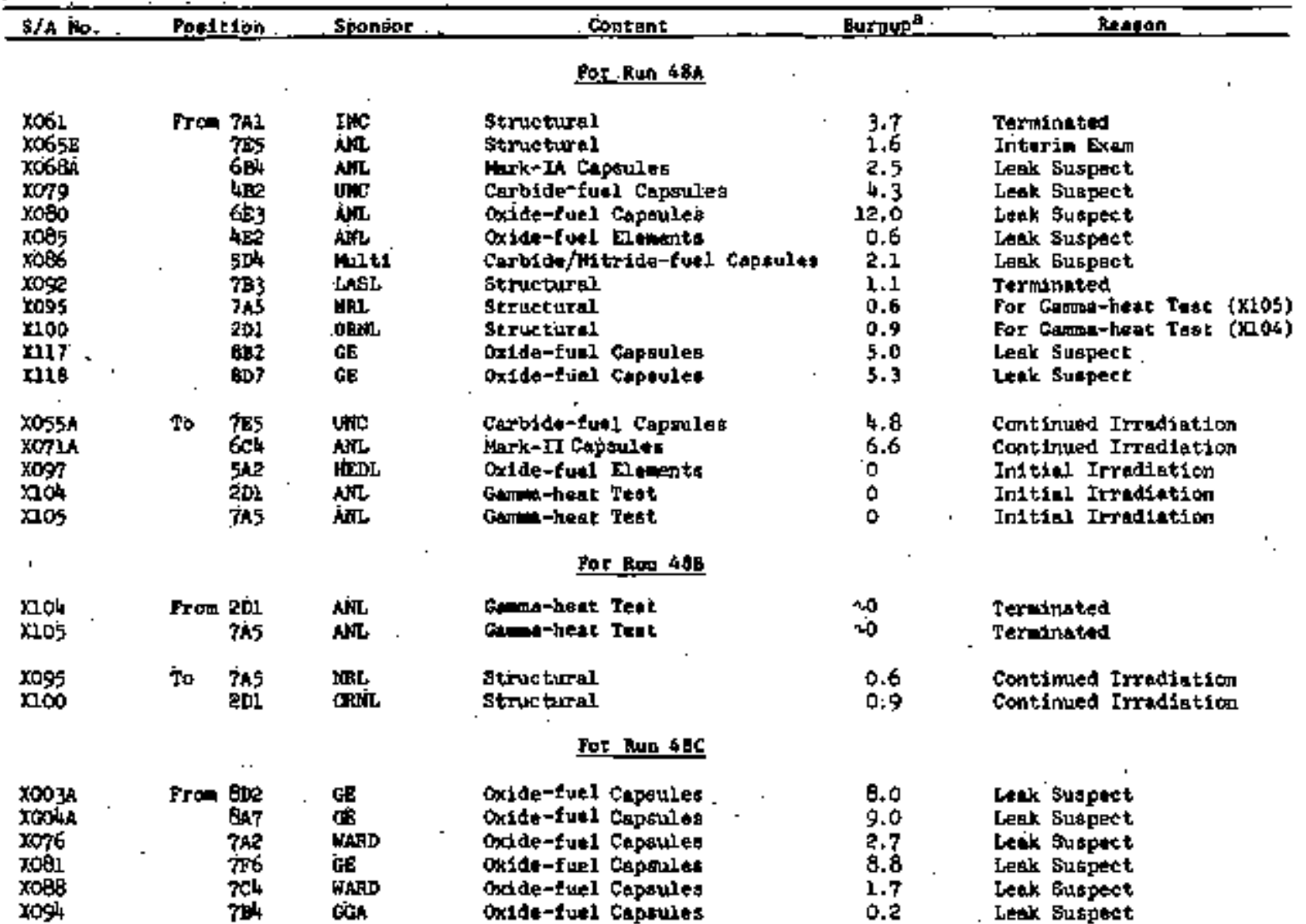


TABLE 1.5 (Contd.)

\begin{tabular}{|c|c|c|c|c|c|c|}
\hline s/a No. & Poot & then & Spontar & Contrat & Burpoper & Megean \\
\hline $\begin{array}{l}\text { xos8h } \\
\text { x079 } \\
x 080 \\
x 086 \\
x 117 \\
x 118\end{array}$ & To & 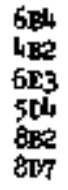 & $\begin{array}{l}\text { ANL } \\
\text { GNC } \\
\text { ANL } \\
\text { Multit } \\
\text { GE } \\
\text { DE }\end{array}$ & 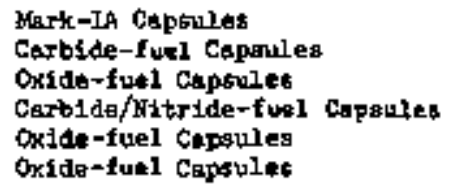 & $\begin{array}{r}2.5 \\
4.3 \\
12.0 \\
2.1 \\
5.0 \\
5.3\end{array}$ & 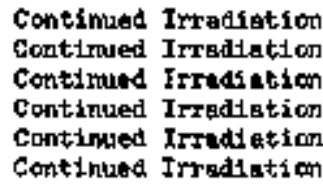 \\
\hline \multicolumn{7}{|c|}{ For Rum 68D } \\
\hline$x 058$ & Frtm & TB6 & (a) & Oxdde-fund Blements & 6.4 & Leak Sugpect \\
\hline $\begin{array}{l}X 065 \% \\
X 0694 \\
X 113 \\
x 114 \\
x 115 \\
x \geq 16\end{array}$ & $\mathbf{T o}$ & $\begin{array}{l}785 \\
6 \mathrm{FH} \\
6 \mathrm{FI} \\
6 \mathrm{CO} \\
6 \mathrm{DI} \\
6 \mathrm{F3}\end{array}$ & $\begin{array}{l}\text { ANL } \\
\text { FEDL } \\
\text { ANT } \\
\text { ANR } \\
\text { WNRD } \\
\text { ARL }\end{array}$ & 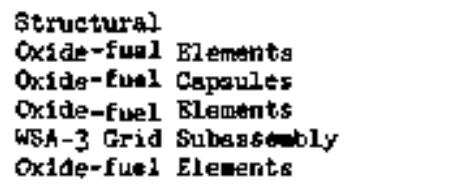 & $\begin{array}{l}1.6 \\
2.9 \\
9.6 \\
5.7 \\
0 \\
5.7\end{array}$ & $\begin{array}{l}\text { Continued Irradiation } \\
\text { Continued Irradiation } \\
\text { Instial Irradiation } \\
\text { Inftial Irradiation } \\
\text { Initial Irradistion } \\
\text { Inttial Irradiation }\end{array}$ \\
\hline \multicolumn{7}{|c|}{ For Run 48E } \\
\hline$x \times 73$ & From & 709 & HEDL & Oxide-futil Bitemente & 2.9 & Leate Suspect \\
\hline $\begin{array}{l}\mathrm{X} 108 \\
\mathrm{X} 120\end{array}$ & To & $\frac{2 \mathrm{Bl}}{7 \mathrm{E} 3}$ & $\begin{array}{l}\text { HEDL } \\
\text { HEXIL }\end{array}$ & $\begin{array}{l}\text { Cxide-fuel Elemente } \\
\text { Control-rod Haterial }\end{array}$ & $\begin{array}{c}5.3 \\
0\end{array}$ & $\begin{array}{l}\text { Initial Irradiation } \\
\text { In1tiol Irradiation }\end{array}$ \\
\hline
\end{tabular}

Entpated sccumulated eepter burnup on peak tod, bated an unpercurbed flux, but conoidertas depletion effecto (fuelo, ak. $x$; nopfuels, nvt $\times 10^{-22}$ )

(b) Precision Gamma Scanner System (J. W. Rizzie). Installation and testing of the precision gamma scanner system are nearing completion in the FEF. The system consists of a DATACRAFT programmed digital controller, a collimator/counter penetration into the FEF air cell, and a programmable in-cell state. The scanner is expected to be in routine operation soon.

Gamma scanning is a nondestructive method for obtaining gamma-ray spectra of a sample as a function of position. From this information, the relative abundances of individual isotopes that make up the complex gamma-ray spectra are determined. The in-cell stage provides the precise positioning function necessary for plotting the gammaray spectra as a function of position. From the activity distribution within a sample, quantities such as relative burnup, dimensions, fission-product migration, power distributions, and gas evolution can be measured directly.

c. Experimental Support, M, J. Feidman, J. P. Bacca, N. R. Grant, R. V. Strain, R. D. Phipps, J, W. Rizzie, A. K. Chakraborty, D. B. Hagmann, G. M. Iverson, H. A. Taylor, and G. C. McClellan (Last reported: ANL-7798, p. 7)

Table 1.6 summarizes the current status of examinations of experimental-ir radiation subassemblies in the FEF, Also shown, as the last entry in the table, is the total number of FEF examinations of various types performed on the 37 experimental-irradiation subassemblies dismantled in fiscal year 1971 (through April 1971). 


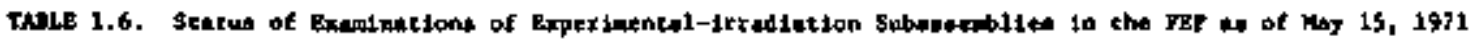

\begin{tabular}{|c|c|c|c|c|c|c|c|c|c|c|c|c|c|c|c|c|c|c|c|c|}
\hline \multirow[b]{2}{*}{$\begin{array}{l}\text { Submasenbly } \\
\text { no, and } \\
\text { \{Typt }\end{array}$} & \multirow[b]{2}{*}{$\begin{array}{l}\text { Cotteara asd } \\
\text { (Expet1oreter) }\end{array}$} & \multirow[b]{2}{*}{$\frac{1}{3}$} & \multicolumn{4}{|c|}{ Subargeably } & \multicolumn{12}{|c|}{ 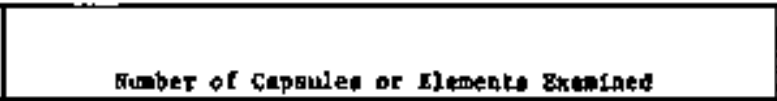 } & \multicolumn{2}{|c|}{ 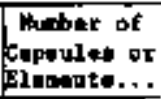 } \\
\hline & & & 案 & 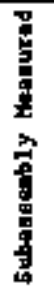 & 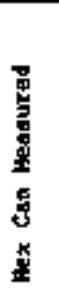 & 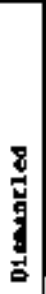 & 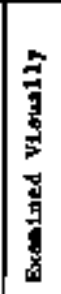 & 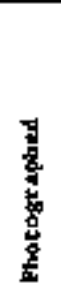 & 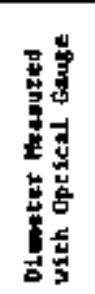 & 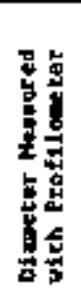 & $\begin{array}{l}8 \\
4 \\
5 \\
5 \\
\frac{8}{2} \\
\frac{n}{5} \\
5 \\
5\end{array}$ & $\begin{array}{l}\mathbf{3} \\
\mathbf{3} \\
\mathbf{5} \\
\mathbf{5} \\
5 \\
5\end{array}$ & 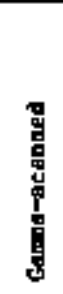 & 量 & 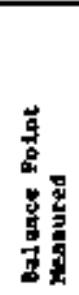 & 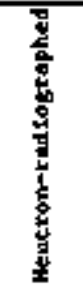 & 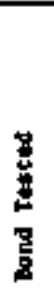 & 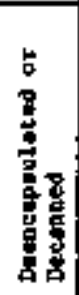 & 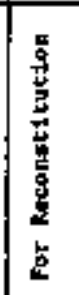 & 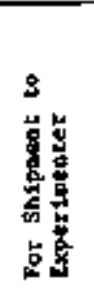 \\
\hline xol2k $(A 19)^{b}$ & $\begin{array}{l}\text { mixed-oxide capoving } \\
\text { (ANL) }\end{array}$ & 11.1 & $x$ & $\mathbf{x}$ & $\mathbf{x}$ & $\mathbf{I}$ & 19 & & $\mathbf{s}$ & & & & 9 & 19 & & 19 & & & 2 & \\
\hline$x 027(k 19)^{\circ}$ & $\begin{array}{l}\text { Mitxed-axide capoulen } \\
\text { (GE) }\end{array}$ & 9.7 & $x$ & $\mathbf{x}$ & $x$ & $x$ & 19 & & 10 & & 10 & 18 & 18 & 19 & & 18 & & & 12 & \\
\hline$x D$ a OA $(B 7)^{b}$ & $\begin{array}{l}\text { Kintd-oxid* ctpsuled } \\
\text { (dKL, } / \mathrm{GE})\end{array}$ & 6.1 & & & & & 15 & 15 & 15 & 7 & 15 & 15 & 5 & 15 & & & & & B & \\
\hline$\times 042 B(B>)^{C}$ & $\begin{array}{l}\text { seructurel captul } \\
\text { (Hebl) }\end{array}$ & 3.5 & & & & & & & 7 & & 7 & 7 & & 3 & & & & & & \\
\hline xusa (f3ra) & $\begin{array}{l}\text { Mixed-oride uleopente } \\
\text { (AED) }\end{array}$ & 3.2 & $x$ & & & $\boldsymbol{x}$ & 37 & 37 & 37 & $3 \mathbf{3}$ & & & & 37 & 3 & 37 & & & 3 & \\
\hline$x 059(F 37 n)^{b}$ & $\begin{array}{l}\text { Mixed-oxide el earats } \\
\text { [HRDL] }\end{array}$ & 4.8 & $x^{d}$ & & & $\mathbf{x}$ & 37 & y) & 37 & 7 & & & & 37 & $\mathbf{3}$ & 3) & & & 33 & \\
\hline$x 061(B ?)^{e}$ & $\begin{array}{l}\text { Seructural chpouleo } \\
\text { (Itwe) }\end{array}$ & 3.7 & $x$ & $x$ & $x$ & $x$ & 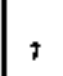 & 7 & 2 & & & & & 7 & & & & & $\mathbf{0}$ & 7 \\
\hline x064 (A19) & $\begin{array}{l}\text { tixed-oxide capouled } \\
\text { (GX) }\end{array}$ & 6.3 & $x$ & $x$ & $\mathbf{I}$ & $x$ & 19 & & 19 & $s$ & 19 & 19 & & 19 & & 19 & & & 14 & \\
\hline$x 065 E(B 37)^{b}$ & $\begin{array}{l}\text { Prefrurtzed creep } \\
\text { tubed (AKL) }\end{array}$ & 1.6 & $x$ & & & $x$ & 25 & & 23 & 25 & & & & & & & & & 21 & 2 \\
\hline vo70 $(219)^{b}$ & $\begin{array}{l}\text { Mrxed-oxide and } \\
\text {-çarbide capaulat }\end{array}$ & & & & & & & & & & & & & & & & & & & \\
\hline & $\left(A N B / U_{A R D}\right)$ & 3.7 & $x$ & $x$ & $x$ & * & 19 & & 19 & 14 & 19 & 19 & & 19 & & 19 & & & 8 & \\
\hline$x 075(419)^{\circ}$ & $\begin{array}{l}\text { Hixted-carbldt ctppules } \\
\text { (undt) }\end{array}$ & $2+7$ & $x$ & & & $\mathrm{x}$ & 18 & & 10 & 9 & 9 & & & 18 & & 18 & & & 9 & \\
\hline $\operatorname{xog} 2(\mathrm{~B} 7)^{t}$ & $\begin{array}{l}\text { Sertierural capaulea } \\
\text { (IASL) }\end{array}$ & 0.6 & $x$ & $\boldsymbol{x}$ & K & K & $\mathbf{1}$ & & 1 & & & & & $\mathbf{t}$ & & & & & 0 & 1 \\
\hline$x 104(B 7 A)^{+}$ & 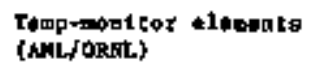 & 0.008 & $\mathbf{x}$ & & & $x$ & 3 & & & & & & & & & $\mathbf{t}$ & & 3 & & $\mathbf{g}$ \\
\hline $\operatorname{mos}(B>A)^{e}$ & $\begin{array}{l}\text { Temp-tositor elemedte } \\
\text { (ANLORL) }\end{array}$ & $0.00 \mathrm{a}$ & $x$ & & & $x$ & 3 & & & & & & & & & $\mathbf{1}$ & & 3 & & B \\
\hline$x \log (\text { Arg })^{e}$ & $\begin{array}{l}\text { Hond-oxide capoules } \\
\text { (HEDL) }\end{array}$ & 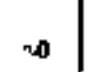 & $x$ & $x$ & $x$ & $x$ & 19 & & & & & & & & & 19 & & & 0 & 19 \\
\hline 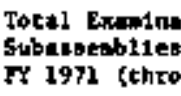 & 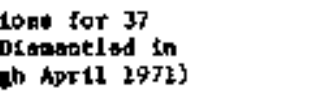 & & & & & & b12 & $r$ & 451 & 329 & & 80 & 254 & 427 & 30 & 997 & D & 15 & $=$ & 121 \\
\hline
\end{tabular}

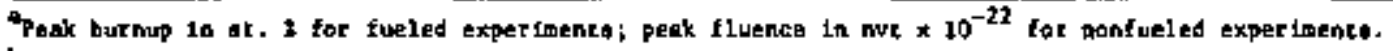

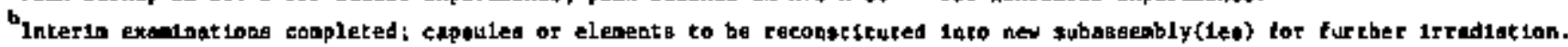

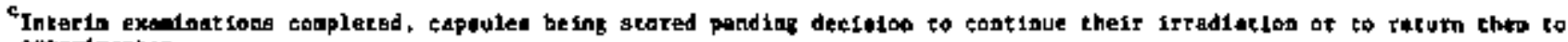
exporibenter.

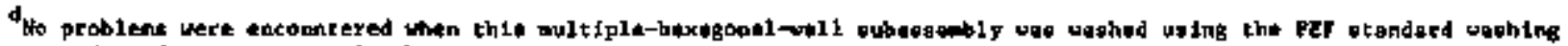

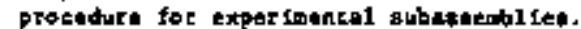

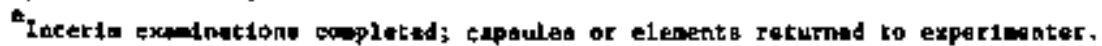

rylt-ulck tomparakura moltare only.

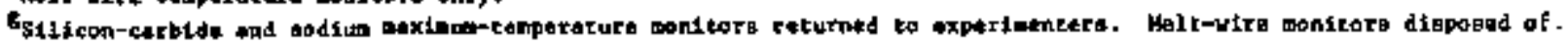


The following new subassemblies were made up with new capsules or elements and sent to the reactor:

$\begin{array}{ccc}\begin{array}{c}\text { Subassembly } \\ \text { No. }\end{array} & \begin{array}{c}\text { Subassembly } \\ \text { Type }\end{array} & \end{array}$

Table 1.7 lists the subassemblies reconstituted and sent to the reactor during this reporting period.

TAELE I.7. Subaggenblies Reconsticuced in the FEF

Subassenbly No. and (Type)

Coptents

X065F (B37)

21 ANl pressurized creep capoules for seventh irradiation (cunulative peak fluence on capgules heving completed sixth 1rcadistion is $1.7 \times 10^{22}$ nvt); 16 dumpy plements

$\mathrm{X074A}$ (H37A)

37 GEOL mixed-oxide fuel elenents - one new and 36 Irradiated to peak burnup of 3.4 at. in subassembly $\times 074$

X108 (A19)

19 hEDl mixed-oxide fuel elements - 16 new, one 1 rradiared to pesk burmup of 1.1 ac, $\mathrm{F}$ in subassembly $\mathrm{X031}$, and two ircadiated to peak burnup of 5.3 ac. 7 in subassenbly K032

X113(A19)

13 AnL aixed-oxide fuel capsules frradiated to peak burnup of 3.7 at. I In subsssembly x072; one ANl structural element irradiated to peak Iluence of $2.5 \times 10^{22}$ nut in subassembly X072; Ilve NIMEC mixed-oxide fuel capsules itradiated to peak butrup of 9.8 at. $*$ in subassembly $x 070$

X114 (E190) 19 HEDL mixed-oxide fuel lements irradiated to peak butrup of 5.7 at. I in subassemb1y $x 054$

X116 (E190)

19 HEDl mixed-oxide fuel elements - four new and 15 1rradiated to peak burnup of $5.7 \mathrm{at}$. I in subasgerbly X054

X119 (Al9)

Three orst mixed-oxide fuel capsules irradiated to peak burnup of 6 at, 7 in subessembly XO50; one WARD mixed-carbide fuel capoule Irradiated to peak butnup af 3.7 at. * In subassembly XO70; seven new BMI mixed-nitride fuel capsules; elght new LASL and WARD mixed-carbide fuel capsules 
B: Fuels and Materials Studies

1. Coolant Chemistry. D. W. Cissel (0Z-051)

a. Monitoring of Sodium-Coolant Quality. W. H. Olson, C. C. Miles, T. P. Ramachandran, and E. R. Ebersole (Last reported:

ANL-7798, p. 10)

(1) Radionuclides in Sodium. Table 1.8 lists results of analyses for ${ }^{137} \mathrm{Cs}$ and ${ }^{131} \mathrm{I}$ in the primary sodium. An increase in ${ }^{137} \mathrm{Cs}$ activity is evident beginning with the sample of April 16. The source of ${ }^{137} \mathrm{Cs}$ is believed to be defective element cladding of experimental-írradiation subassembly X073. (Also see Sect. I.D.2.a.) This is the second increase in the ${ }^{137} \mathrm{Cs}$ activity of EBR-II primary sodium. The first occurred in June 1967.

TARLE I.8. ${ }^{137} \mathrm{Cs}$ and ${ }^{131}$ I in Primary Sodium

\begin{tabular}{|c|c|c|c|c|c|c|c|}
\hline $\begin{array}{l}\text { Sample } \\
\text { Date }\end{array}$ & $\begin{array}{l}\text { Sample } \\
\text { Size, } \mathrm{g}\end{array}$ & $\begin{array}{l}\text { Sample } \\
\text { Flow, gpn }\end{array}$ & $\begin{array}{l}\text { Flush } \\
\text { rime, tin }\end{array}$ & $\begin{array}{l}\text { Sample } \\
\text { Temp, }{ }^{\circ} \mathrm{F}\end{array}$ & $\begin{array}{l}\text { Bulk } \\
\text { Sodium } \\
\text { Teup, }{ }^{\circ} \mathrm{F}\end{array}$ & $\begin{array}{l}{ }^{137} \mathrm{Cs}, \\
{ }_{\mathrm{n}} \mathrm{Ci} / \mathrm{s}\end{array}$ & $\begin{array}{l}131_{\mathrm{I}}, \\
\mathrm{PCi} / \mathrm{g}\end{array}$ \\
\hline$-3 / 5 / 71$ & 13,2 & 0.4 & 15 & 620 & 660 & 11 & 25 \\
\hline $3 / 10 / 71$ & 12.2 & 0.4 & 15 & 570 & 670 & 12 & 67 \\
\hline $3 / 12 / 71$ & 13.2 & 0.4 & 15 & 589 & 670 & 13 & 150 \\
\hline $3 / 15 / 71$ & 12,5 & 0.4 & 15 & 630 & 665 & 13 & 140 \\
\hline $3 / 26 / 71$ & 12.1 & 0.4 & 18 & 575 & 665 & 13 & 86 \\
\hline $4 / 5 / 71$ & 12.0 & 0.4 & 15 & 600 & 665 & 14 & 47 \\
\hline $4 / 12 / 71$ & 13.1 & 0.4 & 18 & 623 & 668 & 14 & 79 \\
\hline $4 / 16 / 71$. & 13.9 & 0.4 & 15 & 660 & 668 & 18 & 140 \\
\hline $4 / 21 / 71$ & 13.6 & 0.4 & 15 & 610 & 665 & 18 & 150 \\
\hline $4 / 27 / 71$ & 13.4 & 0.4 & 15 & 612 & 665 & 19 & 143 \\
\hline $4 / 27 / 71^{g}$ & 13.1 & 0.5 & 15 & 520 & 695 & 18 & 130 \\
\hline
\end{tabular}

asmple taken from the primary puriftcation loop; all other sạnples taken from the fuel-element-rupture detection loop.

Table I. 9 lists total activities of activation products in the primary sodium. Determinations were made on the residue from distillation of $\sim 50 \mathrm{~g}$ of sọdiurn. 
TABLE I.9. Aftivation Products in 86,000 gal of Primary Sodium

\begin{tabular}{|c|c|c|c|c|c|}
\hline \multirow[b]{2}{*}{ Isotope } & \multicolumn{2}{|c|}{ Total Activity, $\mathrm{Ci}$} & \multirow[b]{2}{*}{ Isotope } & \multicolumn{2}{|c|}{ Total Activity, Ci } \\
\hline & $2 / 16 / 71$ & $4 / 23 / 71$ & & $2 / 16 / 71$ & $4 / 23 / 71$ \\
\hline $\operatorname{Irom}_{A g}$ & 0.17 & 0.18 & $\lim _{\mathrm{Sn}}$ & 0.023 & 1,33 \\
\hline${ }^{54} \mathrm{Mn}$ & None dekected & 0.014 & ${ }^{113} \mathrm{Sn}+{ }^{113 m^{1 n}}$ & 2.41 & 1.51 \\
\hline${ }^{125} \mathrm{Sb}$ & $0.04 \mathrm{~J}$ & 0.14 & & & \\
\hline
\end{tabular}

(2) Trace Metals in Sodium. Table 1.10 lists results of analyses for trace metals in sodium. Samples were taken in titanium crucibles and vacuum-distilled in the laboratory. Metals in the residue are measured by atomic-absorption spectrophotometry.

\begin{tabular}{|c|c|c|c|c|c|c|c|c|c|c|c|c|c|c|c|c|c|c|c|c|}
\hline \multirow{2}{*}{ Sampir } & \multirow{2}{*}{$\begin{array}{c}\text { Somplo } \\
\text { Siner } \\
9\end{array}$} & \multirow{2}{*}{ Simpla } & \multirow{2}{*}{ 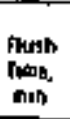 } & \multirow{2}{*}{ 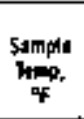 } & \multirow{2}{*}{$\begin{array}{l}\text { fulk } \\
\text { Semp. } \\
\text { Temp. }\end{array}$} & \multicolumn{15}{|c|}{ Concendralian, $k_{0}$} \\
\hline & & & & & & M & $N$ & Di & co & cis & Gr & w & Fe & $\ln$ & 为 & $m$ & $m$ & NII & $\mathbf{A}$ & $5 n$ \\
\hline \multicolumn{21}{|c|}{ Primury solusur } \\
\hline $40 * 1\}$ & 35 & 0.5 & $\mathbf{3}$ & 50 & $m$ & 005 & 0.6 & 3.0 & $\Phi 0$ & 402 & 408 & 03 & $a, n$ & क. & ons & $\operatorname{cocos}$ & Qtor & of tos & 48 & 235 \\
\hline \multicolumn{21}{|c|}{ Soctindary sodiun } \\
\hline $\begin{array}{l}\text { yinhl } \\
\text { X7wn } \\
\text { with }\end{array}$ & $\begin{array}{l}45 \\
5 \\
5\end{array}$ & $\begin{array}{l}0.8 \\
0.55 \\
0.5\end{array}$ & $\begin{array}{l}71 \\
17 \\
15\end{array}$ & 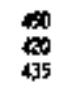 & 䑾 & $\begin{array}{l}00 \mathrm{~J} \\
0.01 \\
0 \times 5\end{array}$ & $\begin{array}{l}0.02 \\
\$ .6 \\
\$ .6\end{array}$ & 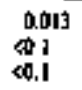 & $\begin{array}{c}\text { ADOh } \\
0013 \\
<0,01\end{array}$ & 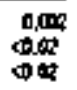 & $\begin{array}{l}0.00] \\
0.00 \\
0.016\end{array}$ & 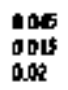 & $\begin{array}{l}0.04 \\
0.03 \\
0.00\end{array}$ & $\begin{array}{l}\text { a.1 } \\
\omega .06 \\
\omega .06\end{array}$ & $\begin{array}{l}0.07 \\
0,043 \\
0.017\end{array}$ & 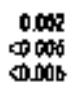 & 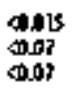 & 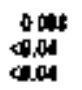 & $\begin{array}{l}06 \\
07 \\
035\end{array}$ & $\begin{array}{r}0.00 \\
\times 5 \\
\text { \& } 5\end{array}$ \\
\hline
\end{tabular}

(3) Oxygen in Sodiurn. Table I.1) lists results of analyses for axygen in sodium. Samples of $15 \mathrm{~g}$ were taken in stainless steel vessels and extrusion-aliquoted for analysis by the mercury-amalgamation method.

TABLE 1.11. Oxygen in Sodiuma

\begin{tabular}{|c|c|c|c|c|c|}
\hline $\begin{array}{l}\text { Sample } \\
\text { Da te }\end{array}$ & $\begin{array}{l}\text { Sample } \\
\text { Flow, gpm }\end{array}$ & $\begin{array}{c}\text { F2ugh } \\
\text { Time, min }\end{array}$ & $\begin{array}{l}\text { Sample } \\
\text { Teap, "F }\end{array}$ & $\begin{array}{l}\text { Bulk Sodium } \\
\text { Teap. "F }\end{array}$ & $\begin{array}{c}\text { Average } \\
\text { Concentration, ppn }\end{array}$ \\
\hline & \multicolumn{5}{|c|}{ Primaky Sodiun } \\
\hline $4 / 7 / 71^{b}$ & 0.4 & 15 & 660 & 665 & $1.3 \pm 0.4$ \\
\hline \multirow[t]{2}{*}{$4 / 23 / 71^{c}$} & 0.65 & 15 & 560 & 699 & $1.8 \pm 0.7$ \\
\hline & \multicolumn{5}{|c|}{ Secondary Sodiun } \\
\hline $3 / 3 / 71$ & 0.3 & 22 & 450 & 470 & $1.0 \pm 0.1$ \\
\hline $4 / 14 / 71$ & 0.80 & 15 & 450 & 490 & $0.4 \pm 0.1$ \\
\hline
\end{tabular}


(4) Carbon in Sodium. Table I.12 lists results of analyses for carbon in secondary sodium. (No analyses were made for carbon in primary sodium.) Samples of $15 \mathrm{~g}$ were taken in stainless steel vessels and extrusion-aliquoted for analysis by the oxyacidic-flux method.

TABLE I.12. Carbon In steondary Sodfun

\begin{tabular}{|c|c|c|c|c|c|c|}
\hline $\begin{array}{l}\text { Sample } \\
\text { Deace }\end{array}$ & $\begin{array}{l}\text { Souplt } \\
\text { Flow, ipe }\end{array}$ & $\begin{array}{l}\text { Flush } \\
\text { Time, D1n }\end{array}$ & $\begin{array}{l}\text { Salp le } \\
\text { Temp, } F\end{array}$ & $\begin{array}{l}\text { Bulk Sod1uk } \\
\text { Teap, "F }\end{array}$ & $\begin{array}{l}\text { Purber of } \\
\text { Allquotsa }\end{array}$ & $\begin{array}{l}\text { Averaga } \\
\text { Concentration, ppt }\end{array}$ \\
\hline $4 / 14 / J 1$ & 0.80 & 15 & 450 & 490 & 4 & $1.4 \pm 0.4$ \\
\hline
\end{tabular}

allquot size nl \&.

A recent sample of sodium taken from a loop operated by ANL-MSD was high in carbon when analyzed by the oxyacidic-flux method at EBR-II. No results as high had previously been obtained on any sodium samples obtained from EBR-II, Fermi, and loops operated by ANL, MSA, and $G E$. Thezefore, the validity of the results for the sodium from the ANLMSD loop was in question. To determine whether the high results could have been caused by contamination of the analytical equipinent. four aliquots of the sodium from the loop were analyzed alternately with four aliquots of EBR-II primary sodium. The results (in ppm) were:

$\begin{array}{lrlr}\text { MSD } & 28.6 & \text { MSD } & 17.8 \\ \text { EBR-II } & 1.8 & \text { EBR-II } & 1.4 \\ \text { MSD } & 27.8 & \text { MSD } & 26.1 \\ \text { EBR-II } & 1.3 & \text { EBR-II } & 2.1\end{array}$

(5) Silicon in Sodium. A method for determining silicon in sodium has been developed. A sample of sodium taken in a tantalum crucible is vacuum-distilled, and the residue is dissolved in aqua regia and hydrofluoric acid. The silicon content of the solution is measured spectrophotometrically using the molybdenum-blue method. The distillation cansot be performed in a titanium crucible, because titanium interferes in the color development. Table 1.13 lists recent results of anaiysis for silicon by this method.

TABLE 1+13. \$111can in Sodiute

\begin{tabular}{|c|c|c|c|c|c|c|}
\hline $\begin{array}{c}\text { Sample } \\
\text { Date }\end{array}$ & $\begin{array}{l}\text { Sanple } \\
\text { Sizt, } 2\end{array}$ & $\begin{array}{l}\text { Sarple } \\
\text { Flow, gpn }\end{array}$ & $\begin{array}{c}\text { Plush } \\
\text { Time, mint }\end{array}$ & $\begin{array}{l}\text { Sacople } \\
\text { Teup, }{ }^{\circ} \mathrm{F} \\
\end{array}$ & $\begin{array}{l}\text { Bulk Sodiun } \\
\text { Temp, }{ }^{\circ} F\end{array}$ & $\begin{array}{l}\text { Concencrecion, } \\
\text { Ppa }\end{array}$ \\
\hline \multicolumn{7}{|c|}{ Pribary sodiup } \\
\hline $2 / 11 / 71$ & 14 & 0.5 & 15 & 310 & $30 ?$ & 1.6 \\
\hline $4 / 29 / 71$ & 14 & 0.4 & 13 & 380 & 698 & 0.9 \\
\hline \multicolumn{7}{|c|}{ Secondary Sodiue } \\
\hline $2 / 16 / 71$ & 8.9 & 0.2 & 15 & 400 & 400 & 1.6 \\
\hline $3 / 15 / 11$ & 9.4 & 0.65 & 63 & 365 & 525 & 0.8 \\
\hline $4 / 21 / 71$ & $9+1$ & 0.6 & 30 & 360 & 535 & 0.9 \\
\hline
\end{tabular}


(6) Boron in Sodium. A method for determining boron in sodium has been developed. A sample of sodium taken in a tantalum crucible is vacuum-distilled, and the residue is mixed with $1 \mathrm{ml}$ of $10 \% \mathrm{NaOH}$. The water is removed by evaporation on a steam bath, and curcumin-acetic acid reagent is added. The boron-curcumin color is developed and is measured spectrophotometrically. The distillation cannot be performed in a titanium crucible, because tifanium interferes with the color development. Table I, 14 lists recent results of analysis for boron by this method.

TABLE I. 14. Boton in Sodiun

\begin{tabular}{|c|c|c|c|c|c|c|}
\hline $\begin{array}{l}\text { Saaple } \\
\text { Date }\end{array}$ & $\begin{array}{l}\text { Sample } \\
\text { S128, g }\end{array}$ & $\begin{array}{l}\text { Sample } \\
\text { Flow, gpo }\end{array}$ & $\begin{array}{l}\text { Flush } \\
\text { Ine, min }\end{array}$ & $\begin{array}{l}\text { Sample } \\
\text { Temp, }{ }^{F}\end{array}$ & $\begin{array}{c}\text { Bulk Sodlum } \\
\text { Temp, }{ }^{\mathrm{D}} \mathrm{F}\end{array}$ & $\begin{array}{c}\text { Concentration, } \\
\text { Ppr }\end{array}$ \\
\hline \multicolumn{7}{|c|}{ Primary Sodlum } \\
\hline $4 / 29 / 71$ & 14 & 0.4 & 15 & 580 & 698 & $<0.05$ \\
\hline & & & · Secondary & Sodtun & & \\
\hline $4 / 26 / 71$ & 9 & 0.7 & 40 & 380 & 570 & $<0.05$ \\
\hline
\end{tabular}

b. Radioactive Sodium Chemistry Loop. G. O. Haroldsen and

C. L. Livengood (Last reported: ANL-7427, p. 66, Feb 1968)

Installation of the radioactive sodium chemistry loòp (RSCL) in EBR-II has been completed. The RSCL was designed and constructed primarily to proof-test on-line devices for monitoring sodium-coolant quality. under operating conditions typical of anticipated future liquid-metal-cooled fast breeder reactors. It is in the basement of the EBR-II reactor building. Figure I.l is a pictorial layout of the loop, and Fig. I. 2 is a schematic diagram of flow and instrumentation.

The facility has three individually shielded cells ( $A, B$, and $C$ ) for experiments and teats, and includes provisions for two more cells $(D$ and $E$ ). The main piping loop is in a shielded tunnel adjacent to the cells. Shielding is designed to protect personnel working in any cell while the main loop and other cells are in operation. Access to the main loop will require shutdown of the loop and sufficient time for radioactivity to decay to safe levels.

The piping of the main loop consists of 2-in. supply and return headers connected on one end by a l-in. bypass. The other end of the loop is connected to the supply and return lines for the primary purification sys tem. Stub lines are provided to connect five subloops to the supply and return headers. Each stub line and the bypass line contain a remotely operated manual valve. The RSCL can be isolated from the primary purification sys. tem by $2-$ in. pneumatic valves in the supply and return headers. Pneumatic 


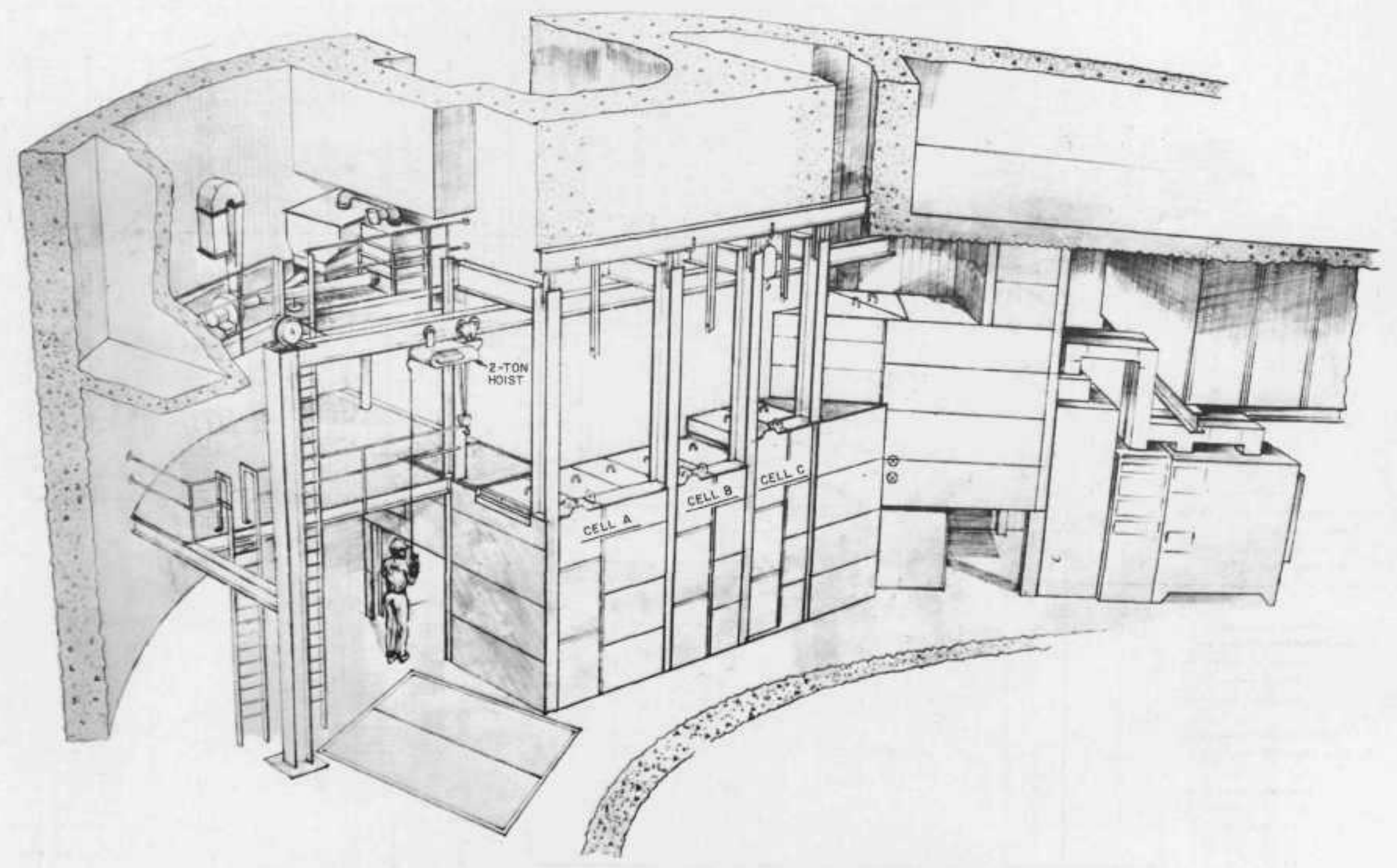

Fig. 1.1. Pictorial View of the Radioactive Sodium Chemistry Loop 


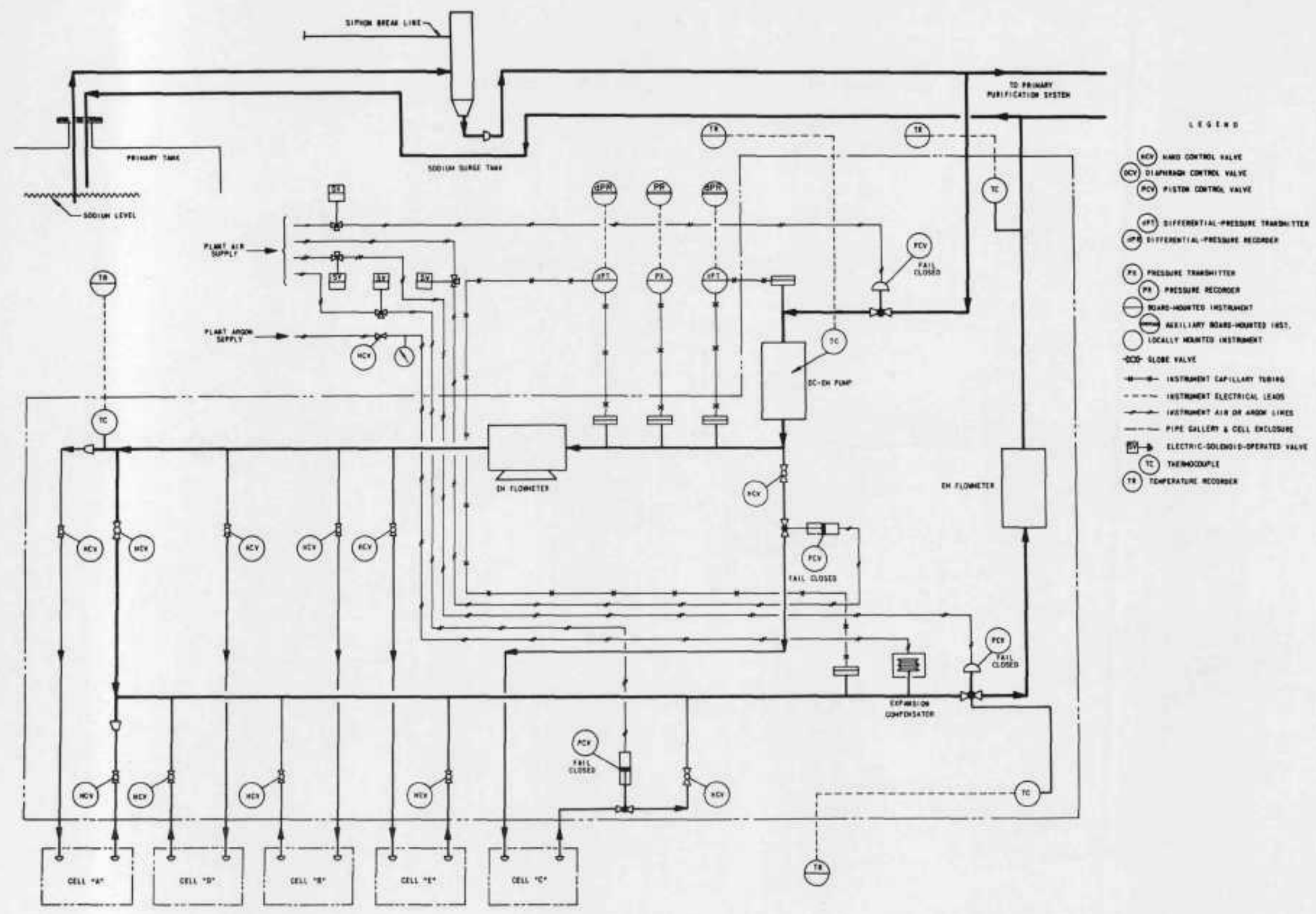

Fig. 1.2. Schematic Diagram of Flow and Instrumentation of the Radioactive Sodium Chemistry Loop 
isolation valves have also been provided in the stub lines to the subloop for cell C. These valves are in the pipe tunnel. Pneumatic isolation valves for the other subloops will be placed in the cells when experiments are installed.

A dc-EM pump provides a flow rate of $30 \mathrm{gpm}$ at $14 \mathrm{psig.} \mathrm{The}$ pump, powered by a rectifier rated at 0-8000 $\mathrm{A}$, has an output voltage that is adjustable between 0 and $2 \mathrm{~V}$. DC-EM flowmeters are in the supply and the return headers.

A highly automated instrumentation system has been provided. Besides the usual flow, temperature, pressure, and power instruments, automatic sodium-leak, smoke, and radiation detectors are provided. The segments of the trace-heating system are automatically controlled to progressively heat the piping starting at the connections to the primary purification system. A spare is installed for each heater segment.

Air ventilation of the RSCL is drawn from and exhausted to the reactor-building basement. Air is drawn into each of the cells, and the cells exhaust into the pipe tunnel through the pipe-sleeve penetrations. A $950-\mathrm{cfm}$ blower exhausts the pipe tunnel. In incident conditions, the vent valves automatically close to aid containment of the hazard. If the hazard involves a sodium fire, the automatic closing of the valves helps suffocate it.

Parallel filters in the ventilation exhaust system are provided to cover both normal and emergency operation. The normal path of the exhaust air is through a roughing filter followed by a high-efficiency (absolute) filter. In incident conditions, the exhaust air will be automatically routed to a combination filter consisting of a high-capacity, graded-media section followed by a high-efficiency filter section. This emergency air-filtering system has sufficient capacity to cope with a sodium spill of $53 \mathrm{lb}$ and an ensuing fire. This amount of sodium is larger than that which could conceivably be spilled in any of the experimental systems proposed at present.

A backup fire-protection system has also been provided. It consists of a Met-L-X powder system having "two-shot" capability. The RSCL area is divided into seven fire-control zones. Each cell is a zone, and the pipe tunnel is divided into two zones. By manual actuation, each of two 500-1b Met-L-X charges can be discharged, as desired, into any of the zones. The backup system can be actuated from inside or outside the reactor building.

The first experimental system is being installed in cell B of the RSCL. It consists of a module containing two Westinghouse oxygen meters, one ANL hydrogen meter, and associated support equipment. This experiment is part of the national meter program for testing on-line liquid-metal analyzers. 
2. Materials-Coolant Compatibility. D. W. Cissel (02-063)

a. Evaluation and Surveillance of EBR-II Materials. W. E. Ruther and D. G. Franklin (Last reported: ANL-7798, p. 22)

(1) Maximum-temperature Monitor for In-reactor Service. An entirely new concept has been originated for temperature-monitoring devices. Fortunately, the vessel for the sodium-expulsion type of monitor (see ANL7753, p. 60) could be modified to take advantage of the new concept. The new monitor depends on posttest, room-temperature measurements of the volume of a sealed stainless steel capsule containing sodium.

When the sealed capsules are heated, the sodium expands more than its stainless steel enclosure. Since liquid sodium has a low compressibility, the stainless steel is plastically deformed. This deformation is permanent, and the volume change of the capsule (measured at room temperature) may be correlated with the maximum temperature that the capsule reached and the mass of the encapsulated sodium.

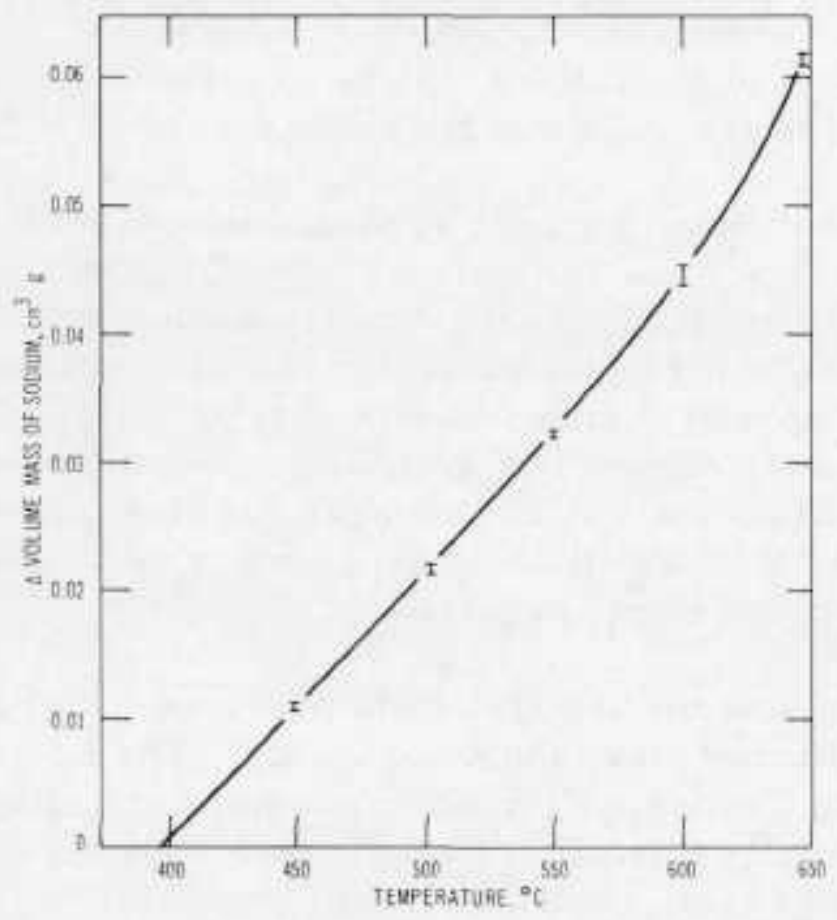

Fig. I.3. Calibration Curve for Maximumtemperature Monitors

A calibration curve (Fig. I. 3) was prepared using small Type 304 stainless steel capsules filled with sodium at $316^{\circ} \mathrm{C}$. First, a "completely filled" volume at a known temperature had to be established for each capsule. This was done by heating the capsules and contents to $399^{\circ} \mathrm{C}$. The volumes of the capsules were determined by the water-immersion technique at room temperature.

The spread of data at each temperature in Fig. I.3 represents three capsules. Deviation from linearity is significant only at the highest temperatures. The calibration will be repeated to determine if this point is in error. The capsules failed by cracking and leaking when heated subsequently to $716^{\circ} \mathrm{C}$. The failure was due to

the nonuniform expansion of the capsules. The range of the monitors could easily be extended by redesigning the capsule for more uniform expansion.

This device potentially has several advantages over the sodium-expulsion type. It requires less care in handling and can be exposed 
directly to the coolant. Routines are well established for measuring capsule volume in hot cells. The technique for preparing the capsule provides several built-in checks for improper filling and for leakage of the sealed capsule.

Obviously, extended exposures in a fast-neutron flux will cause errors due to swelling of the stainless steel. These can be compensated for by making normal postirradiation swelling measurements or by using a more swelling-resistant metal such as V-20 wt \% Ti. The initial calibration of these devices has suggested that they might be quite useful. Additional ex-reactor tests of stability as a function of time are planned, as well as temperature-cycling experiments. Two of the monitors are currently being exposed in EBR-II in Subassembly X101.

b. Examination of Materials from EBR-II Surveillance Subassemblies (Last reported: ANL-7705, p. 70, June 1970)

(1) Postirradiation Examination of SURV-3 (R. V. Strain). SURV - 3 is the third of a series of eight surveillance subassemblies containing materials of interest to the EBR-II program that are being irradiated in EBR-II. (Two other subassemblies are being held in the storage basket in the primary tank to determine the long-time effects of sodium and temperature on materials in the absence of appreciable radiation.) SURV-3 was transferred to the FEF for postirradiation examination after having been in the reactor core for 2178 days and having received a total exposure of 41,111 MWd in grid position 12A7. This subassembly contained the following surveillance materials simulating EBR-II components:

(a) three graphite-containing cans in a holding fixture, which were exposed directly to primary sodium; (b) a control-rod-drive labyrinth assembly that was exposed directly to primary sodium; (c) 18 capsules containing samples of various materials (nine were open to primary sodium, and nine were sealed); and (d) one sealed capsule containing four flux wires.

The postirradiation examination in the FEF showed that there were no significant changes in the dimensions of the graphitecontaining cans or the aluminum-bronze section of the control-rod-drive labyrinth assembly. Examination of selected samples from the 18 capsules indicated that all the materials tested, except Be-Cu and tantalum, had very good corrosion resistance to the EBR-II primary sodium. Of the materials examined, tantalum was the only one to exhibit a significant decrease in density.

3. Metal Driver Fuel Development and Application. C. M. Walter (02-145)

a. Advanced Fuel (Mark II). R. V. Strain and G. L. Hofman (Last reported: ANL-7798, p. 26)

(1) Interim Nondestructive Examination of Mark-II Driver Fuel at Peak Burnup of 4.2 at. \%. Nondestructive examination was performed on unencapsulated Mark-II driver-fuel elements at a peak burnup of $\sim 4.2$ at. \% . 
The elements had been irradiated for $8428 \mathrm{MWd}$ in Subassembly C-2205S, in reactor grid position 3F1, and then for $3030 \mathrm{MWd}$ in Subassembly C-2234S, in reactor grid position $5 \mathrm{E} 4$. They were irradiated in standard Mark-II driver-fuel subassemblies composed of 91 unencapsulated elements. About: half the elements were clad with annealed Type 316 stainless steel and half with annealed Type $304 \mathrm{~L}$ stainless steel. The elements had a nominal length of $26 \mathrm{in}$. and contained $54.5 \mathrm{~g}$ fuel pins consisting of $\mathrm{U}-5$ wt $\%$ fissium alloy $64 \%$ enriched in ${ }^{235} \mathrm{U}$.

The following summarizes the results of this examination:

(a) During dismantling, the subassembly and the elements appeared normal.

(b) The visual and photographic examination at a magnification of approximately $2 X$ revealed a thin coating of a white substance in some areas on the elements. This coating was easily removed by wiping the elements with a damp cloth. The appearance of the substance and its capability of being removed with a damp cloth indicate that it was a sodiumreaction product that had not been completely removed during the sodiumremoval operation.

(c) The results of the neutron radiography of the elements are summarized in Table I.15. The neutron radiographs show that most of the fuel pins have grown up to the restrainers located $1 / 2 \mathrm{in}$, above the top of the unirradiated fuel and that a few pins have grown up to the restrainers located $1 \mathrm{in}$. above the top of the unirradiated fuel. The maximum length of a fuel pin was $15 \frac{1}{2}$ in.; this was in Element 38 , which had a 1 -in. restrainer. The pins in four of the 18 elements radiographed have lifted off the bottom end plug. One of the other elements (E68) contained a broken pin. The greatest gap $(\sim 1 / 4$ in.) between the bottom end plug and a pin was in Element 59, which has a $1 / 2$-in. restrainer. The pin in this element had grown the least of any in the elements radiographed. This pin apparently lifted off the bottom plug early in its irradiation, and the restrainer has reduced its axial growth. In general, lift-off of the pins appears to be about the same at a burnup of 4,2 at. $\%$ as at a burnup of 3.3 at. $\%$.

(d) The changes in the element diameters are summarized in Table I.15 also. All elements except No. 1 and 86 were measured before they were irradiated; preirradiation diameters for those two elements were determined from postirradiation measurements of plenum OD. The diameter changes listed are the difference between the average preirradiation diameters and the maximum diameters taken from a best-fit curve of the postirradiation measurements. The average maximum diameter change for the elements clad with Type 316 stainless steel is $0.42 \%$; that for the elements clad with Type $304 \mathrm{~L}$ stainless steel is $1.33 \%$. The maximum diameter change occurred at a higher position on the elements clad with Type $304 \mathrm{~L}$ SS than 
TABLE 1.15. Results of Nondestructive Examination of Mark-II Elements from Subassemb1y C-2234S

\begin{tabular}{|c|c|c|c|c|c|c|c|c|c|c|}
\hline $\begin{array}{c}\text { Element } \\
\text { No. }\end{array}$ & $\begin{array}{l}\text { Jacket } \\
\text { No. }\end{array}$ & $\begin{array}{c}\text { Cladding } \\
\text { Material } \\
\text { (Type of SS) }\end{array}$ & $\begin{array}{l}\text { Res } \\
\text { Hei }\end{array}$ & $\begin{array}{l}\text { strainer } \\
\text { ight, in. }\end{array}$ & $\begin{array}{l}\text { Maximum } \\
\text { Diameter } \\
\text { Change, in. }\end{array}$ & $\begin{array}{l}\text { Maxinum } \\
\text { Diameter } \\
\text { Change, } \%\end{array}$ & $\begin{array}{l}\text { Distance of } \\
\text { Max Diameter } \\
\text { Change from } \\
\text { Bottom, in. }\end{array}$ & $\begin{array}{l}\text { Fuel-pin } \\
\text { Liftoff, } \\
\text { in. }\end{array}$ & $\begin{array}{c}\text { Contact } \\
\text { Restrainer? }\end{array}$ & $\begin{array}{l}\text { Change in Overall } \\
\text { Fuel-element } \\
\text { Length, 1n. }\end{array}$ \\
\hline 1 & 797 & 316 & & 1 & 0.0008 & 0.45 & 6.0 & $1 / 16$ & No & 0.04 \\
\hline 16 & 780 & 316 & No & restralner & 0.0006 & 0.35 & 7.0 & 0 & - & 0.05 \\
\hline 17 & 405 & 316 & & $1 / 2$ & 0.0006 & 0.33 & 7.5 & 0 & Yes & 0.04 \\
\hline 18 & 677 & 316 & & 1 & 0.0007 & 0.41 & 7.0 & $1 / 8$ & No & 0.05 \\
\hline 19 & 155 & 304 & No & restrainer & 0.0020 & 1.15 & 9.0 & 0 & - & 0.10 \\
\hline 24 & 22 & 304 & & 1 & 0.0023 & 1.31 & 8.5 & 0 & No & 0.10 \\
\hline 28 & 743 & 316 & & $1 / 2$ & 0.0010 & 0.60 & 8.0 & 0 & Yes & 0.05 \\
\hline 33 & 538 & 316 & & $1 / 2$ & 0.0007 & 0.42 & 7.0 & 0 & Yes & 0.04 \\
\hline 38 & 323 & 304 & & 1 & 0.0023 & 1.33 & 8.5 & 0 & No & $\cdots$ \\
\hline 43 & 18 & 304 & No & restrainer & 0.0022 & 1.28 & 7.5 & 0 & - & $\ldots$ \\
\hline 49 & 728 & 316 & No & restrainer & 0.0008 & 0.48 & 6.5 & 0 & - & $\cdots$ \\
\hline 54 & 673 & 316 & & 1 & 0.0007 & 0.41 & 6.5 & $1 / 16$ & Yes & 0.04 \\
\hline 59 & 297 & 304 & & $1 / 2$ & 0.0020 & 1.13 & 8.5 & $1 / 4$ & Yes & 0.09 \\
\hline 64 & 158 & 304 & & $1 / 2$ & 0.0026 & 1.52 & 9.5 & 0 & Yes & 0.11 \\
\hline $68^{a}$ & 725 & 316 & & 1 & 0.0008 & 0.45 & 8.0 & 0 & Yes & $\ldots$ \\
\hline 73 & 739 & 316 & No & restrainer & 0.0008 & 0.46 & 7.0 & 0 & $\cdots$ & $\ldots$ \\
\hline 74 & 79 & 304 & & 1 & 0.0028 & 1.60 & 10.5 & 0 & No & $\ldots$ \\
\hline 75 & 798 & 316 & & $1 / 2$ & 0.0007 & 0.43 & 7.0 & 0 & Yes & 0.04 \\
\hline 76 & 32 & 316 & No & restrainer & 0.0004 & 0.24 & 6.0 & 0 & - & $\cdots$ \\
\hline 86 & 745 & 316 & No & restrainer & 0.0007 & 0.41 & 7.0 & 0 & - & $\ldots$ \\
\hline
\end{tabular}

a Fuel pin broken. 
on the elements clad with Type 316 stainless steel. The differences in cladding behavior are illustrated in Fig. I.4, which compares the diameter profiles for elements clad with the two types of stainless steel. (The elements are those having the largest $\Delta D_{\max } / D_{0}$ for each cladding type.) Comparison of the pre- and postirradiation data shows that the diameter at the plenum region near the top of each element has not changed.

(e) The change in the overall lengths of 12 elements are listed in Table I. 15 also. The average overall length of the irradiated elements clad with Type 316 stainless steel is 26.13 in.; that of the irradiated elements clad with Type $304 \mathrm{~L}$ stainless steel is $26.19 \mathrm{in}$. The data for length change should be considered semiquantitative, because preirradiation length measurements were not taken. The $\Delta \ell$ values in the table are based on a preirradiation length of 26.09 in., a value that is the average of the measured lengths of similar unirradiated Mark-II elements.

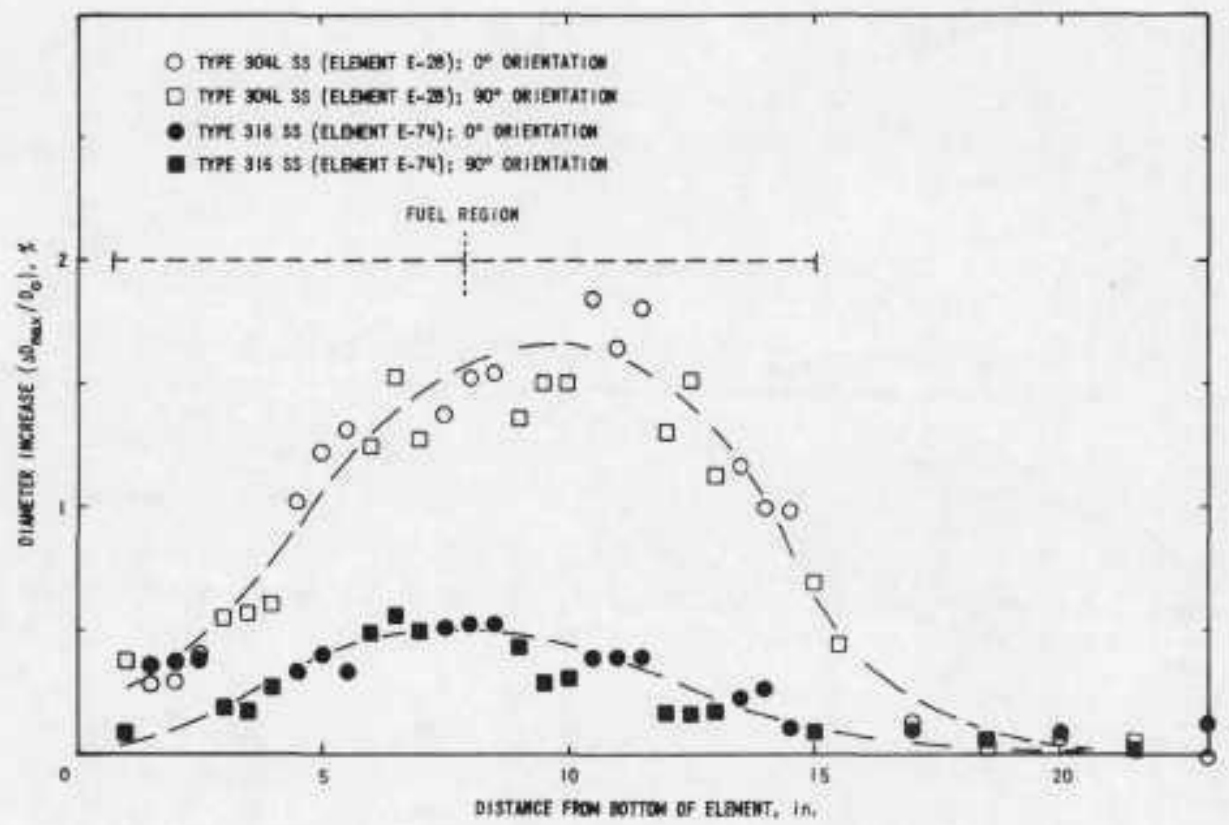

Fig. 1.4. Diameter Changes of Mark-II Fuel Elements Clad with Types $304 \mathrm{~L}$ and 316 Stainless Steel: Bumup, 4.2 at, \%

The difference in diameter behavior for the two types of stainless steel cladding (item d, above) was also observed at a burnup of 3.3 at. $\%$ (see Fig. I. 5). Whether this difference is to be attributed to creep of the Type 304L stainless steel cladding (BEMOD predicts zero creep up to a burnup of $6-7$ at. $\%$ ) or to an inherent difference in swelling behavior of the two stainless steels, or to both, can only be determined by measurements of cladding density. The results of these measurements should be available soon. However, comparison of the change in element diameter with the change in element length suggests that some creep (about onethird of the $\Delta D_{\max } / D_{0}$ ) has taken place in the elements clad with $T$ ype $304 \mathrm{~L}$ stainless steel. This conclusion is based on the assumption that the change 
in length should equal the integrated change in diameter if isotropic volume swelling is the sole reason for changes in the cladding dimensions. This condition appears to be the case for the Type 316 stainless steel cladding, but not for the Type 304L (see Table I.16). Furthermore, based on the data for $\Delta l / l_{0}$, the swelling of Type 304L stainless steel is about twice that of Type 316 (i.e., $\Delta \mathrm{D}_{\max } / \mathrm{D}_{0}$ due to swelling is about $0.9 \%$ in Type $304 \mathrm{~L}$ and about $0.4 \%$ in Type 316 stainless steel). The WADCO swelling equation predicts a $\Delta D_{\max } / D_{0}$ of $0.58 \%$ for annealed Type 316 and annealed $T y p e 304 \mathrm{~L}$ stainless steel.*

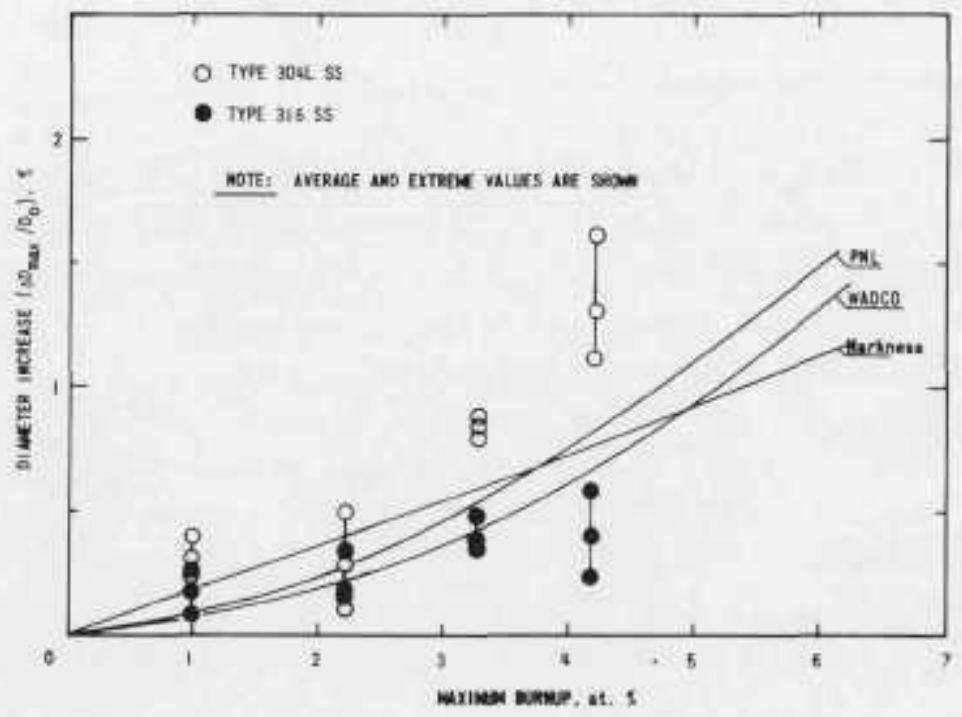

Fig. 1.5. Comparison of Mcasured Changes in Cladding Diameters of Mark-II Elements with Changes Calculated Using Three Different Swelling Correlations

TABLE I.16. Comparison of Measured Length Change of Mark-II Elements with Length Change Calculated by Integrating the Diameter Change

\begin{tabular}{cccc}
\hline Element No. & $\begin{array}{c}\text { Cladding } \\
\text { Material } \\
\text { (Tvpe of SS) }\end{array}$ & $\begin{array}{c}\text { Measured } \\
\Delta \ell / l_{0}\end{array}$ & $\begin{array}{c}\text { Calculated } \Delta \ell / l_{0} \\
\text { Obtained by } \\
\text { Integrating } \\
\Delta \mathrm{D} / \mathrm{D}_{\mathrm{o}}\end{array}$ \\
\hline 28 & 316 & 0.19 & 0.21 \\
33 & 316 & 0.15 & 0.16 \\
16 & 316 & 0.19 & 0.13 \\
64 & $304 \mathrm{~L}$ & 0.47 & 0.64 \\
24 & $304 \mathrm{~L}$ & 0.38 & 0.58 \\
19 & $304 \mathrm{~L}$ & 0.38 & 0.47 \\
\hline
\end{tabular}

*J, L. Straalsund and J. F. Bates, A Note on the Interdependency of Swelling Void Diameter and Void Number Density in Annealed AISI Type 304 Stainless Steel, WHAN-FR-15 (Oct 1970). 
In addition to strengthening the material somewhat, the presence of molybdenum and higher carbon in Type 316 stainless steel may affect the behavior of point defects in the material, and therefore may affect the irradiation-induced swelling and creep.

Whatever the reason for the observed differences in behavior of the cladding materials, changing the creep models used in BEMOD appears necessary to account for these differences. Figure 1.5 compares the results of $B E M O D$ calculations based on the WADCO equation and two other correlations* for stainless steel swelling.

\section{b. Cladding Studies}

(1) In-reactor Creep Experiments with Stainless Steel Tubing. L. C. Walters (Last reported: ANL-7776, p. 35). In the first of a series of in-pile creep experiments in EBR-II, diameter changes of 18 annealed Type $304 \mathrm{~L}$ stainless steel tubes are being measured after each of several irradiation cycles. The tubes, or capsules, have a $0.290-$ in. OD, a 20-mil wall, and a length of $60 \mathrm{in}$. Some are pressurized with helium to give initial hoop stresses of $10-35 \mathrm{kpsi}$ at the $700^{\circ} \mathrm{F}$ sodium inlet temperature; others are unpressurized. All extend $30 \mathrm{in}$. above and below the core midplane. Type 304 stainless steel filler rods, 0.238 in, in OD, are used inside each capsule to reduce the potential energy release of an unexpected failure. The capsules are exposed to the flowing primary sodium while in reactor.

The subassembly containing the experiment has been irradiated for six in-reactor cycles. After the sixth cycle, the capsules had accumulated a total fast fluence $(>0.1 \mathrm{MeV})$ of $1.2 \times 10^{22} \mathrm{n} / \mathrm{cm}^{2}$. Details of the method of data analysis were discussed in ANL-7679, p. 78, March 1970.

The diameter data were analyzed to determine the dependence of the neutron-flux-enhanced creep rate on hoop stress. The enhanced hoop strain in the core region of the capsules was calculated for all the capsules according to the procedure outlined in ANL-7679. For the pressurized capsules, both swelling and creep contribute to the hoop strain. The hoop strain in the core region of the capsules that are not pressurized represents the diameter change due to swelling. The swelling component of the hoop strain, determined from the unstressed capsules, is then subtracted from the total enhanced strain calculated for the pressurized capsules. The remaining hoop strain is then the strain due to neutron-fluxenhanced creep. The enhanced creep strain is then plotted as a function of time (or fluence) at each stress level. The creep rate is calculated from the slope of the plotted line.

*PNL: T. T. Claudson, R. W. Barker, and R. L. Fish, The Effects of Fast Flux Irradiation on the Mechanical Properties and Dimensional Stabllity of Stainless Steel, Nucl. Appl. and Technol. 9, p. 10 (July 1970); Harkness: S. D. Harkness and C. Y. Li, A Model for Void Formation in Metals Irradiated in a Fast-neutron Envitonment, ANL-7588 (Aug 1969). 
Figure I.6 plots the swelling hoop strain for the unstressed capsules as a function of fluence $(>0.1 \mathrm{MeV})$. The solid line on the plot is a least-squares linear fit that represents the expression

$$
\epsilon_{\mathrm{H}}^{\text {Swelling }}=0.44(\phi t)+1.7 \text {, }
$$

where the fluence, $\phi \mathrm{t}$, is in units of $10^{21} \mathrm{n} / \mathrm{cm}^{2}(>0.1 \mathrm{MeV})$, and the swelling hoop strain, $\epsilon_{\mathrm{H}}^{\mathrm{Sw}} \mathrm{elling}$, is in units of $10^{-4} \mathrm{in}$./in. The correlation coefficient for this least-squares fit was 0.84. Equation 1 was used to calculate the swelling component of the total enhanced strain for the pressurized capsules. The dashed curve on Fig. I.6 was calculated from the recent WADCO swelling correlation (WHAN-FR-15). The component for swelling hoop strain was calculated from the WADCO correlation by taking one-third of the component for volume swelling. An irradiation temperature of $380^{\circ} \mathrm{C}$ was used for the calculation. The agreement between the WADCO correlation and the data for the unstressed capsules is reasonable when one considers that the WADCO correlation was determined from Type 304 stainless steel that for the most part was irradiated to fluences above $10^{22} \mathrm{n} / \mathrm{cm}^{2}$.

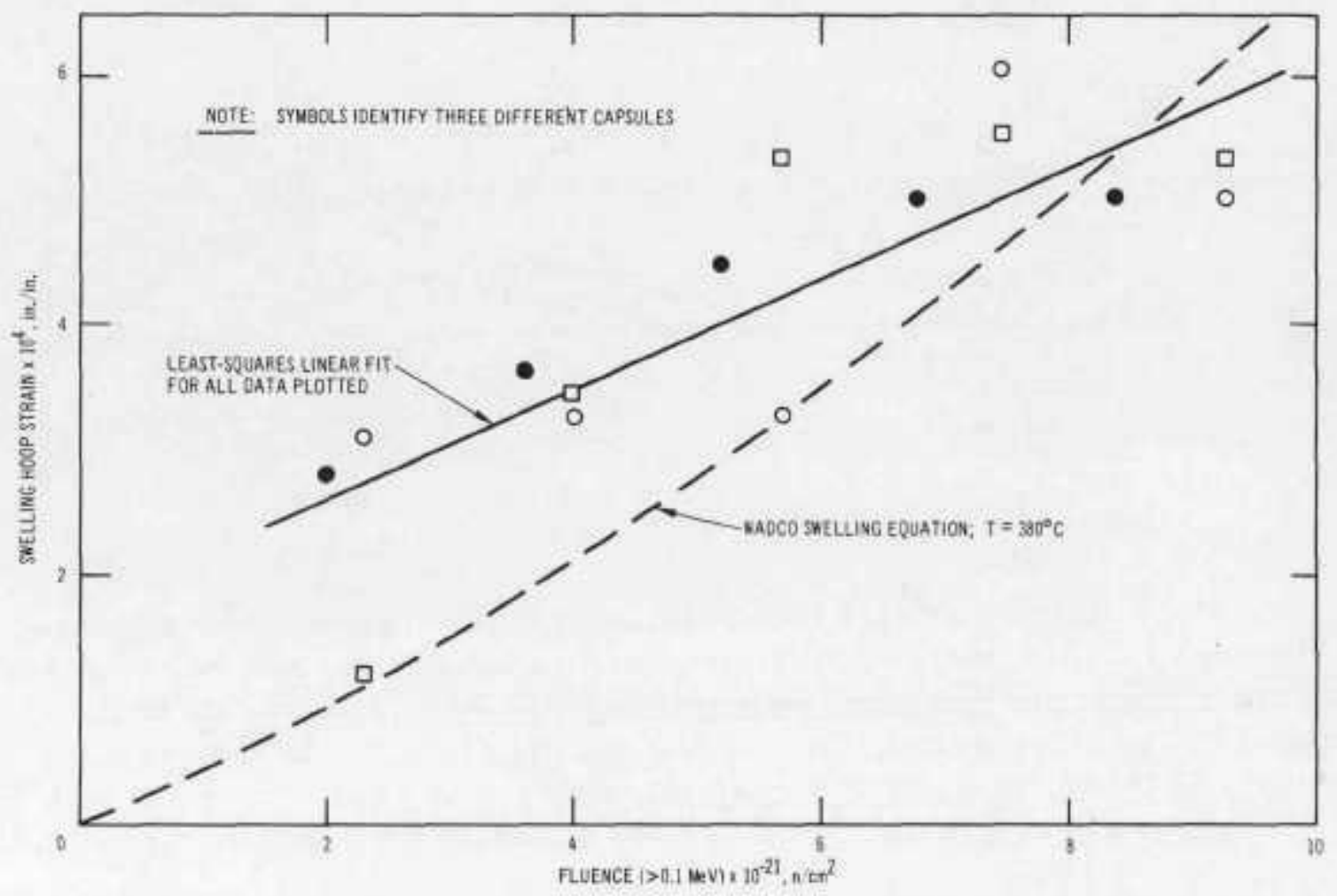

Fig. 1.6. Irradiation-induced Swelling as a Function of Fast-neutron Fluence ( $>0.1 \mathrm{MeV})$ in Three Type 304L Stainless Steel Capsules at Zero Hoop Stress: Imadiation Temperature, $380^{\circ} \mathrm{C}$; Flux $(>0.1 \mathrm{MeV}), \sim 10^{15} \mathrm{n} / \mathrm{cm}^{2}-3 e c$

Figure I. 7 plots the enhanced-creep hoop strain for each value of hoop stress as a function of time at power or fluence. Flux was taken to be $10^{15} \mathrm{n} / \mathrm{cm}^{2}(>0.1 \mathrm{MeV})$. Each point on Fig. I. 7 represents the average value of the creep hoop strain for the capsules at that particular 
hoop stress. Attention is directed to the data for the capsules stressed at 24.7 and $27.3 \mathrm{kpsi}$. There appears to be a transient portion to the creep plot that extends at least to a time of about $800 \mathrm{hr}$, or a fluence of $3 \mathrm{x}$ $10^{21} \mathrm{n} / \mathrm{cm}^{2}$. After this period, the creep hoop strain appears to be linear with the time at power. For the capsules at the lower hoop stresses, a linear relationship with time at power is also assumed to hold. As data are accumulated at higher fluences, the linear time dependence of the creep strain can be better tested.

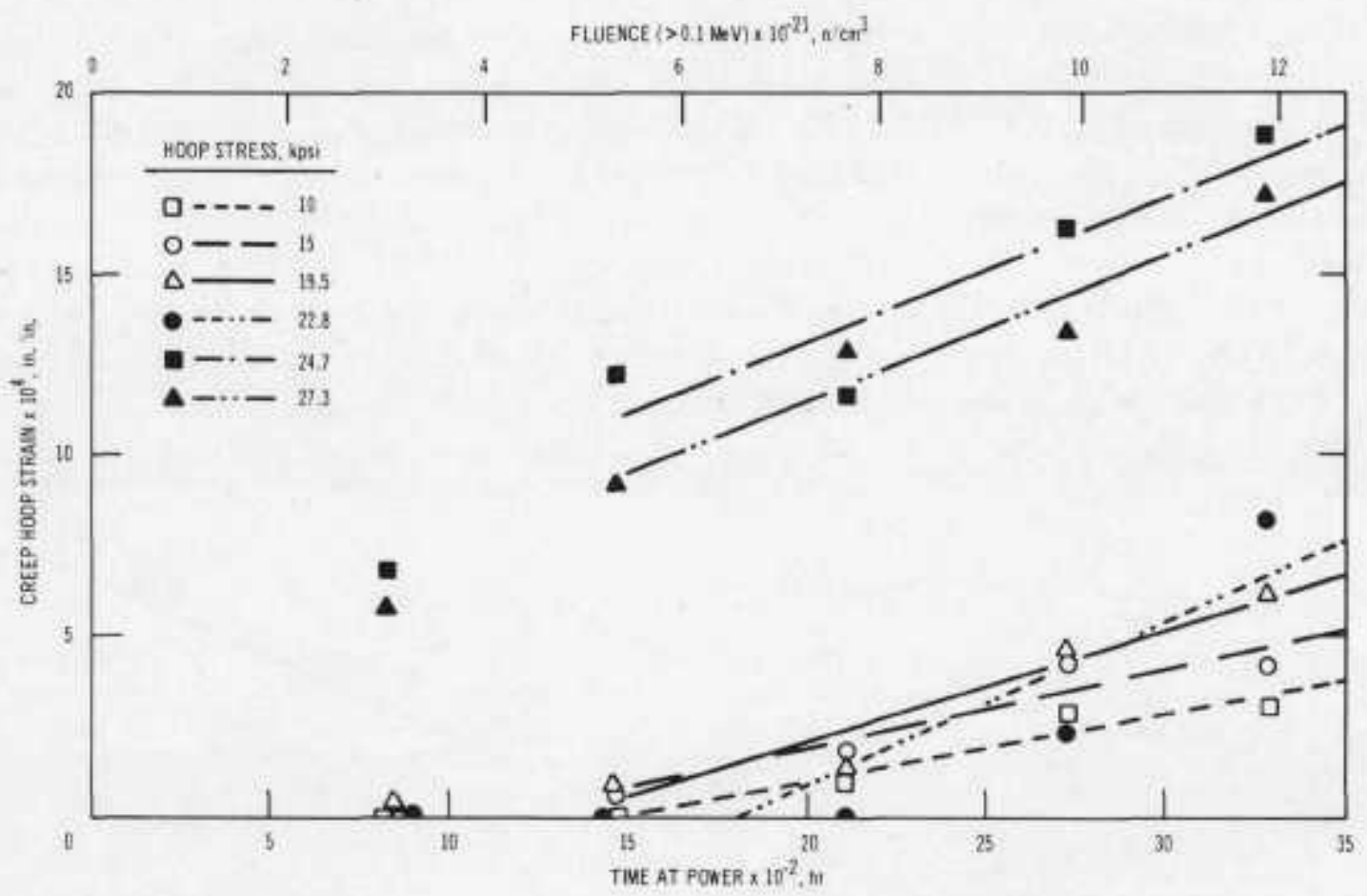

Fig. 1.7. Irradiation-enhanced Creep Strain as a Function of Fluence and Time at Power for Helium-pressurized Type 304L Stainless Steel Capsules: Irradiation Temperature, $380^{\circ} \mathrm{C}$; Flux $(>0.1 \mathrm{MeV}), \sim 10^{15} \mathrm{n} / \mathrm{cm}^{2}-\mathrm{sec}$

On the basis of the assumption of a linear time dependence of the creep strain, the steady-state creep rate at each value of hoop stress was calculated from the slope of a line for the least-squares fit to the data shown in Fig. I.7. Table I.17 gives the results from the linear least-squares analysis of those data. (Note: Hoop-strain data at a fluence of $5.3 \times 10^{21} \mathrm{n}$ / $\mathrm{cm}^{2}(>0.1 \mathrm{MeV})$ and greater were used to generate the least-squares line.)

Figure 1.8 shows the neutron-flux-enhanced creep rate, $\dot{E}_{\mathrm{H}}$, plotted as a function of hoop stress, $\sigma_{\mathrm{H}}$. The creep rate appears to have a linear dependence on hoop stress. The following expression represents the linear least-squares fit to the data shown in Fig. I.8:

$$
\dot{\epsilon}_{\mathrm{H}}=1.5 \times 10^{-11} \sigma_{\mathrm{H}}+2.8 \times 10^{-8}, \mathrm{hr}^{-1} \text {. }
$$


TABLE I.17. Results of Linear Least-squares Analysis to Determine Neutron-flux-enhanced Creep Rate

\begin{tabular}{lccc}
\hline $\begin{array}{c}\text { Hoop Stress, } \\
\text { kpsi }\end{array}$ & $\begin{array}{c}\text { Slope: } \\
\text { Creep Rate }\left(\dot{\varepsilon}_{\mathrm{H}}\right)\end{array}$ & $\begin{array}{l}\text { Intercept: } \\
\text { in./in. } \times 10^{4}\end{array}$ & $\begin{array}{c}\text { Correlation } \\
\text { Coefficient }\end{array}$ \\
\hline 10 & 1.87 & -2.71 & 0.97 \\
15 & 2.22 & -2.61 & 0.97 \\
19.5 & 3.06 & -4.11 & 0.97 \\
22.8 & 4.39 & -7.9 & 0.88 \\
24.7 & 3.95 & 5.25 & 0.92 \\
27.3 & 4.02 & 3.44 & 0.96 \\
\hline
\end{tabular}

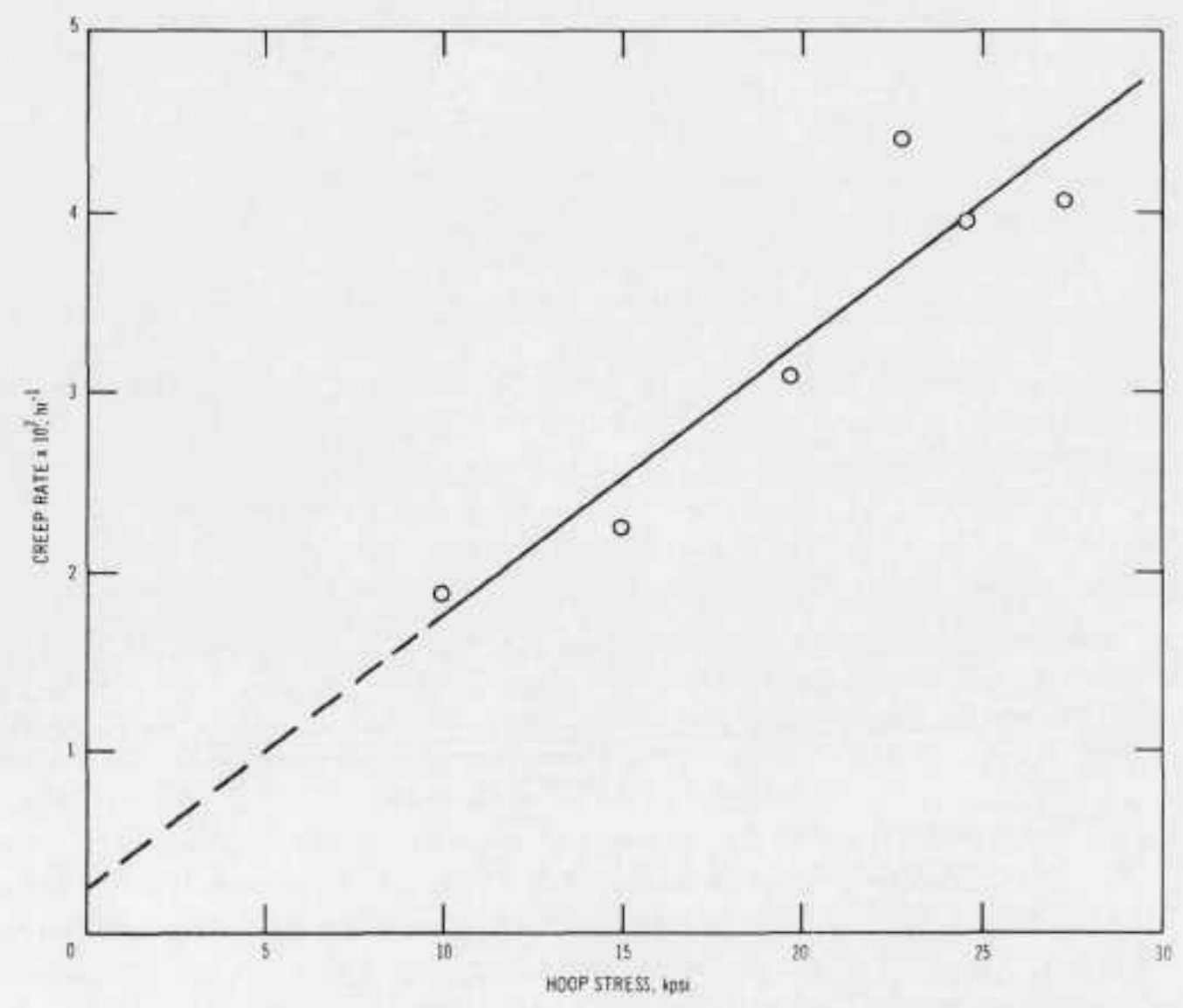

Fig. I.8. Irradiation-enhanced Creep Rate as a Function of Hoop Stress of Heliumpressurized Type 304L Stainless Steel Capsules: Irradiation Temperature, $380^{\circ} \mathrm{C}$; Flux $(>0.1 \mathrm{MeV}), \sim 10^{15} \mathrm{n} / \mathrm{cm}^{2}-\mathrm{sec}$ 
The correlation coefficient for this equation is 0.93 . The hoop stress, $\sigma_{H}$, is in psi, and the irradiation conditions for which the above expression is representative are an irradiation temperature of $380^{\circ} \mathrm{C}$ and a fast-neutron flux $(>0.1 \mathrm{MeV})$ of $10^{15} \mathrm{n} / \mathrm{cm}^{2}-\mathrm{sec}$. Equation 2 represents the apparent steady-state creep rate that occurs at fast fluences $(>0.1 \mathrm{MeV})$ above approximately $3 \times 10^{21} \mathrm{n} / \mathrm{cm}^{2}$.

In summary, the hoop strain due to neutron-flux-enhanced creep appears to behave linearly with the time at power at irradiation times above $800 \mathrm{hr}$. The capsules at higher stress show an apparent transient region where the creep rate is changing with time. Whether the enhanced creep strain remains linear with irradiation time will be determined upon further irradiation of these capsules. The analysis of the creep data showed that the neutron-flux-enhanced creep rate was linear with stress. This observation contradicts an earlier observation, reported in ANL-7776, that the neutron-flux-enhanced creep strain was nonlinear with hoop stress. Our earlier observation neglected the fact that the transient portion of the creepversus-time curves for the higher-stressed capsules contributes an appreciable fraction to the total creep strain. Thus, when the enhanced creep strain was plotted as a function of hoop stress, the creep strain for the higher-stressed capsules (24.7 and $27,3 \mathrm{kpsi}$ ) was larger than expected from a linear extrapolation of the creep strain from capsules at lower values of hoop stress.

(2) Ductility of Irradiated Cladding of Mark-IA Driver Fuel.

D. Franklin (Not previously reported). To obtain a better understanding of the effect of loading conditions on cladding failure, a program of burst-testing driver-fuel cladding (annealed Type $304 \mathrm{~L}$ stainless steel) irradiated in EBR-II has been undertaken. In some cladding samples, pressing of fuel against the cladding is simulated by pressurizing cold-worked Type 316 stainless steel tube inserts fit inside the sample. In other samples, plenumpressure loading is simulated by pressurizing the cladding tube directly. During the direct pressurization, the stress causes necking of some portions of the sample and will increase at those portions. Failure occurs when the increase in work hardening is not enough to offset the increase in stress. For irradiation-hardened material, the stress is high when plastic deformation begins, and plastic instability occurs soon. When loading is due to the insert pressing out against the cladding, neck formation in the cladding is resisted and delayed by the friction between the insert and the cladding. This friction opposes any movement of the cladding relative to the insert. The amount of delay in failure will depend on the amount of friction and the amount of stress the insert can support.

Table 1.18 identifies five samples tested and gives the test conditions. Figure I. 9 gives the test results. These experimental results indicate that diametral expansion of irradiated cladding may be increased 
TABLE 1.18. Identification of Samples and Conditions ${ }^{a}$ for Burst Testing of Irradiated Type 304L Stainless Steel Cladding of Mark-IA Driver Fuel

\begin{tabular}{cccc}
\hline Sample & $\begin{array}{c}\text { Irradiation } \\
\text { Temperature, } \\
{ }_{C}\end{array}$ & $\begin{array}{c}\text { Fluence } \\
(>0.1 \mathrm{MeV}) \\
1022 \mathrm{n} / \mathrm{cm}^{2}\end{array}$ & $\begin{array}{c}\text { Sample } \\
\text { Location, } \\
\text { in. }\end{array}$ \\
\hline a & 435 & 1.3 & $4.75-7.75$ \\
b & 435 & 1.5 & $10.5-13.5$ \\
c & 447 & 1.5 & $10.5-13.5$ \\
d & 471 & 1.6 & $4.75-7.75$ \\
e & 432 & 1.6 & $4.75-7.75$ \\
\hline
\end{tabular}

${ }^{\mathrm{a}} \mathrm{All}$ test temperatures, $500^{\circ} \mathrm{C}$; all pressurization rates, $2000 \mathrm{psi} / \mathrm{min}$.

bistance above bottom of core.
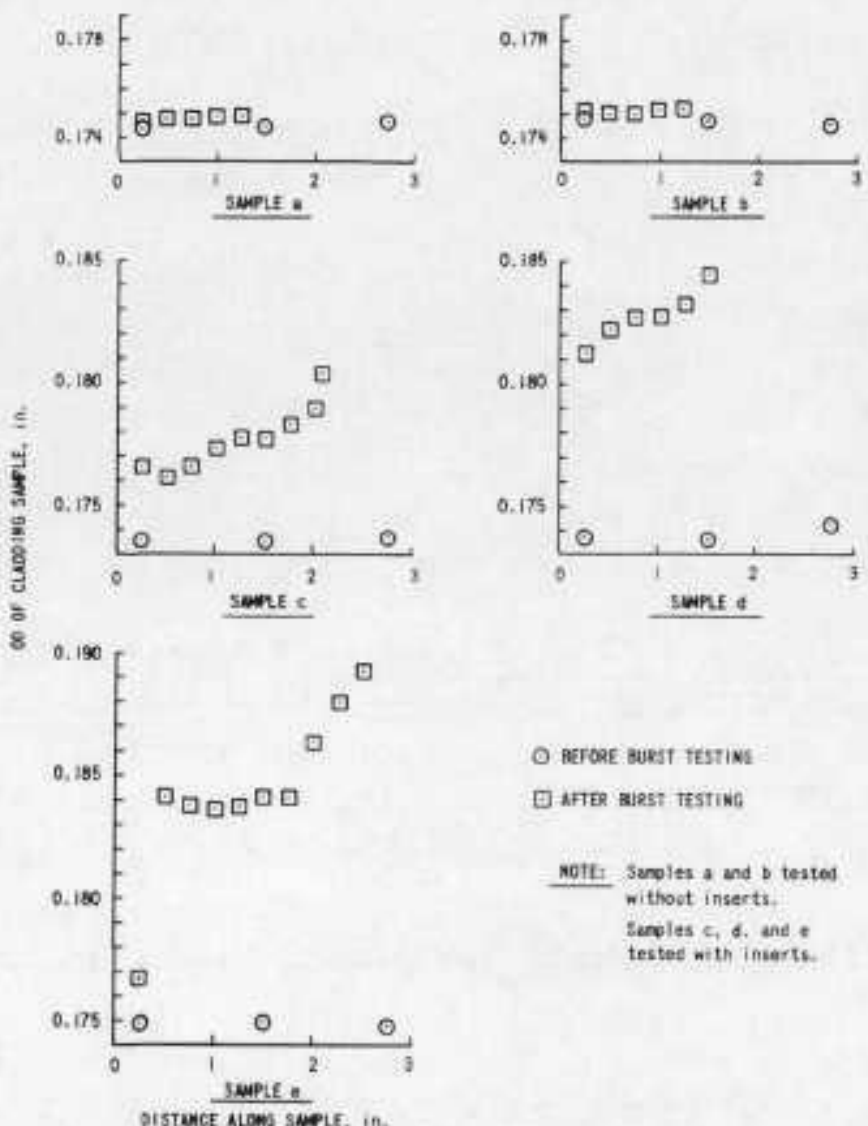

Fig. I.9

Results of Burst Testing of Cladding of Mark-LA Driver Fuel

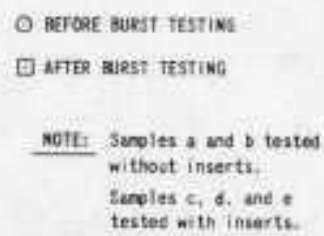


by as much as an order of magnitude when expansion is caused by pressurizing the insert rather than by pressurizing the cladding tube directly. These results demonstrate that burst testing by direct pressurization does not seem to be a suitable method of determining the ductility of cladding material for reactor use.

c. Surveillance Support. J. P. Bacca, N. R. Grant, A. K. Chakraborty, R. V. Strain, and G. C. McClellan (Last reported: ANL-7753, p. 83)

Summarized here is the postirradiation surveillance work and the subassembly reconstitutions performed under the various programs of this task.

(1) Subassembly C-2234S. The following interim examinations were made on elements from this subassembly, which had been irradiated to a peak burnup of 4.2 at. $\%$ : visual examination, neutron radiography, diameter measurements with the DR-25 optical gauge and profilometer, measurements of fuel-element length, sampling for fission gas, and metallographic sectioning and sampling. This subassembly has been reconstituted as Subassembly C-2236S with six new Mark-II elements and 85 irradiated Mark-II elements from Subassembly C-2234S.

(2) Subassembly C-2232S. This subassembly was reconstituted with 13 new Mark-II elements and 78 irradiated Mark-II elements (peak burnup, 3.3 at. \%) from Subassembly C-2203S.

(3) Tests of Fuel Cladding in the BRATT. Thirty-three cladding samples were sectioned from 19 Mark-IA fuel elements selected from Subassemblies B-3120, B-3122, and C-2180, and the diameters of the samples were measured in preparation for testing with the BRATT (biaxial ruptureanticipating tubing tester). Twenty-two of the samples have been tested in the BRATT, and their diameters have been measured after the tests.

(4) Heat-treated Vendor Fuel Elements. Preirradiation diameter surveys with the DR-25 optical gauge were made of selected vendor fuel elements that had received the double reclamation heat treatment. The data will be used in the postirradiation evaluation of the performance of these fuel elements.

4. Surveillance and Failure Evaluation of Experimental Fuel Irradiations. J. R. Honekamp (02-194)

\section{a. Surveillance of Current Tests}

(1) Evaluation of Reaction between Sodium and Mixed-oxide

Fue1. S. Greenberg and W. E. Ruther (Last reported: ANL-7798, p. 29). Sodium exposure of deliberately defected Sample 59B-11 from Element 007 was terminated after 45.7 days at $650^{\circ} \mathrm{C}$. Table I. 19 summarizes the results 
of the exposure. The slight cracking of the cladding, reported in ANL7798 , did not progress after the first 5.2 days of exposure.

TAst.E 1.19. Results of Exposure of Sample $59 \mathrm{~B}-11^{3}$ to Sod1un at $650^{\circ} \mathrm{C}$

\begin{tabular}{|c|c|c|c|c|}
\hline \multirow{2}{*}{$\begin{array}{l}\text { Elapsed Tine, } \\
\text { days }\end{array}$} & \multicolumn{2}{|c|}{ Gunulative Daseter Change, $\mathrm{nfl}$ s } & \multirow{2}{*}{$\begin{array}{l}\text { Cumulat ive Length } \\
\text { Increane, =1ls }\end{array}$} & \multirow{2}{*}{$\begin{array}{l}\text { Cumulative Wt } \\
\text { Galn, mg }\end{array}$} \\
\hline & Normal to Defect & Plane of Defect & & \\
\hline 1.7 & 4.0 & 4.9 & 5.0 & 195 \\
\hline 5.2 & 5.0 & - & - & - \\
\hline 6.9 & 5.0 & 4.7 & 7.0 & 199 \\
\hline 11.9 & 5.4 & 5.6 & 7.5 & 202 \\
\hline $25.5^{c}$ & 6.1 & 7.2 & 9.1 & 207 \\
\hline 45.7 & 6.6 & 7.2 & 9.1 & 216 \\
\hline
\end{tabular}

\footnotetext{
Fuel is coprecipltated mixed oxide $\left(202 \mathrm{PuO}_{2}\right)$.

baximum sodfun talceup, based on assumed accessibility of all porosity, is 255 mg.

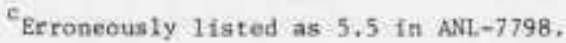

Metallographic examination is now in progress. A technique developed by A. E. Martin (CEN) has been used to retain the friable sodiumfuel compounds. The section is mounted "as exposed" and is rough-polished under anhydrous conditions. The sodium metal is then etched out by ethyl alcohol; sodium-fuel compounds are not soluble in this etchant. The sample is then backfilled with epoxy to retain these compounds.

The prepared sample has the "etched" appearance previously reported for another mixed-oxide fuel pin exposed at $650^{\circ} \mathrm{C}$ (Sample 66B-8 from Element C15; see ANL-7798). Preliminary results of electron-microprobe examination indicate the presence of $\mathrm{Na}-\mathrm{O}-\mathrm{U}-\mathrm{Pu}$ compounds.

Unlike previous defected fuel samples exposed to sodium, the porosity of 59B-11 was not completely filled with sodium after exposure. Metallographic sectioning also revealed that axial expansion of the fuel could not account for the increase in sample length observed.

Exposure of defected fuel pins to flowing sodium has been suspended pending receipt of vibratory-compacted samples. These samples will be exposed at EBR-II basket $\left(370^{\circ} \mathrm{C}\right)$ conditions. 


\section{Engineering}

1. Systems Engineering. B. C. Cerutti (02-068)

a. Surveillance, Evaluation, and Studies of Systems (Last reported: ANL-7798, p. 32)

(1) Installation of Mark-II Oscillator-rod System (J. B. Waldo). The Mark-II oscillator-rod system was installed in the No. 8 control-rod position during the loading changes for Run $48 \mathrm{~A}$.

The control-rod drive in the No. 8 position was first removed using the 3 -in. universal coffin. The radiation level at the gripper end was $200 \mathrm{R} / \mathrm{hr}$ at $4 \mathrm{in}$. Since the drive was still operable, it was trans ferred into a special storage tube, seal-welded in, and pressurized with argon to preserve it for future use.

The oscillator-rod thimble and the oscillator rod were loaded into the reactor with the normal fuel-handling system. The special handling tools and procedures all worked as planned, and no problems were encountered.

The oscillator-rod drive shaft was then installed in the primary tank using the 3 -in, universal coffin. The assembled bearing carrier was lowered in over the drive shaft, again using the universal coffin. Primary-tank temperature was $580^{\circ} \mathrm{F}$ during the installation. The support structure was installed, and the drive shaft was aligned with the control-rod lifting platform at the "reactor operating" position. The torque required to drive the in-vessel components including the oscillator rod was 5 to 8 in. $-1 \mathrm{~b}$. The jaw-drive system and the rotational-drive system were then installed. A complete interlock checkout of all oscillator switches, relays, and wiring was performed in fuel-handling sequences $\mathrm{A}$ and $\mathrm{H}$. Installation and checkout of the drive system (not including rod and thimble) took six days.

The oscillator rod has now been operated electrically over the full speed range $(0-8.8 \mathrm{~Hz})$, at reactor power levels up to $40 \mathrm{MWt}$, with no indication of the previous rubbing on the thimble. The rod has also been rotated manually at $62.5 \mathrm{MWt}$ without rubbing.

(2) Replacement of Instrumented Subassembly (J. B. Waldo). Instrumented subassembly XX02 was replaced by instrumented subassembly XX03, a HEDL instrumented creep test, at the end of Run 48.

The XX02 gripper and extension tube were first removed using the 3-in. universal coffin. The maximum torque required to cut the instrument leads was $50 \mathrm{ft}-1 \mathrm{~b}$. The new strain-gauge torque transmitter and recorder worked well. Separation of the extension tube from the subassembly 
was very smooth. The radiation levels encountered were $200 \mathrm{R} / \mathrm{hr}$ at 4 in. for the gripper and $300 \mathrm{R} / \mathrm{hr}$ at $4 \mathrm{in}$. for the lower end of the extension tube. The subassembly was transferred to the storage basket using the normal fuel-handling system.

The XX03 subassembly, in the inner container, was transferred into the reactor building. It was removed from the container while in the vertical position and transferred to a special storage tube. Complete dimensional and instrumentation checkouts were then performed. The subas sembly was also $\mathrm{X}$-rayed to determine the exact position of the ANL flux monitor installed at the core centerline.

The subassembly was transferred to a preheater, where the temperature of the test section was raised to $600^{\circ} \mathrm{F}$ in $8 \mathrm{hr}$. The subassembly was then transferred from the preheater to the primary tank. It cooled to about $550^{\circ} \mathrm{F}$ before reaching the $580^{\circ} \mathrm{F}$ bulk sodium.

The entire subassembly exchange was done in five days. Final mechanical-installation and electrical checkouts of XX03 are in progress.

2. Equipment--Fuel Related. E. Hutter (02-045)

a. Handling Subassemblies Containing Failed Fuel (Last reported: ANL-7753, p. 44)

(1) Black-chrome Plating of Type 304 Stainless Steel (C. Divona). In conjunction with the development of the EBR-II failed-fuel transfer system, several tests have been performed on samples of black-chrome-plated Type 304 stainless steel to determine the stability of the plating in $700^{\circ} \mathrm{F}$ sodium. In addition, several tests were also performed in pure helium at $1600^{\circ} \mathrm{F}$.

The plating tested was Duramir Bk, developed by Diamond Shamrock Company. This plating appears as a matte black surface with very low reflectivity on Type 304 stainless steel. Although no emittance tests were conducted, a reference* indicates that this type of plating process attains hemispherical total emittances in the range 0.7-0.9. This high emittance makes this type of plating very interesting from the standpoint of radiation heat-transfer properties.

Two types of samples were tested; one contained a nickel undercoating under the black chrome (total plating thickness, 500-1000 $\mu$ in.), and the other contained only black-chrome plating (total thickness, 50$75 \mu$ in.). All samples were exposed to reactor-grade $700^{\circ} \mathrm{F}$ sodium (coldtrapped at $250^{\circ} \mathrm{F}$ ) for a total of 19 days. The resulting average weight loss

*W. D. Wood, H. W. Deem, and C. F. Lucks, Thermal Radiative Properties of Selected Materials,

DMIC Report 177 (Nov 15, 1962). 
was $0.057 \mathrm{mg} / \mathrm{cm}^{2}$ after 3 days and $0.042 \mathrm{mg} / \mathrm{cm}^{2}$ after 19 days. The plating remained intact, and no reduction of the oxide coating by the sodium could be observed.

Other samples of the same types were tested in stagnant ultrapure helium $(99.999 \%)$ for $48 \mathrm{hr}$ at $1600^{\circ} \mathrm{F}$. At the end of this test, the samples with the nickel undercoat showed considerable degradation and spalling. The samples containing only black-chrome plating, however, had remained intact, but their color had changed to a dark gray. Bending the latter samples $180^{\circ}$ did not crack the plating.

3. EBR-II In-core Instrument Test Facility. E. Hutter (02-131)

a. Design and Development of Facility (Last reported: ANL-7798, p. 36)

(1) Testing of Flow-control Valve (O. S. Seim, J. Wendte, and C. J, Divona). To control the temperature within the in-core instrument test facility (INCOT), the flow rate of the sodium coolant is varied by a flow-

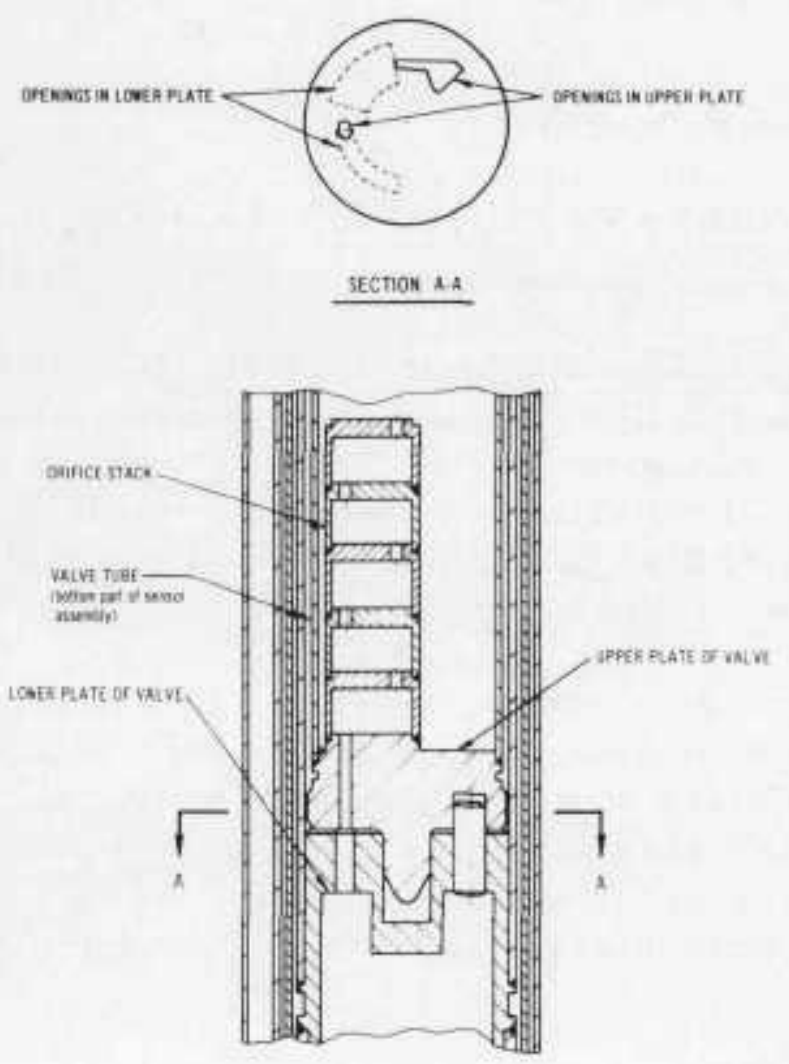

Fig. I.10. INCOT Flow-control Valve control valve whose cross section is shown in Fig. 1.10. The valve contains two flat plates with irregularly shaped orifice openings. One plate (the lower) is fixed; the other rotates. The fixed plate is a part of the installed INCOT thimble assembly; the movable plate is on the bottom end of the INCOT sensor assembly. The valve is actuated by rotating the sensor assembly at $0.6^{\circ} / \mathrm{sec}$ with a reversible electric motor and associated gearing on the reactor operating floor. When the valve is closed, a minimum bypass flow of $0.5 \mathrm{gpm}$ is maintained through an orifice stack. Then, when the upper plate is rotated, the opening of the main orifice becomes larger, and the flow rate increases. The fullopen position is intended to be used as a calibration point when experimental flow sensors are being tested in the facility.

The valve tested has a flow range of $0.5-15$ gpm over an angular displacement of 0 to $68^{\circ}$. It was flowtested with water first, and the flow rate-versus-pressure drop was obtained for various valve openings. Next, for 31 days the valve was soaked in $700^{\circ} \mathrm{F}$ sodium and actuated 76 times over 
its full rotational range. This was done to observe the torque characteristics and to determine the dimensional stability of the orifice plates at the higher temperature. Finally, the valve was removed from the sodium and again flowtested in water to determine if the testing in sodium had affected its characteristics.

Figure 1.11 shows some of the results of the initial flow tests. Plots of this type were obtained at $2^{\circ}$ increments of valve rotation, both before and after the sodium soak test. Figure 1.12 compares flow rate to valve opening at $38 \mathrm{psi}$, the expected valve pressure drop at the INCOT location, for the initial test and the final test (after the sodium exposure). In the full-open position $\left(68^{\circ}\right)$, the difference between the flows before and after sodium exposure is $1.5 \%$ of full flow. This difference can be explained in terms of the accuracy of the flow- and pressure-measuring equipment; in combination, this equipment could yield an error of $\pm 1.9 \%$.

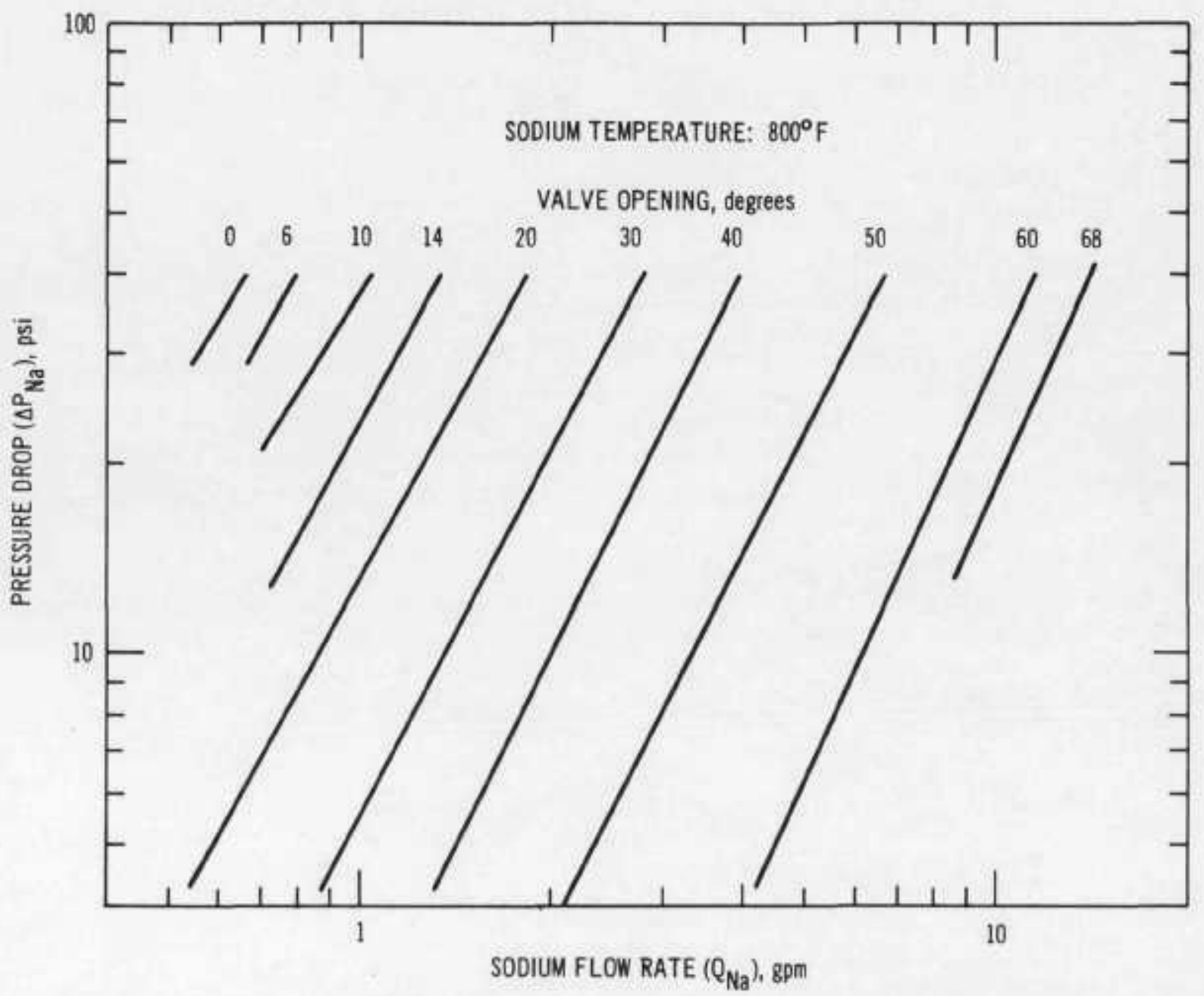

Fig. I.11. Results of Initial Test of Flow-control Valve 


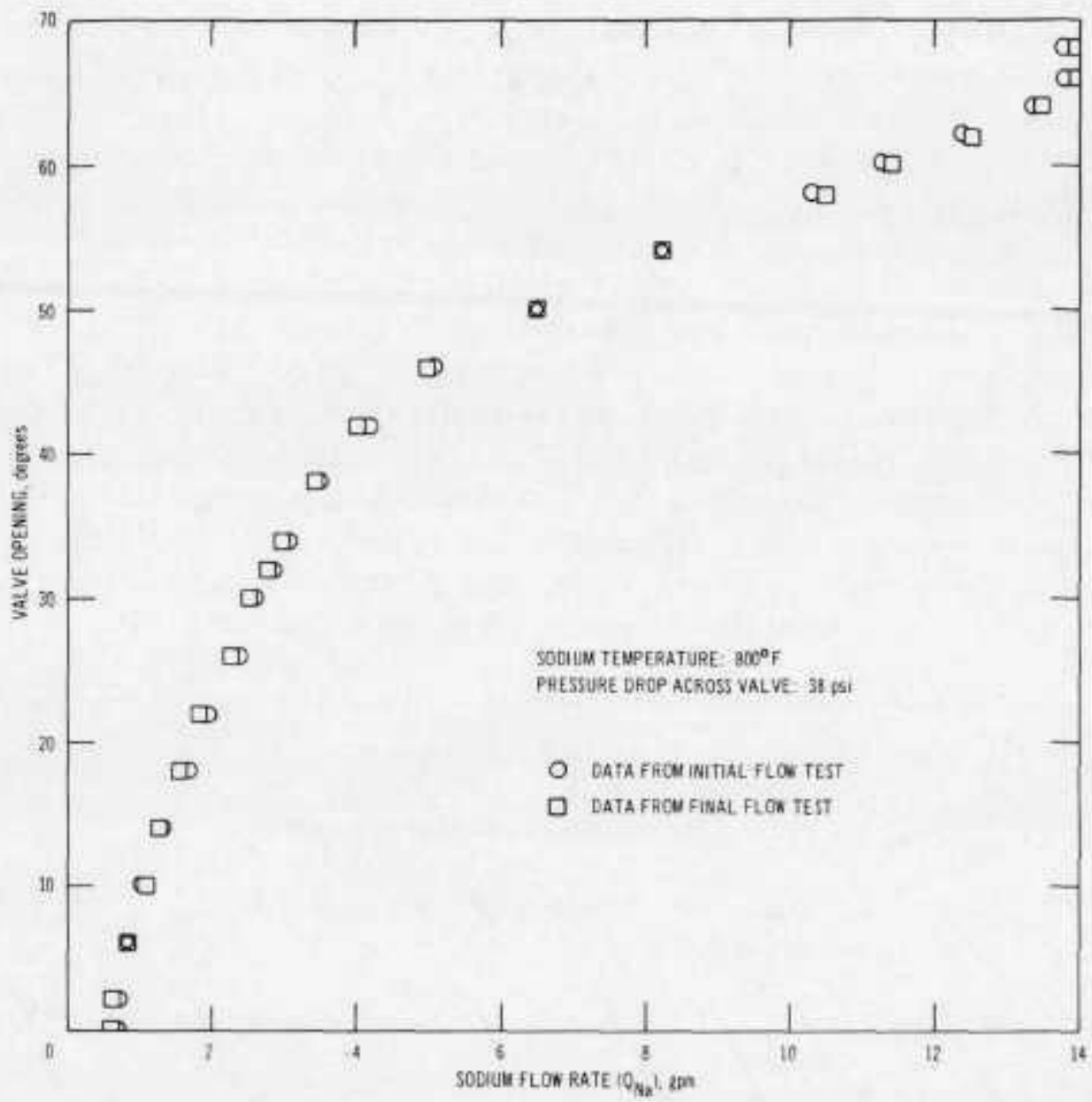

Fig. 1.12. Compatison of Characteristics of Flow-control Valve before and after Sodium Exposure 


\section{Analysis and Testing}

1. Reactor Analysis, Testing, and Methods Development

a. Nuclear, Thermal, and Hydraulic Surveillance ANL- 7783, p. 32)

(1) Heating of a Control Rod When Its Fueled Portion Is below a Core with a Stainless Steel Radial Reflector (R. A. Gushman). The question has been raised as to the effect of the proposed stainless steel radial reflector on power production (and hence fuel-element temperature) in a control rod in the down position (i.e.. with the fueled portion of the rod below the core). The imminent use of a high-worth control rod--one containing boron carbide rather than sodium and stainless steel in the follower portion above the fuel-- has made the question more practical, although the heating effect in either a high-worth or a normal control rod should be virtually the same for a given control-rod position. The high-worth control rod, however, possibly would operate with less of the fueled portion in the core, since the bor on carbide in the rod provides much of the reactivity control for the necessary shutdown margin and thereby allows use of the fueled portion for reactivity control to compensate for burnup during an operating run.

An indirect measurement of the power produced in a fully withdrawn control rod has been made for a core with a depleted-uranium radial blanket (but with stainless steel upper and lower axial reflectors).* The measurement indicated that a fully withdrawn control rod produced $52 \%$ as much power as a fully inserted one. A stainless steel reflector in Rows 7-10, however, causes an increase in lower-energy neutrons in the axial reflectors and a resultant increase in power production in the fuel when the control rod is in the down or partially withdrawn condition.

Power production in the fueled portion of a control rod fully withdrawn from the core with the stainless steel radial reflector has been estimated based on analytical and experimental work reported in ANL-7737, p. 82 (Aug 1970), ANL-7742, p. 17 (Sept 1970), and ANL-7765. p. 48. The estimate was deduced indirectly because of the difficulty of reproducing the actual geometry with a calculational model. The results show that $72 \%$ as much power is produced in the control rod with the fuel withdrawn as with the fuel fully inserted.

The design of the EBR-II control rod incorporates a variable orifice that decreases the flow rate of the coolant as the fuel is removed from the core. The temperature of the fuel element is determined by the flow rate of the coolant and by the power produced by the fuel. The nominal

*R. R. Smith, C. B. Doe, and E. R. Ebersole, Exposed-fuel Calibration Study in EBR-II, Second Series, ANL-7558 (Jan 1970). 
flow of coolant through a fully inserted control rod is $61 \mathrm{gpm}$, and the nominal flow through a Row -5 driver is $77 \mathrm{gpm}$. Since a control rod has 61 elements, compared with 91 for a driver subassembly, an element in a control rod receives an average of $(91 / 61)(61 / 77)=118 \%$ as much flow as an element in a driver subassembly. Because a higher percentage of elements in a control rod are next to the hexagonal can, however, the flow per element in the triflute coolant passages in a control rod is only $110 \%$ of that for a Row-5 driver.

The flow through a present control rod in the fully withdrawn position is $65 \%$ of nominal. The corresponding flow through the current design of the high-worth control rod is $68 \%$. Taking into account the $10 \%$ excess flow per element in a control rod, calculations show a power/ flow ratio of $0.72 / 0.72$ for the present control rod when withdrawn, and $0.72 / 0.75$ for the high-worth control rod when withdrawn, as compared with a ratio of $1.0 / 1.0$ for each when fully inserted.

(2) Flow Coastdown in the Primary-sodium System (J.R. Karvinen and C.C.Price). Tests have been performed to establish a record of flow decay following loss of power to the EBR-II primarysodium pumps. Two modes of power loss were considered: (1) loss of

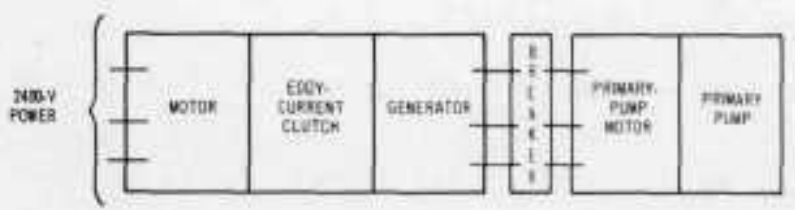

Fig. 1.13. Block Diagram of System for Driving Primary Pump power to the motor-generator $(\mathrm{M}-\mathrm{G})$ sets--see Fig. I,13 (clutch power between the motor and generator is also lost in this mode); (2) loss of power between the generators and the motors of the primary pumps. The second mode causes the most rapid flow coastdown, because the inertial capabilities of the $M-G$ sets are no longer present to oppose the coastdown of the motors of the pumps. Because the recovery (startup) times for the primary pumps and the auxiliary pump had not previously been recorded, tests of these were also included.

Figure I.14 shows (from top to bottom) the recovery time of the auxiliary pump, the recovery time of the primary pumps, the flowcoastdown time when the circuit breakers between the generator and the primary-pump motors are opened (loss mode No. 2), and the flowcoastdown time when power is lost to the M-G set (loss mode No. 1). The latter coastdown is typical of the instances when site power is lost owing to lightning, power transients, etc.

in $7 \mathrm{sec}$.

The auxiliary-pump flow ( $5 \%$ of full flow) is reestablished 


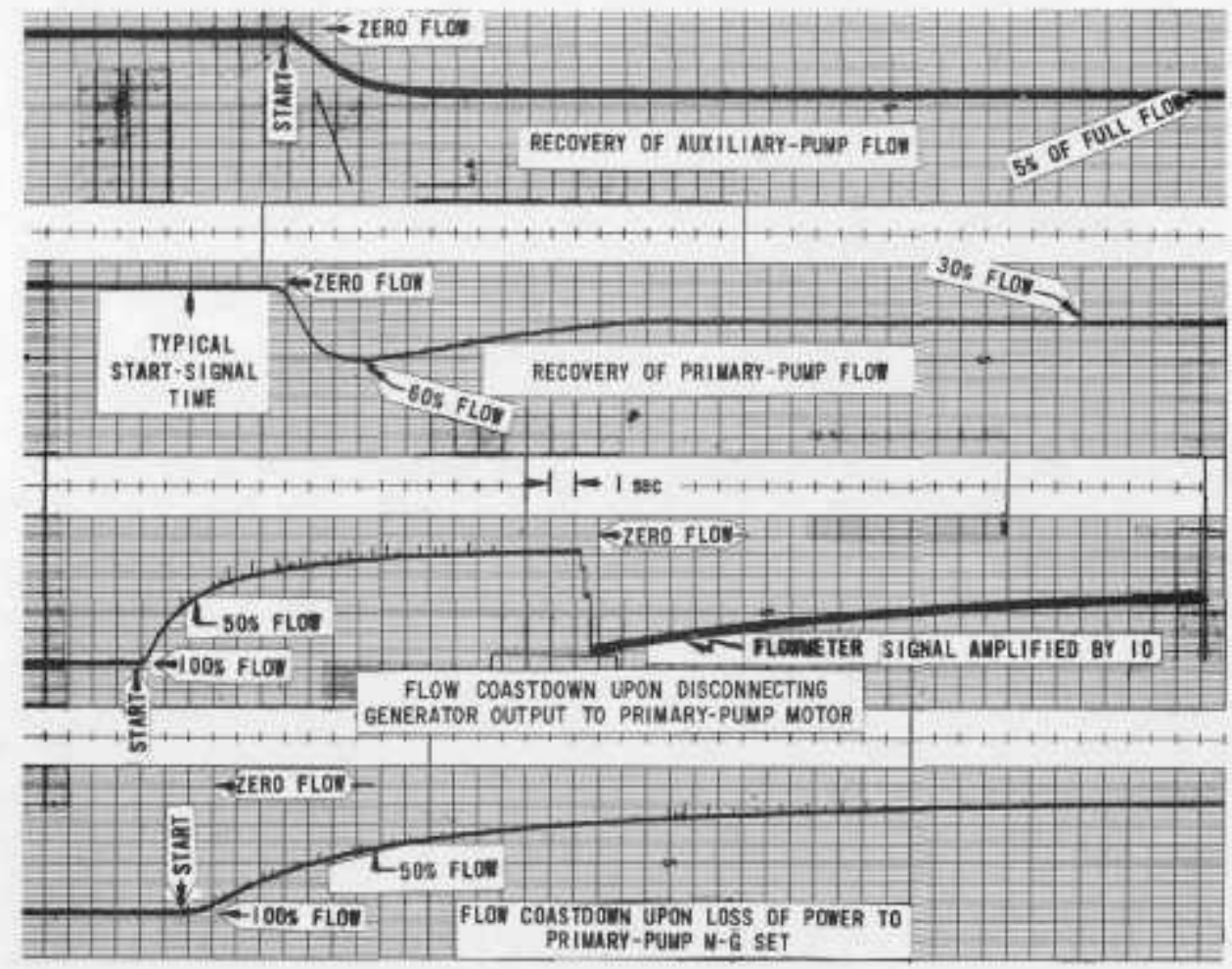

Fig. I.14. Recovery and Coastdown of Flow in Primary System (all flows measured with flowmeter of instrumented subassembly)

Minimum flow ( $30 \%$ of full flow) for the primary pump is reached within $4 \mathrm{sec}$. This is longer than would be expected under operating conditions. In the test, the operator manually opened the breakers that supply the power to excite the pump START button, then closed them, and then pushed the START button. Under operating conditions, pump recovery to minimum flow would require less than $2 \mathrm{sec}$. Note that the flow overshoots by $100 \%$ the minimum flow of $30 \%$ in the first few seconds and does not drop to steady-state minimum flow until about $20 \mathrm{sec}$ after initiation.

The flow coastdown without the electrical and mechanical inertia of the M-G sets (mode No, 2, third trace) is very fast. Flow is reduced to $50 \%$ in less than $3 \mathrm{sec}$. The right-hand side of this trace represents flow of the auxiliary pump only ( $5 \%$ of full flow).

The last trace shows the coastdown time for the situation (mode No. 1) that typically occurs with any loss-of-power scram. The $50 \%$ flow occurs about $7 \mathrm{sec}$ after loss of power to the M-G sets. Minimum flow $(5 \%)$ occurs $90 \mathrm{sec}$ after loss of power.

(3) Signature Analysis (C. C. Price and J. R. Karvinen). Noise signatures of the intermediate heat exchanger (IHX) and primarysodium pumps were obtained during reactor run $47 \mathrm{~B}$. Figure $\mathrm{I} .15$ shows the Fourier spectrum from accelerometers on the IHX, and Figs. I.16 and I.17 show Fourier spectra from accelerometers on the pumps. 

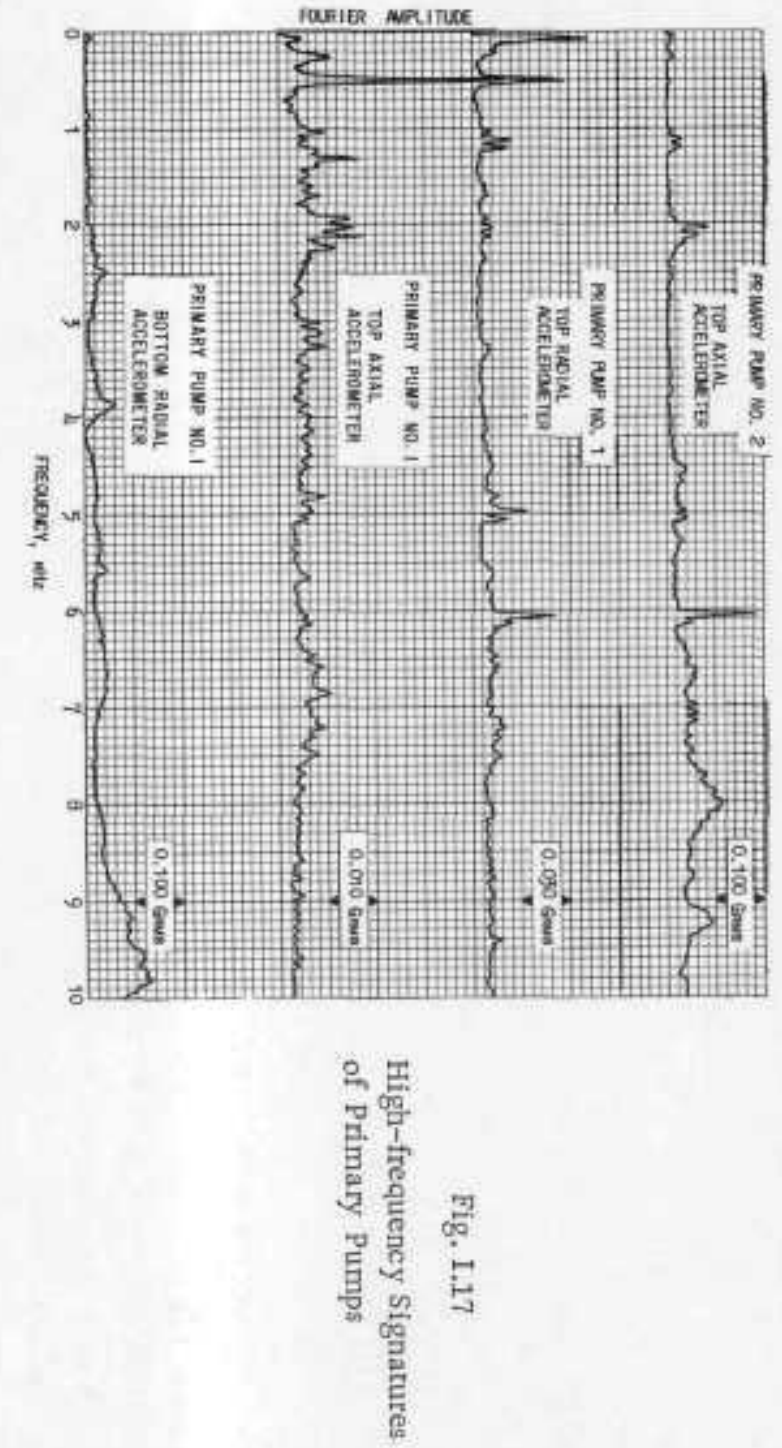

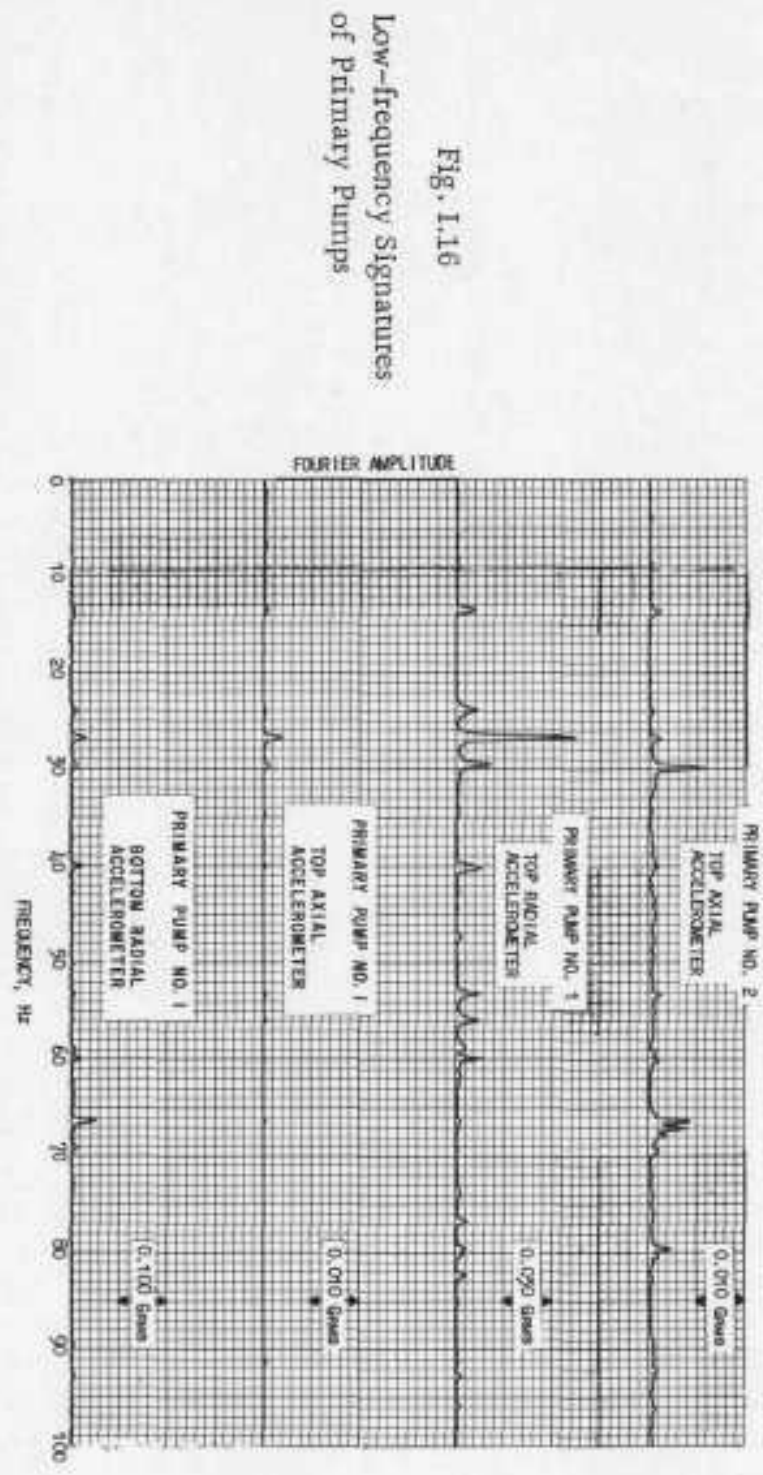

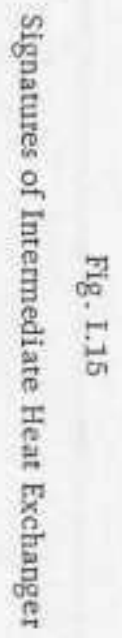


The signatures shown were obtained 8 days after a reactor power of 62.5 MWt had been reached and are considered "stationary" (equilibrium) signatures. The term "stationary" denotes a signature expected during normal reactor operation that is time-independent. Experience has shown that although the characteristic frequency components of a signature spectrum are present throughout the reactor startup, the amplitudes of these components vary somewhat after reaching operating power $(62.5 \mathrm{MWt})$.

The route toward achieving a stationary signature is under investigation. The most perturbed path encountered was after the startup of Run $47 \mathrm{~B}$. Run $47 \mathrm{~B}$ was the first run after the long shutdown for modification of the IHX and overhaul of primary-sodium pump No. 1. On the other hand, a sequence of signatures taken after a power level of $62.5 \mathrm{MWt}$ had been reached, in Run $48 \mathrm{C}$, showed only minor variations in amplitude.

For the IHX, the spectral peaks near 2.6 and $2.7 \mathrm{kHz}$ correspond very well to a calculated natural circular frequency of $2.8 \mathrm{kHz}$ for the secondary-sodium inlet and outlet pipes. The low-frequency peaks are $60-$ and $120-\mathrm{Hz}$ pickup.

The signature of pump No. 1 in Run 47B (after pump overhaul) is distinctly different from the signature in Run 47A (before overhaul). This difference lies in the relative amplitudes of the first and second harmonics of the pump's rotational speed. The second harmonic now is substantially higher than the first. This pump had previously exhibited a similar signature during operation (see ANL-7742, p. 57, Sept 1970). It now is operating properly, and there are no noticeable perturbations of its power requirements. Present plans are to monitor the pump signature on a daily basis during operation.

(4) Reactivity Effects of Displacements of Subassemblies in ${ }^{238} \mathrm{U}$ - and Steel-reflected Homogeneous EBR-II Types of Cores (D. Meneghetti and K. E. Phillips). The reactivity resulting from radial movement, in unison, of the subassemblies in any given row in EBR-II has been calculated for an idealized EBR-II type of core having a homogeneous composition and radially reflected by a depleted-uranium type of blanket and by a reflector having a high content of stainless steel. The reference separation by sodium between rows of subassemblies was assumed to be 30 mils. The radial displacements of a row of subassemblies for which the reactivities were calculated were plus and minus 20 mils (i.e., the gap on one side of a subassembly row was reduced to $10 \mathrm{mils}$ and on the other side was increased to $50 \mathrm{mils}$ ). In these analyses, the six-group cross-section set No. 23806 was used with the one-dimensional, cylindrical-geometry, $\mathrm{S}_{6}$-approximation SNARG transport code. 
Results of inward and outward displacements for both the depleted-uranium type of blanket and for the stainless steel reflector are shown in Fig. I.18. Beyond Row 10, the system was surrounded by an additional four rows of depleted-uranium type blanket in both cases. The reactivity effects with the different reflectors do not differ greatly, and the positive reactivity of inward movement of a row is generally similar in magnitude to the negative reactivity of outward movement of the row, except for the movement of the outer core row (Row 6 in this example). Here, the outward movement results in noticeably larger reactivities than does the corresponding inward movement.

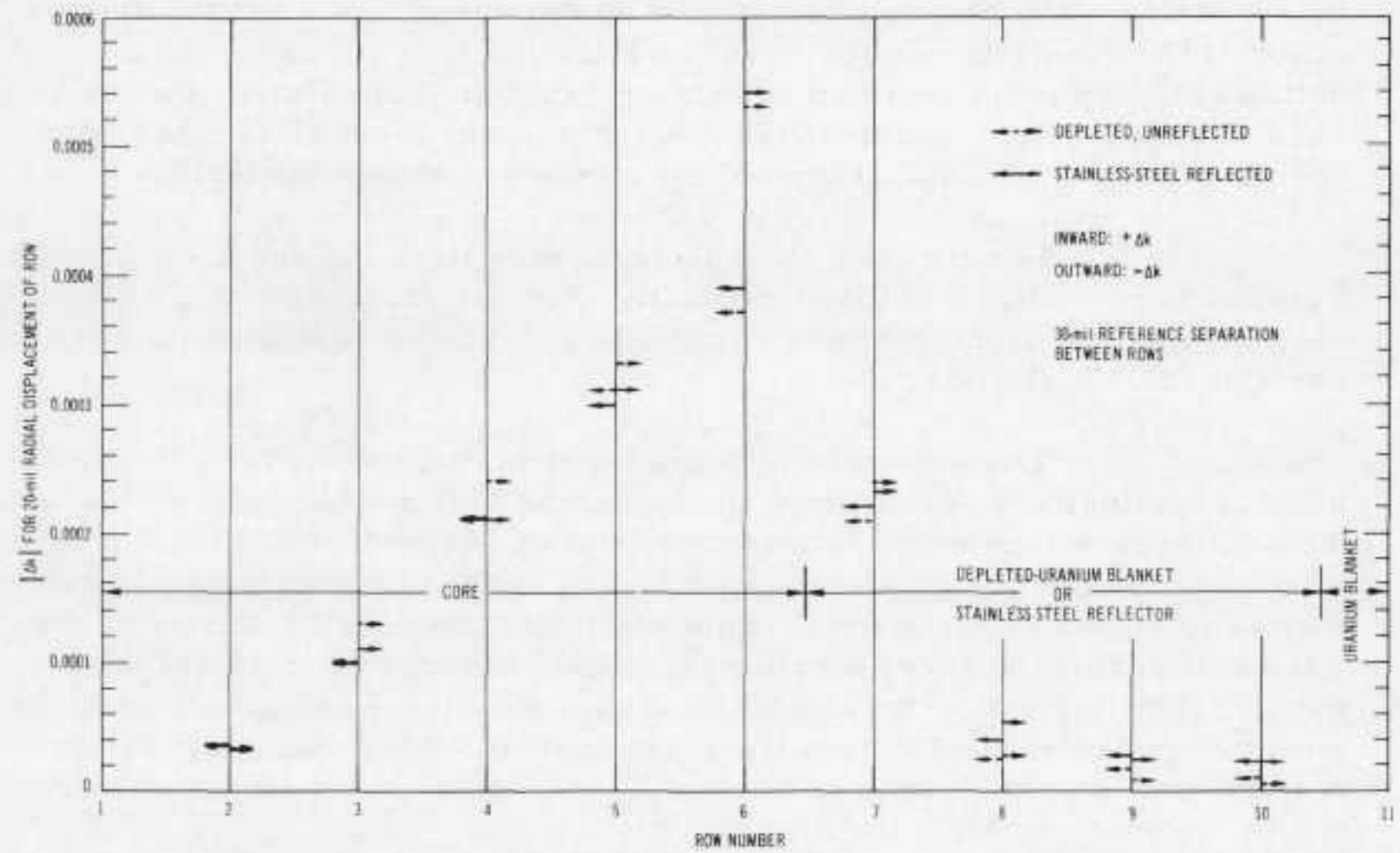

Eig. I.18. Calculated Reactivity Effects of Radial Displacement of Subassembly Rows

(5) SECTOR--A Computer Program for Determining the Steadystate, Three-dimensional Temperature Distributions in Thermally Interconnected Subassemblies in and around the EBR-II Radial Reflector (A. Gopalakrishman). The EBR-II Project has investigated several alternatives for installing an inert radial reflector in EBR-II. As a result, a radial reflector of four rows of stainless steel subassemblies, properly orificed for coolant flow to achieve desired specific thermal conditions, will replace part of the depleted-uranium radial blanket.

In previous EBR-II experience with a stainless steel reflector, the depleted-uranium blanket in Rows 7 and 8 was replaced by subas semblies containing stainless steel rods. This change was made before the 
start of Run 25, because the results of the surveillance measurements on depleted-uranium blanket material indicated a potential for swelling that was not then completely understood. The subassemblies containing stainless steel were later replaced during Run 29 with subassemblies containing depleted uranium of the original design because of the measured undesirable effects on the power-reactivity decrement of the core. Subsequent analyses* suggest that the reactivity effects during Runs 25-28 could have resulted from overcooling of the stainless steel reflectors. The subsequent radial temperature differentials would cause the effects of reverse bowing.

The depleted uranium in the radial blanket subassemblies in Rows 7-10 will be replaced by reflector subassemblies of stainless steel. The flow rates for these subassemblies will be selected to minimize the bowing effects due to radial temperature gradients noted during Runs 25-28. Because the available thermal-hydraulic codes are not directly useful for the analysis of the proposed reflector region, the SECTOR code was developed specifically for this purpose.

The geometry chosen for analysis is a $30^{\circ}$ segment of the EBR-II, Rows 5-12. This segment consists of 36 subassemblies: six in the core region, 18 in the four-row stainless steel reflector region, and 12 subassemblies of depleted uranium in the two blanket rows adjacent to the steel reflector. The heat generation in the reflector, which is due to deposition of gamma energy, generally decreases rapidly with increase in distance from the core center. In addition, depending on the coolant temperatures in the reflector subassemblies, heat exchange could occur between this region and surrounding core and blanket zones. Even for subassemblies within the same row, rates of heat generation usually differ with the position within the row; therefore, heat transfer between subassemblies in the same row also must be considered. The existing heat-transfer codes for subassembly analyses consider only a single subassembly or a part of it. Also, analysis of a set of thermally interconnected subassemblies by such programs requires tedious input preparation, time-consuming iterative calculations, and simplifying assumptions of the actual problem.

The SECTOR code is built up of a main program and 27 as sociated subroutines that solve the heat-balance relations for the different types of segments into which the total geometry is subdivided. The code determines the three-dimensional, steady-state temperature profiles within 36 subassemblies for which the individual rates of heat generation, their axial distributions, and the flow rates are specified as input data. The central hexagonal slug in each reflector subassembly is subdivided into 36 nodes at every axial position; the coolant and the hexagonal can are each described by 12 circumferential nodes per axial position. The multipin configurations

\footnotetext{
${ }^{*}$ R. R. Smith et al., The Effects of an Overcooled Stainless Steel Reflector on the EBR-II Power Coefficient, ANL-7544 (May 1969).
} 
of the core and blanket subassemblies have been simulated only by approximate smeared subdivisions, because this approximation is considered adequate for determining the approximate coolant-temperature distributions within these subassemblies. These distributions in turn are used in calculating the temperature distributions in the wall of the hexagonal can and heat transfer between subassemblies, which occurs through the tank sodium in the space between adjacent hexagonal cans. There are 170 tank-sodium nodes in the code per axial position. This sodium can be assumed to be either stagnant or flowing under free-convection forces. Within the subassemblies, in addition to the circumferential conduction in the coolant, an additional mode of heat transfer can be simulated in the code by selecting appropriate mixing coefficients, which can be input as functions of axial position for each subassembly. This feature is especially useful in treating subassemblies that have built-in mixing promoters, such as the triflute sections in the EBR-II driver-fuel subassemblies.

The present version of SECTOR uses 19 axial sections, with a total of approximately 34,000 nodes. Typical problems can be completed in 25-35 min of IBM 360/75 computer time. Temperatures are initialized by assuming zero heat transfer between the subassemblies and by suppressing the axial and circumferential conduction within each subassembly. The program then enters an iterative calculational loop in which these restrictions are removed and temperatures are reset at the end of each cycle. These calculations are terminated when two successive iterations give temperatures that agree within a specified convergence limit for all nodes. Final heat-balance calculations are then made to ensure that the total heat-generation rate agrees with the total rate of heat transport due to coolant flow.

Figures I.19 and I.20 show the calculated radial distributions of the temperature differentials within the hexagonal cans, for two different sets of flow rates and the same heat-generation rates. These temperature differentials are across flats of a can radially from the core center. They are part of the detailed results from SECTOR used in the subsequent analysis for thermal bowing.

Subassemblies in Rows 5-8, along the chosen radial line from the core center, had the same flow rates of $81.4,48.7,3.4$, and $2.0 \mathrm{gpm}$, respectively, for the two cases reported here. The selected changes were made only in the flow rates through reflector subassemblies in Rows 9 and 10. For these two sets of flow rates, the EBRFLOW program (ANL-7705, p. 92, June 1970; ANL-7737, p. 61, Aug 1970) was used to analyze the reactor flow distribution under the constraint of constant rate of total flow through the primary system. These analyses gave the flow rates through the blanket subassemblies in Rows 11 and 12 . For a flow rate of $2.0 \mathrm{gpm}$ through Rows 9 and 10, the EBRFLOW calculations resulted in a flow rate in the blanket of $2.63 \mathrm{gpm}$. The corresponding value was $3.0 \mathrm{gpm}$ for flows of 0.9 and $0.7 \mathrm{gpm}$ through the reflector subassemblies in Rows 9 and 10 , respectively. 


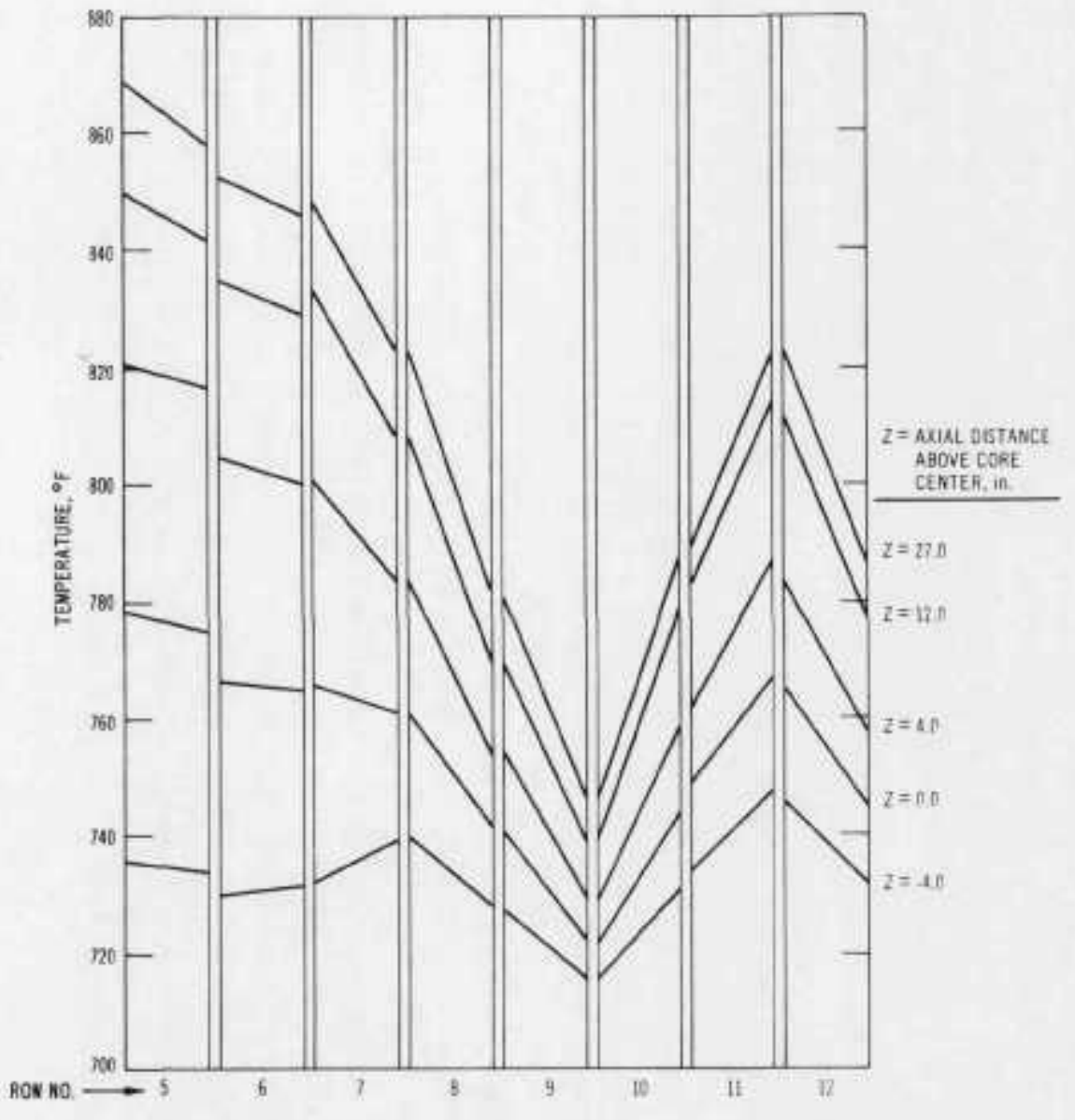

Fig. I.19. Radial Distribution of Hexagonal-can Temperatures for a Flow of $2.0 \mathrm{gpm}$ through Rows 9 and 10

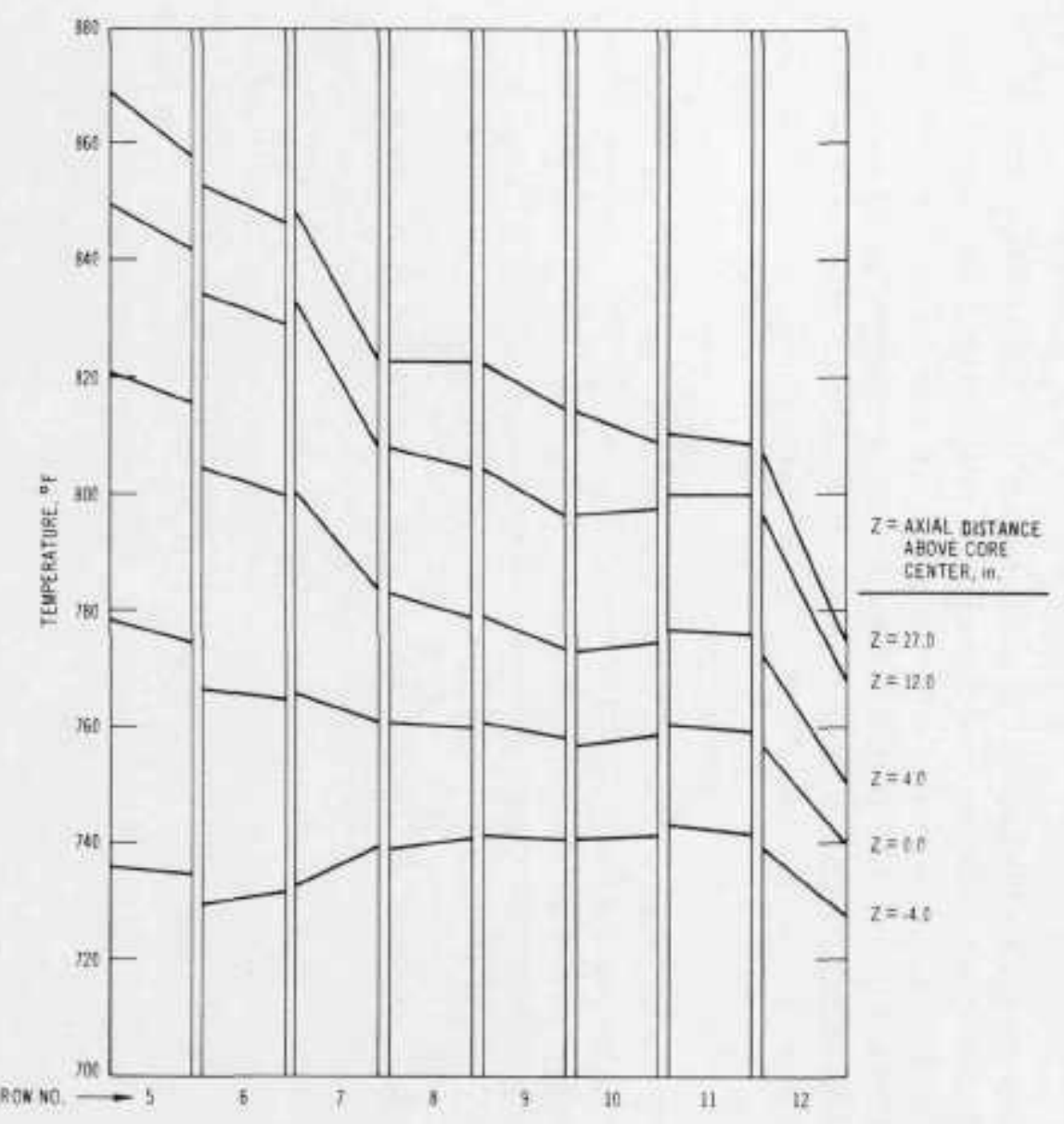

Fig. 1.20. Radial Distribution of Hexagonal-can Temperatures for a Flow of 0.9 and $0.7 \mathrm{gpm}$ through Rows 9 and 10 , Respectively; 
Figure 1.19 shows that maintaining the same flow rates through Rows 8-10 resulted in overcooling of the reflector subassemblies in Rows 9 and 10, which caused reverse temperature gradients in those rows and across Rows 11 and 12. This behavior also is typical of a temperature distribution that results in undesirable reactivity effects due to thermal bowing. Thus, it should be avoided by proper modification of the flow rates.

Figure 1.20 shows how the temperature distributions are altered if the flow rates in Rows 9 and 10 are 0.9 and $0.7 \mathrm{gpm}$, respectively. The strong reverse temperature gradients have been eliminated, and the associated analysis of thermal bowing shows acceptable levels of reactivity effects due to this temperature distribution.

(6) Comparison of Calculated and Measured Flow Rates in XX02 during Runs 42-48A (J, L, Gillette). Use of EBR-II as an irradiation facility requires frequent and significant changes in reactor loading. As a result of these changes, the patterns of coolant flow within the reactor may be altered and any particular subassembly may have different flow rates for different reactor loadings, even though the total flow in the primary system remains the same. The EBRFLOW computer program was written in an attempt to describe the flow distribution as a function of reactor loading.

Before Run 42, instrumented subassembly XXO2 was inserted into grid position 5F3. This subassembly, which had a permanentmagnet in-core flowmeter, was in the reactor for several runs. It thus offers the opportunity to compare calculated flow rates with measured rates for this grid position over a wide variation in reactor loadings.

The flow from each of the two primary pumps was assumed to be $4670 \mathrm{gpm}$ for each reactor loading. This value represents $100 \%$ of nominal full flow as reported in ANL-5719 (Addendum).*

Table I.20 shows the calculated and measured flow rates in Subassembly XX02 for Runs 42-48A. Also shown is the percentage difference (based on the measured value) between the two flow rates.

The flow rates in the driver-fuel, safety, and control subassemblies also showed similar variations with reactor loading.

The agreement between the calculated and measured flow rates for Subassembly XX02 during Runs $42-45 \mathrm{~B}$ is considered excellent. The flow rates changed by about $3 \mathrm{gpm}$, or $6 \%$, during this series of runs, but the difference between the calculated and measured flow rates changed

"L. J. Koch, W. B. Loewenstein, and H. O. Monson, Addendum to Hazard Summary Report, Experimental Breeder Reactor-II (EBR-II), ANL-5719 (Addendum) (June 1962). 
by only about $1 \%$. Beginning with Run $46 \mathrm{~A}$, however, the agreement is not as good. The difference between calculated and measured flow rates was $8.4 \%$ for Run $47 \mathrm{~B}$.

TABLE 1.20. Calculated and Measured Flow Rates in Subassembly XX02

\begin{tabular}{lccc}
\hline \multirow{2}{*}{ Run } & \multicolumn{2}{c}{ Flow Rate, $\frac{\text { gpm }}{2}$} & \\
\cline { 2 - 4 } & Calculated & Measured & Difference \\
\hline 42 & 53.0 & 52.5 & $\sim 1$ \\
43 & 51.9 & 51.5 & $\sim_{1}$ \\
$44 \mathrm{~A}$ & 51.4 & 51.0 & $\sim 1$ \\
$44 \mathrm{~B}$ & 51.1 & 50.5 & 1.2 \\
$45 \mathrm{~A}$ & 51.0 & 50.0 & 2.0 \\
$45 \mathrm{~B}$ & 50.2 & 49.2 & 2.0 \\
$46 \mathrm{~A}$ & 49.8 & 46.5 & 7.1 \\
$46 \mathrm{~B}$ & 49.4 & 46.5 & 6.2 \\
$47 \mathrm{~A}$ & 49.8 & 46.6 & 6.9 \\
$47 \mathrm{~B}$ & 50.1 & 46.2 & 8.4 \\
$48 \mathrm{~A}$ & 49.8 & 46.5 & 7.1 \\
\hline
\end{tabular}

The most probable explanation for the decrease in agreement is errors in the calculational technique. The data used for distribution of pressure drop in EBRFLOW calculations were supplied by the Franklin Institute.* These data show a variation in pressure drop across the inner seven rows of the reactor (i.e.. across the high-pressure plenum region), but they do not allow for a difference in $\triangle P$ between two subassemblies in the same row. Thus, for an irradiation facility, the pressure drop across a driver-fuel subassembly would be assumed to be the same as that across a structural experimental-irradiation subassembly with low coolant flow in the same row. In addition, no special allowance is made for the effect of a low-flow experimental-irradiation subassembly on the pressure drop of an adjacent subassembly in another row.

The above effects evidently were of little consequence to the flow rates in Subassembly XX02 in Runs $42-45 B$, because there were few experiments in Rows 5 and 6 and the grid locations surrounding XX02 were changed hardly at all during this time. Before Run 46A, however, many experiments were moved from the inner rows of the core to Rows 5 , 6 , or 7 . These moves were made in preparation for the first run at design

*D. T. Rymsa and G.P. Wachtell, Flow Model Study of the EBR-II, E-A2201, Franklin Institute, July 15, 1958 to December 2, 1960. 
power (62.5 MWt); each previous run in this series was at $50 \mathrm{MWt}$. As a result of the many changes in the immediate vicinity of Subassembly XX02, the above effects possibly became very important in determining the flow rates in this subassembly. Because these effects are not accounted for in the EBRFLOW code at this time, the calculated flow rates could differ somewhat from the measured rates for these runs.

The above effects are not currently included in the EBRFLOW code, because there is now no quantitative information. One of the functions of the hydraulic test facility being assembled at the EBR-II site is to supply this information. The facility is the same 0.6-scale mockup of EBR-II used by the Franklin Institute for the original flow tests. Flow tests will be made for various irradiation loadings, and the information obtained from these tests will be incorporated into the code.

Another possible source of error in the calculations is in the assumption of $100 \%$ nominal flow. Examination of data on pump speeds, discharge pressures, and pressure drops, data from flowmeters, and data comparing heat balances of the primary and secondary systems suggests that the total primary-system flow may have decreased for Run $46 \mathrm{~A}$. These data indicate that the flow remained below the nominal value at least through Run $47 \mathrm{~B}$. If the indications from these data are correct, the measured flow in Subassembly XX02 would be considerably less than the calculated flow, beginning with Run 46A. This effect is shown in Table I.20.

The EBRFLOW code gives good agreement with the measured flow rates in instrumented subassembly XX02 over a wide variety of core loadings. Use of the code has shown that subassembly flow depends on the reactor loading and that the code can be used to predict the variations in flow in each subassembly as the reactor loading changes from run fo run. Data from the hydraulic test facility will be used to calibrate the code for EBR-II so that predicted trends can be applied directly with a high degree of confidence.

(7) Displacements and Stresses in the Mark-II Fuel Element (L. K. Chang, R, K. Lo, and B, R, Sehgal). A major concern with Mark-II fuel is that it might be prevented from expanding. When swollen, fuel is in the contact with the cladding and is restrained at the top end. A preliminary investigation of this problem was made with a code* with which stresses and displacements in a rotationally symmetric finite cylinder with applied temperature and pressure fields are computed. The code allows for nonlinear and temperature-dependent properties of material and does analysis of elastic and plastic behavior. The part of this code for elastic behavior has been tested, and the results have been compared with an exact solution.**

\footnotetext{
${ }^{*}$ F. E. Peterson, User's Supplement for Finite Element Analysis of Solid with Nonlinear Material Properties, Aerojet-General Corporation (Mar 1966).

${ }^{* *}$. A. Valentin, Interim Report on Finite Element Investigation, unpublished report, Argonne National Laboratory (Jan 28, 1970).
} 
Displacements and stresses of a Mark-II fuel pin in Row 5 were calculated for the following five cases:

(a) Freely expanding fresh fuel pin under steady-state conditions.

(b) Freely expanding fresh fuel pin at a particular time during a startup transient.

(c) Fuel element under steady-state conditions at 3 at. $\%$ burnup.

(d) Fuel element at a particular time during a startup transient at 3 at. $\%$ burnup.

(e) Case d, except that the outside surface of the cladding is "cold," i.e., at the reference temperature along its whole length.

The fresh fuel pin is $14.22 \mathrm{in.}$ long and $0.065 \mathrm{in.}$ in radius. At 3 at. $\%$ burnup, the pin is assumed to swell axially by 1 in. and radially by 0.01 in., so that the sodium bond is squeezed out to contact the cladding over its entire length and the restrainer at the top. In this condition, the fuel is assumed to be welded to the 0.012 -in.-thick cladding.

In the calculations of stress and displacement, the mechanical (external) and thermal (internal) loadings must be specified. The temperature profiles of the fuel element were calculated by using the THTB code* at steady state and in the startup transient (inadvertent insertion of control rod) corresponding to the two cases of fresh fuel and fuel with 3 at. $\%$ burnup. The fresh fuel is assumed to be free of mechanical loading; a plenum-pressure loading of $375 \mathrm{psi}$ is assumed for the fuel with 3 at. $\%$ burnup.

The calculated radial displacements of the outer surface of the fuel element are shown in Fig. I.21. The total axial displacements of the fuel pin at its centerline due to thermal and mechanical loadings are shown in Table 1.21. These displacements are the calculated expansions at temperatures above the reference temperatures shown in the third column of the table. The differential expansions (above the steady-state value) of the pin at a particular time in the startup transient are shown in the fifth column. These values have been adjusted to have a common reference temperature of $751^{\circ} \mathrm{F}$ for all cases. The magnitude of the reactivity feedback due to fuel expansion during the startup transient will be proportional to the magnitude of the differential expansion of the pin in Cases 2, 4, and 5 .

\footnotetext{
*G. L. Stephens and D. J. Campbell, Program THTB for Analysis of General Transient Heat Transfer Systems, R60FPD647, General Electric Co. (Apr 1961).
} 


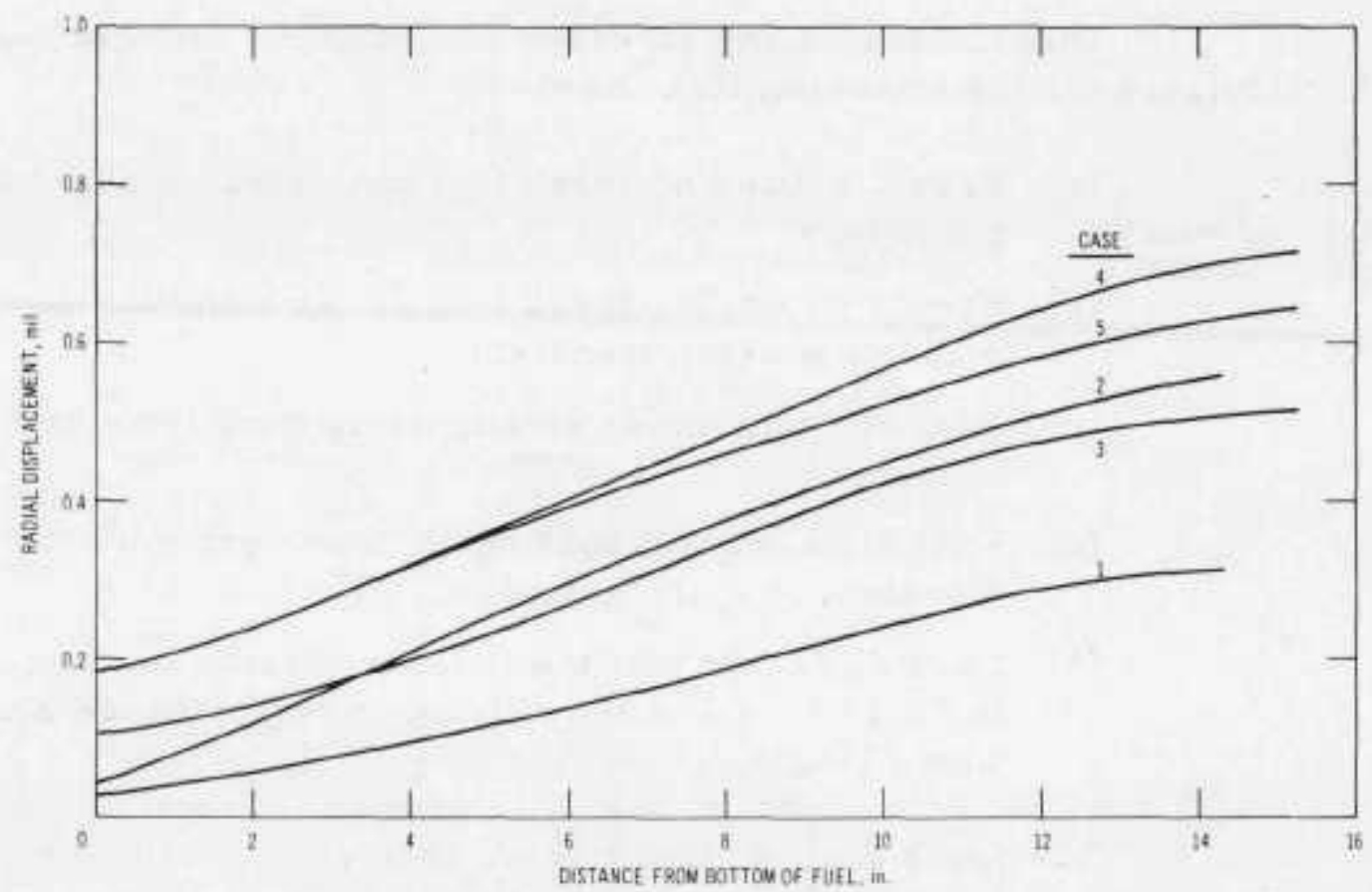

Fig. 1.21. Radial Displacements of Outer Surface of Mark-II Fuel Element

TABLE 5.21. Axial Expansion of Mark-1I Fuel

\begin{tabular}{|c|c|c|c|c|c|c|}
\hline $\begin{array}{l}\text { Case: } \\
\text { No. }\end{array}$ & Conditions & $\begin{array}{l}\text { Reference } \\
\text { Temperature, } \\
{ }_{\text {"F }} \mathrm{F}\end{array}$ & $\begin{array}{l}\text { Axial Expansion from } \\
\text { Reference Teaperature, } \\
\text { In. }\end{array}$ & $\begin{array}{l}\text { Adjusted }{ }^{a} \\
\text { Expansion, } \\
\text { in. }\end{array}$ & $\begin{array}{l}\text { Differential } \\
\text { Expansion, } \\
\text { fn. }\end{array}$ & $\begin{array}{l}\text { Z of Free } \\
\text { Expansion }\end{array}$ \\
\hline 1 & Eresh fuel, steady atate & 775 & 0.0375 & 0.04091 & $m$ & - \\
\hline 2 & Fresh fuel, startup transient & 863 & 0.07047 & n.0835s & 0.04264 & 100 \\
\hline 3 & $\begin{array}{l}\text { Fuel "weIded" to cladding, steady } \\
\text { ntate }\end{array}$ & 721 & 0,05336 & 0.04879 & - & $\rightarrow$ \\
\hline 4 & $\begin{array}{l}\text { Euel "Welded" to cladding, startup } \\
\text { transient }\end{array}$ & 751 & 0.07406 & 0.07406 & 0.02527 & 59.3 \\
\hline 5 & $\begin{array}{l}\text { Fuel "welded" to cladding, startup } \\
\text { transient and outer surface of } \\
\text { cladding cold }\end{array}$ & 751 & 0.06354 & 0.06354 & 0.01475 & 34.6 \\
\hline
\end{tabular}

Adfusted to a camon reformee tenperature of $751^{\circ} \mathrm{F}$.

Table I.21 shows that the fuel expansion during a transient is reduced significantly if the fuel becomes attached to the cladding, i.e., cannot slip at the contact surface. The case of an element with "cold" cladding, although not realistic, shows an expansion of about $35 \%$ of that of a freely expanding Mark-II fuel pin.

If $\sigma_{\mathrm{rr}}, \sigma_{\theta \theta}, \sigma_{\mathrm{zz}}$, and $\sigma_{\mathrm{rz}}$ are the radial, hoop, axial, and shear stresses of the fuel element, the principal stresses $\sigma_{1}, \sigma_{2}$, and $\sigma_{3}$ can be expressed as 


$$
\begin{aligned}
& \sigma_{1}=\sigma_{\theta \theta}, \\
& \sigma_{2}=\frac{1}{2}\left[\left(\sigma_{\mathrm{zz}}+\sigma_{\mathrm{rr}}\right)+\sqrt{\left(\sigma_{\mathrm{zz}}-\sigma_{\mathrm{rr}}\right)^{2}+4 \sigma_{\mathrm{rz}}^{2}}\right],
\end{aligned}
$$

and

$$
\sigma_{3}=\frac{1}{2}\left[\left(\sigma_{\mathrm{zz}}+\sigma_{\mathrm{rr}}\right)-\sqrt{\left(\sigma_{\mathrm{zz}}-\sigma_{\mathrm{rr}}\right)^{2}+4 \sigma_{\mathrm{rz}}^{2}}\right]
$$

The maximum principal stresses for Cases 1-5 are tabulated in Table 1.22 , as are locations of maximum stresses and their corre-

\begin{tabular}{|c|c|c|c|c|c|c|c|c|}
\hline \multirow[b]{2}{*}{$\begin{array}{l}\text { Case } \\
\text { No. }\end{array}$} & \multirow[b]{2}{*}{ Conditions } & \multicolumn{2}{|c|}{$\begin{array}{l}\text { Sode of Max } \\
\text { Stress } \\
\end{array}$} & \multicolumn{3}{|c|}{ Principal Stress, pai } & \multirow[b]{2}{*}{$\begin{array}{c}\text { Temperature, } \\
\qquad F\end{array}$} & \multirow{2}{*}{$\begin{array}{l}\text { Cladding } \\
\text { Yteld Strength, a } \\
\text { pei }\end{array}$} \\
\hline & & $\begin{array}{l}\text { Radius. } \\
\text { In. }\end{array}$ & $\begin{array}{l}\text { Height, } \\
\text { in. }\end{array}$ & $\sigma_{1}$ & $\sigma_{2}$ & ${ }^{8}$ & & \\
\hline 1 & Fresh fuel, oteady state & 0.01 & 8.86 & $-6170^{b}$ & -5790 & $-11,200$ & 1120 & - \\
\hline 2. & Freah fuel, startup transient & 0.01 & 7.86 & $-10,000$ & $-10,600$ & $-13,200$ & 1383 & - \\
\hline I & $\begin{array}{l}\text { Fuel "velded" to eladdingt, steady } \\
\text { state }\end{array}$ & 0.08 & 9.29 & 58,200 & 46,800 & -4900 & 1016 & 80,000 \\
\hline 4 & $\begin{array}{l}\text { Fuel "welded" to cladding, startup } \\
\text { transient }\end{array}$ & 0.08 & 5.30 & 73.500 & 59.000 & -5900 & 980 & 82.000 \\
\hline 5 & $\begin{array}{l}\text { Fuel "velded" to cladding, scartup } \\
\text { tranatent and outer surtace of } \\
\text { eladidtng cold }\end{array}$ & 0.08 & 15.11 & 124,700 & 102,000 & -9600 & 1127 & 62,000 \\
\hline
\end{tabular}
sponding values for temperature and yield strength.

TABLE 1.22. Maxtmin Principal Stresses in Mark-II Fuel

AThe quoted yield strength is fron the neasured data on 25t-coldworked transwerse Type $30 \mathrm{~h}$ stainless Bteel vith a fluence

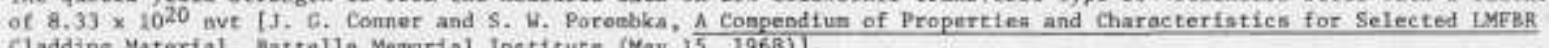
cladding Material, Battelle Menorial Institute (May $\left.\frac{15}{5}, 1968\right) 1$.

Sogative afgn fndicates compression.

The stresses shown in Table 1.22 are primarily induced by temperature differences. Thermal stresses are never classed as primary stresses; they are secondary and peak stresses. Thermal stresses that can produce distortion in a structure are considered secondary stresses. Thermal stresses that result from almost complete suppression of the differential expansion, and thus cause no significant distortion, are classed as peak stresses. The stresses shown in Table I. 22 can be reasonably classed as secondary. A calculated secondary elastic stress equal to twice the yield strength is considered to be the safe design value, because some plastic action during overloads is tolerable.*

If corrosion and stress-corrosion cracking of the cladding are not considered, cladding failure is unlikely because:

(a) In Cases 3-5 in Table I.22, the maximum cladding stress intensities are less than, or about equal to, twice their corresponding yield strengths.

"Criteria of Section III of the ASME Boiler and Pressure Vessel Code for Nuclear Vessels, The American Society of Mechanical Engineers (1964). 
(b) The yield strengths in Table 1.22 are considered to be conservative because their values are based on a fluence of $8.33 \times 10^{20}$ nvt. At 3 at. \% burnup, the fluence of the cladding is about $4.84 \times 10^{21} \mathrm{nvt}$; at this fluence, yield strengths should be higher than those tabulated in Table 1.22.

\section{b. Improved Experimenta1-irradiation Capability (Last reported: ANL-7765, p. 35)}

(1) Gamma Heating in Row 5 above the Core (L. R. Miller and R. E. Jarka). Some experiments in instrumented subassemblies to be irradiated in Row 5 of EBR-II are more than $60 \mathrm{~cm}$ above the core midplane. Because none of the distributions of gamma-heating rates listed in the Guide for Irradiation Experiments in EBR-II are for more than $60 \mathrm{~cm}$ above the core midplane, additional calculations have been done to obtain distributions to $100 \mathrm{~cm}$ above the midplane. The computed gamma-heating rates in uranium and stainless steel as a function of axial position in Row 5 of EBR-II are shown in Fig. I.22.

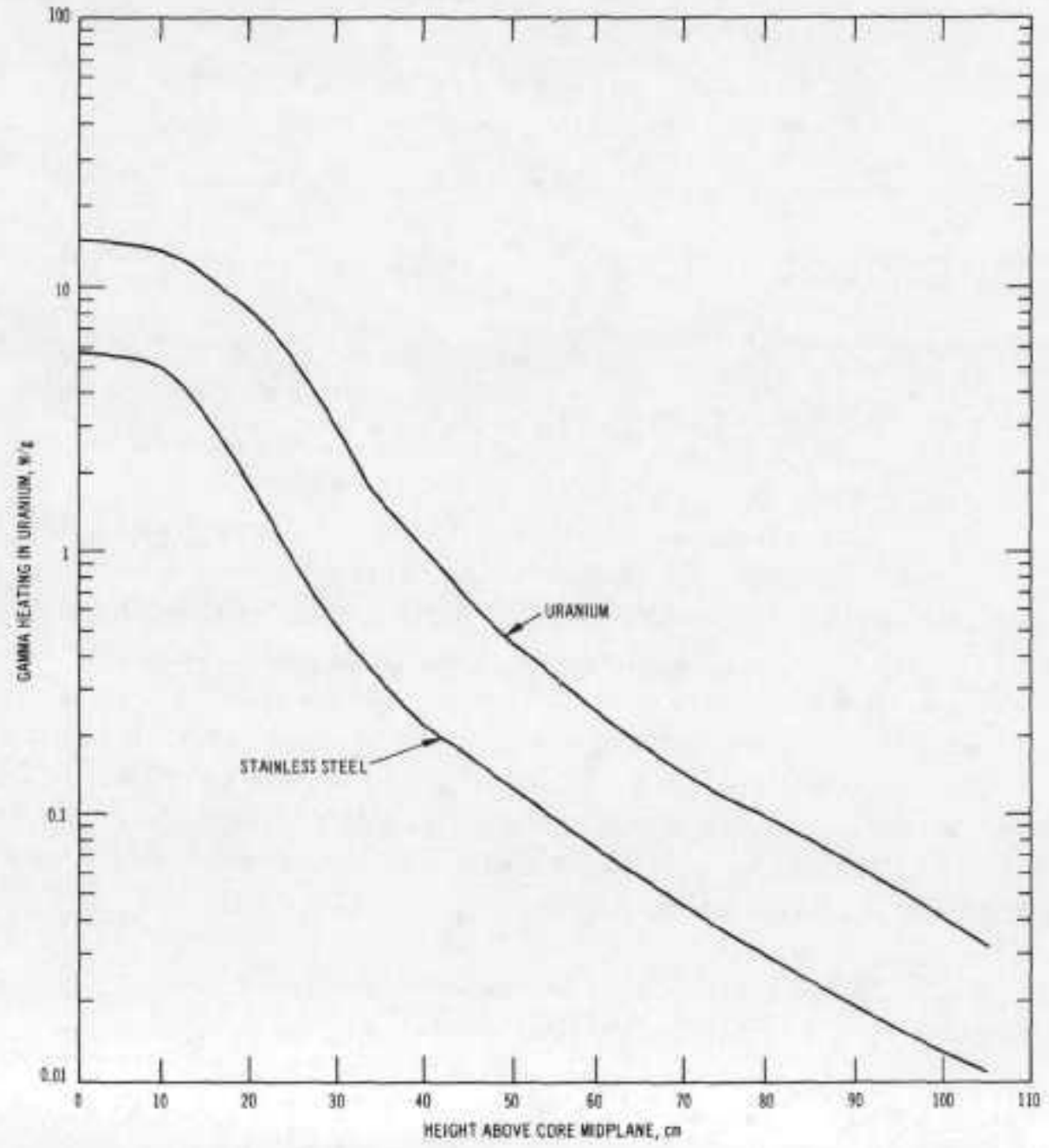

Fig. 1.22. Gamma-heating Rate as a Function of Axial Position in Row 5 of EBR-II 
(2) Flux Asymmetry in the Run-47B Loading (L. B. Miller and R. E.Jarka). Analysis of the preliminary loading pattern for Run $47 \mathrm{~B}$ revealed a significant flux tilt toward the $C$ sector of the reactor. The pattern was modified to reduce the tilt. The principal changes were:

(a) Replacement of a Mark-II subassembly in position 5C2 by experimental Subassembly X084, Because the experimental subassembly has one-third the worth of a driver subassembly, this change effectively removed two-thirds of a driver-fuel subassembly from the C sector.

(b) Replacement of Subassembly X084 in position 5 F2 by a half-worth driver-fuel subassembly. This change effectively added onesixth of a driver-fuel subassembly to the $F$ sector.

(c) Interchange of Subassembly X091, previously in position 4E3, with a driver-fuel subassembly in position 4B3.

(d) Replacement of the oscillator rod in position $5 \mathrm{~A} 3$ by a control rod.

A $360^{\circ} \mathrm{XY}$ problem to determine the extent of flux asymmetry in the revised core loading was done with the DOT 380 neutrontransport code.

An indication of flux asymmetry is the relative variation in the values of the square of the total flux at the control-rod positions. These values, which are approximately proportional to the control-rod worths, are shown in Table 1.23 as calculated approximate control-rod worths along with the measured worths. The squares of the total flux were normalized to the total of the measured control-rod worths to obtain the calculated values. The measured worth of the high-worth control rod (position 11) was 54\% greater than the average measured worth of symmetrically placed normal control rods. The calculated value of the square of the flux in the highworth control rod was increased by this percentage for the comparison in Table I.23.

The approximate control-rod worths are plotted on polar coordinates in Fig. I.23, which also shows measured worths. The calculated approximate values agree well with the measured values.

Approximate control-rod worths calculated for the preliminary loading pattern for Run 47B are also shown in Fig. I.23 for comparison. This comparison shows graphically the reduction in flux tilt effected by the changes in the pattern. 
TABLE I.23. Contro1-rod Worths in Run $47 \mathrm{~B}$

\begin{tabular}{ccc}
\hline & \multicolumn{2}{c}{ Worth, Th } \\
\cline { 2 - 3 } $\begin{array}{c}\text { Control Rod } \\
\text { Number }\end{array}$ & $\begin{array}{c}\text { Calculated } \\
\left(\phi^{2}\right)\end{array}$ & Approximate \\
\hline 1 & 171 & Measured \\
2 & 131 & 169 \\
3 & 166 & 134 \\
4 & 150 & 161 \\
5 & -153 \\
6 & 152 & 152 \\
7 & 182 & 174 \\
8 & 136 & 133 \\
9 & 150 & 138 \\
10 & 190 & 220 \\
11 & 153 & 147 \\
12 & 1581 & 1581 \\
Total & & 152 \\
\hline
\end{tabular}

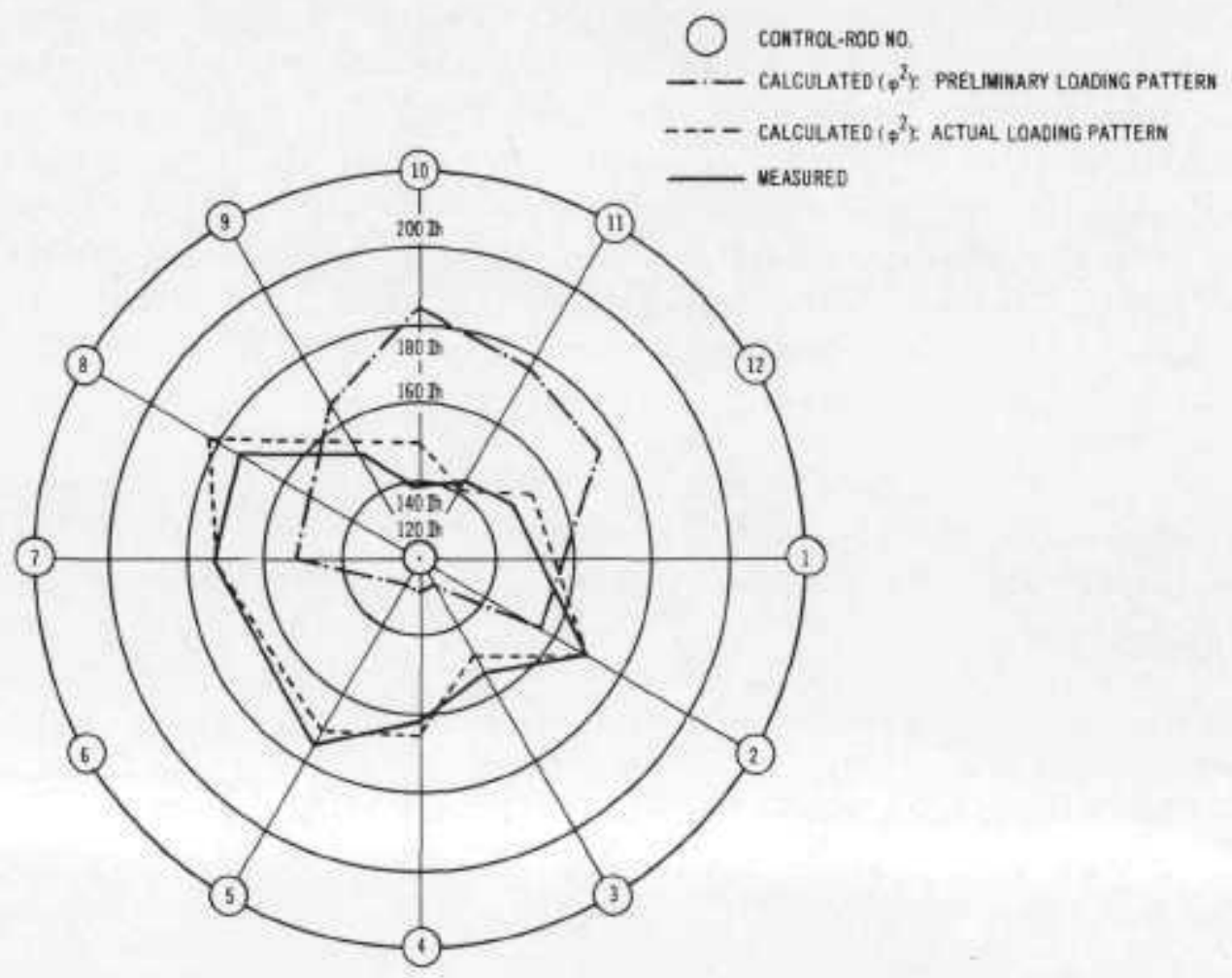

Fig. 1.23. Polar Plot of Control-rod Worths in Run 47B 
2. Operation with Failed Fuel (02-148)

a. Failure Diagnostics and Procedures (Last reported:

(1) Increases in Cover-gas Activity during Runs 47 and 48

(R. M. Fryer, E. R. Ebersole, and R. R.Smith). Following the annual EBR-II shutdown for plant maintenance, full-power operation (for Run 47B) was resumed March 4. Operation continued until March 12, when cover-gas activity increased. The increase was indicated by grab samples of the cover gas, which are analyzed off-line for ${ }^{135} \mathrm{Xe}$ and ${ }^{133} \mathrm{Xe}$. Table 1.24 shows the characteristics of this increase. The increase actually occurred in two steps, but the data in Table I.24 represent the overall S/ $\mathrm{N}$ ratios for the sum of the two steps. The increase in ${ }^{133} \mathrm{Xe}$ activity is shown in Fig. I.24.

Following the increase, two xenon-tag samples of the cover gas were taken. No evidence of a tag release was noted in either sample. The fission-product isotopes ${ }^{134} \mathrm{Xe}$ (stable) and ${ }^{133} \mathrm{Xe}$ ( 5.3 days) were detected, however, in the tag analysis, and the concentration ratio of ${ }^{134} \mathrm{Xe}$ to ${ }^{133} \mathrm{Xe}$ was measured to be approximately 700 . Calculation of the buildup of ${ }^{134} \mathrm{Xe}$ and ${ }^{133} \mathrm{Xe}$, based on fission-yield data, resulted in the conclusion that ${ }^{134} \mathrm{Xe}$ was present in a disproportionate amount, thus indicating the existence of marked fractionation effects.

The important conclusions derived from these date were:

(a) The lack of a signal from the FERD, which de ects delayed-neutron emitters, indicated thit no exposed fuel was involved.

Table I.24. Characteristics of Increase in Cover-gas Activity during Run $47 \mathrm{~B}$

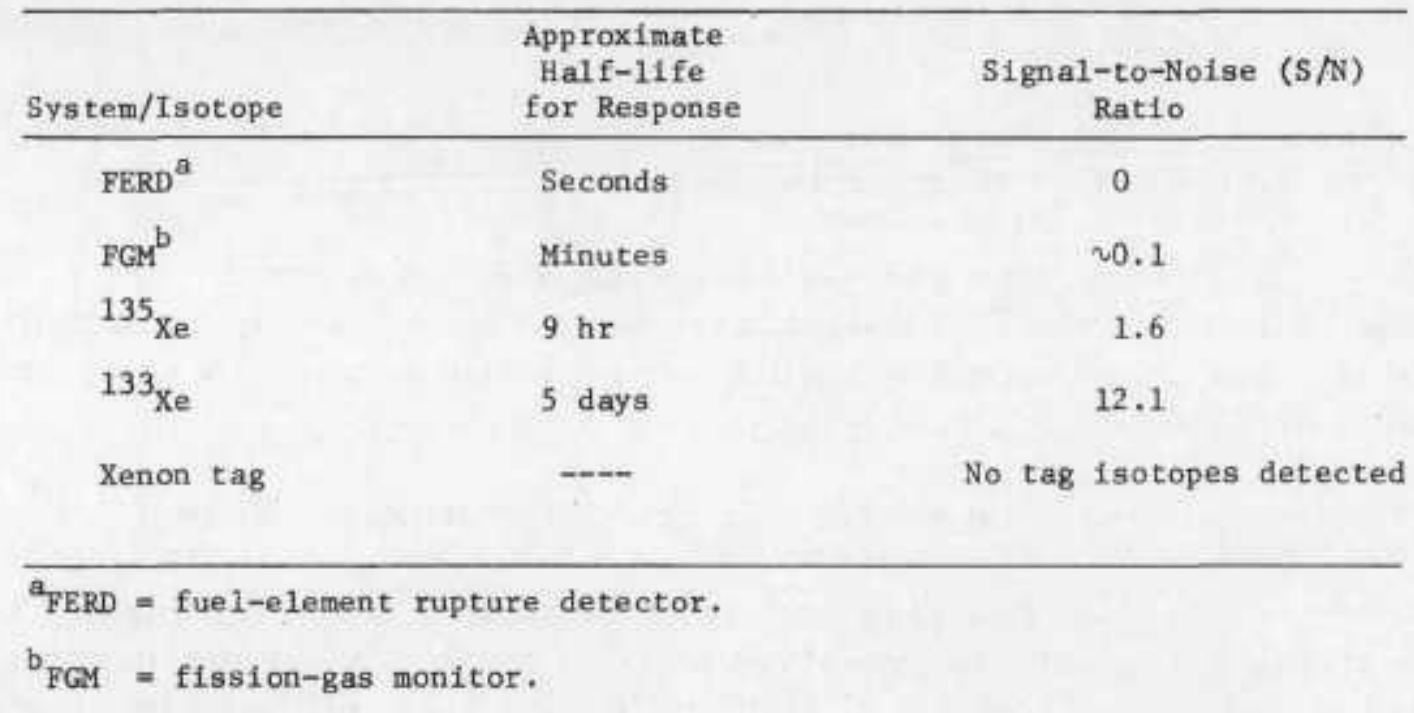




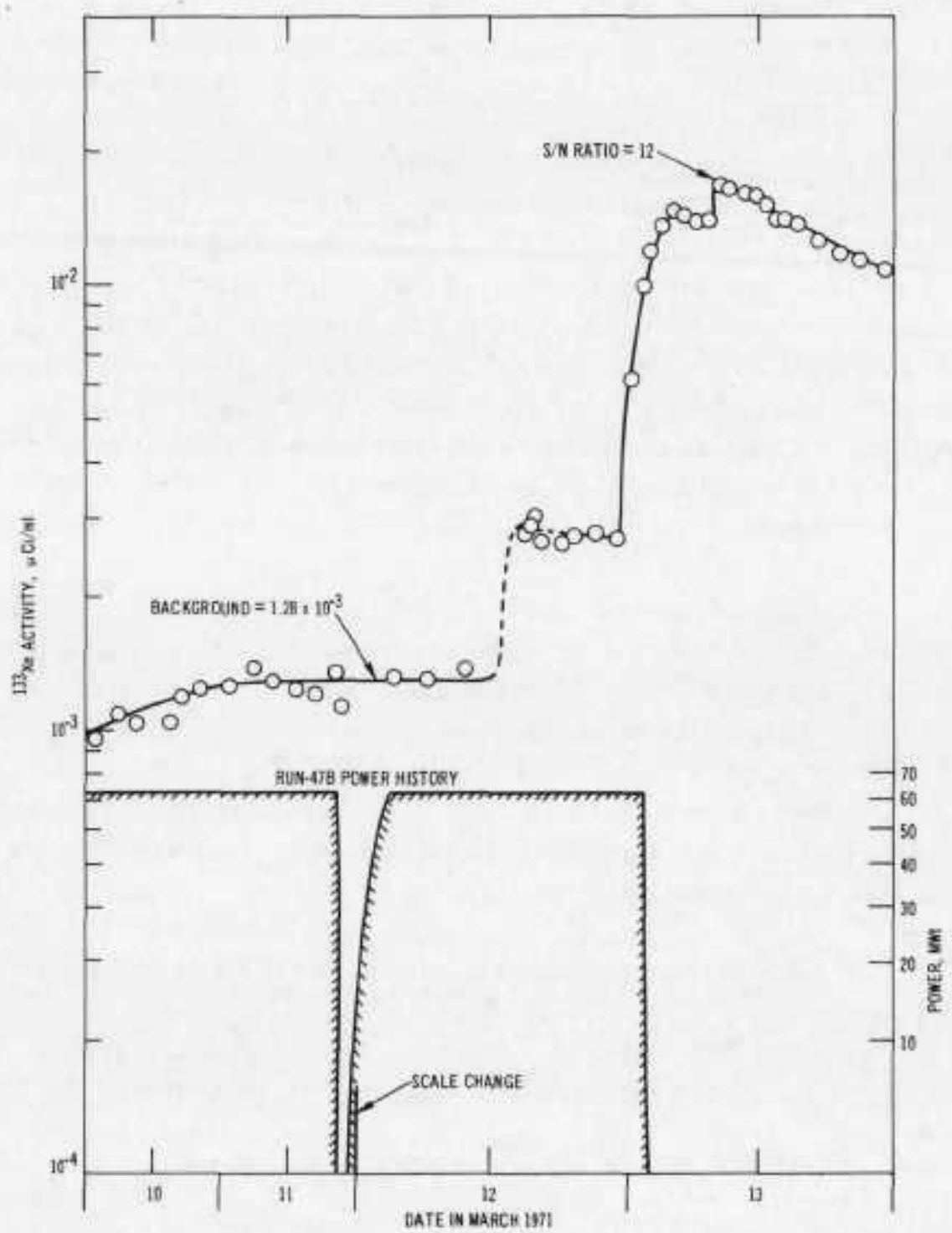

Fig. 1.24, Increase in $133 \times$ e Activity in Cover Gas during Run $47 \mathrm{~B}$

(b) The abrupt changes in gas activity indicated expulsion of a gas bubble rather than bond sodium.

(c) The sharply ascending $\mathrm{S} / \mathrm{N}$ ratios for the gas species as the half-life of the species increase suggested a holdup mechanism involving a two-stage expulsion. Such a mechanism is possible in an encapsulated fuel element.

(d) The source was probably not xenon-tagged.

(e) The very high ratio of stable ${ }^{134} \mathrm{Xe}$ to 5.3 -day ${ }^{133} \mathrm{Xe}$ also strongly suggested a two-stage expulsion. One likely mechansim is based on expulsion from a fuel element to a capsule, followed by a period of holdup, and then expulsion to the reactor. Such a mechanism was consistent with the available information. 
It was concluded that an encapsulated experiment was the most likely source. Twelve subassemblies containing encapsulated experiments resided in the core during Run 47B: X068A, X079, X080, X086, X117, X118, XG03A, XG04A, X076, X081, X088, and X094. Because of limited space in the storage basket, all of these could not be removed; therefore, the first six were placed in the basket, and the remaining six were left in the core. Test A, one of the run-to-failure experiments, which is in Subassembly X085, was also removed from the core to avoida possible second series of activity increases during the search.

The reactor was restarted (for Run 48A) on April 1. After a shutdown to remove the gamma-heating experiments, operation was resumed (for Run 48B) on April 3. A second increase in cover-gas activity was observed late on April 4, and the reactor was shut down. The characteristics of this increase were nearly identical to those of the first. (See Table 1.25.) The integrated power of the reactor between the first increase and the second was only $79 \mathrm{MWd}$. The characteristics of the second increase again strongly implied that the source was encapsulated.

TABLE I.25. Characteristics of Increase in Cover-gas Activity during Run $48 \mathrm{~B}$

\begin{tabular}{cc}
\hline System/Isotope & S/N Ratio \\
\hline FERD & 0 \\
FGM & Negligible \\
$135 \mathrm{Xe}$ & 1.2 \\
${ }^{133} \mathrm{Xe}$ & 19.7 \\
Xenon tag & No tag isotopes detected \\
\hline
\end{tabular}

The first set of six suspect subassemblies was returned to the core, and the second set of six (XG03A, XG04A, X076, X081, X088, and $\mathrm{X094)}$ was removed. Test A (X085) was left in the basket.

Power operation (for Run 48C) was resumed on April 8. The run was terminated on April 20, after $726 \mathrm{MWd}$, because of a third increase in cover-gas activity. Its characteristics were nearly identical to those of the first two. The $\mathrm{S} / \mathrm{N}$ ratios for ${ }^{133} \mathrm{Xe}$ and ${ }^{135} \mathrm{Xe}$ were 5.6 and 0.45 , respectively. On this occasion, however, the results of xenon-tag analysis demonstrated conclusively the presence of xenon-tag isotopes in the cover gas. (See Table I.26.)

Of eight xenon-tag mixtures in use, only two, those is Subassemblies $\mathrm{X} 058$ and $\mathrm{X} 073$, had isotopic ratios similar to those measured. Of these two subassemblies, X058 seemed to be the more logical 
choice as the source, simply on the basis of a better agreement between the ${ }^{129} \mathrm{Xe} /{ }^{124} \mathrm{Xe}$ and ${ }^{129} \mathrm{Xe} /{ }^{126} \mathrm{Xe}$ ratios. On the other hand, the amount of tag gas found in the cover-gas system constituted only $1.5 \%$ of the original tag-gas inventory. (The implementation of the xenon-tag method was predicated on the assumption that positive identifications could only be made for expulsions in which $>10 \%$ of the initial tag inventory is lost.) This is equivalent to a dilution of approximately $0.015 \mathrm{~cm}^{3}$ of tag gas in more than $10^{7} \mathrm{~cm}^{3}$ of cover gas. Clearly, a small amount of natural xenon in the cover gas could have increased the ${ }^{129} \mathrm{Xe} /{ }^{124} \mathrm{Xe}$ and ${ }^{129} \mathrm{Xe} /{ }^{126} \mathrm{Xe}$ ratios. Despite this possibility, X058 was regarded as the more likely suspect and was accordingly transferred from the core to the storage basket.

TABLE 1.26. Results of Xenon-tag Analysis on Apri1 20 at Time of Activity Increase during Run $48 \mathrm{C}$

\begin{tabular}{cccc}
\hline $\begin{array}{c}\text { Xenon } \\
\text { Isotopic Ratio }\end{array}$ & $\begin{array}{c}\text { Measured } \\
\text { Value }\end{array}$ & $\begin{array}{c}\text { Xenon-tag Ratios } \\
\text { in X058 }\end{array}$ & $\begin{array}{c}\text { Xenon-tag Ratios } \\
\text { in X073 }\end{array}$ \\
\hline $129 / 124$ & 9.77 & 11.76 & 6.3 \\
$128 / 124$ & 1.75 & 1.80 & 1.46 \\
$126 / 124$ & 0.369 & 0.346 & 0.398 \\
$129 / 128$ & 5.59 & 6.3 & 4.3 \\
$129 / 126$ & 26.5 & 33.6 & 15.8 \\
$128 / 126$ & 4.75 & 5.2 & 3.67 \\
\hline
\end{tabular}

Run 48D began on April 22 and continued uneventifully until May 3, when small, but significant, increases were noted in the signals for ${ }^{133} \mathrm{Xe}$ and ${ }^{135} \mathrm{Xe}$. This time, the $\mathrm{S} / \mathrm{N}$ ratios for ${ }^{133} \mathrm{Xe}$ and ${ }^{135} \mathrm{Xe}$ were only 3.4 and 0.37 , respectively.

In an effort to evaluate the effects, if any, of power level on the characteristics of the increase in activity, the power was reduced to $30 \mathrm{MWt}$ and held at this level for $7 \mathrm{hr}$. Then, power was increased in 5-MWt increments and held at each step for about $4 \mathrm{hr}$. A level of $60 \mathrm{MWt}$ was reached at 1409 on May 4. Shortly thereafter, another activity increase occurred. This time, the $\mathrm{S} / \mathrm{N}$ ratio for ${ }^{133} \mathrm{Xe}$ exceeded the limits specified in the reactor operating procedures, and an anticipatory shutdown was performed.

Analysis of the cover gas for xenon-tag isotopes after this increase revealed that the levels of such isotopes were too low to be identifiable. Subsequently, it was concluded that the original tag identification was likely complicated by natural xenon in the cover gas. Accordingly, the other tagged suspect, X073, has been removed from the core for the next power run. 
(2) GLASS (Ge-Li Argon-scanning System) (G.S. Brunson). The germanium-lithium argon-scanning system (GLASS)--last reported in ANL7737, p. 94, Aug 1970--is now in preliminary on-line operation with the analyzer and data-reduction equipment installed in the digital data-acquisition system (DAS) room and the detector system in the depressed area of the reactor building. Figure I.25, a preliminary spectrum from the system, illustrates the resolution being obtained. Because of irregular reactor operation and a leaking element, the gamma spectrum of the cover gas at the time was far different from what it will be during reasonably stable operation. Several

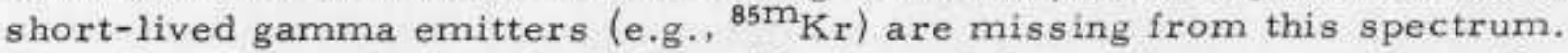
Note that the vertical scale is logarithmic, and the peaks are consequently sharper than they appear in this plot. No shielding was used; when that is installed, the Compton level will be markedly reduced.

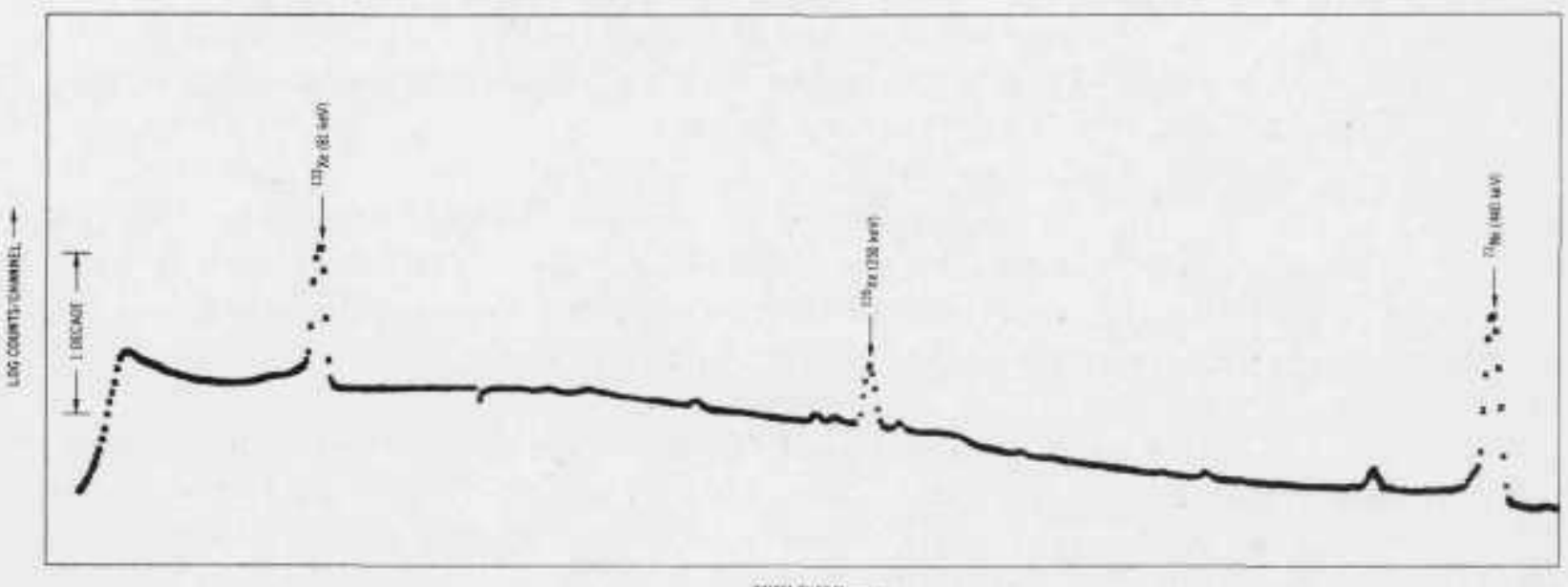

Fig. L.25. Preliminary Spectrum from GLASS Made Overnight, May 6-7. Not an equilibrium spectrum.

For reasons of space, only the lower portion of the spectrum is shown. Lines at high energies indicated the presence of ${ }^{137} \mathrm{Cs},{ }^{41} \mathrm{Ar},{ }^{24} \mathrm{Na}$, and ${ }^{40} \mathrm{~K}$.

Fully automatic operation may be some months away. That will require completion of software and effective interfacing with the Sigma-5 computer.

Following preliminary tests of the prototype circuit for the on-line digital subtract unit (ODSU), two such circuits were fabricated into a single NIM module in a configuration that was expected to be similar to the final configuration for actual application. Arrival of the GLASS pulseheight analyzer and data-reduction equipment made possible a morecritical examination of the ODSU. Tests were designed to answer two questions:

(a) If a relatively low activity is being counted for one isotope of interest, what is the effect of bringing up a substantial interfering source of another isotope having a higher gamma energy? That is, what is the response to a spurious signal? 
(b) If a strong background of higher-energy gammas is present, what is the effect of increasing the count rate of the isotope of interest? That is, what is the response to a genuine signal in the presence of interference?

In the test measurements, ${ }^{137} \mathrm{Co}(0.66-\mathrm{MeV}$ gamma) was taken as the isotope of interest: ${ }^{60} \mathrm{Co}(1.17-$ and $1.33-\mathrm{MeV}$ gamma) was used as the interfering background.

Typically, the quantitative answers to the above questions

were:

(a) With the system counting at a rate of approximately 20 counts/sec in the ${ }^{137} \mathrm{Cs}$ peak under ambient background conditions, putting into the detector 3500 gross counts/sec with the ${ }^{60} \mathrm{Co}$ source had the effect of reducing the indicated ${ }^{137} \mathrm{Cs}$ count rate by about $10 \%$ because of deadtime effects.

(b) In the presence of ambient background plus 3500 counts/ sec for the gross ${ }^{60} \mathrm{Co}$ count rate, increasing the ${ }^{197} \mathrm{Cs}$ count rate (adding a larger source to the smaller one) by a factor of approximately 9.4 raised the indicated increase by a factor of approximately 8.7.

Thus, it seems that from an operational viewpoint the circuit is worthwhile, is not unduly affected by a spurious signal, but is capable of responding with reasonable fidelity to a real signal in the presence of a strong interfering background.

An alternative on-line digital subtract unit also is being investigated. The proposed circuit is shown in Fig. I.26, and a prototype of it is expected to be available for evaluation soon. Briefly, the operation of the circuit is as follows.

A preset timer (with a range of 1-15 sec), set for, say, $10 \mathrm{sec}$, cycles a scaler circuit continuously. The front-end stages of the scaler consist of four bits of up-downscaling into which the signal plus background is counted "up" and the background is counted "down." Thus , the scaler repeatedly takes $10-\mathrm{sec}$ samples that represent accurately the difference between the signal plus background and the background. The scaler is automatically reset before each count begins. At the end of each 10 - sec count, the state of the upper scaler stages is transferred to a 12 -bit latch. The state of the latch is passed through a digital-to-analog (D/A) converter and a log converter to produce a dc signal that is logarithmically related to the digital state of the latch. This signal is presented on a recorder. At the end of each $10-\mathrm{sec}$ count, a new scaler state is transferred to the latch and a new dc level read on the recorder. The net effect is to produce a chart that is actually a histogram with bars $10 \mathrm{sec}$ wide. 


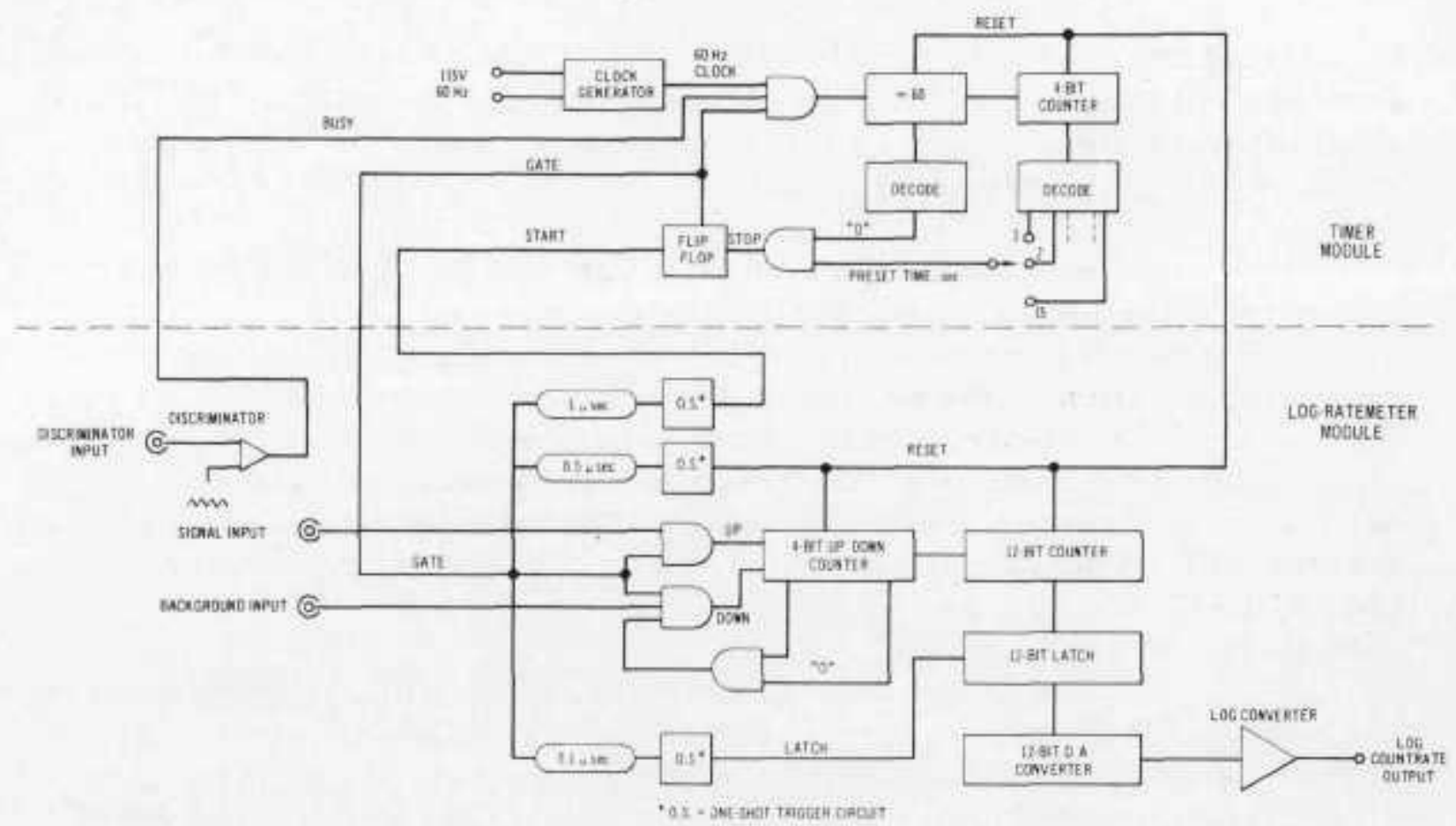

Fig. 1.26. Proposed Circuit for Alternative On-line Digital Subtract Unit for GLASS

As described so far, this circuit has no advantage over the earlier one and has the disadvantage of a somewhat delayed output. The circuit concept is being explored because it offers the possibility for correcting for circuit dead-time. A discriminator is set to produce a logic signal that lasts as long as the output of the pulse amplifier is above some reasonable threshold, i,e., as long as the amplifier channel is "dead" to subsequent inputs. The logic signal from the discriminator is used to inhibit the timing operation in the preset timer. Thus, the preset timer actually counts only "live" time, and the output of the overall circuit should not exhibit the deadtime effect found in the earlier model. It remains to be seen if this operation can be realized and whether the absence of dead-time problems offsets the disadvantage of a delayed output.

(3) Mechanical Deformation of an EBR-II Hexagonal Can due to Rapid Expulsion of Fission Gas from an Unencapsulated Oxide Element (L. K. Chang and G. H. Golden). As the burnup of unencapsulated oxide-fuel elements in EBR-II approaches 10 at. \%, the pressure of the fission gas in the plenums of the elements may approach 1000 psia. There has been concern that rapid expulsion of fission gas from a possible breach in the cladding of such a high-burnup element could cause significant mechanical deformation of the hexagonal can of the subassembly holding the element. The flow of the gas from the plenum to the breach depends strongly on the location of the breach (i.e., on the impedance of internal fittings as well as of the oxide fuel itself). As an exploratory worst case, burst tests in EBR-II hexagonal cans in water were conducted with pressurized predefected aluminum tubes having 
no internal impedance to gas flow (see ANL-7765, p. 41). These tests deformed cans as much as $0.060 \mathrm{in}$. Since most experiments in EBR-II are adjacent to safety or control rods, these results indicated that further study of this problem was required.

In structural analyses of the hexagonal can subjected to pressure-pulse loadings, one side of the can was simulated by a clamped plate. The natural period of the plate was computed to be less than onefourth the duration of the pressure pulse, which was measured as -1 msec (see ANL-7765). Hence, a quasi-static analysis of the pressure response is considered adequate (i.e., the response of the hexagonal can depends on the maximum pressure on the can only). Earlier hydrostatic tests indicated that the EBR-II hexagonal can yields at about 100 psi at room temperature. (See ANL-7737, p. 67, Aug 1970.)

The model used to estimate the maximum pressure on the can assumed that the pressure was produced by coolant being accelerated ahead of a spherical bubble of fission gas growing around the breach.* Since it was intended only to describe the burst tests of the empty tube, this relatively simple bubble-growth model did not account for internal flow impedance. To make the half-width and peak of the computed pressure pulse agree with those of the measured pulse in a given test, the breach area had to be made to vary with time. The variation with time was deduced from the decay of plenum pressure with time observed in the test. Resulting curves of breach area versus time were found to be related to the product $(\mathrm{PV})$ of the initial plenum pressure and plenum volume, as shown in Fig. I.27.

In-pile restructuring and cracking of oxide fuel make it difficult to characterize the internal flow impedance. Some oxide elements in EBR-II, however, contain a nickel reflector slug just below the plenum, as shown conceptually in Fig. 1.28. Such a slug provides a well-characterized flow impedance if fast-flux-induced differential swelling between the cladding and the slug is neglected. The effect of the slug on the gas flow from the idealized element shown in Fig. I.28 was estimated in a two-stage analysis. First, the bubble-growth model was used to calculate the can pressure due to gas release only from the free volume in the fuel region; for this calculation, the gas flow from the plenum was assumed small in the time scale in which the can pressure peaks. Second, to test this assumption, the resulting relationship of fuel-region pressure to time was used to estimate the rate of gas flow from the plenum to the fuel region versus time.

Figure 1.29 shows the fuel-region pressure and the canwall pressure versus time computed with the bubble-growth model for simple tubes and using the dashed curve of Fig. I.27. Figure 1.30 shows the

\footnotetext{
*A. Judd, ANL-RAS, private communication (Nov 1970).
} 


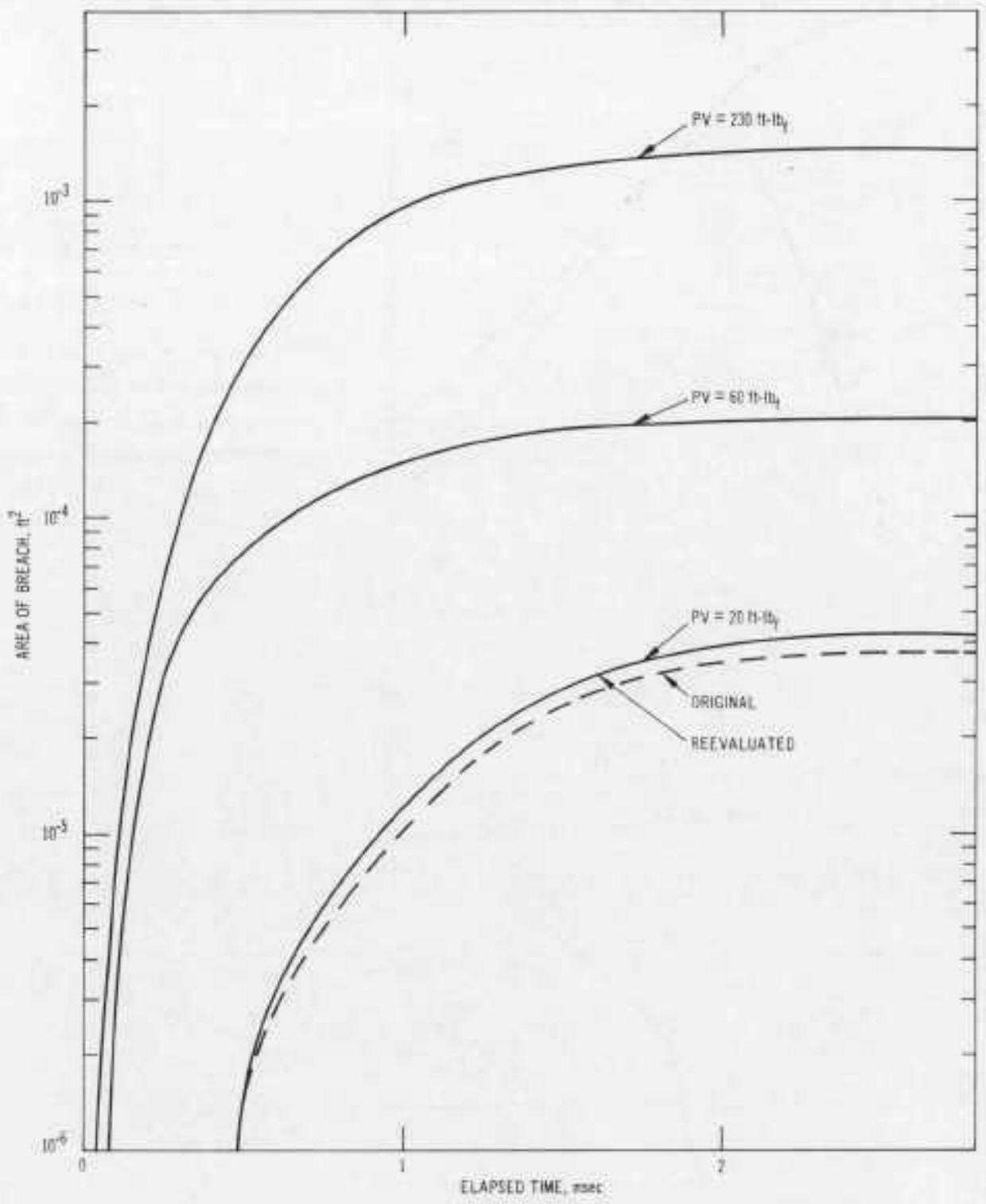

Fig. I.27. Curves of Area of Breach in Cladding vs Time, PVI is product of initial plenum pressure and volume.

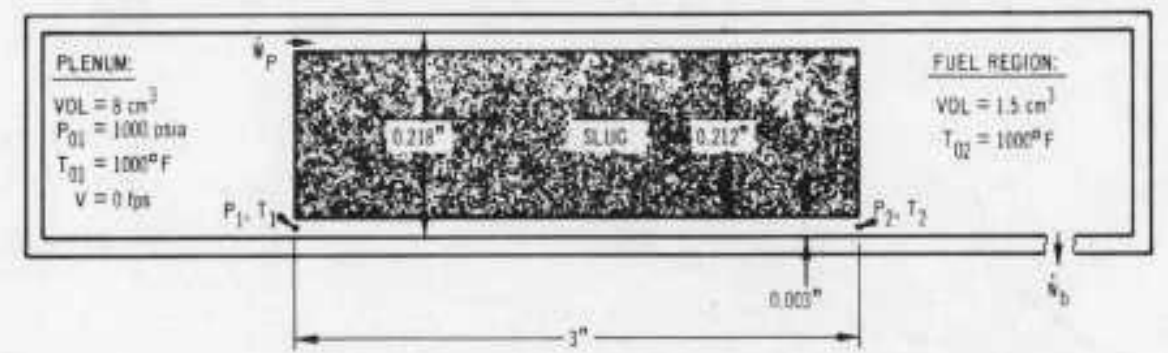

Fig. I.28. Geometry of Oxide-fuel Element Assumed for Flow Analysis 


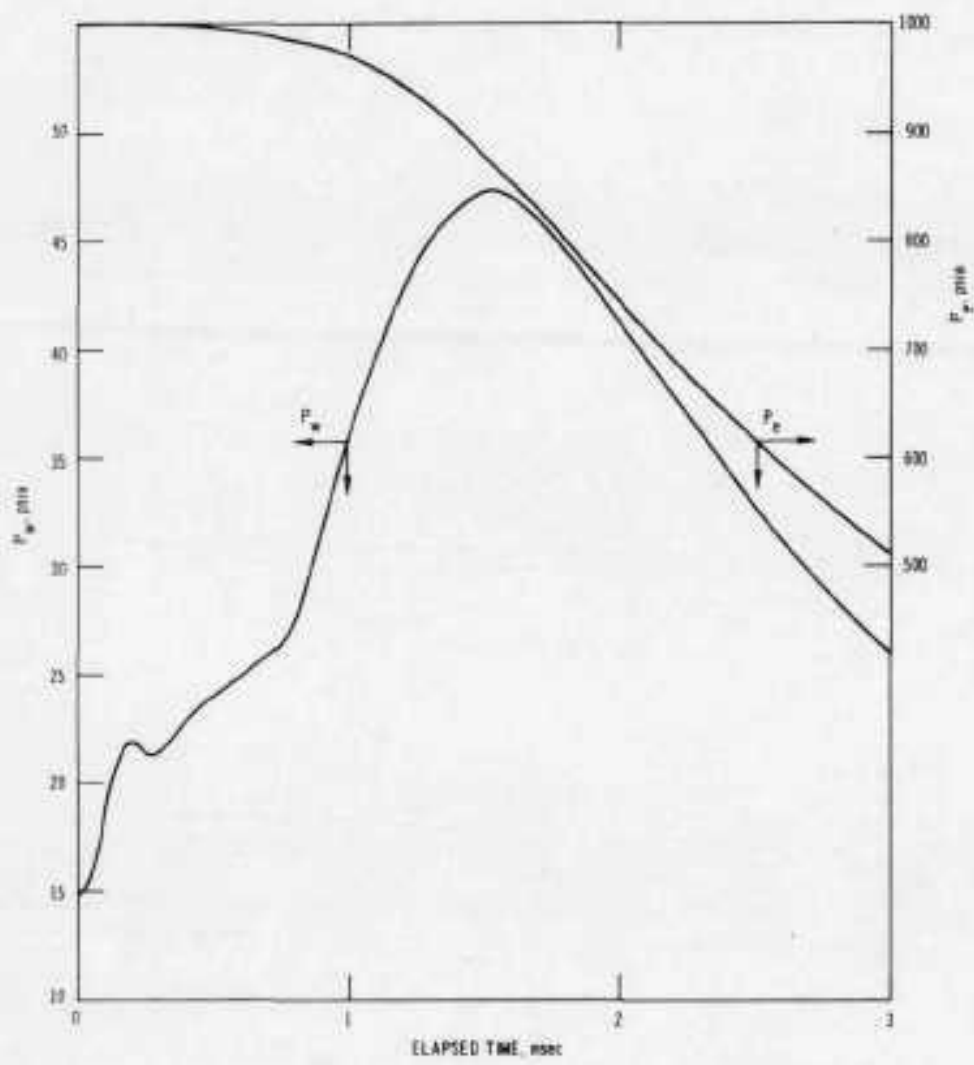

Fig. I.29

Pressure in Fuel Region $\left(\mathrm{P}_{\mathrm{C}}\right.$ ) of Breached Oxide Element and Corresponding Pressure at Wall of Hexagonal Can $\left(\mathrm{P}_{\mathrm{w}}\right)$ : Xenon gas; $\mathrm{P}_{\mathrm{e}}(\mathrm{O})=$ 1000 psia; $\mathrm{T}_{\mathrm{e}}(\mathrm{O})=1000^{\circ} \mathrm{F}$; Volume $=$ $1.5 \mathrm{~cm}^{3}$

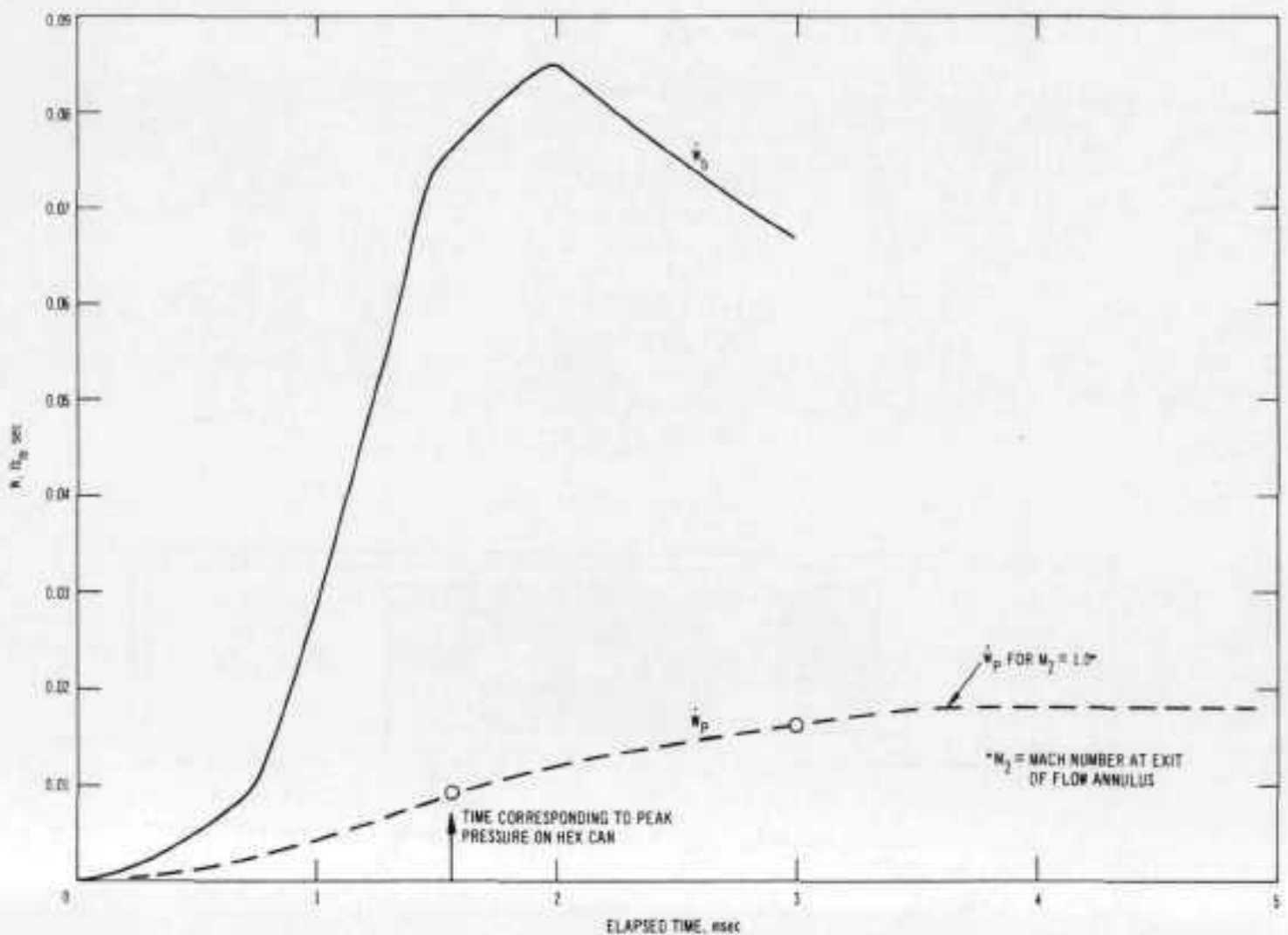

Fig. I.30. Mass Flow Rate from Breach ( $\left.\dot{w}_{b}\right)$ and Mass Flow Rate Past Upper Reflector Slug $\left(\dot{W}_{p}\right)$ in Breached Oxide Element: Xenon gas; $\mathrm{P}_{01}(\mathrm{O})=1000$ psia; $\mathrm{T}_{01}(\mathrm{O})=1000^{\circ \mathrm{F}}$ 
corresponding rate of gas flow from the breach $\left(\dot{w}_{b}\right)$. The procedure for calculating the gas flow through the annulus around the slug was based on concepts and equations for adiabatic flow in a duct of constant area.* Results of the calculations indicated that, for the typical geometry and conditions shown in Fig. I.28, the rate of flow from the breach is -8 times as great as the rate of flow from the plenum at or near the time the can-wall pressure peaks. Thus, as a good first approximation in calculating the peak wall pressure, the bubble-growth model for simple tubes can be applied directly to the free volume in the fuel region if flow from the plenum is neglected. Specifying the actual free volume instantly available to a breach is an oxide element is difficult: an upper limit $\left(1.5 \mathrm{~cm}^{3}\right)$ was used in these studies. It was also found that the plenum pressure decreases only about $1.3 \%$ in $3.0 \mathrm{msec}$ and requires about $60 \mathrm{msec}$ to decrease from 1000 to 500 psia. A wide variation is the assumed roughness parameter $\left(\epsilon / D_{e}=0.01\right)$ resulted in only moderate changes in the critical flow rate from the plenum at a pressure of 1000 psia.

The bubble-growth model for simple tubes was used to calculate the effects of a release of helium, argon, and xenon gas from $1.5 \mathrm{~cm}^{3}$ of free volume in the fuel region. Table I,27 summarizes the results. Note that these results are for a hexagonal can with a length of 16.5 in., a can length used in some of the tube-burst tests. But the bubble-growth model indicates that the wall pressure varies approximately as the square root of the can length. Thus, for the real EBR-II can length of $-65 \mathrm{in}$, the wall pressure would be approximately twice the values shown in the second column of Table 1.27. Preliminary analysis suggests that at the operating temperature, permanent deformation of the hexagonal can resulting from a maximumpressure at the can wall of about 94 psia is less than 0.030 in.

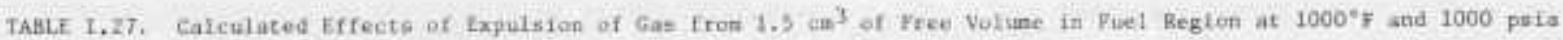

\begin{tabular}{|c|c|c|c|c|c|}
\hline $\begin{array}{l}\text { Cus in } \\
\text { Pienuin }\end{array}$ & $\begin{array}{l}\text { Maxinum Eressure it } \\
\text { hexagonal Can, psit }\end{array}$ & $\begin{array}{l}\text { Presgure of Gas in } \\
\text { Free Votune of } \\
\text { Poet at Maximut } \\
\text { Pressure in } \\
\text { Hexagonal Can, pat }\end{array}$ & 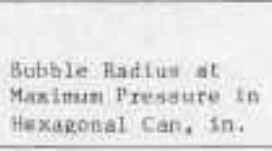 & 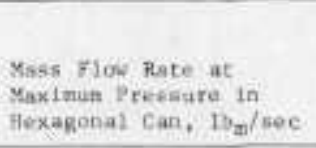 & $\begin{array}{l}\text { Tine llequired to } \\
\text { lieach Masiaum Pressure } \\
\text { in Bexagonal Can, msec }\end{array}$ \\
\hline Belfun & \% & 642 & 0.388 & 0.00738 & 1.32 \\
\hline Argon & 57 & 286 & 0.393 & 0.0375 & 1.53 \\
\hline Xenes & 47 & 865 & 0.326 & 0.0753 & 1.56 \\
\hline
\end{tabular}

Can length $-16.5 \mathrm{itr}$.

A third series of tube-burst tests is to be run to check the foregoing analyses. Tubes with internal flow impedances and geometries like those shown in Fig. I.28 will be used in these tests. The effects of using argon as well as helium for the fill gas will also be studied.

\footnotetext{
*A. H. Shapiro, The Dynamics and Thermodynamics of Compressible Fluid Flow, Vol. 1, Chap. 6, Ronald Press,
} New York (1953). 


\section{b. Xenon-tag Technique (Last reported: ANL-7753, p. 88)}

(1) Experiment on Xenon-tag Burnout (P. B. Henault). Implementation of the existing xenon-tag technique at EBR-II is based on the as sumption that interference from tag burnout and from light fission-product xenon isotopes is negligible. However, the validity of this assumption has never been experimentally confirmed. Because of the lack of definitive information on the effects of isotopic burnout, the variations between specific tag mixtures have been kept sufficiently large to preserve tag identity in the unlikely event of interference effects.

Since the implementation and experimental verification of the xenon-tag technique for EBR-II, the possible application of the technique at other LMFBR facilities has been considered. Because other reactor plants have different physical characteristics and different neutron-flux and energy spectra, the question of interference becomes of greater significance in determining the full merit of the xenon-tag technique for these facilities.

To determine the effect of isotopic burnout on the xenontag technique, ANL and HEDL are undertaking a cooperative experimental program in which a number of carefully chosen samples of xenon-tag gas will be irradiated in EBR-II for a period sufficiently long to measure any significant change in isotopic ratios of the samples. Samples will be where: (1) the EBR-II flux spectrum most nearly duplicates the anticipated spectrum of the FFTF; (2) the location is typical of the gas-plenum region of experimental fuel elements now being irradiated in EBR-II; and (3) the boron absorption rate is maximum. The combination of these locations in a single irradiation experiment is expected to answer the tag-burnout questions of greatest concern to EBR-II and to help resolve possible burnout problems in FFTF.

In addition to the tag-burnout experiment, the EBR-II Project plans to analyze samples of plenum gas from irradiated tagged and untagged experimental fuel elements. Data obtained from these measurements, analyzed together with data obtained from the proposed experiment, are expected to provide the needed information about the effects of interference resulting from fission yields of light xenon isotopes.

The irradiation vehicle will be a standard driver subassembly. The various samples will be in holes drilled longitudinally in the triflute stainless steel reflector pieces. Figure I.31 shows the arrangement of the samples in the subassembly. 


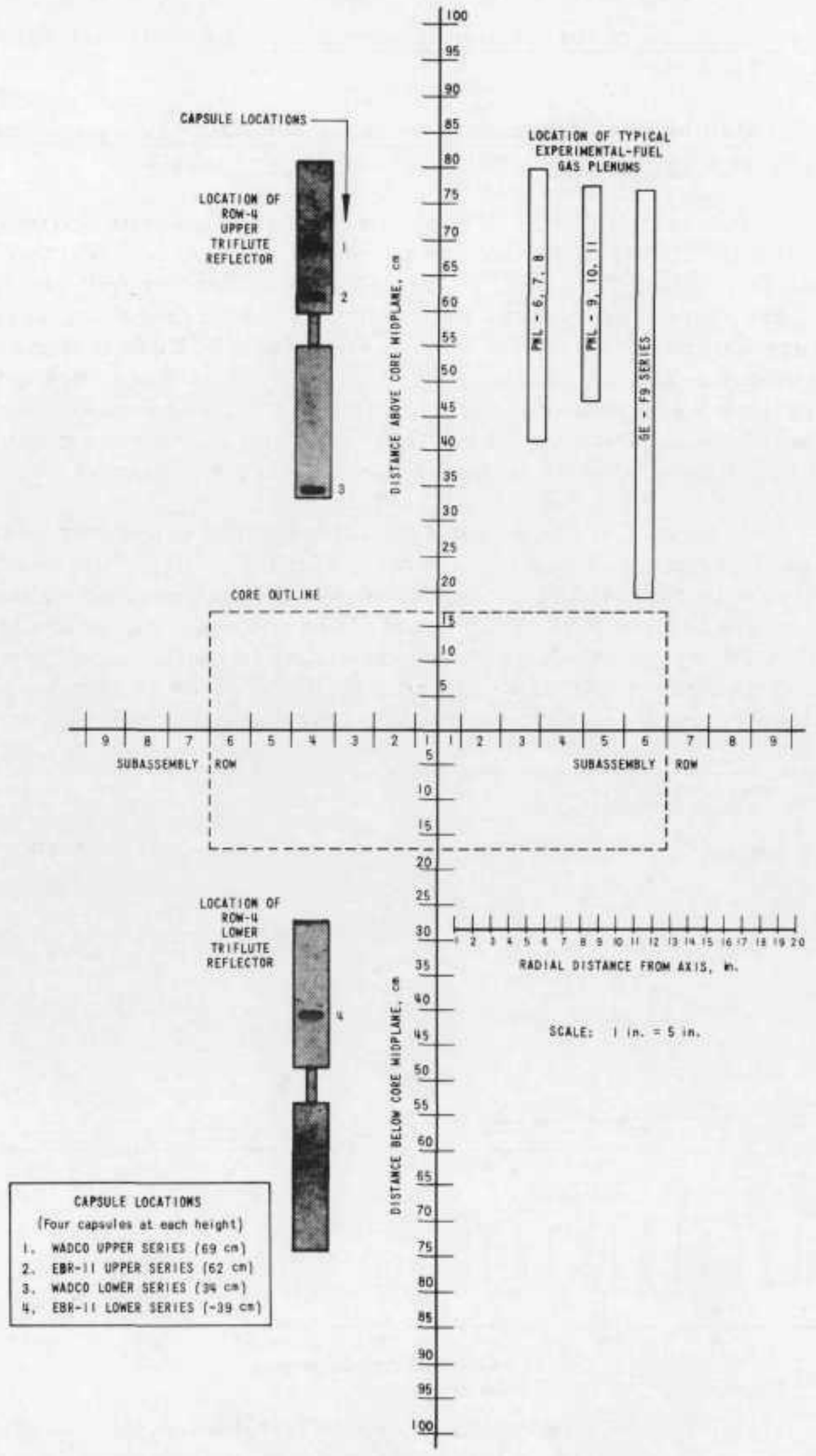

Fig. 1.31. Locations of Samples for Experiment on Bumout of Xenon Tag in EBR-II. ANL Neg. No. 103-05712 Rev. 1. 
3. Characterization of Irradiation Environment (02-151; last reported: ANL-7783, p. 46)

a. Radial Reaction-rate Traverses for ZPR-3 Assemblies 63B

Two-dimensional, XY-geometry, $\mathrm{S}_{4}$ transport neutronics analyses with the DOT code were used to calculate the detailed reaction-rate traverses for ${ }^{235} \mathrm{U}_{\mathrm{f}},{ }^{238} \mathrm{U}_{\mathrm{f}}$, and ${ }^{10} \mathrm{~B}_{\mathrm{C}}$ in $\mathrm{ZPR}-3$ Assemblies $63 \mathrm{~B}$ and $63 \mathrm{C}$. The results were compared with the experimental traverses of the assemblies, which were heterogeneously loaded, steel-reflected, EBR-II types of critical assemblies. The 29-group cross-section set was used, and detector cross sections were averaged for the various regional compositions by the $\mathrm{MC}^{2}$ code. An axial buckling of 0.00235 was used in the core region, and an axial buckling of 0.00085 in the stee1-reflector and blanket regions.

Figures I.32, I.33, and I.34 compare the calculated radial traverses through the $\mathrm{P}$ row of Assembly $63 \mathrm{~B}$ for ${ }^{235} \mathrm{U}_{\mathrm{f}},{ }^{238} \mathrm{U}_{\mathrm{f}}$, and ${ }^{10} \mathrm{~B}_{\mathrm{c}}$, respectively, with corresponding experimental values reported by the $\mathrm{ZPR}-3$ experimental group in ANL-7776, p. 12. The individual drawers in the core region through which the detector traverses were made are shown in the figures. The notations OXIDE- 19 and OXIDE-37 refer to compositions simulating 19- and 37-pin mixed-oxide subassemblies, respectively.

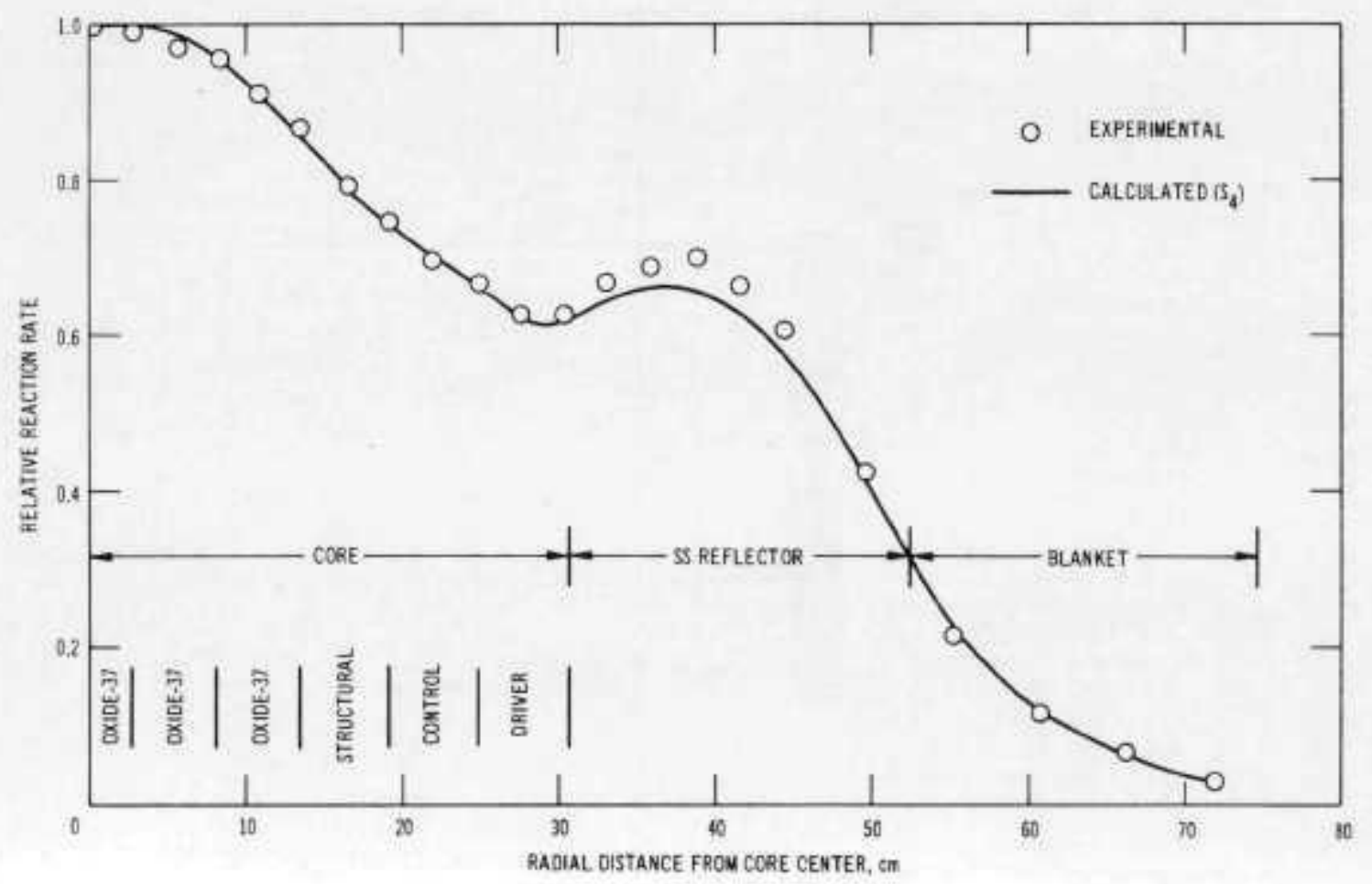

Fig. 1.32. Experimental and Measured 235 $U_{f}$ Radial Traverses at Axial Midplane of Core of ZPR-3 Assembly 63B 


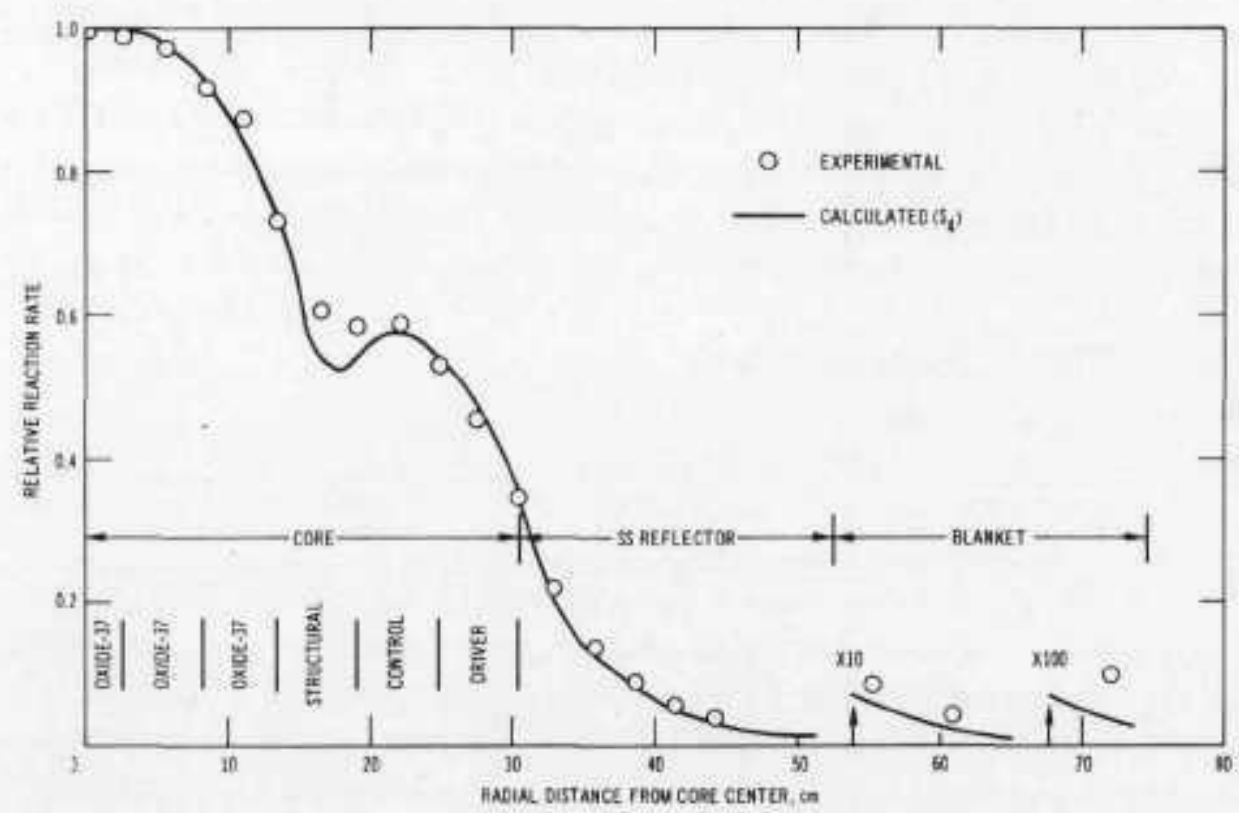

Fig. 1.33. Experimental and Calculated $238 \mathrm{U}_{\mathrm{f}}$ Radial $\mathrm{T}$ raverses at Axial Midplane of Core of ZPR-3 Assembly 63B

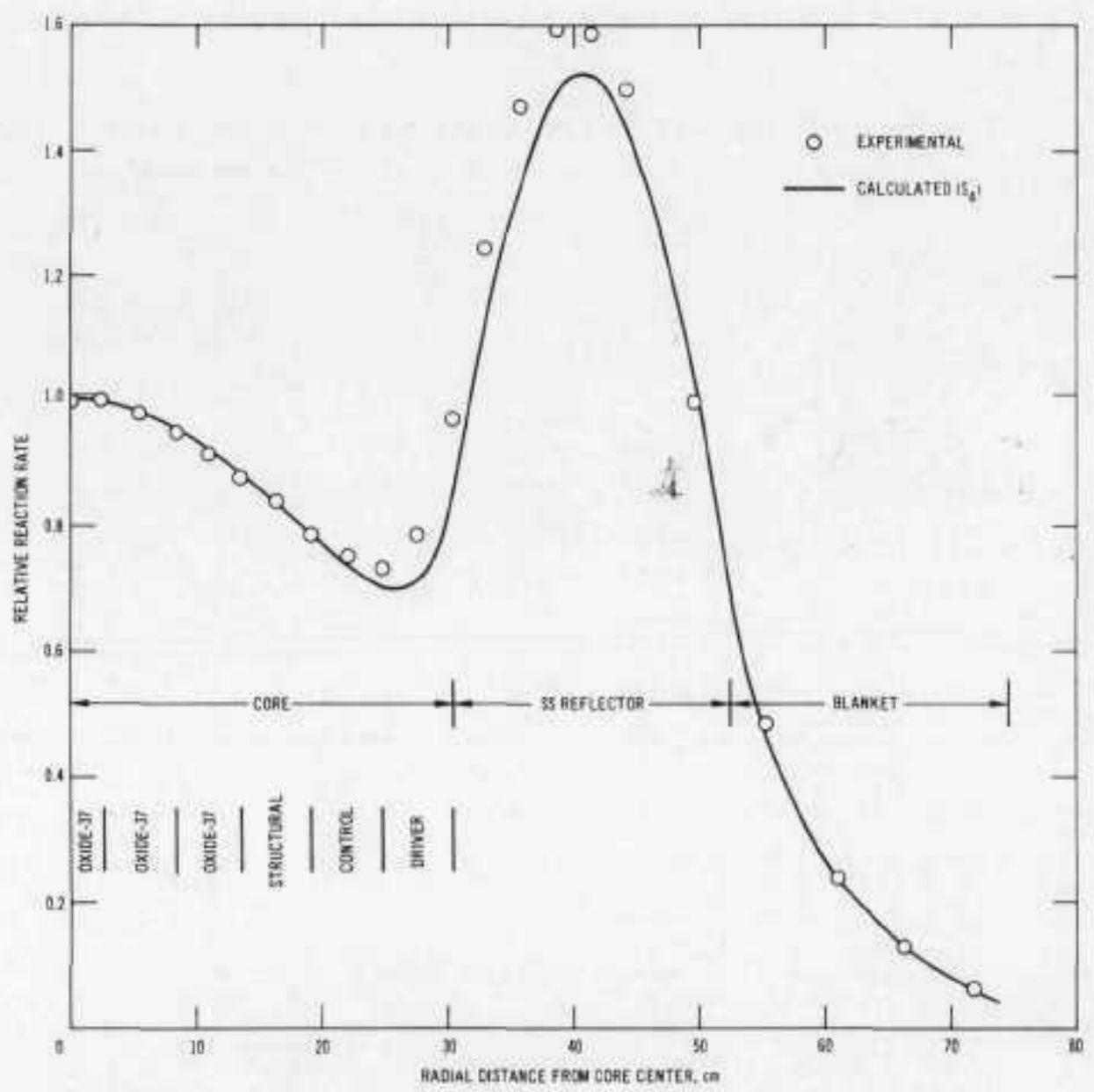

Fig. 1.34. Experimental and Calculated ${ }^{10} \mathrm{~B}_{\mathrm{c}}$ Radial Ttaverses at Axial Midplane of Core of ZPR-3 Assembly 63B 
Figures I. 35 and I.36 compare the calculated ${ }^{235} \mathrm{U}_{f}$ and ${ }^{238} \mathrm{U}_{f}$ radial traverses, respectively, through half the $\mathrm{P}$ row of Assembly $63 \mathrm{C}$ with the corresponding experimental values obtained by the ZPR-3 experimental group (see ANL-7765, p. 20). These figures present the results for the traverses through the half of the $\mathrm{P}$ row that contains the cluster of simulated 19-pin oxide subassemblies. Figures 1.37 and 1.38 show the corresponding results for the half of the $\mathrm{P}$ row containing the cluster of simulated 37 -pin oxide subassemblies.

\section{b. Activation-rate Measurements in ZPR-3 Assembly 62 Mockup Experiments. N. D. Dudey, R. J. Popek, and R. R. Heinrich}

Foil-activation rates in Assembly 62 of the ZPR-3 mockups of EBR-II have been measured. The measurements were made similarly to those for Assemblies 60 and 61 (see ANL-7753, p. 92: and ANL-7765. p. 53). Foil packets containing ${ }^{235} \mathrm{U},{ }^{238} \mathrm{U}$, nickel, gold, and aluminum were irradiated perpendicularly to the fuel plates near the core center location $(0-15)$, on the core side of the core-reflector interface location (O-11), and in the radial reflector $(\mathrm{O}-8)$ in the left side of Half 1 of ZPR-3. Gold and nickel foils were also irradiated at symmetric positions in the right side of Half 1 , at locations $0-17,0-21$, and $0-23$ to examine flux symmetry within the assembly.

The foil packets were irradiated as $2-x 2$-in, foils and subsequently were cut into smaller pieces to optimize the sensitivity to

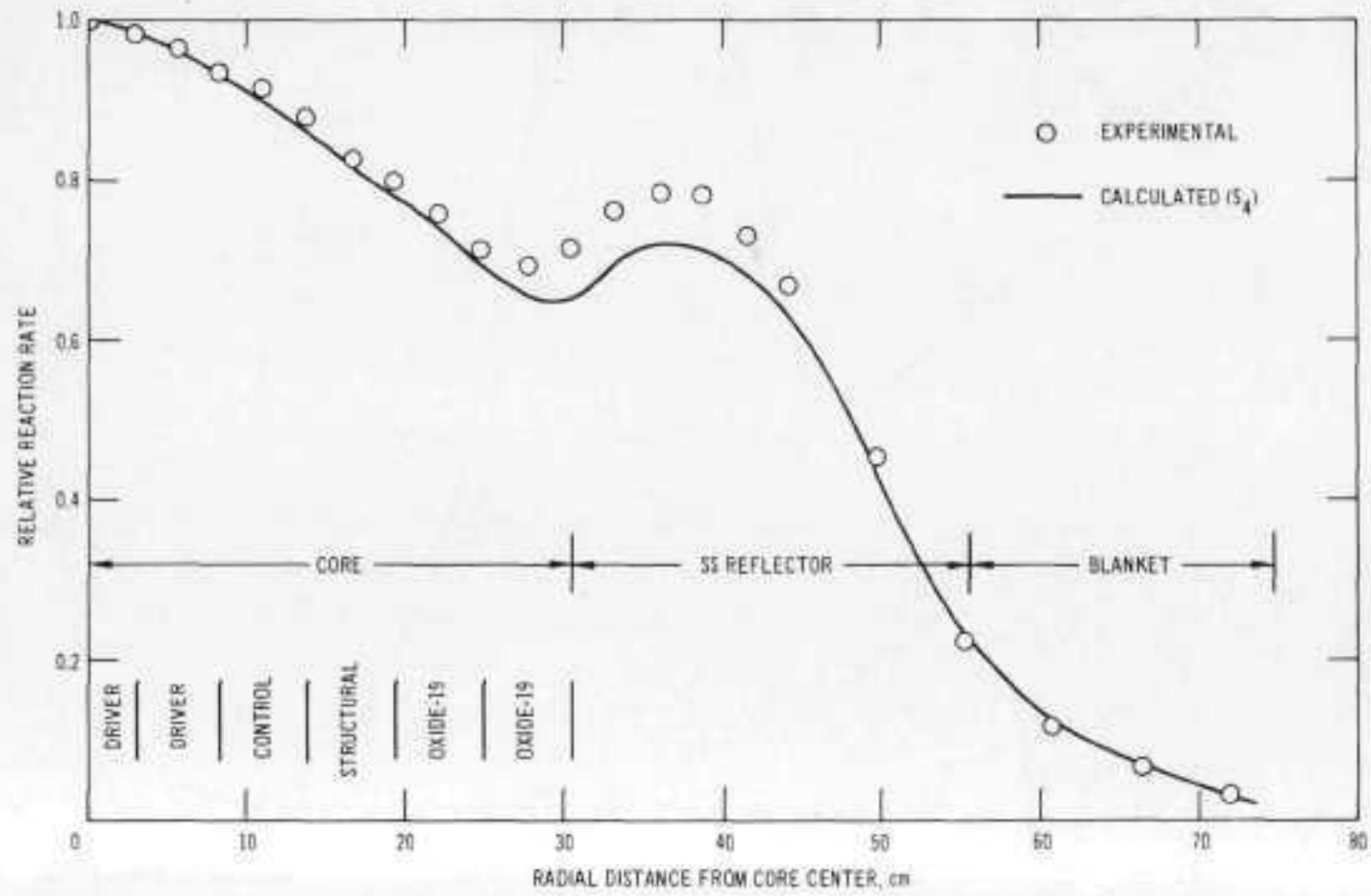

Fig. I.35. Experimental and Calculated $235 \mathrm{U}_{\mathrm{f}}$ Radial Traverses toward 19 -pin Oxide Region at Axial Midplane of Core of ZPR-3 Assembly 63C 


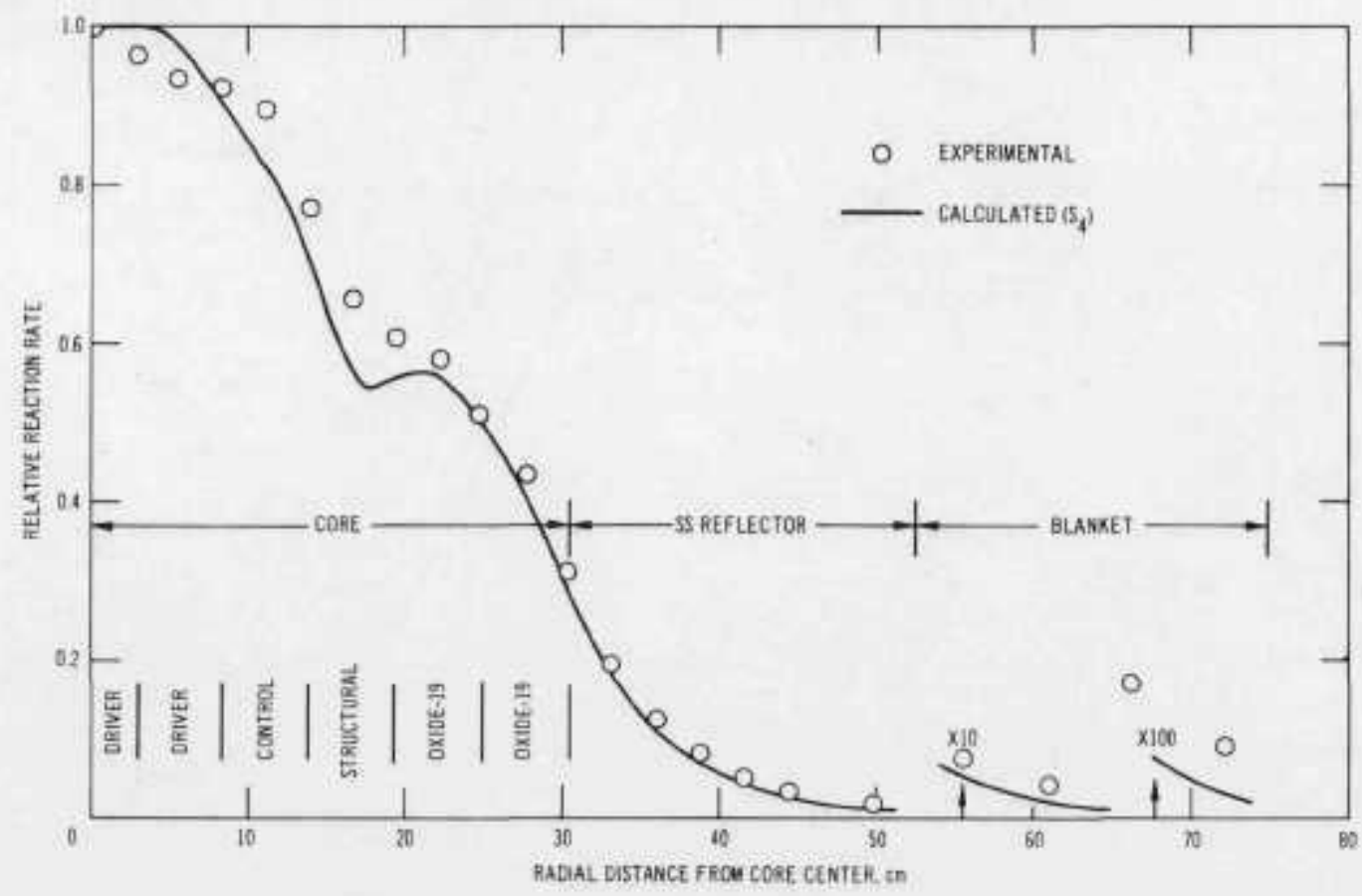

Fig. 1.36. Experimental and Calculated ${ }^{238} \mathrm{U}_{\mathrm{f}}$ Radial Traverses toward 19 -pin Oxide Region at Axial Midplane of Core of ZPR-3 Assembly 63C

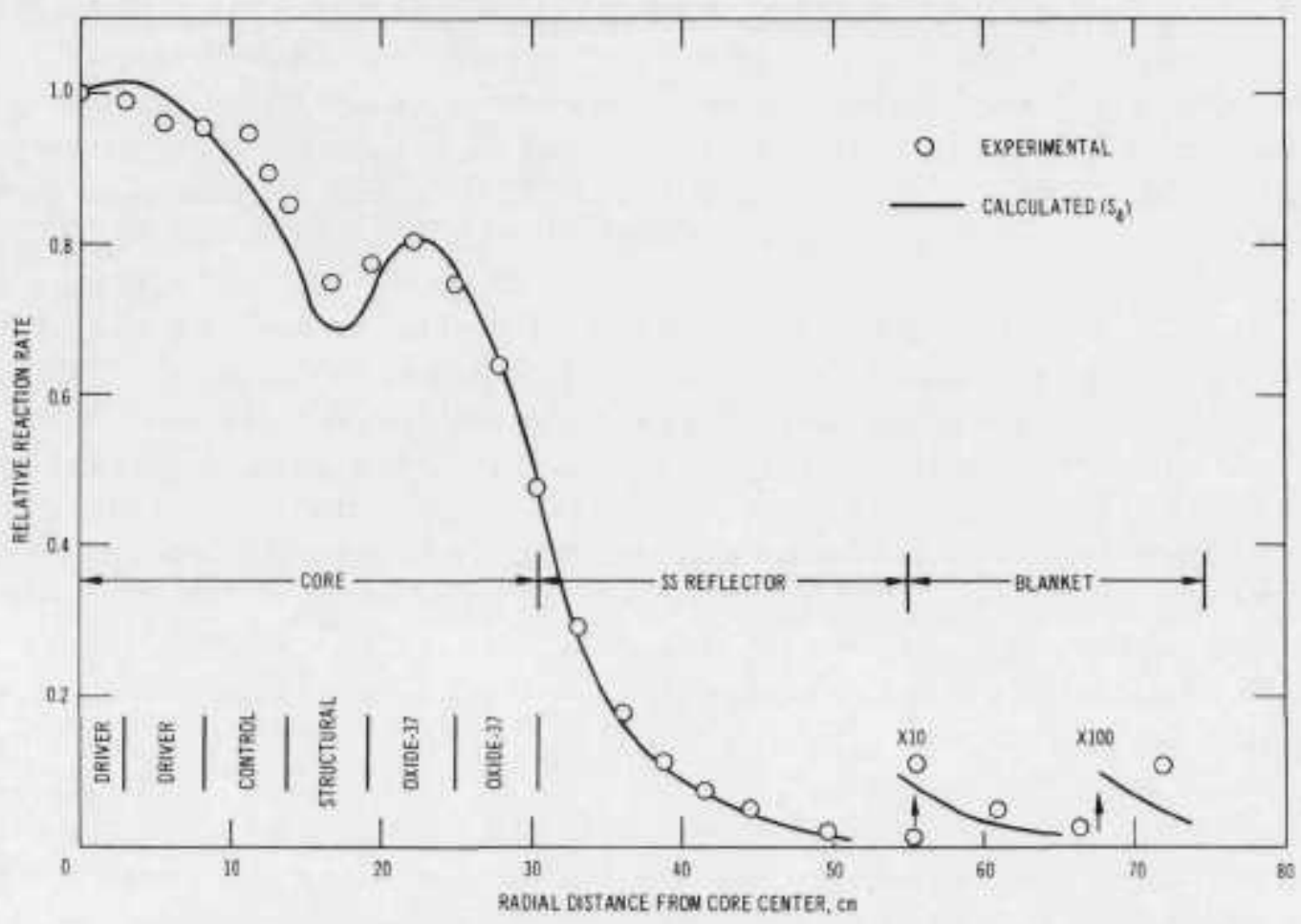

Fig. I.37. Experimental and Calculated ${ }^{238} \mathrm{U}_{\mathrm{f}}$ Radial Traverses toward 37 -pin Oxide Region at Axial Midplane of Core of ZPR-3 Assembly 63C 


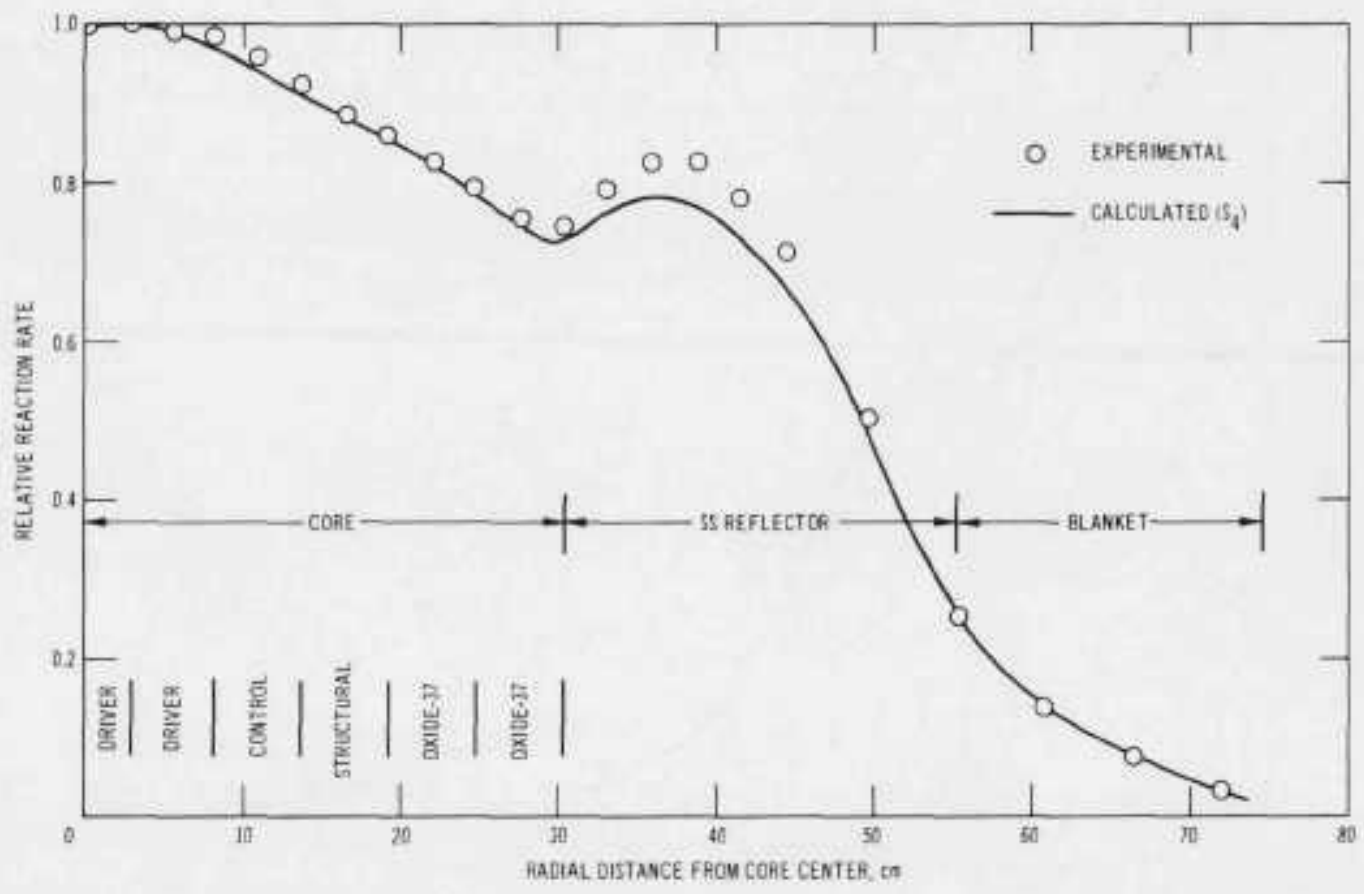

Fig. I.38. Experimental and Calculated $235 \mathrm{U}_{f}$ Radial Traverses toward 37 -pin Oxide Region at Axial Midplane of Core of ZPR-3 Assembly $63 \mathrm{C}$

heterogeneity effects due to the drawer-plate structure of the assembly. The cutting patterns were similar to those of Assembly 61. The samples were irradiated for a nominal $600 \mathrm{~W}-\mathrm{hr}$ exposure. As in Assembly 61 , three separate 0.1 -mil-thick gold foils were assembled into each interface and reflector packet to examine the effects of resonance self-absorption in the gold. Methods of counting and data reduction for all samples were identical with those reported for Assembly -60 and -61 foils.

Table I. 28 gives the number of pieces into which each foil was cut and the drawer location in which each foil was irradiated. The numbers preceding the symbol Au differentiate the three foils in each packet of the self-absorption test; 1 designates the foil in the packet closest to the front of Half 1:2 designates the middle foil; and 3 the foil farthest from the front of Half 1. Table 1.29 summarizes the fission rates determined from the ${ }^{235} \mathrm{U}$ and ${ }^{238} \mathrm{U}$ foils. The relative errors represent all sources of uncertainty associated with comparing relative fission rates, but does not include uncertainties associated with fission yields. (The rates were determined by an analysis of seven individual fission-product activities.) Table I, 30 summarizes the ${ }^{197} \mathrm{Au}(n, \gamma){ }^{198} \mathrm{Au},{ }^{58} \mathrm{Ni}(n, \mathrm{p}){ }^{58} \mathrm{Co},{ }^{27} \mathrm{Al}(n, \alpha){ }^{24} \mathrm{Na}$, and ${ }^{238} \mathrm{U}(\mathrm{n}, \gamma){ }^{239} \mathrm{~Np}$ reaction rates for the reflector, interface, and core irradiation locations. The absolute error is these values for the respective reactions are $8.1,5.9,8.0$, and $6.0-6.8 \%$.

The reaction rates reported in Tables 1.29 and 1.30 were determined from foils irradiated in the left side of Half 1 of Assembly 62 . Table 1.31 compares the reaction rates for the goldand nickel foils irradiated 
in symmetrical positions in the opposite sides of Half 1 . The values given in the table are averages of the reaction rates determined from the individual pieces of each 2- $\times 2$-in. foil. The ratios ( $\mathrm{right} / \mathrm{left}$ ) in Table I.31 are accurate to $- \pm 1 \%$, because all experimental uncertainties except counting statistics cancel out. Recognizing that the ${ }^{197} \mathrm{Au}$ reaction is sensitive only to neutron energies below $-1 \mathrm{MeV}$ and the ${ }^{58} \mathrm{Ni}$ reaction only to neutron energies above $\sim 1 \mathrm{Mev}$, we can draw the following conclusions:

Flux spectral and physical symmetry existed in the two core locations. At the symmetric interface locations, flux symmetry existed for high-energy neutrons, but there were $-10 \%$ more low-energy neutrons on the right side. At the two physically symmetric reflector locations, neither flux nor spectral symmetry was observed; the right side had a significantly softer and somewhat more intense neutron spectrum. The origin of this neutron asymmetry and the possible effects upon the fission-yield measurements performed in Assemblies 60 and 61 are being investigated.

TABLE 1.28. Irradiation Locations and Foil-cutting Arrangement for Activation-rate Maasurenentil in 2PR-3 Assembly 62

\begin{tabular}{|c|c|c|c|c|c|c|}
\hline \multirow[b]{2}{*}{ Fot1 } & \multicolumn{6}{|c|}{$\begin{array}{l}\text { Number of Pieces Cut from Foils Irradiated at } \\
\text { Indicated Drawer Location in Half } 1\end{array}$} \\
\hline & $\begin{array}{c}\text { Core } \\
(0-15)\end{array}$ & $\begin{array}{l}\text { Interface } \\
(0-11)\end{array}$ & $\begin{array}{l}\text { Refloctor } \\
(0-8)\end{array}$ & $\begin{array}{c}\text { Core } \\
(0-17)\end{array}$ & $\begin{array}{l}\text { Interface } \\
(0-21)\end{array}$ & $\begin{array}{l}\text { Reflector } \\
(0-23)\end{array}$ \\
\hline $235 \mathrm{u}$ & 8 & B & 4 & - & - & - \\
\hline $238_{v}$ & B & 8 & 4 & - & - & - \\
\hline $\mathrm{Ni}$ & 8 & 8 & 4 & 8 & 8 & 4 \\
\hline Al & 8 & 8 & 4 & - & - & - \\
\hline I. Aut & 8 & 8 & 4 & 8 & 8 & 4 \\
\hline $2 \mathrm{Aa}$ & $\theta$ & 8 & 4 & B & $B$ & 4 \\
\hline $3 \mathrm{Au}$ & 8 & 8 & 4 & 8 & 8 & 4 \\
\hline
\end{tabular}

TABLE 1.29. Absolute Fission Rates (in $10^{-19}$ ators $/$ atom-cm) for ${ }^{299} \mathrm{U}$ and ${ }^{212} \mathrm{U}$ Samples Ir radiated in ZPR-3 Assembly 62

\begin{tabular}{|c|c|c|c|c|c|c|c|c|c|}
\hline \multirow[b]{2}{*}{ Sample } & \multicolumn{2}{|c|}{${ }^{235} \mathrm{U}$} & \multicolumn{2}{|c|}{${ }^{218} \mathrm{U}$} & \multirow[b]{2}{*}{ Sample } & \multicolumn{2}{|c|}{${ }^{235} \mathrm{U}$} & \multicolumn{2}{|c|}{${ }^{25 \mathrm{a}} \mathrm{u}$} \\
\hline & Rate & $\begin{array}{l}\text { Relative } \\
\text { Error. \% }\end{array}$ & Rate & $\begin{array}{l}\text { Relative } \\
\text { Error.\% }\end{array}$ & & Rate: & $\begin{array}{l}\text { Relative } \\
\text { Error. \% }\end{array}$ & Rate & $\begin{array}{l}\text { Relative } \\
\text { Error, } \%\end{array}$ \\
\hline Reflector & & & & & Core & & & & \\
\hline 1 & 22.4 & 2.5 & 0.178 & 4.2 & 1 & 30.0 & 2.2 & 2.07 & 2.0 \\
\hline 2 & 22,9 & 3.2 & 0,213 & $3: 2$ & 2 & 29.2 & 1.8 & 1.99 & 1.7 \\
\hline 3 & 23.2 & 3,0 & 0.245 & 2.5 & 3 & 29.5 & 2.3 & 2.03 & 2,3 \\
\hline 4 & 23.7 & 3.5 & 0.304 & 2.6 & 4 & 28.6 & 1.9 & 2.08 & 1. 8 \\
\hline Interface & & & & & 5 & 29.2 & 1.8 & 2.11 & 1.9 \\
\hline 1 & 22.0 & 2.3 & 0.954 & 2.0 & 6 & 30,3 & 2,0 & 2.20 & 1.9 \\
\hline 2 & 20.5 & 2.0 & 0,992 & $1, B$ & 7 & 30.3 & 2,0 & 2.17 & 1.9 \\
\hline 3 & 20.7 & 1.9 & 1.05 & 1.7 & 8 & 28.9 & 2,0 & 2,06 & 2.0 \\
\hline 4 & 20.5 & 2.3 & 1.17 & 1.8 & & & & & \\
\hline 3 & 20.7 & 1.9 & 1.26 & 1.8 & & & & & \\
\hline 6 & 21.4 & 2.0 & 1.35 & 1,7 & & & & & \\
\hline 7 & 22.0 & 2.0 & 1,38 & 1.7 & & & & & \\
\hline 8 & 21.3 & 1.8 & 1.38 & 1.9 & & & & & \\
\hline
\end{tabular}


TABLE 1, 30. Absolute Reaction Rates (In $10^{-16}$ atoms/atom-sec) for ${ }^{197} \mathrm{Au}(\mathrm{n}, \mathrm{Y})^{195} \mathrm{Au}$, $58_{\mathrm{NI}}(\mathrm{n}, \mathrm{p})^{58} \mathrm{Co},{ }^{27} \mathrm{Al}(\mathrm{n}, n)^{24} \mathrm{Na}$, and ${ }^{238} \mathrm{U}(\mathrm{n}, \mathrm{r})^{239} \mathrm{~Np}$ in $\mathrm{ZPR}-3$ Assenbly 62

\begin{tabular}{|c|c|c|c|c|c|c|c|c|}
\hline \multirow[b]{2}{*}{ Sanple } & \multicolumn{2}{|c|}{${ }^{197} \mathrm{Au}(\pi, \gamma)^{198}{ }_{\mathrm{Au}}$} & \multicolumn{2}{|c|}{${ }^{58} \mathrm{Ni}(\mathrm{n}, \mathrm{p})^{58} \mathrm{Co}$} & \multicolumn{2}{|c|}{${ }^{27} \mathrm{Al}(\mathrm{n}, \mathrm{a})^{24} \mathrm{Na}$} & \multicolumn{2}{|c|}{${ }^{238} \mathrm{U}(\mathrm{n}, \mathrm{y})^{239} \mathrm{~Np}$} \\
\hline & Rate & $\begin{array}{l}\text { Relative } \\
\text { Error, } 2\end{array}$ & Rate & $\begin{array}{l}\text { Relative } \\
\text { Error, \& }\end{array}$ & Rate & $\begin{array}{l}\text { Relative } \\
\text { Errot, } z\end{array}$ & Rate & $\begin{array}{l}\text { Relative } \\
\text { Errot, Z }\end{array}$ \\
\hline \multicolumn{9}{|c|}{ Reflector } \\
\hline $\begin{array}{l}1 \\
2 \\
3 \\
4\end{array}$ & $\begin{array}{l}195 \\
191 \\
184 \\
176\end{array}$ & $\begin{array}{l}0.2 \\
0.1 \\
0.5 \\
0.5\end{array}$ & $\begin{array}{l}0.384 \\
0.451 \\
0.550 \\
0.685\end{array}$ & $\begin{array}{l}0.8 \\
0.3 \\
0.6 \\
0.3\end{array}$ & $\begin{array}{l}0.00177 \\
0.00201 \\
0.00244 \\
0.00312\end{array}$ & $\begin{array}{l}3.3 \\
3.0 \\
0.7 \\
2.0\end{array}$ & $\begin{array}{l}51.2 \\
51.7 \\
51.5 \\
50.9\end{array}$ & $\begin{array}{l}1.2 \\
1.0 \\
0.9 \\
1.1\end{array}$ \\
\hline \multicolumn{9}{|c|}{ Interface } \\
\hline $\begin{array}{l}1 \\
2 \\
3 \\
4 \\
5 \\
6 \\
7 \\
8\end{array}$ & $\begin{array}{l}77.6 \\
73.8 \\
62.7 \\
55.1 \\
50.9 \\
48.4 \\
47.3 \\
46.7\end{array}$ & $\begin{array}{l}0.1 \\
0.1 \\
0.4 \\
0.1 \\
0.2 \\
0.5 \\
0.3 \\
0.2\end{array}$ & $\begin{array}{l}2.70 \\
2.83 \\
3.13 \\
3.34 \\
3.67 \\
4.00 \\
4.10 \\
4.02\end{array}$ & $\begin{array}{l}0.3 \\
0.5 \\
0.3 \\
0.4 \\
0.1 \\
0.3 \\
0.1 \\
0.2\end{array}$ & $\begin{array}{l}0.0142 \\
0.0151 \\
0.0177 \\
0.0185 \\
0.0206 \\
0.0231 \\
0.0229 \\
0.0221\end{array}$ & $\begin{array}{l}4.4 \\
0.1 \\
0.1 \\
1.6 \\
0.2 \\
2.2 \\
1.3 \\
1.4\end{array}$ & $\begin{array}{l}30.9 \\
30.1 \\
27.4 \\
26.3 \\
26.0 \\
25.1 \\
25.8 \\
26.6\end{array}$ & $\begin{array}{l}1.3 \\
1.1 \\
1.0 \\
1.3 \\
1.1 \\
1.4 \\
1.4 \\
1.3\end{array}$ \\
\hline \multicolumn{9}{|l|}{ Core } \\
\hline $\begin{array}{l}1 \\
2 \\
3 \\
4 \\
5 \\
6 \\
7 \\
8\end{array}$ & $\begin{array}{l}50.6 \\
50.0 \\
49.6 \\
51.5 \\
51.7 \\
50.8 \\
50.1 \\
51.1\end{array}$ & $\begin{array}{l}0.5 \\
0.1 \\
0.3 \\
0.4 \\
0.3 \\
0.4 \\
0.1 \\
0.5\end{array}$ & $\begin{array}{l}6.24 \\
6.25 \\
6.41 \\
6.18 \\
6.32 \\
6.63 \\
6.65 \\
6.41\end{array}$ & $\begin{array}{l}0.3 \\
0.1 \\
0.1 \\
0.1 \\
0.1 \\
0.2 \\
0.6 \\
0.1\end{array}$ & $\begin{array}{l}0.0335 \\
0.0347 \\
0.0356 \\
0.0355 \\
0.0353 \\
0.0368 \\
0.0370 \\
0.0353\end{array}$ & $\begin{array}{l}0.2 \\
1.0 \\
2.2 \\
0.4 \\
0.6 \\
0.4 \\
1.3 \\
1.1\end{array}$ & $\begin{array}{l}32.3 \\
31.7 \\
31.0 \\
31.1 \\
31.6 \\
32.4 \\
32.1 \\
31.3\end{array}$ & $\begin{array}{l}0.8 \\
0.9 \\
1.1 \\
1.3 \\
1.5 \\
0.9 \\
0.9 \\
0.9\end{array}$ \\
\hline
\end{tabular}

TABLE I.31. Reaction Rates (in $10^{-16}$ atous/atom-sec) in Symmetrical Drawer Posittons in Half 1 of ZPR-3 Assembly 62

\begin{tabular}{|c|c|c|c|c|c|c|}
\hline \multirow[b]{2}{*}{ Location } & \multicolumn{3}{|c|}{${ }^{197} \mathrm{Au}(\mathrm{n}, \gamma)^{198} \mathrm{Au}$} & \multicolumn{3}{|c|}{${ }^{58} \mathrm{Ni}(\mathrm{n}, \mathrm{p})^{58} \mathrm{Co}$} \\
\hline & $\begin{array}{l}\text { Weft } \\
\text { Side }\end{array}$ & $\begin{array}{l}\text { Right } \\
\text { Side }\end{array}$ & $\begin{array}{c}\text { Ratio } \\
\text { (right/left) }\end{array}$ & $\begin{array}{l}\text { Left } \\
\text { Side }\end{array}$ & $\begin{array}{l}\text { Fight } \\
\text { Side }\end{array}$ & $\begin{array}{c}\text { Ratio } \\
\text { (right/1eft) }\end{array}$ \\
\hline Reflector & 185 & 270 & 1.46 & 0.532 & 0.446 & 0.838 \\
\hline Interface & 55.6 & 61.9 & 1.11 & 3.50 & 3.49 & 0.997 \\
\hline Core & 50,9 & $\$ 1.1$ & 1.00 & 6.35 & 6.34 & 0.998 \\
\hline
\end{tabular}

c. Comparison of Calculated and Experimental Capture/Fission Ratios for EBR-II Loadings. D. Meneghetti and R, H. Rempert

Two-dimensional, XY-geometry, $\mathrm{S}_{4}$ transport analyses using 29 neutron-energy groups have been made for four EBR-II core-loading configurations (Runs $7,14,17$, and 20) representative of the detailed environments during the foil-irradiation experiments (EBR-II Runs 5-23) made to obtain the capture/fission $(\alpha)$ ratios of the isotopes ${ }^{239} \mathrm{Pu},{ }^{240} \mathrm{Pu}$, ${ }^{233} \mathrm{U},{ }^{235} \mathrm{U}$, and ${ }^{238} \mathrm{U}$. The 29 -energy-group cross-section set is based on the ENDF/B (Version I) data.

Tables I.32-I.36 give calculated radial capture/fission ratios for the respective isotopes at the midplane positions of various subassemblies 
TABLE 1.32. Calculated and Experimenta1 ${ }^{239} \mathrm{Pu}$ Capture/Fission Ratios ( $\alpha$ ) for EBR-II Runs 7, 14, 17, and 20

\begin{tabular}{|c|c|c|c|c|c|}
\hline \multirow{3}{*}{$\begin{array}{l}\text { Subassembly } \\
\text { Position }\end{array}$} & \multicolumn{4}{|c|}{ Calculated } & \multirow[b]{3}{*}{ Experimenta $1^{a}$} \\
\hline & \multicolumn{4}{|c|}{ EBR-II Run No. } & \\
\hline & 7 & 14 & 17 & 20 & \\
\hline $1 \mathrm{Al}$ & 0.080 & 0.080 & --- & -- & 0.085 \\
\hline 3B2 & 0.081 & 0.81 & $-\cdots$ & $\cdots$ & 0.082 \\
\hline $5 \mathrm{~B} 2$ & -- & 0.89 & 0.090 & -- & 0.098 \\
\hline $7 B 4$ & 0.119 & -- & -- & -- & 0.134 \\
\hline $9 B 5$ & 0.155 & 0.151 & 0.154 & 0.150 & 0.143 \\
\hline $11 B 6$ & 0.174 & 0.172 & 0.173 & 0.171 & 0.185 \\
\hline $13 \mathrm{~B} 7$ & 0.182 & 0.180 & 0.181 & 0.179 & 0.241 \\
\hline
\end{tabular}

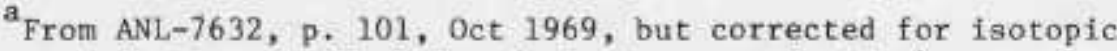
contributions by $N$. Dudey (private communication).

TABLE 1.33. Calculated and Experimental ${ }^{240} \mathrm{Pu}$ Capture/Fission Ratios $(\alpha)$ for EBR-II Runs $7,14,17$, and 20

\begin{tabular}{|c|c|c|c|c|c|}
\hline \multirow{3}{*}{$\begin{array}{l}\text { Subassemb1y } \\
\text { Position }\end{array}$} & \multicolumn{4}{|c|}{ Calculated } & \multirow[b]{3}{*}{ Experimental ${ }^{a}$} \\
\hline & \multicolumn{4}{|c|}{ BBR-II Run No. } & \\
\hline & 7 & 14 & 17 & 20 & \\
\hline $1 \mathrm{Al}$ & 0.277 & 0.277 & $\cdots$ & $\cdots$ & 0.305 \\
\hline $3 B 2$ & 0.280 & 0.280 & -- & $\cdots$ & 0.308 \\
\hline $5 \mathrm{~B} 2$ & -- & 0.317 & 0.324 & $\cdots$ & 0.352 \\
\hline 784 & 0.571 & -- & -- & $\ldots$ & 0.594 \\
\hline $9 \mathrm{~B} 5$ & 1.13 & 1.07 & 1.12 & 1.05 & 1.37 \\
\hline $11 B 6$ & 1.58 & 1.53 & 1.56 & 1.51 & -- \\
\hline $13 \mathrm{~B} 7$ & 1.81 & 1.76 & 1.79 & 1.74 & 3.42 \\
\hline
\end{tabular}

a From ANL-7737, p. 106, Aug 1970, but corrected for isotopic contributions by $\mathrm{N}$. Dudey (private communication). 
TABLE I.34. Calculated and Experimental ${ }^{233} \mathrm{U}$ Capture/Fission Ratios $(\alpha)$ for EBR-II Runs 7, 14, 17, and 20

\begin{tabular}{|c|c|c|c|c|c|}
\hline \multirow{3}{*}{$\begin{array}{l}\text { Subassembly } \\
\text { Position }\end{array}$} & \multicolumn{4}{|c|}{ Calculated } & \multirow[b]{3}{*}{ Experimental ${ }^{a}$} \\
\hline & \multicolumn{4}{|c|}{ EBR-II Run No. } & \\
\hline & 7 & 14 & 17 & 20 & \\
\hline $1 \mathrm{~A} 1$ & 0.069 & 0.069 & $-\cdots$ & -- & 0.073 \\
\hline $3 \mathrm{~B} 2$ & 0.069 & 0.069 & $-\cdots$ & $m$ & $m$ \\
\hline $5 B 2$ & $-\cdots$ & 0.072 & 0.072 & $-\infty$ & 0.071 \\
\hline $7 B 4$ & 0.084 & $\cdots$ & $-\cdots$ & $\cdots$ & $\cdots$ \\
\hline $9 B 5$ & 0.094 & 0.093 & 0.095 & 0.093 & 0.095 \\
\hline $11 B 6$ & 0.098 & 0.098 & 0.098 & 0.098 & $-\infty$ \\
\hline $13 B 7$ & 0.100 & 0.099 & 0.099 & 0.099 & 0.106 \\
\hline
\end{tabular}

${ }^{a}$ From ANL-7618, p. 89, Sept 1969, but corrected for isotopic contributions by N. Dudey (private communication).

TABLE I.35. Calculated and Experimental ${ }^{235} \mathrm{U}$ Capture/Fission Ratios $(\alpha)$ for EBR-II Runs $7,14,17$, and 20

\begin{tabular}{|c|c|c|c|c|c|}
\hline \multirow{3}{*}{$\begin{array}{c}\text { Subassembly } \\
\text { Position }\end{array}$} & \multicolumn{4}{|c|}{ Calculated } & \multirow[b]{3}{*}{ Experimenta $1^{a}$} \\
\hline & \multicolumn{4}{|c|}{ EBR-II Run No. } & \\
\hline & 7 & 14 & 17 & 20 & \\
\hline lAl & 0.161 & 0.161 & $\ldots$ & $\cdots$ & 0.180 \\
\hline 3B2 & 0.162 & 0.163 & $\cdots$ & $\cdots$ & 0.183 \\
\hline $5 B 2$ & $\cdots$ & 0.173 & 0.174 & $-\cdots$ & $\cdots$ \\
\hline $7 B 4$ & 0.210 & $-\infty$ & $-\cdots$ & + & 0.230 \\
\hline $9 \mathrm{BS}$ & 0.247 & 0.244 & 0.247 & 0.242 & $-\infty$ \\
\hline $11 B 6$ & 0.261 & 0.262 & 0.264 & 0.261 & 0.291 \\
\hline $13 B 7$ & 0.267 & 0.269 & 0.270 & 0.268 & $\ldots$ \\
\hline
\end{tabular}

arom ANL-7737, p. 106, Aug 1970, but corrected for isotopic contributions by N. Dudey (private communtcation). 
TABLE I.36. Calculated and Experimental ${ }^{238} \mathrm{U}$ Capture/F1ssion Ratios (a) for EBR-II Runs $7,14,17$, and 20

\begin{tabular}{|c|c|c|c|c|c|}
\hline \multirow{3}{*}{$\begin{array}{l}\text { Subassembly } \\
\text { Position }\end{array}$} & \multicolumn{4}{|c|}{ Calculated } & \multirow[b]{3}{*}{ Experimental } \\
\hline & \multicolumn{4}{|c|}{ BBR-II Run No. } & \\
\hline & 7 & 14 & 17 & 20 & \\
\hline 1 AI & 1.65 & 1.65 & $\cdots$ & - & $\cdots$ \\
\hline 382 & 1.66 & 1.67 & $\cdots$ & $\cdots$ & $\cdots$ \\
\hline 582 & $\cdots$ & 1.93 & 1.99 & -. & $\ldots$ \\
\hline 784 & 4.85 & - & $\cdots$ & - & $\cdots$ \\
\hline 985 & 19.7 & 17.6 & 19.0 & 16.9 & $\cdots$ \\
\hline 1186 & 46.2 & 43.2 & 45.0 & 41.5 & 33.8 \\
\hline $13 \mathrm{~B} 7$ & 74.7 & 71.7 & 69.9 & 68.8 & $\ldots$ \\
\hline
\end{tabular}

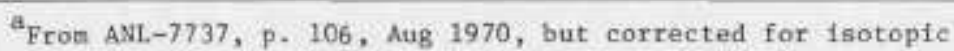
contributions by $\mathrm{X}$. Dudey (private communtcation).

in the four runs. The differences in calculated values for each run are indicative of the variations of $\alpha$ expected because of the somewhat different loading patterns and contours of the core/blanket interface for each run. For comparison, the reported experimental values from the foil irradiations are also listed.

d. Comparison of Neutronics Methods. P. L. Walker

An EBR-II subassembly-loading pattern was calculated using the $2 \mathrm{D}$ diffusion code DIF2D and the $2 \mathrm{D}$ transport code DOT with $S_{2}, S_{4}$, and $\mathrm{S}_{6}$ angular quadrature to compare the accuracies of the neutronics calculations. The problem used for comparison was an XY calculation of EBR-II Run $42 \mathrm{~A}$ using the standard $42 \times 42$ mesh and the six-group cross-section set 23806. The same axial leakage terms used in DOT were also used in the DIF2D calculation. The calculated values of $k_{\text {eff }}$ were: DIF 2D--0.9949; DOT $S_{2}=-0.9961$; DOT $S_{4}=-0.9994 ;$ DOT $S_{6}=-0.9990$.

The activity rates for ${ }^{235} \mathrm{U}$ and ${ }^{238} \mathrm{U}$ were compared. The ${ }^{235} \mathrm{U}$ activity curves were smooth and were reasonably similar for all calculations. Figure I.39 is a plot of the ${ }^{238} \mathrm{U}$ activity along a horizontal slice through the center of the core. The type of subassembly at each position is indicated along the bottom of the graph, with D designating a driver subassembly, B a blanket subassembly, S a safety rod, L a control rod, and ST a structural experiment. Subassembly X021 is an experimental structural subassembly, and X059 is an experimental fueled subassembly.

These results indicate that the diffusion calculation does not show the peaks and depressions sufficiently and that the $S_{2}$ transport 
calculation tends to exaggerate the peaks and depressions. The $\mathrm{S}_{4}$ curve follows the $\mathrm{S}_{6}$ curve very closely; therefore, $\mathrm{S}_{4}$ transport calculations should be adequate for two-dimensional XY-geometry analysis of EBR-II configurations in which the subassemblies are delineated.

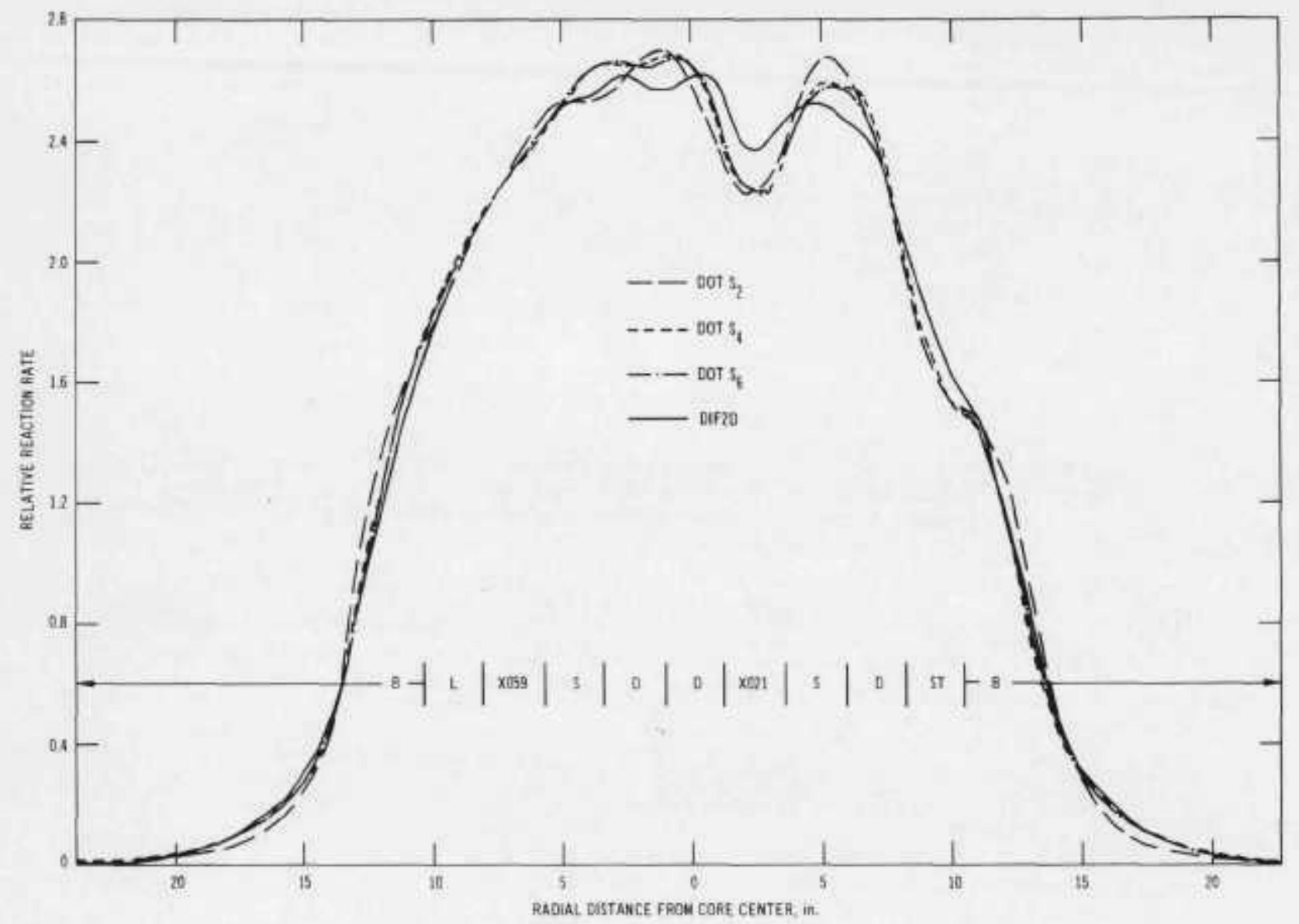

Fig. 1.39. ${ }^{238} \mathrm{U}$ Activity along Horizontal Line through Core Center of Run 42A, as Calculated Four Different Ways

4. Operation of Data Acquisition System (DAS) (02-530; last reported: ANL-7783, p. 50)

\section{a. Rod-drop Studies. H. A. Larson and E. M. Dean}

Studies of feedback in EBR-II are made by analyzing, with an inverse-kinetics code, the transient behavior of the reactor following a rod drop. The inability to determine a critical state of the reactor at initiation of a rod drop may cause inaccuracies in the value of the feedback reactivity. It is estimated that reactor operators canvisually maintain a critical state within only $0.2 \mathrm{Ih}$; further, the large amount of $10-\mathrm{Hz}$ noise in the power signal complicates this problem.

The EROS-2 computer code was run to determine the effect of a noncritical rod-drop condition. A difference of about $4.4 \%$ was found between 
the values for feedback reactivity when the drop is initiated at critical and when it is initiated with the excess reactivity about $0.19 \mathrm{Ih}$. Therefore, reactivity drift may cause as much as $9 \%$ difference between two successive rod-drop tests.

\section{b. Rod-drop Initiation Code. I. A. Engen, H. A, Larson, and} R. W. Hyndman

As a result of the EROS-2 studies described in Sect. I.D.4.a, a computer code to signal the proper critical state for a rod drop was written for the Sigma-5 computer. The inverse-kinetics procedure was used to calculate 60 values of reactivity a second, average these arithmetically, and post the average on a graphic-display unit every second. When N successive average values (currently $\mathrm{N}=3$ ) are less than a preset value of excess reactivity (currently $0.1 \mathrm{Ih}$ ), the signal to drop the rod is displayed, and the transient may be initiated.

\section{c. DAS Operation. R. W. Hyndman and M. R. Tuck}

The DAS is now operating as a data-acquisition device. At present, 142 channels are connected and are being sampled at sampling rates from 10 to 0.0033 per second. The data obtained are placed in a data table for use by all calling programs. Data are collected from the data table, converted to engineering units, and used for display. Data are also logged on magnetic tape at 1 -min intervals in engineering units.

\section{d. RODCAL: Control-rod Calibration Code. E. W. Laird}

A program that provides for using the DAS for calibrating the EBR-II control rods was tested. The program (RODCAL) monitors the position of two control rods and the system reactivity during the incremental interchange of the two rods. When the rods reach their extreme positions, all values for incremental worths are stored with the respective rod positions for later use by another program that plots a rod-worth curve.

Comparison was made between the incremental worths of control rod No. 2 as obtained by period measurement and with RODCAL. The results were:

\begin{tabular}{|c|c|c|}
\hline Test Number & Incremental Worth, Ih & Rod Increment, in. \\
\hline & From RODCAL & \\
\hline 1 & 38,32 & $5.00-7.63$ \\
\hline 2 & 38,20 & $5.00-7.63$ \\
\hline 3 & 38,37 & $5.00-7.64$ \\
\hline & From Period Measurement & \\
\hline 4 & 38,06 & $5.00-7.64$ \\
\hline 5 & 38.25 & $5.00-7.64$ \\
\hline 6 & 38.17 & $5,00-7,64$ \\
\hline
\end{tabular}


The deviation between successive runs with the RODCAL program is $<0.4 \%$, and the two methods compare to within $0.4 \%$.

After criticality had been achieved, a RODCAL determination could be made in about $45 \mathrm{sec}$; a period measurement requires about $10 \mathrm{~min}$. RODCAL therefore provides potential for a considerable saving of time, because measurements of incremental worth must be made after every major loading change in the reactor.

e. Oscillator Studies. I. A. Engen, R. W, Hyndman, H. A. Larson, M. R. Tuck, and K. D. Tucker

To assess the dynamic stability of EBR-II, a new oscillator rod has been installed in the reactor for Run 48B. Oscillator data were collected at severalfrequencies for the power levels of $500 \mathrm{kWt}, 20 \mathrm{MWt}, 30 \mathrm{MWt}$, and $40 \mathrm{MWt}$. These data were used to check out the mechanical operation of the oscillator rod and to check for correct execution of the computer programs* recently constructed and installed on the Sigma-5 computer. equations**

The transfer function of the reactor was calculated from the

$$
R(G)=k_{1} \sum_{n=1}^{N_{1}} \Delta E O_{n} \cos \left(\omega t_{n}\right)
$$

and

$$
I(G)=k_{2} \sum_{n=1}^{N_{1}} \Delta E O_{n} \sin \left(\omega t_{n}\right),
$$

where $\triangle E O_{n}$ represents the varying component of the power, and $k_{1}$ and $k_{2}$ are normalization constants.

Figure I.40 shows the data taken at the four power levels. Except for magnitude at $0.93 \mathrm{~Hz}$ and phase at $8.72 \mathrm{~Hz}$, the data for $500 \mathrm{kWt}$ are in fair agreement with the theoretical zero-power linearized transfer function. The magnitude and phase of the reactor transfer function at power are normalized in both magnitude and phase to the zero-power linearized trans fer function at approximately $8.72 \mathrm{~Hz}$. A relatively small amount of scatter is evident, except for phase at higher power levels and lower frequencies. The general behavior of the transfer function is similar to that seen in the oscillator studies of Run 26B and published in ANL-7686.

\footnotetext{
*I. A, Engen, A New Technique for Investigating Feedback and Stability of a Nuclear Reactor, ANL-7686 (June 1970).

$*_{R}$. W. Hyndman and M. R. Tuck, An On-Line Method of Transfer Function Analysis of EBR-II, Nucl. Appl. 6. 137-141 (Feb 1969).
} 


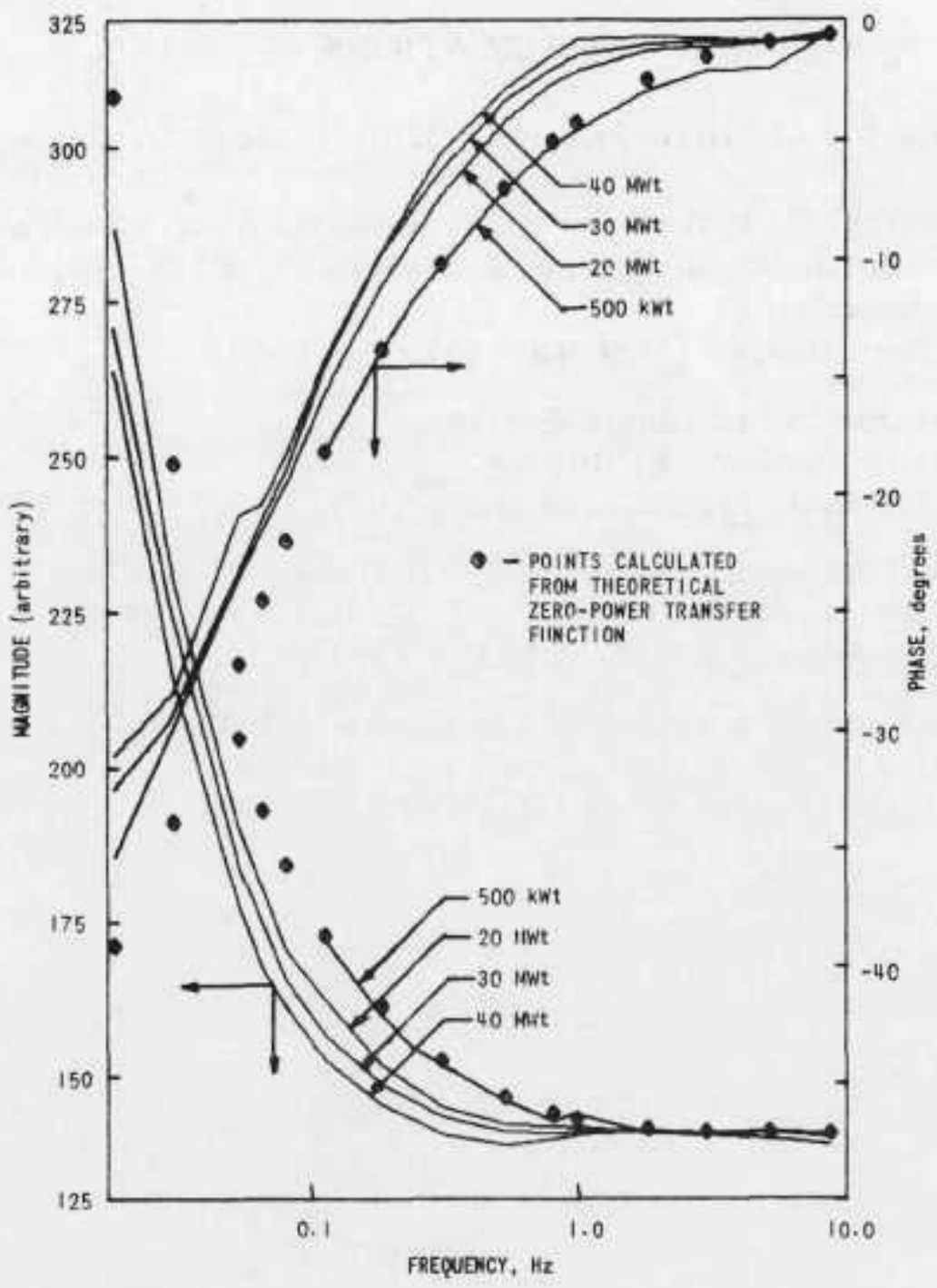

Fig. 1.40. Magnitude and Phase of EBR-II Transfer Function: Run 48B

The feedback transfer function, $\mathrm{H}(\mathrm{s})$, may be calculated from

$$
G(s)=\frac{G_{0}(s)}{1+G_{0}(s) H(s)},
$$

where $G_{0}(s)$ is the theoretical linearized zero-power transfer function and $G(s)$ is the transfer function measured at power. Analysis of feedback transfer function is continuing, as is comparison of the data with the feedback transfer function obtained from rod-drop data. 


\section{PUBLICATIONS}

Transient Behavior of "High-Swelling" EBR-II Mark IA Driver Fuel in TREAT

A. B. Rothman, C. J. Renken, R. R. Stewart, A. K. Chakraborty,

C. E. Dickerman, G. G. Dewey, S. Matras, R. V. Strain, and

D. R. Hutchinson

Nucl. Eng. Design 15(2), 187-207 (Apr 1971)

An Inexpensive Pump for Liquid Sodium

R. R. Schlueter and W. E. Ruther

Nucl. Technol. 11, 266-267 (June 1971)

Anisotropic Irradiation Growth of EBR-II Driver Fuel Pins

C. M. Walter, A. K. Chakraborty, J. P. Bacca, and P. G. Shewmon

J. Nucl. Mater. 39, 122-124 (Apr 1971)

Application of Fuel-Element Modeling Codes to EBR-II Driver Fuel

C. M. Walter, P. G. Shewmon, and J. P. Bacca

Nucl. Technol. 11, 38-44 (May 1971) 


\section{LMFBR DESIGN SUPPORT}

\section{A. Core Component Test Loop (CCTL). \\ R. A. Jaross $(02-026)$}

The CCTL is operated, maintained, and modified to facilitate longterm tests of prototype FFTF fuel assemblies and in-core instrumentation in sodium under conditions established by the FFTF and LMFBR Programs. Technologies pertinent to sodium-loop operation (e.g., surveillance of sodium and cover-gas quality, and material compatibility, including the Type 304 loop structure) are developed and improved concurrently.

1. Preparation of Mark-II FFTF Fuel Assembly for Shipment. F. A. Smith (Not previously reported)

After removal from the CCTL test vessel on March 23,1971, the Mark-II FFTF fuel assembly was cleaned of residual sodium on the surfaces preparatory to shipment to HEDL for interim examination, possible modification, and return to ANL for completion of the 9000-hr flowtest.

The cleaning procedure consisted of two separate rinses with Dowanol, followed by a final rinse with ethyl alcohol. After the alcohol rinse, a very thin film of what appeared to be sodium oxide was observed on various portions of the fuel assembly. With HEDL approval, the assembly was subjected to an additional rinse with water. Samples of each rinse solution were forwarded to the Argonne Chemistry Division for analysis and determination of sodium concentration.

No unusual problems were encountered in the analysis. The sample solutions were simply diluted with deionized water to a convenient working range $(0.25-1.0 \mathrm{Na} / \mathrm{ml})$, and the sodium concentration determined by a conventional atomic-absorption method, using an Instrumentation Laboratories Model 153 Atomic Absorption Unit. To make certain that the results were not masked by either the Dowanol or alcohol, separate solutions were first evaporated to dryness and then diluted with water before analysis. Both techniques yielded essentially the same results: 17.1 and $2.1 \mathrm{~g}$ of sodium were removed with the first and second Dowanol rinses, respectively, and $0.2 \mathrm{~g}$ with the final alcohol rinse. The amount of sodium oxide in the additional water-rinse solution was too small to be of any significance.

The Mark-II fuel assembly was a vailable for shipment to HEDL on April 2, 1971. However, shipment was delayed pending the results of a dry-run test of the shipping box, loading scheme, sponge-rubber packing material, and the recording accelerometers used to monitor the fuel assembly while en route in the moving van. This test was completed during the week of April 26. On May 7, the fuel as sembly was shipped, arriving at HEDL on May 13. 
2. Preventive Maintenance and Modifications of the CCTL. F. A. Smith (Not previously reported)

Preventive maintenance and modifications of the CCTL are under way to ensure operational reliability during resumption of flowtesting the FFTF Mark-II fuel assembly and related instrumentation. Thus far:

a. A portion of the 1 -in. Schedule 40 pipe leading from the plugging meter-loop outlet to the CCTL cold trap was modified to reduce the calculated stress level at high operating temperature. Subsequent radiographic and dye-penetrant tests indicated that the weldments are equal to the high quality of the original installation.

b. Clamshell ceramic bare resistance-type heaters on the NaK circulation system of the cold trap were replaced with tubular resistancetype heaters.

c. The four Taylor pressure transducers associated with the Mark-II fuel assembly were removed, cleaned of residual sodium, and recalibrated. Each transducer was calibrated, using an air furnace and the appropriate receiving (read-out) unit. There were no anomalies, with all transducers equivalent to the "as-new" condition.

\section{B. Heat Transfer and Fluid Flow. R. P. Stein (02-097)}

Analytical and experimental investigations of liquid-metal heat transfer and fluid flow in components and systems are conducted to provide information of immediate interest to the FFTF and LMFBR Programs. Fundamental studies in heat transfer and fluid flow also are conducted to improve current, or to devise new engineering-prediction methods essential to the advancement of reactor technology in general.

\section{LMFBR Flow Stability Studies. R. Rohde}

This activity covers (1) the acquisition and analysis of experimental data on the vaporization and superheating of sodium in operating ranges (pressures, flow rates, temperatures, and equivalent diameters) and flow circuits of interest to the LMFBR Program; and (2) the determination, by both experiment and analysis, of two-phase flow phenomena related to flow stability. An LMFBR Simulation Heat Transfer Loop is being constructed for the experiments.

\section{a. Preparation of Apparatus (Last reported: ANL-7776, p. 82)}

The status of construction of the LMFBR Simulation Heat

Transfer Loop is as follows: A smoke-detector system is being installed in the air discharge duct of the air-cooled heat exchanger. This system 
operates on the principle that smoke in the effluent air will interrupt a light beam that traverses the duct. The light beam is reflected several times across the air stream by a system of mirrors before impinging a photocell. Thus far, the light source, mirrors, and photocell have been positioned and checked out. Minor corrections were made, and the installation is about $80 \%$ complete.

Insulation and counterbalancing of the inlet piping to the test section was initiated. This involves fabrication and suspension of a steel tray containing vermiculite insulating material, because test-section changes will require access to this portion of the piping system.

The sodium fill line and isolation valve were welded into the system. Design work was started on parts to be fabricated for an existing porous stainless steel filter cartridge. This filter will be used during sodiumfilling operations. Additional thermocouples were attached to the sodium dump tank to enhance overall surveillance of the loop.

A leak check of the gas-pressurization system revealed two leaky pressure-relief valves. Replacement of these valves with rupture disks is being considered. The baffle for the oscillating plugging-meter air duct has been fabricated and delivered to the loop site.

Bench tests were performed to ascertain the electronics compatibility of the solid-state relay system with the electromechanical safety interlock relays. The results were satisfactory, and the equipment will be installed in the power control panel.

Four of the 15 temperature controllers on order for the trace heating system were received and checked for conformance to specifications. One unit was defective and was returned to the vendor.

Operating amplifiers for the loop sensors are being procured. Bifilar-wound ceramic-coated coils for the liquid level sensors were fabricated and tested satisfactorily for continuity.

The loop surveillance system (Dymec System) was checked out and adjudged ready for use. This system will be used by the operators for general surveillance of loop operating conditions.

The assignment of various sensor inputs to the computer dataacquisition system, the control and interlock system, and the surveillance system is about $75 \%$ complete. In some instances, sensors can be assigned to all three systems; in others, an alternate sensor must be specified.

Work has started on processing of thermocouple signals in the computer, including software for converting the signals to digital data. 
b. Experiments with Superheat (Last reported: ANL-7783, p. 80)

Parallel with construction of the LMFBR Simulation Heat Transfer Loop, an analytical effort is focused on prediction of stability and boiling lengths for safe operation of the loop. Least-squares-fit polynomial curves for maximum allowable superheats over the expected ranges of pressure and heat flux are being generated. These curves will be stored in the Hewlett-Packard computer of the data-acquisition system and used to guide specific tests during the experimental program.

\section{Nonboiling Transient Heat Transfer. R. P. Stein}

The objective of this activity is to develop improved engineering prediction methods to account for nonboiling forced-convection heat transfer in ducts during transients.
a. Analysis of Heat-fiux Transients p. 84)
(Last reported: ANL-7758,

Improvements in accuracy obtained by use of the new prediction methods were evaluated in detail by analysis and by comparison with results predicted by exact calculations for a variety of specific heat-flux transients. It was found that for transients considered reasonable for LMFBR accident studies, the improvements in accuracy are probably not sufficient to warrant replacement of current quasi-steady-state prediction methods implicit in LMFBR safety codes. Consequently, it was decided that the program of research related to nonboiling transient heat transfer need not be as inclusive as previously planned for FY 1971, but to plan instead on completing the experimental phase of the program during FY 1972. This decision was also influenced by considerations of LMFBR priorities and available resources, including an evaluation of experimental facilities.

Attempts were then made to apply the new prediction methods to specific transient heat-generation problems, i.e., cases in which the heat flux into the fluid and the temperature must be predicted. These attempts included more realistic mathematical formulations of physical conditions at the duct inlet. However, as before, the current computer program resulted in numerical instabilities: It is still unknown whether these instabilities are attributable to the programming techniques, or are characteristic of the unusual mathematical formulations that result when applying the new prediction methods.

An effort is being made to derive alternate improved prediction methods based on analysis of wall-temperature-specified models. The current prediction methods were derived on the basis of wall-heat-fluxspecified models. 
3. Liquid-metal Heat Transfer in Pin Bundles. T. Ginsberg (Last reported: ANL-7776, p. 83)

The objectives of this activity are to: (1) develop and evaluate analytical models for predicting steady-state temperature distributions in LMFBR fuel assemblies, and (2) develop empirical data and correlations for use in the analytical models. The latter objective includes development of a model that describes the interchannel-mixing mechanism in fuel assemblies containing helical-wire-wrapped fuel elements.

\section{a. Preparation of Apparatus}

The design of the test section for the interchannel-mixing experiments was reviewed, and modifications were made accordingly. Fabrication specifications and test procedures were prepared.

Bench tests were performed on the electrolyte conductivity apparatus to be used in the mixing experiments. Solutions of known salt $(\mathrm{NaCl})$ concentrations were prepared in the ranges anticipated in the experiments, and their respective conductivities measured, using Beckman conductivity cells. The results indicated that the concentrations can be measured with an error of less than $1 \%$.

4. Electron Bombardment Heater (EBH) Development. R. D. Carlson (Last reported: ANL-7765, p. 71)

Electron-bombardment (EB) heaters are being developed to supply heat fluxes greater than $1.5 \times 10^{6} \mathrm{Btu} /(\mathrm{hr})\left(\mathrm{ft}^{2}\right)$ to liquid metals. These heaters will be used as backups to resistance-type heaters in various heattransfer and reactor-safety experiments pertinent to the LMFBR Program. Current effort is directed toward EB pin-type heater test sections containing simulated LMFBR fuel pins for use in these experiments. Such heaters $\left(1 / 4\right.$-in. OD $\times 24$ in. long) have supplied heat fluxes up to $2.3 \times 10^{6} \mathrm{Btu} /$ $(\mathrm{hr})\left(\mathrm{ft}^{2}\right)$ to water.

\section{a. Preparation of Single Pin}

An anode-cathode configuration for testing 1/4-in.-OD x 18-in.long pins has been assembled in the vacuum chamber. The cathode is a 0.070 -in.-dia rod of pure tungsten. A tensile load of $3 \mathrm{lb}$ is applied to this cathode to maintain concentricity in the anode tube. The sodium annulus and water-cooling coil of the chamber have been satisfactorily checked for leaks preparatory to sodium-filling operations.

An analysis is in progress to determine the magnetohydrodynamic characteristics of $\mathrm{EB}$ heaters versus resistance-type heaters under various experimental conditions. The results will be used to develop designs that will minimize flow perturbations caused by interaction between the liquid metal and the magnetic field generated by the electrical heaters. 


\section{Engineering Mechanics. G. S. Rosenberg (02-099)}

Stress-analysis methods based on various continuum theories are developed to resolve reactor design problems that are not amenable to conventional engineering approximations or direct numerical computations employing general-purpose computer programs. Studies of structure-fluid interaction dynamics also are conducted to develop new methods of analysis and testing that can be used by designers to minimize the potential of detrimental flow-induced vibration of reactor components.

1. Structure-fluid Dynamics. M. W. Wambsganss

a. Near-field and Far-field Flow Noise. M. W. Wambsganss (Last reported: ANL-7753, p. 133)

An equation for rms response has been developed, based on the experimentally-supported assumption that the intensity or magnitude of the near-field mean-square spectrum $\phi_{0}(U)$ is approximately constant for a Strouhal number $\mathrm{S}\left(=\mathrm{fd}_{\mathrm{h}} / \mathrm{U}\right.$ ) less than 2.5. (U is mean axial flow velocity, $f$ is frequency, and $d_{h}$ is hydraulic diameter.) Evaluation of the equation requires a mathematical characterization of the intensity of the near-field spectra in the low-frequency range of interest ( $f<300 \mathrm{~Hz}$ ). Because of difficulty in making the required measurements, attempts at scaling the intensity with mean axial flow velocity have not been very successful; additional study is required.

To gain insight into the flow-velocity dependence of the intensity, the equation for rms response was solved for the intensity $\phi_{0}(U)$ in terms of

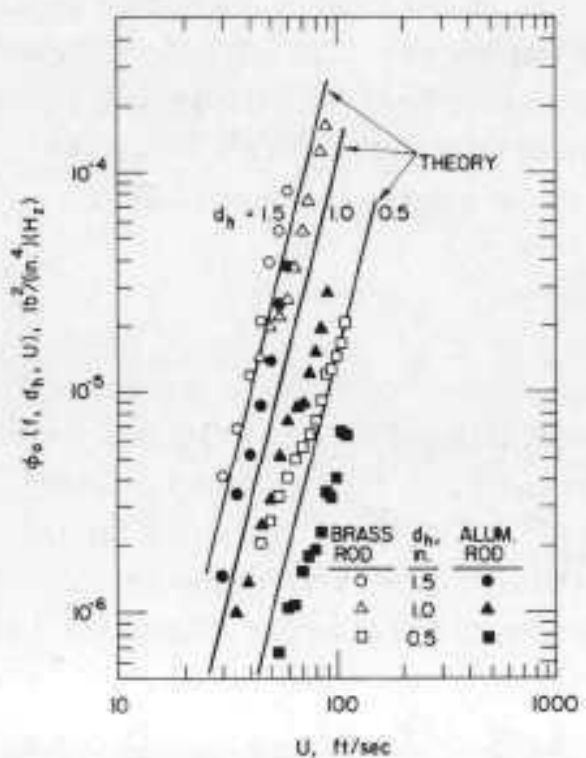

Fig. II.1. Intensity of Near-field Mean-square Spectra resonant frequency $f_{1}(U)$, damping $\zeta_{1}(U)$, and rms response $y_{r m s}(x, U)$. In the experimental study of damping, the quantities $f_{1}, \zeta_{1}$, and $\mathrm{y}_{\mathrm{rms}}(l / 2, \mathrm{U})$ were measured. Knowing the dimensions of the system and material properties of the rod, $\phi_{0}$ was computed for two rod materials (brass and aluminum) and three hydraulic diameters at various mean axial flow velocities.

The results (see Fig. II.1) show the intensity to be approximately proportional to the mean axial flow velocity raised to the fourth power. As expected, the intensity is strongly dependent on the hydraulic diameter, which, in turn, is a measure of the turbulence for a given flow velocity and fluid, Considering the small magnitude of the quantities involved and the difficulties in making the associated measurements, the agreement between the computed 
intensities and those measured with an instrumented test element (see ANL7726 , July 1970 , p. 134) is very good.

The data plotted on Fig. II.1 can be approximately correlated by the empirical relationship

$$
\phi_{0}\left(\mathrm{~d}_{\mathrm{h}}, \mathrm{U}\right)=\mathrm{K}^{2} \mathrm{~d}_{\mathrm{h}}^{3} \mathrm{U}^{4},
$$

where

$$
\mathrm{K}^{2} \approx 3.2 \times 10^{-10}\left(1 \mathrm{~b}^{2}\right)\left(\mathrm{sec}^{5}\right) /\left(\text { in }^{4}\right)\left(\mathrm{ft}^{7}\right) \text {. }
$$

Equation 1 is tentative, since it is based on limited results (e.g., $0.5<\mathrm{d}_{\mathrm{h}}<$ $1.5)$; additional investigation is planned.

b. Mathematical Modeling of Flow-induced Vibration. M. W. Wambsganss and S. S. Chen (Last reported: ANL-7737, p. 141, Aug 1970)

A draft of a design guide on parallel-flow-induced vibration of flexible rods has been completed. The basic analysis assumes a pressure field that is homogeneous in space. The relationship developed is based on the results of a parameter study. It is valid for component systems which have parameters in the range specified by the study and which can be approximated as simply supported or fixed-fixed beams. The expression is given in terms of rod natural frequency, damping factor, and the intensity of the near-field spectrum in the low-frequency range; all three are functions of mean axial flow velocity. Using empirical relationships for the flow-velocity dependences of damping and intensity of the mean-square pressure, an empirical equation for $\mathrm{rms}$ rod response is presented. The design guide is being reviewed preparatory to publication.

A draft of a paper describing a more general mathematical model for parallel-flow-induced vibration of fuel rods also has been completed. Analysis is presented for rods with arbitrary end conditions. Numerical results are computed for fixed-fixed rods and cantilevered rods. Calculated values of natural frequency, dependence of damping on flow velocity, and rms rod displacement are in good agreement with experimental results.

c. Damping and Virtual Mass. M. W. Wambsganss and S. S. Chen (Last reported: ANL-7776, p. 86)

In practice, the added mass of a cylindrical rod is frequently assumed to be equal to the mass of the fluid replaced by the rod. This is true for a rod submerged in an infinite fluid. In the fuel bundle, the adjacent rods and the duct wall will affect the added mass. To understand the boundary effect, the added mass of a cylindrical rod submerged in a fluid annulus was analyzed. 
Consider a cylindrical rod of length $\ell$ and radius $D$ vibrating in a fluid-filled circular shell with inside radius d. Further assuming that the rod motion is sinusoidal, it is found that the added mass is given by

$$
\mathrm{M}=\mathrm{C}_{\mathrm{M}} \pi \mathrm{D}^{2} \rho,
$$

where $\rho$ is fluid density, and $C_{M}$ is given by

$$
C_{M}=\frac{\left[b J_{0}(b)-J_{1}(b)\right] Y_{1}(a)-\left[b Y_{0}(b)-Y_{1}(b)\right] J_{1}(a)}{\left[b Y_{0}(b)-Y_{1}(b)\right]\left[a J_{0}(a)-J_{1}(a)\right]-\left[b J_{0}(b)-J_{1}(b)\right]\left[a Y_{0}(a)-Y_{1}(a)\right]},
$$

where

$$
\begin{aligned}
& a=\frac{\omega D}{2 c}, \\
& b=\frac{\omega d}{2 c},
\end{aligned}
$$

$c$ is the wave velocity in fluid, $\omega$ is the vibration frequency, and $J_{n}$ and $Y_{n}$ are Bessel functions of order $n$ and of the first and second kind, respectively.

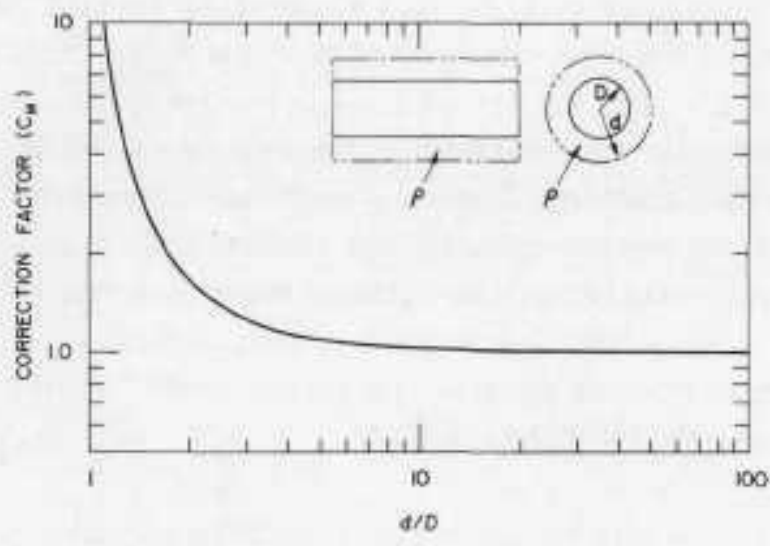

Fig. 11.2, Correction Factor as a Function of Radius Ratio d/D for $a=0,001$
It is seen from Eq. 2 that the correction coefficient $\mathrm{C}_{\mathrm{M}}$ depends on the frequency, wave velocity, and the diameters of the rod and the wall. Results of computation for $a=0.001$ are plotted in Fig. II.2.

The correction factor $C_{M}$ is insensitive to the values of a. In general, a is a small parameter; therefore we may assume that $a \approx 0$; i.e., the fluid is incompressible. But $C_{M}$ depends on the ratio $d / D$. When $d / D$ is small, $C_{M}$ is very large, and as the value of $d / D$ increases, $C_{M}$ approaches unity. Consequently, the boundary effect is important only when the rod is relatively close to the wall, i.e., for $d / D<3$. This is the case in many typical reactor applications.

The experimental study of the flow-velocity dependence of system damping is continuing. Brass and aluminum elements with both fixedfixed and cantilevered supports have been tested for three different hydraulic diameters. The tests involved measurement of natural frequencies, damping, and rms displacement for a range of mean axial flow velocities. Results are in qualitative agreement with expectations based on theoretical considerations. Among other things, the data are being used to evaluate the mathematical model. 


\section{d. Preparation of Crossflow Test Chamber. H. Halle (Last reported: ANL -7776, p. 85 )}

Fabrication of the test chamber, the flow channels, and the test fixture was started. Supports to mount anemometer probes inside the test chamber were designed. Design efforts for the test-chamber support structure were started.

Fabrication of a 5 -ft-long spool piece (containing a flowstraightener section) was completed; it is to be installed upstream of the flowmeter in the Structural Dynamics Test Loop. Updating of the 1oop operating procedure and of the flow and instrument schematic was completed.

The initial wind-tunnel experiments indicated that a steel element specifically designed for water service was too stiff to provide sufficient response to air excitation. Consequently, a test element capable of higher vibration amplitudes was constructed. This was done by suspending a plastic test-element body on coaxial steel wires extending from both ends. Tensioning of the wire permitted adjustment of the natural frequency. Upon exposure to airflow, very large amplitudes were observed at flow rates generating resonance. The increased response of the element was due, in part, to a decreased suspension-spring constant and to lower damping of the wire suspension, compared to the steel tube suspension system initiallyused.

Real-time spectrum analysis of the anemometer signal in the wake of the cylinder indicated a fairly linear relationship between the vortex shedding frequency and the "free-stream" airflow velocity upstream of the cylinder. The analysis also indicated the existence of synchronization between the cylinder and vortex shedding frequencies within a certain flowvelocity range. These results were obtained by monitoring: (1) the optical transducer following the transverse vibrations of the cylinder, and (2) the downstream anemometer in the flow.

e. Tube-stop Impact. B. L. Boers (Last reported: ANL-7776,

Hardware has been fabricated for the experimental investigation of beam-stop impact phenomena.

The effects of nonsymmetrically located stops are being evaluated analytically. This work has progressed to the point of calculating the eigenvalues and mode shapes of a clamped-clamped beam with a stop at any specified position along the beam length. 


\section{PUBLICATION}

Vibrations and Stability of a Tube Conveying Fluid

S. S. Chen and G. S. Rosenberg ANL-7762 (Mar 1971) 


\section{INSTRUMENTATION AND CONTROL}
A. Instrumentation Development for Instrumented Subassembly. T. P. Mulcahey $(02-024)$

Instruments for in-core measurement of flow, fuel and coolant temperatures, and fuel-pin pressure are being developed consistent with requirements defined by the EBR-II Instrumented Subassembly test program. Development encompasses instrument design, performance analysis, fabrication, and tests leading to specifications and quality-assurance procedures for procurement from commercial vendors.

1. Euel-pin Thermocouples. A. E. Knox (Last reported: ANL-7798, p. 46)

Capsule No. 1 containing Fuel Center Thermocouple No. 1 (FCTC 1), which was irradiated in EBR-II Test ISA XX01, was sectioned by EBR-II Idaho personnel. Some sections were taken in the region of FCTC 1. Metallographic examination is in progress.

\section{Coolant Thermocouples. A. E. Knox (Not previously reported)}

Six commercially procured subassembly outlet coolant thermocouples (three each from separate vendors) were shipped to HEDL. Five units are to be used in HEDL P-17A Experiment in EBR-II Test XX04 ISA, with one unit serving as a spare. All units were selected on the basis of exceptional as received conformance to loop resistance, insulation resistance, calibration, and radiography.

Before shipment, loop and insulation resistances were remeasured, and step response times were determined by plunging the thermocouples in hot water; pertinent measured characteristics for each unit were included.

\section{B. FFTF Instrumentation Development. \\ R. A. Jaross $(02-025)$}

Prototypes of permanent-magnet, eddy-current, and magnetometer probe-type flowsensors are being designed, fabricated, and flowtested to establish detailed specifications and design for the FFTF permanent-magnet probe-type flowsensor, and to provide technical guidance to ensure competence in commercial fabrication of probe-type flowsensors. Supporting tests are conducted to determine long-term thermal effects on permanent-magnet materials of interest, and to study the effects of simulated fission-gas release on flowsensor response.

Flowtests and certain supporting tests are conducted in existing facilities (CCTL or CAMEL); new specialized facilities are designed and constructed, as required. 
1. Permanent-magnet Probe-type Flowsensors. F. Verber (Last reported: ANL-7798, p. 47)

A work plan for the applied long-term temperature stability testing of Alnico VIII was completed and is being reviewed.

Data on the fundamental temperature-stability tests of Alnico magnets were not taken in April. The test cycle has been changed from once per month for the full complement of magnets, to once each $1000 \mathrm{hr}$.

2. Eddy-current Probe-type Flowsensors. J. Brewer (Last reported:

During concurrent testing of the FFTF Mark-II fuel assembly and Eddy-current Probe No. 12 in the CCTL, an improvement in simulated fission-gas bubble signal output from Probe No. 12 was obtained by using amplitude detection. Since it was desired to observe only the bubble signal, the flow signal was nulled out with the balance control. The remaining signal output was amplified and then half-wave rectified. A $0.5-\mu \mathrm{F}$ capacitor was connected across the rectified output. The charging time constant was about $10 \mu \mathrm{sec}$. The discharge time constant was approximately $0.5 \mathrm{sec}$, which was more than adequate for chart recording.

The gain characteristic (A) of the amplifier was: 804 at $1000 \mathrm{~Hz}$, 735 at $500 \mathrm{~Hz}, 377$ at $100 \mathrm{~Hz}$, and 239 at $50 \mathrm{~Hz}$. It is expected that a more suitable bandpass amplifier would yield improved results.

Previous data, obtained with a spectrum analyzer, have shown that, for the current test conditions, most of the gas-bubble signals are recorded in the range $50-300 \mathrm{~Hz}$. The test conditions were as follows:

$\begin{array}{ll}\text { Excitation current: } & 500 \mathrm{~mA} \text { at } 1000 \mathrm{~Hz} \\ \text { Average sodium velocity: } & 16.4 \mathrm{ft} / \mathrm{sec}(525 \mathrm{gmm}) \\ \text { Sodium temperature: } & 1100^{\circ} \mathrm{F} \\ \text { Display instrument: } & \text { Storage oscilloscope } \\ \text { Horizontal sweep: } & 2 \mathrm{sec} / \mathrm{cm} \\ \text { Scope vertical sensitivity: } & 1.0 \mathrm{~V} / \mathrm{cm}\end{array}$

Argon gas was injected with a hand-operated syringe, and the injections were timed with a stopwatch.

The oscilloscope traces (see Fig. III.1) show the normal sodiumturbulence modulation of the flowsensor output signal before gas injection, and typical bubble signals in response to various average gas-injection rates. Scope timing was poor in Fig. III.1(e), and part of the bubble signal 


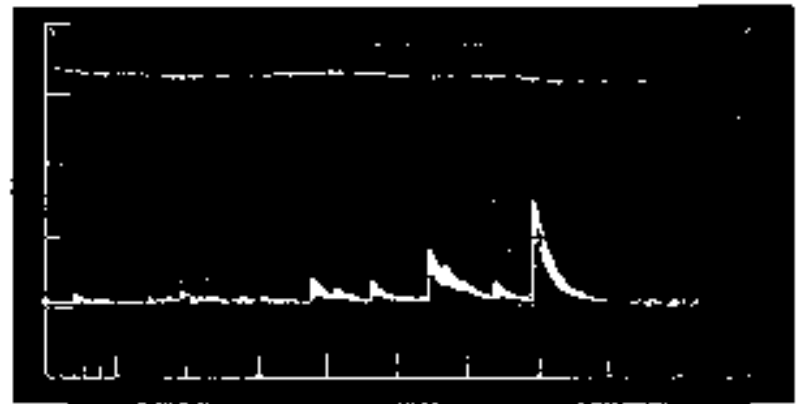

(O) DLAING GAS NJEETLON 5 EC/ BeC

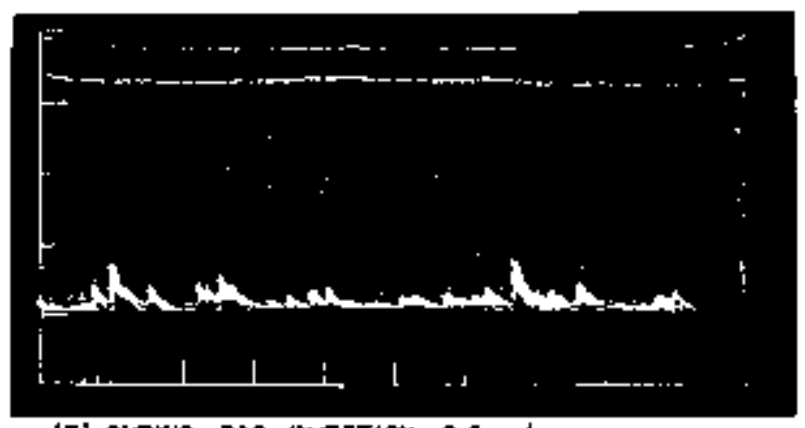

(D) OURING GAS IHECTION $2 \mathrm{SCC} / \mathrm{LAC}$

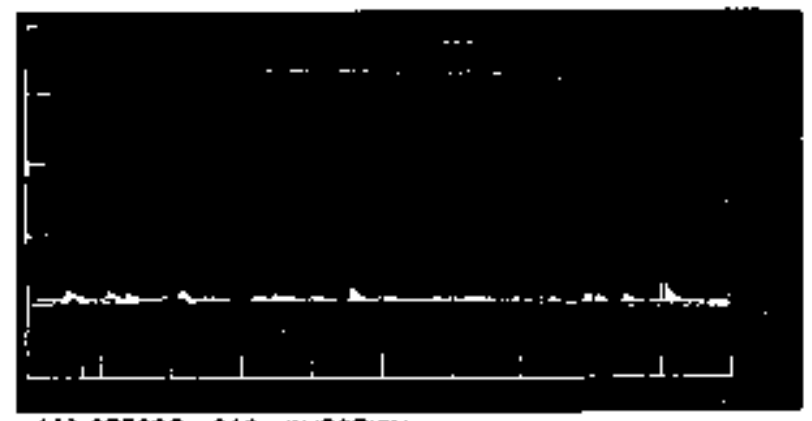

(A) ESFOAE GAS INJECTION

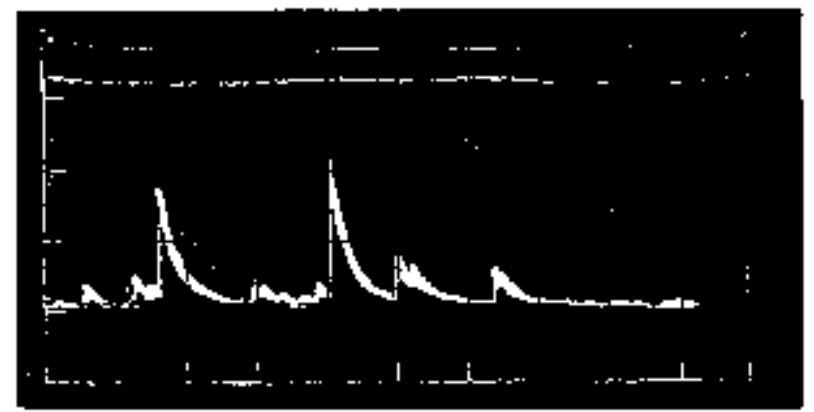

(a) GuAING GAS INWECT1ON Dac/rec

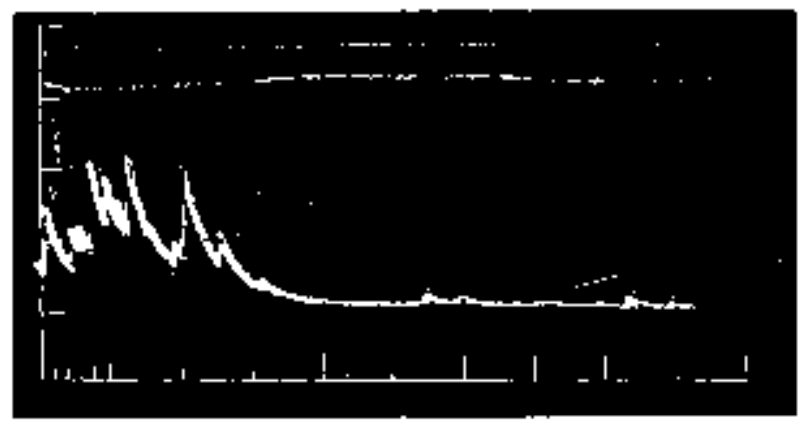

(E) DUFING GAS INJECTION \$OCe/sec

FJg. III.1

Gas-bubble \$1gnals Obtained with Eddy-curtent Probe No, 12 in the CCTL. Using Flow-signal Suppression and Half-wave Ampitude Detection. ANL Neg. No, 113-\$762. 
was missed. The significance of this test series is the visibility of $g$ as bubble signals at the low injection rate of $2.5 \mathrm{cc} / \mathrm{sec}$.

As in previous gas-injection tests performed with a spectrum analyzer. the results of this test series were recorded on magnetic tape to facilitate more rigorous analyses of the bubble signals.

After removal from the CCTL. Probe No. 12 was cleaned of residual sodium preparatory to crosstalk tests with Probe No. SSX-6-Z (see ANL7765, p. 25) in a simulated sodium environment. In these tests, both probes were positioned parallel to each other. with spaces of $i \frac{1}{2}, 2,3$. and 4 in. between probe axes. The annulus around Probe SSX-6-Z included ambient room temperature air, and $1 / 4-$ and $t / 2$-in.-thick aluminum to sinulate sodium. Each test consisted of exciting the primary of Probe No. SSX-6- 2 and reading the secondary differential voltage of Probe No. 12, with one secondary coupled more closely than the other to the primary as a worst possible case. The excitation current was $500^{\circ} \mathrm{mA}$ at $1000 \mathrm{~Hz}$ and $80^{\circ} \mathrm{F}$.

The results, in mV rms, are listed below.

\begin{tabular}{|c|c|c|c|}
\hline $\begin{array}{l}\text { Space between } \\
\text { Probe Axes, in. }\end{array}$ & Air & $1 / 4-\mathrm{in}, \mathrm{Al}$ & $1 / 2$-in. Al \\
\hline 4 & 0.446 & 0.036 & \\
\hline 3 & 1.43 & 0.143 & \\
\hline $\begin{array}{l}2 \\
1 \frac{1}{2}\end{array}$ & $\begin{array}{r}6.43 \\
17.40\end{array}$ & 0.625 & $\begin{array}{l}0.107 \\
0.500\end{array}$ \\
\hline
\end{tabular}

It is evident that in the FETF configuration in sodium, the crosstalk will be negligible.

3. Magnetometer Probe-type Flowsensors. D. E. Wiegand (Last reported: ANL-7798, P. 4B)

Recent tests have demonstrated that the secondary winding of the fluxgate magnetometer can be made to serve a dual function: (a) sensor for the second harmonic carrier. and (b) feedback element. In the latter function, a current from the demodulated carrier output is fed back into the primary coil in the form of a magnetic field in opposition to the signal field. The result is a reduction in the effects of variations in fluxgate sensitivity and of changes in gain in the entire amplifying chain, including the preamplifier, tuned amplifier, phase-sensitive detector, and power amplifier.

The feedback function was demonstrated with a fluxgate similar to that used in Magnetometer Flowsensor No. 2 (MFS-2) and the lock-in amplifier equipment. In one teat to simulate temperature effects on magnetic properties of the fluxgate core, the primary current was varied over a range that resulted in a change of $20 \mathrm{~dB}$ in open-loop sensitivity. The variation in 
closed-100p sensitivity was reduced to a mere $0.2 \mathrm{~dB}$. In another test, a gain change of $40 \mathrm{~dB}$ in the amplifying chain resulted in change of only 0.1 dB in closed-loop sensitivity.

These tests indicate that the feedback system will effectively eliminate wide variations in the fluxgate core, including temperature effects and aging short of complete loss of ferromagnetic properties. This, in turn, will eliminate the need for precision-type signal-conditioning equipment and thus reduce significantly the cost per signal channel.

Magnetic imbalance effects, discussed in ANL-7783, p. 24, originate outside the feedback loop and must be controlled through appropriate design of the sensor element.

$$
\text { C. Neutron-detector Channel Development. }
$$

Development under contract with industrial vendors is focused on complete neutron-detection channels, including cabling and circuitry to transmit, process, and display information from high-and low-temperature ionization chambers and self-powered detectors in out-of-core and in-care Fegions of LMFBR's. Advanced circuitry for intermediate- and wide-range applications, and high-temperature neutron detectors are procured comme $x$ cially; vendor tests are administered; and parameter determination and operational tests are performed in ANL and EBR-II nuclear-instrument test facilities.

1. Intermediate- and.Wide-range Systems. G. F. Popper (Last reported: AN $\bar{L}-7705$, June 1970 , P. 42)

Bids on a second-generation Logarithmic Mean Square Voltage (MSV) Intermediate-Range Neutron Flux Monitoring System have been received and are being reviewed. More definitive quality-asaurance requirements for the channel were established.

A meeting was held with WARD to obtain additional information on MSV aystems for the FFTF.

Routine processing of performance data from the Gulf General Atomic Ten Decade and the Milletron Wide-Range Neutron Flux Monitoring Systems was continued. Both systems are being evaluated in the EBR-II.

2. Out-of-core Detectors and Cables. G. F. Popper, A. Hirsch, and V. J. Elsbergas (Last reported; ANL-7783, p. 26)

Atternpts are being made to complete the neutron-detector testing programs at both Westinghouse and Reuter-Stokes. 
Analysis of collection-time measurements made on detectors with mineral-insulated cables is continuing.

Reuter-Stokes and Westinghouse cable assemblies are being oventested up to $850^{\circ} \mathrm{F}$ and consistent with RDT Standard F3-39.

An approval-in-principle was prepared for the overall neutrondetector cable-assembly test program to be conducted in the EBR-II NITF. Experimental procedure EX 49-70 was subsequently modified to zllow detectors to be installed in both the $O-1$ and $J-2$ thimbles in EBR-IL. Data packages for the Reuter-Stokes RSN-286 and the Westinghouse WX-31384 detectors were revised accordingly.

The WX-30950 Compensated Iontzation Chambers were received from Westinghouse, and plans were initiated for installing one of these units in the EBR-II $\mathrm{J}-2$ thimble. One of the redesigned and repaired $W X-3184$ detectors also was received from Westinghouse. Two of these units had previously failed during shipment from ANL to ldaho and handling at ANL, respectively.

Analysis of data from the Reuter-Stokes RSN-286 M402 detector is in progress. This detector is installed in the EBR-II O-l thimble.

$$
\text { D. Advanced Technology Instrument Development. }
$$

New and unique instrumentation is being developed to diagnose per formance and detect abnormalities in LMFBR cores. Included are sensors and techniques for acoustical detection of sodium-coolant boiling. monitoring of flowrate-related phenomena that could detect imbalances between cooling and power, and the measurement of vibrations that might disturb overall reactor stability.

1. Boiling Detector. T. T. Anderson

a. Acoustic Method

(1) Irradiation and Resistance Tests on Piezoelectric and Insulator Materials. T. T. Anderson (Last reported: ANL-779B. P. 51). Polished disks of lithium niobate and sapphire, which were recently bombarded with deuterium ions, have been subjected to extensive optical examination in the Solid State Science Division at Argonne. In the sapphire specimens, gas blisters formed at a depth of 1.5 microns are growing in size, suggesting a postirradiation segregation of the gas (see Fig. III.2(a)). In the lithium niobate specimens, fractures are evident in the most heavily bombarded zones (see Fig. III.Z(b)). The fractures appear to be oriented along the z-axis, 

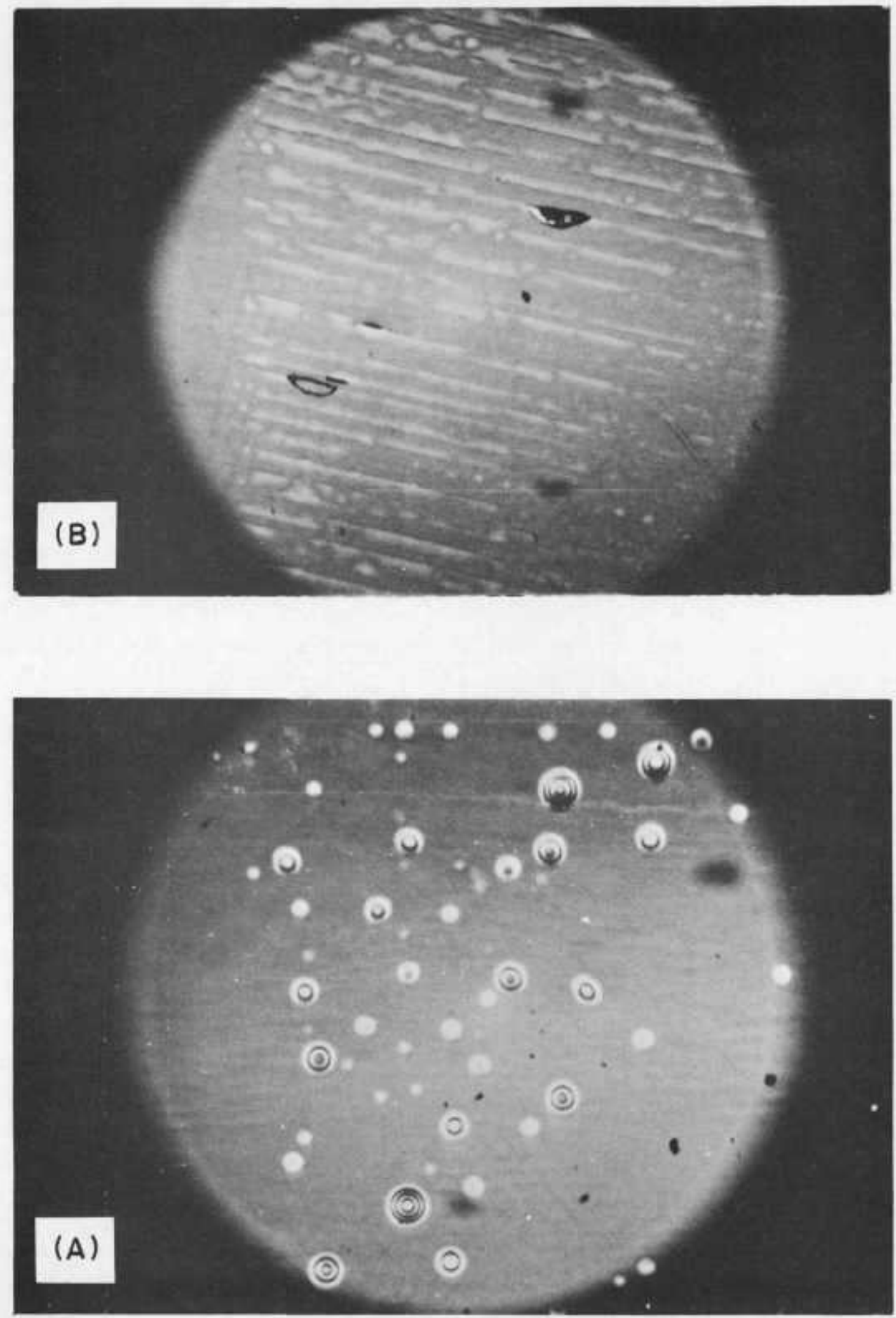

Fig. III.2. (a) Blisters on Sapphíre and (b) Fractures in $60^{\circ} \gamma$-cut Lithium Niobate Disks Which Haye Developed Since Bombardment with $140-\mathrm{keV}$ Deuterium Ions to a Dose of $0.07 \mathrm{C} / \mathrm{cm}^{2}$. ANL Neg. No. $113-3763$. 
The effects of neutron damage to lithium niobate also are being investigated. One encapsulated lithium niobate crystal was irradiated to a fluence of $6.5 \times 10^{i 7}$ nut thermal in the core of the CP-5 reactor. Special care was taken in the capsule design to disgipate an estimated heat generation of $4.5 \mathrm{~W}$ in the $0.3-\mathrm{g}$ erystal. This was done by positioning the crystal between spring-loaded, polished aluminum plates, which, in turn, were heat-sinked to the capsule wall.

Apparently, the heat-sink assembly was successful. Fostmortem examination of the assembly in the Argonne Chemistry Division Hot-Lab Facilities revealed that the lithium niobate crystal was lightly colored. This indicated that the temperature had remained well below $200^{\circ} \mathrm{C}$, at which temperature annealing of the erystal would have been complete. Measurements of force-to-charge (d) coefficients and electromechanical resonances showed no significant changes in piezoelectrit properties of the crystal.

In view of these results, a second irradiation of the same crystal to $10^{19}$ nvt thermal has been scheduled.

(2) Development of High-temperature Detector, A. P. Gavin (Last reported: ANL-7798, P. 52). Two more senoors of the HT-5 Series (HT-5-4 and HT-5-7) were cycled to $1200^{\circ} \mathrm{F}$ in a furnace test facility. These sensors feature $36^{\circ} \mathrm{Y}$-cut lithium niobate crystals, platinum foil electrodes, stainless steel housings, and 3-ft lengths of aluminum-oxideinsulated, $1 / 8-i n$ - $O D$ stainless steel-clad coaxial cable with a stainless steel conductor. Each sensor is backfilled with oxygen at $150 \mathrm{~mm} \mathrm{Hg}$.

Each sensor was cycled, using the newly acquired charge amplifier (with a filter to eliminate low-frequency noise) to record response to sound pressure in the furnace. The response was uniform and the noise level very low over the entire temperature range.

The procedure for connecting the central platinum foil electrode to the central stainless steel conductor of the coaxial cable has been modified to prevent recurrence of defective connections experienced in sensors HT-5-6 and HT-5-8. This procedure also provides for alignment of the central electrode to eliminate cracking of the lithium niobate crystals due to unequal pressure during assembly.

The first sensor (HT-5-9) assembled to this procedure developed a short between the central electrode and one outer platinum cushion. This fault will be eliminated by reducing the size of the cushion and decreasing the tolerance on the ID of the quartz alignment sleeve.

The basic dimensions of the sensor have been modified slightly to simplify machining of parts and to facilitate fabrication. Sensors 
of this type will comprise the HT-6 series. A new assembly and welding fixture has been built to accommodate the dimensional changes. Equipment for evacuating, backfilling with clean dry oxygen, and crimping the vent tube of each sensor has been assembled. Experiments to establish the procedure for sealing the vent tube are in progress.

Procedures are being revised to reflect these and other changes in design and assembly as they occur. All parts are being fabricated from certified material. Procedures for recording actual dimensions and material sources for each sensor are being established.

(3) Test of High-temperature Detectors in Water, Furnace, and Sodium. A. P. Gavin and T. T. Anderson (Last reported: AN L-7798, p. 52). Furnace test procedures are being improved constantly. The objective is a reproducible standard procedure for evaluating all hightemperature acoustic sensors in air.

A circuit has been designed for continuously monitoring sensor resistance during furnace tests, despite a four-decade change in resistance. In operation, resistance is sensed by the voltage induced in the sensor from a low-level current source (100 pA ac). The circuit has been checked out satisfactorily, using resistors to simulate sensor resistance; and construction has started on a module for use in the furnace test facility.

2. Flow Monitor. T. T. Anderson
a. Two-thermocouple Method.
A. E. Knox

(1) Temperature Variations of Coolant Sodium at Outlet of EBR-II ISA (Last reported: ANL-7798, p. 53). Attempts to record noise and temperature fluctuations in EBR-II Test ISA XXO2 during a reduced power ( $25 \mathrm{MW})$ and flow $(50 \%)$ condition were precluded when fission products in the cover gas exceeded permissible levels, necessitating reactor shutdown. Plans are to perform these recordings on ISA XX04 (HEDL Experiment Pl7-A) in late 1971. Time constants for the inlet and outlet coolant thermocouple wires in ISA XX04 have been measured.

3. Vibration Sensor. T. P. Mulcahey

a. Out-of-pile Tests of Sodium-immersible Commercial Transducers. G. A. Forster (Last reported: ANL-7705. June 1970, p. 155)

As reported in ANL-7705, one of the accelerometers purchased to earlier specifications for use in sodium up to $1150^{\circ} \mathrm{F}$ was to be evaluated concurrent with flowtesting of the FFTF Mark-II fuel assembly in CCTL. However, the accelerometer failed during initial heat-up of the loop. The 
specifications were then revised to include better quality control and performance testing up to $1200^{\circ} \mathrm{F}$, and requests for bids were issued. The objective is to procure accelerometers for evaluation during flowtesting of the FFTF Mark-IIA assembly.

Quotations were received from two vendors; however, neither vendor could meet the specifications completely, and there was a marked difference in delivery dates. Vendor No. 1 quoted on units for operation at $1150^{\circ} \mathrm{F}$, because of a basic limitation on their piezoelectric material. Three units are being procured, with delivery scheduled for June 1971. Each unit will be equipped with ANL-supplied triaxial cables.

Vendor No. 2 cannot use the triaxial cables on their units; also, the delivery schedule is early August. Purchase of these units is pending resolution of technical and funding problems. 


\section{SODIUM TECHNOLOGY}

\section{A. Monitoring and Sampling Systems Development and Reactor Proof-test (02-021)}

A national program has been instituted for developing, testing, and establishing commercial availability of meters for the sodium systems of FFTF and LMFBRs. Argonne is coordinating the national program as well as participating in it. In this program, meters for oxygen, carbon, and hydrogen and a leak detector for steam generators are being developed and characterized. Meter modules that provide flow and temperature control are being developed for FFTF; these modules will be tested at EBR-II.

Recently the Advisory Group of the National Meter Program met to review the progress made in the program and to establish plans for fieldtesting standardized on-line impurity meters during FY 1972. At another meeting, the expected needs of the LMFBR program for meters and modules were described to potential manufacturers, and purchase specifications were discussed. All the manufacturers participating in the meeting indicated considerable interest in becoming suppliers for the meters, components, or modules.

1. Oxygen Meter. J. T. Holmes, V. M. Kolba, and J. M. McKee (Last reported: ANL-7798, p. 54)

A program has been established that is expected to result in the commercial availability of improved electrochemical oxygen meters by July 1971 . ANL is coordinating efforts at WADCO and the Zirconium Company of America (Zircoa) to produce improved solid electrolyte tubes (isostatically pressed thoria-7.5 wt \% yttria) for the meters and is also coordinating efforts at Westinghouse and Brookhaven National Laboratory to evaluate the material by performance tests in sodium. Two cells with electrolyte tubes produced at WADCO have been operated for more than $2000 \mathrm{hr}$ at $370-485^{\circ} \mathrm{C}$. Most of the test time was at the higher temperature. An acceptable tube life is expected at the lower operating temperature of $370^{\circ} \mathrm{C}$, which has been selected for the oxygen-meter characterization program.

A Westinghouse gas-reference oxygen meter with a WADCO electrolyte tube was installed and operated up to $425^{\circ} \mathrm{C}$ in the sodium loop of the Oxygen Meter Calibration Apparatus (OMCA). A total of $\sim 1350 \mathrm{hr}$ of satisfactory operation was accumulated before a scheduled shutdown. These tests showed that the high-purity electrolyte material produced at WADCO is more resistant to attack by sodium and gives better electrical performance at the low oxygen levels typical of reactor sodium systems than previously available materials. Preliminary information on tube life in sodium is encouraging. 
The first electrolyte tubes produced by Zircoa using WADCO process specifications appeared to be satisfactory in corrosion tests at WADCO and in tests of the electrolytes in meters at Westinghouse Advanced Reactor Division (WARD). However, slight differences in purity and in performance between the Zircoa tubes and those produced by WADCO indicate that batchto-batch differences in properties may be expected. Twelve Zircoa tubes from four batches will be incorporated into oxygen meters at Westinghouse, and these will be used for meter-characterization tests at ANL.

The performance of 10 of these standard meters will be determined over an extended period of time. (A matching set of 10 meters having electrolytes from the same Zircoa sintering batches will be tested at WARD.) In the ANL tests, the 10 meters will be connected in series with a specimenequilibration module, which will be used to calibrate the oxygen meters by the vanadium-wire equilibration method,* and with a cold trap to control the oxygen content of the sodium. Construction of the module and the supporting sodium system is in progress and is expected to be completed by the time the meters are received.

2. Hydrogen Meter. J. T. Holmes and D. R. Vissers (Last reported: ANL-7798, P. 55)

Development work is being continued on a hydrogen-activity meter having a direct pressure readout of the equilibrium hydrogen pressure above the sodium. In recent studies, the sensitivity of the hydrogen meter was evaluated. The results showed that the meter is capable of measuring hydrogen levels in sodium of $0.1 \mathrm{ppm}$ or less. During these studies, known quantities of hydrogen were added through a nickel membrane into a sodium loop, and material balances of the hydrogen were obtained from the hydrogenmeter measurement. By this means, the hydrogen concentration in the sodium was increased from about 0.05 to $0.5 \mathrm{ppm}$ in increments of 0.1 and $0.2 \mathrm{ppm}$. Approximately $80-90 \%$ of the hydrogen added was accounted for by the increases in concentration measured by the meter. Studies were also carried out on the solubility of hydrogen in sodium by adjusting the coldtrap temperature between 110 and $190^{\circ} \mathrm{C}$ and measuring the hydrogen concentration in the sodium with the meter. The data obtained were self-consistent and agreed with an extrapolation of data obtained by Meacham et al **

An evaluation was made of the potential hydrogen losses on removing reactor cover-gas samples through a vapor trap. This evaluation indicated that $<1 \%$ of the hydrogen content of the gas would be lost if equilibrium were maintained between the gas and the condensed sodium during the cooling process.

*Sodium Technology Quarterly Report: January, February, March 1970, ANL/ST-2, pp. 2-4 (July 1970). **S. A. Meacham, E. F. Hill, and A. A. Gondus, The Solubility of Hydrogen in Sodium, APDA-241 (1970). 
3. Carbon Meter. J. T. Holmes and C. Luner (Last reported: ANL-7798, p. 55)

The goal of this work is a commercially available on-line carbon meter that will indicate the probability of significant carbon transfer taking place in R\&D and LMFBR systems; this meter will be incorporated into a prototype module containing the necessary flow and temperature control devices (see Sect. 4, below). Present work is directed toward testing and improving the United Nuclear Corporation (UNC) diffusion meter, which measures the rate of diffusion of carbon through an iron membrane. Two diffusion-type carbon meters are being operated in a flowing sodium system (Test and Evaluation Apparatus, TEA): one is a UNC meter with a stainless steel housing; the other is an ANL modification, which has a molybdenum liner in the high-temperature housing and in which all hot surfaces in contact with collected carbon-bearing gas are copper-plated.

Improved operation of both carbon meters has resulted from revisions in the carbon detection systems; $*$ these revisions allow instrumental compensation for trace carbonaceous impurities in the decarburizing gas. Measurements taken over a one-month period, during which time no significant change was made in the carbon content of the sodium in the TEA, showed that both meters gave carbon flux readings of $0.001 \mu \mathrm{g} /\left(\mathrm{cm}^{2}\right)(\mathrm{min}) \pm 25 \%$. When an $\mathrm{Fe}-5 \% \mathrm{C}$ alloy was added to the high-temperature test section $\left(630^{\circ} \mathrm{C}\right)$, the carbon flux increased and remained constant at the higher level until the temperature of the test section was lowered.

The effects of system variables on the responses of the meters were also investigated. These included separately increasing the cold-trap temperature, the loop temperature, and the primary sodium flow rate. Only transient increases in the carbon fluxes were obtained in all three instances. Some of these were large increases (as much as $1000 \%$ ) lasting for several hours. These observations suggest that the transients may have been caused by carbon-containing particulate being carried past the carbon meters. Such transients can probably be avoided by maintaining all parts of the loop at temperatures above $500^{\circ} \mathrm{C}$.

4. Meter Modules for FFTF. J. T. Holmes, V. M. Kolba, and J. M. McKee (Last reported: ANL-7798, p. 56)

The objective of this work is to design,** proof-test, and establish commercial availability for on-line meter modules to be installed at FFTF. These modules include flow and temperature controls as well as the meters for monitoring impurities.

*The carbon that diffuses through the iron membrane is converted first to $\mathrm{CO}$ and then to $\mathrm{CH}_{4}$, which is continuously monitored by a flame-ionization detector.

**For both modules, the electrical design work is being done by M. A. Slawecki, Chemical Engineering Division, and the mechanical and structural design work by E. C. Filewicz, EBR-II Project. 
a. Oxygen-Hydrogen Meter Module

Fabrication of two oxygen-hydrogen meter modules and electrical consoles was completed. One unit will be tested at ANL; the other has been sent to EBR-II for installation on the Radioactive Sodium Chemistry Loop (RSCL), Cell B.

The data package for installation and testing of the oxygenhydrogen meter module in Cell B of the RSCL at EBR-II was prepared and has received EBR-II management approval. Installation procedures have been initiated.

b. Carbon-meter and Specimen-equilibration Module

The data package for installation and testing of the specimen equilibration module in Cell C of the RSCL at EBR-II has been completed and sent to EBR-II for review and approval.

5. Detection of Leaks in Steam Generators. J. T. Holmes, D. R. Vissers, and C. C. McPheeters (Last reported: ANL-7798, p. 57)

The evaluation of requirements for a leak detector for LMFBR steam generators and the development and proof-testing of a detection system to meet these needs are part of this program. A diffusion-type hydrogen monitor is being developed at ANL. This monitor appears to have a capability of detecting a $4 \%$ change in the hydrogen level at a concentration of $0.1 \mathrm{ppm}$ hydrogen in sodium. This is well above the sensitivity required for detecting water inleakage that would lead to rapid perforation of adjacent tubes in a large generator $\left(10^{6} \mathrm{lb}\right.$ of sodium per $\mathrm{hr}$ ).

\section{a. Leak Detector for LMFBR Steam Generator}

Design of a preliminary model of the leak detector has been completed, and fabrication has been started. This model will be tested on the Sodium Analytical Loop. Detailed designs of the system will be provided to EBR-II for use in instrumenting their steam-generator plant with waterto-sodium leak detectors. Linear actuators are being considered for use as sodium pumps on this system; two of these units are being procured for testing.

\section{b. LMEC Leak-detection System}

ANL is supplying a hydrogen-meter leak detector to the Liquid Metal Engineering Center (LMEC) where it will be used on the Sodium Components Test Installation. Fabrication of this leak detector was completed and the unit was shipped to LMEC. The document submittal requirements of LMEC were satisfied, and an operating manual was written. Completion of the instrument package is awaiting delivery of some of the components. 


\section{PUBLICATIONS}

An Equilibration Method for Measuring Low-Oxygen Activities in Liquid Sodium

D. L. Smith

Nucl. Technol. 11, 115-119 (May 1971)

Interim Methods for the Analysis of Sodium and Cover Gas ANL/ST-6 ( $\operatorname{Tan} 1971$ )

Sodium Technology Quarterly Report, October-December 1970 ANL/ST-8 (Mar 1971) 


\section{FUELS AND MATERIALS DEVELOPMENT}

A. LMFBR Cladding and Structural Materials

1. In-pile Stainless Steel Swelling and Mechanical Behavior...(02-526)

a. Effect of Helium on Void and Dislocation Loop Nucleation.

S. D. Harkness and B. J. Kestel (Not previously reported)

The effect of helium on void and interstitial dislocation loop formation has been studied. A series of Type 304 stainless steel samples (see Table V.1) that had been cyclotron-injected with helium to concentrations between $10^{-7}$ and $10^{-4}$ atomic fraction were obtained from Atomics International (AI). Helium determinations were conducted at AI by massspectrographic techniques. Also, the samples were given different heat treatments (at AI) after cyclotron bombardment, a procedure that was unexpectedly important to the subsequent microstructure developed by neutron irradiation.

The microtensile samples were cut in half upon receipt from AI. One-half of each sample was kept as a control on the starting microstructure, and the other half placed in EBR-II Subassembly X018. Since only the gauge lengths of the samples were injected with helium, this allowed knowledge of the material in four important conditions: (1) as-received, no helium injection; (2) helium injected; (3) helium injected and EBR-II irradiated; and (4) as-received, EBR-II irradiated. The samples were irradiated $13 \mathrm{in.}$ above the core center in Row 4 of EBR-II Subassembly X018B. The samples reached a total dose of $1 \times 10^{21} \mathrm{n} / \mathrm{cm}^{2}$ (calculated) in this position and were irradiated at a temperature of $450^{\circ} \mathrm{C}$ (calculated). The experiment was limited to a very low neutron dose to facilitate investigation of the effect of helium on both void and dislocation loop nucleation.

Two distinct types of microstructure were observed in the helium-injected samples, depending on their postinjection heat treatment. Samples heat-treated at $760^{\circ} \mathrm{C}$ showed a relatively clean microstructure consisting of a few carbides $\left(\sim 1 \times 10^{13}\right)$ ranging in size between 200 and $1000 \AA$. A few bubbles were observed in the samples, both at grain boundaries and in the matrix of the grains.

The samples that were heat-treated for short periods at $650^{\circ} \mathrm{C}$, or that received no heat treatment after alpha-particle bombardment, exhibited a distinctly different microstructure. The samples contained high number densities of dislocation loops. These loops presumably are formed during alpha bombardment, since they are observed in samples $M, R$, and $V$ that received no further heat treatment. The loops are quite possibly nucleated by the helium atoms during the bombardment. Analysis of the nature of the loops is in progress. 
TABLE V.1. Effect of Helium Concentration on Void and Dislocation Loop Formation

\begin{tabular}{|c|c|c|c|c|c|c|c|c|c|c|c|}
\hline \multirow[b]{2}{*}{ Sample } & \multirow[b]{2}{*}{$\begin{array}{l}\text { Inftisl Helfum } \\
\text { Concentration }\end{array}$} & \multicolumn{4}{|c|}{ Before EBR-II Irradiation } & \multicolumn{6}{|c|}{ After EBR-II Irradiation } \\
\hline & & $\begin{array}{l}\text { Heat Treat- } \\
\text { nent after } \\
\text { Heltun } \\
\text { tojection }\end{array}$ & $\begin{array}{l}\text { Intelal Loop } \\
\text { Number } \\
\text { Density } / \mathrm{cm}^{3} \text {. } \\
\quad \times 10^{14}\end{array}$ & $\begin{array}{c}\text { Initial Loop } \\
\text { Average Size, } \\
\text { A }\end{array}$ & Bubbles & $\begin{array}{l}\text { Average } \\
\text { Void } \\
\text { Slze }\end{array}$ & $\begin{array}{c}\text { Vold } \\
\text { Number } \\
\text { Dens1ty, } \\
\times 10^{14}\end{array}$ & $\begin{array}{l}\text { Average } \\
\text { Loop } \\
\text { Size, } \\
\text { A. }\end{array}$ & $\begin{array}{c}\text { Loop } \\
\text { Number } \\
\text { Dens1ty, } \\
\times 10^{14}\end{array}$ & $\begin{array}{l}\text { Foll } \\
\text { Thickness } \\
\text { Determinat Ion } \\
\text { Method }\end{array}$ & $\begin{array}{l}\text { Calculated } \\
\text { Void } \Delta v, \\
\text { z }\end{array}$ \\
\hline $\mathbf{H}$ & $1.1 \times 10^{-7}$ & None & 0.77 & 247 & None & 151 & 1.1 & 537 & 2.6 & $a, a$ & 0.02 \\
\hline N & $1.1 \times 10^{-7}$ & $\begin{array}{l}100 \mathrm{hr} \\
650^{\circ} \mathrm{C}\end{array}$ & None & - & Very few & 176 & 1.9 & 727 & 5.7 & b & 0.05 \\
\hline $\mathrm{K}$ & $1.5 \times 10^{-6}$ & $\begin{array}{l}8 \mathrm{hr} \\
760^{\circ} \mathrm{C}\end{array}$ & None: & - & $\begin{array}{c}\text { Few at grain } \\
\text { boundary }\end{array}$ & 138 & 4.6 & 582 & 6.8 & b & 0.05 \\
\hline B & $7.6 \times 10^{-6}$ & None. & 2.4 & 291 & None & - & Sone & - & Very low & c & None \\
\hline 0 & $3.8 \times 10^{-5}$ & $\begin{array}{l}10 \mathrm{hr} \\
760^{\circ} \mathrm{C}\end{array}$ & None & - & Some & 98 & 33.0 & 470 & 12.1 & $b$ & 0.16 \\
\hline $\mathbf{P}$ & $3.8 \times 10^{-5}$ & $\begin{array}{l}10 \mathrm{hr} \\
650^{\circ} \mathrm{C}\end{array}$ & 3.3 & 273 & None & 117 & $<0.1$ & 75 & 3.2 & d, a & - \\
\hline$Q$ & $3.8 \times 10^{-5}$ & $\begin{array}{l}100 \mathrm{hr} \\
760^{\circ} \mathrm{C}\end{array}$ & None: & - & Few & 132 & 6.05 & 535 & 4.25 & b & 0.07 \\
\hline V & $1 \times 10^{-4}$ & None & 1.5 & 360 & None & - & None & 234 & 62.0 & $a, a$ & None \\
\hline Control & None & - & None & - & None & 151 & 0.7 & 540 & 3.2 & d & 0.013 \\
\hline
\end{tabular}

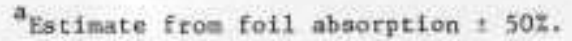

bsereo pair $+30 z ;-5 \%$.

csilp trace $\pm 20 \%$.

dDislocation projection $\pm 30 z$. 
The presence of the dislocation loops had a dramatic effect on the microstructure developed during EBR-II irradiation. Samples without the initial loop structure developed large numbers of both voids and dislocation loops in response to the helium additions. Samples that contained the initial dislocation structure formed many fewer voids or loops, even though the same amount of helium was present. A comparison of sample P with $O$ or $Q$ (see Table V.1) illustrates this behavior. Even sample V, which had the most helium injected, did not develop any observable voids, but did develop a rather high density of small dislocation loops.

Samples that had been heat-treated after helium injection to remove the dislocation structure $(N, K, O$, and $Q$ ) developed higher number densities of both voids and dislocation loops with increasing helium content. Void and loop number densities were measured in the same foil area. In general, the average void size decreased as the number density increased, with the exception of sample $\mathrm{N}$ (as compared with the control).

A further observation was that at low helium concentrations (control and sample M) dislocation loops tended to cluster near precipitate particles and grain boundaries, indicating that nucleation occurred more easily in areas of high impurity concentration. Whether this is due to nucleation directly on the impurity atom or on a helium atom generated by the impurity is difficult to establish. The increasing dislocation-1oop concentration with increasing helium content indicates, however, that it may be the latter. In this case, impurity atoms with high $(n, \alpha)$ cross sections, such as nitrogen and boron, would be expected to be especially important.

One explanation of the present results is that during the alpha bombardment, vacancy and interstitial dislocation loops are formed. During EBR - II irradiation, these preferentially attract interstitials due to the misfit strain interaction. Presumably the excess vacancies accumulate at grain boundaries and precipitate particles. The excess interstitial flux to the loops will, of course, either make the loops grow or shrink, depending on whether they are interstitials or vacancies. It would be expected that this type of process should, at some dose, lead to a microstructure consisting of small vacancy dislocation loops and a heavy dislocation network due to the unfaulting and gliding of large interstitial loops. This was observed in sample P. It would be expected that upon longer irradiation the vacancy loops would completely shrink, and the helium atom would become an available void nucleation site.

b. Swelling of IN-744. S. D. Harkness and B. J. Kestel (Not

The swelling characteristics of International Nickel Company experimental alloy IN-744 (nominal composition: Fe-26 wt\% Cr-6.5 wt \% Ni) have been studied after EBR-II ir radiation. This alloy has a microduplex 
structure (see Fig. V.1) consisting of about equal numbers of ferritic and austenitic grains. The grain size, as measured by transmission electron microscopy (TEM), was $0.75 \mu \mathrm{m}$. The initial intent of irradiating the ma-

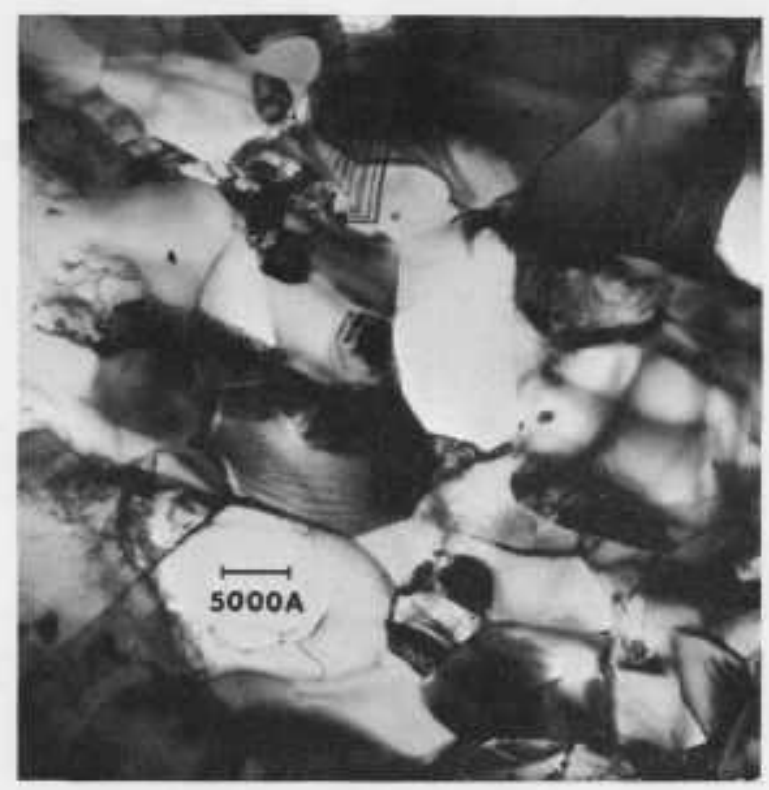

Fig. V.1. As-received Microstructure of $\mathrm{N}-744$. Neg. No. MSD-54588. terial was to assess experimentally the effectiveness of the high-angle grain boundary in reducing swelling. The austenitic phase has a composition near that of an 18-8 stainless steel, and the ferritic phase has a composition of approximately $\mathrm{Fe}$ 30 wt $\% \mathrm{Cr}$. The material was irradiated in the EBR-II core in the form of $1 / 8$-in. disks of 20 -mil sheet in Subassembly X018B to a total dose of $2 \times 10^{22} \mathrm{n} / \mathrm{cm}^{2}$ (calculated) and a temperature of $450^{\circ} \mathrm{C}$ (calculated). The samples were ir radiated $8 \mathrm{in}$. above core center in a Row 4 position.

The irradiated microstructure is shown in Fig. V.2. The austenitic grains (as determined by electron diffraction) exhibited "normal" void formation in the sense that it was similar to the void formation which would be seen in Type 304 stainless steel after exposure to the same irradiation conditions. The denuded zone along the high-angle ferritic-austenitic grain boundary is very narrow $(\sim 50 \AA)$, indicating that grain refinement is not a practical method to limit swelling.

\section{Fig. V.2}

EBR-II Irradiated Microstructure of IN-744. The F grains are face-centered cublc, and the $B$ grains are body-centered cubic (nvt $=2 \times 10^{22} \mathrm{n} / \mathrm{cm}^{2}$, $\left.T=450^{\circ} \mathrm{C}\right)$. Neg. No. MSD-54586.

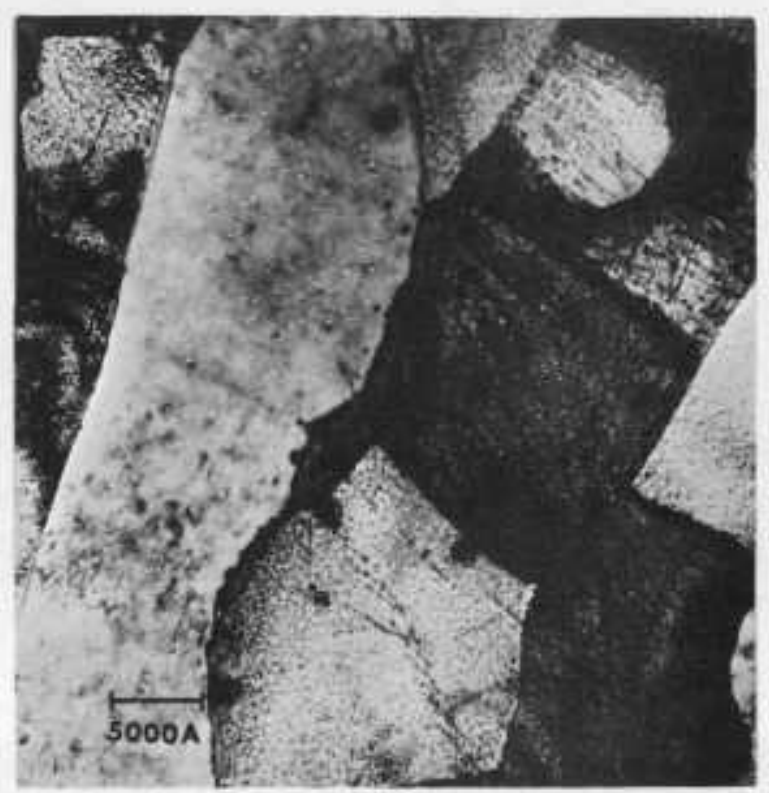


The ferritic grains, quite unexpectedly, formed very few, if any, voids. Instead, a high density $\left(\sim 5 \times 10^{15} / \mathrm{cm}^{3}\right)$ of coherent precipitate developed.

These precipitates evidently acted as point-defect recombination centers during irradiation, thus preventing void formation. The fact

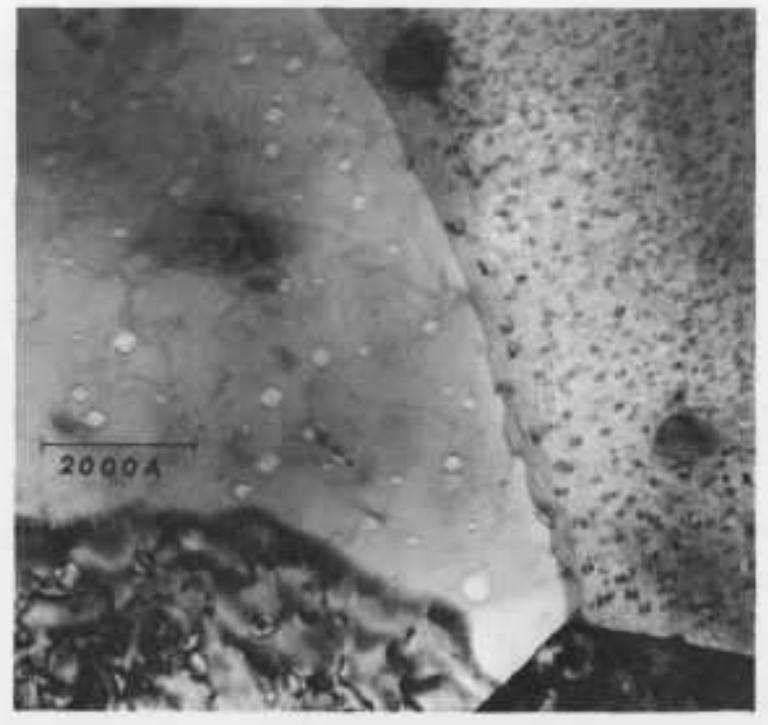

Fig. V.3, Deformed Grain Boundary in EBR-II Irradiated $\mathrm{IN}-744$. Note voids in facecentered-cubic phase (F) and coherent precipitate in body-centered-cubic phase (B). Neg. No. MSD-54587. that the ferritic grains swelled much less than the austenitic grains must have caused the austenitic grains to attempt to push into surrounding ferritic grains. Some evidence of the deformed, irregular nature of the grain boundaries can be seen in Figs. V.2 and V.3.

The nature of the precipitates is also of some interest. It is well known that alloys of $\mathrm{Fe}-30$ wt $\% \mathrm{Cr}$ suffer embrittlement, as reflected by Charpy testing, after aging at $475^{\circ} \mathrm{C}$. Lagneborg* attributed this embrittlement to a precipitate formed spinodal decomposition. The diffraction contrast from the precipitates in this study is consistent with a particle having a spherically symmetric strain field, and suggests a Guinier-Preston zone structure such as is found in

Cu-Co and other systems. To assess the kinetics of formation of these precipitates, some of the original IN-744 starting material was held at $500^{\circ} \mathrm{C}$ for 8 days and examined by TEM; small coherent precipitates were observed. Based on this result, it is somewhat surprising that an overaged structure was not observed in the irradiated sample since it had been at temperature $\left(450^{\circ} \mathrm{C}\right)$ for over 6 months. It may be that some type of resolution mechanism is playing a role in the in-pile aging kinetics.

In summary, our results appear to be consistent with those recently reported by Nelson,** which indicated that the formation of a semicoherent phase limited void formation in the British Nimonic alloy PE-16

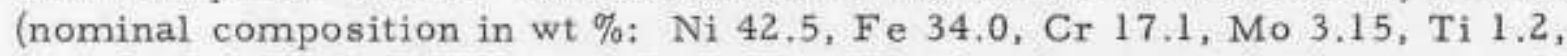

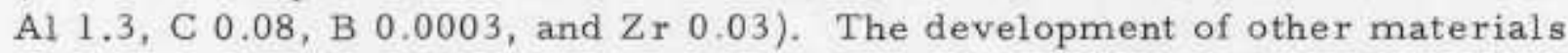
containing high number densities of coherent precipitates may offer one solution to the swelling problem.

\footnotetext{
*R. Lagneborg, Acta Met. 15, 1737 (Nov 1967).

**R. S. Nelson, New Scientist and Science J. 664 (Mar 1971).
} 
c. Neutron Simulation Studies Using 4-MeV Dynamitron. A. Taylor

The study of the swelling behavior of Type 304 stainless steel subjected to ${ }^{1} \mathrm{H}^{+}$and ${ }^{58} \mathrm{Ni}^{+}$bombardment is continuing. Samples with and without injected helium have been irradiated to fluences up to 300 displacements per atom (calculated) at temperatures between 450 and $600^{\circ} \mathrm{C}$. Stereoelectron microscopy is now used to obtain quantitative data on void and dislocation structures. The details of all irradiations conducted to date are summarized in Table V.2, and the status of the electron microscopy is given in Table V.3. The results are summarized in Table V.4. The accuracy of the void number density and swelling data is approximately $\pm 25 \%$.

TABLE V.2. Samples of Type 304 Stafnless Steel Irradiated at ANL with $58 \mathrm{Ni}^{+}$or ${ }^{1} \mathrm{H}^{+}$Ions

\begin{tabular}{|c|c|c|c|c|c|c|}
\hline $\begin{array}{l}\text { Sample } \\
\text { Reference } \\
\text { Number }\end{array}$ & $\begin{array}{c}\text { Noninal } \\
\text { Temperature, } \\
{ }^{\circ} \mathrm{C}\end{array}$ & Particle & $\begin{array}{l}\text { Energy, } \\
\mathrm{MaV}\end{array}$ & $\begin{array}{l}\text { Current } \\
\text { Density }\end{array}$ & $\begin{array}{l}\text { Total } \\
\text { Charge }\end{array}$ & $\begin{array}{c}\text { Hellum, } \\
\text { Ppa }\end{array}$ \\
\hline $70-1120$ & 550 & $\mathrm{~B}^{+}$ & 1.25 & $0.32 \mathrm{~mA} \mathrm{~cm}-2$ & $2.8 \mathrm{c} \mathrm{cm}^{-2}$ & 0 \\
\hline $70-0806$ & 500 & $\mathrm{H}^{+}$ & 1.25 & $0.155 \mathrm{gA}^{-2}$ & $6.6 \mathrm{C} \mathrm{cm}^{-2}$ & 0 \\
\hline $71-0204$ & 640 & $\mathrm{~B}^{+}$ & 1.25 & $0.760 \mathrm{~m} \mathrm{~cm}-2$ & $6.0 \mathrm{c} \mathrm{cm}^{-2}$ & 0 \\
\hline $71-0208$ & 600 & $\mathrm{u}^{+}$ & 1.34 & $0.496 \mathrm{~m}^{-2} \mathrm{~cm}^{-2}$ & $17.0 \mathrm{c} \mathrm{cm}^{-2}$ & 0 \\
\hline $71-0219$ & 450 & $\mathrm{H}^{+}$ & 1.25 & $0.38 \mathrm{~mA} \mathrm{~cm}-2$ & $23.0 \mathrm{c} \mathrm{cm}^{-2}$ & 0 \\
\hline $71-0326-1$ & 620 & $\mathrm{H}^{+}$ & 1.25 & $0.326 \mathrm{~mA} \mathrm{~cm}^{-2}$ & $6.0 \mathrm{C} \mathrm{cm}^{-2}$ & 0 \\
\hline $71-0327-1$ & 600 & $\mathrm{~B}^{+}$ & 1.25 & $0.388 \mathrm{~mA} \mathrm{~cm}-2$ & $7.0 \mathrm{c} \mathrm{cm}^{-2}$ & 10 \\
\hline $71-0327-2$ & 500 & $\mathrm{~B}^{+}$ & 1.25 & $0.362 \mathrm{~mA} \mathrm{~cm}^{-2}$ & $6.0 \mathrm{c} \mathrm{cm}^{-2}$ & 10 \\
\hline $70-1201-1$ & 520 & $\mathrm{N1}^{+}$ & 3.0 & $1.4 \mathrm{uA} \mathrm{cm}^{-2}$ & $3.9 \mathrm{mC} \mathrm{cm}-2$ & 0 \\
\hline $70-1201-2$ & 520 & $\mathrm{N1}^{+}$ & 3.0 & $0.63 \mathrm{uA} \mathrm{\textrm {cm } ^ { - 2 }}$ & $7.8 \mathrm{mC} \mathrm{cm}-2$ & 0 \\
\hline $70-1202-1$ & 517 & $\mathrm{Ni}^{+}$ & 3.5 & $0.35 \mathrm{HA} \mathrm{cm}^{-2}$ & $7.1 \mathrm{mc} \mathrm{cm}-2$ & 0 \\
\hline $71-0319-1$ & 600 & $\mathrm{Ni}^{+}$ & 3.5 & 1.3 मA $\mathrm{cm}^{-2}$ & $20.0 \mathrm{nC} \mathrm{\textrm {cm } ^ { - 2 }}$ & 0 \\
\hline $71-0319-2$ & 600 & $\mathrm{Ni}^{+}$ & 3.75 & $0.7 \mathrm{HA} \mathrm{cm}^{-2}$ & $3.0 \mathrm{mC} \mathrm{\textrm {cm } ^ { - 2 }}$ & 0 \\
\hline $71-0320-1$ & 500 & $\mathrm{Ni}^{+}$ & 3.75 & $0.67 \mathrm{HA} \mathrm{cm}^{-2}$ & $3.2 \mathrm{mC} \mathrm{\textrm {cm } ^ { - 2 }}$ & 0 \\
\hline $71-0425-1$ & 600 & $\mathrm{N1}^{+}$ & 3.75 & 0.9 wA $\mathrm{cm}^{-2}$ & $6.0 \mathrm{mC} \mathrm{cm}^{-2}$ & 10 \\
\hline
\end{tabular}

TABLE V.3. Current Status of Electron-ntcroscopic Examination of Irradiated Samples

\begin{tabular}{|c|c|c|}
\hline $\begin{array}{l}\text { Sample } \\
\text { Reference } \\
\text { Nunber }\end{array}$ & $\begin{array}{c}\text { Depth of Foll Specimens Exanined, } \\
\text { un }\end{array}$ & $\begin{array}{l}\text { Status of Analysis } \\
\text { of Photomlerographs }\end{array}$ \\
\hline 700806 & $\begin{array}{c}3.5,5.0,6.2,7.8,8.2, \\
59.2 \text { (rrange) }\end{array}$ & Completed \\
\hline $701202-1$ & $0.25,0.5,0.8$ (>range) 1.2 & Completed \\
\hline $701201-1$ & $0.2,0.3,0.5$ & In progreas \\
\hline 710208 & $2.5,4.5,8.0$ & Completed \\
\hline
\end{tabular}


TAaLE V.4. Data from Quantitative Electron Microscopy

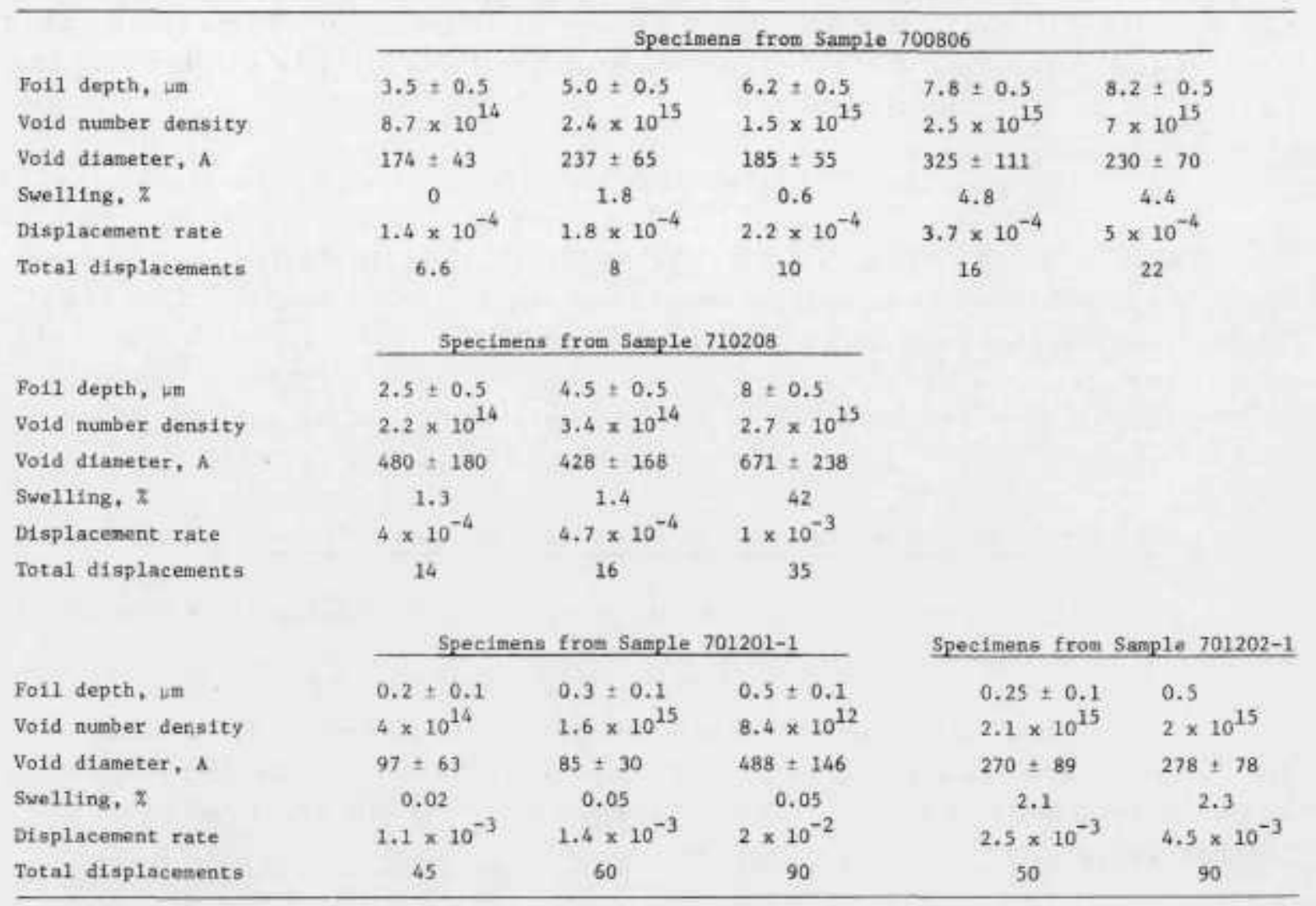

The current observations are consistent with the view that nucleation and growth of voids are essentially sequential processes. We ascribe the increase in void number density with depth to the influence of dose rate upon void nucleation. Our results are similar to data obtained by Keefer et al,* for proton-irradiated Type 316 stainless steel preinjected with several parts per million of helium. We infer that the injected helium does not contribute significantly to the nucleation process in protonirradiated Types 304 and 316 stainless steel. Although differences in behavior under ion irradiation are apparent between the two types of steel (Type 304 does not appear to transform from austenitic to ferritic, as is reported for Type 316 ), the magnitude of the swelling is similar.

At present, only two nickel-irradiated samples have been examined. The data from the second sample $(701202-1)$ are similar to those reported by Brager et al, ${ }^{* *}$ for a Type 316 stainless steel specimen irradiated with $5-\mathrm{MeV}$ copper ions to a dosage of $\approx 50$ displacements/atom. The data obtained for the first sample (701201-1) are anomalously small. However, both sets of data exhibit significantly smaller swelling than was observed in the proton-irradiated samples compared on a basis of total number

*D. W. Keefer, H. H. Neely, J. C. Robinson, A. G. Pard, and D. Kramer, A1-AEC-12961 (June 30, 1970). **H. R. Brager, H. E. Kissinger, and G. L. Kulcinski, Rad. Effects $\underline{5}, 281$ (1970). 
of displacements per atom. Although the dose rate is a factor of 10 greater for the nickel irradiation, the void number densities are comparable, which further indicates that the foreign-injected ion (e.g., $\mathrm{H}^{+}$) is influencing the nucleation of the void structure.

The proton-irradiated data have been fitted to the Harkness-Li* model of void growth. The significant aspect of this work is that, to match the observed number density with the theoretical formulation, a surfaceenergy value higher than that used in the simulation of reactor data must be included in the void nucleation rate expression. The result suggests that heterogeneous nucleation gives way to homogeneous nucleation with increasing dose rates, the analytical formulation of which will be essential to referencing the ion-bombardment studies to reactor irradiation.

2. Creep, Fracture, and Fatigue Studies on Stainless Steel (02-091)

a. Low-cycle Fatigue. R. W. Weeks, C, F. Cheng, and Che-Yu Li (Last reported: ANL-7776, p. 75)

The low-cycle, elevated temperature, creep-fatigue testing program at ANL is currently providing fatigue data on Type 304 stainless steel in support of FFTF design evaluations and for future LMFBR component design.

The specimens used at ANL to date have been of hourglass configuration and were obtained from the previous General Electric-Nuclear Systems Programs (GE-NSP) low-cycle fatigue research. Since some uncertainty existed about the actual heat treatment the specimens received before shipment to ANL, metallography and hardness tests were performed on (1) an as-received specimen, (2) a specimen stress-relieved at $760^{\circ} \mathrm{C}$ for $15 \mathrm{~min}$, and (3) a specimen annealed at $1092^{\circ} \mathrm{C}$ for $30 \mathrm{~min}$. The results are given in Table V.5.

TABLE V.5. Hardness and Grain-size Results for Three Heat Treatments

\begin{tabular}{lcc}
\hline Specimen & Hardness, VHN & ASTM Grain Size \\
\hline As-received & 148 & $3-4$ \\
Stress-relieved & 139 & $3-4$ \\
Annealed & 119 & $3-4$ \\
\hline
\end{tabular}

*S. D. Harkness and C.-Y, Li, to be published in Met. Trans. (1971). 
The required Vickers hardness was $\sim 139$; the required grain size was ASTM 3-5.* It was therefore verified that the specimens received by ANL had been annealed before machining and that the final stress relief remained to be done at ANL before testing. This procedure has been followed at ANL, and all specimens tested have thus received the same heat treatment as the specimens tested in the former GE-NSP program.

Creep-fatigue data generated at ANL are summarized in Tables V.6-V.8. Table V.6 gives ANL base-line results for fully reversed, strain-controlled fatigue tests run to failure. These data and similar data from the GE-NSP program are plotted in Fig. V.4. Tables V.7 and V.8 list the results obtained in creep-fatigue hold-time tests, where the specimen was subjected to a hold period at the peak of the tensile portion of each strain cycle. This interaction of creep and fatigue is of most concern in design applications, because of the present difficulty in making accurate failure predictions. Scanning electron microscopy (SEM) at ANL has shown that the mode of fatigue crack propagation can change from intragranular to intergranular by introducing tensile hold periods into the strain cycles. Both SEM and acoustic-emission techniques are being used to aid in understanding creep-fatigue interactions and to predict their influence on specimen lifetime.

3. Nondestructive Testing Research and Development (02-092)

a. Electromagnetic Field Studies. C. J. Renken (Last reported: ANL-7776, p. 76)

(1) Development of Pulsed Eddy-current Equipment for Testing Fuel-element Jackets in FEF. Equipment for nondestructive inspection of fuel elements has been designed and is currently under construction. The equipment will be used at ANL-Idaho for interim inspections of fuel-element jackets irradiated in EBR-II. The test system is designed to test the jackets of fuel elements containing mixed-oxide fuel with the same sensitivity required in specification RDT E 13-8. However, since the test will be conducted with the spacing wire in place, a complete $360^{\circ}$ inspection of the jacket will not be possible. The area actually inspected will depend upon the diameter of the fuel element and the size and pitch of the spacing wire. The electronic instrumentation has been designed for simultaneous inspection for discrete defects and a measurement of effective wall thickness. The mechanical inspection arrangement will be able to cope with swelling of up to $0.25 \mathrm{~mm}$ on the diameter and some bowing of the fuel element. The inspection of fuel elements containing sodium bonds will probably not be possible, because of interference from the inevitable small defects in the sodium bond. The effectiveness of the test on fuel elements containing carbide fuel is at present unknown, but if the test system sample points are carefully selected, an effective test on these fuel elements should be possible.

*J. B. Conway, GEMP-1012, Part II, pp. 81-166. 
TABLE V.6. Lav-cycle Fatigue Data for Annealed AISI Type 304 Stainless Steel Tested in Air

\begin{tabular}{|c|c|c|c|c|c|c|c|c|c|c|c|c|c|c|c|}
\hline \multirow[b]{2}{*}{$\begin{array}{l}\text { Test } \\
\text { No. }\end{array}$} & \multirow[b]{2}{*}{ Temp., } & \multicolumn{3}{|c|}{ Axtal Strain } & \multicolumn{3}{|c|}{ Diametral Scrain } & \multicolumn{2}{|c|}{ Strain Rate } & \multirow[b]{2}{*}{$\begin{array}{l}\text { Frequency } \\
\text { of Loading, } \\
\text { cycles/sec }\end{array}$} & \multirow[b]{2}{*}{$\begin{array}{l}\text { Stress Range } \\
\text { so at } \mathrm{N}_{\mathrm{f}} / 2 \text {, } \\
\text { psi }\end{array}$} & \multicolumn{4}{|c|}{ Pat1gue Life } \\
\hline & & $\frac{\Delta E_{t}}{z}$ & $\frac{\Delta E_{p}^{\prime}}{p^{\prime}}$ & $\underset{x}{A c_{e},}$ & $\frac{\Delta \varepsilon_{d} .}{x}$ & ${ }^{\Delta e} d p^{\prime}$. & $\frac{\Delta E_{d e}}{z}$ & $\dot{k}_{\mathrm{d}} \times 10^{3}$ & $\varepsilon_{t} \times 10^{3}$ & & & $\begin{array}{l}\mathrm{N}_{5}, \\
\text { cycles }\end{array}$ & $\begin{array}{l}\mathrm{N}_{5} \text {, } \\
\mathrm{hr}\end{array}$ & $\begin{array}{c}\mathrm{N}_{\ell}, \\
\text { cycles }\end{array}$ & $\begin{array}{l}\mathrm{N}_{\mathrm{f}} \text {. } \\
\mathrm{hr}\end{array}$ \\
\hline 3 & 806 & 1.15 & 0.80 & 0.35 & 0.50 & 0.40 & 0.10 & 2.0 & - & 0.2 & 82.116 & 4.290 & 5.17 & 4,353 & 6.22 \\
\hline 4 & 806 & 2.22 & 1.66 & 0.56 & 1.00 & 0.83 & 0.16 & 2.0 & - & 0.1 & 131,440 & 779 & 2.32 & 834 & 2.47 \\
\hline 6 & 806 & 0.60 & 0.37 & 0.23 & 0.25 & 0.19 & 0.06 & 2.0 & - & 0.4 & 52,800 & a & a & 29,825 & 20.71 \\
\hline 12 & 806 & 2.07 & 1.65 & 0.42 & 1.03 & 0.91 & 0.12 & - & 4.1 & 0.1 & 96,208 & 2,303 & 6.44 & 2,361 & 6.6 \\
\hline 21 & 806 & 1.07 & 0.81 & 0.26 & 0.48 & 0.40 & 0.73 & - & 4.3 & 0.2 & 60,679 & 10,166 & 14.12 & 10,192 & 14.15 \\
\hline 37. & 806 & 0.52 & 0.28 & 0.25 & 0.21 & 0.14 & 0.07 & - & 4.2 & 0.4 & 57,240 & 61,806 & 43.16 & 61,818 & 43.17 \\
\hline 7 & 1202 & 0.60 & 0.35 & 0.25 & 0.25 & 0.17 & 0.08 & 2.0 & - & 0.4 & 56,278 & 6,260 & 4.25 & 6,591 & 4.35 \\
\hline 8 & 1050 & 0.58 & 0.32 & 0.26 & 0.24 & 0.16 & 0.08 & 2.0 & - & 0.4 & 57,741 & 11,600 & 7.89 & 11,760 & 8.0 \\
\hline 10 & 1050 & 2.06 & 1.58 & 0.44 & 0.92 & 0.79 & 0.13 & - & 4.1 & 0.1 & 96,248 & 1,096 & 2.85 & 1,139 & 2.94 \\
\hline 11 & 1050 & 0.41 & 0.22 & 0.20 & 0.17 & 0.11 & 0.06 & - & 3.3 & 0.4 & 44,112 & $1,024,160$ & 688.5 & $1,024,330$ & 688.6 \\
\hline 13 & 1050 & 3.16 & 2.67 & 0.49 & 0.98 & 0.84 & 0.15 & - & 3.8 & 0.07 & 108,782 & 497 & 2.05 & 548 & 2.23 \\
\hline 15 & 1050 & 1.90 & 1.46 & 0.44 & 0.86 & 0.73 & 0.13 & 1.7 & - & 0.1 & 98,323 & 986 & 2.71 & 991 & 2.72 \\
\hline 16 & 1050 & 1.18 & 0.82 & 0.36 & 0.52 & 0.41 & 0.11 & 2.0 & - & 0.2 & 81.577 & 2,545 & 3.47 & 2,611 & 3.53 \\
\hline 18 & 1050 & 3.93 & 3.40 & 0.53 & 1.86 & 1.70 & 0.16 & 3.7 & - & 0.1 & 119,162 & 302 & 0.84 & 336 & 0.93 \\
\hline 19 & 1050 & 0.99 & 0.70 & 0.29 & 0.44 & 0.35 & 0.87 & - & 3.9 & 0.2 & 64,251 & a & a & 6,708 & 9.36 \\
\hline 22 & 1050 & 0.57 & 0.36 & 0.21 & 0.24 & 0.18 & 0.06 & - & 4.5 & 0.4 & 43,772 & a & a & 42,034 & 29.10 \\
\hline 31 & 1050 & 0.49 & 0.29 & 0.20 & 0.21 & 0.15 & 0.06 & - & 3.9 & 0.4 & 45,216 & 29,205 & 19.44 & 29,568 & 19.69 \\
\hline 32 & 1050 & 0.45 & 0.24 & 0.21 & 0.18 & 0.12 & 0.06 & - & 3.6 & 0.4 & 47,544 & a & a & 97.807 & 67.89 \\
\hline
\end{tabular}

Data omitted because of recorder failure. 
TABLE V.7. Fatigue Data ${ }^{a}$ obtained in Hold-tine Tests of AISI Type 304 Stainless Steel in Ait

\begin{tabular}{|c|c|c|c|c|c|c|c|c|c|c|c|c|c|}
\hline \multirow[b]{2}{*}{$\begin{array}{l}\text { Test } \\
\text { No. }\end{array}$} & \multirow[b]{2}{*}{$\begin{array}{c}\text { Specimen } \\
\text { No. }\end{array}$} & \multicolumn{2}{|c|}{ Hold Period, min } & \multirow[b]{2}{*}{$\dot{e}_{t} \times 10^{3}}$, & \multicolumn{3}{|c|}{ Axial Strain Range } & \multicolumn{5}{|c|}{ Fatigue Life } & \multirow[b]{2}{*}{$\begin{array}{l}\text { Temp. } \\
{ }^{\circ} \mathrm{F}\end{array}$} \\
\hline & & Tension & $\begin{array}{c}\text { Com- } \\
\text { pression }\end{array}$ & & ${ }_{z}^{\Delta E}$, & $\frac{\Delta e_{p}{ }^{b}}{z^{b}}$ & $\frac{\Delta \varepsilon_{e}}{z^{b}}$ & $\begin{array}{c}\mathrm{N}_{5}, \\
\text { cycles }\end{array}$ & $\begin{array}{l}\mathrm{N}_{5}, \\
\mathrm{hr}\end{array}$ & $N_{s} / N_{f}$ & $\begin{array}{l}\mathrm{N}_{\mathrm{f}}, \\
\text { cycles }\end{array}$ & $\begin{array}{l}\mathrm{N}_{f} \text {, } \\
\mathrm{hr}\end{array}$ & \\
\hline 9 & $12 A-6$ & 1.0 & 0 & 4.2 & 2.06 & 1.76 & 0.30 & 295 & 5.43 & 0.95 & 311 & 5.70 & 1202 \\
\hline 14 & $12 \mathrm{~A}-12$ & 600.0 & 0 & 4.3 & 2.13 & 1.84 & 0.285 & - & - & - & 93 & 919.13 & 1050 \\
\hline 23 & $14 \mathrm{~A}-1$ & 179.2 & 0 & 2.7 & 1. 35 & 1.05 & 0.291 & 224 & 669.7 & 0.95 & 236 & 704.99 & 1050 \\
\hline 33 & $15 \mathrm{~A}-4$ & 58.5 & 0 & 4.2 & 1.04 & 0.75 & 0.289 & 476 & 463.9 & 0.71 & 672 & 655.2 & 1050 \\
\hline 35 & $15 \mathrm{~A}-5$ & 28.8 & 0 & 4.1 & 1.03 & 0.738 & 0.302 & 478 & 230.1 & 0.79 & 606 & 290.5 & 1050 \\
\hline 36 & $15 A-6$ & 15.9 & 0 & 3.5 & 0.869 & 0.451 & 0.418 & 329 & 86.5 & 0.88 & 375 & 99.56 & 1050 \\
\hline
\end{tabular}

aControl mode: Axial strain.

bValues are based on the relaxed stress range $\Delta \sigma_{\mathrm{r}}$ at $\mathrm{N}_{\mathrm{f}} / 2$.

TABLE V.8. Stress Felaxation Data obtained in Low-cycle Fatigue Tests of AISI Type 304 Stainless Steel 1n Air

\begin{tabular}{|c|c|c|c|c|c|c|c|c|c|}
\hline $\begin{array}{l}\text { Test } \\
\text { No. }\end{array}$ & $\begin{array}{c}\text { Specimen } \\
\text { No. }\end{array}$ & $\begin{array}{l}\text { Do at } \\
\mathrm{x}_{\mathrm{f}} / 2 \text {, } \\
\mathrm{psi}\end{array}$ & $\begin{array}{l}\Delta O_{r} \text { at } \\
N_{f} / 2, \\
p s 1\end{array}$ & $\begin{array}{c}a_{t} \text { Maximum } \\
\text { at } N_{f} / 2, \\
\text { psi }\end{array}$ & $\begin{array}{c}a_{t} \text { Minimun } \\
\text { at } N_{f} / 2, \\
p s i\end{array}$ & $\begin{array}{c}\sigma_{\mathrm{c}} \text { Maximun } \\
\text { at } \mathrm{N}_{\mathrm{f}} / 2, \\
\text { psi }\end{array}$ & $\begin{array}{c}\sigma_{x} \\
\text { psi }\end{array}$ & $\begin{array}{l}\text { Total Time } \\
\text { under Tensile } \\
\text { Stress, hr }\end{array}$ & ${ }_{{ }^{\circ} \mathrm{F}}^{\text {Temp. }}$ \\
\hline 9 & $12 \mathrm{~A}-6$ & 72,040 & 65,672 & 35,821 & 39,851 & 35,821 & 5,970 & 5.70 & 1202 \\
\hline 14 & $12 A-12$ & 81,238 & 63,872 & 39,321 & 21,956 & 41,916 & 17,365 & 919.13 & 1050 \\
\hline 23 & $14 A-1$ & 72,295 & 65,150 & 35,329 & 28,184 & 36,946 & 3.513 & 704.99 & 1050 \\
\hline 33 & $15 \mathrm{~A}-1$ & 73,413 & 63,653 & 35,449 & 25.549 & 38,103 & 10,060 & 655.2 & 1050 \\
\hline 35 & $15 \mathrm{~A}-5$ & 72,755 & 67,625 & 35,848 & 30,858 & 36,767 & 4,990 & 290.5 & 1050 \\
\hline 36 & $15 A-6$ & 98,503 & 93,673 & 48,663 & 43,832 & 49,840 & 4.830 & 99.56 & 1050 \\
\hline
\end{tabular}




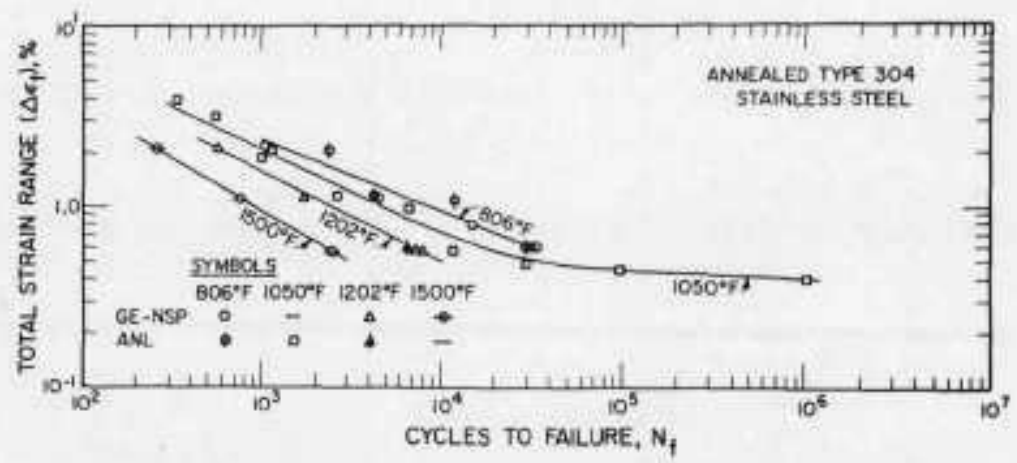

Fig. V.4. ANL and GE-NSP Low-cycle Fatigue Data for Type 304 Stainless Steel. Neg. No. MSD-54611.

(2) Development of Pulsed Eddy-current Test Equipment for High-speed Jacket Tubing Inspection. The high-resolution transducers recently developed have also had the effect of increasing the amounts of test-system circuitry necessary for a given tubing throughput. The circuits required in a high-speed, pulsed eddy-current test system were recently redesigned to take advantage of the simplification possible with the latest advances in semiconductor technology. In particular, the pulse-sampling sections of the system were simplified by use of dual-gate, depletion-type MOSFET transistors. As a result, a system that uses 18 high-resolution masked pickups now needs no more bulk in circuitry than was necessary with the six-pickup systems used in the past two years.

b. Neutron Radiography. J. P. Barton (Last reported: ANL-7783,

Studies have been undertaken to compare ${ }^{244} \mathrm{Cm}-\mathrm{Be}$ with ${ }^{252} \mathrm{Cf}$ as an isotopic source for neutron radiography. The ${ }^{252} \mathrm{Cf}$ source could be produced inexpensively in $100-\mathrm{g}$ quantities by special irradiation in a largevolume high-flux reactor. The ${ }^{244} \mathrm{Cm}$ will be produced as a byproduct of U.S. electrical nuclear power progress, and the cost per neutron for the two sources might be competitive. The half-life of ${ }^{252} \mathrm{Cf}$ is about 2.5 yr; the half-life of ${ }^{244} \mathrm{Cm}-\mathrm{Be}$ is about $17.6 \mathrm{yr}$. The neutron-radiography measurements were performed with a source containing $0.64 \mathrm{~g}$ of ${ }^{244} \mathrm{Cm}$, which, when mixed with beryllium, produced $1.2 \times 10^{8} \mathrm{n} / \mathrm{sec}$. The ${ }^{252} \mathrm{Cf}$ source yielded $2.2 \times 10^{8} \mathrm{n} / \mathrm{sec}$. All results quoted have been normalized to compare equal source yields of the two types of sources.

Indium-foil ir radiations with and without cadmium covers were used to compare the peak thermal flux for each source when surrounded by a water-moderator assembly. It was found that ${ }^{252} \mathrm{Cf}$ had an advantage factor of 1.5 over ${ }^{244} \mathrm{Cm}-\mathrm{Be}$. Measurements of the thermal-neutron flux were also made at the exposure position of a collimator using a $\mathrm{BF}_{3}$ proportional counter in the longitudinal orientation as well as a directional cadmiumwindow technique. 
A more direct test was to take a series of radiographs under various beam-extraction conditions for the two sources and compare exposure times and radiograph quality. Results showed that ${ }^{252} \mathrm{Cf}$ was consistently more efficient than ${ }^{244} \mathrm{Cm}-\mathrm{Be}$ by a factor of two. Moreover, ${ }^{252} \mathrm{Cf}$ produced a better quality neutron radiograph as determined by an image quality indicator. Comparative tests with the much slower and much finergrain gadolinium-foil converter showed equal speed for ${ }^{252} \mathrm{Cf}$ and ${ }^{244} \mathrm{Cm}-\mathrm{Be}$, but again ${ }^{252} \mathrm{C}$ produced slightly superior image quality if the gamma radiation from the ${ }^{252} \mathrm{C} f$ was adequately filtered.

Further studies concentrated on optimization of ${ }^{252} \mathrm{Cf}$ techniques, and, in all cases, measurements were based on the total end product, the radiograph. rather than on instrument readings such as foils or pulse counters. One factor that affects image quality is the source position in the moderator relative to the collimator input aperture, assuming the collimator and the air gap are held constant.

In another study concerned with collimator dimensions, it was noted that an increase in the thickness of the water shield between the source and the detector significantly improved the image quality.

Cooling the water moderator by modest amounts (without any cooling of the detector combination) significantly improves the exposure speed, although, for the temperature range studied, no change in image sharpness or hydrogen contrast was discernible. A reduction of moderator temperature from 20 to $5^{\circ} \mathrm{C}$ improves the exposure speed by $25 \%$.

Other factors that have been incorporated and found to improve the capabilities of the ${ }^{252} \mathrm{C}$ f facility include (1) a $0.3-\mathrm{mm}$ lead filter in the beam. (2) a $0.3-\mathrm{mm}$ lead lining to the collimator, (3) the use of boron shielding walls around the exposure position, (4) the use of rhodiumgadolinium double converter foils, and (5) the use of a vacuum cassette.

\section{B. Fuel Properties}

1. Thermodynamics of Carbide Fuel. A. D. Tevebaugh and P. E. Blackburn (02-088)

a. Total Vapor Pressures and Carbon Potentials in the Ternary U-C-Pu System. P. E. Blackburn (Last reported: ANL-7776, p. 70)

A program for investigating the carbon potentials and total pressures of the U-Pu-C system is in progress. Total pressure of actinide metal species, as well as carbon activity, are being measured by a transpiration technique. Activity measurements over a wide range of temperature and with well-defined composition are needed to establish reliable thermodynamic quantities and to define phase-boundary composition. In particular, 
carbon-activity data are important in predicting possible carbon embrittlement of cladding by carbide fuel, the chemical state of fission products, and effects of additives on the properties of fast-reactor fuels. Current emphasis has been placed on the effects of oxygen contamination in uranium carbide on the system's uranium, carbon, and oxygen potentials. These studies are important in establishing allowable levels of impurity in carbide fuels, Little is known about the stability and phase relations of the uraniumcarbon-oxygen system. The oxycarbide phase has mostly been investigated in the presence of other phases, such as $\mathrm{U}, \mathrm{UO}_{2}, \mathrm{U}_{2} \mathrm{C}_{3}$, and $\mathrm{UC}_{2}$.

Phase transformations in the uranium oxycarbide system can be effected by controlling the carbon and oxygen potentials in the equilibrating gas. For example, multiphase uranium oxycarbide was prepared by heating a charge of "oxygen-free" uranium carbide of composition $\mathrm{UC}_{0.95} \mathrm{O}_{0.002} \mathrm{~N}_{0.006}$ at $2020^{\circ} \mathrm{K}$ in a carrier gas having a $\mathrm{CO}$ partial pressure of $\sim 75$ Torr (balance to 1 atm was $\mathrm{He}$ ) and a $\mathrm{CO} / \mathrm{CO}_{2}$ ratio of $-7 \times 10^{3}$. These conditions, relative to previous studies* ( $\mathrm{PCO} \approx 4-10$ Torr, $\mathrm{CO} / \mathrm{CO}_{2} \approx 4 \times 10^{4}, \mathrm{~T}=2355^{\circ} \mathrm{K}$ ) with single-phase uranium oxycarbide, were chosen to increase both the carbon and oxygen content in the ternary $\mathrm{U}-\mathrm{C}-\mathrm{O}$ system. (For a fixed $\mathrm{CO} / \mathrm{CO}_{2}$ ratio, the carbon activity increases with decrease in temperature.) In addition, we wanted to check whether the results of our oxygen partial-pressure measurements over urania compositions** were consistent with predicting the formation of $\mathrm{UO}_{2}(\mathrm{~s})$ in uranium carbides; i.e., to form $\mathrm{UO}_{2}(\mathrm{~s})$, the oxygen partial pressure must be greater than that needed for $\mathrm{UO}_{2}(\mathrm{~s})$ formation. The $\mathrm{CO} / \mathrm{CO}_{2}$ ratio of $\sim 7 \times 10^{3}$ yields a calculated value of $\log \mathrm{PO}_{2}(\mathrm{~atm})=-13.18$ at $2020^{\circ} \mathrm{K}$. From our oxygen partial-pressure measurements, $\log \mathrm{P}_{2}(\mathrm{~atm})=-14.85$ over stoichiometric urania. Metallographic as well as X-ray examination of the residues showed the presence of $\mathrm{UO}_{2}(\mathrm{~s})$ as well as "UC" and "UC. formation of $\mathrm{UO}_{2}(s)$ is consistent with expectations. The gross composition of the residues was $\mathrm{UC}_{1.01} \mathrm{O}_{0.14} \mathrm{~N}_{0.01}$ and $\mathrm{UC}_{1.07} \mathrm{O}_{0.81} \mathrm{~N}_{0.01}$ after equilibration with the carrier gas for -17 and $24 \mathrm{hr}$, respectively. From the $\mathrm{CO} / \mathrm{CO}_{2}$ ratio, the calculated carbon activity $\left({ }^{a} \mathrm{C}\right)$ is 0.015 at $2020^{\circ} \mathrm{K}$, whereas the carbon activity estimated from our measurements ${ }^{\dagger}$ with $\mathrm{H}_{2}-\mathrm{CH}_{4}$ mixtures over "oxygen-free" $\mathrm{UC}_{1.07}$ was about $0.8-0.9$ at $2020^{\circ} \mathrm{K}$. Thus, consistent with previous observations, it appears that the dissolution of oxygen in the carbide lattice decreases the activity of carbon in this system. Since the oxycarbide composition was hyperstoichiometric with respect to carbon, this reduction in carbon activity can have important implications in the transfer of carbon from fuel to cladding materials.

The question arose whether conditions could be adjusted so that the removal of $\mathrm{UO}_{2}$ and $\mathrm{UC}_{2}$ from the multiphase residue could be attained.

*Chemical Engineering Division Annual Report--1970, ANL-7775 (to be published).

***M. Tetenbaum and P. D. Hunt, J. Chem. Phys. 49,4739 (1968).

TChemical Engineering Division Annual Report--1969, ANL-7675, p. 86 (1970); and M. Tetenbaum and

P. D. Hunt, High Temperature Thermodynamic Properties of Hypo and Hyperstoichiometric Utanium

Carbides, J. Nucl. Mater. (in press). 
We could proceed via two paths, (1) by changing the $\mathrm{CO} / \mathrm{CO}_{2}$ ratio such that the value of the oxygen partial pressure would be less than that required to form $\mathrm{UO}_{2}(\mathrm{~s})$ at $2020^{\circ} \mathrm{K}$, or (2) by increasing the temperature and maintaining the same $\mathrm{CO} / \mathrm{CO}_{2}$ ratio used to form the multiphase residue. The latter procedure was chosen for our exploratory investigation. The multiphase residue was heated for $\sim 12 \mathrm{hr}$ at $2355^{\circ} \mathrm{K}$ in a carrier gas having a $\mathrm{CO} / \mathrm{CO}_{2}$ ratio of $\sim 7.6 \times 10^{3}$ and a CO partial pressure of $\sim 72$ Torr (balance helium). Under these conditions, $\log \mathrm{PO}_{2}=-11.20 \mathrm{~atm}$ and ${ }^{a} \mathrm{C}=3.4 \times 10^{-3}$. From oxygen partial-pressure measurements* over stoichiometric urania, $\log \mathrm{PO}_{2}=-11.04$ at $2355^{\circ} \mathrm{K}$. Metallographic analysis of the residue revealed a uniform structure containing UC as the major phase, a small amount of Widmanstäten $\mathrm{UC}_{2}$ precipitate within the UC grains, and, in addition, what appears to be a very fine Widmanstätten precipitate** along the grain boundaries. $\mathrm{UO}_{2}$ was not observed; $\mathrm{X}$-ray examination showed UC only. The composition of the residue was $\mathrm{UC}_{0.87} \mathrm{O}_{0.09} \mathrm{~N}_{0.02}$, as determined from carbon, oxygen, and nitrogen analysis (uranium by difference). The oxygen content was reduced from $\sim 28$ at. $\%$ in the multiphase residue containing $\mathrm{UO}_{2}$ to $\sim 4.4$ at. $\%$ in the $\mathrm{UO}_{2}$-free final residue. The results are summarized in Table V.9 and Fig. V.5, which shows the phase fields traversed during these runs. The phase diagram, proposed by Henry et al., + shows that the composition of the final residue falls in the single-phase $\mathrm{UC}_{\mathrm{x}} \mathrm{O}_{\mathrm{y}}$ region, which is consistent with the observations based on metallographic and $\mathrm{X}$-ray analysis. It is also apparent that we are able to effect phase transformations in the U-C-O system by means of controlled carbon and oxygen potentials in the equilibrating carrier-gas stream.

TABLE V.9. Composition and Phase Transformation Traverse via Controlled Oxygen and Carbon Potentials in Carrier Gas

\begin{tabular}{|c|c|c|c|c|c|c|}
\hline \multirow{2}{*}{\multicolumn{2}{|c|}{$\begin{array}{l}\text { Designation } \\
\text { on Ternary } \\
\text { Phase Diagram }\end{array}$}} & \multirow[b]{2}{*}{$\stackrel{\mathrm{T}}{\left({ }^{\circ} \mathrm{K}\right)}$} & \multirow{2}{*}{$\begin{array}{l}\text { Heating Time, } \\
\text { Cumulative } \\
\text { (hr) }\end{array}$} & \multicolumn{2}{|c|}{ Phases Found } & \multirow[b]{2}{*}{$\begin{array}{c}\text { Gross } \\
\text { Composition }\end{array}$} \\
\hline & & & & $\begin{array}{l}\text { Metallographic } \\
\text { Examination }\end{array}$ & $\begin{array}{c}\text { X-ray } \\
\text { Exanination }\end{array}$ & \\
\hline 0 & $\begin{array}{l}\text { (starting } \\
\text { material) }\end{array}$ & - & - & vC & vc & ${ }^{U C} 0.95^{0} 0.002^{\mathrm{N}_{0}} 0.006$ \\
\hline$\nabla$ & & 2020 & 16.6 & $u c, \quad v C_{2}, \mathrm{UO}_{2}$ & $\mathrm{UC}, \mathrm{aUC}_{2}, \mathrm{LO}_{2}$ & $\mathrm{vC}_{1.01^{0} 0.14^{\mathrm{N}} 0.01}$ \\
\hline$\square$ & & 2020 & 24 & $\mathrm{vC}, \mathrm{UC}_{2}, \mathrm{UO}_{2}$ & - & ${ }^{\mathrm{UC}} \mathrm{C}_{1.07} 0.81^{\mathrm{N}} 0.01$ \\
\hline$\bullet$ & & 2355 & 12 & $\begin{array}{c}\text { UC } \\
\text { wid. } v C_{2}\end{array}$ & UC only. & ${ }^{U C} 0.87^{\circ} 0.09^{N} 0.02$ \\
\hline
\end{tabular}

asee Fig. V.5.

*Ihid., see previous page.

**Widmanstattten precipitate $\left(\mathrm{UC}_{2}\right)$ indicates the presence of a high-temperature solid solution of monocarbide and dicarbide that precipitated upon cooling.

T. L. Henry, D. L. Paulson, R. Blickensderfer, and H. J. Kelly, BM-RI-6968 (1967). 


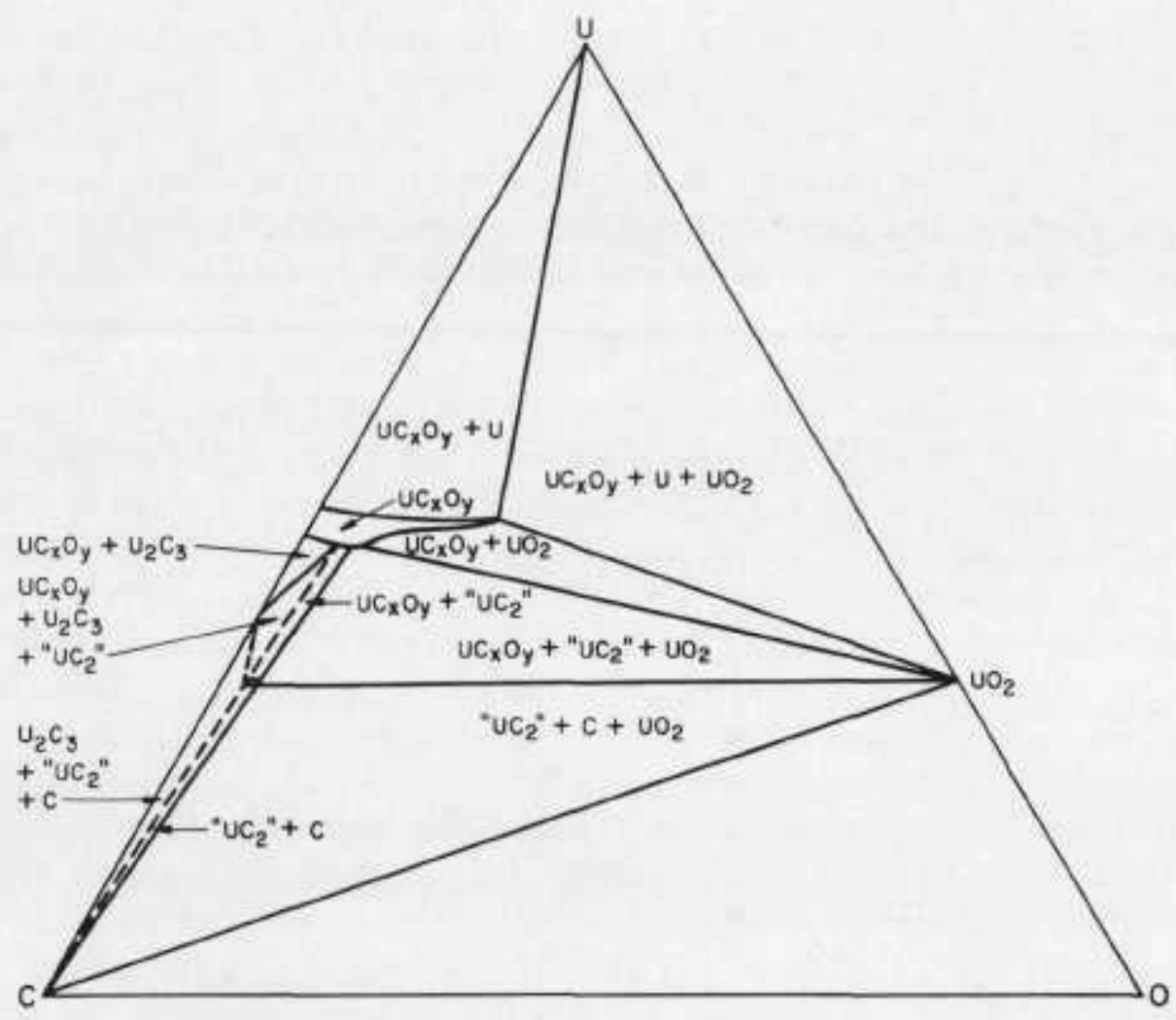

Fig. V.5. Tentative Phase Diagram of the U-C-O System at $\sim 1700^{\circ} \mathrm{C}$.

2. High-temperature Properties of Ceramic Fuels (02-094)

a. Irradiation Effects in Creep of Oxide Fuels. A. A. Solomon,

J. L. Routbort, and J. C. Voglewede (Last reported: ANL-7758, p. 78)

The effect of fission-induced creep on the behavior of mixedoxide fuel materials under typical reactor operating conditions has been evaluated using the LIFE-I modeling code.* The equation used to describe the creep of the fuel was

$$
\dot{\epsilon}=\mathrm{A}(\phi) \sigma^{4.5} \exp (-\mathrm{Q} / \mathrm{RT})+\frac{\mathrm{A}_{1}(\phi) \sigma}{\mathrm{d}^{2}} \exp \left(-\mathrm{Q}_{1} / \mathrm{RT}\right)+\mathrm{B} \phi \sigma,
$$

where

$$
\begin{aligned}
\dot{\epsilon} & =\text { plastic strain rate, } \mathrm{hr}^{-1}, \\
\phi & =\text { neutron flux, nv, } \\
\mathrm{A}(\phi) & =\left(1.38 \times 10^{-4}+3.24 \times 10^{-17} \phi\right) /(-90.5+\mathrm{D}),
\end{aligned}
$$

*V. Z. Jankus and R. W. Weeks, LIFE-I, a FORTRAN-IV Computer Code for the Prediction of Fast-reactor Fuel-element Behavior, ANL-7736 (Noy 1970). 


$$
\begin{aligned}
A_{1}(\phi)= & \left(9.73 \times 10^{6}+2.29 \times 10^{-6} \phi\right) /(-87.7+D), \\
Q= & 132 \mathrm{kcal} / \text { mole, } \\
Q_{1}= & 90 \mathrm{kcal} / \mathrm{mole}, \\
\mathrm{B}= & 8 \times 10^{-23} \text { to } 8 \times 10^{-25}, \\
\mathrm{~d}= & \text { grain size, } \mu \text { (assumed constant, } 10 \mu \mathrm{m}), \\
\mathrm{D}= & \text { percent theoretical density if greater than } 92.0 \text { (if less than } \\
& 92.0, \text { then } 92.0 \text { is used), } \\
\sigma= & \text { stress, psi, } \\
\mathrm{R}= & \text { universal gas constant, }
\end{aligned}
$$

and

$$
\mathrm{T}=\text { temperature in }{ }^{\circ} \mathrm{K} .
$$

Although the fission rate is probably the critical parameter, neutron flux is retained for convenience. A more meaningful description* of in-reactor creep in terms of fission rate is

$$
\begin{aligned}
\dot{\epsilon}= & {\left[\left(1.38 \times 10^{-4}+4.6 \times 10^{-16} \dot{\mathrm{F}}\right) /(-90.5+\mathrm{D})\right] \sigma^{4.5} \exp (-\mathrm{Q} / \mathrm{RT}) } \\
& +\left[\left(9.73 \times 10^{6}+3.24 \times 10^{-5} \dot{\mathrm{F}}\right) /(87.7+\mathrm{D})\right] \sigma \exp \left(-Q_{1} / \mathrm{RT}\right)+7 \times 10^{-3} \dot{\mathrm{F}} \sigma,
\end{aligned}
$$

where all parameters are in the same units as in Eq. 1. However, Eq. 1 was used for convenience in the LIFE-I code.

Two hypothetical reactor cycles were considered in which the reactor was brought to 12 and $16 \mathrm{~kW} / \mathrm{ft}$ in $24 \mathrm{hr}$, held at constant power $( \pm 1 \%)$ for 400 days, and cooled in $24 \mathrm{hr}$. The fuel element considered had the following characteristics: (1) 0.23 -in. cladding OD, (2) 0.015 -in.-thick Type 316 stainless steel cladding material, (3) 0.001 -in.-initial fuel/cladding gap, (4) $96 \%$ TD $\left(\mathrm{U}_{0.8} \mathrm{Pu}_{0.2}\right) \mathrm{O}_{2}$ fuel or $93.6 \%$ smeared density, and (5) 14.27 -in. fuel length and 12.88 -in. plenum length.

The effect of low-temperature, fission-induced creep was examined by setting values of $B=0,8 \times 10^{-25}$, and $8 \times 10^{-23}$ and calculating $\triangle D / D$ as a function of burnup. $A$ and $A_{1}$ were assumed flux-independent and were evaluated for $\phi=0$. As shown in Fig. V.6, at $12 \mathrm{~kW} / \mathrm{ft}, \Delta \mathrm{D} / \mathrm{D}$ can be dramatically increased by fission-induced creep. If the change in $\triangle D / D$ of 0.8 , solely due to thermal expansion, is subtracted from the total $\triangle D / D$ values, then fission-induced creep for $B=8 \times 10^{-24}$ increases $\triangle D / D$ by $62 \%$ after $8.93 \%$ burnup.

*J. L. Routbort and A. A. Solomon, Bull. Am. Ceram. Soc, 49, 9 (1970); A. A. Solomon, J. L. Routbort, and J. C. Voglewede (to be submitted to J. Nucl. Mater.). 


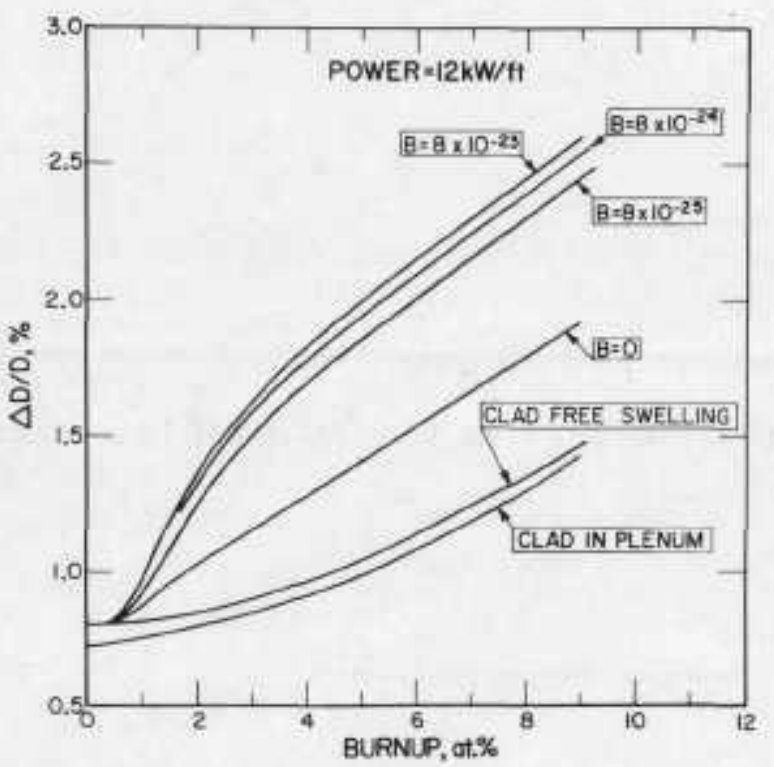

Fig. V.6. Prop strional Diametral Change $\Delta D / D$ of a $\left(\mathrm{U}_{0.8} \mathrm{Pu}_{0.2}\right) \mathrm{O}_{2}$ Fuel as a Function of Burnup. Neg. No. MSD -54274 .
As shown in Fig. V.6, the predicted swelling of the cladding at its operating temperature is considerably less than that due to fuel/ cladding interaction. The predicted cladding swelling in the plenum at the calculated plenum pressure is considerably lower than that obtained in the fuel region. It therefore appears that in this situation $\sim 60 \%$ of the fuel-element dimensional change is caused by the fuel. Similar results were obtained at $16 \mathrm{~kW} / \mathrm{ft}$. Thus, it is seen that a large increase in $\triangle D / D$ results from the increase in the plasticity in the outer portion of the fuel, which is caused by the fission process.

In Figs. V.7-V.9, the calculated tangential, radial, and axial

stresses in the fuel, $\sigma_{\theta}, \sigma_{x}$, and $\sigma_{z}$, respectively, are seen to be significantly affected by the operation of fission-induced creep. Fission-induced plasticity allows the large constraining tangential stresses in the outer portions of the fuel to be relaxed. However, these large stresses imply that fuel cracking would have occurred early in the fuel cycle.

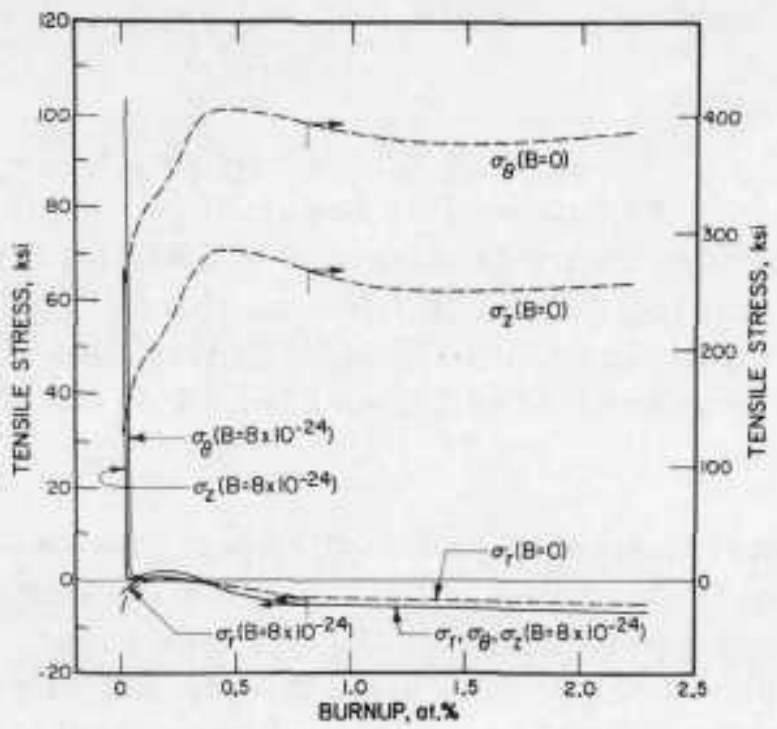

Fig. V.7. Evolution of Stresses in the Undisturbed Region of a $\left(\mathrm{U}_{0.8} \mathrm{Pu}_{0.2}\right)_{2}$ Fuel as a Function of Burnup. Neg. No. MSD-54216.

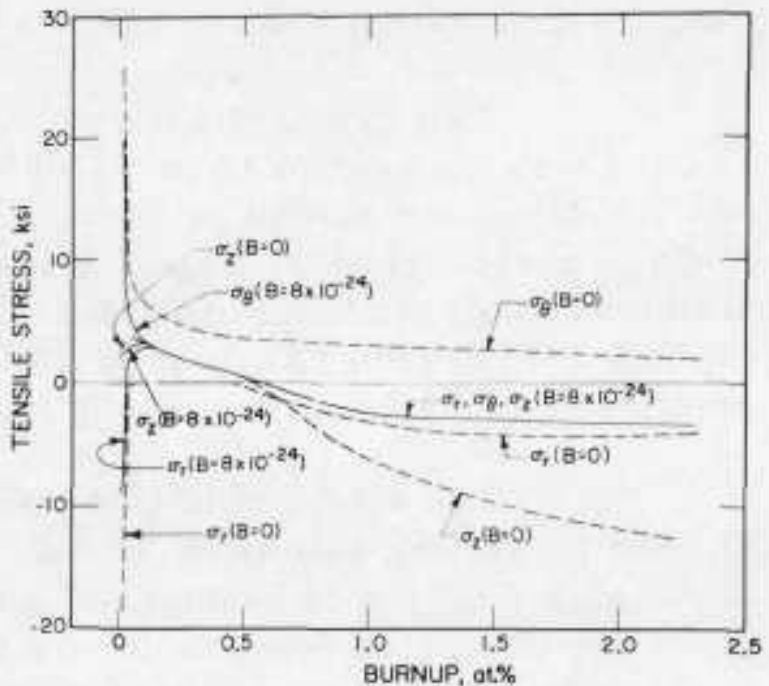

Fig. V.8. Evolution of Stresses in the Equiaxed Region of a $\left(\mathrm{U}_{0.8} \mathrm{Pu}_{0.2}\right)_{2}$ Fuel as a Function of Burnup. Neg. No, MSD-54262. 


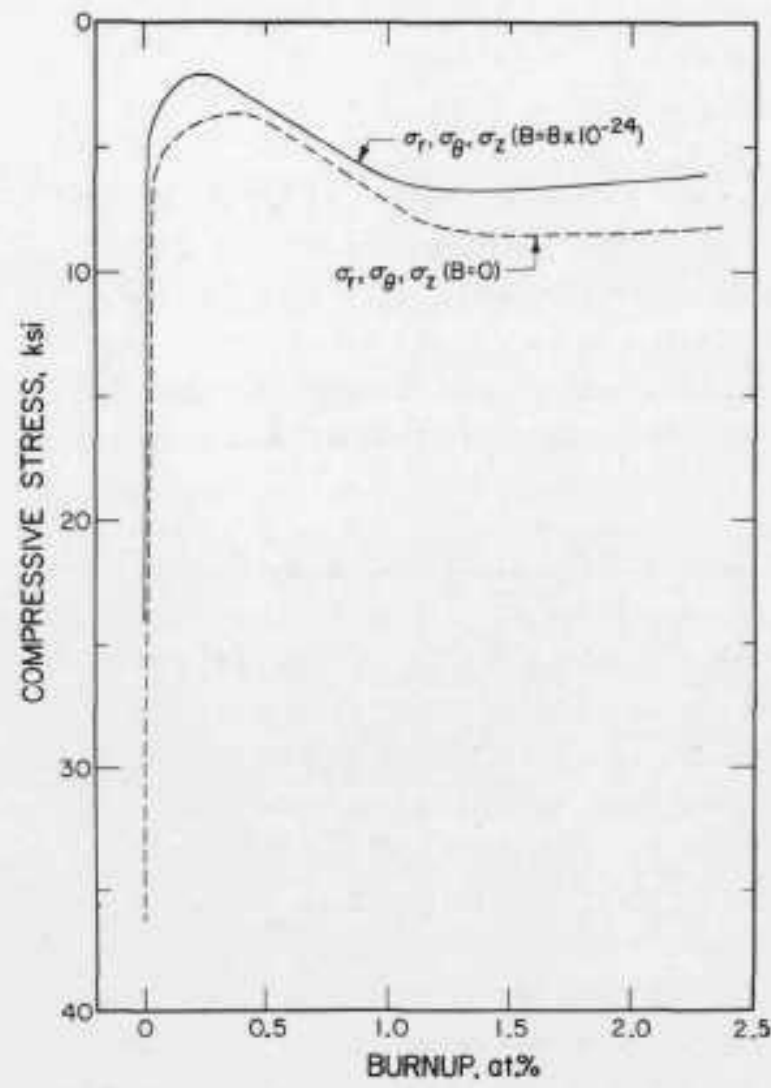

Fig. V.9. Evolution of Stresses in the Columnar Region of a $\left(\mathrm{W}_{0.8} \mathrm{Pu}_{0.2}\right)_{2}$ Fuel as a Function of Burnup. Neg. No. MSD-54264. b. X-ray and Density Measurements of Hypostoichiometric (U,Pu) Oxides. N.A. Javed (Not previously reported)

Equilibration experiments were conducted to determine the hightemperature thermodynamics and phase relations as part of a program to study the mechanical properties of mixed oxides.* Lattice constant and density measurements were also made on quenched specimens that had various oxygen-to-metal (O/M) values. The lattice constants were calculated using a computer program, developed by the Materials Science Division Scattering Studies Group, in which the maximum error is estimated to be $0.0005 \AA$. The densities were obtained using the $\mathrm{CCl}_{4}$ immersion method, which in this case had an error estimated as $\pm 0.05 \mathrm{~g} / \mathrm{cm}^{3}$. A plot of lattice parameter versus $O / M$ is shown in Fig. V.10. The theoretical densities that resulted from the two types of defect structures possible

in hypostoichiometric (U, $\mathrm{Pu}) \mathrm{O}_{2}$, i.e., (1) cation interstitials or (2) anion vacancies, were calculated from the following relations:

$$
\rho_{M_{i}}=n s[(M / s-\delta)+X] / A V
$$

Fig. V.10

Variation of Lattice Parameter with $\mathrm{O} / \mathrm{M}$ in $\left(\mathrm{U}_{0.8} \mathrm{Pu}_{0.2}\right)_{2-\mathrm{x}}$

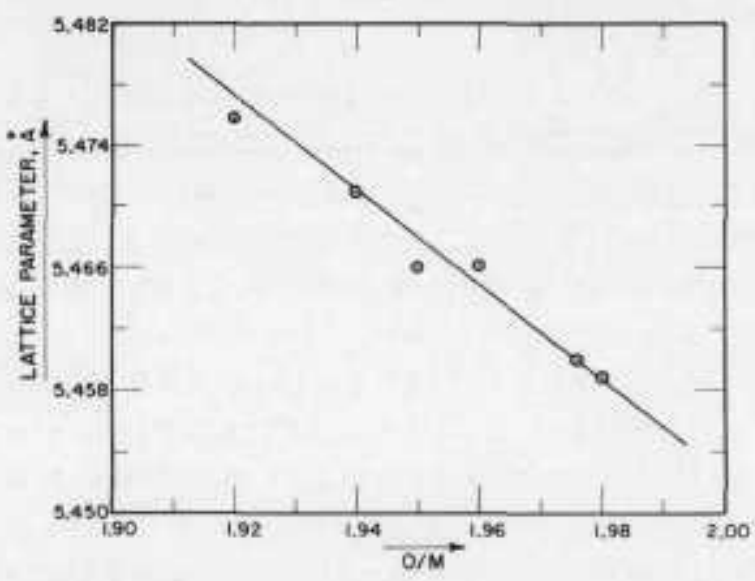

*N. A. Javed and A. A. Solomon, Bull. Am. Ceram, Soc. 50(4), 425 (Apr 1971). 
and

$$
\text { (2) } \rho \mathrm{X}_{V}=n(M+s X-\delta X) / A V \text {, }
$$

where $\mathrm{M}$ and $\mathrm{X}$ are the atomic weights, $\mathrm{s}$ is the atomic ratio, $\mathrm{A}$ is the Avogadro's number $\left(6.0249 \times 10^{23}\right), V=a_{0}^{3}$ is the volume of a unit cell, $a_{0}$

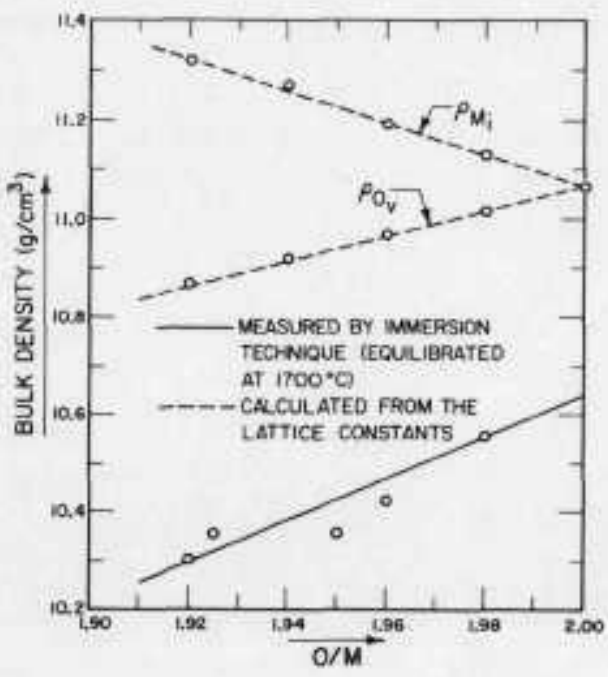

Fig. V.11. Bulk Density vs $\mathrm{O} / \mathrm{M}$ in $\left(\mathrm{U}_{0.8} \mathrm{Pu}_{0.2}\right)^{\mathrm{O}_{2-x}}$ is the lattice constant, $\delta$ is the deviation from the stoichiometric value, and $\rho_{M_{1}}$ and $\rho_{\mathrm{X}}$ are the theoretical densities due to cation interstitials or anion vacancies, respectively.

The calculated and measured densities are plotted as a function of $\mathrm{O} / \mathrm{M}$ in Fig. V.11. It shows that if the defect structure is due to cation interstitials, the density should increase as $\mathrm{O} / \mathrm{M}$ decreases, but if the defects are due to anion vacancies, the density should decrease as $\mathrm{O} / \mathrm{M}$ decreases. The measured densities decrease as $\mathrm{O} / \mathrm{M}$ decreases, which indicates that the cause of nonstoichiometry in this solid solution is predominantly due to the anion vacancies in the lattice rather than to cation interstitials. The difference in the calculated and measured densities is attributed to defects such as closed pores and voids, which were clearly observed during the metallographic examination.

3. Thermophysical Properties of Reactor Fuels. A. D. Tevebaugh and P. E. Blackburn $(02-162)$

a. Oxygen Gradients, Total Vapor Pressures, and Oxygen Potentials in Reactor Fuels. P. E. Blackburn (Not previously reported)

A transpiration apparatus, which uses a recirculating carrier gas, has been constructed to measure the pressures of oxygen and metalbearing species in equilibrium with condensed fuel oxides. The equipment was tested with $\mathrm{UO}_{2-x}$, where partial pressures of oxygen were determined as a function of composition with the temperature maintained at $2109^{\circ} \mathrm{K}$.

The carrier gas used in these experiments was a $\mathrm{H}_{2} \mathrm{O} / \mathrm{H}_{2}$ mixture. A constant $\mathrm{H}_{2} \mathrm{O}$ concentration was used to establish that equilibrium between the recirculating gas mixture and the sample had been achieved. We tried to reproduce as many of the data points as possible by doing two experiments for each point, approaching equilibrium from a lower $O / M$ value than the one desired and then approaching equilibrium from a higher $\mathrm{O} / \mathrm{M}$ value. Samples were analyzed for oxygen content at the conclusion of an equilibration by oxidizing to $\mathrm{UO}_{2.000}$ with 100 to $1000 \mathrm{ppm} \mathrm{H}_{2} \mathrm{O}$ in $\mathrm{H}_{2}$ at $1200-1300^{\circ} \mathrm{C}$. 
Table V.10 summarizes the results obtained by equilibrating $\mathrm{H}_{2} \mathrm{O} / \mathrm{H}_{2}$ mixtures with the $\mathrm{UO}_{2-\mathrm{x}}$ system. The data pertaining to oxygen pressures arose from calculations which used the equation

$$
\log \mathrm{PO}_{\mathrm{O}}=\frac{-26240}{\mathrm{~T}}+\log \frac{\mathrm{P}_{\mathrm{H}_{2} \mathrm{O}}}{\mathrm{P}_{\mathrm{H}_{2}}}
$$

with $\mathrm{P}$ in atmospheres and $\mathrm{T}$ in degrees Kelvin. This equation was employed by Tetenbaum and Hunt* for their transpiration experiments on $\mathrm{UO}_{2-\mathrm{x}}$. It may be derived from the equilibrium constant by the reaction

$$
\mathrm{H}_{2}+\frac{1}{2} \mathrm{O}_{2}=\mathrm{H}_{2} \mathrm{O}
$$

The estimated precision in the $\log \mathrm{P}_{\mathrm{O}}$ values is \pm 0.2 .

\begin{tabular}{|c|c|c|c|}
\hline Expt. No. & $\begin{array}{l}\text { Temperature, Corrected } \\
\left( \pm 3.0^{\circ} \mathrm{K}\right)\end{array}$ & $\begin{array}{l}\log P_{0} \\
(\approx 0.1 \quad \mathrm{~atm})\end{array}$ & $\begin{array}{c}0 / \mathrm{M} \\
( \pm 0.002)\end{array}$ \\
\hline vo $\$ 10$ & 2105 & -10.8 & 1.976 \\
\hline vo 12 & 2110 & -10.2 & 1.994 \\
\hline vo $\$ 13$ & 2105 & -10.8 & 1.981 \\
\hline vo 014 & 2109 & -10.4 & 1.991 \\
\hline to 015 & 2110 & -10.5 & 1.978 \\
\hline vo $\$ 16$ & 2110 & -11.0 & 1.976 \\
\hline to 17 & 2111 & -11.3 & 1.964 \\
\hline บo 918 & 2111 & -11.5 & 1.958 \\
\hline บo $\$ 19$ & 2109 & -9.8 & 2.000 \\
\hline
\end{tabular}

TABLE v.10. Summary of Data on $\mathrm{UO}_{2-\mathrm{x}}$

As indicated in the table, temperatures were measurable to $\pm 3^{\circ} \mathrm{C}$ and the precision in the $\mathrm{O} / \mathrm{M}$ values appears good. As long as the volume of the recirculating gas is large and the amount of condensate is small, the contribution by the condensate to the oxygen pressure in the gas phase would be inconsequential. A favorable comparison between our work and that of Tetenbaum and Hunt shows that the data produced with the apparatus are reliable and therefore that the method of analysis is satisfactory and the recirculating technique is appropriate.

b. Partial Pressures of Vapor Species in the U-Pu-O System and in the U-Pu-O System Containing Fission Products. P. E. Blackburn (Last reported: ANL-7783, p. 84)

Further mass-spectrometric studies of the volatilization behavior of the $\mathrm{UO}_{2}-\mathrm{PuO}_{2}$ fuel materials have been temporarily discontinued,

*M. Tetenbaum and P. D. Hunt, J. Chem. Phys. 49, 4739 (1968). 
and efforts are being directed toward studies of the reactions between liquid sodium and fuel materials. In particular, the studies are being directed toward determining the oxygen and sodium partial pressures (thermodynamic activities) of the sodium-mixed oxide reaction products [e.g., $\mathrm{Na}_{3} \mathrm{UO}_{4}$, $\mathrm{Na}_{3} \mathrm{PuO}_{4}$, or $\mathrm{Na}_{3}(\mathrm{U}, \mathrm{Pu}) \mathrm{O}_{4}$ ]. From knowledge of the oxygen partial pressure needed for the formation of the reaction products, it will be possible to estimate the $\mathrm{O} / \mathrm{M}$ atom ratio of the fuel that will not react with sodium in case of fuel-cladding failure.

Additional measurements of the $\mathrm{Na}(\mathrm{g})$ and $\mathrm{O}_{2}$ pressuretemperature relationship in the three-phase region $\mathrm{NaUO}_{3}-\mathrm{Na}_{2} \mathrm{U}_{2} \mathrm{O}_{7}-\mathrm{Na}_{2} \mathrm{UO}_{4}$ have been completed using the modified cell assembly (i.e., the iridiumlined platinum effusion cell with a $\mathrm{Pt}-\mathrm{Pt}+10 \% \mathrm{Rh}$ thermocouple attached to the cell base). The weight-loss measurements (total rate of effusion) and the temperature dependency of $\mathrm{Na}(\mathrm{g})$ agree reasonably well with the previous results (ANL-7783). However, an anomalous behavior was observed in the temperature dependency of oxygen. At temperatures greater than $1360^{\circ} \mathrm{K}$, the ion intensity deviated (decreased) from the linear extrapolation of the lower-temperature data. In fact, the data seem to indicate some type of hysteresis as the temperature was decreased. When the sample was rapidly reheated to the higher temperature, the initial data were close to the extrapolated line and then additional data decreased with time. This anomalous behavior was not observed in three subsequent experiments at temperatures less than $1360^{\circ} \mathrm{K}$. Although its cause is not presently understood, this behavior probably accounts for the erratic data obtained for $\mathrm{O}_{2}$ in earlier experiments (ANL-7783).

For the three-phase region $\mathrm{Na}_{3} \mathrm{UO}_{4}-\mathrm{Na}_{4} \mathrm{UO}_{5}-\mathrm{NaUO}_{3}$, the partial enthalpy of vaporization for $\mathrm{Na}(\mathrm{g})$ was determined from the slope of the temperature-dependency data (i.e., $\log I^{+} T$ versus $1 / T$ ). The average value is $59.89 \pm 4.21 \mathrm{kcal} / \mathrm{mol} \mathrm{Na}$. The partial pressure of $\mathrm{Na}(\mathrm{g})$ was determined from the rate-of-effusion (weight-loss) measurements with the assumption that the vapor phase was entirely $\mathrm{Na}(\mathrm{g})$. This is a valid assumption, since the $\mathrm{PO}_{2}$ is about $10^{-12}$ atm. An average value of $4.57 \times 10^{-6}$ atm was obtained for $\mathrm{P}_{\mathrm{Na}}$ at $1131^{\circ} \mathrm{K}$. When the values for the partial enthalpy and partial pressure for sodium at $1131^{\circ} \mathrm{K}$ are used to evaluate the intercept, the following equation is obtained for the pressure-temperature relationship:

$$
\log \mathrm{P}_{\mathrm{Na}}=\frac{-13,090 \pm 920}{\mathrm{~T}}+6.230, \quad 1081-1243^{\circ} \mathrm{K} .
$$

Similar analysis of the pressure- and temperature-dependency data yield the following pressure-temperature relationship for $\mathrm{Na}(\mathrm{g})$ in the threephase region $\mathrm{NaUO}_{3}-\mathrm{Na}_{2} \mathrm{UO}_{4}-\mathrm{Na}_{4} \mathrm{UO}_{5}$ :

$$
\log \mathrm{P}_{\mathrm{Na}}=\frac{-13,200 \pm 320}{\mathrm{~T}}+6.020, \quad 1059-1305^{\circ} \mathrm{K}
$$


For the three-phase region $\mathrm{NaUO}_{3}-\mathrm{Na}_{2} \mathrm{U}_{2} \mathrm{O}_{7}-\mathrm{Na}_{2} \mathrm{UO}_{4}$, the pressuretemperature relationship for $\mathrm{Na}(\mathrm{g})$ and $\mathrm{O}_{2}(\mathrm{~g})$ may be calculated by two procedures. In the first procedure, the ionization cross sections for $\mathrm{Na}(\mathrm{g})$ and $\mathrm{O}_{2}(\mathrm{~g})$ are assumed equal, thus permitting the determination of the vaporphase composition. With this information and the weight-loss data, the partial pressures can be calculated by means of the equation for molecular effusion, i.e.,

$$
P_{i}=\frac{2.256 \times 10^{-2} W F_{i}}{A t k} \sqrt{\frac{T}{M_{i}}}
$$

where W/At is the rate of effusion in $\mathrm{g} / \mathrm{cm}^{2}-\mathrm{sec}, F_{i}$ is the weight fraction of total vapor, and $\mathrm{k}$ is the Clausing correction factor. This procedure was used in calculating the $\mathrm{P}_{\mathrm{Na}}$ and $\mathrm{P}_{2}$ values listed in Table II.D.1 of ANL-7758, p. 90 .

In the second procedure, the partial pressures of $\mathrm{Na}(\mathrm{g})$ and $\mathrm{O}_{2}$ can be calculated by determining the constant, $\mathrm{K}$, in the relationship

$$
\mathrm{I}_{\mathrm{i}}^{+} \mathrm{T}=\mathrm{KP}_{\mathrm{i}} \text {, }
$$

where $\mathrm{I}_{\mathrm{i}}{ }^{+}$is the measured ion current of a given species, $\mathrm{T}$ is the absolute temperature, and $P_{i}$ is the partial pressure. The constant $K$ includes the instrument and geometric factors, the ionization cross section, the multiplier efficiency, and the ionization energy. In this system (Na-U-O), the three-phase regions ( $\mathrm{NaUO}_{3}-\mathrm{Na}_{3} \mathrm{UO}_{4}-\mathrm{Na}_{4} \mathrm{UO}_{5}$ and $\mathrm{NaUO} \mathrm{O}_{3}-\mathrm{Na}_{4} \mathrm{UO}_{5}-\mathrm{Na}_{2} \mathrm{UO}_{4}$ ) vaporize almost entirely as $\mathrm{Na}(\mathrm{g})\left(\mathrm{P}_{2}\right.$ is extremely low), whereas the three-phase region $\left(\mathrm{NaUO}_{3}-\mathrm{Na}_{2} \mathrm{UO}_{4}-\mathrm{Na}_{2} \mathrm{U}_{2} \mathrm{O}_{7}\right)$ vaporizes as $\mathrm{Na}(\mathrm{g})$ and $\mathrm{O}_{2}(\mathrm{~g})$. Therefore, the constant $\mathrm{K}$ can be evaluated in the regions where the vapor is entirely $\mathrm{Na}(\mathrm{g})$ and then used to calculate $\mathrm{P}_{\mathrm{Na}}$ and $\mathrm{PO}_{2}$ in other regions. The partial pressure of $\mathrm{Na}(\mathrm{g})$ at a given temperature was determined in the first two regions from weight-loss measurements (as noted above). Also, the ion current was measured during these experiments. Additional values of the ion current were obtained from the temperature-dependency data $\left(\log \mathrm{I}^{+} \mathrm{T}\right.$ versus $\left.1 / \mathrm{T}\right)$. The value of $\mathrm{K}$ obtained from all data is $8.7 \mathrm{x}$ $10^{8} \pm \sim 15 \%$.

For the three-phase region $\mathrm{NaUO}_{3}-\mathrm{Na}_{2} \mathrm{UO}_{4}-\mathrm{Na}_{2} \mathrm{U}_{2} \mathrm{O}_{7}$, the partial pressure of $\mathrm{Na}(\mathrm{g})$ was calculated from the measured ion intensity $\mathrm{I}_{\mathrm{Na}} \mathrm{ob}-$ tained during the weight-loss experiments (constant temperature) and the value of $\mathrm{K}$ given above. The weight loss due to the vaporization of $\mathrm{Na}(\mathrm{g})$ was calculated (Eq. 3), and the weight loss due to the vaporization of $\mathrm{O}_{2}$ was obtained by difference, which permits calculation of the $\mathrm{PO}_{2}$. Applying the same procedure described above (Eq. 1), the following pressure-temperature relationships for $\mathrm{Na}(\mathrm{g})$ and $\mathrm{O}_{2}(\mathrm{~g})$ were obtained:

$$
\log \mathrm{P}_{\mathrm{Na}}=\frac{-14,050 \pm 630}{\mathrm{~T}}+5.180, \quad 1086-1398^{\circ} \mathrm{K}
$$




$$
\log \mathrm{P}_{\mathrm{O}_{2}}=\frac{-20,240 \pm 660}{\mathrm{~T}}+9.090, \quad 1086-1398^{\circ} \mathrm{K} .
$$

The partial pressures of $\mathrm{Na}(\mathrm{g})$ and $\mathrm{O}_{2}(\mathrm{~g})$ obtained by this procedure are independent of any assumptions of the ionization cross-section values. These pressures differ considerably from the pressures calculated earlier, where the ionization cross sections were assumed equal.

Weight-loss and temperature-dependency measurements for the three-phase regions $\mathrm{NaUO}_{3}-\mathrm{Na}_{3} \mathrm{UO}_{4}-\mathrm{UO}_{2}$ and $\mathrm{Na}_{3} \mathrm{UO}_{4}-\mathrm{UO}_{2}-\mathrm{Na}$ are being conducted. Preliminary results indicate that the partial pressure of $\mathrm{Na}(\mathrm{g})$ in region $\mathrm{Na}-\mathrm{UO}_{2}-\mathrm{Na}_{3} \mathrm{UO}_{4}$ is about the same as for pure sodium.

c. U-Pu-O Phase Diagram. P. E. Blackburn (Last reported:

The reaction of liquid sodium with uranium-plutonium mixed oxides is being studied. This reaction is of great importance because of the possible interaction of the sodium coolant with reactor fuel. The reaction could cause fuel swelling and cladding rupture in the event of a breach in the fuel cladding. The severity of the problem may determine how long failed fuel elements can be stored in the reactor core and also whether failed fuel elements can be stored in the reactor coolant sodium. Possibly the potential reaction could be avoided by using a fuel element sufficiently low in $\mathrm{O} / \mathrm{M}$ composition.

The reaction of sodium with sintered mixed-oxide pellets having a $\mathrm{Pu} /(\mathrm{U}+\mathrm{Pu})$ ratio of 0.20 yields a product identified as $\mathrm{Na}_{3} \mathrm{MO}_{4}$, where $\mathrm{M}$

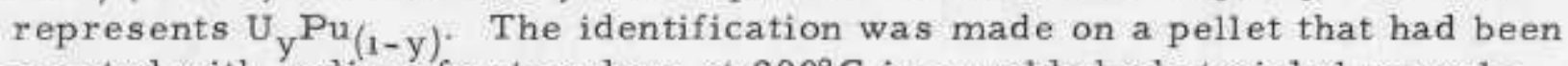
reacted with sodium for two days at $900^{\circ} \mathrm{C}$ in a welded-shut nickel capsule. The free sodium was removed from the product by dissolution in ethyl alcohol. Two samples of the product pellet, one from the surface and one from the interior, were examined by $\mathrm{X}$-ray diffraction. The phases identified in both samples were $\mathrm{Na}_{3} \mathrm{MO}_{4}$ and $\mathrm{MO}_{2-\mathrm{x}}$. The $\mathrm{Na}_{3} \mathrm{MO}_{4}$ was the major phase in the surface sample and the minor phase in the interior sample.

Some progress has been made in establishing the $\mathrm{O} / \mathrm{M}$ composition of the mixed-oxide phase for $\mathrm{Pu} /(\mathrm{U}+\mathrm{Pu})=0.20$ after reaction with sodium. The lattice-parameter method is being used. The lattice parameters of the $\mathrm{MO}_{2-x}$ phase in samples of the pellet described above and a pellet that had been reacted with sodium for 14 days at $900^{\circ} \mathrm{C}$ were $5.467_{1}$ and 5.4655 , respectively. Based on our present calibration graph of lattice parameter versus $\mathrm{O} / \mathrm{M}$ composition, these values correspond to $\mathrm{O} / \mathrm{M} \mathrm{com}$ positions of 1.956 and 1.961 , respectively.

These $\mathrm{O} / \mathrm{M}$ compositions can be compared with compositions calculated from the weight increases of pellets reacted with sodium under 
similar conditions. As previously reported (ANL-7776), weight increases of $0.48,0.53$, and $0.60 \%$ were obtained for pellets reacted for 1,7 , and 20 days at $800^{\circ} \mathrm{C}$. From these weight increases, the $\mathrm{O} / \mathrm{M}$ compositions of the product pellets were calculated to be $1.957,1.953$, and 1.947 , respectively. For these calculations, it was assumed (1) that the sodium, which contained only 4 ppm oxygen, was a negligible source of oxygen for the formation of $\mathrm{Na}_{3} \mathrm{MO}_{4}$ and (2) that the reaction which occurred was as follows:

$$
\mathrm{MO}_{1.995}+3 \mathrm{yNa}=\mathrm{yNa} \mathrm{MO}_{4}+(1-\mathrm{y}) \mathrm{MO}_{2-\mathrm{x}} .
$$

Thus there is a fair agreement between the $\mathrm{O} / \mathrm{M}$ compositions calculated from weight increases and the $\mathrm{O} / \mathrm{M}$ compositions determined from latticeparameter measurements.

For the establishment of the calibration graph of lattice parameter versus $\mathrm{O} / \mathrm{M}$ composition, as well as for other purposes associated with the U-Pu-O phase study, mixed-oxide pellets $[\mathrm{Pu} /(\mathrm{U}+\mathrm{Pu})=0.20]$ were reduced at temperatures higher than those normally used commercially. The degree of reduction achieved may be of some general interest. Single pellets, each weighing about $1.5 \mathrm{~g}$, were reduced with $6 \% \mathrm{H}_{2}-94 \% \mathrm{He}, 1.5-\mathrm{ppm}$ nominal oxygen content, at a flow rate of $42 \mathrm{cc} / \mathrm{min}$ for $7 \mathrm{hr}$. At reduction temperatures of $1551,1692,1793$, and $1930^{\circ} \mathrm{C}$, the $\mathrm{O} / \mathrm{M}$ compositions of the product pellets were $1.942,1.935,1.925$, and 1.908 , respectively. Volatilization losses of uranium and plutonium were not significant. At the two highest temperatures, the $\mathrm{O} / \mathrm{M}$ compositions of the products based on weight loss were calculated to be 1.927 and $1.90_{3}$, respectively, in fair agreement with the analyses.

4. Physical and Chemical Studies--Molten Fuel, Cladding, and Coolant. A. D. Tevebaugh and M. G. Chasanov $(02-175)$

a. Thermal Diffusivity of Reactor Materials: Liquid $\mathrm{UO}_{2}$. M. G. Chasanov (Last reported: ANL-7783, p. 89)

Values of the thermal diffusivity of $\mathrm{UO}_{2}$ in the liquid state are of importance to the reactor safety program. This information is needed to evaluate means of safely cooling the core of an LMFBR in the event of a meltdown incident. A knowledge of the thermal conductivity of liquid $\mathrm{UO}_{2}$ will also be useful in determining the temperature distribution in the clad fuel under operating conditions.

We will determine the thermal diffusivity from the phase change in a thermal wave produced by heating the sample with a sinusoidally modulated electron beam. Two new electron-beam guns installed on the furnace did not perform as specified. Adequate grid control was not obtained, and, because of conductive coating of the ceramic filament support, loss of grid control occurred within a short period of operation ( 1 to $2 \mathrm{hr}$ ). Since a 
representative of the vendor failed to correct the malfunction, one gun has been returned to the vendor for testing. In the meantime, we modified the electrode system of the other gun in order to provide electrical insulation between the filament support, holder-plate, and grid housing. We have been able to operate the gun for $4 \frac{\mathrm{l}}{2} \mathrm{hr}$ without losing grid control. Testing will be continued to determine the minimum time of operation before grid control is lost or the filament requires replacement.

Uranium dioxide disks, for use in the thermal-diffusivity experiments, have been obtained from Battelle Memorial Institute (Columbus, Ohio). The capability of the ANL shop for electron-beam-welding a tungsten cell containing one of the disks is now being evaluated.

Modification and replacement of components of the beam-control systems continue. This was found necessary because of the age of the electronic equipment received with the electron-beam furnace, which had been previously used in another ANL division. 


\section{Fuel Elements}

1. Behavior of Reactor Materials (02-086)

a. Migration of Major Fuel Constituents. R. O. Meyer and D. R. O'Boyle (Last reported: ANL-7776, p. 65)

The radial distribution of uranium and plutonium has been measured on four pellet-type fuel elements that were irradiated in EBR-II at moderate power levels and burnups of 0.9-10.8 at. \%. The fuel and the operating conditions are described in Table V.11. A radial section from the midplane of each fuel element was examined with a shielded electron microprobe analyzer. Uranium and plutonium X-ray data were collected on each specimen along three radial lines roughly $120^{\circ}$ apart, and the measured X-ray intensities were corrected by means of the MAGRAM* computer code to obtain weight concentrations of uranium and plutonium.

TABLE V.11. Measured Maximum Plutonfum Concentrations in Four Mixed-axide Fuel Blements Irradiated in EBR-II

\begin{tabular}{|c|c|c|c|c|c|c|}
\hline $\begin{array}{l}\text { Fuel-element } \\
\text { Identffication }\end{array}$ & $\begin{array}{l}\text { Burnup, } \\
\text { at. } \mathbf{z}\end{array}$ & $\begin{array}{c}\text { Linear Power, } \\
\qquad \mathrm{kW} / \mathrm{ft}\end{array}$ & $\begin{array}{c}\text { Intefa1 Puel } \\
\text { Dens1ty, } \\
\text { X TD }\end{array}$ & $\begin{array}{c}\text { Initial } \\
\text { Plutoniua } \\
\text { Concentration, } \\
\text { wt } \mathbf{z}\end{array}$ & $\begin{array}{l}\text { Maxinum } \\
\text { Plutonium } \\
\text { Concontration, } \\
\text { we } \&\end{array}$ & $\begin{array}{c}\text { Increase in } \\
\text { Plutonfum } \\
\text { Concentration, } \\
z\end{array}$ \\
\hline P\&L-1-14 & 0.85 & 10.3 & 92.5 & 22.1 & 22.0 & 0 \\
\hline ANL-012 & 2.9 & 16.0 & 81.6 & 17.7 & 23.7 & 34 \\
\hline ANT- -007 . & 4.7 & 15.6 & 79.3 & 17.7 & 26.1 & 48 \\
\hline NUMEC C-11 & 10.8 & 13.9 & 90.6 & 17.7 & 25.6 & 45 \\
\hline
\end{tabular}

Figure V.12 shows the measured plutonium distribution along one radius of NUMEC fuel element C-11, which is typical of the fuel elements that exhibited plutonium redistribution. The plutonium concentration increased near the center of the fuel element and decreased in the cooler region, causing a minimum in the concentration profile. This concentration

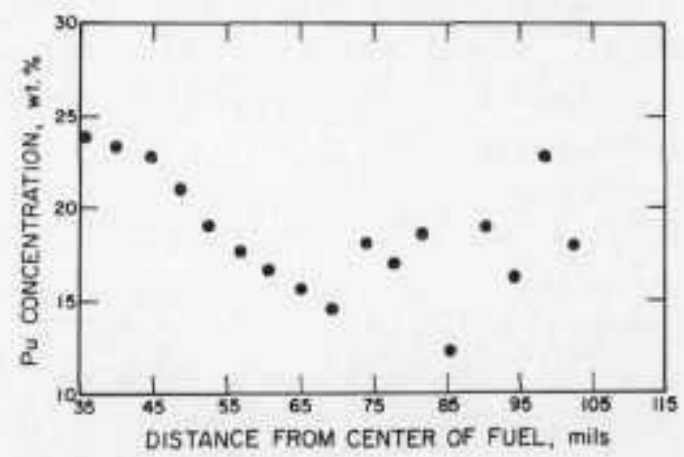

Fig. V.12

Radial Plutonium Concentration at the Midplane Section of Fuel Element C-11 Irradiated in EBR-II to $10.8 \mathrm{at}$. \% Burnup at $13.9 \mathrm{~kW} / \mathrm{ft}$. The initial plutonium concentration was 17.7 wt \%. Neg. No, MSD-54491.

*R. Natesh, E. M. Butler, and D. R. O'Boyle, MAGRAM--A Computer Code for Quantitative Electron-microprobe Analysis of Radioactive Materials, ANL-7794 (to be published), 
distribution of fissile atoms suggests that a steady state has not been attained. The large scatter in plutonium concentration in the unrestructured region of the fuel reflects the inhomogeneity of the starting fuel material. A complementary curve for uranium concentration was obtained, and it was found that the sum of the plutonium and uranium concentrations was constant along the radius of the fuel.

Using least-squares methods, the three data sets for each fuel element were combined and extrapolated to the edge of the central void and to the center of fuel element PNL-1-14, which had no central void. The resultant values of the maximum plutonium concentrations found in the four fuel elements are also given in Table V.11. The burnup and linear power values listed correspond to the fuel sections analyzed. The maximum plutonium concentration values shown have been adjusted so that the sum of the measured plutonium and uranium concentration is equal to $88.2 \mathrm{wt} \%$, thereby eliminating fission-product dilution effects. The percent increase in plutonium concentration was calculated by comparing the initial plutonium concentrations in the fuel pellets with the maximum plutonium concentrations observed. The data indicate that in mixed-oxide fuel elements irradiated at less than $10 \mathrm{~kW} / \mathrm{ft}$ to low burnups, the amount of plutonium redistribution is negligible. However, substantial plutonium redistribution occurs in fuel elements irradiated at linear power ratings of $14-16 \mathrm{~kW} / \mathrm{ft}$. The fuel element with the highest burnup $(C-11)$ did not exhibit the greatest amount of plutonium redistribution; it was not operated at as high a power level as Elements ANL-012 or ANL-007. Thus it appears that plutonium redistribution continues to occur during a significant portion of the fuel lifetime. Further analysis of these data and data from other cross sections is in progress.

b. Fuel-Fission-product-Cladding Interactions. P. S. Maiya and D. E. Busch (Not previously reported)

The lifetime of mixed-oxide, fast-reactor fuel elements is dependent on the intergranular penetration of austenitic stainless steel by volatile fission products, mainly cesium and molybdenum. Therefore, it is important to predict the conditions under which fission-product-cladding interactions occur and to determine the reaction kinetics and the mechanism of the process. Since the activity of oxygen in cesium is controlled by the oxygen-to-metal ratio $(\mathrm{O} / \mathrm{M})$ of the mixed-oxide fuel, the effect of oxygen activity in cesium on cladding attack has been examined.

To compare the oxygen potential of the fuel with that of cesium containing oxygen, the partial molal free energy of oxygen in $\left(\mathrm{U}_{0.8} \mathrm{Pu}_{0.2}\right) \mathrm{O}_{2} \pm \mathrm{x}$ was plotted as a function of $\mathrm{O} / \mathrm{M}$ from 400 to $1200^{\circ} \mathrm{C}$ and then related to that of cesium at several oxygen concentrations. From the published phase diagram, the oxygen solubility data were obtained. The variation in the solubility of oxygen in liquid cesium $\left(\underline{Q}_{C_{s}}\right)$ is given by

$$
\log \underline{\mathrm{C}}_{\mathrm{s}}(\text { wt } \%)=0.9382-\frac{179.5}{\mathrm{~T}\left({ }^{\circ} \mathrm{K}\right)} \text {. }
$$


From the above data and assuming Henry's law to be valid, the partial molal free energy of oxygen in cesium was calculated and related to

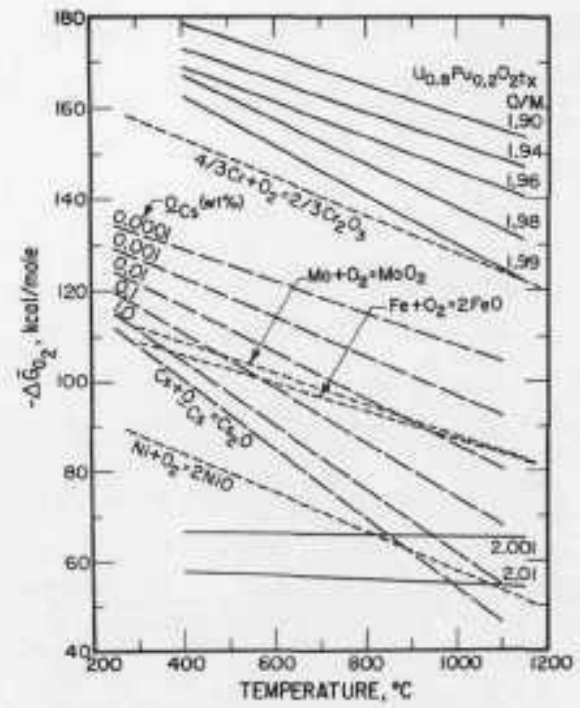

Fig. V.13

The Partial Molal Free Energy of Oxygen in $\left(\mathrm{U}_{0.8} \mathrm{P}_{0.2}\right) \mathrm{O}_{2 \pm \mathrm{x}}$ Compared with that of Cesium at Seycral Oxygen Concentrations. Neg. No. MSD -54507 . the fuel $\mathrm{O} / \mathrm{M}$ in $\left(\mathrm{U}_{0.8} \mathrm{Pu}_{0.2}\right) \mathrm{O}_{2}+\mathrm{x}$, as shown in Fig. V.13. It is clear that from 400 to $900^{\circ} \mathrm{C}$, hypostoichiometric mixed-oxide fuel is thermodynamically more stable than cesium containing 1-1000 ppm oxygen.

To determine whether a critical concentration of oxygen in cesium exists for the initiation of cladding attack, a series of outof-pile experiments has been completed in which solution-treated Type 304 stainless steel was exposed to cesium at various oxygen potentials. Some of the results are shown in Table V.12. The results suggest that cesium containing up to $\sim 1 \mathrm{wt} \%$ oxygen is compatible with Type 304 stainless steel at $690^{\circ} \mathrm{C}$, but the saturated solution, which contains $\mathrm{Cs}_{2} \mathrm{O}$, severely attacks stainless steel. Therefore, it appears that when the oxygen potential becomes sufficiently high to form $\mathrm{Cs}_{2} \mathrm{O}$, severe grainboundary attack occurs.

Cesium oxide was observed to attack the grain boundaries in both solution-treated Type 304 stainless steel and $20 \%$ cold-worked Type 316 stainless steel. However, the rate of attack was less rapid in Type 316 than in Type 304 stainless steel. For example, the penetration depth in Type 316 stainless steel exposed to $\mathrm{Cs}_{2} \mathrm{O}$ at $690^{\circ} \mathrm{C}$ for $36 \mathrm{hr}$ was 4.5 mils compared with 10.8 mils in Type 304 stainless steel under identical exposure conditions. The microstructure of Type 316 austenitic stainless steel attacked intergranularly by $\mathrm{Cs}_{2} \mathrm{O}$ is shown in Fig. V.14. Further out-of-pile experiments are being conducted to establish the kinetics of attack from 500 to $700^{\circ} \mathrm{C}$.

TABLE V.12. Effect of Oxygen Potential on the Attack of Type 304 Stainless Steel by Cesium at $690^{\circ} \mathrm{C}$

\begin{tabular}{cccc}
\hline $\begin{array}{c}\text { Oxygen } \\
\begin{array}{c}\text { Concentration } \\
\text { In Cesium, } \\
\text { wt } z\end{array}\end{array}$ & $\begin{array}{c}\text { Oxygen Potential } \\
\left(-\Delta \bar{G}_{\mathrm{O}_{2}}\right), \\
\text { kcal/mole }\end{array}$ & $\begin{array}{c}\text { Exposure Time, } \\
\text { hr }\end{array}$ & $\begin{array}{c}\text { Metallographic } \\
\text { Observation } \\
\text { of Cladding }\end{array}$ \\
\hline 0.17 & 93.5 & 672 & No attack \\
1.05 & 86.4 & 36 & No attack \\
$\begin{array}{c}5.65 \\
\text { (saturated) }\end{array}$ & 80.0 & 14 & Severe attack
\end{tabular}




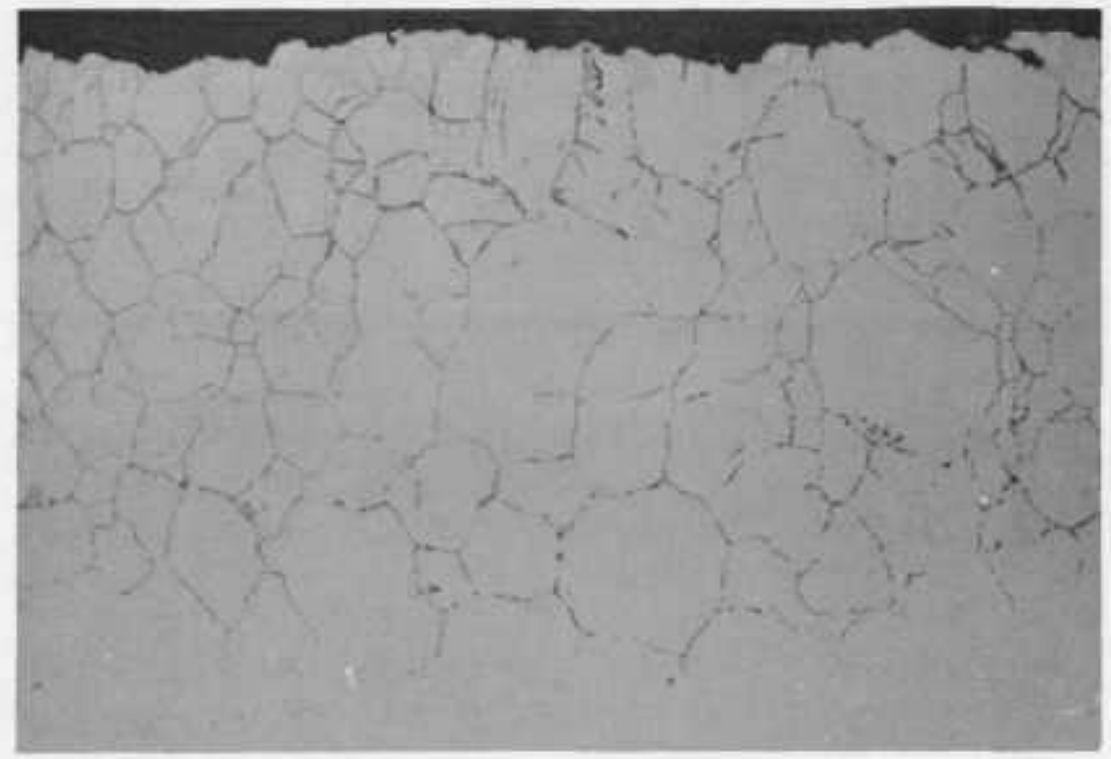

Fig. V.14. Microstructure of $20 \%$ Cold-worked Type 316 Stainless Steel Exposed to Cesium Oxide at $690^{\circ} \mathrm{C}$ for $36 \mathrm{hr}$, Showing Intergranular Penetration (as-polished). Mag. 500X. Neg. No. MSD-54450.

An investigation of the grain-boundary corrosion product in Type 304 stainless steel by scanning electron microscopy and energydispersive $\mathrm{X}$-ray analyses indicated that (1) cesium was present at the penetrated grain-boundary regions, (2) the $\mathrm{Cr}-\mathrm{Fe}$ ratio was as high as 1.2 in the grain-boundary region compared with 0.5 in the matrix, (3) no cesium was present in the cladding matrix, and (4) some iron and chromium from the stainless steel was transferred to the $\mathrm{Cs}_{2} \mathrm{O}$ during the anneal. Thus, it is likely that cesium oxide forms a complex phase with chromium oxide at the austenitic grain boundaries.

The above results suggest that the mechanism of intergranular penetration of austenitic stainless steel involves internal oxidation of chromium to chromium oxide followed by a complex reaction between cesium oxide and chromium oxide. Both preferential oxidation of the cladding and the presence of $\mathrm{Cs}_{2} \mathrm{O}$ are essential for cladding attack. This mechanism is consistent with the fact that cesium containing 1 wt $\%$ oxygen, which is sufficient to oxidize chromium to chromium oxide, does not attack Type 304 stainless steel. However, a saturated solution containing $\mathrm{Cs}_{2} \mathrm{O}$, which causes both oxidation and interfacial reactions between $\mathrm{Cs}_{2} \mathrm{O}$ and $\mathrm{Cr}_{2} \mathrm{O}_{3}$, does severely attack the stainless steel. Both processes necessary for the cladding attack occur more readily at the grain boundaries because chromium-rich phases (e.g., carbides) are present, and also because grain boundaries provide easy paths for reaction and mass transport; therefore, the attack is intergranular. 
The rate-determining mechanism for cladding attack may be due to (1) diffusion of cesium and oxygen in the corrosion-product phase at the grain boundary, (2) diffusion of oxygen ahead of the corrosion product, or (3) interfacial reaction between cesium oxide and chromium oxide to form a complex phase at the tip of the penetrated zone. If the advance of the interface is controlled by either (1) or (2), which are diffusion-controlled, the penetration kinetics are parabolic. If the rate-limiting step is (3), which is interfacial-reaction-controlled, the kinetics are linear. Preliminary data on the time-dependence of penetration at $690^{\circ} \mathrm{C}$ show that the penetration process has parabolic kinetics, indicating that it is diffusion-controlled. Additional data are being obtained to determine the rate of cesium attack more precisely and to confirm the proposed cladding-attack mechanism. The interactions of cesium and molybdenum with Type 316 stainless steel are also being studied.

c. Experimental Studies of Swelling Mechanisms and Gas Release in Fuel Materials. S. R. Pati and D. R. O'Boyle (Last reported: ANL-7758, p. 70)

(1) Re-solution of Gaseous Fission Products in Oxide Fuels. To establish the quantity of fission gas in metastable solid solution (due to re-solution) and to improve our understanding of the re-solution process, a series of controlled irradiation experiments has been planned to determine the fraction of fission gases that are in solution in $\mathrm{UO}_{2}$ as a function of fission rate, irradiation dose, and temperature.

The kinetic solubility of gaseous fission products in $\mathrm{UO}_{2}$ has been calculated as a function of fission rate, irradiation dose, and temperature based on the re-solution model proposed by Nelson.* Figure V.15 shows the calculated solubility of xenon at $1150^{\circ} \mathrm{C}$ as a function of irradiation time and dose for two fission rates, $10^{13}$ and $10^{14}$ fissions $/ \mathrm{cm}^{3} \mathrm{sec}$. Since the expected fission rate in the FFTF driver fuel occurs between these two values, they will be studied in the experimental irradiations. These calculations show that the atomic diffusion rate of xenon in $\mathrm{UO}_{2}$ plays an important role in establishing the amount of gas in solid solution. Figure V.13 shows the expected solubility based on the diffusion coefficient of xenon assumed by Nelson* and the out-of-pile diffusivity of xenon deduced by Cornell.** It is evident that a difference of a factor of 4 in xenondiffusivity $r$ sults in a difference of a factor of $\sim 2$ in calculated solubility. Since irradiation is expected to affect the diffusivity of xenon in $\mathrm{UO}_{2}$, one of the major uncertainties in calculating fission-gas solubility is in the use of out-of-pile diffusion coefficients of xenon for calculating in-pile solubility. Experimental observations by Turnbull and Cornell ${ }^{\dagger}$ indicate that the diffusion rate of

*R. S. Nelson, J. Nuc1. Mater. 31,153 (1969).

**R. M. Comell, Phil. Mag. $19, \overline{5} 39$ (1969).

†T. A. Turnbull and R, M. Cornell, J. Nuc1. Mater. 37 , 355 (1970). 
fission-gas atoms in $\mathrm{UO}_{2}$ is considerably enhanced by irradiation at temperatures up to $1300^{\circ} \mathrm{C}$. Accepting the results based on out-of-pile diffusion data, we conclude that an appreciable fraction of the inert fission gases remain in solution at typical LMFBR operating conditions. For example, at burnups up to 1 at. $\%$, as much as $90 \%$ of the fission-gas atoms remain in solution at $1150^{\circ} \mathrm{C}$ under fission rates of $10^{13}$ to $10^{14}$ fissions $/ \mathrm{cm}^{3} \mathrm{sec}$, and at burnups to 7 at. $\%$, as much as $80 \%$ of the fission gases remain in solution.

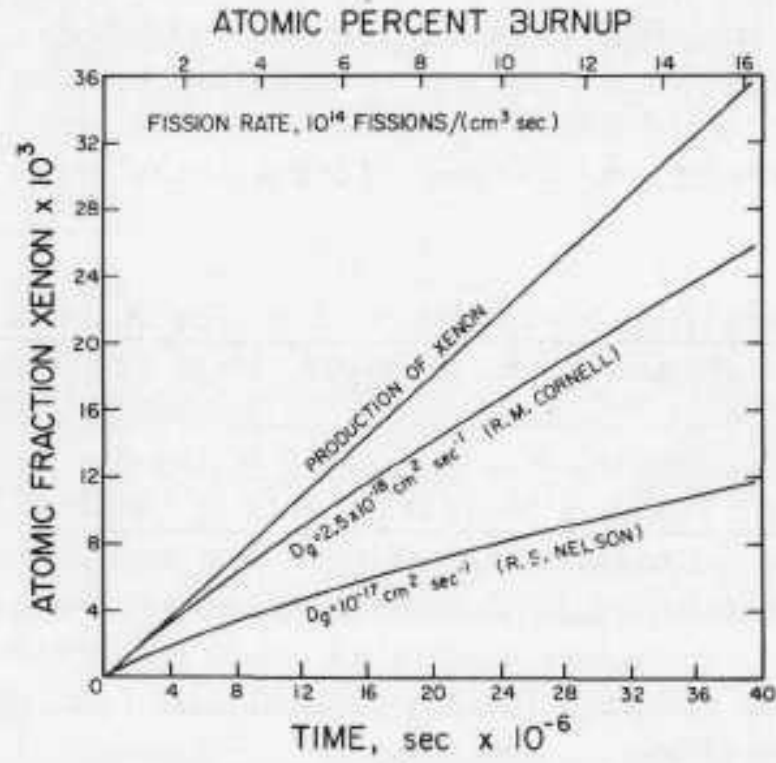

(a)

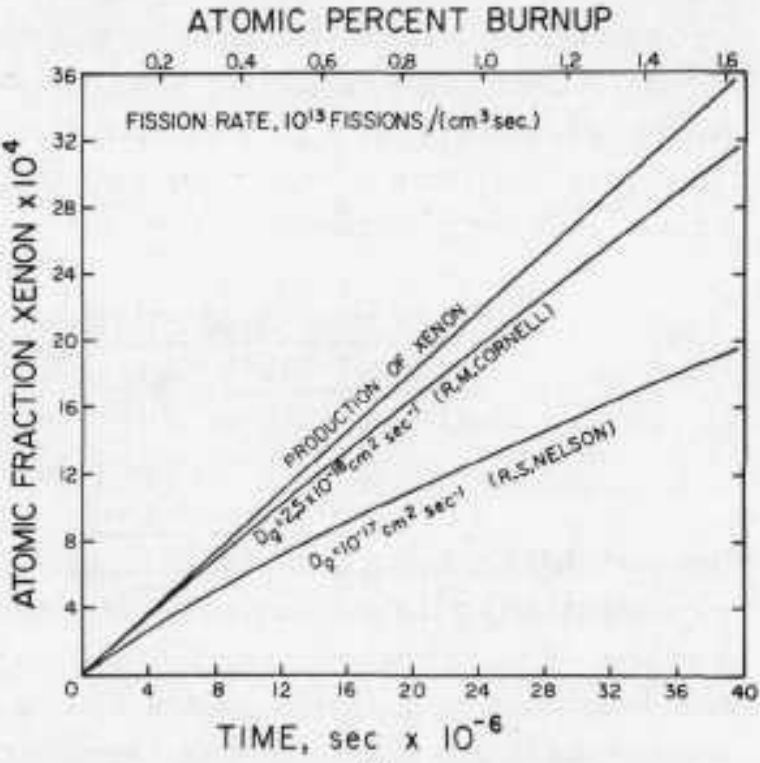

(b)

Fig. V.15. Calculated Atomic Fraction of Xenon Produced and in Metastable Solid Solution in $\mathrm{UO}_{2}$ at $1150^{\circ} \mathrm{C}$ for Two Assumed Diffusion Coefficients. Fission rates: (a) $10^{13}$ fissions $/ \mathrm{cm}^{3} \mathrm{sec}$ and (b) $10^{14}$ fissions $/ \mathrm{cm}^{3}$ sec. Neg. Nos. (a) MSD-54505 and (b) 54506 .

In the ANL irradiation program, the amount of fission gas in solution under various irradiation conditions will be determined. Initially. fuel specimens from instrumented subassembly XX01, irradiated in EBR-II, will be examined to establish the distribution of gaseous fission products as a function of irradiation temperature. Experimental techniques for preparing thin films of unirradiated $\mathrm{UO}_{2}$ for transmission-electron-microscopy examination have been established, and the techniques are being modified for preparing thin films from irradiated fuel samples. By comparing the experimentally determined dynamic solubility with the calculated solubility. it will be possible to establish the re-solution mechanism and to obtain a better understanding of the re-solution process. In addition, the in-pile diffusion coefficients of inert-gas atoms under various irradiation temperatures and fission rates will be determined from the experimental data. 
2. Chemistry of Irradiated Fuel Materials. C. E. Crouthamel and C. E. Johnson (02-087)

a. Postirradiation Studies of Reactor Fuels and Cladding (Last reported: ANL-7765, p. 61)

The principal factors governing the extent of attack of the cladding in mixed-oxide fuel are believed to be the cladding temperature and the oxidizing potential at the cladding wall. Various studies have shown that the alkali metals, in conjunction with oxygen, are capable of markedly accelerating corrosive attack on a wide variety of stainless steels and refractory metals.

Recent work in this laboratory has indicated that in irradiated mixed-oxide fuels, the mechanism of attack of the cladding is oxidation of the grain boundaries. To assess this mechanism further and to evaluate the possibility that the cladding is acting as an oxygen sink, small rings of cladding ( $3 / 16$ in. wide) were selected from seven different irradiated fuels for oxygen analysis. After the cladding rings were cut and flattened and all adherent material was removed, the cladding sections were scraped with a knife edge and brushed with a steel wire brush. After each scraping and brushing, the specimens were ultrasonically cleaned, and checked for alpha activity. Residual alpha activity was taken as an indication that fuel still adhered to the cladding. Cladding sections were considered to be ready for oxygen analysis only when they were completely free of alpha activity. At this point, each cladding section was divided into three segments and each segment was analyzed separately. The results of the analyses, which were performed by an inert-gas fusion technique, are given in Table V.13. All the samples of irradiated fuel cladding showed significantly higher oxygen contents than the unirradiated materials, which had oxygen contents of 50$97 \mathrm{ppm}$. Thus, it appears that the cladding is acting as an oxygen sink during irradiation. Oxygen may enter the cladding from the sodium side; however, the greater driving force is expected from the irradiated fuel. The variation in oxygen content among different segments of the same fuel cladding is larger than expected. Although this is believed to be a real effect, additional analyses would be required to establish the exact nature of this variation.

A section of cladding (SOV-1) was analyzed by gamma spectrometry, using a Ge(Li) detector to determine the amount of fission-product cesium located in the grain-boundary region. Even with the as sumption that the cesium is present as $\mathrm{Cs}_{2} \mathrm{CO}_{3} \cdot 2 \mathrm{H}_{2} \mathrm{O}$ (which has the highest oxygen content of any species expected to be present), the cesium found accounts for $500 \mathrm{ppm}$ oxygen, only a fraction of the total ( $3000 \mathrm{ppm})$ found. Thus, more oxygen is present in the bulk cladding than can be accounted for by the oxygen associated with cesium. 
TABLE V.13, Oxygen Content ${ }^{a}$ of Irradiated Stainless Steel Cladding $\left(235 \mathrm{UO}_{2}-20\right.$ wt $\%{ }^{239} \mathrm{PuO}_{2}$ fuels irradiated in EBR-II)

\begin{tabular}{|c|c|c|c|c|c|c|c|}
\hline Sample Designation & $\begin{array}{l}\text { Stainless } \\
\text { Steel } \\
\text { Cladding }\end{array}$ & $\begin{array}{l}\text { Average Fue 1- } \\
\text { Pin Burnup, } \\
\text { at. } z\end{array}$ & $\begin{array}{l}\text { Peak Linear } \\
\text { Power Rating, } \\
\mathrm{kW} / \mathrm{ft}\end{array}$ & $\begin{array}{l}\text { Inner Clad- } \\
\text { ding Temp., }\end{array}$ & $\begin{array}{l}\text { Inter- } \\
\text { granular } \\
\text { Attack, } \\
\text { mils }\end{array}$ & $\begin{array}{l}\text { Fuel } \\
\text { Density, } \% \\
\text { of Theor. }\end{array}$ & $\begin{array}{c}\text { Oxygen } \\
\text { Content, } \\
\text { ppm }\end{array}$ \\
\hline Sov-1 $(45 \mathrm{G}-14)$ & 304 & 5.0 & 20 & 593 & 9 & 80 & $\begin{array}{l}3300 \\
3000\end{array}$ \\
\hline SOV-1 $(45 G-18)$ & 304 & 5.0 & 20 & 530 & 2 & 80 & $\begin{array}{r}1600 \\
1300 \\
870 \\
\end{array}$ \\
\hline$C-11(66 A-11)$ & $316 \mathrm{~L}$ & 9.5 & 14 & 530 & $0-1.5$ & 88.3 & $\begin{array}{l}1800 \\
1300\end{array}$ \\
\hline$C-15(66 B-7)$ & $316 \mathrm{~L}$ & 9.5 & 13 & 525 & $0-1.5$ & 82.7 & $\begin{array}{l}2100 \\
1300\end{array}$ \\
\hline SOV-6 $(43 B-25)$ & 304 & 2.7 & 17 & 560 & 2 & 83.5 & $\begin{array}{r}1100 \\
470 \\
420 \\
\end{array}$ \\
\hline $007(59 B-20)$ & $304 \mathrm{~L}$ & 4.7 & 15.7 & 567 & $0-2$ & 84 & $\begin{array}{l}610 \\
560 \\
\end{array}$ \\
\hline F2R-3 (General Electric) & 347 & 6.5 & 16.5 & 550 & none & 95 & $\begin{array}{r}1600 \\
940 \\
740\end{array}$ \\
\hline
\end{tabular}

a Analysis of irradiated stainless steel cladding performed by Los Alamos Scientific Laboratory and Argonne by an inert-gas fusion technique. 
A section of cladding having the highest oxygen content (SOV-1, $45 \mathrm{G}-14$ ) was studied in detail with the electron microprobe by scanning areas 80 by $100 \mu \mathrm{m}$. A rubidium acid phthalate (RAP) diffraction crystal was used for oxygen analysis (see ANL-7776, pp. 69-70). The X-ray images for oxygen, cesium, and molybdenum are shown in Fig. V.16; this area was located about $0.006 \mathrm{in}$. from the fuel-cladding interface. The intergranular penetration in this area is evident.

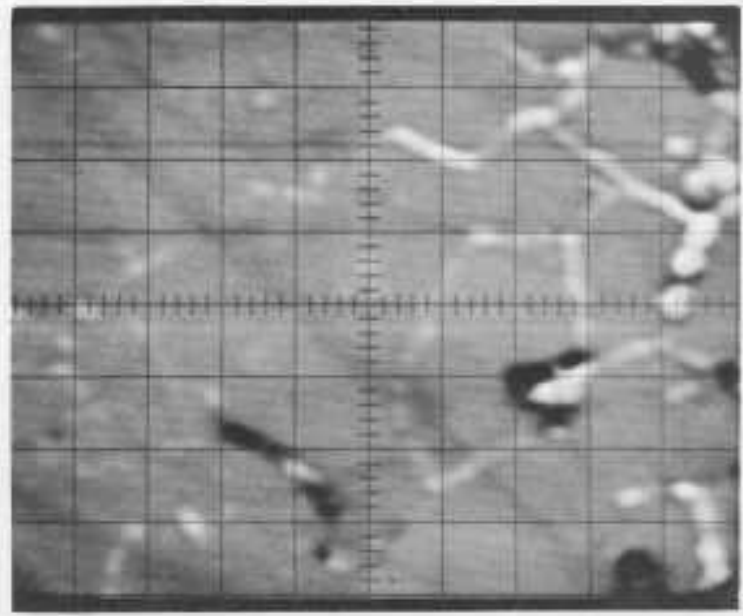

Specimen Current

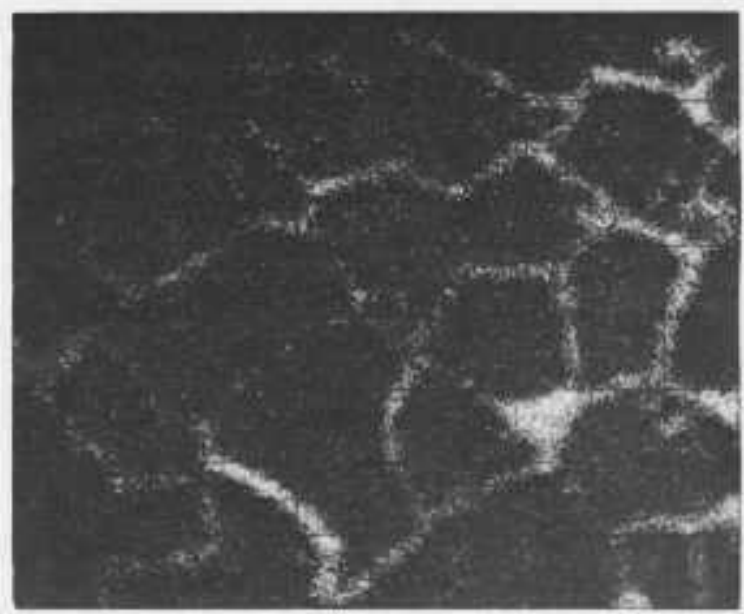

Cesium $\mathrm{L}_{\alpha}$

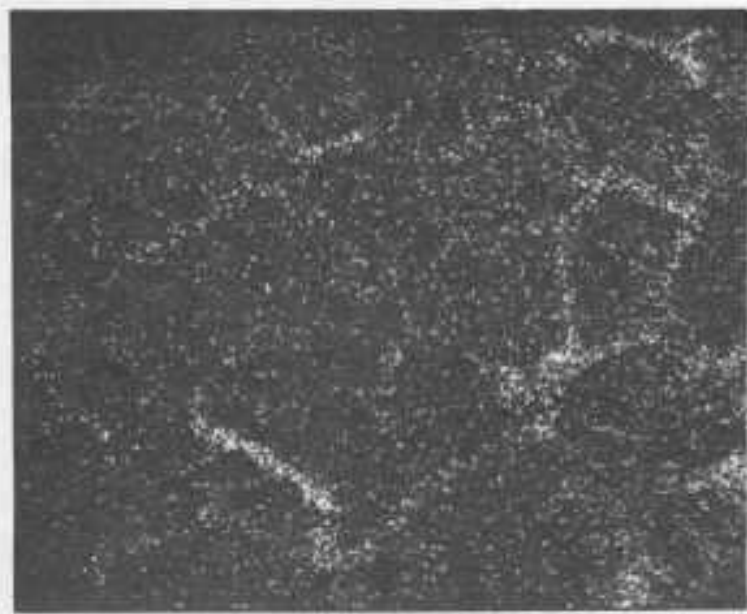

Molybdenum $\mathrm{L}_{a}$

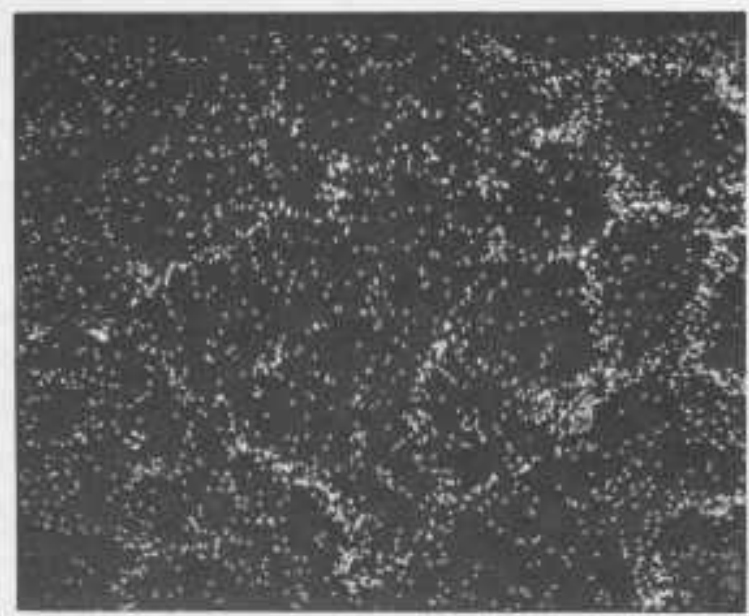

Oxygen $\mathrm{K}_{\alpha}$

Fig. V.16. Electron-microprobe Scanning Images of Stainless Steel Cladding from SOV-1 (all images are 80 by $100 \mu \mathrm{m}$ ). ANL Neg. No. 308-2480.

The area of intergranular attack was then analyzed at $1-\mu \mathrm{m}$ intervals with the electron microprobe for oxygen, fission products, and cladding constituents. These data are given in Fig. V.17. The data show an increase by a factor of four in the $\mathrm{O}_{\mathrm{K} \alpha}$ counts in the grain boundaries. The most prominent and consistent features of the intergranular attack 


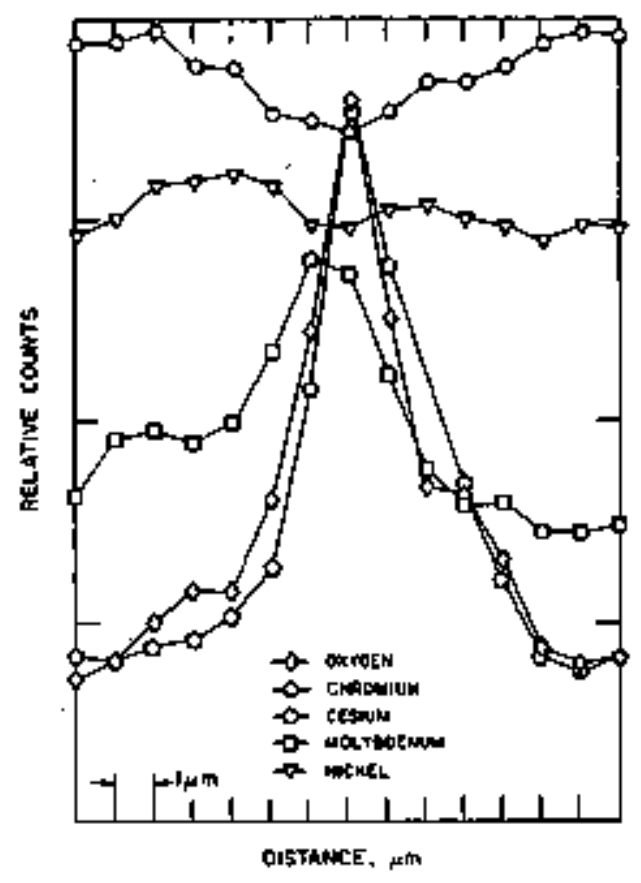

Fig. V.iT. Electron-mic roprobe Analysis of an Area of Intergranular Antack in Irradiated Stainless Steel Cladding (5OV-1). ANL Neg. No. 308-2525. were depletion of iron and chromium and enhancement of cesium, molybdenum, and axygen. Although it is not apparent in Fig. V.17, studies of other areas of attack have frequently shown a migration of nickel, also to the grain boundaries.

It has been suggested ( $R$. A. Rapp, The Ohio State University, private communication) that the intergranular attack may be proceeding by an induced, accelerated oxi* dation (hot corrosion) of the stainless steel cladding. This mechanism requires that a thin film of fused electrolyte be condensed on the cladding surface and that the accelerated oxidation occur through this film. In irradiated fuels, condensation of an electrolyte is a real possibility. Although this electrolyte has not been identified, it is expected to be an oxide mixture of $\mathrm{fis}$. sion products and pos sibly some cladding components. Relatively pure cesium oxide would not be thermodynamically stable at the oxygen potentials expected; however, the possibility exists for a lower oxygen activity for cesium oxide in complex multicomponent electrolyte (e.c.,

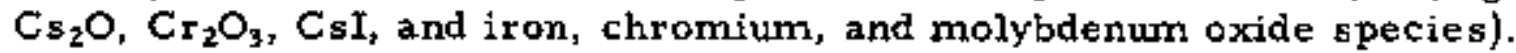
The presence of cesium and molybdenum in the intergranular areas gives substance to the hypotheais of corrosion through an electrolyte. In a study of the $\mathrm{Cs}_{2} \mathrm{O}-\mathrm{MOO}_{3}$ system, Spitsyn and Kuleshon* found a temperature minimum of $450^{\circ} \mathrm{C}$ for a 50-50 mixture of $\mathrm{Cs}_{2} \mathrm{MOO}_{4}$ and $\mathrm{MoO}_{3}$; this temperature is well below the expected temperature of the eladding near the fuel-cladding interface. Furthermore, the oxygen activity at the cladding wall is a rapidly changing parameter near stoichiometric compositions of the fuel, and an abrupt transformation of cesium from a metal to an electrolyte form would bring about an abrupt change in corrosion conditions and provide the necessary conditions for cladding attack.

\section{Oxide Fue1 Studies (02-005)}

a. Fuel-swelling Studies. L, C. Michels and R. B. Poeppel (Last reported: ANL-7737, p. 114, Aug 1970)

An analysis of "trails" seen in etched metallographic sections of irradiated mixed-oxide fuel has been completed. This study was conducted to determine the in-pile migration velocities of solid fission-product inclusions and fission-gas bubbles.

W. Spirsyn and I. M. Kuleshon, Zhur Obshchei Khim 21, 1372 (1851). 
A specimen from ANL fuel element HOV-15 was chosen for analysis. This element operated for most of its life in a partially molten condition at a peak power rating of $21.4 \mathrm{~kW} / \mathrm{ft}$, but was operated at a peak power rating of only $14.2 \mathrm{~kW} / \mathrm{ft}$ for $29.75 \mathrm{hr}$ at the end of the irradiation period. As a result of the low-power operation, solid inclusion and gasbubble movement occurred across the large, once-molten grains. Any trails seen in what was previously the molten region of the fuel as well as in the nonmolten region near the melt radius would very likely have been formed during the last low-power cycle, for which the time interval is accurately known.

Pertinent measurements made for 155 solid inclusions and 145 gas bubbles included trail length, inclusion or bubble diameter, trail width, and radial position of the middle of the trail relative to the fuel surface. The trail lengths and known time interval were used to calculate the migration velocities. The trail widths were assumed equal to the correct section diameters to compensate for errors in measured section diameters incurred as a result of metallographic preparation. An average correction factor was established based on those inclusions and bubbles for which both trail width and diameter could be measured accurately (60\% of the inclusions and $78 \%$ of the bubbles). This correction factor was then applied in the cases in which the section diameter but not the trail width could bemeasured accurately. The measured diameters of the bubble and inclusion sections were in error by as much as +100 and $-50 \%$, respectively. The radial positions of the centers of the trails relative to the fuel surface were used to calculate the average temperature and temperature gradient for each inclusion and bubble during migration.

Several sources of error were involved in this analysis. Measurement errors produced errors not greater than $\pm 0.25 \mu \mathrm{m}$ and $\pm 0.09 \AA / \mathrm{sec}$ in the diameters and velocities, respectively. Another possible error is that part of the trails may have annealed out during migration, which would make the measured velocities lower than the actual velocities. Finally, the distribution of section diameters is not the actual distribution of inclusion and bubble diameters, because the plane of polish intersection occurs at different diametral positions. Taking these errors into consideration, we concluded that:

(1) The solid fission-product-inclusion-migration velocity dependence on diameter is given by

$$
v=25.9 d^{-2.19}
$$

where $v$ is the velocity in $\AA / \mathrm{sec}$, and $\mathrm{d}$ is the diameter of the inclusion in microns. The inclusion diameters range from $\sim 2.5$ to $10 \mu \mathrm{m}$, and the velocities range from $\sim 4.0$ to $0.2 \AA / \mathrm{sec}$. The calculated temperature range and average temperature gradient were $1650-1850^{\circ} \mathrm{C}$ and $5300^{\circ} \mathrm{C} / \mathrm{cm}$, respectively. 
(2) No velocity dependence on diameter was found for the fission-gas bubbles. The bubble diameters appear to range from $* 2.5-$ $6.5 \mu \mathrm{m}$ and the velocities from $\sim 0.6-13.0 \AA / \mathrm{sec}$. The calculated temperature range and average temperature gradient were $1585-1835^{\circ} \mathrm{C}$ and $5450^{\circ} \mathrm{C} / \mathrm{cm}$, respectively.

\section{Core Materials Applications}

1. Core Design Technology

a. Empirical Assessment of Swelling and Creep Correlations. P. R. Huebotter and T. R. Bump (Last reported: ANL-7798, p. 75)

Contemporary LMFBR core design requires reliable expressions for fast-neutron-induced swelling and radiation-enhanced creep of stainless steel, as well as an understanding of integral swelling-creep effects on core structural components. Existing correlations involve considerable uncertainty and are based on controlled experiments to a fluence that is a small fraction of FTR and LMFBR Demonstration Plant targets.

Core components removed from EBR-II, at fluences now approaching these targets, exhibit deformations that are attributable to a combination of swelling and creep. These deformations are being analyzed to ascertain the reliability of existing swelling and creep correlations and to gain further insight into the response of stainless steel, in typical core structural applications, to the LMFBR environment. The EBR-II Project provides the neutron fluxes, temperatures, and nondestructive measurements used in the analyses. Destructive measurements are obtained from EBR-II and other projects within ANL and from other participating United States laboratories.

(1) Wrapper-tube Bow (T.R. Bump). The planned procedure for analyzing wrapper-tube bow includes the construction of a transverse displacement curve from measured densities. This curve indicates the bow the tube would have if its shape were determined by differential swelling alone. A comparison of the curve with curves based on density data calculated with different correlations checks the integral validity of the correlations under a variety of flux-fluence-temperature combinations. A comparison of the curve with the measured displacement curve indicates whether significant creep occurred in the tube.

To permit construction of a measured-density, transversedisplacement curve for the experimental assembly XA08 wrapper tube, 
density data were collected from four sources.* (This Type 304 stainless steel tube had a peak fluence of about $8.5 \times 10^{22}$ nvt.) As indicated in

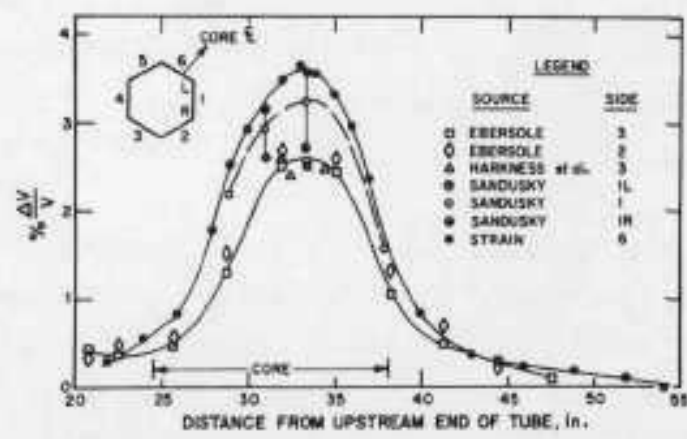

Fig. V.18. Percent $\Delta V / V$ ys Distance from Upstream End of Tube for EBR-II Assembly XA08 Wrapper Tube. Neg. No. MSD-54647.

Fig. V.18, the data are mutually consistent. (The low Harkness values reflect reduced swelling near the spacer pads.)

Tube transverse displacements that result from these $\Delta V / V$ values were calculated with a version of the GROW code, assuming that $\Delta \mathrm{V} / \mathrm{V}$ varied linearly across the tube. The maximum relative transverse displacement obtained was 98 mils, which can be compared with the previously reported values of $112 \mathrm{mils}$ from the WADCO swelling correlation, 65 mils from the ANL swelling correlation, and $53 \pm 14$ mils measured (see ANL-7798, p. 75 and ANL-7783, p. 62). This comparison suggests that (a) the WADCO correlation gives better differential-swelling predictions than the ANL correlation, for the conditions under which Assembly XA08 was irradiated, and (b) creep must have occurred to keep the wrapper tube straighter than the density data would indicate.

Figure V.19 compares calculated-density and measured** displacements for safety-and control-rod thimbles 3A1,5A3, and 5D1. The measured maximum displacements are no larger than the XA08 wrappertube value, even though the thimbles had peak fluences 1.7-2.1 times greater, as reflected in the large calculated-density displacements. The comparatively

Fig. V.19

Permanent T tansverse Displacement vs Distance from Upstream End of Tube for EBR-II Safetyand Control-rod Thimbles $3 \mathrm{~A} 1,5 \mathrm{~A} 3$, and 5D1. Neg. No. MSD-54648.

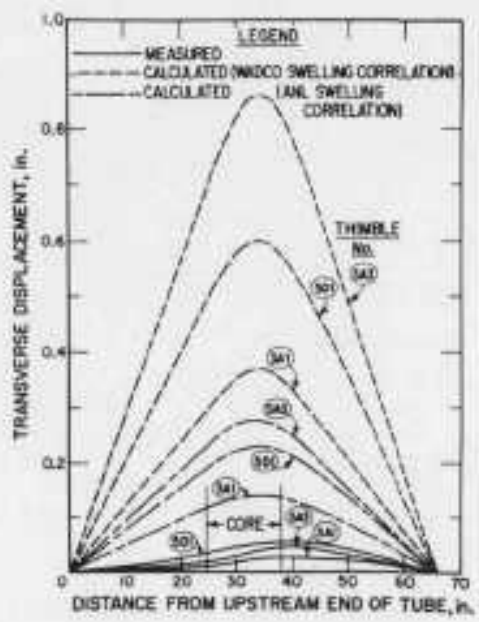

*E. R. Ebersole, ANL-Idaho, private communication (Feb 1970); S. D. Harkness, B. J. Kestel, and D. G. Franklin, Swelling in the Dimple Region of Subassembly XA08, ANL-7758, p. 5 (Nov 1970); D. W. Sandusky, General Electric (BRDO), private communication (Feb 1971); and R. V. Strain, EBR-II Project, private communication (Apr 1971).

**R, D. Phipps, EBR-II Project, private communication (Nov 1970). 
small measured displacements must mean either that swelling saturated, or that even the relatively loose EBR-II core provided enough restraint, and thereby enough creep occurred, to keep the thimbles quite straight (as in the case of the XA08 wrapper tube). In view of the large amount of dilation and creep observed near the spacer pads of these thimbles, the latter alternative seems more likely. Density measurements yet to be made on the thimbles should resolve this uncertainty.

(2) Fuel-element Bow (T. R. Bump). This bow is believed to be primarily due to creep resulting from transverse differential thermal stresses in the highly restrained elements, rather than to differential swelling as in the case of the relatively loose wrapper tubes. Figure V.20 compares calculated and measured* displacements for several fuel elements

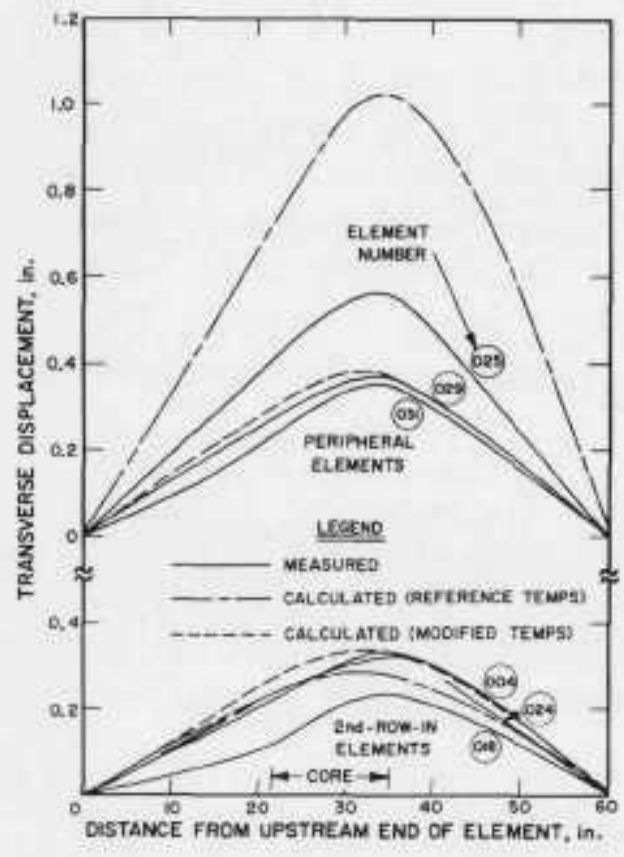

Fig. V.20, Permanent Transverse Displacement vs Distance from Upstream End of Cladding for Fuel Elements from EBR-1I Assembly X040A. ANL Neg. No. 306-1004. from experimental assembly X040A. The element claddings are $0.290-$ in. $O D$ by 0.020 -in. wall thickness, "annealed" (Rockwell B85), Type 304L stainless steel, and had a peak fluence of about $4.3 \times 10^{22} \mathrm{nvt}$. The calculated values were obtained by using the CRASIB code** in conjunction with the WADCO swelling correlation for solutiontreated austenitic stainless stee $1^{\dagger}$ and the LIFE-I (NOH $=0$ option) creep correlation. ${ }^{\#+}$

The elements were assumed to be restrained transversely at 29 different axial positions; that is, an exaggerated amount of transverse restraint was imposed. One check calculation was made in which the element was restrained at only 11 axial positions. This reduced restraint, which is probably less than that actually imposed by the 6 -in.-pitch helical spacer wires on the fuel elements, decreased calculated permanent displacements by only $0.1 \%$.

The reference temperatures for the X040A assembly indicate that the gradients across the peripheral elements in the as sembly are substantially greater than for the elements of the second row in from the periphery ( 450 versus $50^{\circ} \mathrm{F} / \mathrm{in}$. at core outlet). As a result, the

*R. V. Strain, EBR-II Project, private communication (Feb 1971).

**W. H. Sutherland and V. B. Watwood, Jr., Creep Analysis of Statically Indeterminate Beams, BNWL-1362 $(1970)$.

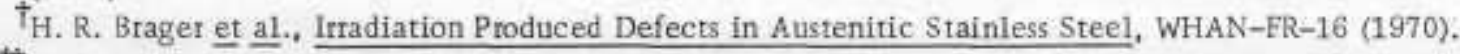

tiV. Z. Jarkus and R. W. Weeks, LIFE-I, a FORIRAN-IV Computer Code for the Prediction of Fast-reactor Fuel-element Behavior, ANL-7736, p. 49 (Nov 1970). 
calculated displacements based on the reference temperatures are substantially greater for the peripheral elements than for the second-row in elements (see Fig. V.20). However, the measured displacements for the peripheral elements are only modestly greater than for the second-row-in elements. Accordingly, it was adjudged that the coolant "mixing coefficient" used to calculate the reference temperatures might have been too small. To demonstrate this possibility, the reference temperatures were modified rather arbitrarily so that the gradients across the peripheral elements were closer to those across the second-row-in elements (135 versus $70^{\circ} \mathrm{F}$ /in, at core outlet). Calculated displacements based on the modified temperatures are in reasonable agreement with the measured displacements, although interesting discrepancies still remain.

Similar calculations were also performed using the WADCO creep correlation.* This correlation, which includes irradiation-induced creep only, gave maximum displacements of $7-13 \%$ less (and $0-5$ in. farther downstream) than the LIFE-I correlation, which includes both thermaland irradiation-induced creep.

Fuel elements discharged from a number of other experimental assemblies have been found to be deformed in the same manner as those from Assembly X040A.**

*E. R. Gilbert and L. D. Blackburn, Irradiation-induced Creep in Austenitic Stainless Steel, WHAN-FR-30, 1 (Oct 1970).

**R. D. Phipps, EBR-II Project, private communication (Apr 1971). 


\section{PUBLICATIONS}

Ultramicrosampling with a Laser Microscope

M. D. Adams

Microscope 19, 157-169 (Apr 1971)

Experiments with ${ }^{241} \mathrm{Am}-{ }^{242} \mathrm{Cm}-\mathrm{Be}$ for Neutron Radiography

J. P. Barton and M. F. Klozar

Mater. Eval. 29(2), 24A (Feb 1971) Abstract

Sodium-Fuel Interactions

P. E. Blackburn, A. E. Martin, J. E. Battles, P. A. G. O'Hare, and

W. N. Hubbard

Trans. Am, Nucl. Soc. 14(Suppl. 1), 20 (Apr 1971) Abstract

Vibration-Analysis Studies Using Changes of Laser Speckle

N. Fernelius and C. Tome

J. Opt. Soc. Am. 61, 566-572 (May 1971)

The Irradiation Behavior of Sodium-bonded (U,Pu)C Fuel Pins

B. L. Harbourne,* P. J. Levine,* A. Biancheria,* T. W. Latimer, and

L. A. Neimark

Trans. Am, Nuc1. Soc, 14 (Suppl. 1), 41 (Apr 1971) Abstract

Design, Research, and Development Implications of Metal Swelling in Fast Reactors

P. R. Huebotter, T. R. Bump, W. T. Sha, D. T. Eggen, ** and

P. J. Fulford ${ }^{\dagger}$

ANL-7786 (Apr 1971)

Analysis of Mixed-oxide Fuel Element Irradiations Using the LIFE-I

Computer Code

V. Z. Jankus and R. W. Weeks

Trans. Am. Nuc1. Soc. 14(Supp1. 1), 8 (Apr 1971) Abstract.

Phase Relations in the System Uranium-Nitrogen-Oxygen

N. A. Javed

Am. Ceram. Soc. Bull. 50(4), 372 (Apr 1971) Abstract

Thermodynamics and Microstructure of Hypostoichiometric $\mathrm{UO}_{2}$

N. A. Javed

Am. Ceram. Soc. 50, 425 (Apr 1971) Abstract

Thermodynamic Behavior of the Hypostoichiometric $\left(\mathrm{U}_{0.8}, \mathrm{Pu}_{0.2}\right) \mathrm{O}_{2}$ Solid Solution System

N. A. Javed and A. A. Solomon

Am. Ceram. Soc. Bull. 50(4), 425 (Apr 1971) Abstract

*Westinghouse Electric Corp., Advanced Reactors Division.

**Northwestern University.

tpundue University. 
Fuel-Clad Reactions in Irradiated Mixed-oxide Fuels

C. E. Johnson and C. E. Crouthamel

Trans. Am. Nucl. Soc. 14 (Suppl, 1), 17 (Apr 1971) Abstract

Distribution of Gaseous Fission Products in Irradiated Mixed-oxide Fuels

C. E. Johnson, D. V. Steidl, and C. E. Crouthamel

Trans. Am. Nuc1. Soc. 14 (Suppl, 1), 27 (Apr 1971) Abstract

Sand-bed Filtration of Aerosols: A Review of Published Information on Their Use in Industrial and Atomic Energy Facilities

R. A. Juvinall, R. W. Kessie, and M. J. Steindler

ANL-7683 (June 1970)

Considerations of Metal Swelling and Related Phenomena Caused by Fast Neutron Irradiation

Che-Yu Li, D. G. Franklin, and S. D. Harkness

Irradiation Effects on Structural Alloys for Nuclear Applications,

ASTM STP 484. Am. Soc, for Testing and Materials, Philadelphia, 1970 , pp. $347-361$

Surface Relaxation Kinetics of Uranium Dioxide

P. S. Maiya

Acta Met. 19(4), 255-262 (1971)

Preparation of Replicas for Electron Microscopy of Irradiated Ceramic

Fuels

L. C. Michels and G. M. Drage1

ANL-7790 (Apr 1971)

Performance of Mixed-oxide Fuel Elements--ANL Experience

L. A. Neimark, C. E. Dickerman, J. D. B. Lambert, and W. F. Murphy Trans. Am. Nuc1. Soc. 14 (Suppl, 1), 22 (Apr 1971) Abstract

An Advanced Gas Release and Swelling Subroutine

R. B. Poeppel

Trans. Am. Nucl. Soc. 14 (Suppl, 1), 13 (Apr 1971) Abstract

Scanning Electron Microscope Study of Fracture in $\mathrm{UO}_{2}$

J. T. A. Roberts and J. E. Sanecki

Am. Ceram. Soc, Bull. 50, 426 (Apr 1971) Abstract

Surface Properties and the Behavior of Materials

P. G. Shewmon

Am. Ceram. Soc. Bull, $\underline{50}, 379$ (Apr 1971) Abstract

Influence of Strain Rate on Brittle-to-Ductile Transition in $\mathrm{UO}_{2} 20$ wt \% $\mathrm{PuO}_{2}$

B. J. Wrona and J. T. A. Roberts

Am. Ceram. Soc. Bull. 50, 426 (Apr 1971) Abstract 
5.44 


\section{VI, FUEL CYCLE}

A. Molten Metal Decladding of LMFBR Fuels. D. S. Webster $(02-173)$

The most difficult and costly aspect of LMFBR fuel reprocessing will probably be the head-end operations, which include fuel-element handling, cladding removal, and introduction of fuel into the processing plant. Laboratory and engineering work is being done to develop a process in which stainless steel cladding is first dissolved in liquid zinc, the resulting zinc-steel solution is separated from the unreacted (U,Pu) $\mathrm{O}_{2}$ fuel, and the fuel oxide is reduced to metal and dissolved in the reduction solvent. The process is expected to be applicable also to the removal of Zircaloy cladding from light-water-reactor fuels.

1. Engineering Development. R. D. Pierce (Last reported; ANL-7798, p. 79)

A series of oxide reduction runs is under way to study the effects of salt and alloy compositions on completeness of reduction and on metal-salt separation.

In the runs discussed here, the $\mathrm{UO}_{2}$ charges were 0.2 or $0.6 \mathrm{~kg}$, the alloy charges were $3-9 \mathrm{~kg}$, the salt charges were $1.0 \mathrm{~kg}$, run durations were 4.5 or $5 \mathrm{hr}$, reduction temperature was $800^{\circ} \mathrm{C}$, agitator speed was $900 \mathrm{rpm}$, and agitator diameter was 3 in. Sintered $\mathrm{UO}_{2}$ pellets were used as a standin for $(\mathrm{U}, \mathrm{Pu}) \mathrm{O}_{2}$.

Additional results have been obtained for oxide reduction runs $\mathrm{Mg}$ $\mathrm{Zn}-\mathrm{R} 10$ to $-\mathrm{R} 12$ (see $\mathrm{ANL}-7798$ ), and reduction run $\mathrm{Mg}-\mathrm{Zn}-\mathrm{R} 13$ has been completed. In these runs, $\mathrm{UO}_{2}$ was reduced to metal by contacting it with a salt-metal system. The purpose of runs $\mathrm{Mg}-\mathrm{Zn}-\mathrm{R} 10$ and $-\mathrm{R} 12$ was to determine the practical limit of $\mathrm{CaO}$ loading of the salt (i.e., the maximum $\mathrm{CaO}$ loading at which good separation of the salt phase from the metal phase is attained along with an adequate reduction rate of $\mathrm{UO}_{2}$. To produce $\mathrm{CaO}$ in excess of its solubility, the $\mathrm{UO}_{2}$-to-salt ratio in the material charged in these two runs was three times the ratio in other runs in this series.

The salt composition was the same in runs $\mathrm{Mg}-\mathrm{Zn}-\mathrm{R} 10$ and $-\mathrm{R} 12$ : $\mathrm{CaCl}_{2}-20 \mathrm{~mol} \% \mathrm{CaF}_{2}$. In run $\mathrm{Mg}-\mathrm{Zn}-\mathrm{R} 10$, the metal phase was $\mathrm{Zn}$ 29 at. $\% \mathrm{Mg}-7$ at. $\% \mathrm{Ca}$; in run $\mathrm{Mg}-\mathrm{Zn}-\mathrm{R} 12$, it was $\mathrm{Mg}-16$ at. $\% \mathrm{Zn}-9$ at. $\% \mathrm{Ca}$. In the former system, the salt floated on the zinc-rich alloy and the agitator blades rotated in the metal phase. In the system containing a magnesiumrich alloy, the metal floated on the salt and the agitator blades rotated in the salt phase. 
Reduction was only $\sim 60 \%$ complete in run $\mathrm{Mg}-\mathrm{Zn}-\mathrm{R} 10$, probably because of lessened contacting of $\mathrm{UO}_{2}$ and salt as a result of the accumulation of a thick layer of $\mathrm{CaO}$ at the salt-metal interface. (The reduction is believed to occur in the salt phase between dissolved oxide and dissolved calcium.) Reduction was greater than $99 \%$ complete in run $\mathrm{Mg}-\mathrm{Zn}-\mathrm{R} 12$ despite the high $\mathrm{CaO}$ content, probably as a result of better contacting.

An earlier reported run, Mg-Zn-R11 (see ANL-7798), and a current run, $\mathrm{Mg}-\mathrm{Zn}-\mathrm{R} 13$, were done to determine the minimum $\mathrm{CaF}_{2}$ concentration in the feed salt that is associated with good separation of the salt phase from the metal phase at the end of reduction. (Elimination of fluoride from the reduction salt would eliminate a potential source of fluorides in the fuel when it is later fed to aqueous fuel processes.) In run $\mathrm{Mg}-\mathrm{Zn}-\mathrm{R} 11$, the salt was $\mathrm{CaCl}_{2}$; in run $\mathrm{Mg}-\mathrm{Zn}-\mathrm{R} 13$, the salt was $\mathrm{CaCl}_{2}-3 \mathrm{~mol} \% \mathrm{CaF}_{2}$. In both runs, a high-zinc alloy was used. Good reductions were obtained in the two runs, but phase separations were poor (as manifested by an accumulation of metal globules in the salt phase near the interface).

Additional treatment was applied to the metal-salt systems from runs $\mathrm{Mg}-\mathrm{Zn}-\mathrm{R} 13$ and $-\mathrm{R} 11$ to gain information on achieving better metalsalt separations. At the end of run $\mathrm{Mg}-\mathrm{Zn}-\mathrm{R} 13, \mathrm{CaF}$ was added incrementally to the salt-metal system, and the system was stirred after each addition. Phase separation improved after each addition and was excellent when the $\mathrm{CaF}_{2}$ content of the system reached $10 \mathrm{~mol} \%$.

To evaluate a technique for improving phase separation, the metalsalt from $\mathrm{Mg}-\mathrm{Zn}-\mathrm{R} 11$ was reheated to $800^{\circ} \mathrm{C}$ and agitated gently (at $200 \mathrm{rpm}$ ), with the agitator blades in the salt phase near the interface. Satisfactory coalescence of the metal phase was obtained. This result suggests that an all- $\mathrm{CaCl}_{2}$ reduction salt may be satisfactory in oxide reductions.

\section{B. LMFBR Reprocessing--Plutonium Isolation. D. S. Webster and A. A. Jonke (02-159)}

1. Centrifugal Contactors for Plutonium Handling. C. J. Bernstein (Last reported: ANL-7798, p. 80)

Performance testing was continued of the stainless steel centrifugal contactor having critically favorable dimensions for processing highplutonium LMFBR fuel. This unit has a 4 -in.-dia rotor and a 12 -in.-long settling zone. Runs are being made to establish maximum separation capacity at various rotor speeds, solution compositions, and aqueous-toorganic phase flow ratios. (Separation capacity is defined as the sum of the flow rates of the organic and aqueous phases when entrainment of one phase in the outlet stream of the other phase is less than $1 \%$.) 
Separation capacities for a system consisting of $0.5 \mathrm{M} \mathrm{HNO}_{3}$ as the aqueous phase and $15 \%$ tributyl phosphate in Ultrasene as the organic phase were determined at rotor speeds of 2000-3500 rpm and aqueous-to-organic (A/O) flow ratios of $0.33,0.5,1,2$, and 3 . Capacity increased with increasing rotor speed. For example, at an A/O ratio of 1 , separation capacity ranged from $\sim 5 \mathrm{gpm}$ at a rotor speed of $2000 \mathrm{rpm}$ to $10 \mathrm{gpm}$ at $3500 \mathrm{rpm}$. At each rotor speed, separation capacities were lower at A/O flow ratios between 1 and 2 , and higher both above and below this $A / O$ range. At the higher rotor speeds, separation capacity was limited by the inadequate size of the inlets, which are being replaced with larger diameter inlets.

Flow surging, which was a problem at the start of these runs, was eliminated by installing an additional set of four baffles, $3 / 8$ in. wide and 2 in. high, in the mixing chamber. By means of this modification, it was possible to achieve the predicted capacity of $10 \mathrm{gpm}$ at a rotor speed of $3500 \mathrm{rpm}$.

2. Plutonium Valence Adjustment Kinetics. M. J. Steindler (Last reported: ANL-7776, p. 89)

An on-stream electrolytic method for plutonium valence adjustment in Purex processes is being developed as a substitute for chemical adjustment. Adjustment of plutonium valence between +4 and +3 is required several times during plutonium isolation (and partitioning) steps of the Purex process to achieve the desired level of decontamination. It is believed that electrolytic reductions offer a method for well-controlled adjustment of plutonium valence in high-plutonium solutions in Purex operations, consistent with target objectives of process stability, safety, economy, and in particular, minimizing the quantity of radioactive waste effluent.

The apparatus (see ANL-7776) for measuring limiting current density has been operated using the $\mathrm{Fe}^{+3}+\mathrm{e}^{-} \rightleftharpoons \mathrm{Fe}^{+2}$ reaction as a stand-in for the $\mathrm{Pu}^{+4}+\mathrm{e}^{-}=\mathrm{Pu}^{+3}$ reaction to identify any unwanted electrode reactions that might occur in addition to the reaction studied. Results of initial runs indicated that nitrous acid might be formed electrolytically from nitric acid and interfere by reoxidizing the reduction product. To investigate this possibility, curves of current versus voltage were recorded for $\mathrm{Fe}^{+3}$ solutions in dilute nitric acid and for dilute nitric acid alone. These measurements were repeated with hydrazine (a candidate reagent for destruction of nitrous acid in the plutonium system) added to each of the solutions. Hydrazine addition had no effect on the curves, indicating that nitrous acid does not interfere with the reduction.

The basic operations and design criteria pertaining to plutonium valence adjustment by electrochemical reduction have been reviewed from an engineering point of view. In the preliminary ANL conceptual design, electrolytic cells would be inserted between contactor stages. The cell 
design would consist of an anode and a cathode in individual compartments, separated by a diaphragm permeable to hydrogen ions. The diaphragm would prevent mixing of the liquids in the two compartments, yet allow ionic conduction of cell current. Because the reaction of concern is reduction of $\mathrm{Pu}^{+4}$ at the cathode, study of cathode design has been emphasized. The cathode, having the configuration of stacks of wire-mesh screen, was analyzed with respect to engineering uncertainties. Alternative configurations for the wire-mesh cathode were proposed for consideration.

A simplified mathematical model of a steady-state flow electrolyzer for the reduction of $\mathrm{Pu}^{+4}$ has been developed that allows overall performance of various experimental units to be compared with conceptual plant designs. Electrolytic cells operated at Savannah River* and Dounreay** were used to reduce $\mathrm{U}^{+6}$ to $\mathrm{U}^{+4}$ in nitric acid solutions; their performance was compared by use of the model with the ANL conceptual design. Reduction-rate coefficients at reported operating conditions were determined for a small-scale Savannah River electrolytic cell, a semiworks-scale Savannah River cell, a series of seven small cells at Dounreay, and the conceptual ANL cell; the coefficients so determined were $0.14,0.062-0.100,0.0092$, and $0.85 \mathrm{~g}$-atom/ $(\mathrm{min})(\mathrm{sq} \mathrm{ft}$ ) ( $\underline{\mathrm{M}}$ of the species to be reduced), respectively.

Reduction-rate coefficients calculated by use of the mathematical model will provide a basis for continuing analysis and evaluation of various designs of electrolytic cells, Other analysis relating the reduction-rate coefficient to mass-transfer variables indicates that a cell design with substantially higher performance can be developed.

*G. Starr Nicko1s, Electrolyte Preparation of Uranous Nitrate, DP-1065 (Aug 1966).

**M. B. Finlayson and J. A. S. Mowat, Electrolytic Reduction of Uranium (VI) and Plutonium (IV) Nitrate

Solution: Development of a Continuous Process, Electrochem. Technol. 3 , No. 5-6, 148 (1965). 


\section{PUBLICATIONS}

Reaction Model for the Fluorination of Uranium and Plutonium Compounds in Fluidized-Bed Reactors

L. J. Anastasia, P. G. Alfredson, and M. J. Steindler

Ind. Eng. Chem. Process Des. Develop. 10, 150 (Apr 1971)

Shielding for a Pyrometallurgical Fuel Processing Plant

L. F. Coleman

Engineering Compendium on Radiation Shielding, Vol. III, Ed. R. G. Jaeger, M. Grotenhuis et al. Springer-Verlag, Heidelberg, 1970, pp, 181-188.

Shielding Windows for Pyrometallurgical Fuel Processing Plant T. W. Eckels

Engineering Compendium on Radiation Shielding, Vol. III, Ed. R. G. Jaeger, M. Grotenhuis et al. Springer-Verlag, Heidelberg, 1970, pp. 188-193. 
6.6 


\section{REACTOR PHYSICS}

\section{A. ZPR Fast Critical Experiments}

1. Fast Critical Facilities; Experiments and Evaluations--Illinois (02-179)

a. Clean Critical Experiments. R. A. Lewis (Last reported: ANL-7798, p. 85)

(1) Direct Plate-Rod Zone Heterogeneity in Assembly 7 of ZPR-6 (J. E. Marshall). The reactivity difference between Assembly 7 with the central $10.9 \times 10.9 \times 24$ in. $\mathrm{PuO}_{2}-\mathrm{UO}_{2}$ rodded zone and with the compositionally matched Pu, U metal plate zone has been evaluated as

$$
\Delta \bar{\rho}(\text { plate-rod })=52.5 \text { Th or } 0.0510 \% \Delta \mathrm{k} / \mathrm{k} \text {. }
$$

The objective was to directly measure the reactivity effect of the configurational differences between the plate and rodded cell structures without the complicating effects of simultaneous compositional differences. Thus the two zones were to be exactly matched in smeared composition so that the measurements would unambiguously reflect only the configurational effect.

In reality, certain compositional mismatches were present primarily because of limitations imposed by the ZPR reactor materials inventory. The matching procedure was to define the rodded zone loading as a reference and choose specific material plates and cans for the plate zone to achieve the closest match possible on an isotopic basis. Matchingvolume units one matrix tube square and 6 in. long $(2.19 \times 2.18 \times 6$ in.) were chosen, and the mass and associated reactivity corrections were made on this basis. A typical matching unit contained the following materials exclusive of the immobile reactor matrix:

Rodded Zone

Sixteen $3 / 8$-in.-dia $x$ 6-in.-long, 15 wt. \% Pu, $\mathrm{PuO}_{2}-\mathrm{UO}_{2}$ fuel pins

One-half of a $2 \times 2 \times$ 12 -in. pin-calandria, Type $\mathrm{F}$ (nonheatable)

One-half of a $0.009 x$ $2 \times 12$-in. Mo strip
Plate Zone

One $1 / 4 \times 2 \times 6$-in. NUMEC Pu-U-Mo metal fuel plate, $11 \frac{1}{2} \mathrm{w} / 0^{240} \mathrm{Pu}$

Six $1 / 4 \times 2 \times 2$-in. $\mathrm{U}_{3} \mathrm{O}_{8}$ plates

Two $1 / 2 \times 2 \times 6$-in. Na cans

Two $0.104 \times 2 \times 3$-in. $\mathrm{Fe}_{2} \mathrm{O}_{3}$ Plates

Two $0.104 \times 1.7 \times 3$-in. $\mathrm{Fe}_{2} \mathrm{O}_{3}$ Plates

Six inches of a $2 \times 2 \times 33.4-$ in.

SS-304 drawer 
Nominally, the zone-integrated composition-mismatch reactivity correction is found by multiplying the isotope mass differences in each matching unit by the appropriate measured specific worth; i.e., Ih $/ \mathrm{kg}$ of ${ }^{239} \mathrm{Pu}$ at $\mathrm{r}=4.4 \mathrm{in.}, \mathrm{z}=3 \mathrm{in}$., summing over all isotopes and then over all matching units. This correction, and its associated $1 \sigma$ uncertainty, is then used to adjust the experimentally measured zone $\Delta$ Ih for the existing composition mismatches.

The reactivity correction term is actually dominated by two of the several dozen material and isotope contributors. The correction itself is made up almost entirely of mismatches in $\mathrm{Fe}, \mathrm{Ni}, \mathrm{Cr}$, and $\mathrm{Mn}$. The correction precision, however, is controlled by the chemical and isotopic (mass-spectroscopic) data available to characterize the $\mathrm{PuO}_{2}-\mathrm{UO}_{2}$ and $\mathrm{Pu}-\mathrm{U}-\mathrm{Mo}$ fuel.

A Technical Memorandum (to be published) will give the details on the experimental technique as well as the computation of the correction term. Table VII.1 summarizes the matching data, and Fig. VII.1 depicts the plate-rod zone in Assembly 7. From Table VII.1, the composition

TABLE VII.1. Zone-integrated Composition-misaatch Correction Terms and the Associated 10 Imprecisions ${ }^{a}$

\begin{tabular}{|c|c|c|c|c|c|}
\hline Material ${ }^{b}$ & $\begin{array}{c}\text { A Mass } \\
\begin{array}{c}\text { (plate-rod), } \\
\mathrm{kg}\end{array}\end{array}$ & $\begin{array}{c}\text {-corr. } \\
\text { (plate-rod), } \\
\text { Th }\end{array}$ & $\begin{array}{c}\sigma_{\rho}^{(1)} \\
\left(\Delta \text { Nass }+{ }_{\text {Ih }}^{- \text {corr. }}\right), \\
\text { Ih }\end{array}$ & $\begin{array}{c}\sigma_{p}^{(2)} \\
\text { (A Mass), } \\
\text { Th }\end{array}$ & {$\left[(1)^{2}+{ }_{\mathrm{Ih}}^{(2)^{2}}\right]^{1 / 2}$,} \\
\hline Total Pu & 0.0088 & 1,41 & $<10^{-3}$ & 3.4 & 3.4 \\
\hline Total V & -0.37 & 1.44 & 0.08 & 2.1 & 2.1 \\
\hline o & -0.270 & 2.11 & 0.7 & 0.02 & 0.7 \\
\hline No & -0.008 & 0.084 & 0.01 & $<10^{-3}$ & 0.01 \\
\hline $\mathrm{Na}$ & 0.017 & -0.066 & 0.02 & $<10^{-3}$ & 0.02 \\
\hline \multirow[t]{2}{*}{$\begin{array}{l}\text { Total Fo, N1, } \\
\mathrm{Cr}, \mathrm{Mn}\end{array}$} & -13.813 & 11.3 & 1.9 & 0.4 & 1.9 \\
\hline & & 16,2 & $2.0^{\mathrm{c}}$ & $4.0^{d}$ & 4.5 \\
\hline
\end{tabular}

additional composition data has becone ayallable and is currently belng statistically evaluated. The inclusion of this new data is not expected to materially change these internediate results.

Materlals wfth small abundances, such as $\mathrm{Th},{ }^{241} \mathrm{Am}, \mathrm{C}, \mathrm{Be}, \mathrm{Cl}, \mathrm{Al}$, and other 1mpurfties, are not included in this simpliffed table. However, they were analyzed and are known to contribute insignificantly in conparison to the aaterials included.

CThis is the imprecision arising from the conversion of known mass differences to reactivity differences. Therefore, the uncertafnties in the material worth measurements are the primary constituents.

${ }^{\mathrm{d}}$ This is the imprecision associated with the knowledge of the mass differences. That 1s, how many $\mathrm{kg}$ of each 1sotope are actually in each of the matching units in both the plate and rodded case. The uncertaintes in the assay (chenical analysis) and 1sotopic (mass spectroscop1c) determinations for reactor materials aro statistically combined to form this coaponent. 


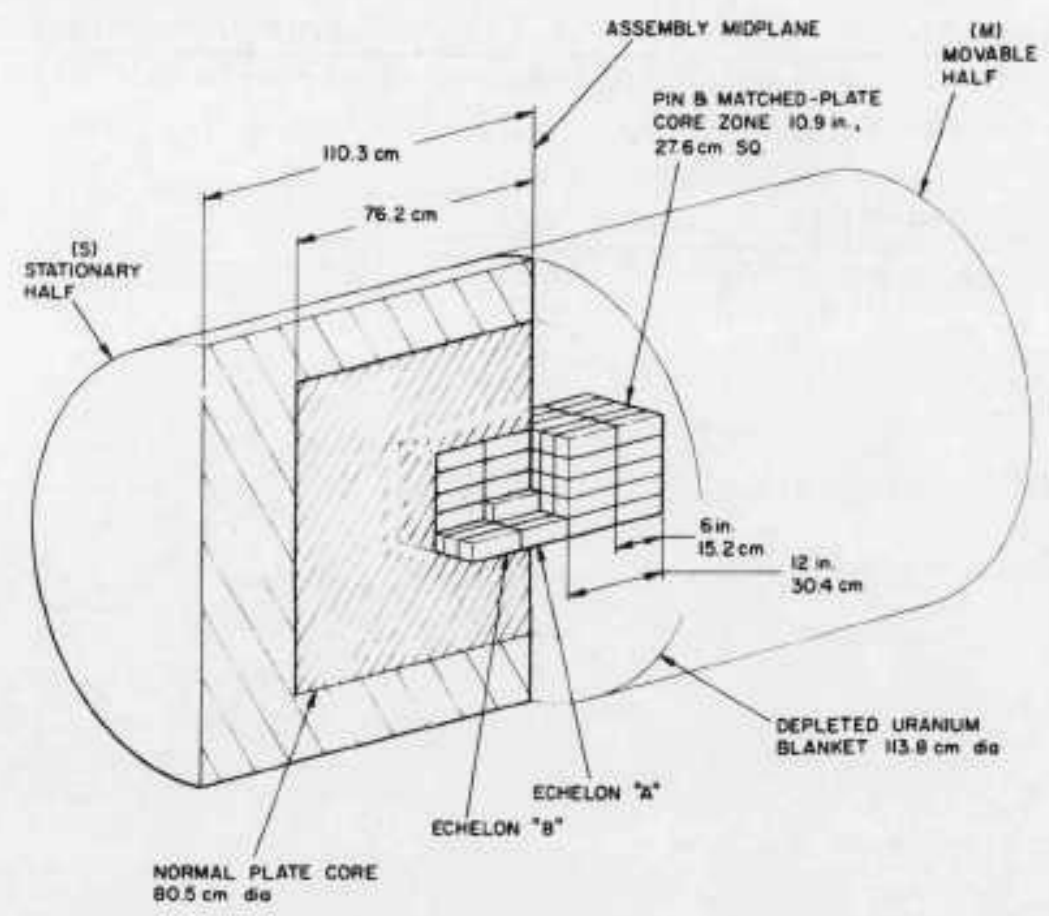

Fig. VII.1. Cylinderized Equivalent of Assembly 7 with Nominal Critical Dimensions Showing the $10.9 \times 10.9 \times 24$-in. Zone Used for the Plate-Rod Measurements

mismatch correction term is seen to be

$$
\bar{p}^{\text {corr. }}(\text { plate-rod })=+16.2 \mathrm{Ih} \text {, }
$$

with a $1 \sigma(67.5 \%$ confidence interval) of

$$
\sigma_{\rho}^{\text {corr. }}=4.5 \text { Ih }
$$

The measured plate-rod reactivity was $68.7 \pm 1.0 \mathrm{Ih}$, so that the equivalent compositionally matched plate-pin zone reactivity effect is calculated as

$$
\begin{aligned}
& \Delta \rho(\text { plate-rod })=\Delta \bar{\rho} \text { measured }(\text { plate-rod })-\bar{\rho}^{\text {corr } .} \text { (plate-rod) } \\
& \sigma_{\Delta \rho}=\left[\left(\sigma_{\Delta \rho}^{\text {measured }}\right)^{2}+\left(\sigma_{\rho}^{\text {corr }}\right)^{2}\right]^{1 / 2}
\end{aligned}
$$

and

$$
\Delta \rho \pm \sigma_{\Delta \rho}=52.5 \pm 4.6 \mathrm{Ih} .
$$

For comparison, the preanalysis calculation of $\Delta p$ (ENDF/B-I, ID diffusion theory, energy- and space-weighted cross sections for rods and plates) predicted a $\Delta \rho$ (plate-rod) of 52 Ih. 
(2) Measurement of the Perturbation Denominator for ZPR - 6 Assembly 7 (L. G. LeSage). The measured perturbation denominator is calculated from the following expression. ${ }^{\dagger}$

$$
\mathrm{PD}=\frac{\mathrm{S}\left({ }^{252} \mathrm{Cf}\right)}{\rho\left({ }^{252} \mathrm{Cf}\right) \mathrm{R}_{\mathrm{f}}^{\mathrm{core}}} \cdot \frac{p^{*}\left({ }^{252} \mathrm{Cf}\right)}{D^{*}(\text { core })}
$$

where

$$
\begin{aligned}
\mathrm{S}\left({ }^{252} \mathrm{Cf}\right)= & \text { absolute strength of the }{ }^{252} \mathrm{Cf} \text { source, neutrons } / \mathrm{sec}, \\
\rho\left({ }^{252} \mathrm{Cf}\right)= & \text { measured reactivity worth of the }{ }^{252} \mathrm{Cf} \text { source neutrons } \\
& \text { in } \Delta \mathrm{k} \text { units, at } \mathrm{r}=0 . \\
\mathrm{R}_{\mathrm{f}}^{\text {core }}= & \text { measured unit-cell averaged fission rate }\left(\mathrm{fiss} / \mathrm{cm}^{3}-\mathrm{sec}\right) \\
& \text { at } \mathrm{r}=0, \\
\bar{\nu}= & \frac{\sum_{i} \nu \Sigma_{\mathrm{f}} \phi_{\mathrm{i}}}{\sum_{\mathrm{i}} \nu_{\mathrm{f}_{\mathrm{i}}} \phi_{\mathrm{i}}} \text { at } \mathrm{r}=0,
\end{aligned}
$$

and

$$
\bar{\phi}^{*}=\sum_{i} x_{i} \phi_{i}^{*} \text { at } r=0 \text {. }
$$

Both $\rho\left({ }^{252} \mathrm{Cf}\right)$ and $\mathrm{R}_{\mathrm{f}}^{\text {core }}$ are functions of the absolute core power level. Both of these measurements must be made at the same power level. The perturbation denominator calculated from the above equation is normalized such that both

$$
\sum_{i} \nu \Sigma_{f_{i}} \phi_{i}
$$

and

$$
\sum_{i} x_{i} \phi_{i}^{*}
$$

are unity at $\mathbf{r}=0$.

Both $\bar{\nu}$ and $\bar{\phi} *\left({ }^{252} \mathrm{Cf}\right) / \bar{\phi} *($ core $)$ are calculated. The final precision in the value for the measurement $P D$ is not much affected by the uncertainty in the calculations, however.

\footnotetext{
$t_{R}$ A. Karam, Measurement of Normalization Integral and Spatial Distribution of the Importance of Fission Neutrons, Nuc1, Sci. Eng. 37,192 (1969).
} 
All the component terms in Eq. 1 have been measured and evaluated, so that it is possible to calculate the Assembly-7 perturbation denominator.

The value of the ${ }^{252} \mathrm{Cf}$ at the time of the measurement of its reactivity was $(6.284 \times 0.019) \times 10^{6}$ neutrons $/ \mathrm{sec}$.

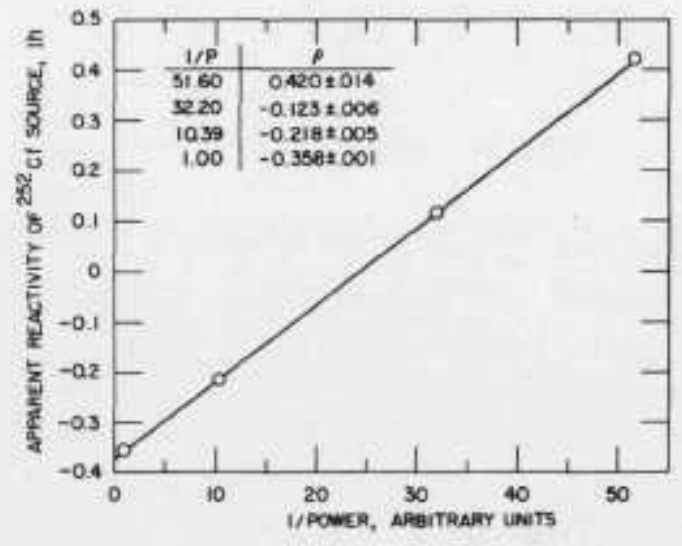

Fig, VII.2. Apparent Worth of a $(6.284 \pm$ $0.019) 10^{16}$ neutron/ $/ \mathrm{sec}^{252} \mathrm{Cf}$ Source as a Function of Power Level in ZPR-6, Assembly 7
The apparent worth of the ${ }^{252} \mathrm{Cf}$ source was measured at four different power levels, using the radial sample changer and the calibrated fine autorod, so that the power level independent absorption and scattering terms associated with the source holder could be separated from the power level dependent worth of the ${ }^{252} \mathrm{Cf}$ source neutrons. These data are plotted in Fig. VII.2 where apparent worth of the source is plotted against the reciprocal of the power level. A recent calculation has shown that the power level associated with $\mathrm{P}=1$ in Fig. VII. 2 is $705 \mathrm{~W}$.

The cell-averaged fission rate at $705 \mathrm{~W}$ at $\mathrm{r}=0$ has been determined by G. S. Stanford and W. R. Robinson from central irradiation to be

$$
3.459 \times 10^{7} \pm 1.5 \% \text { fissions in }{ }^{239} \mathrm{Pu} \text { per gram of }{ }^{239} \mathrm{Pu} \text {. }
$$

The unit-cell-averaged core fission rate was then determined using known atom densities in the core and the measured fission ratios between the other fissionable isotopes and ${ }^{239} \mathrm{Pu}$. Since the ${ }^{241} \mathrm{Pu} /$ ${ }^{239} \mathrm{Pu}$ fission ratio had not been measured, the calculated ratio was used in this one case.

The values of the terms in Eq. 1 are as follows:

$$
\begin{aligned}
S\left({ }^{252} \mathrm{Cf}\right) & =(6.284 \pm 0.019) 10^{6} \mathrm{n} / \mathrm{sec}, \\
\rho\left({ }^{252} \mathrm{Cf}\right) & =\left(1.551 \times 10^{-7} \pm 0.05\right) \Delta \mathrm{k} / \mathrm{k}, \\
\mathrm{R}_{f}^{\text {core }} & =1.489 \times 10^{7} \pm 0.023 \text { fissions } / \mathrm{cm}^{3}-\mathrm{sec}, \\
\bar{\nu} & =2.92 \pm 0.04,
\end{aligned}
$$

and

$$
\bar{\phi}^{*}\left({ }^{252} \mathrm{Cf}\right) / \bar{\phi} *(\text { core })=1.01 \pm 0.005 .
$$


The measured perturbation, determined from Eq. 1, is $(9.48 \pm 0.35) 10^{5}$. The calculated perturbation denominator for As sembly 7 using ENDF/B Version 1 cross sections corrected for plate heterogeneity in a one-dimensional cylindrical diffusion calculation was $7.504 \times 10^{5}$. This calculation also gave a k for for "as-built" Assembly 7 of 0.9795 . The ratio of the calculated to experimental perturbation denominators is 0.792 .

b. Mockup Critical Experiments. J. W. Daughtry (Last reported: ANL-7798, p. 86)

(1) The FTR Engineering Mockup. J. W. Daughtry

(a) End-of-Cycle Configuration. In ANL-7798, the FTR engineering mockup and the approach-to-critical were described and the

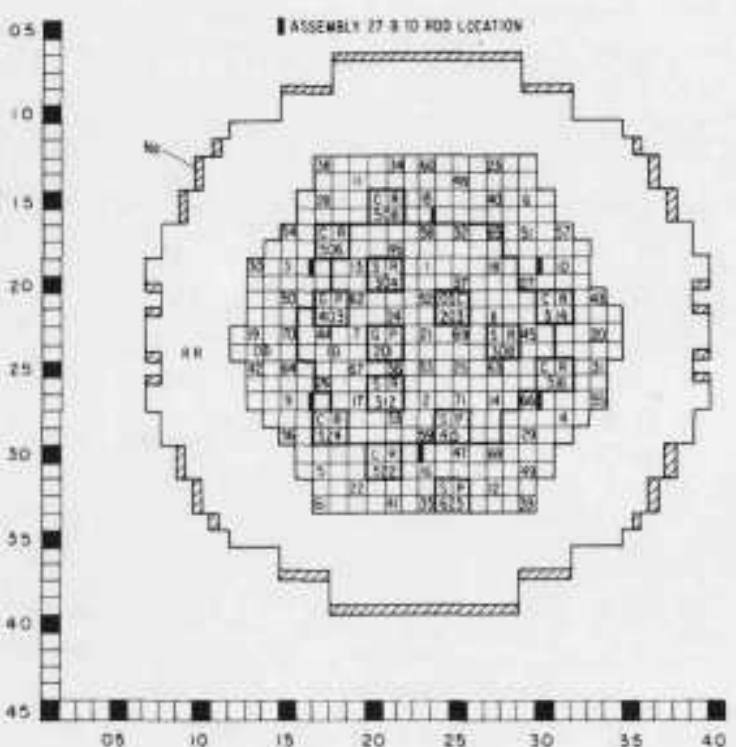

Fig. VII.3. The EOC-3 Configuration Showing the Revised Depletion Pattern transition from the EOC-1 configuration to the EOC-2 configuration was reported. The EOC-2 configuration was shown in Fig. VII. 7 of that report. The core contained $483.7 \mathrm{~kg}$ of ${ }^{239} \mathrm{Pu}+{ }^{241} \mathrm{Pu}$ and $4.3 \mathrm{~kg}$ of ${ }^{235} \mathrm{U}$. There were 63 tubes of depleted driver composition. The excess reactivity of EOC-2 without any neutron detectors in the core or reflector regions was $127 \pm 4$ Ih at $25^{\circ} \mathrm{C}$ (1071 Th $=1 \% \Delta \mathrm{k} / \mathrm{k})$.

The EOC - 3 configuration differed from the EOC- 2 configuration only in the locations of the depleted driver tubes. The EOC- 3 configuration showing the revised depletion pattern is given in Fig. VII. 3 of this report. At criticality, EOC-3 contained the same number of depleted tubes as EOC-2 (63) and thus the same mass of plutonium and uranium. The excess reactivity of EOC- 3 was $152 \pm 4$ Th at $25^{\circ} \mathrm{C}$.

(2) Temperature Coefficient, FTR-EMC (A. B. Long). To measure the temperature coefficient of the FTR-EMC, 24 thermocouples were positioned throughout the critical assembly. Twenty-one of these thermocouples were attached to fuel plates in three axial traverses at different radial locations within the core. The remaining three thermocouples were placed between the matrix tubes at the front face of the movable half, again at different radial locations.

The temperature coefficient of this assembly can be expressed as a weighted integral of the temperature coefficient at a given 
position integrated over the entire core. In this case, the weighting would reflect the importance in reactivity of a temperature change at a given position in the assembly. However, because of the complexity of this type of approach and the limited number of thermocouples available, it was necessary to perform a simplified measurement of the temperature coefficient. For this method to yield an accurate coefficient, some constraints had to be placed on the variation in the temperature distribution within the assembly for which the coefficient would hold. The reason for this was demonstrated when two different temperature profiles were obtained which yielded average temperatures only $0.1^{\circ} \mathrm{C}$ apart and yet were associated with an excess reactivity difference of $2.6 \mathrm{Ih}$.

The temperature coefficient of the assembly was measured in a manner that duplicated the day-to-day variances in operating temperature. This was done by adjusting the cooling controls on the air-conditioning system while the reactor was critical and the cooling fans were running. This technique permitted the temperature profile of the reactor to reach an equilibrium shape and then just vary in magnitude. The assembly temperature was found by averaging 21 of the thermocouple readings. If the profile for a given temperature measurement did not fall within certain restrictions, the measurement was discarded. The restrictions ensured that the temperature profile along the axis of the reactor is nearly flat.

On three separate days in EOC-2, EOC-3, and IC1, the temperature coefficient of the assembly was determined according to the above procedure. The measured temperatures were fit as a function of excess reactivity by a straight line for each day. The average temperature coefficient is $-4.1 \pm 0.4 \mathrm{Ih} /{ }^{\circ} \mathrm{C}$, providing the temperature is between 25 and $32^{\circ} \mathrm{C}$ and the profile falls within the accepted limits.

(3) Noise Analysis by the Cross-power Spectral-density Technique in the FTR-EMC. C. E. Cohn, A. B. Long, and J. W. Daughtry

(a) Equipment and Calibration. The neutron detectors for noise-analysis measurements being made in the FTR-EMC are two NE-905 glass scintillators manufactured by Nuclear Enterprises. Each scintillator is $1 \frac{1}{2} \mathrm{in}$. in diameter and 1 in. thick, weighs about $72 \mathrm{~g}$, and contains about $4.7 \mathrm{~g}$ of ${ }^{6} \mathrm{Li}$. The scintillator is cerium-activated silicate glass. It is attached to an RCA 6199 photomultiplier tube. The photomultiplier output passes through a unity-gain cable-driving preamplifier, mounted in the drawer with the scintillator and phototube, through coaxial cables to the reactor control room. There the output enters a General Radio 1925-9707 multifilter, which allows the selection of one of thirty 1/3-octave bands with center frequencies ranging from 100 to $80,000 \mathrm{~Hz}$. Both filters are set to the same frequency, and their outputs enter the two inputs of an analog multiplier. The multiplier output is integrated by a voltage-tofrequency converter. This converter has two pulse outputs: one active on 
positive excursions of the multiplier output, the other active on negative excursions. These outputs are counted in two separate scalers, and the difference between the scaler readings indicates the cross-power spectral density at that frequency.

The system is calibrated by exposing a plastic scintillator to white noise in the form of a ${ }^{60} \mathrm{Co}$ source. (Plastic is used instead of glass for greater gamma sensitivity. The change in scintillator type does not introduce any errors, because both scintillators have decay times much shorter than the reciprocal of the highest frequency analyzed.) Both multifilter inputs are connected to the preamplifier output, and measurements are taken as described above. For each frequency channel, the reading taken on a reactor run is divided by the white-noise reading, thus calibrating out the frequency response of the equipment.

(b) Preliminary Evaluation of the CPSD Noise Analysis Technique. In view of the importance of reactivity measurements in this part of the FTR-EMC experiments, it was agreed that when the subcriticality of a configuration was to be determined, it would be measured by inverse kinetics and by at least one noise-analysis technique. The first noise technique used during these measurements was "Cross-Power Spectral Density" (CPSD). During the approach-to-critical, measurements were made to check the operation of the neutron detectors and the data-handling instrumentation. After initial criticality of the EMC was achieved and during the subsequent steps leading from EOC-1 to IC2, noise measurements were made to evaluate the CPSD technique in the following three areas: (1) statistical uncertainties, (2) effect of detector location on measured roll-off frequency, and (3) comparison with the roddrop inverse-kinetics method.

\section{Statistical Uncertainties. In EOC-3, five CPSD} noise measurements were made yielding roll-off frequencies for a single near-critical configuration. The values obtained were: $637.4,658.3,647.6$, 663.1 , and $636.7 \mathrm{~Hz}$. The best estimate for the standard deviation from this sample is 12. These data indicate that the uncertainty in the roll-off frequency measured near critical is about $1.8 \%$. To determine the subcriticality of a configuration by this noise-analysis technique, the roll-off frequency must be determined for the subcritical configuration and for a reference configuration at or very near critical. The roll-off frequency is related to subcriticality by the expression

$$
2 \pi f_{r}=\frac{1-k_{p}}{\ell}=\frac{1-(k-\beta)}{\ell}=\frac{\Delta k+\beta}{\ell},
$$

where

$$
\begin{aligned}
& f_{r}=\text { roll-off frequency, } \\
& k_{p}=\text { prompt multiplication, }
\end{aligned}
$$




$$
\begin{aligned}
& \beta=\text { effective delayed-neutron fraction, } \\
& \boldsymbol{l}=\text { prompt-neutron lifetime, }
\end{aligned}
$$

and

$$
\begin{aligned}
& \Delta \mathrm{k}=1-\mathrm{k}=\text { subcriticality; } \\
& \Delta \mathrm{k}=2 \pi \mathrm{f}_{\mathrm{r}} \ell-\beta .
\end{aligned}
$$

If $f_{r c}=$ critical roll-off frequency,

$$
\begin{aligned}
2 \pi f_{r c} & =\beta / \ell, \\
\ell & =\frac{\beta}{2 \pi f_{r c}},
\end{aligned}
$$

and

$$
\Delta \mathrm{k}=\frac{2 \pi \mathrm{f}_{\mathrm{r}} \beta}{2 \pi \mathrm{f}_{\mathrm{rc}}}-\beta=\left(\frac{\mathrm{f}_{\mathrm{r}}}{\mathrm{f}_{\mathrm{rc}}}-1\right) \beta .
$$

The uncertainty in the subcriticality, $\sigma_{\Delta \mathrm{k}}$, that one measures by this technique can be obtained from

$$
\sigma_{\Delta k}^{2}=\left(\frac{f_{r}}{f_{r c}}\right)^{2}\left[\left(\frac{\sigma_{r c}}{f_{r c}}\right)^{2}+\left(\frac{\sigma_{r}}{f_{r}}\right)^{2}\right] \beta^{2} .
$$

For small values of subcriticality, where $f_{r}$ is not much larger than $f_{r c}$, $\sigma_{\Delta \mathrm{k}}$ can be approximated by

$$
\sigma_{\Delta \mathrm{k}} \sim \sqrt{2} \beta \frac{\sigma_{\mathrm{rc}}}{f_{\mathrm{rc}}}
$$

With the value of 0.018 obtained earlier for $\sigma_{r c} / f_{r c}$, the uncertainty in $\sigma_{\Delta k}$ is approximately $0.026 \beta$ or $2.6 \phi$.

With the equipment now available at ZPR-9, each measurement to obtain a roll-off frequency requires about $1 \mathrm{hr}$. Thus, to measure the worth of a control rod, for example, by this method would require approximately $2 \mathrm{hr}$ and could give a precision no better than $8 \mathrm{Ih}$ in that length of time. The worth of a ZPR-9 control rod was measured by this method. The measurement will be discussed in Sect. $\underline{3}$ below in comparing the inverse-kinetics and noise-analysis results.

To determine the reproducibility of the roll-off frequency one obtains with this technique in the vicinity of $2 \%$ subcritical, a set of measurements was obtained in SUB1. The values obtained for the roll-off frequency were $3554,3565,3467,3484$, and 3550 . The best estimate for the standard deviation from this sample is 45 or about $1.3 \%$. The 
statistical uncertainty can again be obtained using Eq. 1. The average rolloff frequency obtained for SUBl was 3524 , and the reference critical rolloff frequency is 713.5 . Assuming $\sigma_{\mathrm{rc}} / \mathrm{f}_{\mathrm{rc}}$ is still 0.018 , we have

$$
\begin{aligned}
\sigma_{\Delta k} & \approx \frac{3524}{713.5} \beta\left|(0.018)^{2}+(0.013)^{2}\right|^{1 / 2} \\
& \approx(4.939)(\beta)(0.0222)=0.11 \beta=11 \varnothing .
\end{aligned}
$$

This is better than one can do by inverse kinetics on ZPR- 9 at this time. However, there seem to be other problems with the CPSD noise-analysis technique in this range of subcriticality, as will be shown in Sects. $\underline{2}$ and $\underline{3}$ below.

2. Effect of Detector Location on Measured Roll-off Frequency. To determine if one would obtain different roll-off frequencies depending on the location of the neutron detectors, measurements were made with the glass scintillators in various locations in the assembly. Table VII.2 summarizes the results obtained near critical. When the detectors were in the special-purpose loop and in the oscillator locations, the front and back drawers normally in those locations were removed. When located in the plenum, only the back drawers needed to be removed. Additional position-dependence comparisons were made in three subcritical states. These are included in Table VII.2. In every case, except the nearcritical EOC- 2 configuration, the location near the center of the core gave a higher roll-off frequency. The differences are greater than the scatter of data presented in Sect. 1 above.

\begin{tabular}{|c|c|c|c|c|c|}
\hline $\begin{array}{l}\text { Core } \\
\text { Configuration }\end{array}$ & $\begin{array}{l}\text { Detector } \\
\text { Pasitian }\end{array}$ & $\begin{array}{l}\text { Messured } \\
\text { Roll-off } \\
\text { Frequency }\end{array}$ & $\begin{array}{c}\text { Suboriticality } \\
\text { Nuring } \\
\text { Neasurement }\end{array}$ & $\begin{array}{l}\text { Critcical Roll-off } \\
\text { Frequency } f_{r c}\end{array}$ & $\begin{array}{l}\text { Prompt-neutron } \\
\text { Lifettale, } \text {, isec } \\
\mathrm{L}=\left(\mathrm{B} / 2 \pi \mathrm{f}_{\mathrm{rc}}\right)\end{array}$ \\
\hline $\operatorname{toc}-1$ & $\begin{array}{l}\text { 3p-Loop, reactor nidplane in } \\
\text { M33-24. M33/25 }\end{array}$ & 6.14 .7 & 4.0 & 605.8 & 0.748 \\
\hline EOC - 1 & $\begin{array}{l}\text { osc, react or midplane in } \\
M 21 / 24, M 22 / 24\end{array}$ & $65 \mathrm{t}, 3$ & $5 . n$ & 543,9 & 0.705 \\
\hline$E O C-2$ & $\begin{array}{l}\text { Dutside RP, reactor nidplane in } \\
\text { H38/17, M39/29 }\end{array}$ & 617.3 & 8.1 & 601.6 & 0.768 \\
\hline$[O C-2$ & $\begin{array}{l}\text { OSC, reactor nidplane in } \\
\mathrm{M}_{21} / 2 \mathrm{~L}, 1422 / 24\end{array}$ & $\mathrm{BIL}_{4}$ ? & 7.9 & 599.4 & 0.771 \\
\hline$E O C-2$ & $\begin{array}{l}\text { Plenum, } 24 \text { in, back from reactor mid- } \\
\text { plane in } 1122 / 23 \text {, } \$ 24 / 23\end{array}$ & 623.2 & 8,1 & 607.3 & 0.761 \\
\hline IC2 & $\begin{array}{l}\text { OSC, reactor nldplane in } \\
\mathrm{M} 21 / 24, \mathrm{M} 22 / 24\end{array}$ & 767.8 & 6.8 & 751.5 & 0.615 \\
\hline $\mathrm{IC2}$ & $\begin{array}{l}\text { Plenum, } 24 \text { in, back from reactor mid- } \\
\text { plane in } 122 / 23,1124 / 23\end{array}$ & 693.0 & 8.1 & 675.3 & 0.634 \\
\hline
\end{tabular}

TAHLE VIt.2. Critteal Roll-off Frequency Measured as a Punction of Reactor Position

Calculated paraneters:

EOC $-1: B=0.002852,12 \Delta \mathrm{k} / \mathrm{k}=1078.93 \mathrm{th}$.

EOC-2: $B=0.002903 ; 18 \Delta K / K=1071.01 \mathrm{Th}$.

IC2: Not calculated, tused EOC-2 paraneters. 
3. Comparison of CPSD Noise Analysis and Rod-drop/ Inverse-kinetics Results. The worth of ZPR-9 fuel-bearing control rod No. 2 was measured in EOC-2 by the rod-drop/inverse-kinetics method and by the CPSD noise-analysis technique. Three rod drops were made; in addition, two noise measurements were made with the rod full in and two with the rod full out. The noise-analysis neutron detectors were located in the core plenum in matrix tubes M22-23 and M24-23 about 24 in. from the midplane of the assembly. The rod worth by inverse kinetics was $0.107 \pm 0.001 \% \Delta \mathrm{k} / \mathrm{k}$, and by noise analysis was $0.114 \pm 0.007$. The results agree within the accuracies of the measurements. However, the noise measurement required approximately $4 \mathrm{hr}$ to achieve a precision of about $6 \%$, compared to inverse kinetics requiring less than one-half hour to achieve a $1 \%$ precision.

When the subcriticality of the SUBI configuration was measured by the same two techniques, a sizable discrepancy was noted. To investigate this discrepancy, a series of subcriticality measurements was made during the transition from SUB2 to IC2. The results are summarized in Table VII.3. Noise and inverse-kinetics measurements were compared in each of three subcritical configurations, and noise data were taken with the detectors in two locations in each configuration as indicated in the

TABLE VII.3. Comparison of CPSD Noise Analysis and Inverse-kinetics Subcriticality Measurements

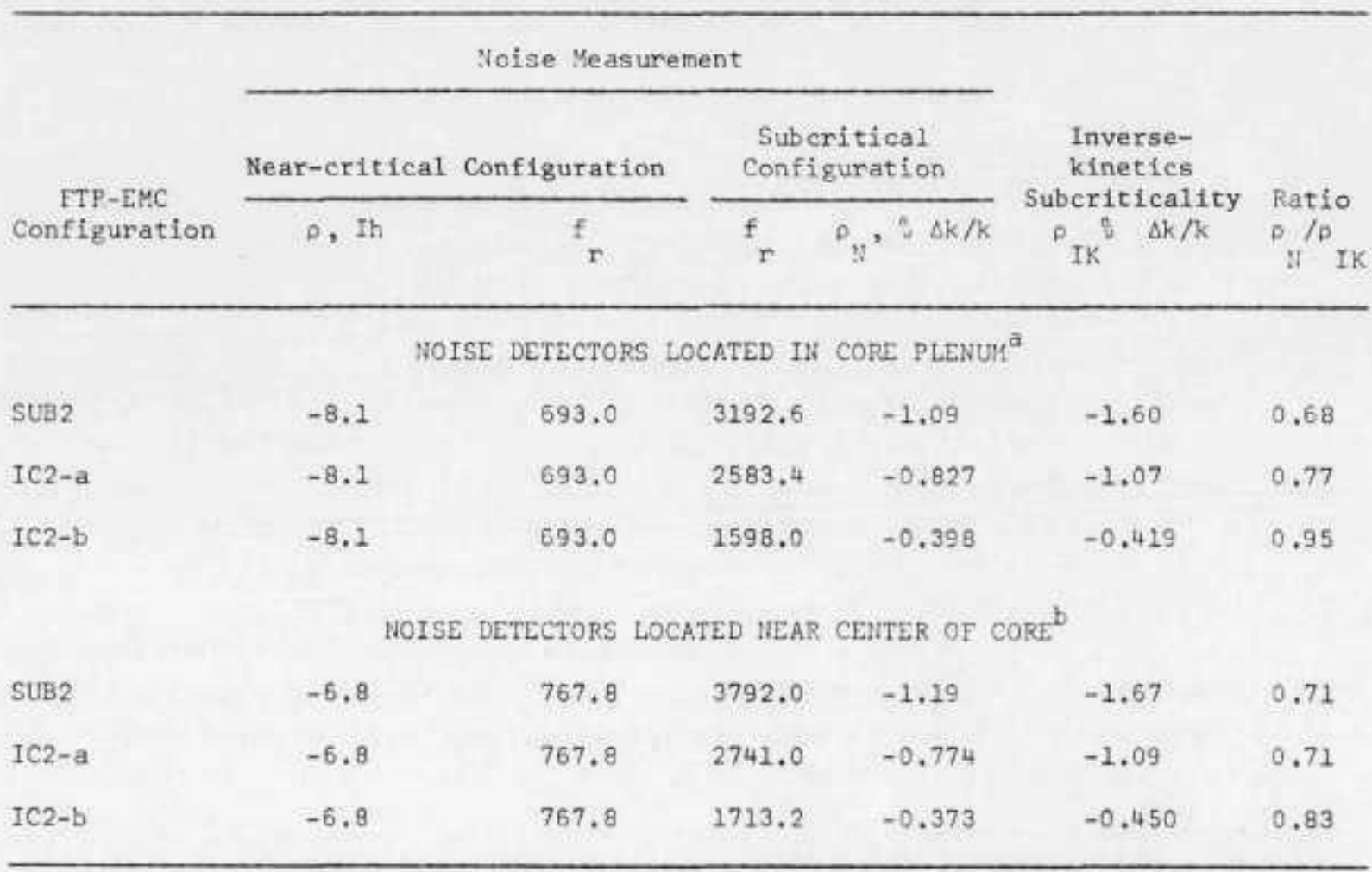

\footnotetext{
$a_{1,22-23}$ and $424-23,24$ in. back from reactor midplane.

${ }^{\mathrm{N}} 21-24$ and $\mathrm{M} 22-24$, at midplane of reactor.
} 
table. The reactivity effect due to removing the noise-analysis neutron detectors from near the center of the core and placing them in the core plenum region was found to be +33.5 Ih by the inverse-kinetics method. Regardless of where the counters are located, the results obtained by the two methods diverge as the degree of subcriticality increases.

(c) Noise Measurements for the Remainder of the

Enrichment Experiments. From the data presented in this report it seems unlikely that the CPSD noise analysis method will be useful as an alternate method for making subcriticality measurements in the EMC. Consequently, ANL personnel have tried to provide other methods for assessing the subcriticality of the configurations assembled in this series of experiments. One additional noise-analysis technique similar to the Albrecht* method appears to be giving good results. This method uses some of the data taken during the CPSD measurements and therefore may provide results for all of the configurations in this series of enrichment experiments.

In addition Bennett has developed a method** for determining subcriticality from rod-drop data that does not rely on inverse kinetics. The usefulness of these alternate methods is being evaluated.

2. Fast Critical Facilities; Experiments and Evaluations--Idaho (02-181)

a. Clean Critical Experiments. P. I. Amundson (Last reported: ANL-7798, p. 94)

(1) ZPPR Assembly 2 (R. E. Kaiser). Axial counter traverses have been performed at the exact center of the inner core, for use in normalization of the radial counter traverses previously obtained at 3,14 and 22 in. from the reactor interface. Counters used included ${ }^{239} \mathrm{Pu},{ }^{240} \mathrm{Pu},{ }^{238} \mathrm{U}$, and ${ }^{235} \mathrm{U}$ fission counters and a ${ }^{10} \mathrm{~B}(\mathrm{n}, \alpha)$ counter.

Radial reactivity traverses were performed $11 \mathrm{in}$. from the interface, and included the samples reported previously for the 14- and 22-in. traverses. Counter traverses were not performed at this location, because the shapes of the countrate-versus-radius curves did not change appreciably in going from the 3 - to the 14 -in. positions.

A series of sodium-void measurements, as prescribed for the FTR mockups, has been completed. The zones included a single drawer, a 21-drawer zone ( $5 \times 5$ with corners missing), and a 93-drawer zone, all voided to a depth of $12 \mathrm{in.}$ in each half. The 93-drawer zone corresponds to

*G. M. Hess and R. W. Albrecht, Polarity Spectral Analysis Reactivity Errors, Trans. Am. Nucl. Soc. 12. 738 (1969).

**E. F. Bennert, Analysis of Noisy Rod Drop Flux Profiles, internal memorandum, Argonne National Laboratory (May 2, 1971). 
the largest voided zone to be built in the pin-calandria experiments scheduled for this summer. This limitation is imposed by calandria availability. Preliminary results of these measurements indicate a high degree of consistency in the specific worth, and a reasonable comparison with the smallsample measurements and the calculations. Preliminary results for the worths of the voided zones are given in Table VII.4.

TABLE VII.4. Preliminary Sodium-void Measurements in the Plate Core of ZPPR Assembly 2

\begin{tabular}{lrc}
\hline Zone & $\begin{array}{c}\text { Mass of Na } \\
\text { grams }\end{array}$ & $\begin{array}{c}\text { Total Worth } \\
\text { Ih }\end{array}$ \\
\hline Single Drawer & 660.3 & $1.8 \pm 0.3$ \\
9 dwr $(3 \times 3)$ & 5943.0 & $16.2 \pm 0.3$ \\
21 dwr & 13867.0 & $44.0 \pm 0.3$ \\
93 dwr & 61410.0 & $196.7 \pm 0.3$ \\
\hline
\end{tabular}

A series of experiments was performed in the voided zone. The first of these was a measurement of the worth of replacing a small amount of sodium. A movable drawer was installed in the center of the zone, and loaded to correspond to the surrounding drawers (voided from 0 to 12 in.). The worth of the drawer as a function of position was determined by inverse-kinetics methods. Then the sodium was replaced in the front 6 in. of the drawer, and the worth measured again. The difference in the two measurements indicated the worth of a small amount of sodium added to a voided zone. A similar experiment had been performed previously in which a normal core drawer was voided of sodium over the first: 6 in. The preliminary results indicate that the specific worth of sodium added to the voided zone is about $25 \%$ higher than the specific worth of sodium removed from the normal core. The amount of sodium involved in each case was about $165 \mathrm{~g}$.

Fission ratios for ${ }^{239} \mathrm{Pu} /{ }^{238} \mathrm{U}$ and ${ }^{238} \mathrm{U} /{ }^{235} \mathrm{U}$ were also measured in the voided zone, as an indicator of the extent of spectral change. The ratios were measured using back-to-back foils in spherical chambers, as was done previously in the unvoided plate core. Results of these measurements are complete and are shown in Table VII.5. The increased hardness of the voided-core spectrum is emphasized by the substantial increase in the ratio for the threshold fission isotope, ${ }^{238} \mathrm{U}$.

Small-sample reactivity measurements were performed at the reactor interface by inserting the traverse tube into the slot that normally accommodates the positioning tab on the side of the drawers. Tabs were removed from a number of spare drawers, which were then 
recessed a small amount into the matrix tubes to allow space for the traverse tube. This technique was used because it will allow direct comparison of plate-core measurements with measurements in the pincalandria system.

TABLE VII.5. Fission Ratios in the Sodium-voided and -unvoided Plate Cores of ZPPR-2

\begin{tabular}{llll}
\hline Ratio & $\begin{array}{c}\text { Unvoided } \\
\text { Core }\end{array}$ & $\begin{array}{c}\text { Voided } \\
\text { Core }\end{array}$ & $\begin{array}{c}\text { Percent Change } \\
\text { on Voiding }\end{array}$ \\
\hline${ }^{238}{ }_{\mathrm{U} /}{ }^{235} \mathrm{U}$ & $0.0201 \pm 0.0004$ & $0.0242 \pm 0.0004$ & +20.5 \\
${ }^{239} \mathrm{Pu} /{ }^{235} \mathrm{U}$ & $0.9372 \pm 0.0142$ & $0.9676 \pm 0.014$ & +3.2 \\
\hline
\end{tabular}

Reactivity Doppler measurements were performed at the center of the voided zone. Both natural $\mathrm{UO}_{2}$ and ${ }^{239} \mathrm{PuO}_{2}$ samples were run at temperatures up to $1100^{\circ} \mathrm{K}$. The standard hot-sample, cold-reactor technique was used, in which the sample is oscillated in and out of the reactor, and the worth measured at each of several temperatures. The difference in the oscillation worth thus represents the reactivity effect (Doppler plus expansion) upon heating of the sample.

Data from most of the experiments in the voided core are still being processed. However, the fission ratios, which were measured using spherical chambers with back-to-back foils, have been reduced and are shown in Table VII. 5, in comparison with the values obtained in the unvoided plate core.

b. Doppler Experiments. R. E Kaiser (Last reported: ANL-7753, p. 32)

The ZPPR reactivity Doppler equipment was set up in the reactor cell, alongside the reactor, for test purposes. Performance tests were run on the drive controls, vacuum system, and heater systems in this configuration. The series of tests culminated in a $5-\mathrm{hr}-\mathrm{long}$ "simulation" of a Doppler experiment in which all the above systems and the SEL 840 data-acquisition program were checked out. Shortly after completion of these tests, the equipment was installed in the reactor for its initial use.

The first reactivity Doppler experiment performed in ZPPR used a natural $\mathrm{UO}_{2}$ capsule in the 93-drawer voided zone of Assembly 2 . The dual-heater system which was installed to eliminate extraneous reactivity effects arising from reactor heating, or temperature changes in the balance material downstream from the sample, worked satisfactorily. 
The auxiliary heater was set to deliver about $270 \mathrm{~W}$ into the cooling-air stream with the sample unheated. As the sample was heated to higher temperatures, the automatic controllers cut back the power to the auxiliary heaters to maintain a constant $( \pm 5-10 \mathrm{~W})$ total power to both heaters. Thus the outer temperatures of the Doppler rod remained essentially constant, thereby isolating the heated sample from the cold reactor.

Performance of the equipment was excellent, and further experiments, including $\mathrm{PuO}_{2}$ in the voided plate core and $\mathrm{UO}_{2}$ and $\mathrm{PuO}_{2}$ in the unvoided core, are now in progress.

3. Planning and Evaluation of FFTF Critical Assembly Experiments. (02-015; last reported: ANL-7798, p. 95)

a. Calculation of Kinetics Parameters for FTR-3, Loading 125. A. Travelli and A. J. Ulrich

Kinetics parameters have been calculated for ZPR-9 Assembly 26, loading 125. This loading corresponds to the FTR-3 "Initial Configuration," which served as a basis for a series of subcritical assemblies (see ANL-7798, p. 92) used to test various techniques under consideration for monitoring the subcriticality of the FFTF during shutdown.

The neutron-flux distribution of the assembly was calculated in two-dimensional R-Z geometry and in 29-group diffusion theory by means of the DIF2D code of the ARC system. The various regions of the core were represented by a succession of concentric cylinders, each containing the same materials as the corresponding regions of the core. Six such cylindrical regions were used to represent the core.

The neutron cross sections used in the calculation corresponded to a modification of Set 29006, in which the broad-group heterogeneity effect due to the plate-loading patterns in the cells of the FTR-3 core were taken into account by means of the MODXSS* code. The modified cross-section set was labeled "Set MD29006." The delayed-neutron data concerned six families of delayed neutrons and described their respective yields,** decay constants,** and energy distributions. ${ }^{*}$ A separate calculation for the same assembly was run in one-dimensional cylindrical geometry. The purpose of the one-dimensional calculation was to assess the effect of the axial reflector and the extent to which this more economical type of calculation may be used to determine kinetics parameters in FFTF-like assemblies.

\footnotetext{
*K. Dance, R. A. Karam, and I. E. Marshall, "Heterogeneity Calculations for Plate-Type Heterogeneous Reactors," Reactor Physics Division Annual Report: July 1, 1967 to June 30, 1968, ANL-7410, p. 140 (Jan 1969).

** R. Batchelor, H. R. McK. Hyden, J. Nucl. Energy 3 , 7 (1956).

† G. R. Keepin, T. J. Wimet, and R. K. Zugler, Phys. Rev. 107, 1044 (1957).
} 
The one-dimensional calculation was run through the DIF1D code of the ARC system with the same cross sections, compositions, radial mesh spacings, and delayed-neutron data as the two-dimensional calculation. The region- and group-independent buckling $\left(5.4075 \times 10^{-4} \mathrm{~cm}^{2}\right)$ was determined so that the effective multiplication constant $(0.991760)$ would be the same in the two problems. In the one-dimensional problem, the flux and the fission cross section were assumed to vanish, respectively, at the extrapolated axial boundary of the core $(67.549 \mathrm{~cm}$ from the reactor midplane) and at the physical axial boundary of the core $(45.801 \mathrm{~cm}$ from the reactor midplane).

Table VII. 6 describes the results of the calculations. One- and two-dimensional calculations agree very well with each other in the values of the perturbation denominator, of the effective delayed-neutron fraction, and of the inhours per percent reactivity. Therefore, one-dimensional calculations appear to be adequate for most static calculations. However, the internal 1/v product is underestimated by approximately $13 \%$ in the one-dimensional calculation, causing a similar bias in the values of the

TABLE VII.6. Kinetics Parameters of ZPR-9/FTR-3, Loading 125, as obtained from One- and Two-dimensional Calculations

Parameter

Effective multiplication constant

$K_{\text {eff }}$

Perturbation denominator

$\mathrm{PD}=\left\langle\phi^{*}\left|\chi \Sigma_{f}\right| \phi\right\rangle$

Interna1 $1 / \mathrm{v}$ product

$\mathrm{IP}=\left\langle\phi *\left|\frac{1}{\mathrm{~V}}\right| \phi\right\rangle$

Neutron generation time

$\Lambda=I P / P D, \sec$

Prompt neutron lifetime

${ }_{\mathrm{p}}^{\mathrm{p}}=K_{\text {eff }} \Lambda, \sec$

Effective delayed neutron fraction

${ }^{\beta}$ eff

Inverse rolloff angular velocity

$\alpha=\Lambda / B_{\text {eff }}$, $\sec$

Inhours per percent reactivity
$6.431304 \times 10^{-7} \quad 7.231854 \times 10^{-7}$

$.00297056 \quad .00294884$

R Calculation

R-Z Calculation
0.991760
0.991760

$1.844777 \times 10^{-5} \quad 1.847618 \times 10^{-5}$

$1.196290 \times 10^{-11} \quad 1.347272 \times 10^{-11}$

$6.484739 \times 10^{-7} \quad 7.291940 \times 10^{-7}$

$218.30 \times 10^{-6} \quad 247.28 \times 10^{-6}$

1036.517

1040.638 
neutron-generation time, the prompt-neutron lifetime, and the inverseroll-off angular velocity. The underestimate is a direct consequence of the inability of the one-dimensional calculations to take properly into account the significant neutron population in the axial reflector.

The value of the inverse-roll-off angular velocity obtained from the two-dimensional calculation $(247.28 \mu \mathrm{sec})$ is in excellent agreement with the corresponding experimental value $(252 \pm 6 \mu \mathrm{sec})$ measured by ORNL personnel in ZPR-9/FTR-3, loading 125 (N. J. Ackermann, A. R. Buhl, and R. C. Kryter, private communication). 


\section{B. Support of ZPR Fast Critical Experiments}

1. Fast Critical Experiments; Theoretical Support--Idaho (02-010)

a. Supplementary Analytical Evaluations of Integral Data. R. G. Palmer (Last reported: ANL-7765, P. 1)

(1) Control-rod Calculations in ZPPR-2 (J. P. Plummer). An effort was begun to determine the effect on the worths of the four-drawer boron and tantalum bundles, used to simulate massive control rods in ZPPR -2, due to the calculational approximation of homogenizing the contents of these four-drawer regions. It was felt that this approximation might have some bearing on the considerable discrepancy between the calculationto-experiment ratio for small-sample worths as compared to the $\mathrm{C} / \mathrm{E}$ ratio for massive-rod worths. Typical values are $\sim 1.25$ for the former and $\sim 1.00$ for the latter.

The two-dimensional diffusion module of the ARC System was used to calculate the worth of a central $\mathrm{B}_{4} \mathrm{C}$ four-drawer bundle, both homogenized and in its full heterogeneous detail. The result was that the rod was worth about $3 \%$ more when treated heterogeneously. This result is not considered to be a satisfactory answer to the question originally posed. It is felt that two-dimensional transport theory calculations are needed and that, if these were done, the heterogeneity correction might well be of the opposite sign. Such a transport-theory investigation is now being considered, the economic question being the major problem.

(2) Reaction-rate Cell Distributions in ZPPR-2

(J, P. Plummer). Reaction-rate distributions are being calculated for ZPPR-2 inner and outer core cells, sodium-voided and nonvoided, for the processes ${ }^{238} \mathrm{U}(\mathrm{n}, \mathrm{f}),{ }^{238} \mathrm{U}(\mathrm{n}, \gamma)$, and ${ }^{239} \mathrm{Pu}(\mathrm{n}, \mathrm{f})$. Both Calhet and the ARC System have been used for this in preliminary calculations. However, the bulk of these calculations will probably be done using the ID transport module of the ARC System. The cell leakages are obtained by calculating group-dependent $D^{2}$ values from a $2 D$ diffusion calculation using $R-Z$ geometry. These are then added to the corresponding macroscopic mixture total cross sections by Type 20 cross-section modification cards. Prelimi nary indications are that in order to get satisfactory agreement with experiment, resonance-dominated processes like ${ }^{238} \mathrm{U}(\mathrm{n}, \gamma)$ and ${ }^{239} \mathrm{Pu}(\mathrm{n}, \mathrm{f})$ must be calculated using an ultrafine-group code having a detailed description of the resonances, such as RABID.

MODXSS, a code with partial ARC status which weights the cell cross sections according to flux volume, is being made operational in Idaho. 
(3) VIM-I Monte Carlo Code (F, L. Fillmore). The VIM-I library based on ENDF/B Version II cross-section data was received from Atomics International (AI). A spherical-geometry version of VIM-I supplied by AI was made operational on the IBM $360 / 75$ computer and modified to use the Version-II library, which contains tables for self-shielding the unresolved resonance cross sections not in the Version-I library. A checkout calculation of 50,000 histories requiring 9 min of computing time on the $360 / 75$ was made for the JEZEBEL critical assembly. The result obtained was $k=0.9900 \pm 0.0040$, which is consistent with the value $0.9848 \pm 0.0029$ obtained at AI. For comparison, the value obtained with the Version-I data was $\mathrm{k}=1.0047 \pm 0.0043$.

The drawer configuration of VIM-I, which is used in making calculations for ZPPR-2, was modified to use the Version-II library. Some other modifications were also made so that this version of the code would correspond more closely to the one presently in use at AI. Provision was made to store the initial coordinates of all source particles on tape so that fixed-source calculations using these coordinates can be done at a later time. A revised ZPPR-2 input data deck was prepared which is based on the Loading-90 information given in ZPR-TM-47.* This deck provides a heterogeneous model of ZPPR-2 containing over 40,000 zones. There are six drawer types and 147 different types of zones. Calculations for this loading using Version-II data are in progress, but only 6000 histories have been finished to date. Results will be reported as soon as satisfactory convergence has been obtained.

Work is continuing to develop a version of VIM-I for calculating isotopic multigroup cross sections by region for the ZPPR - 2 as sembly. A part of the coding is finished and is being checked out.

A version of VIM-I has been prepared which has provision for one additional drawer type and 20 additional zone types. This version of the code is required for making calculations on loadings which contain additional features, such as control-rod experiments, which require a separate drawer type for their description.

b. ZPR Heterogeneity Method Development. R. G. Palmer (Last reported: ANL -7783, p. 8)

A code, SARCASM, has been developed for calculating sample size effects in reactivity-perturbation samples. The code was a broadgroup collision-probability method to calculate a correction for selfmultiplication, self-absorption, and multiple scattering to the first-order perturbation-theory worth. The method is similar to that described by

\footnotetext{
${ }^{*}$ R. E. Kaiser, A. L. Hess, and R. J. Norris, Experimental Evaluations of the Critical Mass for ZPPR Assembly 2 , intemal memorandum (Jan 20, 1971).
} 
Dance (see ANL-7527, December 1968) for slab samples, but reaction rates are weighted with the adjoint fluxes to form the numerator of the perturbation expression. Any shape of sample may be treated by the code by addition of the appropriate collision-probability routine. The geometries currently incorporated include infinite slabs, infinite cylinder, infinite annulus, and finite thin-walled annulus.

The code has been used to obtain size corrections for perturbation-sample measurements made at the center of ZPPR. For sets of six different-size plutonium samples, the variation of worth agrees with measurements within the experimental error. Reasonable, although not as good, agreement is also obtained for sets of five tantalum samples and seven enriched-boron samples. Because of the broad-group restriction of the code, appropriately resonance-shielded data must be used as input. Difficulties arise for materials with large resonances and in particular for ${ }^{238} \mathrm{U}$, where the shielding of the sample resonances by resonances in the core plates will be appreciable. These aspects are being investigated.

\section{Fast Critical Experiments; Experimental Support--Illinois (02-013)}

\section{a. Development of Techniques for Critical Experiments.}

E. F. Bennett (Not previously reported)

(1) Improved Noise Method for Subcriticality Determination (C. E. Cohn). A noise method recently developed for subcriticality measurement has given results normally agreeing with rod-drop measurements within 100 Th when applied to various configurations in ZPR-9. Like the methods of Seifritz* and Hess and Albrecht,** this method measures the coherence between the signals from two neutron detectors, but unlike their methods it uses the equipment we have been using for cross-powerspectral-density (CPSD) rolloff measurements. (Incidentally, the discrepancies we have observed between CPSD and rod-drop measurements are believed to be attributable to departures from point kinetics in the behavior of the CPSD in the rolloff region.)

Our CPSD equipment consists of two glass-scintillator neutron detectors, whose outputs are processed by two multifilters that select 1/3-octave frequency bands centered at various frequencies. (Normally, each multifilter is set to the same frequency.) The multifilter outputs go to the two inputs of an analog multiplier whose output goes to a voltage to-frequency converter (VFC) having a full-scale output frequency of $1 \mathrm{MHz}$.

\footnotetext{
*W. Seifritz, The Polarity Correlation of Reactor Noise in the Frequency Domain, Nuc1. Appl. Tech. 1 , 513-522 (1969).

${ }^{* *}$ G. M. Hess and R. W. Albrecht, Polarity Spectral Analysis Reactivity Errors, Trans. Am. Nuc1, Soc. 12, 738 (1969).
} 
The VFC has two pulse outputs. One is operative when the VFC input is positive; the other is operative when the input is negative. The outputs are counted by two separate scalers, which are started and stopped simultaneously by an electromechanical timer. Thus, one scaler integrates the multiplier output whenever the multiplier inputs are of the same sign, while the second scaler integrates the multiplier output whenever the multi plier inputs are of opposite sign. The CPSD at a given frequency is indicated by the difference between the two readings, while the coherence is indicated by their ratio.

The ratio $R$ between the readings of the first and second scalers is given by

$$
R=\frac{\int_{0}^{\infty} \int_{0}^{\infty} x y P(x, y) d x d y+\int_{-\infty}^{0} \int_{-\infty}^{0} x y P(x, y) d x d y}{\int_{0}^{\infty} \int_{-\infty}^{0} x y P(x, y) d x d y+\int_{-\infty}^{\infty} \int_{0}^{\infty} x y P(x, y) d x d y},
$$

where $P(x, y)$ is the bivariate Gaussian probability density function, which may be written as

$$
\mathrm{P}(\mathrm{x}, \mathrm{y})=\frac{1}{2 \pi \sqrt{1-\gamma^{2}}} \exp \left[-\frac{1}{2\left(1-\gamma^{2}\right)}\left(\mathrm{x}^{2}-2 \gamma \mathrm{xy}+\mathrm{y}^{2}\right)\right]
$$

(with $\mathrm{x}$ and $\mathrm{y}$ normalized to unit standard deviation). Here $\gamma$ is the coher ence or correlation, and ranges from zero with no correlation to unity with complete correlation.

These integrals are not integrable analytically, but they were evaluated numerically for values of $\gamma$ spaced by 0.01 with simple summation over a mesh of 0.1 in $x$ and $y$ to 10. (The resulting $R$ values are good to three significant figures.) At present, the value of $\gamma$ corresponding to a measured $\mathrm{R}$ is determined from these results by linear interpolation. We plan to refine the integration by going to one-tenth the mesh size, and to seek a good analytic approximation function for $R$ versus $\gamma$. Use of such a function could refine the $\gamma$ determinations and facilitate error estimates.

given by

With coherence determined, the subcriticality in dollars is

$$
\$_{2}=\left(1+\$_{1}\right) \sqrt{\frac{\gamma_{1}}{1-\gamma_{1}} \cdot \frac{1-\gamma_{2}}{\gamma_{2}}}-1 \text {, }
$$


where $\gamma_{2}$ is the coherence observed in the subcritical state, $\gamma_{1}$ is the coherence observed at the near-critical reference, and $\$_{1}$ is the subcriticality of the reference, which is normally small $(\sim 3 q)$ and is determined by inverse kinetics. Results are not too sensitive to detector location; good results have been obtained on ZPR-9 with the detectors either in the center of the core or in the axial reflector. However, the detector location must be identical in the critical and subcritical states. At present, coherence meas urements are being made at the lowest multifilter frequency, i.e., $100 \mathrm{~Hz}$.

Table VII. 7 summarizes the measurements that have been done to date by this technique.

TABLE VII.7. Comparison of Noise-coherence and Rod-drop Measurements of Subcriticality in a Series of Loadings in ZPR-9

\begin{tabular}{lcr}
\hline & \multicolumn{2}{c}{ Subcriticality, Ih } \\
\cline { 2 - 3 } ZPR-9 Loading & By Noise Coherence & By Rod Drops \\
\hline 28 (SUB 1) & 2117 & $2059 \pm 37$ \\
32 (SUB 2) & 1718 & $1715 \pm 24$ \\
40 (SUB 3) & 463 & $435 \pm 3$ \\
41 (SUB 4) & 1812 & $1545 \pm 19$ \\
44 (SUB 5) & 1694 & $1660 \pm 29$ \\
45 (SUB 6) & 1384 & $1448 \pm 18$ \\
49 (SUB 7) & 2309 & $2250 \pm 65$ \\
\hline
\end{tabular}

3. Fast Critical Experiments; Experimental Support--Idaho.

S. G. Carpenter (02-011)

a. Neutron Spectroscopy. G. G. Simons (Last reported: ANL-7753,

Fast-neutron spectra have been measured in the inner and outer cores of ZPPR-2 in the normal configuration and for the inner-core sodiumvoided case. Companion fundamental-mode calculations are also available for these configurations.

Details of the experimental technique and spectra obtained for bare and lead-encased detectors operated in the inner core and bare detectors used to complete an outer-core measurement were reported in the June 1970 Progress Report, ANL-7705. A critical-loading diagram and the reactor composition for the normal core were reported in the March 1970 Progress Report, ANL-7679. 
Comparisons of the measurements and fundamental-mode calculations made with the $\mathrm{MC}^{2}$ Code using ENDF/B Version I cross sections were also discussed in ANL-7705. Unreported work includes the sodiumvoided study and calculations completed using ENDF/B Version II cross sections.

Figure VII.4 shows the smoothed ultrafine-group spectra, obtained using ENDF/B Version I and II cross sections, from $\mathrm{MC}^{2}$ superimposed upon the experimental results for the inner core. Version II data show significantly improved agreement between measurement and calculation around $30 \mathrm{keV}$. This results from an addition iron cross-section resonance at $34 \mathrm{keV}$ in the Version II data set which did not exist in Version I. The energy range from 60 to $100 \mathrm{keV}$ shows the most disagree ment between calculation and experiment. Unfortunately, Versions I and II both give the same result within this energy region. This is believed to be caused by inaccuracies in the basic iron cross-section set.

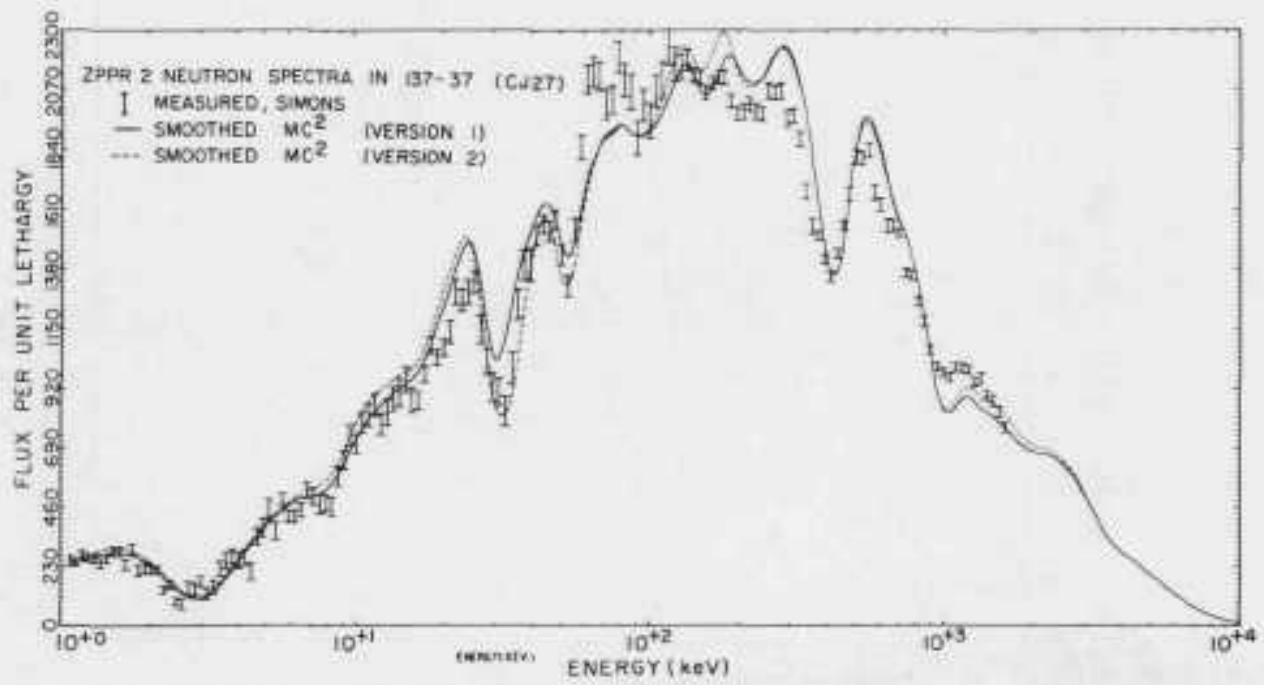

Fig. VII.4. Experimental and Smoothed MC ${ }^{2}$ Calculated Spectra in ZPPR-2 (137-37). ANL Neg. No. 103-A11739.

Neutron spectra measured in the normal and sodium-voided ZPPR - 2 cores are shown in Fig. VII.5. These measurements were made using similar detector configurations and the same high-count-rate electronics. Thus the spectral change between the two assemblies can be attributed solely to the effect of the sodium voiding.

4. ZPR Materials Procurement (02-020; last reported: ANL-7726, p. 18, July 1970)

a. Technical Administration and Quality Control

(1) Quality Assurance Program for ZPR Fuels (A. B. Shuck, F. B. Huke, and H. B. Evans). The ANL program for quality assurance of the ZPR fuels included qualification of the Kerr-McGee procedures, 
surveillance of manufacture and quality control, and receiving inspection at ANL. The qualification of procedures was accomplished by a detailed review of fabrication, analytical, and inspection procedures, followed by a statistical evaluation of the variability of the first $10,000(\mathrm{U}, \mathrm{Pu}) \mathrm{O}_{2}$ pellets and 1000 fuel rods produced. Chemical analyses and measurements from ANL and Kerr-McGee were cross-checked throughout the program by comparison analyses of split pellets. Acceptance and rejection standards were selected from the preproduction components. Production was approved on the basis of statistical acceptability within the specified limits.

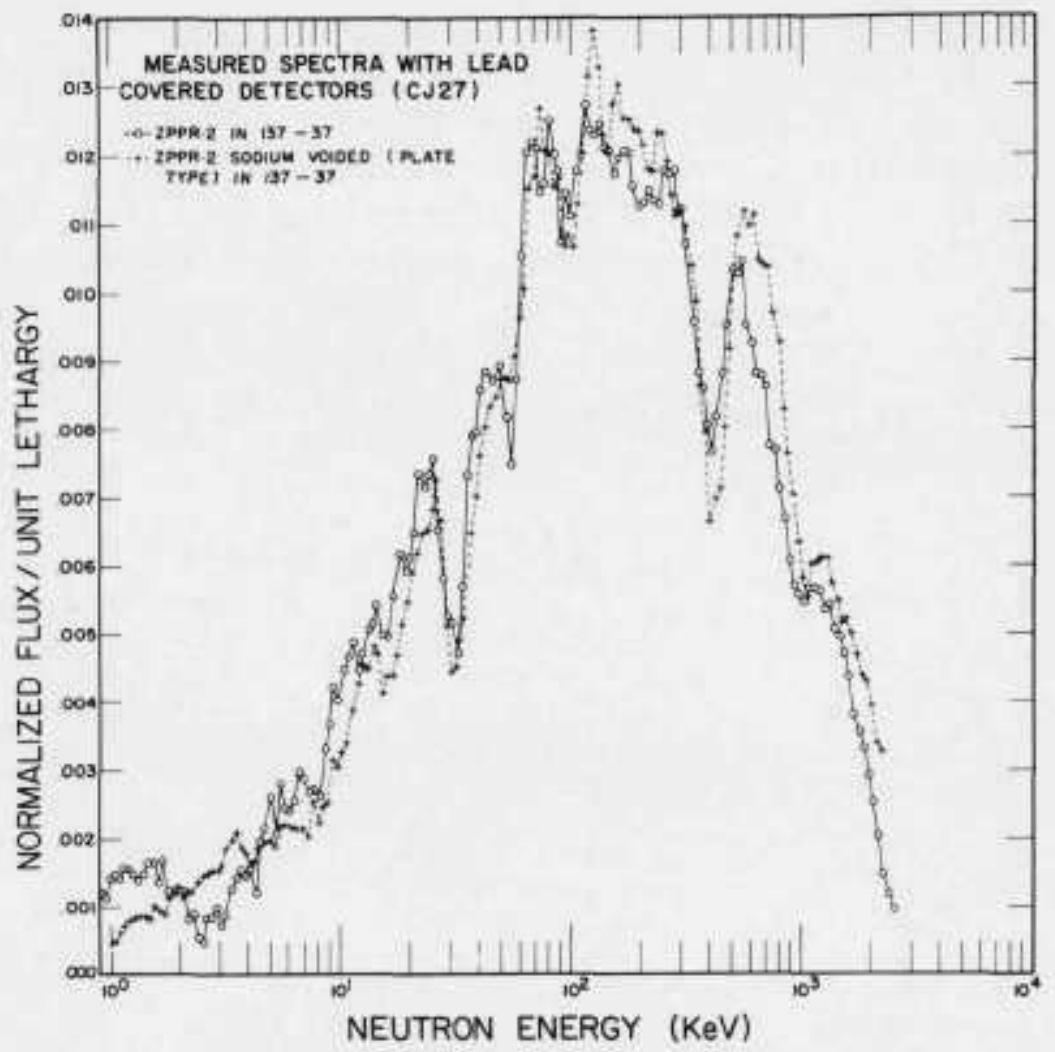

Fig. VII.5. Neutron Spectra Measured in ZPPR-2 (137-37) with and without a Central Sodium Voiding. ANL Neg. No. 103-A11738.

Surveillance of Kerr-McGee manufacture and quality control was by ANL resident representatives who maintained liaison by alternating weekly between ANL and Kerr-McGee. Fuel rods received at ANL were inspected and about $10 \%$ were nondestructively assayed by gamma-scan techniques.* Fuel rods from each lot were selected on a statistical basis, destructively inspected, sampled, and analyzed.

The results of analysis of the $\left(\mathrm{U}_{0.85}, \mathrm{Pu}_{0.15}\right) \mathrm{O}_{2}$ composition is shown in Table VII.8.

\footnotetext{
"N. S. Beyer, R. B. Perry, R. W. Brandenburg, and R. N. Lewis, "Four Passive Assay Techniques Applied to Mixed Oxide Fuel," Proceedings of the Institute of Nuclear Material Management 12 th Annual Meeting, June 1971.
} 
TABLE VII.8. Comparison of ANL and Kerr-McGee Analytical Data for $\left(\mathrm{U}_{0.85}, \mathrm{Pu}_{0}, 15\right) \mathrm{O}_{2}$ ZPR Fuel Pellets

\begin{tabular}{|c|c|c|c|c|c|c|c|c|}
\hline \multirow{3}{*}{$\begin{array}{l}\text { Lot } \\
\text { No. }\end{array}$} & \multicolumn{4}{|c|}{ Weight Percent } & \multirow{2}{*}{\multicolumn{2}{|c|}{$0 / M$}} & \multirow{2}{*}{\multicolumn{2}{|c|}{$\begin{array}{c}\text { ppm } \\
\text { Impurities }\end{array}$}} \\
\hline & \multicolumn{2}{|c|}{ Plutonium } & \multicolumn{2}{|c|}{ Uranium } & & & & \\
\hline & ANL & $K M$ & $\overline{\mathrm{ANL}}$ & $\mathrm{KM}$ & $\overline{\mathrm{ANL}}$ & $\overline{K M}$ & $\overline{\mathrm{ANL}}$ & $\mathrm{KM}^{\mathrm{a}}$ \\
\hline 1 & 13.33 & 13.26 & 74.57 & 74.86 & 2.000 & 2.000 & 999 & 809 \\
\hline 2 & 13.23 & 13.27 & 74.92 & 74.69 & 2.000 & 2.000 & 926 & 777 \\
\hline 3 & 13.28 & 13.26 & 74.95 & 74.63 & 1.990 & 2.010 & 794 & 851 \\
\hline 4 & 13.20 & 13.16 & 74.92 & 74.59 & 1.990 & 2.000 & 1061 & 769 \\
\hline 5 & 13.17 & 13.16 & 74.94 & 74.62 & 1.991 & 1.988 & 988 & 740 \\
\hline 6 & 13.17 & 13.18 & 74.89 & 74.83 & 1.996 & 1.988 & 1109 & 854 \\
\hline 7 & 13.11 & 13.16 & 74.98 & 74.73 & 1.994 & 1.985 & 1167 & 952 \\
\hline 8 & 13.05 & 13.01 & 74.88 & 74.72 & 1.998 & 1.988 & 1218 & 949 \\
\hline 9 & 13.12 & 13.16 & 74.90 & 74.74 & 1.999 & 1. 989 & 1133 & 763 \\
\hline Avg $\bar{x}$ & 13.184 & 13.180 & 74.883 & 74.712 & 1.996 & 1.994 & 1044 & 829 \\
\hline$\sigma$ & 0.087 & 0.080 & 0.012 & 0.092 & 0.004 & 0.0085 & 132 & 79 \\
\hline $\bar{\Delta}$ & & & & & & & & \\
\hline$\overline{\Delta \Delta}$ & & & & & & & & \\
\hline
\end{tabular}

a Kerr-McGee impurity analyses did not include ${ }^{241} \mathrm{Am}$, which was 250 to $300 \mathrm{ppm}$ in ANL analyses.

There is close agreement between the plutonium analyses of the two laboratories. Kerr-McGee used the coulometric method of plutonium analysis; ANL used amperimetry. A gradual drifting apart of results was noted in the first five lots, and investigation revealed that KerrMcGee was not correcting for iron, about $1.6 \%$ relative to the plutonium content. A similar correction of about $0.3 \%$ relative was required for chromium and manganese in the amperimetric method. Since analyses of these elements had been done, the corrections were made without rerunning the samples. The agreement between uranium analysis was not as good as for plutonium. The same method was used in both laboratories, but it is extremely sensitive to operator technique. The oxygen/metal ratios were essentially in agreement. Kerr-McGee did not analyze for ${ }^{241} \mathrm{Am}$ as part of the total impurity; this element adds 250 to $300 \mathrm{ppm}$ to the ANL results. With this correction, the impurity analyses are in acceptable agreement. The ANL analyses add up to an average of $99.98 \%$; Kerr-McGee analyses add up to an average of $99.79 \%$. The error difference is assigned to the Ker $x-$ McGee uranium analyses.

Kerr-McGee inspection data were supplied on cards suitable for electronic data processing. Individual fuel-rod data were put on one card, and chemical data, constant for all fuel rods in the lot, were put on another card. These cards were used to derive various fuel-rod characteristics and greatly facilitated the statistical analysis of these characteristics as the fuel was delivered to ANL. 
A statistical summary of reported data for the $\left(\mathrm{U}_{0.85}, \mathrm{Pu}_{0.15}\right) \mathrm{O}_{2}$ zero-power reactor fuel rods is shown in Table VII.9.

TAZLE VII.9. Statistical sumary of Reported Dats for $\left(U_{0}, 45\right.$. Pug.15) $O_{2}$ ZPR Fuel Hods

\begin{tabular}{|c|c|c|c|c|c|c|c|c|c|c|c|}
\hline $\begin{array}{l}\text { Process Lot } \\
\text { Number of Ro }\end{array}$ & & $\begin{array}{l}1 . \\
909\end{array}$ & $\stackrel{2}{1273}$ & $\begin{array}{l}3 \\
923\end{array}$ & ${ }_{1829}^{4}$ & $1^{5} 470$ & $\begin{array}{c}6 \\
1603\end{array}$ & $\begin{array}{c}7 \\
1749\end{array}$ & $\begin{array}{c}8 \\
1539\end{array}$ & $\begin{array}{c}9 \\
1671\end{array}$ & $\begin{array}{r}\text { A1] Lats } \\
12,966\end{array}$ \\
\hline Core & $\bar{x}$ & 5.710 & 5.703 & 5.704 & 5.703 & 5.718 & 5.692 & 5.722 & 5.710 & 5.696 & 5.706 \\
\hline Length, fo. & 20 & 0.022 & 0.022 & 0.020 & 0.022 & 0.024 & 0.020 & 0.020 & 0.024 & 0.010 & 0.028 \\
\hline Core & $\bar{x}$ & 89.408 & 89.977 & 89.913 & 89.875 & 89.471 & 89.650 & 89.726 & в8.79 & 89.135 & 89.538 \\
\hline Wt, $\mathrm{g}$ & 20 & 0.762 & 0.670 & 0,694 & 0.611 & 0.842 & 0.406 & 0,378 & 0.388 & 0.438 & 0.992 \\
\hline Total Pu & $\bar{x}$ & 11.855 & 11.940 & 11.922 & 11.829 & 11.775 & 11.817 & 12.809 & 11.554 & 11.731 & 11.793 \\
\hline Grams & 20 & 0.100 & 0.090 & 0.092 & 0.082 & 0.110 & 0.054 & 0.050 & 0,058 & 0.058 & 0.242 \\
\hline${ }^{239} \mathrm{Pu}+241 \mathrm{Pu}$ & $\bar{x}$ & 10.469 & 10.541 & 10.514 & 10.424 & 10.374 & 10.414 & 10,407 & 10,184 & 10.345 & 10,421 \\
\hline Grams & 20 & 0.090 & 0.090 & 0.082 & 0.072 & 0.093 & 0.048 & 0.064 & 0.052 & 0.050 & 0.220 \\
\hline${ }^{2+D} \mathrm{Pu}$ & $\bar{x}$ & 1.357 & 1.370 & 1,377 & 1,375 & 1.371 & 1.371 & 1.371 & 1.362 & 1.356 & 1.366 \\
\hline Crams & 20 & 0.012 & 0.010 & 0.010 & 0.010 & 0.012 & 0.006 & 0.006 & 0,006 & 0.006 & 0.013 \\
\hline Total $\theta$ & $\bar{x}$ & 66.935 & 67.205 & 67.107 & 67.037 & 66.764 & 67.086 & 67.053 & 66.351 & 66.620 & 66.890 \\
\hline Grams & 20 & 0.570 & 0.504 & 0.518 & 0.464 & 0.626 & 0.304 & 0.282 & D. 292 & 0.326 & 0.554 \\
\hline oxygen & $\bar{x}$ & 10.585 & 10.672 & 10.691 & 10.642 & 10.540 & 10.561 & 10.562 & 10.461 & 10.510 & 10.574 \\
\hline Grans: & 20 & 0.090 & 0.078 & 0.082 & 0,074 & 0.098 & 0.048 & 0.044 & 0.046 & 0.052 & 0.168 \\
\hline
\end{tabular}

The lot average and 20 limits are plotted against the lots as received. Upon completion of deliveries, these statistics are pooled to give an overall average and $2 \sigma$ limits. Plots of some typical characteristics are shown in Figs. VII. 6 and VII.7. The computer sorts rods, which may not be in specification or within some predetermined control limit. At the same time, frequency-distribution information is provided if the range between limits is divided into an appropriate number of cells. It is often of interest to know whether the production follows the "Normal" curve. Typical distributions are shown in Figs. VII.8 and VII.9.

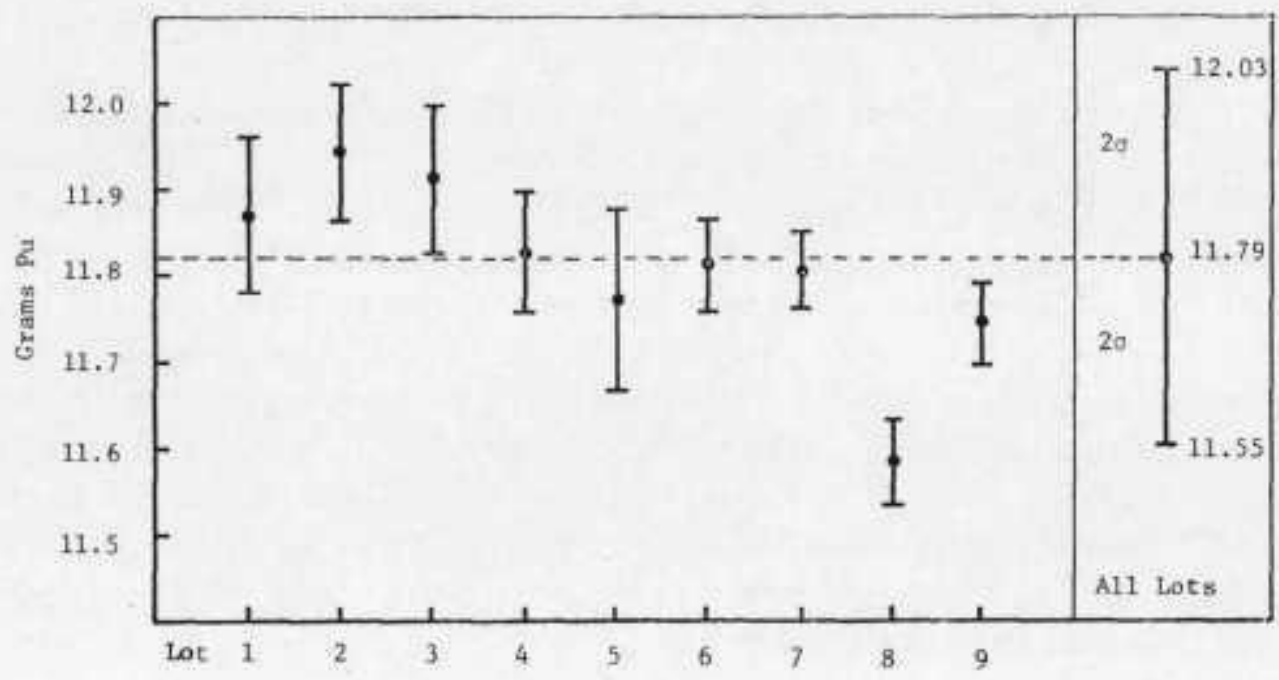

Fig. VII.6. Lot $\bar{x}=20$, Grams $\mathrm{Pu}$ in $\left(\mathrm{U}_{0.85}, \mathrm{Pu} 0.15\right) \mathrm{O}_{2}$ Fuel Rods Supplied by Kerr-McGee 


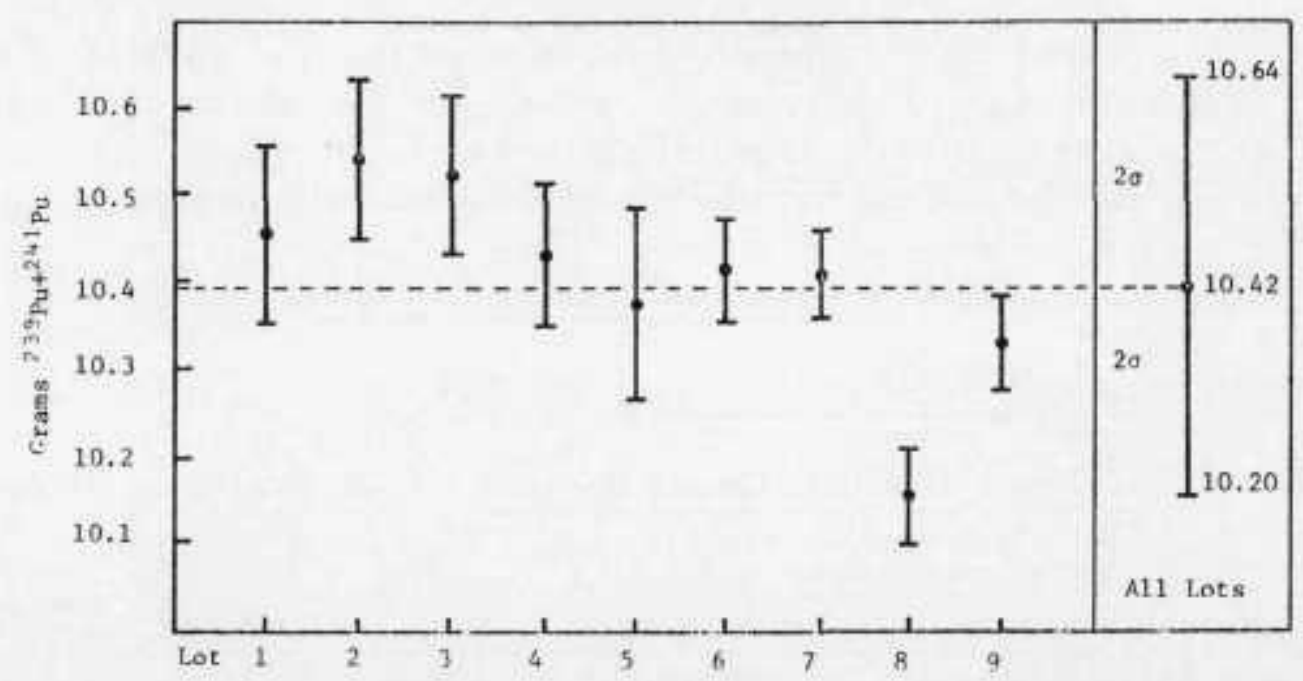

Fig. VII.7. Lot $\overline{\mathrm{x}}+20$, Grams ${ }^{239} \mathrm{Pu}+{ }^{241} \mathrm{Pu}$ in $\left(\mathrm{U}_{0.85}, \mathrm{Pu}_{0.15}\right) \mathrm{O}_{2}$ Fuel Rods Supplied by Kerr-McGee

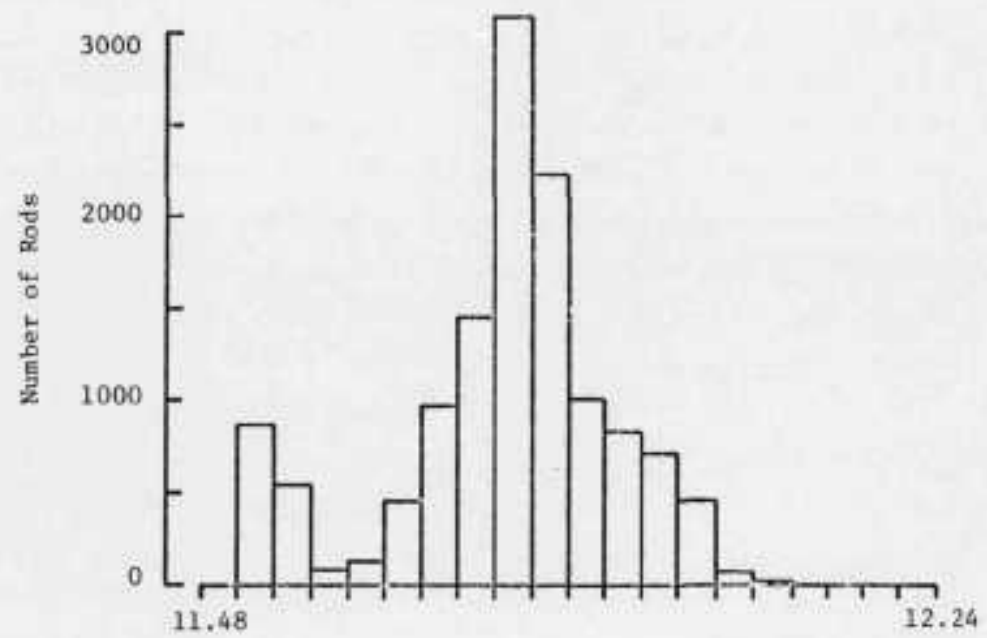

Fig. VII.8. Distribution of Grams Plutonium in $\left(\mathrm{U}_{0.85}, \mathrm{Pu}_{0} .15\right) \mathrm{O}_{2}$ Fuel Rods Supplied by Kerr-McGee

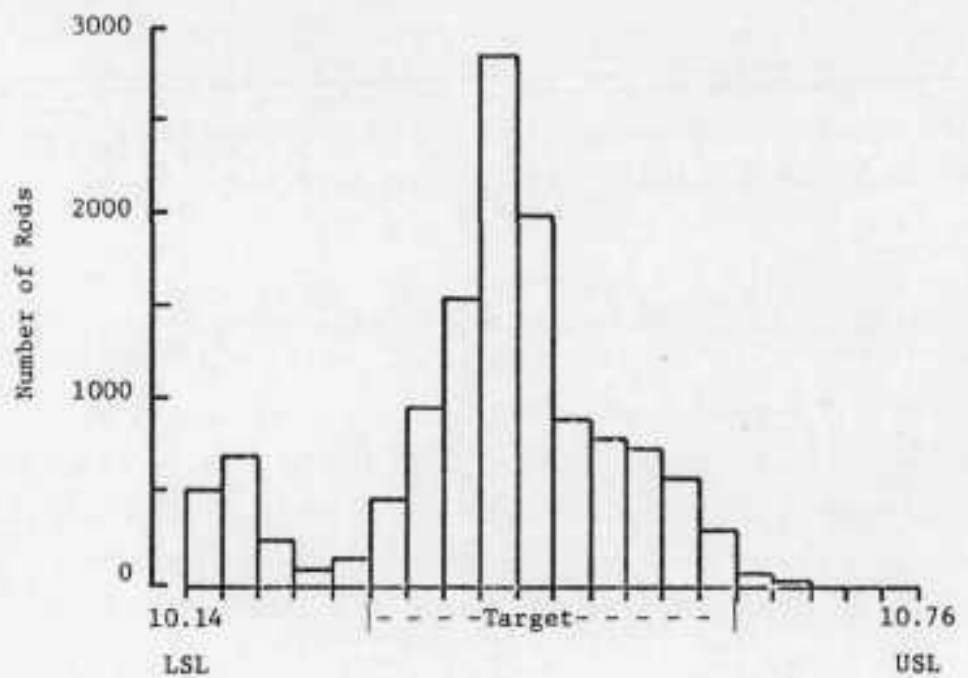

Fig. VII. 8 Distribution of Grams ${ }^{239} \mathrm{Pu}+{ }^{241} \mathrm{Pu}$ in $\left(\mathrm{U}_{0.85}, \mathrm{Pu}_{0.15}\right)_{\mathrm{O}_{2}}$ Fuel fods Supplled by Kerr-McGee 
The fissile plutonium content of the fuel rods is of particular interest and subject to close control. A "target" was set up well within the upper and lower specification limits. No material supplied was outside the specification range, and all but one lot was essentially on target.

\section{Acquisition of Nuclear Data}

\section{Determination of Nuclear Constants $(02-084)$}

a. Total and Reaction Cross Section. A. B. Smith (Last reported: ANL-7776, p. 59)

(1) Interpretation and Comparison of Standard Cross Sections. The cross sections for the reactions $\mathrm{H}(\mathrm{n}, \mathrm{n}),{ }^{10} \mathrm{~B}(\mathrm{n}, \alpha, \gamma),{ }^{6} \mathrm{Li}(\mathrm{n}, \alpha), \mathrm{Au}(\mathrm{n}, \gamma)$, and ${ }^{235} \mathrm{U}(\mathrm{n}, \mathrm{f})$ have been accepted in recent years as standards justified by their practical use in experiments. The restriction to these cross sections supplies a feasible means of measuring and comparing cross sections of different types of reactions. However, a standard cross section is determined by many absolute measurements. Thus, the interpretation and evaluation of such data become a vital part in establishing the standard cross section to be used. Many of the data evaluations presented in the past appear to use contradictory interpretations of data and various evaluation concepts which may be questioned as to their validity, and, most notably, the evaluations for ${ }^{238} \mathrm{U}$ contribute further to the confusion in absolute cross sections.

Therefore, consideration has been given to the interpretation of data based on their experimental origin and evaluation methods related to this interpretation. The absolute cross-section data of ${ }^{235} \mathrm{U}(\mathrm{n}, \mathrm{f}),{ }^{238} \mathrm{U}(\mathrm{n}, \gamma)$, ${ }^{197} \mathrm{Au}(\mathrm{n}, \gamma)$, and ${ }^{6} \mathrm{Li}(\mathrm{n}, \alpha)$ and the ratios $\sigma_{\gamma}(\mathrm{Au}) / \sigma_{\mathrm{f}}\left({ }^{235} \mathrm{U}\right), \sigma_{\gamma}\left({ }^{238} \mathrm{U}\right) / \sigma_{\mathrm{f}}\left({ }^{235} \mathrm{U}\right)$ and $\sigma_{\alpha}\left({ }^{6} \mathrm{Li}\right) / \sigma_{\mathrm{f}}\left({ }^{235} \mathrm{U}\right)$ have been evaluated for the energy range $25-1000 \mathrm{keV}$. Data have been classified according to their origin as relative data (ratio values) and absolute data. A separation of the information contained in the shape and the magnitude of data was possible for most experimental results. Absolute and ratio data have been selected using independent results from measurements only. Consistency of the data has been obtained by a proper fit which eliminated the over-determination of the input values. The data were weighted in the evaluation by a weight combined from the given error bars, the age of the measurements, and the deviation from the average of all available data.

The evaluation method used is thus summarized: In a first step, the shapes of $\sigma_{\gamma}(\mathrm{AU}), \sigma_{\gamma}\left({ }^{238} \mathrm{U}\right), \sigma_{\alpha}\left({ }^{6} \mathrm{Li}\right), \sigma_{f}\left({ }^{235} \mathrm{U}\right), \sigma_{\gamma}(\mathrm{Au}) / \sigma_{\mathrm{f}}\left({ }^{235} \mathrm{U}\right)$, $\sigma_{\gamma}\left({ }^{238} \mathrm{U}\right) / \sigma_{f}\left({ }^{235} \mathrm{U}\right)$, and $\sigma_{\alpha}\left({ }^{6} \mathrm{Li}\right) / \sigma_{f}\left({ }^{235} \mathrm{U}\right)$ were assigned, using smooth curves through the original data and the given error bars as weights. In a second step, the amplitude has been adjusted by minimizing the average deviations. The weights have been composed from (1) the absolute given error bars, (2) the number of years between the measurements and the present time, 
plus 5 , and (3) the deviation from the unweighted average, plus 2 . The numbers 5 and 2 are chosen somewhat arbitrarily. The resulting adjusted values have been used in an evaluation including all the above named absolute cross sections and ratios in order to obtain a consistent set of data. The results are given in Table VII.10. The input data for $(\mathrm{Li}(\mathrm{n}, \alpha)$ in the resonance region are insufficient and thus lead to no result for this cross section.

TABLE VII.10. A Consistent Set of Adjusted Cross-section Values Based on an Evaluation of Measured Absolute Cross Sections and Cross-section Ratios

\begin{tabular}{rllll}
\hline $\mathrm{En} / \mathrm{keV}$ & $\sigma_{\gamma}\left({ }^{238} \mathrm{U}\right)$ & $\sigma_{\gamma}(\mathrm{Au})$ & $\sigma_{\alpha}(\mathrm{Li})$ & $\sigma_{f}{ }^{\left({ }^{235} \mathrm{U}\right)}$ \\
\hline 25 & 0.482 & 0.639 & 1.002 & 2.221 \\
30 & 0.443 & 0.576 & 0.922 & 2.061 \\
40 & 0.382 & 0.489 & 0.800 & 1.851 \\
50 & 0.344 & 0.439 & 0.733 & 1.769 \\
65 & 0.287 & 0.381 & 0.665 & 1.629 \\
80 & 0.235 & 0.344 & 0.638 & 1.556 \\
100 & 0.205 & 0.320 & 0.636 & 1.509 \\
120 & 0.186 & 0.303 & 0.657 & 1.495 \\
150 & 0.166 & 0.299 & 0.847 & 1.475 \\
200 & 0.145 & 0.270 & & 1.342 \\
250 & 0.129 & 0.237 & & 1.260 \\
300 & 0.118 & 0.207 & & 1.187 \\
400 & 0.112 & 0.165 & & 1.133 \\
500 & 0.111 & 0.138 & & 1.088 \\
650 & 0.122 & 0.110 & & 1.116 \\
800 & 0.139 & 0.098 & & 1.169 \\
1000 & 0.134 & 0.084 & & \\
\hline
\end{tabular}

The result from this evaluation compares well with the absolute cross-section data from the last 10 years for gold and ${ }^{238} \mathrm{U}$. Good agreement is also obtained with the ${ }^{6} \mathrm{Li}(\mathrm{n}, a)$ data in the energy range 25-150 keV. Figure VII.10 compares data for the fission cross section of ${ }^{235} \mathrm{U}$ with the result of the evaluation. The evaluation result is on the low side of the data as a result of the absolute $\mathrm{Li}(n, \alpha), \mathrm{Au}(n, \gamma)$ and ${ }^{238} \mathrm{U}(n, \gamma)$ data. This may indicate the need for lower ${ }^{235} \mathrm{U}$ fission cross sections.

2. Cross-section Measurements. C. E. Crouthamel and N. D. Dudey

a. Spectrum-averaged Measurements (Last reported: ANL-7765, P. 59)

Determinations of capture-to-fission ratios (alpha) for samples of fissile and fertile materials irradiated in EBR-II are nearing completion. Preliminary results for ${ }^{233} \mathrm{U},{ }^{235} \mathrm{U},{ }^{238} \mathrm{U},{ }^{239} \mathrm{Pu}$, and ${ }^{240} \mathrm{Pu}$ have been previously 


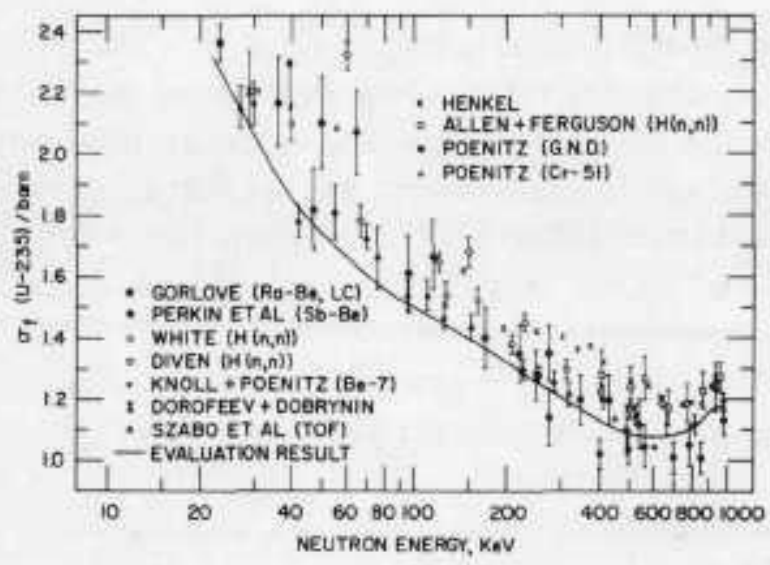

Fig. VII.10. Comparison of Some Experimental Data on the Fission Cross Section of $235 \mathrm{U}$ with the Evaluation Result. ANL Neg. No. 116-322. reported. (See Progress Reports for September and October 1969 and August 1970 , ANL-7618, p. 88 , ANL-7632, p. 100, and ANL-7737, p. 108.) These results have been modified slightly as a result of corrections for fissioning of isotopic impurities. The corrected results, together with a detailed description of the experimental procedures, will be presented in a topical report, now being prepared.

The analytical problems associated with alpha determinations for the ${ }^{242} \mathrm{Pu}$ samples were previously discussed (see ANL-7737 and

ANL-7765). These problems arose because of the isotopic impurities present in the ${ }^{242} \mathrm{Pu}$ material used in the irradiations. Two assumptions were necessary in order to correct for the number of fissions resulting from fission of ${ }^{238} \mathrm{Pu},{ }^{239} \mathrm{Pu},{ }^{240} \mathrm{Pu}$, and ${ }^{241} \mathrm{Pu}$ present in the samples. First, we assumed that the burnup (fissions plus captures) for ${ }^{238} \mathrm{Pu}$ was identical to the burnup for ${ }^{242} \mathrm{Pu}$. Second, we as sumed that for ${ }^{241} \mathrm{Pu}$ the production rate for ${ }^{137} \mathrm{Cs}$ atoms was 1.2 times the production rate of ${ }^{137} \mathrm{Cs}$ atoms from ${ }^{239} \mathrm{Pu}$. (The number of fissions is determined from radiochemical analysis for ${ }^{137} \mathrm{Cs}$.) The production rates of ${ }^{137} \mathrm{Cs}$ from ${ }^{239} \mathrm{Pu}$ and ${ }^{240} \mathrm{Pu}$ were then measured in the samples of ${ }^{239} \mathrm{Pu}$ and ${ }^{240} \mathrm{Pu}$ that had been irradiated in reactor locations corresponding to the locations of the ${ }^{242} \mathrm{Pu}$ samples. For ${ }^{242} \mathrm{Pu}$ samples irradiated outside the core regions, the impurity isotopes contributed more ${ }^{137} \mathrm{Cs}$ atoms than did the ${ }^{242} \mathrm{Pu}$ itself; therefore the uncertainties in fission rates, and consequently in alpha, resulting from the necessary assumptions were so large that the data are not meaningful. It was possible, however, to calculate meaningful alpha values for the ${ }^{242} \mathrm{Pu}$ samples irradiated in the core; these data are being included in the final report.

Preliminary comparison of reactor-physics calculations of capture rates, fission rates, and alpha with experimental data from the radial core positions are being made by the EBR-II Project. Comparisons at four radial core locations indicate that the agreement between meas urement and calculation of alpha is $\pm 2 \%$ for ${ }^{233} \mathrm{U}, \pm 10 \%$ for ${ }^{235} \mathrm{U}, \pm 6 \%$ for ${ }^{239} \mathrm{Pu}, \pm 8 \%$ for ${ }^{240} \mathrm{Pu}$, and about a factor of two for ${ }^{242} \mathrm{Pu}$. Further evaluations regarding the comparison of theory and experiment are in progress.

b. Low-mass Fission-product Yields. (Last reported: ANL-7765, p. 59)

Proof-testing of the radiochemical procedure for separating tritium from all other fission products has verified the feasibility of the 
method. The procedure involves exchanging tritium with hydrogen carrier gas in a closed gas-handling system, pumping the tritium and hydrogen through a silver-palladium valve, and counting the tritium in a gas proportional counter. Two modifications to the gas -handling system were made to overcome previous difficulties in pumping the tritium quantitatively through the valve (see ANL-7765). First, a charcoal trap was added to re place the original collection vessel to increase the rate of transmission of hydrogen isotopes through the silver-palladium valve. Second, a platinum gauze was added to the reaction vessel to enhance hydrogen-tritium exchange. With these modifications, we achieved $100 \%$ recovery of the hydrogen carrier gas in the charcoal collection vessel, in contrast with $80 \%$ recovery in previous tests.

The procedure was then tested by measuring tritium yields in thermally irradiated ${ }^{235} \mathrm{U}$ and comparing the results with published values for the thermal yields. One difficulty arose in these tests. The fact that the path length of thermal neutrons in ${ }^{235} \mathrm{U}$ is less than the path length of the energetic tritium atoms produced in fission resulted in a significant lose of tritium by recoil from the ${ }^{235} \mathrm{U}$ sample during irradiation. However, corrections for recoil loss were made by assuming that the kinetic-energy distribution of tritium produced from ${ }^{235} \mathrm{U}$ fission is the same as for ${ }^{252} \mathrm{Cf}$, for which data are available in the literature. By integrating over the sample geometry, we were able to compute the fission distribution from cross-section data and the range-energy distribution of tritium from theory, and were thus able to arrive at the tritium-recoil loss out of the sample. The thermally irradiated ${ }^{235} \mathrm{U}$ samples were measured for tritium, the fission rates were computed from the ${ }^{140} \mathrm{Ba}$ activity, and recoil loss for each sample was calculated. The fission-yield value obtained was $(1.2 \pm 0.14) 10^{-4}$ tritons per fission ( $\mathrm{T} / \mathrm{f}$ ), which may be compared with literature values ranging from $0.9 \times 10^{-4}$ to $1.1 \times 10^{-4}$. The quoted error in our data is based on the standard deviation of three individual measurements and does not reflect the uncertainty in the correction factor for recoil loss, which is estimated to be about $\pm 10 \%$.

A final experimental verification is being made by irradiating a $2-\mathrm{mil}{ }^{235} \mathrm{U}$ foil sandwiched between $10-\mathrm{mil}{ }^{238} \mathrm{U}$ foils. The ${ }^{238} \mathrm{U}$ foils will produce no tritium and will act as recoil catchers for the tritium, so that no corrections for recoil loss will be necessary. Tritium from this sample has been separated and is awaiting counting.

Tritium yield values for three ${ }^{235} \mathrm{U}$ samples irradiated in a fastneutron beam at the Dynamitron have been measured. Although the number of fissions occurring in each sample has not been absolutely established, very preliminary values at three neutron energies are as follows: $(4.9 \pm 0.4) 10^{-4} \mathrm{~T} / \mathrm{f}$ at $420 \pm 93 \mathrm{keV} ;(3.9 \pm 0.4) 10^{-4} \mathrm{~T} / \mathrm{f}$ at $483 \pm 100 \mathrm{keV}$; and $(3.9 \pm 0.2) 10^{-4} \mathrm{~T} / \mathrm{f}$ at $539 \pm 105 \mathrm{keV}$. These yields are more than a factor of 
four higher than we had previously predicted on the basis of a rough theoretical calculation. These high yield values are not at present understood, but attempts to verify the yields by particle-identification techniques are scheduled.

A single fast-neutron-yield measurement of tritium from ${ }^{233} \mathrm{U}$ irradiated at $483 \pm 100 \mathrm{keV}$ neutron energy resulted in a very preliminary yield value of $(1.4 \pm 0.3) 10^{-4} \mathrm{~T} / \mathrm{f}$; this value agrees with our expectations. (The thermal tritium yield for ${ }^{23} \mathrm{U}$ is reported to be $1.1 \times 10^{-4} \mathrm{~T} / \mathrm{f}$.) Tritium from a ${ }^{239} \mathrm{Pu}$ sample irradiated at a neutron energy of $483 \pm 100 \mathrm{keV}$ has been separated and is presently being counted.

3. Burnup Analysis and Fission Yields for Fast Reactors. C. E. Crouthamel and R. P. Larsen (02-083)

a. Determination of Fast Fission Yields and Nonfission Nuclear Transformations in a Fast Reactor (Last reported: ANL-7776, p. 56)

Measurements of fission rates (atoms fissioned per atom of fissile material per second) are needed in critical assemblies such as $Z P R-3$. The number of atoms fissioned is determined by measuring the number of atoms of a particular fission-product nuclide formed and dividing by the fractional fission yield of that nuclide. The fission product used in a particular experiment depends on a number of factors: the fluence, the length of the irradiation, the out-of-reactor decay time, the accuracy with which the physical constants (fission yields and gamma-branching ratios) are known, and the analytical capabilities of the laboratory performing the experiments. (For some fission products, radiochemical separations are required.)

Our fission-yield measurements in the ZPR-3 mockup experiments provided an excellent opportunity to compare various fission-rate monitors under the same set of conditions. Data were available from foils of ${ }^{235} \mathrm{U}$ and ${ }^{239} \mathrm{Pu}$ which were irradiated at the same time in the neutron spectrum of the core of Assembly 61 and assayed using a well-calibrated $\mathrm{Ge}(\mathrm{Li})$ detector (without resorting to chemical separations). The number of atoms of each fission product induced in the ${ }^{235} \mathrm{U}$ and ${ }^{239} \mathrm{Pu}$ foils was divided by the appropriate mass-chain yield* for an EBR-I spectrum and the fission rate calculated. Relative fission rates were then compared by dividing each fission rate by the fission rate calculated from the data for ${ }^{95} \mathrm{Zr}$. These relative fast-fission rates are presented in Table VII.11. Zirconium-95 was chosen as the basis for this comparison for two reasons: (1) The ${ }^{95} \mathrm{Mo}-$ to $-{ }^{137} \mathrm{Cs}$ fission-yield ratio calculated from Lisman's data is in excellent agreement with the ratio calculated from ANL data

${ }^{*}$ F. L. Lisman, R. M. Abernathy, W. I. Maeck, and J. E. Rein, Nuc1. Sci. Eng. 42, 191-214 (1970). 
TABLE VII.11. A Comparison of Fast-fission-rate Monitors for $235 \mathrm{U}$ and $239 \mathrm{Pu}$

\begin{tabular}{llr}
\hline $\begin{array}{l}\text { Measured } \\
\text { Nuclide }\end{array}$ & \multicolumn{2}{c}{ Relative Fission Rates } \\
\hline${ }^{95} \mathrm{Zr}$ & 1.000 & $239 \mathrm{Pu}$ \\
$97_{\mathrm{Zr}}$ & 0.875 & 1.000 \\
${ }^{99} \mathrm{Mo}^{\mathrm{b}}$ & 1.091 & $0.943^{\mathrm{a}}$ \\
$103_{\mathrm{Ru}}$ & $0.901^{\mathrm{C}}$ & - \\
$131_{\mathrm{I}}$ & 0.957 & $0.998^{\mathrm{c}}$ \\
$132 \mathrm{Te}$ & 1.068 & 1.109 \\
$133_{\mathrm{I}}$ & 0.953 & 0.950 \\
$140 \mathrm{Ba}$ & 1.016 & 0.945 \\
$143_{\mathrm{Ce}}$ & 0.859 & 1.062 \\
\hline
\end{tabular}

a This value is probably high; the gamma assay of $97 \mathrm{Nb}$ was subject to interference from a $239 \mathrm{pu}$ ganma ray.

b Analysis for 99 \%o was performed by radiochemical separation and beta assay (by R. J. Armani, Applied Physics Division).

C The ${ }^{103} \mathrm{Ru}$ fission yields used were interpolations between ${ }^{102} \mathrm{Ru}$ and ${ }^{104} \mathrm{Ru}$ yields.
( ${ }^{95} \mathrm{Mo}$ is the stable product of ${ }^{95} \mathrm{Zr}$ decay), and (2) the gamma-branching ratios of both ${ }^{95} \mathrm{Zr}$ and its daughter ${ }^{95} \mathrm{Nb}$ are well established.

In Table VII. 11, the difference between the ${ }^{95} \mathrm{Zr}$ value and the value for another fission product is a measure of the error in determining fission rates under optimum experimental conditions; i.e., one laboratory, one detector, one set of nuclear standards, one set of physical constants, and no chemical separations. When two laboratories are involved in the measurement of fission rates on foils from the same irradiation, additional errors can be introduced, particularly if the laboratories use different fission-product nuclides to make these measurements.

The variations from unity of the relative fission rates are, for

most of the nuclides, not attributable to a single source of error, but rather to an accumulation of errors in the measurements and in the nuclear constants. The errors in an individual fission-rate measurement are as follows: The minimum propagated error in an individual fission-rate measurement is estimated to be $\pm 3.9 \%$. The sources contributing to this error are as follows: counting statistics, $\pm 1 \%$; detector efficiency, $\pm 2 \%$; decay scheme, $\pm 2.5 \%$; and fission yield, $\pm 2 \%$. Since the relative fission rate is the ratio of two individual rates, the error in the relative value is $\pm 5.5 \%$ and the $95 \%$ confidence limit is $\pm 11 \%$.

Of the nuclides listed in Table VII. $11,{ }^{97} \mathrm{Zr},{ }^{95} \mathrm{Zr},{ }^{132} \mathrm{Te},{ }^{140} \mathrm{Ba}$, and ${ }^{99} \mathrm{Mo}$ are commonly used as fast-fission-rate monitors. Of these, ${ }^{97} \mathrm{Zr}$ is the only one whose relative fission rate is outside the estimated error of $\pm 11 \%$. (The ${ }^{235} \mathrm{U}$ thermal fission rates calculated from ${ }^{97} \mathrm{Zr}$ and ${ }^{95} \mathrm{Zr}$ are in disagreement by the same percentage as the ${ }^{235} \mathrm{U}$ fast fission rates.) This finding is inconsistent with expectations. Several factors indicate that the estimated error in the ${ }^{97} \mathrm{Zr}-$ to $-{ }^{95} \mathrm{Zr}$ relative fission rate should be about $\pm 4 \%$ rather than $\pm 11 \%$. Both ${ }^{95} \mathrm{Zr}$ and ${ }^{97} \mathrm{Zr}$ decay to stable molybdenum nuclides, and the error in the ratio of the fission yields of these nuclides, for both ${ }^{235} \mathrm{U}$ and ${ }^{239} \mathrm{Pu}$ fission, is $\pm 0.5 \%$. The energies of the measured gamma rays are all within a few percent of the same value, and the relative errors in detector efficiency are therefore judged to be negligible. 
Possible sources of error in relative fission-rate values of ${ }^{97} \mathrm{Zr}$ are (1) an independent fission yield of ${ }^{97} \mathrm{Nb}$ that is much larger than that predicted from mass - charge distribution theory or (2) an error in the published decay scheme of ${ }^{97} \mathrm{Zr}$, i.e., the gamma-branching $r$ atio. To test these possibilities, a sample of ${ }^{235} \mathrm{U}$ was irradiated in a thermal-neutron spectrum for $100 \mathrm{sec}$, the sample was dissolved within $6 \mathrm{~min}$ in hydrochloric acid in the presence of zirconium and niobium carriers, and the ${ }^{97} \mathrm{Nb}(72 \mathrm{~m})$ was extracted and counted. The extraction was repeated after the ${ }^{97} \mathrm{Nb}$ was in transient equilibrium with its ${ }^{97} \mathrm{Zr}(17 \mathrm{~h})$ parent. The amounts of ${ }^{97} \mathrm{Nb}$ activity found in the two extracts provided the data for calculating the ratio of atoms of ${ }^{97} \mathrm{Nb}$ to atoms of ${ }^{97} \mathrm{Zr}$ at zero time out of the reactor. The value obtained for this ratio, $<0.003$, indicates that the independent fission yield of ${ }^{97} \mathrm{Nb}$ is neglible and strongly suggests that the published information on the decay scheme of the mass -97 chain is in error.

\section{Fast Reactor Analysis and Computational Methods}

1. Theoretical Reactor Physics (02-081)

a. Cross-section Data Evaluation. E. M. Pennington (Last reported: ANL-7783, p. 53)

ENDF/B tape 700 was received from Brookhaven National Laboratory containing preliminary neutron cross-section data for ${ }^{235} \mathrm{U}$, ${ }^{238} \mathrm{U}$, and ${ }^{239} \mathrm{Pu}$. These data had been modified from those of Version-II ENDF/B in view of the low values of $\mathrm{k}_{\text {eff }}$ obtained in ENDF/B data testing, expecially for ${ }^{239} \mathrm{Pu}$-fueled assemblies (see ANL-7783). Tape 700 was processed through CHECKER, RIGEL, ETOE, and MERMC 2 to form an MC 2 library including the three new materials, the Version II materials, and some other materials. Dimensions had to be increased in the resonance subroutines of ETOE because the new ${ }^{238} \mathrm{U}$ has 412 resolved resonances. Data testing with the new data has begun. A value of $\mathrm{k}_{\text {eff }}$ of 0.9989 was obtained for ZPR-3-56B using $\mathrm{MC}^{2}$ cross sections in $\mathrm{S}_{4}$ transport calculations in the ARC System. ZPR $-3-56 B$ is a new data-testing assembly fueled with ${ }^{239} \mathrm{Pu}$.

b. Reactor Computations and Code Development (Last reported: ANL-7798, p. 106)

(1) The ARC System (B. J. Toppel and W. L. Woodruff). The documentation of the ARC System standard paths and catalogued procedures, The ARC System Standard Paths, ANL-7712, is almost completed and edited for typing and graphic-art work. Several transparent changes have been made in the catalogued procedures on the AMD procedure library to remove inconsistencies in the capabilities of the paths and procedures. Change requests have been submitted for improvements in the paths STP001, 
STP002, STP003, STP006, and STP007. These changes are completely transparent and consist of (1) the addition of path-dependent default values for the corresponding path-dependent data sets A.PDIF 1D, A.PRTID, A.PDIF 2D, A.STP006, and A.STP007 consistent with those implied by their D23.INTRFACE listings and (2) the use of a new subroutine PRCLOZ, which lists and closes all OPEN sequential data sets after the execution of each module. The default values will also include, as a default, no edit of the cross-section data by NUC001. A path-dependent data set will no longer be required unless other than the default values are desired. The subroutine PRCLOZ makes use of the existing assembly-language subroutines OPENDS and CLOSE and eliminates the need for multiple REWINDS.

Modifications have been made to the 1-D and 2-D diffusiontheory modules (NUC002, NUC004) and (NUC005, NUC006) which allow the user to supply an adjoint flux guess in the execution of a combined real and adjoint "BOTH" computation. A subroutine has been added which tests for and reads the user's guess. If no adjoint flux guess is supplied by the user, the latest real flux is used, as was the case before the modification.

A "bug" has been found in the 1-D diffusion modules (NUC003 and NUC004) in the handling of a flux guess for an adjoint-only computation. The NUI002 -generated initial flux (an array of 1.0 values) was being unnecessarily group-reordered, while any user-supplied flux guess was not being properly reordered by group.

The microscopic and macroscopic cross-section group collapse modules, AJC007 and AJC008, have also been modified to allow the use of the dynamic storage-allocation routine BP $\varnothing$ INTER and to provide the capability of specifying BP INTER container array sizes in MAIN and BULK core storage. The new BCD code-dependent data set A.C $\varnothing_{L}$ is listed in D23.INTRFACE.

Testing of $\phi S 360$, IBM Release-19 versions of the ARC System I/O package has not uncovered any difficulties in either reading or updating old (Release-17) data sets. The new Release-19 capability of using instream catalogued procedures has been helpful in testing various record formats (RECFM) for incompatibilities. Currently the ARC System is successfully using the load modules for I/Ocreated under Release-17 with the Release-19 operating system. There would appear to be no difficulty in updating the ARC System I/O package to Release-19.

(2) The $\mathrm{MC}^{2}-2$ Code (H. Henryson II, C. Stenberg, and B. J. Toppe1). Preliminary testing has been performed on the library preparation module (Area 1) that creates file 2 (unresolved resonance data) and file 3 (resolved resonance data) of the library. Several materials, including molybdenum, were used in the testing since currently it is the only material in the Version II ENDF/B data that has more than one isotope 
per material. The preliminary testing and checking of the binary $\mathrm{MC}^{2}-2$ library data sets indicate that the ENDF/B data are being written correctly into files 3 and 4 of the library. A large portion of the data in files 3 and 4 of the library is just the given ENDF/B data in a reordered form, so it is not surprising that the execution time (central-processor time plus wait time) to create files 3 and 4 of the library is only approximately 3 sec per material.

Work has begun on the coding in the resonance section that generates the tabulated scattering, capture, and fission cross sections to replace the unresolved and resolved resonance parameters for "light" materials. Some of the code of the current ETOE* can be used almost directly. An example is the subroutine ETP, which calculates the energypoint grid between the minimum and maximum energies for the resolved resonance data. The cross sections derived from the resonance parameters will reflect the proper Doppler broadening in generating tabulated cross sections. The usual Doppler-broadened line-shape functions $\psi$ and $\chi$ will be generated by interpolating values to the tabulated complex probability integral W using the subroutine QUICK1. The present ETOE calculates $\psi(\mathrm{x}, \xi)$ and $\chi(\mathrm{x}, \xi)$ using a convergent or asymptotic series expansion** depending on the values of $\mathrm{x}$ and $\xi$.

If it is desired to examine Doppler broadening of a "light" material, it is planned to allow the user to generate a pseudo version of the ordinary material. For example, iron will be in the library without resonance parameters. A "pseudo" iron which has resonance parameters could also be written. To study the pseudo iron, a base problem would be run with ordinary iron to generate a spectrum. Then a second and third problem might be run with the pseudo iron at two different temperatures. For these problems, the original spectrum would be used to generate the broad-group $\sigma_{C}$ for the pseudo iron. The pseudo iron could, for example, have only $\sigma_{C}$ with all other cross sections zero.

The coding in area 5 (unresolved resonances) is complete and has been compiled through the option of generating unresolved-resonance capture and fission cross sections. Timing tests in a portion of the coding which involves matrix manipulations has shown that the optimization afforded by the FORTRAN H Compiler using OPT $=2$ is sufficient that twodimensional array manipulations are about equal in efficiency to equivalent one-dimensional array manipulations. This is not true in OPT $=0$. Owing to the greater clarity of the coding, two-dimensional arrays are being used and the OPT $=2$ optimization will be used. The user will have the option of eliminating the calculation of the self-overlap term for the unresolved resonances. This calculation is the most time-consuming part of the algorithm.

*D. M. Green and T. A. Pitterle, ETOE, A Program for ENDE/B to $\mathrm{MC}^{2}$ Data Conversion, APDA-219 (1968).

${ }^{* *}$ C. A. Stevens and C. V. Smith, FASDOP, A Fortran-IV Computer Program for Computing Cross Sections from Resonance Parameters, GAMD-6562 (1965). 
The two modes of operation for the unresolved resonance area, namely, generation of resonance integrals versus generation of cross sections, present rather different coding problems. For example, for the resonance-integral/attenuation-factor approach, resonance integrals are required on the same energy grid for all isotopes and spin states. For the cross-section approach, each isotope's cross sections may be on a distinct grid. The former approach requires interpolation in area 5 to obtain the $J$ on a common energy grid and involves substantially more data management, since the overlap terms for all other sequences are required to evaluate each integral. For the cross-section approach, the overlap terms of the other sequences are not involved, since they are assumed to cancel to first order, as in $\mathrm{MC}^{2}$. Coding is under way to include the option of generating resonance integrals for use in the continuous-slowing-down treatment.

In the area 7 (Elastic Scattering Matrices and Macroscopic Cross Sections) coding, the function subprogram $Q_{L}$ which calculates

$$
Q_{N+1}(i \Sigma / k) / Q_{N}(i \Sigma / k)
$$

has been speeded up by incorporating the backward-recursion relation developed by Gautschi.* The recursion relation has the form

$$
r_{n-1}=-\frac{b_{n}}{a_{n}+r_{n}}, n=\nu, \nu-1, \ldots, 1,
$$

where

$$
a_{n}=\frac{(2 n+1) z}{n+1}, b_{n}=\frac{n}{n+1},|z|=|i \Sigma / k|>1
$$

and

$$
r_{n} \simeq \frac{Q_{n+1}(Z)}{Q_{N}(Z)} .
$$

In the routine $Q_{L}, \nu$ is taken as $N+9$ and the recursion is begun with $r_{\nu}=0$. Using this relation for

$$
\begin{aligned}
& |z|>1.15, \quad k^{2}<0, \\
& |z|>1.0, \quad k^{2}>0 .
\end{aligned}
$$

gives accuracy comparable to the method reported in ANL-7798 with a savings of more than $40 \%$ in computing time. For $|z|>1,2000$ calls to $Q_{L}$ require approximately $0.75 \mathrm{sec}$.

*W. Gautschi, Computational Aspects of Three-Term Recurrence Relations, SIAM Review, 9, 1, 24 (1967). 
Testing of the inelastic and $(n, 2 n)$ scattering-source calculation for the spectrum (area 8 ) is continuing. Some timing estimates have been obtained using the ENDF/B data for ${ }^{63} \mathrm{Cu}$. Copper -63 has five discrete inelastic levels and two $(n, 2 n)$ scattering laws. The threshold for inelastic scattering is $679 \mathrm{keV}$ (group 373 for EMAX $=15 \mathrm{MeV}, \Delta \mathrm{U}=1 / 120$ ) and $11 \mathrm{MeV}$ for $(\mathrm{n}, 2 \mathrm{n})$ scattering (group 38 ). Continuum inelastic scattering begins at $1.75 \mathrm{MeV}$ (group 258). Using these data, the scattering source calculation for a 2000 -group problem (EMAX $=15 \mathrm{MeV}, \Delta \mathrm{U}=1 / 120$ ) requires approximately $12 \mathrm{sec}$ if the ENDF/B $(n, 2 n)$ scattering laws are used. Noting that a typical $\mathrm{MC}^{2}-2$ problem might have 20 materials with inelastic scattering, and that the source calculation must be performed during each flux iteration (energy - or material-dependent X) of each buckling iteration, this calculation will almost certainly control the timing of an $\mathrm{MC}^{2}-2$ calculation. Most of the time in the routine is spent in evaluating the evaporation model scattering probabilities

$$
\left(1+\frac{E_{j}}{T_{k}}\right) \exp \left(-E_{j} / T_{k}\right) \text {, }
$$

where $K$ ranges over all source groups with continuum inelastic or $(n, 2 n)$ scattering and $j$ ranges over all ultra-fine-group sink groups. The evaluation of the exponential has been speeded up by expanding $\exp \left(-E_{j} / T_{k}\right)$ in a Taylor series about $\exp \left(-E_{j-1} / T_{k}\right)$ and retaining six terms. Use of the standard FORTRAN exponential function requires approximately $15 \mathrm{sec}$, thus yielding a savings of $20 \%$ in the expansion method. If Segev's* $(n, 2 n)$ scattering algorithm is used in lieu of the ENDF/B $(n, 2 n)$ laws, the timing becomes considerably worse, since this algorithm requires a separate continuum calculation for each sink group of the initial $(n, 2 n)$ neutron. Studies are proceeding to determine the accuracy of a direct ENDF evaluation versus Segev's algorithm. Because of the significant times involved, a fine-group evaluation of the continuum inelastic and $(n, 2 n)$ source is being considered. If such an evaluation significantly reduces running times, a possible computational strategy might be to evaluate the source on a finegroup basis $(\sim 10 \mathrm{ufg} / \mathrm{fg})$ distributing the fine-group source as $\Delta \mathrm{E}_{\mathrm{ufg}} / \Delta \mathrm{E}_{\mathrm{fg}}$ during the iteration, and on convergence switch to $u f g / f g$.

3. Reactor Code Center. M. Butler (02-085; last reported: ANL-7798, p. 111)

During April and May, 10 program packages were assimilated into the Center library and readied for distribution. Seven of these contain new programs; the remaining three consist of one revision and two new machine versions of existing library programs.

\footnotetext{
${ }^{*} M$. Segev, Inelastic Matrices in the New MC ${ }^{2}$ Code, internal memorandum (Mar 5, 1971).
} 
ANL contributed five program packages. These include IBM 360 versions of the $\mathrm{MC}^{2}$ multigroup cross section code* (ACC No. 355 ) and the CHECKER ENDF/B processing routine** (ACC No. 475) written in FORTRAN IV and CDC 3600 FORTRAN programs MERMC2 and MAGIC (ACC No.473), MC ${ }^{2}$ library-tape utility routines ${ }^{+}$MERMC2 is designed to add new ENDF/B data to existing $\mathrm{MC}^{2}$ library tapes; MAGIC edits $\mathrm{MC}^{2}$ library-tape data or prepares plots of these data for an auxiliary CALCOMP 580 plotter. In addition, both IBM 360 and CDC 3600 versions of the QXI fast-reactor kinetics programtt are now available as ACC No. 474. The code solves the transient one-dimensional multigroup diffusion equations in the three standard geometries by factoring the total flux into the product of a time-dependent amplitude function and a spaceenergy-time-dependent shape function.

Two programs prepared in FORTRAN IV for the CDC 6600 by Bettis Atomic Power Laboratory have been added to the Center collection. These are SPAN4 (ACC No. 462) and BUSHL (ACC No. 473). SPAN4 ${ }^{\ddagger}$ is a shieldevaluation program which calculates fast-neutron dose rate, thermal-neutron flux, and gamma-ray flux, dose rate, and energy-absorption rate in rectangular, cylindrical, and spherical geometries by integration of the appropriate exponential kernels over a source distribution. BUSHL ${ }^{\ddagger}$ determines the load at which a finite-length shell of revolution will buckle when subjected to hydrostatic pressure and axial compression.

Battelle Northwest submitted two UNIVAC 1108 FORTRAN IV packages --the ETOX-2 group-constant calculation program, which replaces the $\mathrm{ETOX}^{\S}$ code (ACC No. 388), and HRG3 ${ }^{\$}$ (ACC No. 467), a program that computes the slowing-down spectrum over the energy range $0.414 \mathrm{eV}-10 \mathrm{MeV}$ in either the $B_{1}$ or $P_{1}$ approximation using 68 groups.

The latest addition written in FORTRAN IV for the IBM 360 was received from Atomics International (ACC No. 482) and consists of two programs, COMMUC and CASCADE, written to analyze compound nucleus

*B. J. Toppel, A. L. Rago, and D. M. O'Shea, MC . A Code to Calculate Multigroup Cross Sections, ANL-7318 (June 1967).

** J. Felberbaum and H. C. Honeck, Description of the ENDF/B Processing Codes CHECKER, CRECT, DAMMET, and Retrieval Subroutines, ENDF-110 (Sept 1967).

E. M. Pennington, J. C. Gajniak, A. B. Cohen, and W. Bohl, Service Routines for the Multigroup Cross-section Code MC2 ANL-7654 (Apr 1970).

\#1 D. A. Meneley, K. O. Ott, and E. S. Wiener, Fast-reactor Kinetics--The QXI Code, ANL-7769 (Mar 1971 ).

†o. J. Wallace, SPAN-4-A Point-Kemel Computer Program for Shielding, WAPD-TM-809 (Dec 1969).

\# A. L. Thurmat, BUSHL-A Computer Program for the Inelastic Buckling of Shells of Revolution under External Pressure and Axial Compression, WAPD-TM-890 (Mar 1971).

5 R. E. Schenter, J. L. Baker, and R. B. Kidman, ETOX, A Code to Calculate Group Constants for Nucleat Reactor Calculations, BNWL-1002 (May 1969).

5S J. L. Carter, HRG3-A Code for Calculating the Slowing-down Spectrum in the $\mathrm{P}_{1}$ or $\mathrm{B}_{1}$ Approximation, BNWL-1432 (June 1970).

"C. L. Dunford, Compound Nucleus Reaction Analysis Programs COMNUC and CASCADE, TI-707-130-013 (Jan 1971). 
interactions. CASCADE prepares ratios of cascade (gamma, n) and cascade (gamma, f) to the gamma-emission probability for each compound-nucleus spin state. These ratios can then be input to COMNUC to calculate more accurate capture cross sections.

The fifth supplement to the Center's Compilation of Computer Program Abstracts, ANL-7411, was issued in May.

Five library programs were tested. Sample problems were executed for the following IBM 360 versions of library programs: $\mathrm{MC}^{2}$ (ACC No. 355), QX1 (ACC No. 474), CHECKER (ACC No. 475), and COMNUC and CASCADE (ACC No. 482 ).

\section{PUBLICATIONS}

Small Back-to-Back Detector for Precise Comparison of Fission and $(n, \alpha)$ Reaction Rates

L. S. Beller

Nucl. Instr. Methods 92, 397-401 (1971)

ZPR-3 Assemblies 48, 48A, and 48B: The Study of a Dilute Plutoniumfueled Assembly and Its Variants

A. M. Broomfield,* A. L. Hess, P. I. Amundson, Q. L. Baird,**

E. F. Bennett, W. G. Davey, J. M. Gasidlo, W. P. Keeney, J. K. Long, and R. L. McVean

ANL-7759 (Dec 1970)

The ARC System One-dimensional Transport Theory Capability, SNARC1D

L. T. Bryant, G. J. Duffy, H. Greenspan, H. Henryson II, and G. K. Leaf ANL-7717 (Jan 1971)

Modular Coding for Reactor Calculations in the United States

D. K. Butler

Meeting on Modular Codes for Reactor Calculations, Varese, Italy, December 1-3, 1970. Newsletter of the ENEA Computer Programme Library No. 11 (EACRP-A-135), p. 50 (Mar 1971)

Argonne Code Center: Compilation of Program Abstracts

M. K. Butler, Pamela Henline, Marianne Legan, L. Ranzini, and

William J. Snow

ANL-7411 Supplement 5 (Feb 1971)

Simplify Turn-On Initialization of Digital Systems

C. E. Cohen

400 Ideas for Design. Hayden Book Co., New York, 1971, Vol. 2, pp. 237-238.

\footnotetext{
*UKAEA, Winfrith.

*** Battelle Northwest Laboratory.
} 
Deciphering and Processing Digital Photographic Data

A. DeVolpi

Proc. 9th Int. Conf. on High Speed Photography, Denver, August 2 -7, 1970. Soc. of Motion Picture and Television Engineers, New York, 1970 , pp. $58-62$.

Estimates of Variance and Merit Ratios from Measured Quantities of Fluctuating Origin and Inherent Correlation

A. DeVolpi

Int. J. App1. Rad. Isotopes 22, 103-110 (1971)

Neutron Escape from Water-Moderated Tanks

A. DeVolpi

J. Nucl. Energy 244(12), 577-586 (Jan 1971)

Digital Pulses Delayed with Substantially Reduced Deadtime

A. DeVolpi, G. E. Caya, C. J. Rush, and S. J. Rudnick

Rev. Sci. Instr. $\underline{42}, 684-689$ (1971)

Functionals for Discontinuous Trial Function Flux Synthesis

P. P. Lambropoulos and V. Luco

J. Nucl. Energy 24, 551-564 (Dec 1970)

${ }^{165}$ Ho Fast Neutron Cross Sections

J. W. Meadows, A. B. Smith, J. F. Whalen, and T. D. Beynon*

Z. Phys. 243(2), 171-187 (1971)

Experimental Determination of the Perturbation Denominator in Fast Critical Assemblies

W. C. Redman and M. M. Bretscher Nucl. Sci. Eng. 44(3), 450-453 (June 1971) Note

Empirical Formula for Interpolation of Tabulated Photon Photoelectric Cross Sections

D. L. Smith ANL-7796 (Mar 1971)

The Effect of Anisotropic Scattering upon the Elastic Moderation of Fast Neutrons

W. M. Stacey

Nucl. Sci. Eng. 44, 194-203 (May 1971)

Approximate Treatments of the Effect of Anistropy upon Elastic Neutron Moderation

W. M. Stacey

Nucl, Sci, Eng. 44(3), 442-444 (June 1971) Note

Applied Physics Division Annual Report; July 1, 1969, to June 30, 1970 January 1971

*University of Birmingham, England. 
7.42 


\section{REACTOR SAFETY}

\section{A. Accident Analysis and Safety Evaluation. G. J. Fischer $(02-112)$}

1. Initiating Accident Code Development. F. E. Dunn (Last reported: ANL-7783, p. 91)

\section{a. Incorporation of Slug-ejection Coolant Model into SASIA Code}

The slug-ejection coolant-voiding model used in the SAS codes has been modified to account for axial variations in the pressure in a vapor bubble, and results have been obtained using this new capability. The model now accounts for pressure gradients due to friction and due to vapor acceleration caused by vaporization and condensation.

Some results obtained for a flow-coastdown accident with failure to scram in the FFTF reactor are shown in Fig. VIII.1; two cases are shown. The cases are identical, except that a superheat of $30^{\circ} \mathrm{C}$ was assumed for one case, and $70^{\circ} \mathrm{C}$ for the other.

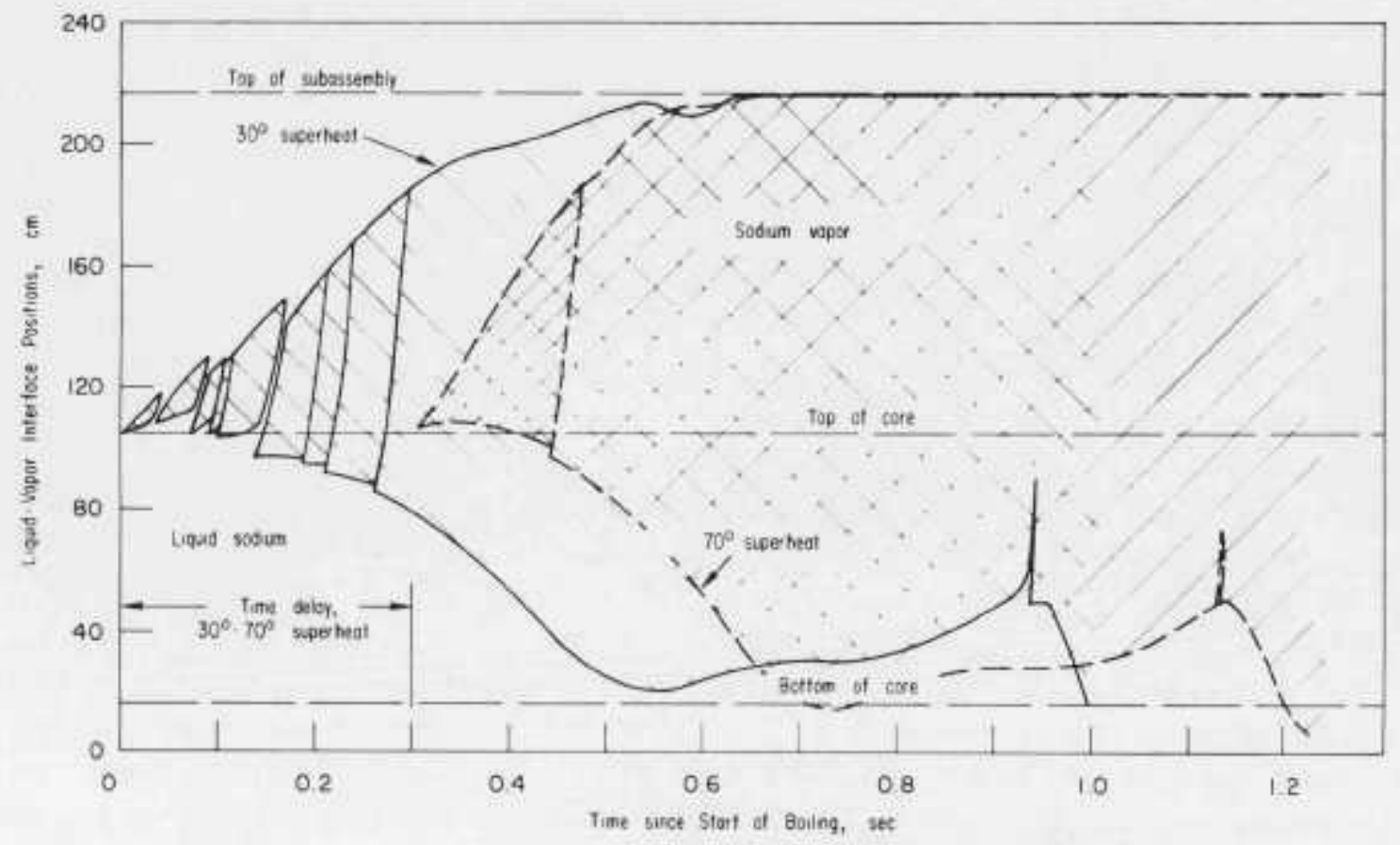

Fig. VIII.1. Sodium-voiding Dynamics including Vapor-pressure Gradients. Coastdown conditions, no fission-product gas.

In the $30^{\circ} \mathrm{C}$-superheat case, the results for the initial stages of voiding were similar to the results obtained with no vapor-pressure gradients (see Fig. III.A.1 on p. 88 of ANL-7765). A number of vapor bubbles were formed near the top of the core, and then were swept upward into the cooler regions above the core, where they collapsed. 
After the initial stages of voiding, the vapor-pressure gradients caused significant changes in the voiding history. The pressure at the lower liquid-vapor interface in the core region was higher than the pressure at the upper interface in the cooler fission-gas plenum, so the lower interface moved downward through the core more rapidly and voided more of the core, whereas the upper interface moved upward more slowly. After the core region was voided, the vapor-pressure gradient was sufficient to retard reentry of the lower liquid slug until film dryout occurred in much of the core and decreased the vapor source. As the lower liquid slug reentered the hot core, the liquid heated until another vapor bubble was formed. The liquid slug between the two vapor bubbles was accelerated rapidly upward and rewetted much of the cladding. The resulting vapor production was rapid enough to drive the lower liquid slug rapidly out of the core.

These results indicate that vapor-pressure gradients have a significant effect on the consequences of a flow-coastdown accident. The vapor-pressure gradients result in a more rapid insertion of voiding reactivity, and they inhibit reentry into the core region and rewetting of the cladding.

2. Disassembly Accident Analysis, Including Computer Code Development and Sensitivity Studies. R. B. Nicholson (Last reported: ANL-7783, p. 91)

\section{a. Sensitivity Studies}

Phases 2 and 3 of the sensitivity study for FFTF disassembly calculations have been completed. Phase 2 was similar to the first phase previously reported, except that a more severe excursion was initiated by a $\$ 100 / \mathrm{sec}$ ramp insertion from somewhat higher initial reactivity, power, and temperature conditions. As before, all the sodium coolant was assumed to be voided from the core at the beginning of the calculations. The parameter variations were similar to the first phase. The results are summarized in Table VIII.1.

In the third phase of the study, the influence of having sodium present during disassembly was investigated. The dominant parameter by far was the amount and distribution of small amounts of initial void space. The study was therefore concentrated on partial voiding. Most of the thirdphase study was also based on the $\$ 100 / \mathrm{sec}$ excursion used in the second phase.

We have treated the Doppler effect as a parameter independent of the amount and distribution of sodium. This was done so that variations in the energy release (due to variations in amount and distribution of sodium) are the result of sodium and void combinations on the pressure and resultant material motions. 
TABLE VIII.1. Sensitivity Results for $\$ 100 /$ sec FFTF Excursion with Al1 Sodium Voided

\begin{tabular}{|c|c|c|c|c|}
\hline $\begin{array}{l}\text { Parameter } \\
\text { Being } \\
\text { Varied } \\
\end{array}$ & Variations & $\begin{array}{l}\text { Total } \\
\text { Energy, } \\
\text { MW-sec }\end{array}$ & $\begin{array}{l}\text { Final Pressure } \\
\text { at Core Center, } \\
\text { atm }\end{array}$ & $\begin{array}{l}\text { Final Temp at } \\
\text { Core Center, }{ }^{\circ} \mathrm{K}\end{array}$ \\
\hline (Base-case) $^{a}$ & & 2620 & 399 & 6287 \\
\hline $\begin{array}{l}\mathrm{Tdk} / \mathrm{dT} \\
(0.0025)\end{array}$ & $\begin{array}{l}-0.00125 \\
-0.005\end{array}$ & $\begin{array}{l}3450 \\
1640\end{array}$ & $\begin{array}{r}977 \\
80\end{array}$ & $\begin{array}{l}7125 \\
5260\end{array}$ \\
\hline $\begin{array}{l}\text { Initial reactivity } \\
(\$ 1.09)\end{array}$ & $\$ 1.15$ & 3047 & 659 & 6724 \\
\hline $\begin{array}{l}\text { Ramp rate } \\
(\$ 100 / \mathrm{sec})\end{array}$ & $\begin{array}{r}\$ 50 / \mathrm{sec} \\
\$ 150 / \mathrm{sec}\end{array}$ & $\begin{array}{l}2170 \\
3100\end{array}$ & $\begin{array}{l}208 \\
692\end{array}$ & $\begin{array}{l}5816 \\
6770\end{array}$ \\
\hline $\begin{array}{l}\text { Initial power } \\
\left(7.8 \times 10^{11} \mathrm{~W}\right)\end{array}$ & $\begin{array}{l}7.8 \times 10^{10} \mathrm{~W} \\
3.9 \times 10^{11} \mathrm{~W} \\
1.56 \times 10^{12} \mathrm{~W} \\
7.8 \times 10^{12} \mathrm{~W}\end{array}$ & $\begin{array}{l}3513 \\
2760 \\
2790 \\
4540\end{array}$ & $\begin{array}{r}1016 \\
472 \\
492 \\
2239\end{array}$ & $\begin{array}{l}7154 \\
6425 \\
6460 \\
8245\end{array}$ \\
\hline $\begin{array}{l}\text { Initial precursors } \\
\left(\mathrm{C}_{10}\right)\end{array}$ & $c_{10} \times 10$ & 2710 & 447 & 6378 \\
\hline $\begin{array}{l}\text { Initial temp } \\
\text { distribution }\end{array}$ & $\begin{array}{l}500^{\circ} \mathrm{K} \text { higher } \\
500^{\circ} \mathrm{K} \text { lower }\end{array}$ & $\begin{array}{l}2180 \\
3690\end{array}$ & $\begin{array}{l}410 \\
398\end{array}$ & $\begin{array}{l}6309 \\
6285\end{array}$ \\
\hline $\begin{array}{l}\text { Prompt-neut. } \\
\text { 11fetime } \\
\left(5 \times 10^{-7} \mathrm{sec}\right)\end{array}$ & $\begin{array}{r}2.5 \times 10^{-7} \mathrm{sec} \\
10.0 \times 10^{-7} \mathrm{sec}\end{array}$ & $\begin{array}{l}2470 \\
2740\end{array}$ & $\begin{array}{l}331 \\
452\end{array}$ & $\begin{array}{l}6142 \\
6389\end{array}$ \\
\hline Heat capacity & $1.2 \times$ base & 3120 & 391 & 6270 \\
\hline $\begin{array}{l}\text { EOS pressure } \\
\text { function }\end{array}$ & $\begin{array}{l}2 \times \text { base } \\
0.5 \times \text { base } \\
0.1 \times \text { base }\end{array}$ & $\begin{array}{l}2360 \\
2900 \\
3570\end{array}$ & $\begin{array}{l}519 \\
286 \\
116\end{array}$ & $\begin{array}{l}5966 \\
6593 \\
7322\end{array}$ \\
\hline $\begin{array}{l}\text { Slope of vapor- } \\
\text { press. function }\end{array}$ & $\begin{array}{l}\text { Base/1.2 } \\
\text { Base/2.0 }\end{array}$ & $\begin{array}{l}2810 \\
3198\end{array}$ & $\begin{array}{r}178 \\
29\end{array}$ & $\begin{array}{l}6508 \\
6929\end{array}$ \\
\hline $\begin{array}{c}\text { Total suppression } \\
\text { threshold }(0.0)\end{array}$ & $\begin{array}{r}1.0 \mathrm{~atm} \\
10.0 \mathrm{~atm}\end{array}$ & $\begin{array}{l}2650 \\
2770\end{array}$ & $\begin{array}{l}414 \\
482\end{array}$ & $\begin{array}{l}6317 \\
6442\end{array}$ \\
\hline $\begin{array}{l}\text { Radial suppression } \\
\text { threshold }(0.0)\end{array}$ & $\begin{array}{l}1.0 \mathrm{~atm} \\
5.0 \mathrm{~atm} \\
20.0 \mathrm{~atm} \\
\text { Infinite }\end{array}$ & $\begin{array}{l}2660 \\
2730 \\
2850 \\
3000\end{array}$ & $\begin{array}{l}419 \\
456 \\
527 \\
642\end{array}$ & $\begin{array}{l}6326 \\
6395 \\
6518 \\
6698\end{array}$ \\
\hline
\end{tabular}

aase-case values of parameters shown in parentheses. 
A method has been developed for the VENUS disassembly code to introduce controlled amounts of void space into the reactor model at the beginning of an excursion. A normalization temperature, $T_{n}$, is first calculated on the basis of the initial temperature, $T_{0}$, as follows:

$$
T_{n}=\operatorname{MAX}\left(T_{0}+\Delta T, T_{\ell}\right) .
$$

The sodium volume fraction is then adjusted at each mesh cell such that all void space will be eliminated (due to fuel expansion) at a temperature $T_{n}$. By specifying nonzero values for the void-space temperature increment $\Delta \mathrm{T}$ and lower temperature limit $T_{b}$, we can obtain initial void distributions that appear plausible for LMFBRs. The actual void fraction corresponding to a given $\Delta T$ will vary throughout the core, because the coefficient of expansion implicit in the fuel equation of state is temperaturedependent. Table VII. 2 shows the relationship between $\Delta T$ and the void fraction at the center and outer edge of the reactor model being considered in this study.

TABLE VIII.2. Temperature Increase Required to Fil1 and Initial Void Space

\begin{tabular}{|c|c|c|}
\hline $\begin{array}{l}\text { Temp. } \\
\text { Increase, } \\
{ }^{\circ} \mathrm{K}\end{array}$ & $\begin{array}{l}\text { Initial Vo } \\
\text { Core Center, } \\
\mathrm{T}_{0}=3501^{\circ} \mathrm{K}\end{array}$ & $\begin{array}{l}\mathrm{ce}, \not{Z} \\
\text { Core Edge, } \\
\mathrm{T}_{0}=1828^{\circ} \mathrm{K}\end{array}$ \\
\hline 100 & 0.3 & 0.1 \\
\hline 250 & 0.7 & 0.3 \\
\hline 500 & 1.4 & 0.7 \\
\hline 1000 & 2.9 & 1.6 \\
\hline 2000 & 7.1 & 3.6 \\
\hline
\end{tabular}

When the initial void distribution is nearly uniform, the energy release is a monotonically increasing function of the void content. Table VIII. 3

TABLE VIII.3. "Uniform" Void Distributions at $\$ 100 / \mathrm{sec} *$

\begin{tabular}{lcccc}
\hline $\begin{array}{l}\text { Temp. Rise } \\
\text { to Fill } \\
\text { Voids, }{ }^{\circ} \mathrm{K}\end{array}$ & $\begin{array}{c}\text { Total } \\
\text { Energy, } \\
\text { MW-sec }\end{array}$ & $\begin{array}{c}\text { Peak Central } \\
\text { Pressure, } \\
\text { atm }\end{array}$ & $\begin{array}{r}\text { Central } \\
\text { Pressure } \\
\text { at End, } \\
\text { atm }\end{array}$ & $\begin{array}{c}\text { Central Temp. } \\
\text { at End, } \\
{ }^{\circ} \mathrm{K}\end{array}$ \\
\hline No void & 563 & 346 & 3.8 & 4104 \\
100 & 704 & 346 & 6.4 & 4255 \\
250 & 905 & 362 & 12.3 & 4471 \\
500 & 1220 & 365 & 29.9 & 4810 \\
1000 & 1810 & 480 & 111.0 & 5437 \\
2000 & 2561 & 373 & 373.0 & 6233 \\
No sodium & 2620 & 399 & 399.0 & 6287 \\
\hline
\end{tabular}

*Phase-II base case void fraction is about 0.40 . 
gives the results for the $\$ 100 / \mathrm{sec}$ case as a function of $\Delta T$. The partial voiding results approach those of the fully voided core at a $\Delta \mathrm{T}$ of about $2000^{\circ} \mathrm{K}$. Table VIII. 2 indicates that this corresponds to an average core void fraction of only about $5 \%$.

The main thrust of the nonuniform voiding studies was a search for a not-too-unusual configuration that could yield more energy than the fully voided case due to implosive tendencies. We found such cases under the constraint that the Doppler effect was held equal to that for sodium-out. When one accounts for the increased Doppler effect with sodium-in, the energy release in the worst implosive cases is expected to be about equal to that for the full-sodium-out case. The conclusion is that full-sodium-out conditions can still be considered sufficiently conservative.

The largest increase in energy release due to implosive effects was $47 \%$ greater than a fully voided situation. This was achieved by voiding the axially central five-ninths of the FFTF inner core zone, with no void space in the remainder of the core or reflector.

Several other voiding patterns that give somewhat smaller increases in the energy release were also studied. It was shown that one must have highly idealized conditions to achieve any significant implosive effect and that slight alterations can mitigate the effect. For example, a small amount of initial void space in either the sodium-in region or the reflectors will sharply reduce the implosive effect.

A few parameter variations have been done about the fullsodium-in base case. The results are given in Table VIII.4.

TABLE VIII.4. Parameter Variations with Sodium-In

\begin{tabular}{|c|c|c|c|c|}
\hline & $\begin{array}{l}\text { Total } \\
\text { Energy, } \\
\text { Mw-sec }\end{array}$ & $\begin{array}{l}\text { Peak Pressure } \\
\text { at Core Center, } \\
\text { atm }\end{array}$ & $\begin{array}{l}\text { Fina1 Pressure } \\
\text { at Core Center, } \\
\text { atm }\end{array}$ & $\begin{array}{l}\text { Final Temp. } \\
\text { at Core } \\
\text { Center, }{ }^{\circ} \mathrm{K} \\
\end{array}$ \\
\hline Base case & 563 & 346 & 3.8 & 4104 \\
\hline Doppler $=-0.00125$ & 586 & 353 & 4.2 & 4127 \\
\hline Doppler $=-0.005$ & 527 & 335 & 3.4 & 4067 \\
\hline $\begin{array}{l}\text { Initial power } \\
\text { twice as large }\end{array}$ & 851 & 681 & 10.3 & 4412 \\
\hline Initial reactivity & & & & \\
\hline 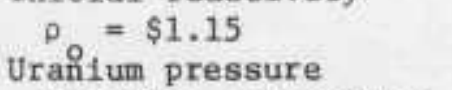 & 650 & 380 & 4.8 & 4171 \\
\hline $\begin{array}{l}\text { function reduced by } \\
\text { factor of ten } \\
\text { Sodium compressibility }\end{array}$ & 593 & 309 & 0.43 & 4137 \\
\hline doubled & 650 & - & 5.2 & 4196 \\
\hline$\$ 50 / \mathrm{sec}$ & 553 & - & 3.7 & 4094 \\
\hline$\$ 150 / \mathrm{sec}$ & 578 & - & 4.1 & 4120 \\
\hline
\end{tabular}


The sensitivity to parameter variations is quite different than it was in the sodium-out studies. This is largely because shutdown is much faster as a result of the high pressures encountered early in a sodium-in situation. Thus, the Doppler effect plays a less dominant role than it did in the sodium-out excursions.

Finally, the change in the parameter variation sensitivity as a function of void space was considered. Table VIII. 5 shows how the sensitivity to the Doppler effect increases as small amounts of initial void are introduced. As with the total energy release, the results for partial voiding approach the fully voided situation after an average initial void of about $5 \%$ is reached.

TABLE VIII.5. Sensitivity to Doppler Effect as a Function of Void Content

\begin{tabular}{|c|c|c|c|}
\hline $\begin{array}{l}\text { Void and } \\
\text { Doppler } \\
\text { Parameter }\end{array}$ & $\begin{array}{l}\text { Total } \\
\text { Energy, } \\
\text { MW-sec }\end{array}$ & $\begin{array}{l}\text { Final Pressure } \\
\text { at Core Center, } \\
\text { atm }\end{array}$ & $\begin{array}{l}\text { Final Temp at } \\
\text { Core Center, } \\
{ }^{\circ} \mathrm{K}\end{array}$ \\
\hline \multicolumn{4}{|l|}{ No Void } \\
\hline 0.0025 & 563 & 3.8 & 4104 \\
\hline 0.005 & 527 & 3.4 & 4067 \\
\hline \multicolumn{4}{|l|}{$500^{\circ}$ Vold } \\
\hline 0.0025 & 1220 & 29.9 & 4810 \\
\hline 0.005 & 1050 & 18.8 & 4626 \\
\hline \multicolumn{4}{|l|}{$2000^{\circ}$ Void } \\
\hline 0.0025 & 2561 & 373.0 & 6233 \\
\hline 0.005 & 1650 & 81.5 & 5272 \\
\hline \multicolumn{4}{|c|}{ Fully Voided } \\
\hline 0.0025 & 2620 & 399.0 & 6287 \\
\hline 0.005 & 1640 & 79.7 & 5260 \\
\hline
\end{tabular}

B. Coolant Dynamics. H. K. Fauske (02-114)

1. Sodium Superheat. R. E. Henry, R. E. Holtz, and R. M. Singer (Last reported: ANL-7798, p. 114)

a. Incipient-boiling Tests with EBR-II Sodium

These incipient-boiling superheat data show excellent agreement with the pressure-temperature history model. Figure VIII. 2 plots the incipient-boiling superheat against deactivation pressure (i.e., maximum pressure experienced by the system for at least $20 \mathrm{~min}$ before conducting the test run). These data points represent superheats for boiling at 1.24 psia for various deactivation pressures. The theoretical curve was obtained from 


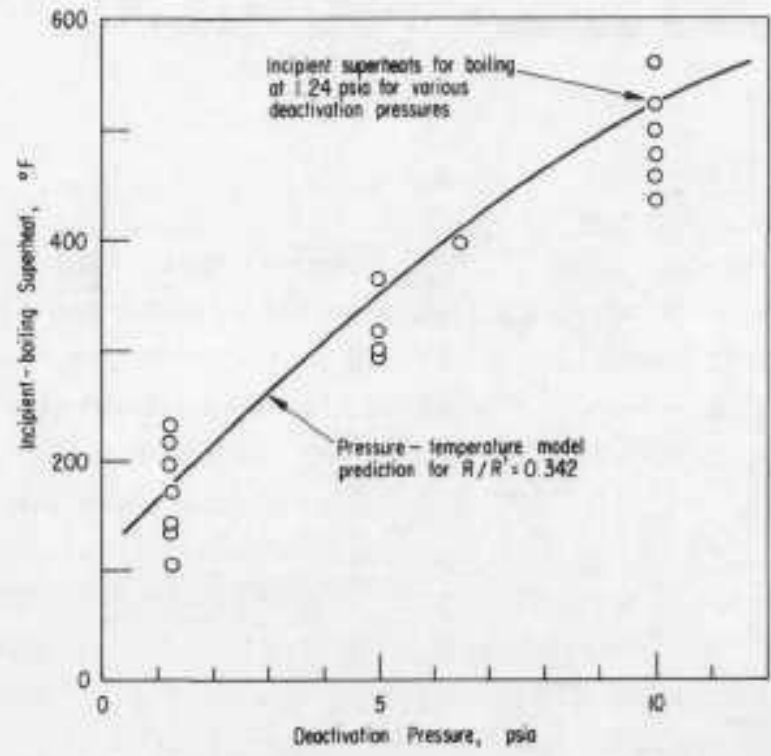

Fig. VIII.2. Plot of Incipient-boiling Superheat vs Deactivation Pressure the pressure-temperature model by using a ratio of receding to advancing radii of curvature of 0.34 . The experimental data and the theory agree excellently, clearly demonstrating the effect of the pressure-temperature history on the incipient-boiling superheats in sodium.

\section{b. Forced-convection Super- heat Experiments with Annular Flow}

Incipient-boiling superheat measurements were made in forcedconvection sodium flow. Measurements were taken at pressures from 2 to 10 psia and velocities up to $5.8 \mathrm{ft} / \mathrm{sec}$.

The heater was a high-flux $\left(700,000-\mathrm{Btu} / \mathrm{hr}-\mathrm{ft}^{2}\right)$ sheathed-coiltype unit whose sheath was $0.230 \mathrm{in}$. in $\mathrm{OD}$. The heater was spiral-wrapped with 0.070 -in. wire and inserted inside a 0.375 -in, - ID tube instrumented for axial temperature measurements. In addition, the tube was also equipped with a separate power supply and voltage taps to locate the point of inception.

A converging-diverging gas-detection nozzle was installed in the test-section bypass. The nozzle measured the average gas concentration in the coolant, and the voltage taps indicated when a single large gas bubble traversed the test section.

Both the gas-detection nozzle and the voltage taps indicated considerable entrained gas at high velocities $(5.8 \mathrm{ft} / \mathrm{sec})$, and the system boiled at a low superheat. At low velocities, the nozzle showed the entrained-gas concentration to be less than what can be measured reliably by the nozzle technique $\left(\alpha<10^{-3}\right)$. However, the voltage taps indicated that individual bubbles did enter the test section periodically. If the coolant was superheated when a bubble traversed the test section, boiling was initiated.

The signals from the voltage taps indicated that the point of inception varies from run to run, with boiling inception frequently occurring at superheats substantially lower than the maximum superheat existing in the channel. Therefore, such instrumentation is necessary to determine incipient superheats under flowing conditions.

The superheat data indicate that the presence of inert gas in the cavities plays a significant role in determining the incipience point. The data also show that when large gas bubbles are not present there is no significant effect of velocity on incipient superheat. 
2. Liquid-Vapor Dynamics. M. A. Grolmes and H. K. Fauske (Last reported: ANL-7776, p. 101)

\section{a. Liquid-film Thickness and Breakup}

Additional data have been obtained on film thickness for transient voiding processes. These data have been obtained for an annulus with and without wire wrap, a seven-pin assembly also with and without wire wrap, and a 19-pin assembly without wire wrap. These tests were carried out with glass test assemblies and were reduced in the same manner as described previously (see ANL-7726, July 1970, p. 147). Previous data for round tubes were taken under conditions in which the expulsion velocity for each run remained constant. These data showed the liquid fraction or film thickness to be independent of velocity. New data obtained under conditions in which the acceleration of the liquid remained constant for each run show that the liquid fraction or film thickness varies both with velocity $u$ and acceleration a, as shown in Fig. VIII. 3 for the annulus with wire wrap; a preliminary correlation of the velocity and acceleration effects is also indicated in the figure. The data for the seven- and 19-pin test assemblies will be analyzed in an attempt to determine similar relations.

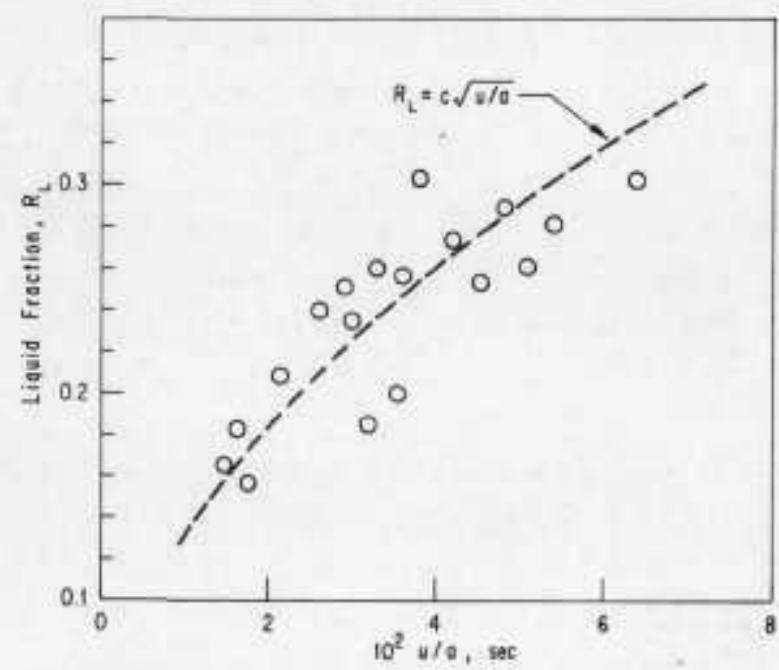

Fig. VIII.3

Liquid-fraction Data in an Air-Water System for Transient Slug-flow Volding in an Annulus with Wire Wrap. $\mathrm{D}_{1}$ was $9 \mathrm{~mm} ; \mathrm{D}_{2}$ was $6 \mathrm{~mm}$; acceleration was constant.

C. Fuel-element Failure Propagation.

B. D. LaMar $(02-116)$

1. Out-of-pile Studies. J. B. van Erp (Last reported: ANL-7776, p. 103)

a. Gas-release Experiments with 91 -pin Array in Freon

Fabrication of components for the Transient Flow Test Facility has been completed, and installation has started. Delays were encountered in the procurement of some stainless steel components. Fabrication of the components for the 91 -pin test section has been completed, and assembly is under way. 
The initial tests will be aimed at the study of flow transients induced by fast gas release due to multiple-pin failures, including evaluation of the possibility of the coolant-gas interface reaching the subassembly inlet and gas spilling over into adjacent subassemblies. Attention will also be given to evaluation of the potential for failure propagation due to transitory mechanical loads on adjacent pins caused by acoustic-inertial pressure pulses. Subsequent tests will be aimed at, inter alia, multiple-pin slow gas release and evaluation of detection techniques.

\section{b. Slow Gas Release in 19-pin Test Section in Water Loop}

Slow-gas-release experiments were continued, using an electrically heated test section having 19 stainless steel pins. A tendency toward gas-blanketing was observed for large sizes of the breach in the cladding, combined with a small pressure drop across the breach. The gasblanketing occurred immediately downstream of the point of gas release. This phenomenon has tentatively been attributed to displacement of the coolant by gas, in one or more subchannels over a limited axial height, since, at low pressure drops across the cladding breach, the gas will initially disperse less efficiently due to the absence of a strong jet action. Experiments in sodium are required to further evaluate this potential failure propagation mode.

c. Persistent-jet Gas-release Tests in Sodium

Fabrication of a three-pin test section has started, and design of a seven-pin test-section is nearing completion.

2. In-pile Studies. R. O. Ivins and C. C. Bolta (Last reported; ANL-7776,

a. Planning and Design of Experiments

A plan of experiments is being developed in conjunction with the development of loop-system design requirements. A sequence of 10 experiments directed toward improved understanding and eventual resolution of key uncertainties in possible single-subassembly accidents in FFTF is being planned. In addition, the use of the FEFPL in other areas of value to the FTR program, such as postaccident heat removal, instrument-package studies, and sodium chemistry, will be considered. The first five experiments, covering FY 1973 and FY 1974, will be planned in as much detail as possible. The second set of five experiments, covering FY 1975, and the additional uses of the loop will receive only preliminary planning. Also to be covered in more detail is the design-basis experiment, a total blockage of as large a fuel bundle as the loop design will permit. This is the most severe experiment planned with respect to loop safety. 
Work is continuing on plans for critical experiments using the ETRC Facility. WADCO has been asked to provide prices and schedules for the necessary critical fuel elements. INC is proceeding with the design of the FEFPL mockup for use in the critical experiments.

The requirement for FEFPL experiments to use fuel elements that are in an end-of-life condition is well established. End-of-life conditions include: loss of cladding ductility, swelling of the cladding, claddingfuel mechanical interaction, cladding-fuel chemical reactions, fission-gas pressure, and fuel restructuring and swelling. These conditions have a deleterious effect on fuel-element cladding and reduce its ability to withstand thermal and mechanical shock. A failure might be propagated under end-of-life conditions that would not have been propagated with fresh fuel.

A survey of available irradiation facilities reveals that each has problems associated with it. The principal concerns in developing a supply of preirradiated fuel elements using EBR-II is the length of element that can be irradiated. EBR - Ir has an active core height of only 13 in. and can accept an element of only $60 \frac{7}{6} \mathrm{in.}$ total height. The irradiated fuel length can be increased somewhat due to flux peaking in the axial reflectors, but the length is limited because it is necessary to protect structural members from neutrons streaming from the core. ETR fast-flux intensities are so low that an element, encased in a filtered capsule to ensure fast-reactor temperatures and flux spectrum, would require 7 yr to achieve a fast fluence of $5 \times 10^{22}$ nvt. Presently no facility exists to assemble preirradiated fuel elements into an FEFPL test train. The development of such a facility will not be completed before FY 1975.

Thus the project is examining the feasibility of simulating the effects of irradiation. These effects are known qualitatively and have been measured, but with considerable scatter. The phenomena are not well enough understood to allow predictions with substantial accuracy. Nevertheless, reasonable efforts to simulate end-of-life fuel can be developed. The following steps appear to be feasible: (1) use excessive cold work or carburization to embrittle the cladding, (2) load elements with an inert-gas pressure representative of end-of-life conditions, (3) use a chemical treatment on the interior of the cladding to produce intergranual cracking typical of high-burnup fuel, and (4) thermal cycle at power in ETR for up to 30 days to restructure and change the thermal properties of the fuel. Each of these concepts must be tested and the results compared to end-of-life fuel. More research will be needed to devise detailed procedures for processing fuel to attain an end-of-life simulation.

An accident fault tree has been developed (including the recommendations and suggestions made by INC) for the loop. Based on the accident sequence and consequences identified from this fault tree, the loop-protection instrumentation requirements were reviewed. To aid in this appraisal, a tabulation was made of the FEFPL levels of protection where, for each 
operational malfunction or experimental accident, a corresponding prime and, if applicable, its backup sensor were identified. This study revealed areas where additional loop-protection instrumentation might be required.

A review was made of the calculational methods and procedures required to evaluate the FEFPL loop containment's ability to withstand the effects of a molten fuel-coolant interaction. A calculational approach was recommended to couple the time-dependent pressure-energy source due to a fuel-coolant interaction to a model that predicts the vessel response to this dynamic load. In addition, the REXCO-H program is being investigated. The results of the investigation will be used to decide the need for an outof-pile explosive test program.

The mathematical model that characterizes FEFPL transient thermal and hydraulic conditions, within the limitation earlier described, was completed. The associated computer program THYME-B (Thermal Hydraulic Model for Experiments) was tested and brought to full operational status, Subsequently, THYME-B was used to calculate FEFPL behavior for the postulated test conditions delineated in Table VIII.6, which includes both single-subassembly and whole-core events.

TABLE VIII.6. Conditions for FEFPL Dynamies Caleulations

\begin{tabular}{|c|c|c|c|c|c|}
\hline \multirow[b]{2}{*}{ Test Conditions* } & \multicolumn{2}{|c|}{ S1ngle-Subassembly Testa } & \multicolumn{2}{|c|}{ Whole-Core Tests (Puep } & \multirow{2}{*}{$\begin{array}{c}\text { Pallure) } \\
\text { Fue1 } \\
\text { Bundle } 3 \\
\end{array}$} \\
\hline & $\begin{array}{l}\text { Complete }+ \\
\text { Blockage }\end{array}$ & $\begin{array}{l}\text { Partial } \\
\text { Blockage }\end{array}$ & $\begin{array}{c}\text { Fue 1 } \\
\text { Bundle } 1 \\
\end{array}$ & $\begin{array}{c}\text { Fuel } \\
\text { Bundle } 2^{\dagger}\end{array}$ & \\
\hline No. of fuel elements & 7 & 7 & 7 & 19 & 37 \\
\hline $\begin{array}{l}\text { Fuel-element power, } \\
\mathrm{kH} / \mathrm{ft}\end{array}$ & 13.1 & 13.1 & 1.3 .1 & 13.1 & 7.8 \\
\hline $\begin{array}{l}\text { Initial fuel-zone } \\
\text { flow, lb/sec } \\
\text { tnitial bypass }\end{array}$ & 1.78 & 1.78 & 1.78 & 4.75 & 9.04 \\
\hline $\begin{array}{l}\text { flow, } 1 \mathrm{~b} / \mathrm{sec} \\
\text { Bypass: Fue1-zone }\end{array}$ & 12.84 & 12.84 & 12.84 & 9.87 & 5.58 \\
\hline flow ratio & 7.21 & 7.21 & 7.21 & 2.08 & 0.62 \\
\hline
\end{tabular}

\begin{abstract}
*General conditions for all tests were: Total fnitial sodium flow rate = $120 \mathrm{gal} / \mathrm{min}(14.62 \mathrm{lb} / \mathrm{sec})$, sodium temperature at inlet to test section = $800^{\circ} \mathrm{F}$, shroud wall thickness $=0.040 \mathrm{in}$, , average sodium velocity through fuel elements $=23 \mathrm{ft} / \mathrm{sec}$, the shape of heat generation in the fuel was a chopped cosine function with axial max/ave - 1.24 , half-diameter spacer wires on the outer elements, no reactor (FFTF) scram, and no control-system action.

These tests calculated for shroud (inner half thickness) conductances: $\mathrm{U}=6530 \mathrm{Btu} / \mathrm{hr}-\mathrm{ft} \mathrm{t}^{2}{ }^{\circ} \mathrm{F}$ (normal), and $\mathrm{U}=50 \mathrm{Btu} / \mathrm{hr}-\mathrm{ft}^{2}-{ }^{\circ} \mathrm{F}$ (1nsulated).
\end{abstract}

A typical set of results obtained from these calculations is shown in Fig. VIII.4. This calculation was made by programming total sodium flow in FEFPL in conformance with that predicted for FFTF primary-system flow decay after loss of pumping power. In Fig. VIII.4, $T_{\text {co }}$ is the fuel-zone coolant outlet temperature, $T_{C_{3}}$ and $T_{C_{1}}$ are the coolant temperatures located 13.5 and $31.5 \mathrm{in}$. upstream, $\mathrm{T}_{\text {cin }}$ is the sodium 


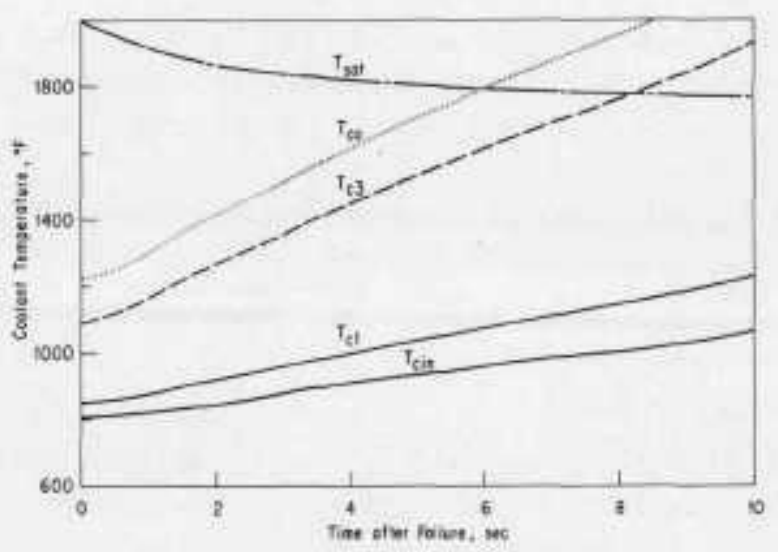

Fig. VHI.4. Fuel-zone Coolant Temperatures after Primary-pump Fallure, with 19 Pins, $13.1 \mathrm{~kW} / \mathrm{ft}$, and Normal Shroud temperature at the inlet to the fuel zone, and $T_{\text {sat }}$ is the saturation temperature based on the instantaneous value of pressure at the axial center of the fuel zone.

Coolant saturation occurs $\sim 6 \mathrm{sec}$ following initiation of the transient; at this time the flow rate is $-33 \%$ of the full-flow value. However, this indication of time for boiling inception is considered premature with respect to that anticipated in FFTF because the calculated rise in inlet temperature in FEFPL is not expected to occur in the reactor.

Thus, the results of Fig. VIII.4 show the need for effective control of coolant inlet temperature for proper simulation of an FFTF loss-of-flow accident.

The observed inlet-temperature rise is caused by the presence of significant heat sources that exist between the heat-exchanger outlet and the test-section inlet plenum in FEFPL. The major heat source is that due to ETR gamma flux. To assess the capability of regulatingagainst this effect, an investigation was made to determine the requirements for a controlsystem concept based on preprogramming the temperature of coolant before and during a loss-of-flow test.

The control analysis was made for a seven-element test section and two values of gamma heating. Salient results are shown in Fig. VIII.5, which depicts uncontrolled test-section inlet temperature and the reservoir temperatures required to hold inlet temperature constant for the indicated levels of garmma heating. When the 200-Btu/ sec-ft estimate was used, the result shows that the reservoir outlet temperature must initially decay at a rate greater than $20^{\circ} \mathrm{F} / \mathrm{sec}$. The corresponding heat-exchanger outlet temperature must decay at a rate at least 20 times as great as the reservoir outlet temperature, i.e., $400^{\circ} \mathrm{F} /$ sec. For reduced gamma heating

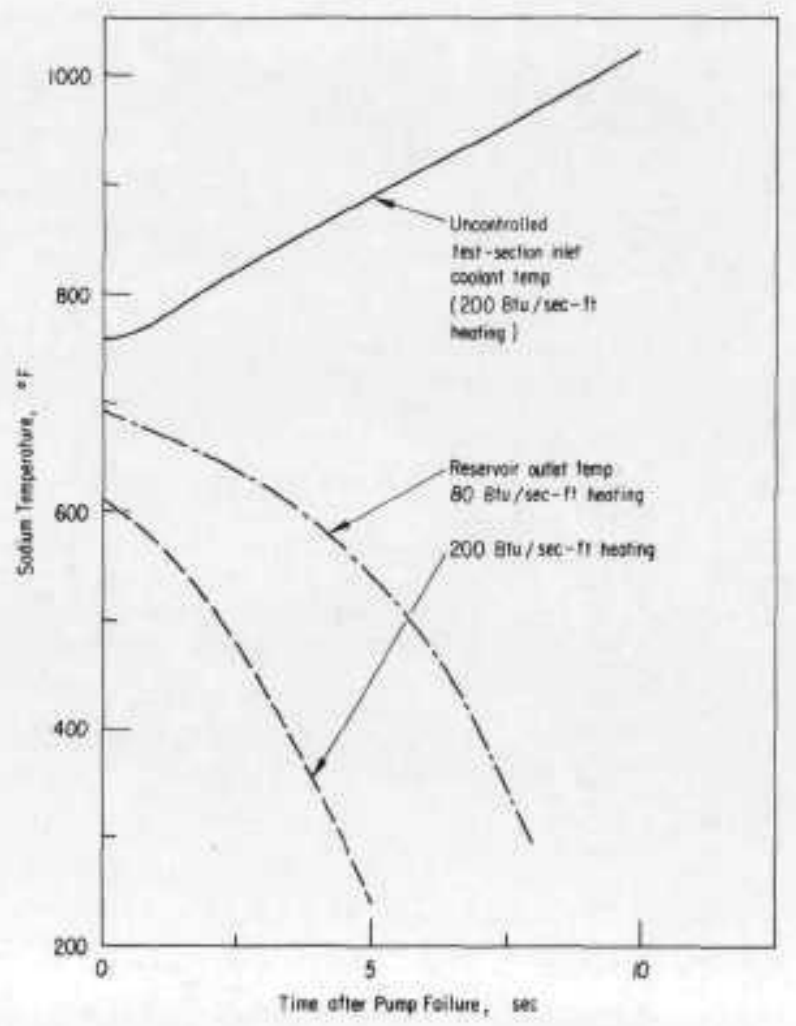

Fig. VIII,5. Loss-of-flow Controlsystem Requitements 
(80 Btu/sec-ft total), the results indicate somewhat less stringent requirements. The reservoir outlet temperature must decay at approximately $10^{\circ} \mathrm{F} /$ $\mathrm{sec}$, and the corresponding heat-exchanger outlet temperature at $200^{\circ} \mathrm{F} / \mathrm{sec}$. Based on these results, it is concluded that it is not feasible to design such a control system, because in both cases the required cooling capacity exceeds heat-exchanger capability. Furthermore, in both cases studied, the heatexchanger sodium outlet temperature would be required to decay below its freezing point.

Therefore, an alternative control concept for loss-of-flow tests is under study. It is based on control of the fuel-zone bypass coolant flow and/or test-section coolant flow, while maintaining total flow through the rest of the loop constant. Capability to simulate FFTF-pump coastdown will depend on test-train design, flow control devices, etc. Analyses are being made to resolve these questions.

The model and computer code that characterize sodium expulsion in the FEFPL continue to be developed. Numerous steady-state pressuredrop calculations have been made to investigate the effect of loop design changes on pressure drop and pump power requirements. Considerable reduction in loop pressure drop has been realized by replacing the coiled-tube expansion device by straight pipe sections and elbows, moving the internal neutron filter inward to touch the flow divider, changing the upper test-train flowmeter from a permanent-magnet flowthrough type to a probe-typedevice, and increasing the number of tubes in the heat exchanger. Steady-state pressure-drop calculations have also been made to determine means for simulating loss of flow in the experiment test subassembly.

Response of the loop system to transient pressures resulting from fuel-coolant interactions and from gas release has been determined. Coolant displacement in the FEFP loop agrees well with results obtained for a gas release in an FFTF core subassembly, as shown in Table V111.7; both calculations were based on the same pressure-time history. The results indicate that even better simulation of expulsion due to gas release would be possible in the FEFP loop if the hydraulic resistance of the pump leg were reduced. Possibilities for further reduction in this flow resistance are being investigated.

\begin{tabular}{|c|c|c|c|c|c|}
\hline \multirow{2}{*}{$\begin{array}{l}\text { time. } \\
\text { misec }\end{array}$} & \multirow{2}{*}{$\begin{array}{l}\text { Pressure, } \\
\text { osia }\end{array}$} & \multicolumn{2}{|c|}{$\begin{array}{l}\text { Qisplacenent of Coniant } \\
\text { asove Fuet Centerplane, in. }\end{array}$} & \multicolumn{2}{|c|}{$\begin{array}{l}\text { Displactement of Cociant } \\
\text { below. Fuet Centerpiane, in }\end{array}$} \\
\hline & & $\overline{\text { FFIF }}$ & FEFP $(00)^{2}$ & $\overline{F F F^{2}}$ & 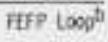 \\
\hline 0 & 800.0 & 0.9 & 0.0 & 0.0 & i. 11 \\
\hline 5 & 9025. & 2.6 & 2.6 & 0.5 & 1.1 \\
\hline 10 & 236.9 & 6.1 & 5,8 & -0.2 & 1.4 \\
\hline 20 & 151.8 & 12.6 & 12.3 & -2.4 & I.S \\
\hline 30 & 109.5 & 180 & 18.5 & -4.2 & 1.5 \\
\hline 8 & 90.3 & 22.5 & 23.6 & -5.2 & 1.7 \\
\hline 30 & 80.0 & 26.6. & 281 & -5.2 & 2.2 \\
\hline 60 & 24.4 & 0.2 & 32.1 & -4.1 & 3.1 \\
\hline$x$ & $\pi .5$ & 33.7 & 35,3 & -2.2 & 4.2 \\
\hline 8) & 00 & 37.1 & 39.0 & 0.4 & 5.9 \\
\hline की & 69.3 & 0.5 & 2.1 & 3.3 & 7.8 \\
\hline
\end{tabular}




\section{Fuel Dynamics Studies in TREAT. C. E. Dickerman (02-117)}

1. Transient In-pile Tests with Ceramic Fuel. C. E. Dickerman (Last reported: ANL-7783, p. 101)

a. First Mark-II-1oop Experiments (L1 and L2) on Fuel-movement Failure of Unirradiated Fuel during a Loss-of-flow Accident

Test L2 is to be the first TREAT simulation of an LMFBR lossof-flow incident carried past the fuel failure threshold. To improve simulation of coolant voiding and postfailure fuel movement in the subassembly. the test will use a seven-pin cluster, the maximum size available in a Mark-II loop. The test section will be a modified Dl test train, with a fluted tube surrounding the seven pins to simulate hydraulic flow conditions in FFTF. The fluted tube will be brazed into upper and lower headers, inside an outer tube to form a radial void as an insulator space. In addition, a prototype void detector will be tried in conjunction with the insulated test section. Analyses were performed on a range of four proposed detectors, and the system having the maximum potential for practical application was selected for checkout in test L2. The L2 test-train drawings were approved in a design review. FTR-type fuel has been supplied from the FFTF project.

Thermal-neutron-filter analyses were completed, and a filter was installed directly on the loop body. The loop and a calibration test section were sent to Idaho for a calibration run to check calculations and give direct measurements of ratios of sample power to TREAT power. In the interim before the scheduled date for the calibration run, this loop was used to check Idaho loop glovebox operations (see Sect. VIII.D.5 below). After the calibration run, the loop must be returned for completion of outfitting and performance of the loop high-pressure prooftest at design temperature.

b. First Mark-II-loop Experiments (D1 and D2) on Effects of Release of a Small Amount of Molten Fuel, Using Pins with Local High-enrichment Sections

Safety approval was granted for the first seven-pin Mark-IIloop test D1. The experiment is ready to be performed when the reactor schedule permits.

2. Experimental Support. M. B. Rodin (Last reported: ANL-7798, p. 123)

a. Cask Fabrication

Fabrication of both 10-ton Mark-II casks is proceeding on schedule. Certifications for all materials have been verified andall quality-control 
and fabrication procedures used in the manufacture of the cask have been approved. An ANL representative has witnessed major tests and critical fabrication procedures performed to date.

All the previously reported corrective work planned for the 24-ton Yankee cask and special-form container has been completed by Argonne personnel. A Mark-II TREAT sodium loop was inserted into the special-form container within the Yankee cask. With the loop is place, the closures of both inner and outer containers operated satisfactorily. Because of mechanical problems with the government-owned vehicle, the Yankee cask and special-form container will be shipped to Idaho by private carrier when necessary highway overload permits are received.

The Yankee cask will be used for returning a TREAT loop containing the E3 experiment to Illinois for examination. The loop is in storage at the TREAT site, but it is planned to load it into the Yankee cask at the TAN facility of Idaho Nuclear Corp. A tentative procedure for this transfer has been formulated and transmitted to Idaho Nuclear.

\section{b. Preparation of Last Six Mark-II Loops from FY 1970 Stocks}

The Mark-II A5 and A6 loop body weldments have been completed and are being prepared for incorporation into their respective integral loop assemblies. All components required for both assemblies are available from inventory with two exceptions. A burst-disk line must be fabricated and a dump tank must be modified and prooftested for use in the A6 unit, Work on both items is in progress.

The associated $\mathrm{A} 3$ and $\mathrm{A} 4$ ALIP units were also completed. In addition, preparation of components to fabricate three additional ALIP units (for the A5, A6, and Prototype Mark-II Loops) was initiated and is approximately $60 \%$ complete.

The inventory of machining stock required to fabricate additional Mark-II loops was made, and orders are being placed to obtain the balance of bars and pipe required.

c. Preparation of Advanced Mark-II Loops for Use in Future Tests

The revised layout for the Mark-IIC (Stretch) loop has received a preliminary review. The design provides for a test section capable of holding 61-in.-long fuel pins. In addition, provisions will be made to increase the number of electrical-instrument and power connections into the loop for future experiments. The design also provides for greater reuse capability. 
3. Analytical Support. A. B. Rothman (Last reported: ANL-7798, p. 124)

\section{a. Automated Handiling of Hodoscope Data}

A backlog of approximately 17 TREAT transients observed by the hodoscope require decoding. Of the 17,11 have been scanned by the new ALICE flying-spot scanner; two are in a preliminary-evaluation stage, in which accurate decoding of the data is attempted; five are in various stages of processing in our main program, DIGLITES, in the CDC 3600; and five have progressed to different degrees of analysis.

The data from a transient are stored on photographic film. After development and shipment, the film is edited to determine the region of interest for scanning. The ALICE personnel carry out the scanning of film where the data are now stored on magnetic tape in a different form. This must be decoded to reconstruct the original arrangement of data, although it is first necessary to make preliminary passes through the computer to pick up the fiducials and ensure proper registration of data. The deciphering of these data then proceeds through various stages in which the results are printed and plotted. It is usually necessary to return the magnetic tapes for reruns with adjusted parameters. Adjustments are necessary for incorrect reading of the timer lamps, obvious spurious scaler rates, and adjustments in channel efficiency.

Signal-to-background ratios can be adjusted to enhance visual contrast. When these various passes through the computer are complete, a magnetic tape can be generated for further plotting. At this stage, the data analysis can start. Even during the analysis stage, certain deficiencies in the previous processing can be uncovered, necessitating reruns at the CDC 3600.

ANL Transients 1281 (Checkout 1), $1317(\mathrm{H} 2)$, and $1322(\mathrm{E} 3)$ and GE Transient 1329 have reached levels of analysis more advanced than other transients.

A visual representation of the transient data is in the form of 35-mm output from the DD- 80 of the CDC 3600 . Examination of these film strips provides the initial integrated impression of fuel activity during the transient. When the signal-to-background ratio is high and the power level does not exceed a few hundred megawatts, the film representations might be sufficient to reflect the major features of interest. On the other hand, there is more detalled information that cannot be quantitatively evaluated from the visual representations. Also, the neutron detectors have nonlinear behavior for powers in excess of $1000 \mathrm{MW}$; such nonlinearity tends to obscure all fuel-pin definition. Cases in which the signal-to-background ratio is degraded due to excessive material surrounding pins of relatively low enrichment require special treatment. 
As a result, the hodoscope data have been analyzed from graphical plots, in which the countrate history of individual channels were plotted as a function of time. Variations due to physical causes, which are otherwise not perceptible in the visual images, were isolated in most cases.

A variety of plotting procedures has been tested to develop the most useful form. Our current procedure consists of recording all rectified data generated from the CDC 3600 program on magnetic tape. Fundamentally, this consists of a countrate for each channel for each unit of time, an average rate for some channels chosen as monitors, and bookkeeping information, such as the transient time, duration of count, sequence number, background factor, normalization factor, and transient number.

Figure VIII. 6 shows how the average monitor count rate (proportional to reactor power where the response is linear) can be plotted in semilog fashion. Figure VIII. 7 shows comparable graphs for a number of detectors plotted simultaneously. It is clearly difficult to discern fuelmotion related activities from Fig. VIII. 7 because of the power-driven change in countrate. Accordingly, for Fig. VIII. 8 the detector rate was di-

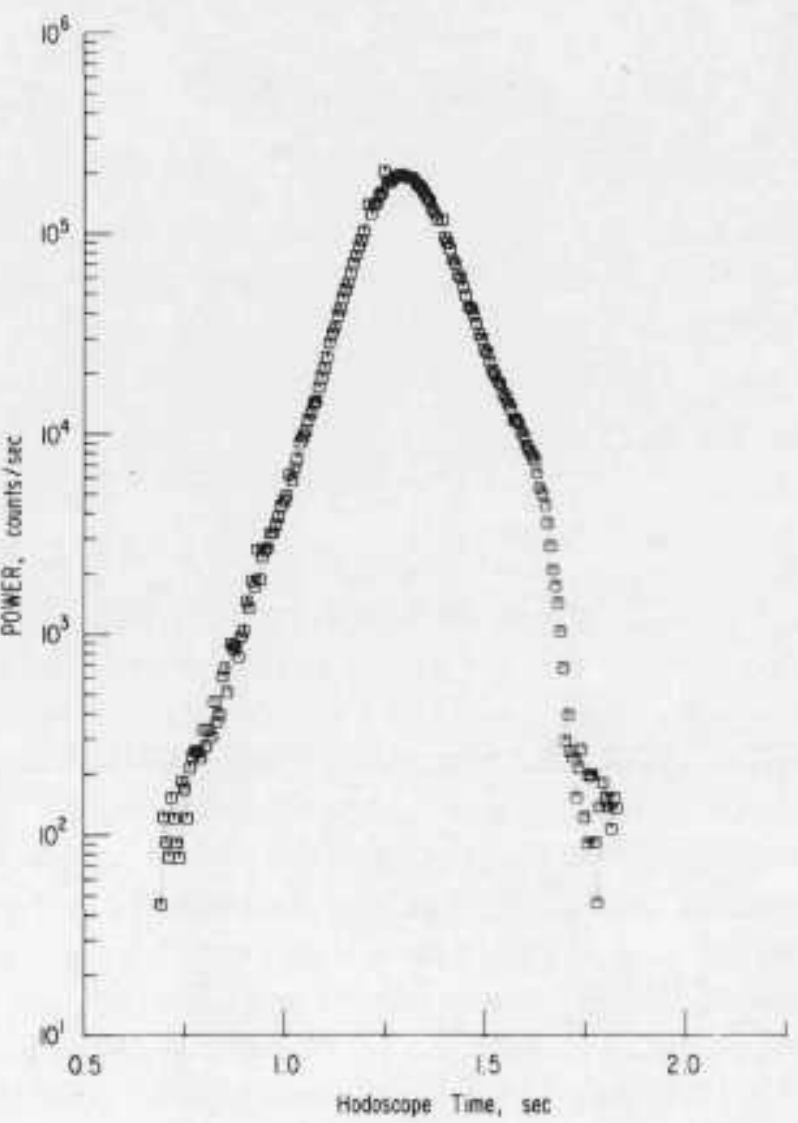

Fig. VIII.6. Average Countrate of Nine Monitor Channels of the Fast-neutron Hodoscope during TREAT Transient 1317 vided by the power monitor rate $(\mathrm{R} / \mathrm{P})$ to remove the power dependence. If there were no nonlinear behavior on the part of the detector channels, then all curves should be essentially straight lines with zero slope in the absence of physical effects. Figure VIII. 8 , though, is a composite of both nonlinear gain effects and real physical effects. Some of the physical effects can be evaluated through careful study of Fig. VIII.8, although the nonlinear influence tends to dominate.

The nonlinear effect appears to be caused by a gain shift (increase) that causes the count rate in each channel to increase at high powers. The dip in the middle of the curves occurs at the peak power $(1.30 \mathrm{sec})$; this dip arises from two effects: (1) from some degree of saturation at high countrates (over $10 \% / \mathrm{sec}$ ) and (2) artificially from division of the rate $R$ by the power level $P$, which itself has undergone a gain shift upward that reaches a 
maximum at peak power. From this evidence and from confirmation of linearity of the TREAT instrumentation, we conclude that the discrepancies that heretofore have appeared in the comparison of power monitors are due to the nonlinear gain shift of the hodoscope instrumentation. Numerous tests in the past have failed to predict or simulate this condition, so more extensive tests are under way to locate the source of trouble.

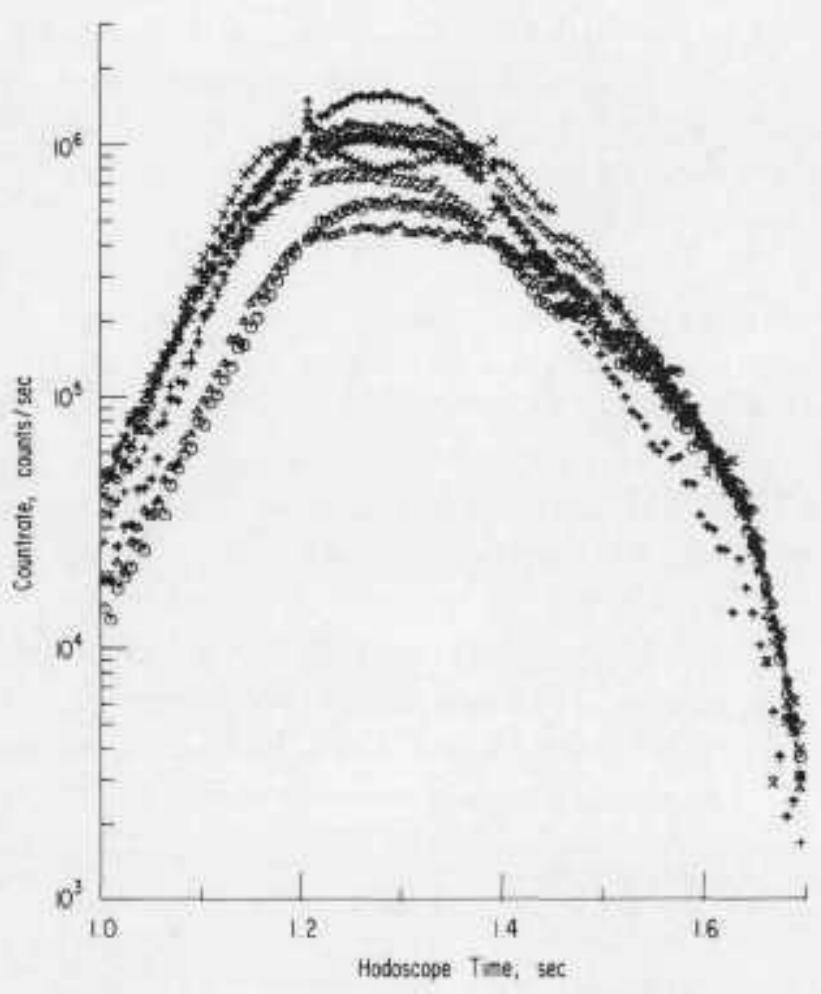

Fig. VIII.7. Countrate History of Eight Channels in Column 8 (centered on the fuel pin) for Transient 1317

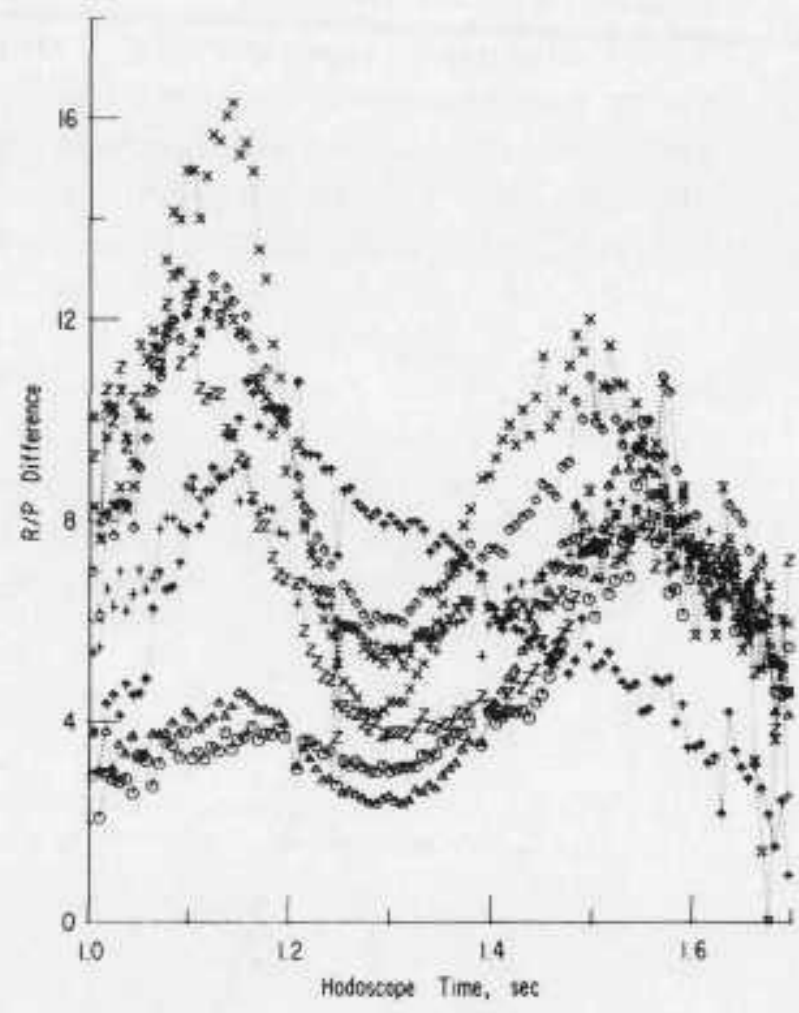

Fig. VIII.8. Countrates (R) of Fig. VIII.7 Divided by Power (P) of Fig. VIII.6

For low-power transients (a few hundred megawatts), the nonlinear effects are not important. Also, if the transient has approximately a symmetrical shape about the peak, the effect is largely removable. Figure VIII. 9 shows what can be done to the data of Figs. VIII. 7 and VIII. 8 when the postpeak data are normalized on the basis of the prepeak response. The $R / P$ value before the peak has been subtracted from the $R / P$ value after the peak. If the gain effect is about the same on each side of the peak, the resulting $\mathrm{R} / \mathrm{P}$ difference should be zero where there are no physical effects. Because Column 8 is lined up with the fuel pin, there are expected physical effects; on the other hand, Column 7 is off to the right of the pin where it should see no fuel activity. Figure VIII.10 supports this conclusion and the validity of the assumptions.

Going back to Fig. VIII.9, we can see (in comparison to baseline data such as Fig. VIII.10 provides) that there are two curve envelopes: 
detectors 13 and 62 going positive, and the remaining detectors going negative. Detectors 13 and 62 are above the original position of the fuel pin; we interpret the positive effect to be fuel expansion into the expansion space above the original pin. This is confirmed by other data in that region and by the visual data taken when powers became lower. The remaining scalers have negative-going responses, indicating dilution of fuel due to expansion compounded with fuel-pin bending bringing the pin in and out of the field of view. There are also possible coherent effects due to expulsion and voiding, alternating with fuel collapse within the pin.

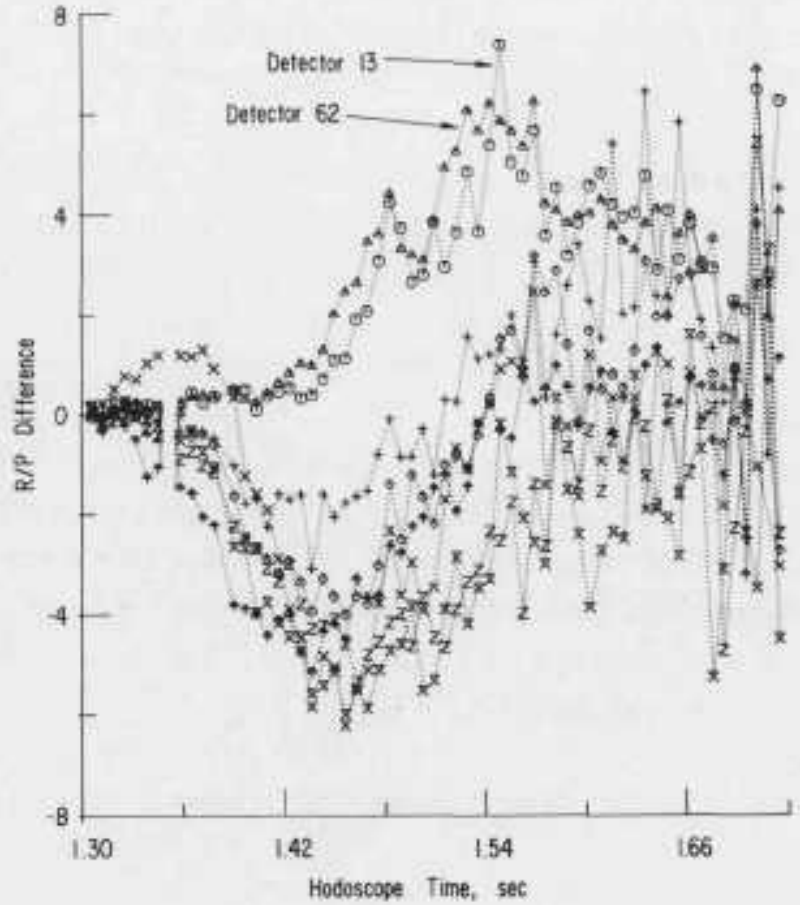

Fig. VIII.9. Postpeak R/P Values of Fig. VIII.8 Normalized on the Basis of Prepeak Values, Thereby Removing Efficiency and Nonlinear Effects

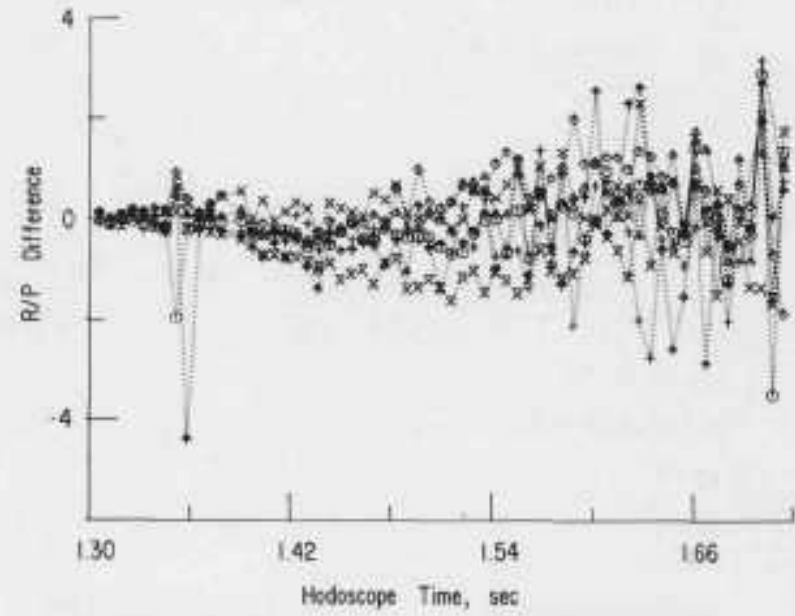

Fig. VIII,10. Similar to Fig. VIII.9, Except That the Data are for Column 7, which is Focused to the Right of the Fuel Pin at the Steel Liner

Despite the limitations imposed by the gain shift, it is evident that us eful data can be derived, at least up to the power of Transient 1317 (1600 MW). The next stages of development involve further compression of data on the magnetic tape to reduce plotting time. Each of these plots takes about $1 \mathrm{hr}$, with about half the time required for reading the tape. The program TIMEPLOT, which produces these graphs, has been written in a way to permit an experimenter to call for any combination of scalers (e.g., rows or columns) to be plotted so as to evaluate suspected physical effects.

Schedule problems are developing with regard to analysis of hodoscope data. The date for the shutdown of the CDC 3600 has not been set. Our plans are to reprogram for both on-line and off-line use of the computer associated with ALICE (the PDP-10), but the workload in analyzing past 
transients has not permitted these plans to be accomplished. The PDP-10 has not been modified and fully checked out with the DDP-80-type of filmproduction capability, which is essential for our application.

Hodoscope display hardware (PDP-11 computer, two magnetic tapes, teletype, display scope, and controllers) are working and mostly debugged. Some intermittent difficulties have occurred with one magnetictape unit.

Assembly programs have been initiated for the magnetic-tape drivers, for reading from the tape, for writing on teletype, for transfer to core, and for storage on magnetic tape.

The hodoscope data generated from the CDC 3600 are being rewritten on magnetic tape in (a) compressed format and (b) binary form more suitable for the handling routines of the PDP-11. Tape-movement time can be reduced significantly by optimizing the data stored in each physical record.

As indicated in the preceding general discussion of analysis of hodoscope transient data, certain fuel motion activities can be determined on a quantitative of semiquantitative scale. Transient 1317 , because of certain technical considerations in film scanning, has reached an advanced stage, and has been used as an illustration of the analysis technique. As reported previously (see ANL-7783, p. 104), the visual presentation (Fig. VIII.11, left) indicates the presence of the fuel during the early low-power stages of the transient. During the peak portion of the transient, the visual images
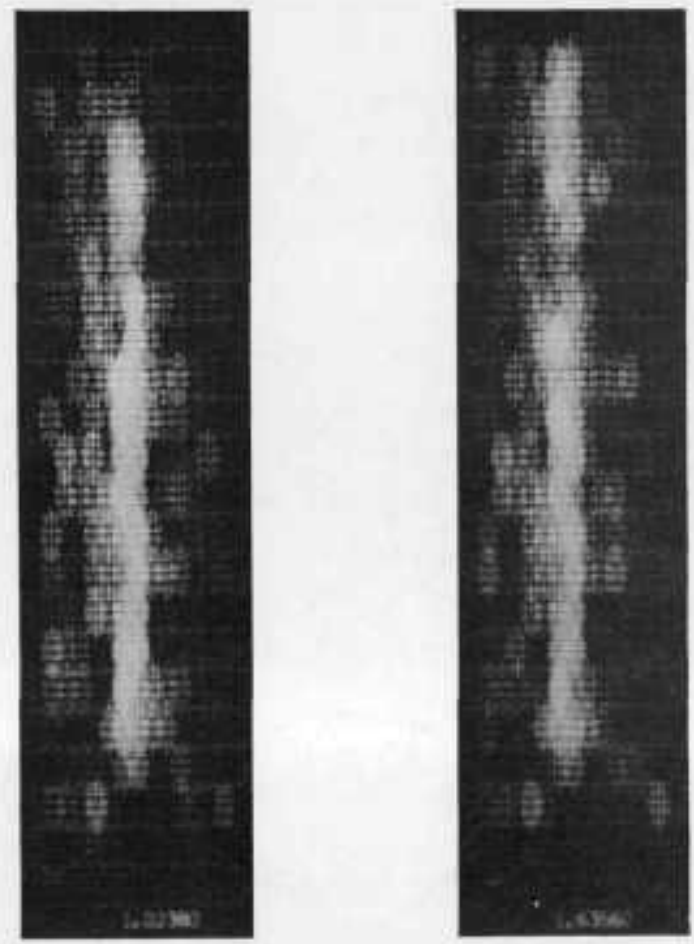

Fig. VII.11

Visual Representation (left) of Fuel Pin, According to the Fast-neutron Hodoscope, for a Prepeak Stage in TREAT Transient 1317, and (right) Visual Representation of Fuel Pin after Peak Power in Transient 1317. The fuel (at right) can be seen to have expanded above the original location of fuel. The void also coincides closely with postmortem radiograph. 
are incoherent, but after the peak (Fig. VIII.11, right) it is evident that fuel has expanded into the expansion region above the initial position of the fuel. Figure VIII.9 confirms this and provides indication that the expansion started at about $1.350 \pm 0.005 \mathrm{sec}$. (The peak was at $1.30 \mathrm{sec}$.)

The fuel pin was centered on Column 8, although Column 9 indicates overlap. The detectors whose data are shown were in Rows $2-9$ of Column 8. Detectors 13 and 62 were above the original fuel location (compare Fig. VIII.11). Thus the positive movement in the top two detectors indicates movement into the expansion region, while the original fuel undergoes dilution. This initial phase of activity appears to subside at about $1.45 \mathrm{sec}$.

Just after $1.45 \mathrm{sec}$, there are some coherent activities of the various channels that suggest rapid expulsion upward of fuel, exiting past the top two detectors at about $1.48 \mathrm{sec}$. At about $1.49 \mathrm{sec}$, there might have been a refilling of the fuel pin through collapse of the expanded fuel column; this might have generated another surge at $1.50 \mathrm{sec}$, leading to expulsion past the top at about $1.52 \mathrm{sec}$. From then on, fuel was apparently being expelled continuously, possibly through a breach in the cladding.

Figure VIII.12 shows the time history of most of the detectors in Rows 10-19 of Column 8, where Detector 192 is at the bottom of the pin.

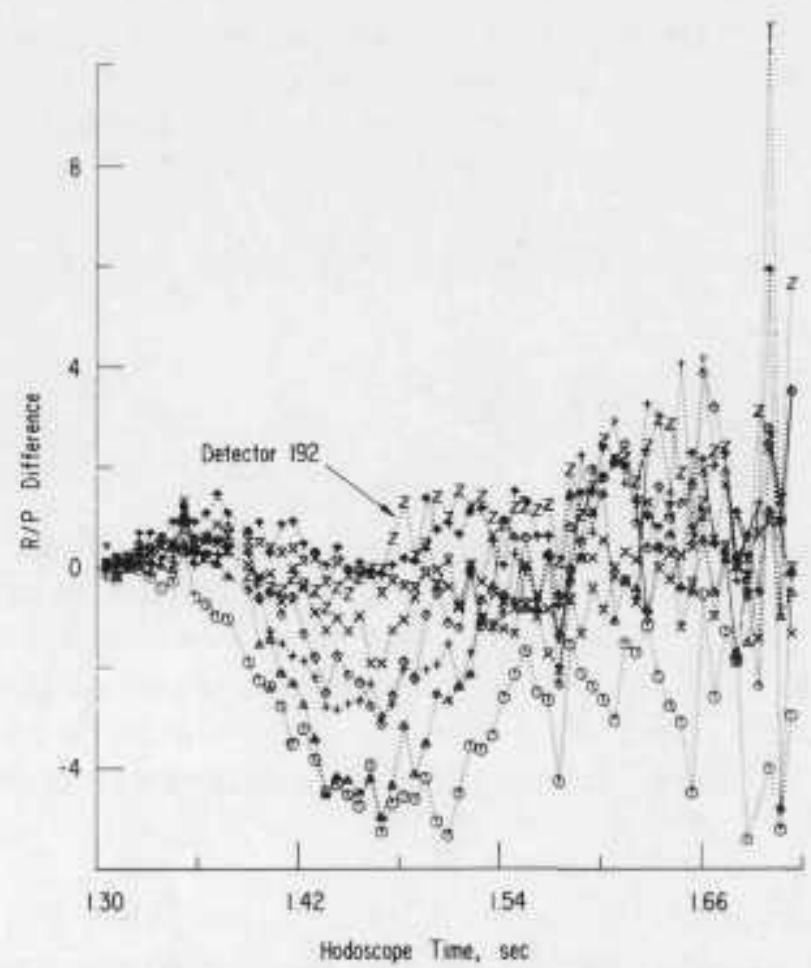

Fig. VIII.12. Normalized Countrate History for Detectors Focused in the Lower Half of Column 8
Observe that there is evidence only of fuel loss, with the predominant and initial losses coming from the uppermost detectors. The lowermost detectors, aimed where the pin is coolest, show little or no loss of fuel.

The data from the top of Column 9 (Fig. VIII.13), with detectors in Rows 3-8, support the initial expansion at $1.35 \mathrm{sec}$. Comparison of Detectors 70 and 169 (Rows 4 and 5) indicates a special phenomenon. The positive rise of Detector 169 might indicate the expulsion of fuel at a height that coincides with the postmortem rupture of the pin.

The time for commencement of this event is as early as $1.32 \mathrm{sec}$. Figure VIII. 14 shows the data from the annular region to the left of the fuel pin (that is, mostly the sodium coolant, although overlapping the fuel of Column 9) from Rows 2-10. 
Actions of some of the detectors are not understood at the moment, but others tend to support the hypothesis that fuel rupture occurred at $1.32 \mathrm{sec}$.

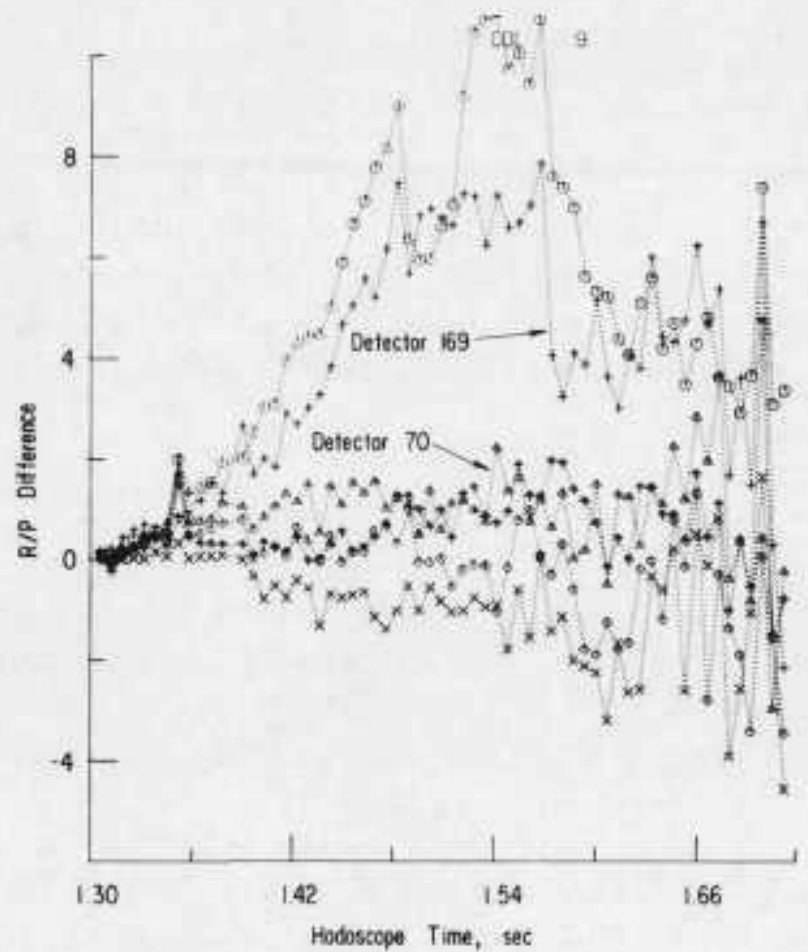

Fig. VIII.13. Normalized Countrate History for Detectors in the Top Half of Column 9. Viewing the sodium coolant region for the most part.

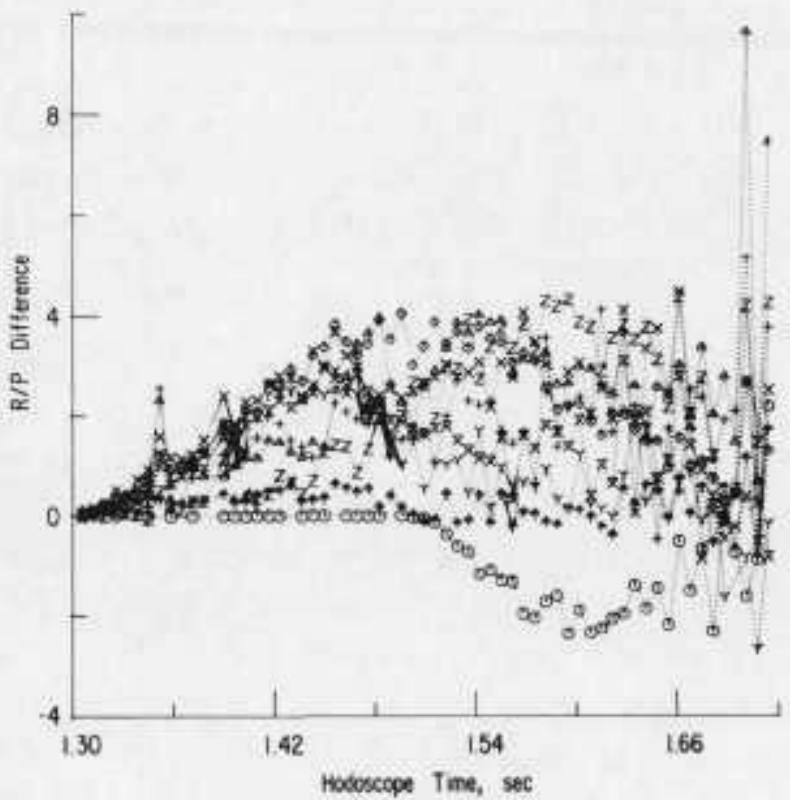

Eig. VIII.14. Nomalized Countrates for Column 10 near the Top: This Column Is Apparently Viewing the Sodium Coolant Region for the Most Part

Studies of other facets of the data are being conducted to interpret the fuel-motion evidence.

\section{b. Analysis of Transient In-pile Experiments}

It has been our experience* that the calculated coolanttemperature profile does not compare satisfactorily at all transient times with the thermocouple measurements, even for a single-pin fuel-dynamics experiment in the TREAT reactor. The comparison does not necessarily become worse for multipin experiments, especially when uncertainties of the extent of coolant mixing are considered. Among other factors, we have attributed this lack of agreement to a nonzero, finite thermocouple-response time. This effect was investigated.

It is assumed that the perturbation caused by a thermocouple is of the first order. The heat balance for the thermocouple can be written as

\footnotetext{
*A. K. Agrawal, C. E. Dickerman, and A. B. Rothman, "Analysis of Fuel Failure Experiments with TREAT," in Proc, of ANS Topical Meeting on New Developments in Mathematical Models and Applications, March 2931, 1971, Idaho Falls, Idaho (to be published).
} 
$\mathrm{wVc} d \mathrm{~T} / \mathrm{dt}=\mathrm{hA}\left(\mathrm{T}_{\mathrm{e}}-\mathrm{T}\right)$,

where $w$ is the specific weight, $V$ is the specific volume, and $c$ is the specific heat, all of the sensor, $h$ is the heat-transfer coefficient, and A the area of the fluid film surrounding it, and $T$ and $T_{e}$ are the thermocouple and the environment temperatures, respectively. Equation 1 can be written as

$$
\frac{\mathrm{dT}}{\mathrm{dt}}=\frac{1}{\tau}\left(\mathrm{T}_{\mathrm{e}}-\mathrm{T}\right)
$$

where $T$ is the first-order thermal time constant, given by

$$
\tau=\mathrm{wVc} / \mathrm{hA} \text {. }
$$

Clearly, $\tau$ depends not only on the design of the thermocouple, but also on the characteristics of the fluid surrounding it. Typically, for groundedjunction-type thermocouples immersed in water, $\tau$ is about $50-60 \mathrm{msec}$ for a sheath diameter of $40 \mathrm{mils}$ (from data sheets of Thermo-Couple Products, Co., Inc., Villa Park, Illinois). In liquid sodium, the response time should be about $25-30 \mathrm{msec}$.

The solution of Eq. 2 is

$$
T(t)=T_{0} \exp \left(-\frac{t-t_{0}}{\tau}\right)+\frac{1}{\tau} \exp \left(-\frac{t}{\tau}\right) \int_{t_{0}}^{t} T_{e}\left(t^{\prime}\right) \exp \left(\frac{t^{\prime}}{\tau}\right) d t^{\prime},
$$

where it is assumed that both the thermocouple and its environment are at thermal-equilibrium temperature $T_{0}$ at time $T_{0}$. Before going into the application of Eq. 4 in TREAT transients, we will consider the simple cases of step and ramp changes.

For a step change, the temperature of the environment is instantaneously changed from $T_{0}$ to another temperature $T_{2} \quad\left(T_{2}\right.$ need not be greater than $T_{0}$ ) at a time of transition $t_{0}$. When this step change of temperature is substituted in the integrand of Eq. 4, we get, after some manipulations,

$$
T_{2}-T(t)=\left(T_{2}-T_{0}\right) \exp \left(-\frac{t-t_{0}}{T}\right),
$$

or alternatively,

$$
T(t)-T_{0}=\left(T_{2}-T_{0}\right)\left[1-\exp \left(-\frac{t-t_{0}}{T}\right)\right] .
$$


In other words, the thermocouple temperature reaches the environment temperature asymptotically. For all practical purposes, the thermocouple

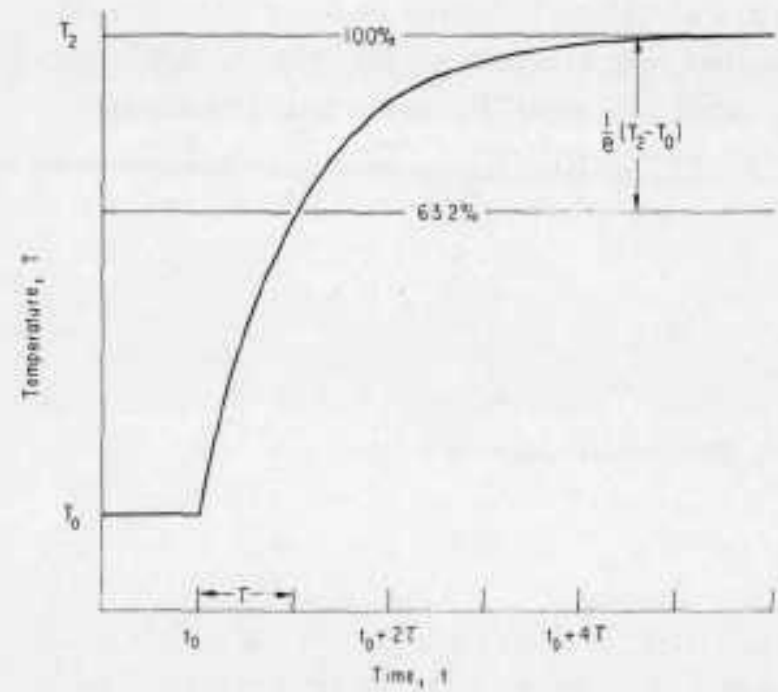

Fig.VIII.15. Thermocouple Response in Step Change temperature is equal to the environment temperature in about $5 \mathrm{~T}$ sec after the step change. Numerical results obtained from Eq. 6 are plotted in Fig. VIII.15. Note that the change in thermocouple temperature reaches $(1-1 / \mathrm{e})$, or $63.2 \%$ of the change in environment temperature, in exactly one $\tau$ time.

For a ramp change, the environment is heated or cooled at a constant rate. A typical example would be a furnace. With to as the time at which both the thermocouple and environment are at an equilibrium temperature $T_{0}$, the environment temperature is then increased linearly as shown in Fig. VIII.16. In other words,

$$
T_{e}(t)=T_{0}+R\left(t-t_{0}\right) \text {, }
$$

where $R$ is the rate of increase. Combining Eqs. 4 and 7 , we get

$$
T(t)=T_{0}+R\left[\left(t-t_{0}-\tau\right)+\tau \exp \left(-\frac{t-t_{0}}{\tau}\right)\right] .
$$

For $\left(t-t_{0}\right) / \tau<<1$, Eq. 8 gives

$$
T(t)=T_{0}+\frac{R}{2 T}\left(t-t_{0}\right)^{2}+\ldots .
$$

Fig. Vய.16

Thermocouple Response to Ramp Change

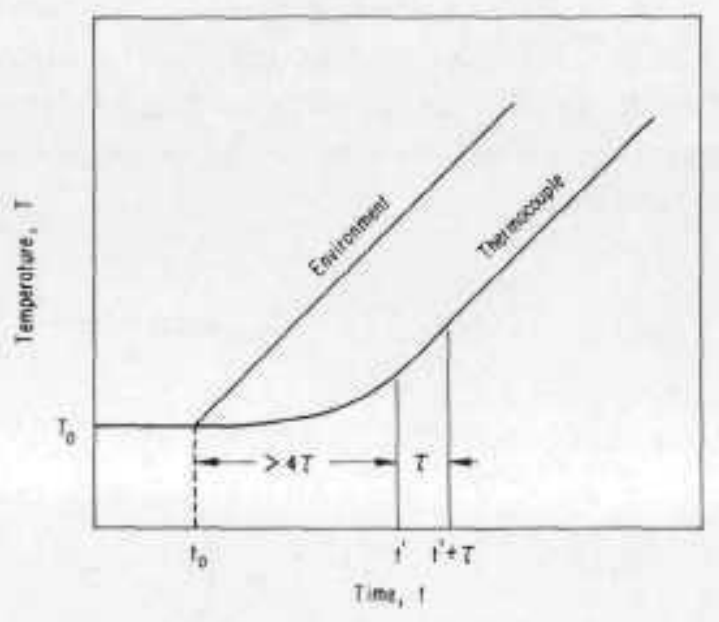


and for large times, i.e., for $\left(t-t_{0}\right) / \tau \gg 1$,

$$
T(t)=T_{0}+R\left(t-t_{0}-\tau\right)
$$

Equations 9 and 10 show that for short times, $T \approx T_{0}$, and for long times, $\mathrm{T}(\mathrm{t})$ differs from the environment temperature by a "delay" time of $T$. Detailed results of Eq. 8 are shown in Fig. VIII.16. It is seen that, for all practical purposes, Eq. 10 is applicable for $\left(t-t_{0}\right)$ greater than $4 T$.

Unfortunately, neither of the two simplified cases is applicable to TREAT transients, because the environment temperature for most transients varies as a polynomial of order higher than one. Therefore, the effect of thermocouple response time has to be evaluated numerically. There are two ways of applying the correction. If the measured record is to be corrected, one can use Eq. 2, which can be rewritten as

$$
T_{e}(t)=T(t)+\tau \frac{d T}{d t},
$$

where $T_{e}(t)$ is the true temperature and $T(t)$ is the thermocouple measurement. This method of correcting the measurements appears to be simple and straightforward, provided that thermocouple readings are noted at time intervals short compared with $\tau$, i.e., in intervals of a millisecond.

In the second method, the calculated temperatures are corrected to evaluate the corresponding temperatures that one expects to compare with the thermocouple readings. In this method, $\mathrm{T}_{\mathrm{e}}(\mathrm{t})$, appearing in Eq. 4 , is replaced by the calculated temperatures. The resulting $T(t)$ 's are then compared with the measurements. The disadvantage of a little more elaborate computation in this method, as opposed to the first one, is more than offset by realizing that the resulting temperature would be free from experimental uncertainties.

A simplified digital-computer program has been written and tested to incorporate the thermocouple time response for TREAT transients. This computer program has been applied to one of the recent Mark-II-loop fuel-dynamics experiments (E3). Because digitized temperature records were available only at time intervals comparable to $\tau(30 \mathrm{msec})$, the SAS1AASH-code-calculated temperatures for this experiment were corrected. Results for both the "checkout" and "failure" transients (No. 1321 and 1322, respectively) are shown in Figs. VIII.17 and VIII.18. For the checkout transient, the agreement between calculation and measurements is slightly improved. Further discrepancy has yet to be accounted for. For the failure transient, the agreement was improved markedly. 


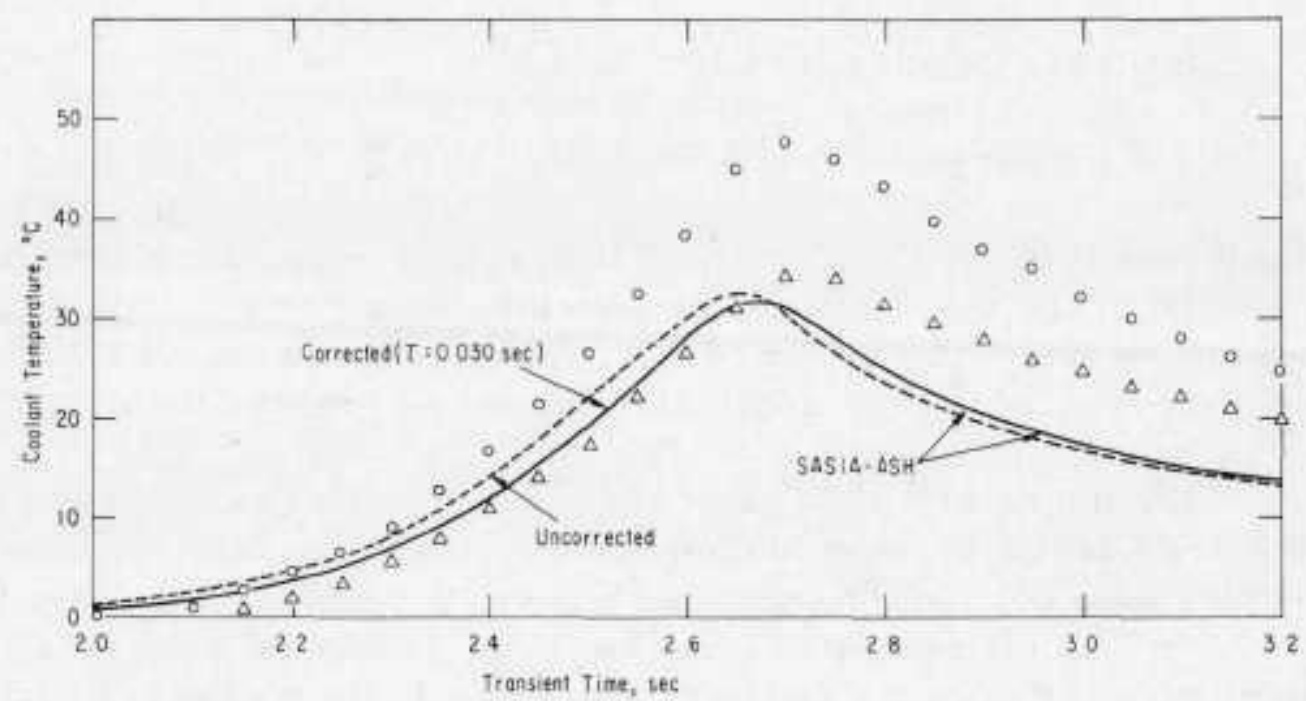

Fig. VIII.17. Corrected and Uncorrected SASIA-ASH Calculations Compared with Measured Rise in Coolant Temperature for Checkout Transient 1321 Preceding Test E3

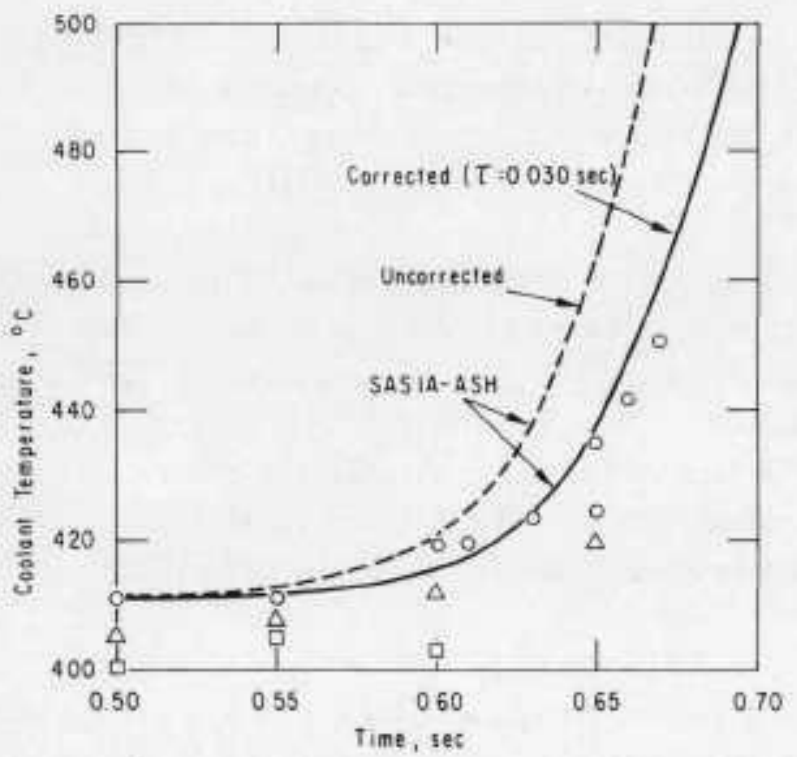

Fig. VHI.18

Corrected and Uncorrected SAS1A-ASH Calculations Compared with Measured Coolant Temperatures for Test E3 (T ransient 1322)

4. Hot Laboratory Examinations. W. F. Murphy (Last reported: ANL-7742, p. 140, Sept 1970)

\section{a. Examination of Pins after TREAT Tests}

Scanning-electron microscopy (SEM) has been used to examine the thin layer of $\mathrm{UO}_{2}$ fuel remaining against the cladding in fuel element 2R-1 from Test E2. (See ANL-7737, p. 116, and ANL-7742, p. 102.)

A section, about $3 / 4$ in. long, from the bottom of the element was cut longitudinally to expose the layer of fuel against the inside of the 
cladding. Some of the fuel broke away as a result of the sawing operation. Visual examination revealed that the fuel adhered tightly to the cladding in some locations but did not contact the cladding in other locations. The fuel, which consists of two layers, was 10-12 mils thick. The layer adjacent to the cladding has the appearance of unrestructured fuel (see Fig. VIII,19a). Above the layer of unrestructured fuel is a thicker layer of columnar grains. The unrestructured layer was practically nonexistent in some areas, but as thick as 2.5 mils in others. The columnar grains generally appeared to be perpendicular to the cladding, although a bias of perhaps $5^{\circ}$ off perpendicular was noted in some places. Figure VIII, $19 \mathrm{~b}$ shows the considerable porosity in the layer of unrestructured grains and the high density of the columnar grains.

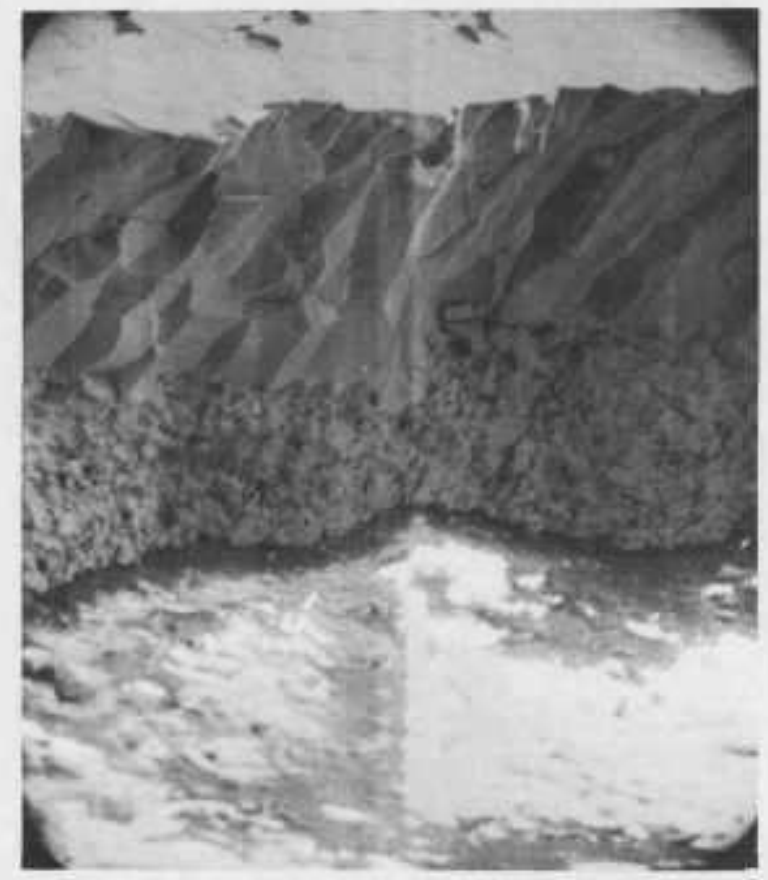

(a)

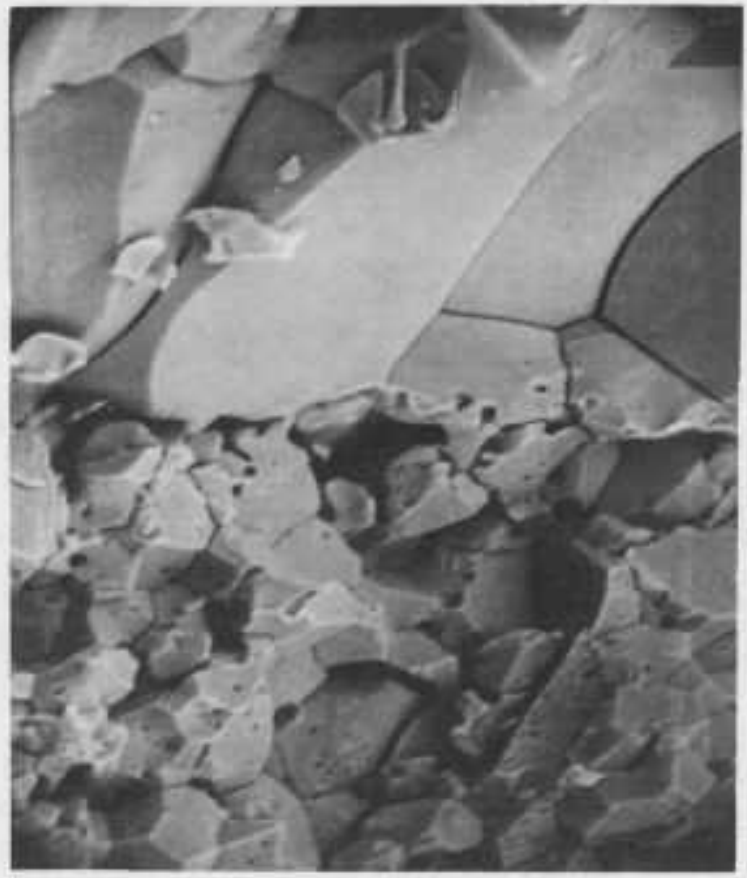

(b)

Fig. VIII.19. SEM Photographs Showing the Nature of the Two Layers of $\mathrm{UO}_{2}$ Fuel against the Cladding.

(a) Mag. $170 \mathrm{X}$. Neg. No. MSD-54656. (b) Mag. 850X. Neg. No. MSD-54653.

The inner surface of the columnar grains (away from the cladding) had a dark, somewhat glassy appearance. The surface was not smooth, and obvious variations in the thickness of the fuel layer existed. In the section examined, a valley in the inner surface appeared along the length of the section with terraces on either side of the valley. The terraces shown in Fig. VIII.20a are sometimes outlined by small dimples along their base. Some bubbles were observed on the inner surface of the fuel (Fig. VIII.20a), and as a group they appeared to have a longitudinal orientation. Some of the bubbles were broken. Figure VIII.20b shows the ends of the columnar grains of the region under a broken bubble. There is evidence, between the grains, of chimneys that provided paths for the gas that 
formed the bubbles. This gas was probably contained within the pores of the original fuel. A very thin layer of fuel material overlays the ends of the columnar grains on the inner surface of the fuel.

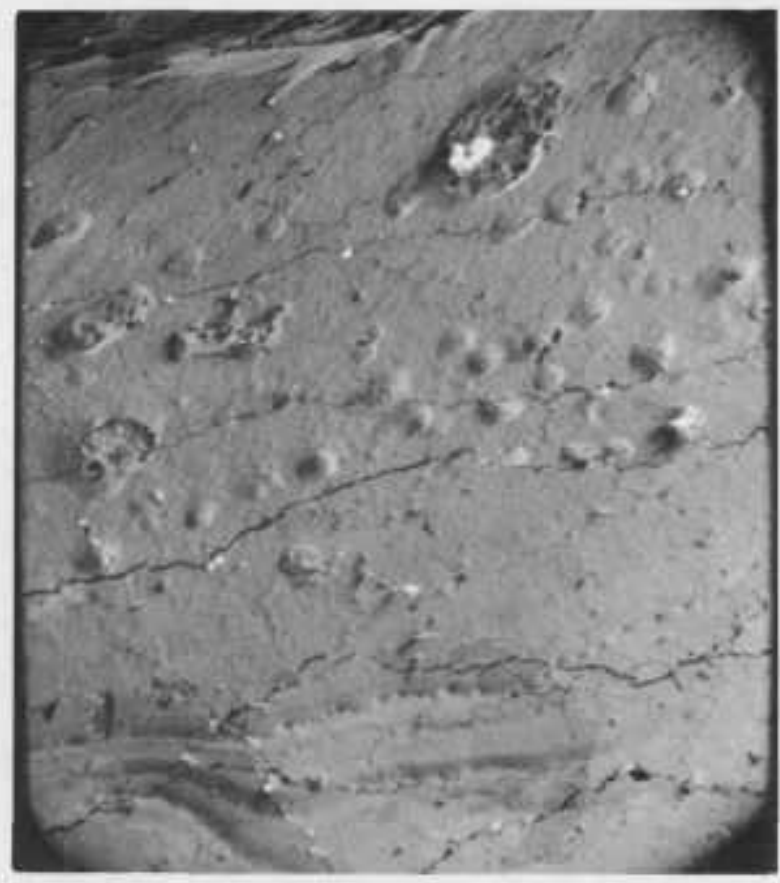

(a)

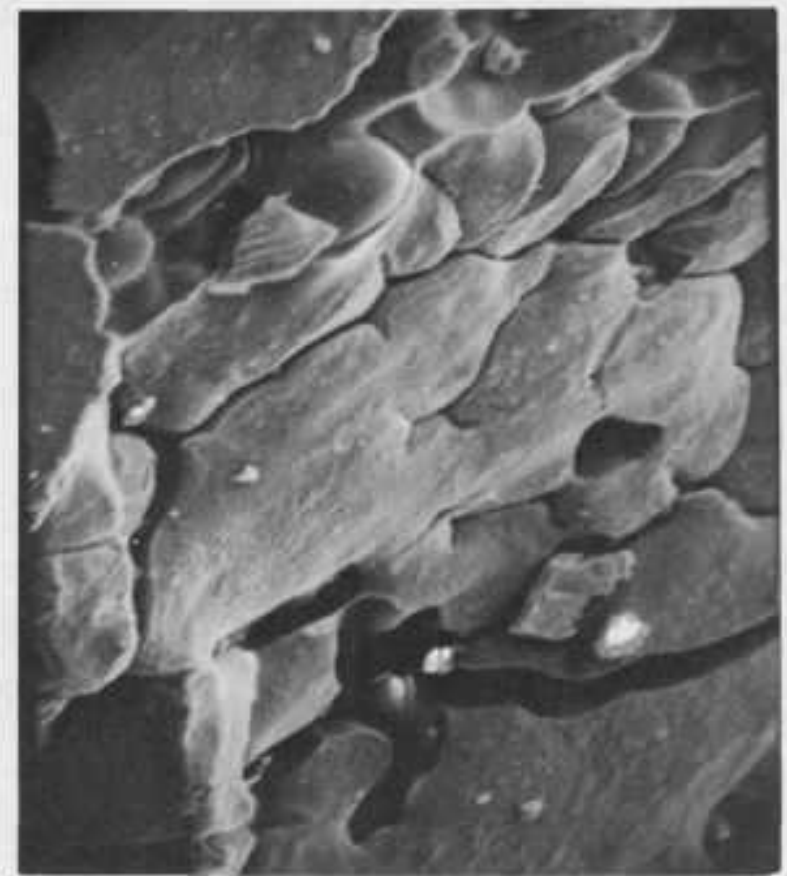

(b)

Fig. VHI.20. SEM Photographs of the Inner Surface of the Layer of Fuel Showing Terraces and Bubbles. A broken bubble is shown in (b). (a) Mag, 42,5X. Neg. No. MSD-54655. (b) Mag. 850 X. Neg. No. MSD-54654.

In conclusion, the local variations in temperature that occured in the fuel remaining in the bottom of the element determined the thickness of the unrestructured fuel and the columnar-grain layer. The layer of unrestructured fuel appeared to be thicker where the fuel adhered tightly to the cladding. It is presumed that the initial contact between the fuel and the cladding at the time of the transient was an important factor in the resulting thickness of the unrestructured fuel.

The irregularities on the inner surface of the fuel could also be indicative of temperature fluctuations during solidification, perhaps because of turbulence during the expulsion of most of the fuel. The poor heat transfer noted under the spacer wire at the top of the fuel element could not be correlated with the temperature differences detected on the specimen.

In view of the bubbles on the inner surface of the fuel, it would seem that solidification took place from the unrestructured fuel toward the center of the element. This would preclude the idea of a quenching action by coolant flowing into the element to replace the expelled fuel. 
5. Idaho Loop Operations. D. Mitchell (Not previously reported)

The transfer-port assembly for connecting the Mark-II loop to the TREAT-loop glovebox at FEF (see ANL-7798, p. 124) was received at the FEF. After the glovebox in FEF Room 22 was modified, the transfer-port assembly and associated loop support table were installed. To perform a complete checkout, an empty Mark-II loop was used to train the technicians and to guide the preparation of an operating procedure. The loop was retained at the Idaho Site for use in the L2 calibration run at TREAT.

A glovebox window (removed to install the port assembly) and new gloves are being installed on the glovebox. When this work is complete. the glovebox will be helium-leaktested and filled with an argon atmosphere. The out-of-cell criticality document, which includes the criticality rules for the glovebox, has been written; when it is approved by OTD, the glovebox will be ready for use. 
E. High-temperature Physical Properties and Equation-of-state of Reactor Materials. M. G. Chasanov (02-119)

1. Theoretical Extrapolation of Measured Physical Properties to Very High Temperatures. M. G. Chasanov (Last Reported: ANL-7783, p. 106)

Preliminary studies of the effect of fission-product vapor pressures on FFTF disassembly calculations indicate that the vapor pressures of fuel and fission-product species play an important role in determining the amount of energy released in the coastdown design-basis accident, particularly for mild excursions (J. F. Jackson and R. B. Nicholson, ANL-Idaho, unpublished results). It is important, therefore, to determine with reasonable accuracy the total vapor pressure above the fuel-fission product system.

At temperatures above $4000-5000^{\circ} \mathrm{K}$, we have estimated the partial pressure of the fuel species to be the most significant contributor to the total pressure; we are engaged in an experimental program (matrix isolation spectroscopy) to provide data that will improve the accuracy of the calculated thermodynamic properties of fuel vapor species and of their vapor pressures. Because the experimental program does not provide data for dissociated or ionized species, calculations of the extent of dissociation and ionization have been carried out as described below. It can be concluded from the computations that thermal ionization is negligible up to at least $6000^{\circ} \mathrm{K}$. Further, calculations of relative concentrations of U, UO, $\mathrm{UO}_{2}, \mathrm{UO}_{3}, \mathrm{O}$, and $\mathrm{O}_{2}$ indicate that the molecular species predominate when all species are in equilibrium with condensed fuel.

Equilibrium constants between the various oxide vapor species and uranium ( $\mathrm{g}$ ) and oxygen used in these calculations were based on Schick's* estimated free energies of formation and the free-energy change for the dissociation of diatomic oxygen into oxygen atoms. Mass constraints on the total amounts of uranium and oxygen in the system allow a solution of the system of equations. The calculations were carried out for vapor phase $0 / M$ ratios of 2 and 3 , since the vapor is expected to become increasingly oxygen-rich with increasing temperature. Because of the uncertainty in the total pressure of uranium-bearing species at elevated temperature, the calculations have been carried out at several pressures in the range of the estimated pressures proposed by others for each temperature. Table VIII. 8 shows that the maximum fractions of uraniumbearing species represented by uranium, itself, are $0.7,3.6$, and $9.8 \%$ at 4000,5000 , and $6000^{\circ} \mathrm{K}$, respectively.

Equilibrium constants for the ionization of UO to $\mathrm{UO}^{+}+\mathrm{e}^{-}$have been calculated as $9.2 \times 10^{-5}, 5.2 \times 10^{-3}$, and $8.4 \times 10^{-2}$ at 4000,5000 , and $6000^{\circ} \mathrm{K}$, respectively, based on an ionization potential of $5.7 \mathrm{eV}$ (133 kcal). The

\footnotetext{
*H, L. Schick, Thermodynamics of Certain Refractory Compounds, Vol. II, Academic Press, New York (1966).
} 
free-energy functions of $\mathrm{UO}(\mathrm{g})$ and $\mathrm{UO}^{+}(\mathrm{g})$ have been assumed to be equal, except for the electronic contributions. These have been calculated on the basis of $T h(I)$ and $T h(I I)$ electronic energy levels, respectively. For typical UO partial pressures of $1 \mathrm{~atm}$ at $4000^{\circ} \mathrm{K}, 10 \mathrm{~atm}$ at $5000^{\circ} \mathrm{K}$, and $100 \mathrm{~atm}$ at $6000^{\circ} \mathrm{K}$, the fraction thermally ionized is calculated to be $1,2.3$, and $2.9 \%$, respectively. Similar results are expected for $\mathrm{UO}_{2}$ (having an ionization potential of $5.5 \mathrm{eV})$. The much higher ionization potential of $\mathrm{UO}_{3}(\sim 10 \mathrm{eV})$ is expected to result in completely negligible ionization of that species.

TABLE VIII.8. Partial Pressure of Fuel Vapor Species at Elevated Temperatures

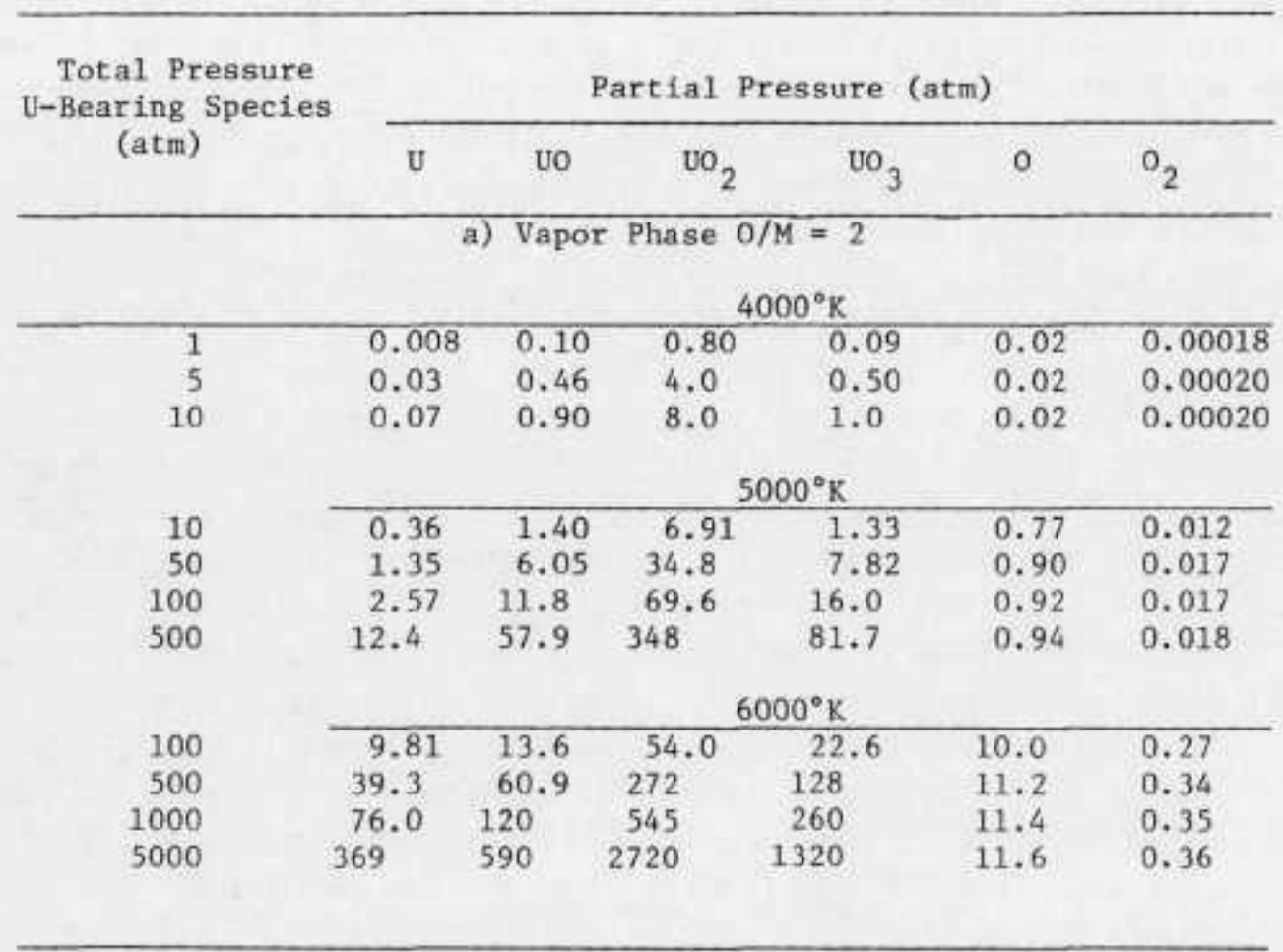

b) Vapor Phase $0 / M=3$

\begin{tabular}{|c|c|c|c|c|c|c|}
\hline & \multicolumn{6}{|c|}{$4000^{\circ} \mathrm{K}$} \\
\hline 1 & 0.00002 & 0.003 & 0.36 & 0.63 & 0.29 & 0.04 \\
\hline 5 & 0.000009 & 0.004 & 1.03 & 3.97 & 0.65 & 0.19 \\
\hline \multirow[t]{2}{*}{10} & 0.000008 & 0.004 & 1.59 & 8.40 & 0.89 & 0.36 \\
\hline & \multicolumn{6}{|c|}{$5000^{\circ} \mathrm{K}$} \\
\hline 10 & 0.008 & 0.17 & 4.72 & 5.10 & 4.31 & 0.38 \\
\hline 50 & 0.004 & 0.22 & 14.0 & 35.8 & 10.2 & 2.14 \\
\hline 100 & 0.003 & 0.24 & 21.9 & 77.8 & 14.2 & 4.14 \\
\hline \multirow[t]{2}{*}{500} & 0.002 & 0.34 & 61.4 & 438 & 28.5 & 16.8 \\
\hline & \multicolumn{6}{|c|}{$6000^{\circ} \mathrm{K}$} \\
\hline 100 & 0.50 & 2.57 & 38.0 & 59.0 & 37.2 & 3.69 \\
\hline 500 & 0.30 & 3.39 & 112 & 385 & 82.7 & 18.2 \\
\hline 1000 & 0.25 & 3.85 & 174 & 822 & 114 & 34.3 \\
\hline 5000 & 0.18 & 5.40 & 482 & 4510 & 225 & 134 \\
\hline
\end{tabular}


F. Fuel-Coolant Interactions. R. W. Wright (02-164)

1. Out-of-Pile Contacting Studies. D. R. Armstrong

a. Pressure Generation by Injection of Small Quantities of Sodium into $\mathrm{UO}_{2}$ and Stainless Steel (Not reported previously)

An experiment has begun to measure the pressures and mechanical work produced by the injection of small quantities of sodium into molten $\mathrm{UO}_{2}$. This experiment is an extension to reactor materials of the investigation of the injection and entrapment mode of molten fuel-coolant interactions that has previously been performed by injecting water into molten sodium chloride at $900^{\circ} \mathrm{C}$. * Mechanical work as high as $20 \%$ of that thermodynamically possible has been observed in these latter experiments. The present experiment will determine whether similar energetic interactions can occur in the molten $\mathrm{UO}_{2}$-sodium system. This experiment can also be regarded as an extension to another mode of $\mathrm{UO}_{2}$-sodium contact of the previous smallscale experiments in which molten $\mathrm{UO}_{2}$ is dropped into sodium.**

A system for injecting sodium into molten $\mathrm{UO}_{2}$ and stainless steel has been assembled and is being tested. The device, shown schematically in Fig. VIII.21, allows several modes of operation. The sodium pump and furnace and the inductively heated crucible containing the molten materials are in a helium furnace chamber equipped with quartz viewports. The sodium is contained in a stainless steel bellows (i.e., a sodium pump) that connects to the injection tube initially located within the sodium furnace. When the molten material reaches the desired temperature, the sodium pump is driven downward so that the injection tube extends out of the furnace to a predetermined point, either above or below the surface of the molten material. The bellows is then compressed, either by gas pressure or by hydraulic drive through the connecting rod, expelling the sodium through the injection tube.

A blast microphone for measuring the overpressure of the interaction is suspended above the crucible, and the crucible itself is connected to a force transducer to measure the reaction force produced by the explosion. The mechanical work is calculated from the total impulse and the mass of the ejected material.

The system can be operated with sodium temperatures ranging from the melting point $\left(100^{\circ} \mathrm{C}\right)$ to above $600^{\circ} \mathrm{C}$ with injection velocities from 0.35 to $35 \mathrm{~m} / \mathrm{sec}$, and with total volume of sodium from 1 to $5 \mathrm{~cm}^{3}$.

*R. P. Anderson and L. Bova, Experimental Investigation of Vapor Explosions in a Molten Salt-Water System, Trans. Am. Nuc1. Soc., 14 (June 1971); ANL-7742, P. 149.

** D, R, Armstrong, F. J. Testa, and D. Raridon, Jr., Molten UO ${ }_{2}$-Sodium Dropping Experiments, Trans. Am. Nuc1. Soc., 13, p, 660 (Nov 1970). 
Parameters to be investigated include sodium temperature, mass-ratio of the interacting sodium and $\mathrm{UO}_{2}$, and the coolant injection rate.

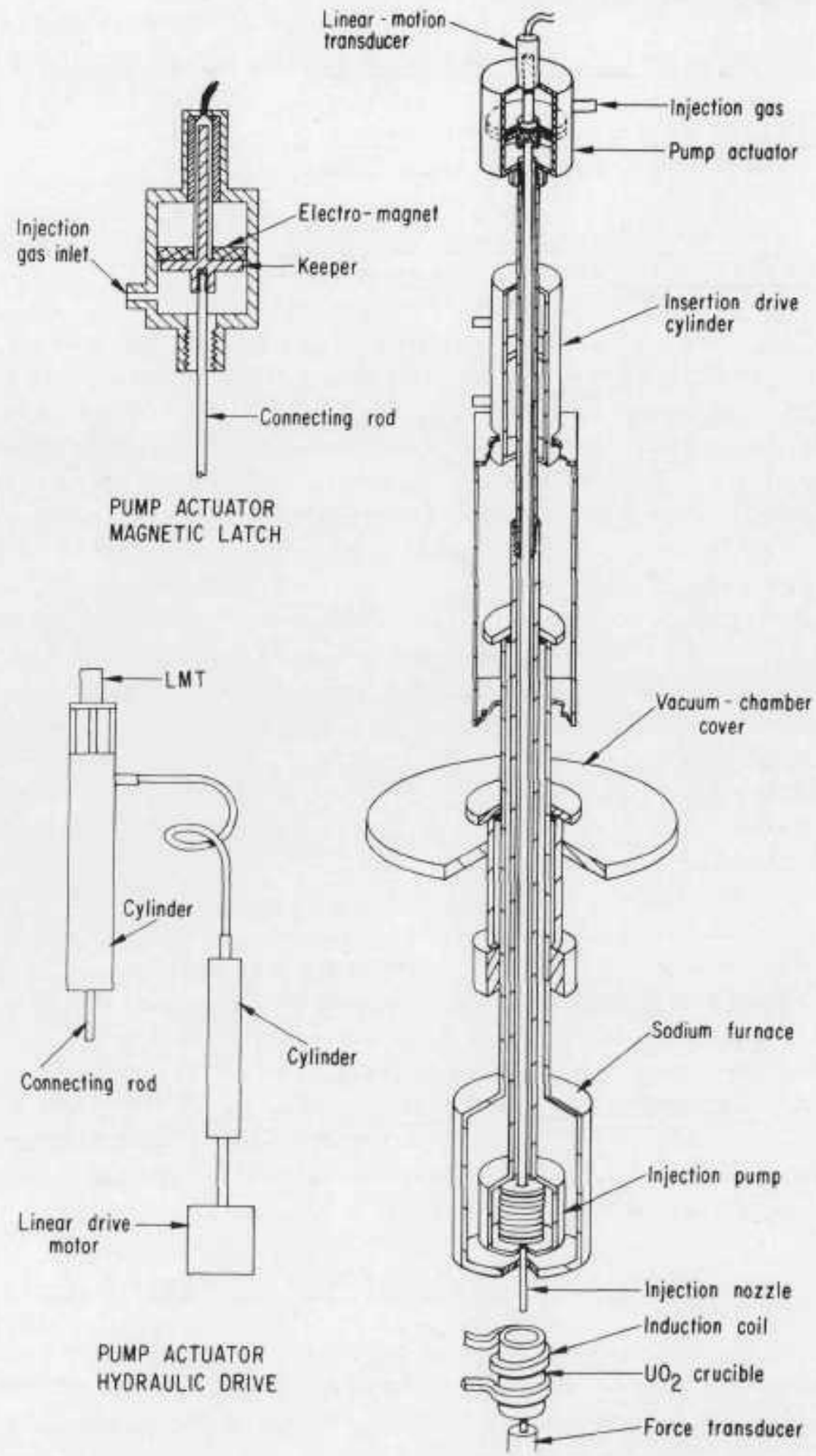

Fig. VIII.21. System for Injecting Sodium into Molten $\mathrm{UO}_{2}$ and Stainless Steel 
The first experiment will involve injection of $5 \mathrm{~cm}^{3}$ of sodium at $200^{\circ} \mathrm{C}$ into $50 \mathrm{~g}$ of molten $\mathrm{UO}_{2}$. A similar experiment will later be performed on sodium injection into molten stainless steel.

\section{G. Post-accident Heat Removal. L. Baker (02-165)}

1. Core-debris Retention within the Reactor or Guard Vessel. J. Hesson and E. Sowa (Last Reported: ANL-7776, p. 122)

a. Simulation Experiments to Verify Heat-transfer Model for Pools with Internal Heat Generation

The model for heat transfer in a molten pool of fuel debris (see ANL-7688, p. 244) is based on the formation of a stagnant inversion layer at the bottom of the pool and the assumption that the induced circulation or eddies in the inversion layer, due to convection in the upper part of the pool, is negligible. To verify this assumption, simulation experiments are being conducted. The experiments use electrical-resistance heating of salt water in suitable containers. Scoping experiments were conducted by using 5.75-in.-wide $\times 9.25$-in.-long $\times 6.5$-in.- deep inside rectangular allglass containers with copper electrodes at each end. Power inputs of up to $2.2 \mathrm{~kW}$ were used. The bubble formation and boiling were predominantly in the upper part of the pool; although vigorous boiling took place, the lower inversion layer remained undisturbed, as noted by movement of sediment particles. High-speed motion pictures of the boiling phenomena were taken. Although heat removal from the bottom was slight due to the construction of the vessel and a tendency for the glass to crack, thermocouple temperature probing indicated an inversion layer.

A more suitable container, consisting of 6-in.-square copperelectrode ends, 8.5 in. apart, double Pyrex glass (with air space for thermal insulation) sides and a water-cooled copper bottom, electrically insulated from the salt water by a Pyrex glass plate, was constructed and tested. For given bottom-plate and pool temperatures, the heat-transfer rate through the bottom can be varied by varying the thickness of the glass plate. Tests will be made in which the power input, heat transfer from the bottom and top, and temperatures in the inversion layer will be measured and compared to values computed from the model.

b. Heat Transfer through $\mathrm{UO}_{2}$ Particle Beds in Sodium

Heat transfer from fixed beds of $\mathrm{UO}_{2}$ particles on flat plates in sodium can be computed. In the case where the sodium is boiling, a method to compute heat transfer due to boiling convection has been given (see ANL7758, p. 121). 
In the case where the sodium is subcooled and the maximum temperature in the fixed bed at the plate is the boiling temperature $\left(900^{\circ} \mathrm{C}\right.$ at $1.18 \mathrm{~atm}$ ) of sodium, the heat transfer from a bed of particles with internal heat generation to the overlying subcooled sodium is

$$
Q=\left[2 \mathrm{k}(1-\epsilon) \mathrm{Fq}\left(900-\mathrm{T}_{\mathrm{S}}\right)\right]^{1 / 2} \mathrm{cal} / \mathrm{sec}-\mathrm{cm}^{2}
$$

and

$$
k=k_{s}\left[1-\frac{(1-\epsilon)\left(1-k_{f} / k_{s}\right)}{k_{f} / k_{s}+(1-\epsilon)^{1 / 3}\left(1-k_{f} / k_{s}\right)}\right] \mathrm{cal} / \mathrm{sec}-\mathrm{cm}-{ }^{\circ} \mathrm{C} \text {, }
$$

where $\mathrm{k}$ is the thermal conductivity of bed in cal $/ \mathrm{sec}-\mathrm{cm}-{ }^{\circ} \mathrm{C}, \mathrm{k}_{\mathrm{s}}$ is the thermal conductivity of sodium in cal $/ \mathrm{sec}-\mathrm{cm}-{ }^{\circ} \mathrm{C}, \mathrm{k}_{\mathrm{f}}$ is the thermal conductivity of particles in $\mathrm{cal} / \mathrm{sec}-\mathrm{cm}-{ }^{\circ} \mathrm{C}, \epsilon$ is the bed porosity, $\mathrm{F}$ is the volume fraction of particles that are fuel, $q$ is the decay heating in the fuel in cal $/ \mathrm{sec}-\mathrm{cm}^{2}$, and $\mathrm{T}_{\mathrm{S}}$ is the sodium pool temperature, ${ }^{\circ} \mathrm{C}$.

\begin{tabular}{|c|c|c|c|c|}
\hline \multirow[b]{2}{*}{$E$} & \multicolumn{2}{|c|}{$\mathrm{UO}_{2} \mathrm{Bed}$} & \multicolumn{2}{|c|}{$50 \% \mathrm{UO}_{2}-50 \%$ SS Bed } \\
\hline & $\mathrm{k}$ & $k(1-\epsilon)$ & $\mathrm{k}$ & $k(1-\epsilon)(0.5)$ \\
\hline 0.30 & 0.0330 & 0.0231 & 0.0618 & 0.0216 \\
\hline 0.35 & 0.0380 & 0.0247 & 0.0657 & 0.0214 \\
\hline 0.40 & 0.0431 & 0.0258 & 0.0697 & 0.0209 \\
\hline
\end{tabular}

Values of $k$ for several values of $\epsilon$ are:

In this case, for fuel, $k_{f}=0.005$, and for stainless steel, $\mathrm{k}_{\mathrm{s}}=0.060 \mathrm{cal} / \mathrm{sec}-\mathrm{cm}-{ }^{\circ} \mathrm{C}$. From the above, it is noted that the heat transfer by conduction from particulate beds in subcooled sodium is largely independent of bed porosity, particle size, and fraction of steel particles in the bed, but is quite dependent on the decay-heat generation.

\section{c. Experiments on Heat Transfer through $\mathrm{UO}_{2}$ Particle Beds in Sodium}

For beds of small $\mathrm{UO}_{2}$ particles in sodium, our experiments indicate that the beds have greater porosity than would be expected for normal beds, and that the particles are partially suspended and mobile in the sodium. This should result in greater heat transfer than computed for fixed beds. Tests have been conducted with bottom-heating (gas flame) of $\mathrm{UO}_{2}$ particle beds on flat stainless steel plates. The heat transfer through the bed is measured by the quantity of, and temperature rise of, $\mathrm{NaK}$ circulated in a coil above the bed. $\mathrm{UO}_{2}$ particle sizes of $25-100$, $100-300,300-600,600-1000$, and 100-1000 microns have been used. 
Equipment difficulties have been encountered in attaining high heat-transfer rates through the stainless steel plate into the bed because of the high temperatures and gradients involved and the tendency of the plates to crack due to the temperature gradients.

Although limitations on heat-transfer rates so far have been in the equipment rather than in bed dryouts, heat-transfer rates of 197,000 and $185,000 \mathrm{Btu} / \mathrm{hr}-\mathrm{ft}^{2}$ have been attained for beds of about $20 \mathrm{~g} \mathrm{UO} / \mathrm{cm}^{2}$ cross section with particle sizes of 300-600 and 100-1000 microns, respectively. These heat-transfer rates are greater than those computed for fixed beds of these weights and particle sizes by either the boilingconvection or subcooled-conduction models. This indicates high porosity, movement, and partial suspension of the beds in boiling sodium. Radiographs of the beds indicate high porosity.

The bottom-heating experiments were conducted at this time because simulation of internal heat generation in the $\mathrm{UO}_{2}$ bed requires inpile tests (such tests are being considered). Greater heat transfer, from a given bed on a plate in sodium, could probably be attained with internal heat generation in the bed than with bottom heating. Thus, the bottomheating experiments would be conservative and set a minimum value of heat transfer to be expected for internal heat generation.

\section{H. TREAT Operations. J. F. Boland (02-122; last reported, ANL-7798, p. 132)}

\section{Operations}

Experiment HEDL PNL-2-10 was subjected to a second test transient after a review of posttransient neutron radiographs and heat-transfer calculations showed that the fuel had not reached the desired temperature during the first test. Experiment HEDL PNL-1-7 was subjected to a test transient almost identical to the second test transient on experiment PNL2-10. Annular-pellet-type fuel clad in stainless steel was tested in both experiments, but experiment PNL-2-10 had been preirradiated to 43. $5 \mathrm{MWd} / \mathrm{kg}$ burnup in EBR-II, while experiment PNL-1-7 had been preirradiated to only $8.9 \mathrm{MWd} / \mathrm{kg}$ in EBR-II. These experiments have been neutron-radiographed and returned to HEDL for examination.

Experiment HEDL PNL-59-8 was received and neutron-radiographed.

Experiment GE-C4H was returned to GE for examination. Experiment GE-C4G, which contained a fuel sample similar to that of $\mathrm{C} 4 \mathrm{H}$, was received, transient-tested at a slightly higher power level than $\mathrm{C} 4 \mathrm{H}$, neutron-radiographed before and after the test, and returned to GE for examination. 
A steady-state calibration run was made on a Mark-I sodium loop that contained foils covered with various neutron-filter materials. Data from this run will be used to help determine which type of filter material should be used for future transient tests planned for EBR-II driver fuel.

A steady-state calibration run was made before experiment ANL RAS-S7 for radiochemical determination of the relationship between TREAT energy release and sample energy release. Experiment S7 was assembled, neutron-radiographed, and transient-tested. This was the first experiment in the piston autoclave using a seven-pin cluster of prototype FFTF fuel; the sodium was at an initial temperature of $500^{\circ} \mathrm{C}$.

Neutron radiographs were made of EBR-II driver-fuel elements, a melt-wire temperature indicator, new experimental capsules, and experimental capsules from Subassembly X108. Neutron radiographs were also made of an ORNL experiment at the end of its irradiation cycle in ETR.

\section{a. Automatic Power Level Control System}

The first flattop transient was run under computer control at an average power of $50 \mathrm{MW}$, and the control-system response was close to that predicted from computer-simulation studies. The reactor power was held constant within $1 \mathrm{MW}$ for $2.7 \mathrm{sec}$ until the test was terminated at an energy release of $152 \mathrm{MW}-\mathrm{sec}$. The approach to power was made on a 0.2 - sec period with the control system operating in the period-control mode. The transfer from period control to power-level control was made within $0.2 \mathrm{sec}$ without exceeding a power level of $52 \mathrm{MW}$.

Following some minor system modifications required by AECRDT to improve administrative control over the computer system, AEC approval for routine testing under computer control was received. Plans were made for using computer control for transient testing of experimental HEDL PNL-59-8.

I. Reactor System and Containment Structural Dynamic Response.

$$
\text { S. H. Fistedis }(02-126)
$$

1. Hydrodynamic Response of Primary Containment to High-energy Excursion. Y. W. Chang

a. Parametric Studies of System Geometries and Excursion Magnitudes and Durations to Assist FFTF Accident Analysis (Last reported: ANL-7798, p. 133)

The coolant-slug impact accident reported previously (see ANL-7726, p. 168 , and ANL-7776, p. 124) has been reexamined with new input data: $97-\mathrm{ft} / \mathrm{sec}$ coolant velocity, 8620 slugs coolant mass, $54.2-\mathrm{MW}$ sec coolant kinetic energy, $3 \frac{3}{8}$-in. vessel-wall thickness, $1,500,000-1 \mathrm{~b}$ plug 
weight, 500-in. ${ }^{2}$ total area of holddown bolts, 200-psig core vapor pressure at time of incipient impact, and 58.2-MW-sec core internal energy. These inputs correspond to the Case B reported previously; Case A was unrealistic and thus was not reexamined. REXCO calculation was terminated at $31.902 \mathrm{msec}$. At that time, slug force has diminished and the system has reached the dynamic equilibrium. Figure VIII. 22 shows the variations of the slug force on the shield plug and various energies, all as functions of time, for the first $30 \mathrm{msec}$. The slug force consists of a large triangularshaped impulse, which lasts for about $2 \mathrm{msec}$, and a long-duration oscillating residual pressure force. The energy transferred to the shield plug from the triangular-shaped impulse was $1.6 \mathrm{MW}-\mathrm{sec}$, and that from the residual pressure force was 9.1 MW-sec. The energy curves enable the energy distribution to be determined at any instant of time. It depicts the strong capability of the REXCO-code system in energy partition. It also shows how the axial kinetic energy of the coolant was transferred first into internal energy of coolant, radial kinetic energy of coolant, and then into strain energy of vessel and energy of plug and bolts. A proper understanding of the energy partition should enable reactor designers to produce a better primary system and containment design.
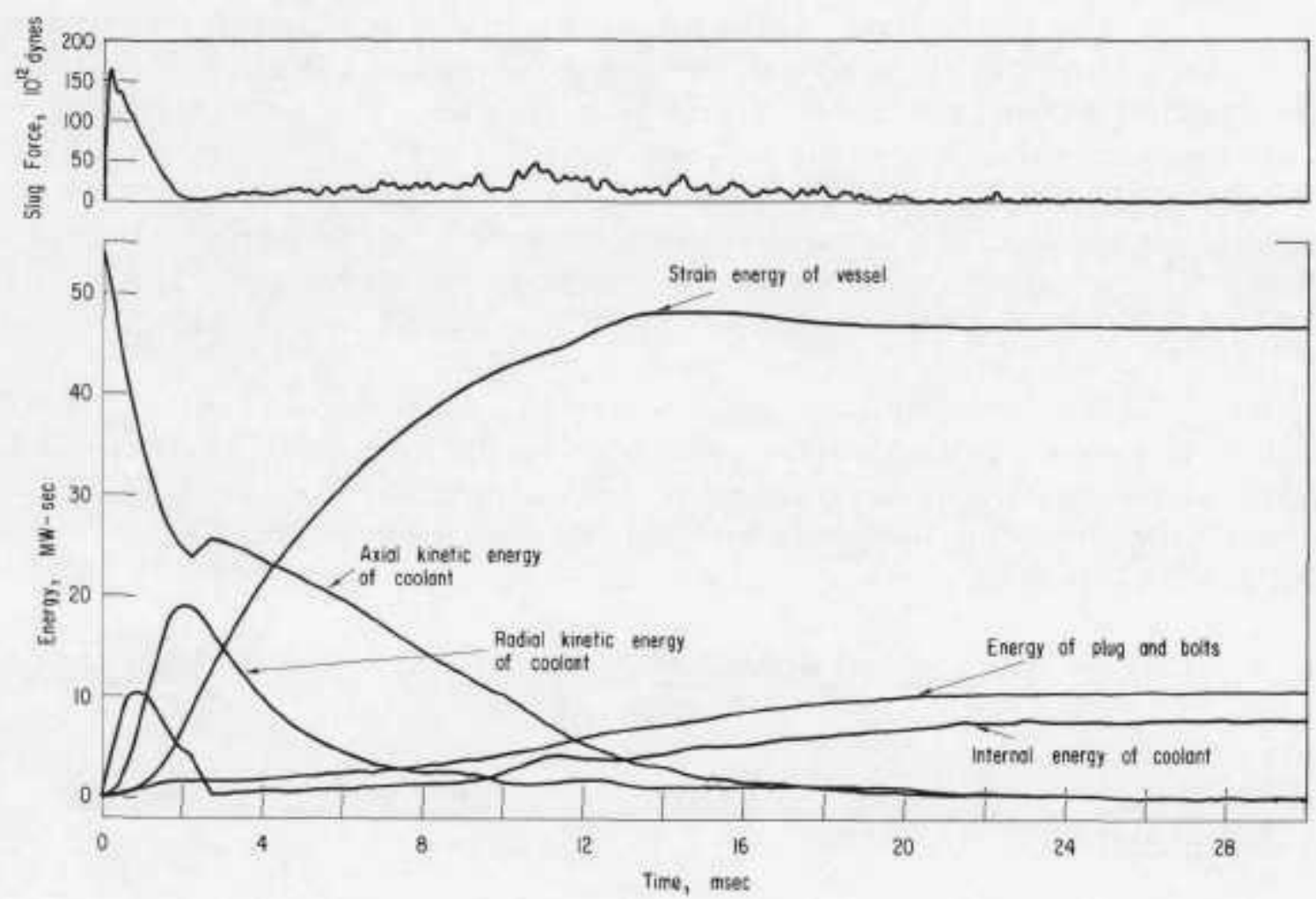

Fig. VII.22. Slug Force and Energy Partition. ANL Neg. No, 900-659 Rev. 1.

To study the effect of two-dimensional calculation on the slug force and energy distribution, the above case was recalculated assuming the vessel wall to be rigid. The slug force is shown in Fig. VIII.23, and 
various energies are shown in Fig. VIII.24. No residual pressure forces were observed in the one-dimensional calculation. The impact was caused by a rectangular-shaped impulse that had the same peak value as the twodimensional calculation and lasted for about $5 \mathrm{msec}$. The energy transferred to the shield plug was $27.60 \mathrm{MW}-\mathrm{sec}$, which was about 2.5 times as large as the two-dimensional calculation. For comparison, the energy curves of the two-dimensional calculation are also shown in Fig. VIII.24. This comparison indicates that a one-dimensional calculation overestimates the impact load and therefore should not be used for determining slug impact in a fast-reactor accident.

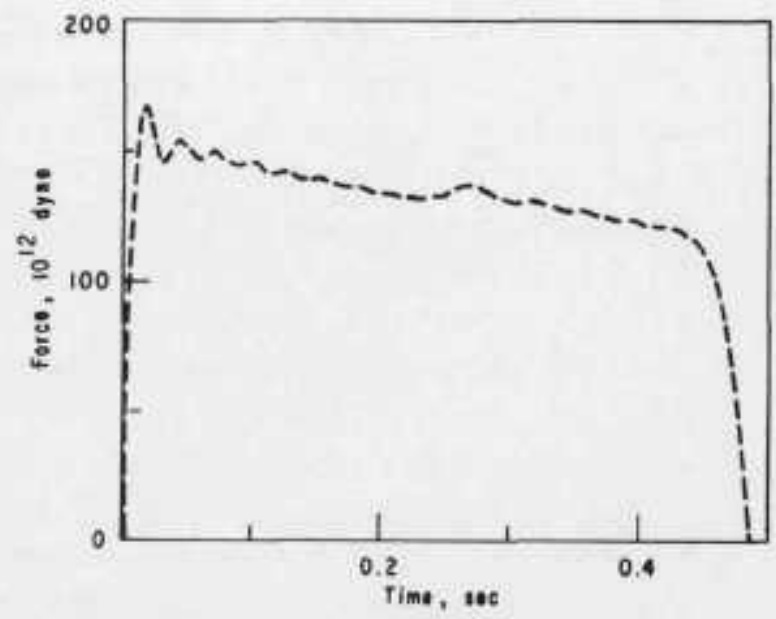

Fig. VIII.23

Slug-impact Force for One-dimensional Case

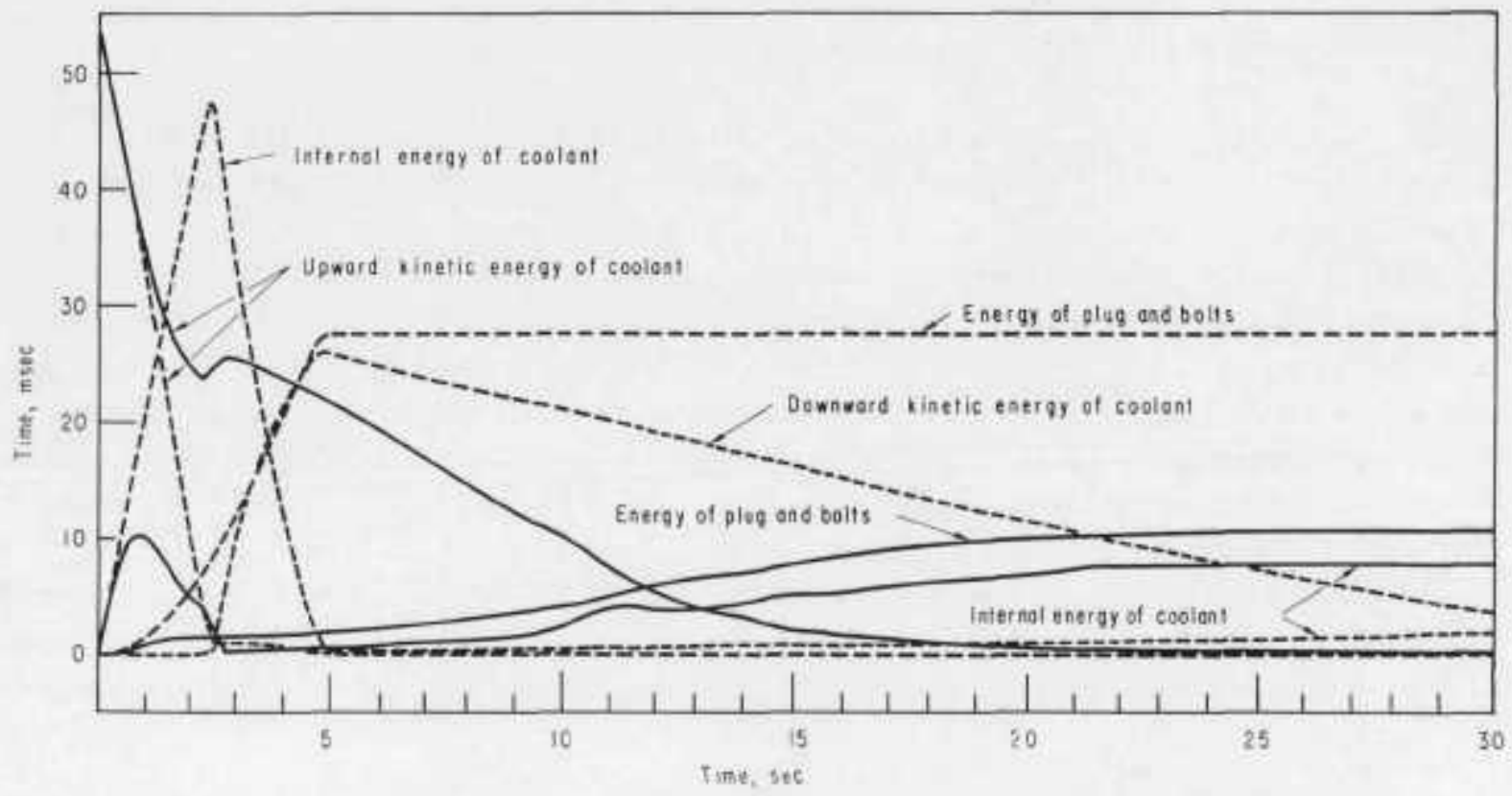

Fig. VIII.24. Comparison of Partition of Energy between One- (broken curves) and Two-dimensional (solid curves) Calculations 


\section{b. Transformation of Code Coordinates from Lagrangian to Eulerian Systems. A. H. Marchertas (Last reported: ANL-7776, p. 125)}

Several example solutions using the Eulerian REXCO-P code are given here to: (1) compare the Eulerian solution with corresponding Lagrangian results, (2) display the performance of the movable-boundary condition of the code, and (3) illustrate the capability of the technique for

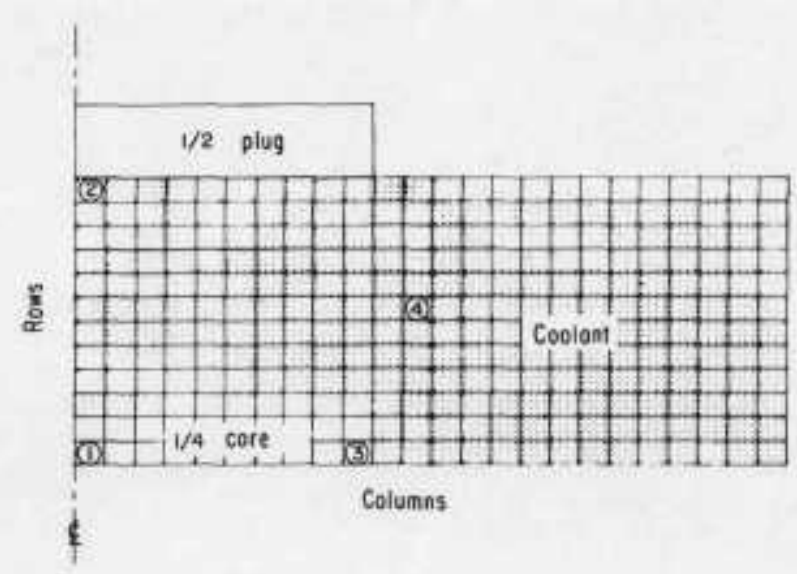

Fig. VIII.25. Configuration of the Reactor Model. ANL Neg. No. 900-660 Rev. 1. possibly accounting for coolant spillage.

The examples are based on a simplified pancake-shaped reactor model. The model consists only of a core and coolant, the initial configuration of which is shown in Fig. VIII.25. For comparison, only one-fourth of the axisymmetrical reactor is considered in the model. The left centerline corresponds to the center axis of the cylindrical reactor; the bottom boundary corresponds to the central horizontal plane dividing the core in half. The coolant in Fig. VIII. 25 is shown by means of dots; the lower left cavity represents the expanding core. All the boundaries of the model are assumed to be ideally rigid with no resistance to slip.

The initial conditions of this example are taken from the power-excursion calculation, a separate analysis, which takes the neutronics of the excursion into account. It is assumed here that at the start of this problem the neutronics have ceased and the core consists entirely of a gasified oxide core. The condition is such that the core behavior can now be represented by an equation of state, and the outside boundaries of the core have not as yet moved. The input conditions of the Lagrangian code are transformed for the Eulerian code by way of the TRANSF routine. Four Eulerian particles are assigned to each Lagrangian cell of the coolant and 16 particles to that of the core. The height and width of the Eulerian cells are made twice as large as those of the undeformed Lagrangian cells. Consequently, at the beginning, each Eulerian coolant cell contains 16 symmetrically positioned particles, and each core cell contains 64 particles.

Figure VIII. 26 shows the initial pressure and internal energy on the centerline of the model, where the first two cells pertain to the core and the rest to the coolant. These initial conditions are identical for the first eight columns of the model; those of columns 9 and 10 are also shown. Initial velocities of both the coolant and the core are taken a sero. 

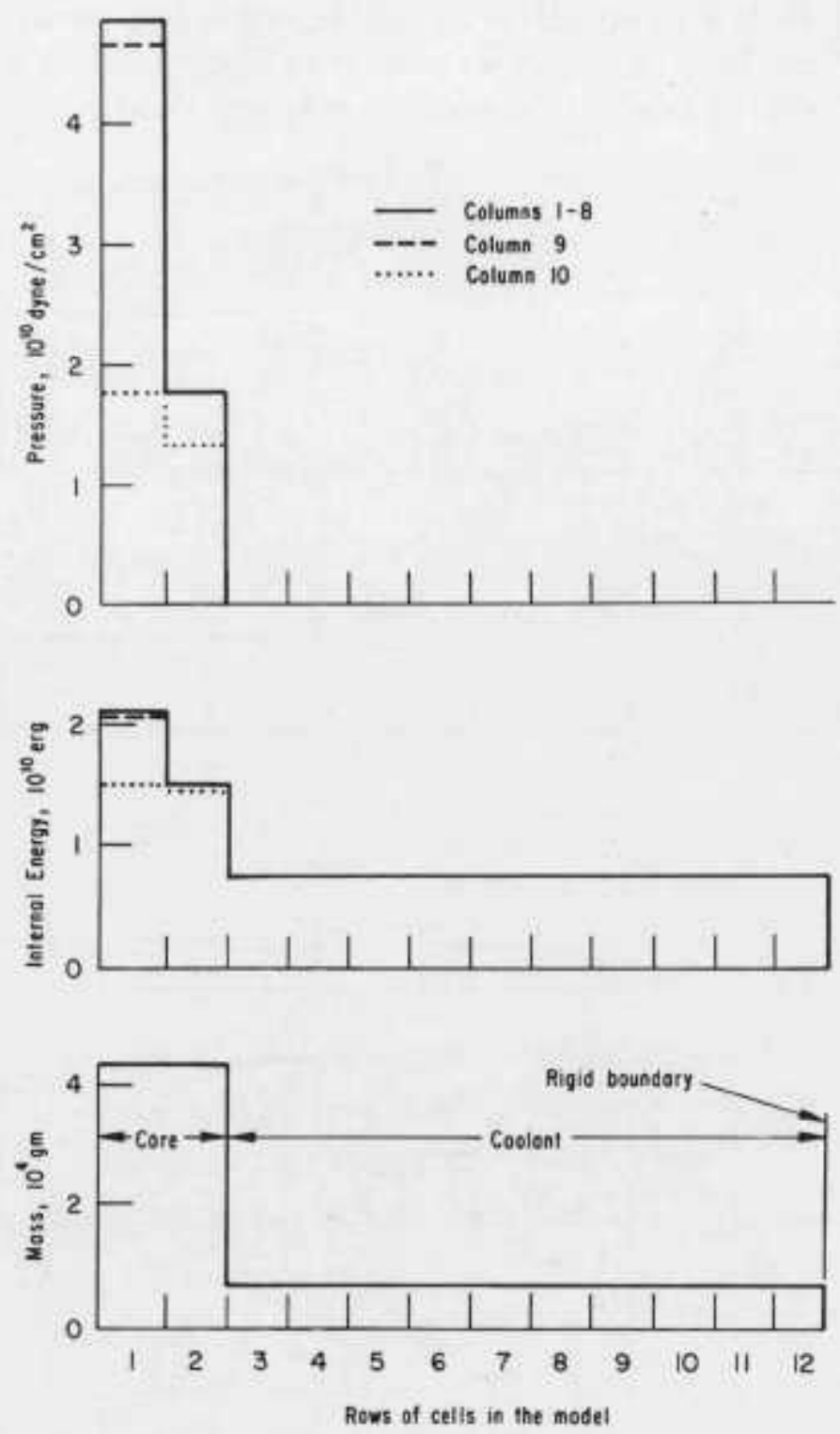

Fig. VIII.26, Initial Input Conditions of the Example. ANL Neg. No. 900-665 Rev. 1.
The movable-boundary condition of this example is not used; the reactor cover is assumed to be rigidly fixed, just like the other rigid walls.

Figure VIII. 27 shows part of one set of results; the changes of properties along the axis of the model are shown at 0.2 and $0.8 \mathrm{msec}$ during the excursion. Variations of pressure, internal energy, mass, and velocity vary from the center of the core to the reactor cover. Although the full results extend only through 1 msec, they show the shock wave traveling from the core to the reactor cover and then being reflected back.

All the characteristics of the Eulerian solution displayed are compared with the corresponding Lagrangian results. For this purpose, the Lagrangian REXCO-H code was modified by incorporating into it the TRANSF routine. The object of the TRANSF code was to convert the Lagrangian results into the form of the Eulerian output without changing the Lagrangian method of

solution. In effect, this modification would cause a superposition of the Eulerian mesh over that of the Lagrangian at specified time intervals. Then the average of the Lagrangian properties within each Eulerian cell would be calculated and given in printed output. Thus, such an Eulerian output of the Lagrangian solution would provide a very convenient means for comparison. Consequently, a smooth curve in the subsequent figures represents the Lagrangian results, while a block diagram portrays the Eulerian solution. This type of representation for the Eulerian results is used because of a rather large variation in properties from cell to cell.

Several representative cells are also selected to display certain characteristics of the solution; these are indicated in Fig. VIII. 26 and identified by numbers 1 through 4 . Point 1 represents the conditions at 
the center of the core; Point 2 is on the centerline of the reactor but on the boundary and within the coolant. Point 3 initially represents the radial outside edge on the core; Point 4 is within the coolant at a location within twodimensional flow.
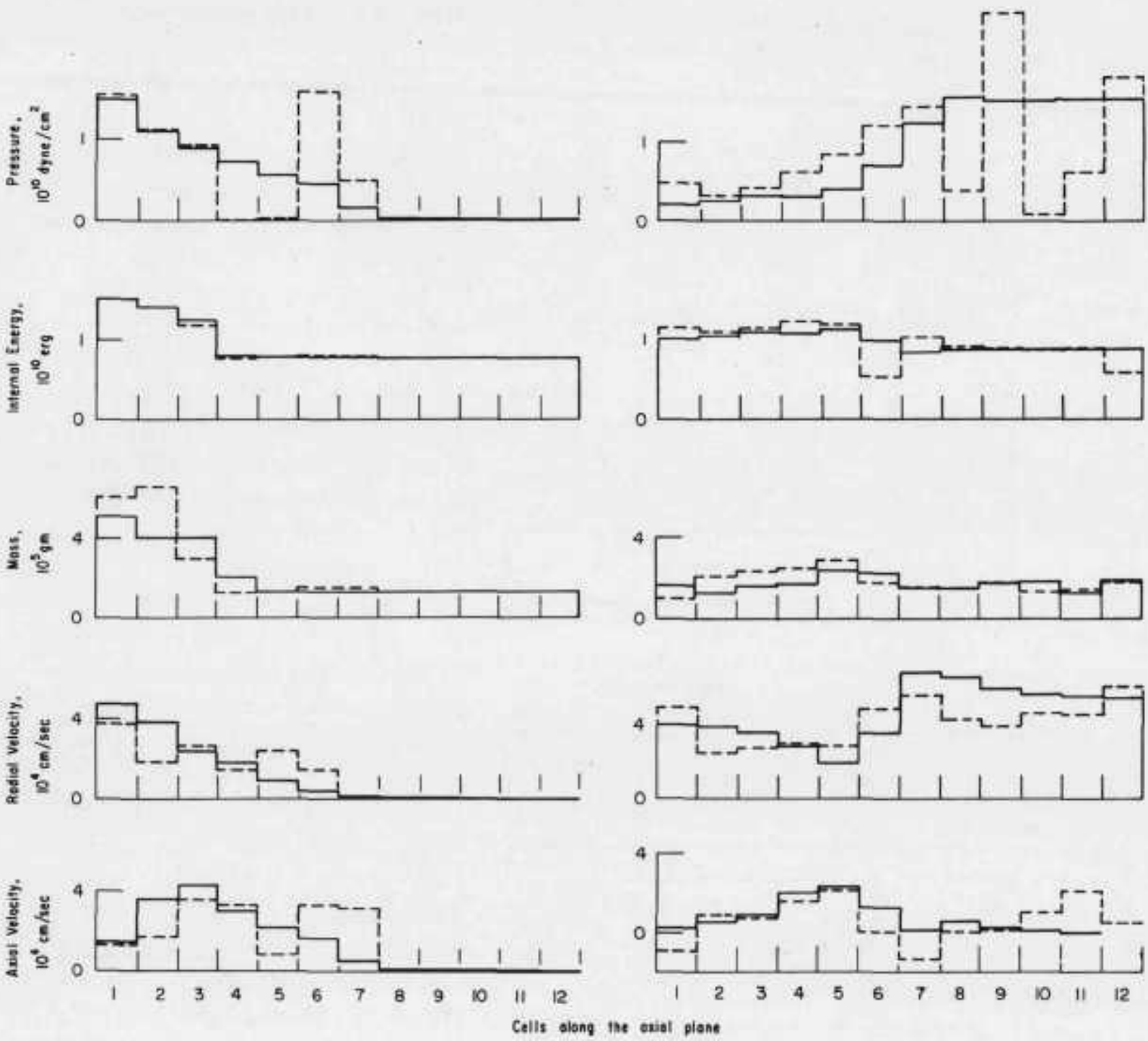

Fig. VIII.27. Variation of Properties at 0.2 (left) and 0.8 (right) msec during the Excursion. ANL Neg. No. 900-858.

Figure VIII. 28 shows the pressure history at Points 1 through 4 within $1 \mathrm{msec}$. This is a time span exhibiting the first pressure pulse on the boundary. The pressure at two points within the core (Points 1 and 3 ) do agree better with the Lagrangian solution than those within the coolant. One reason for this is the type of equation of state used, or rather the kind of material considered in the analysis. Actually, the pressure of the coolant depends to a small degree on the internal energy. Primarily, however, the stepwise Eulerian pressure distribution depends on the number of particles within the respective cells. The pressure of liquids (and solids) is 

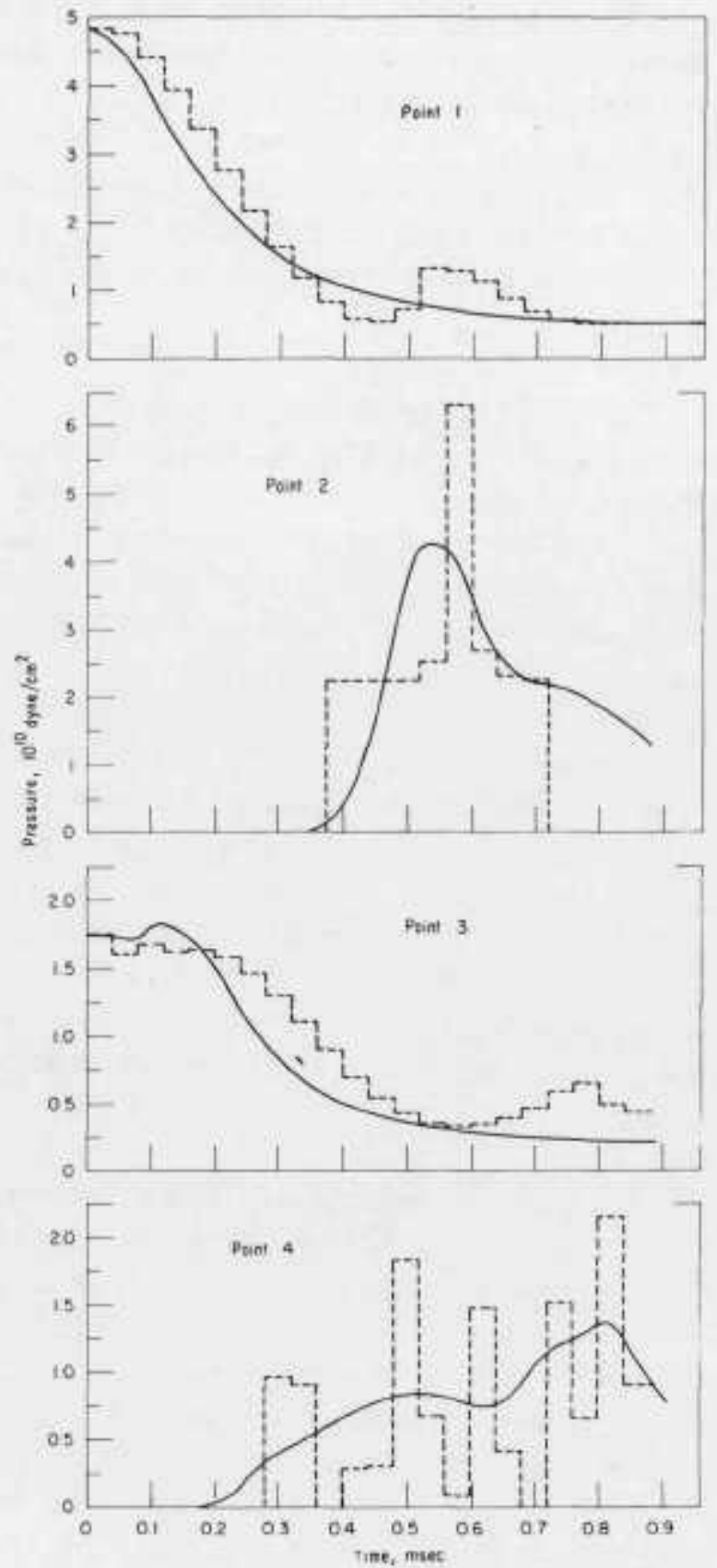

Fig. VII.28. Pressure Histories at Four Locations. ANL Neg. No. 900-661 Rev. 1. naturally much more sensitive to changes in density. Even if the configurations of the pressures due to Eulerian and Lagrangian solutions do not quite coincide, the area under the curves, representing an associated force, is fairly close. The pressure oscillations from cell to cell are transmitted subsequently to the velocities. Radial and axial velocities of Points 3 and 4 are shown in Fig. VIII. 29.

The general trend of variations in pressures and velocities at the selected locations, due to the Eulerian and Lagrangian solutions, are comparable. Areas under the respective curves or block diagrams are of the same magnitude if averaged over several cycles of calculations. When considered on an averaged basis, agreement in this rather restrictive sample calculation is not only qualitative, but to a degree also quantitative.

The time used for the comparison of results is very small. The model is also somewhat unrealistic with respect to the ideally rigid boundary conditions, as are also some of the input quantities used in the calculations. However, the intent of the sample problem is to demonstrate the performance of the technique, rather than to provide a close description of the excursion effects. The fixed boundaries create con-

ditions that effectively shorten the time of the excursion, permitting longer runs of the computer program.

To illustrate the plug movement, the reactor model shown in Fig. VIII.26 was used. Everything was assumed to be the same as in the previous sample problems, except that the plug was permitted to move under the action of the increased coolant pressure. No other restraints against motion were specified, except the mass of the plug. 

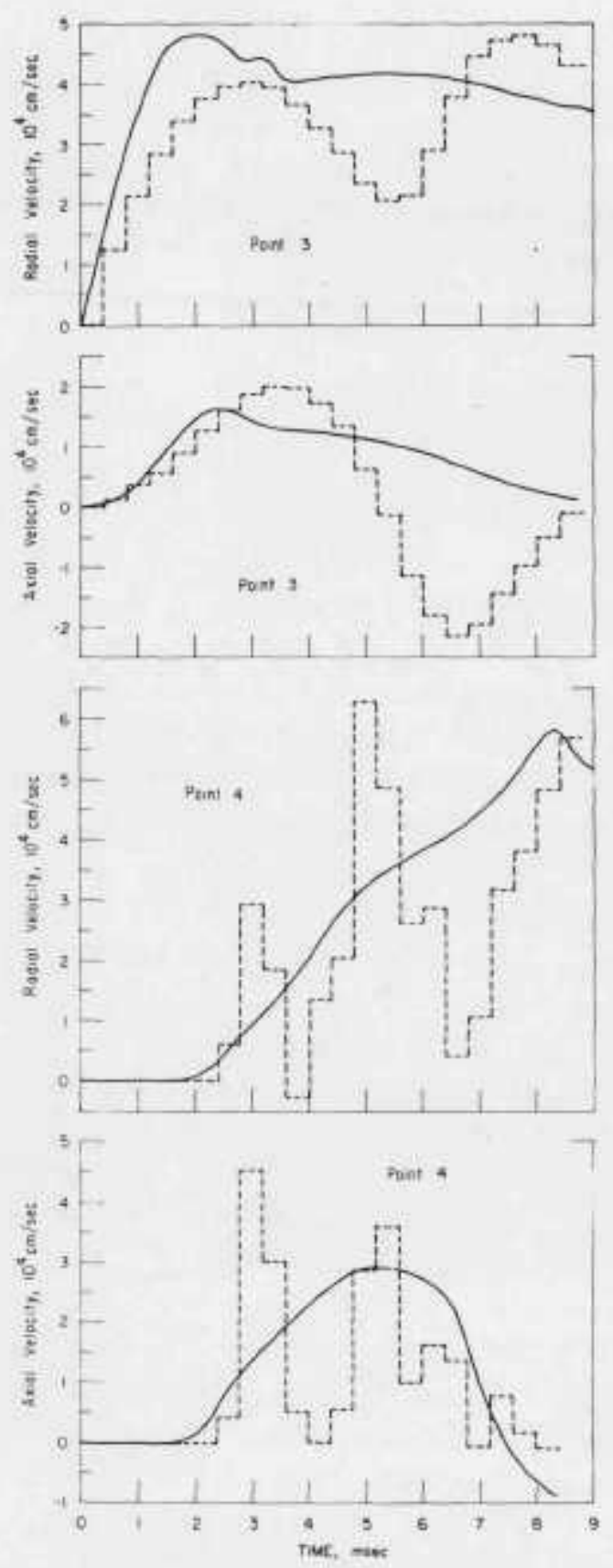

Fig. VIII.29. Velocity Histories at Points 3 and 4. ANL Neg. No. $900-662$ Rev. 1.
The results are shown in Fig. VIII. 30. This solution is particularly characterized by a noticeable oscillation of the fluid particles adjacent to the movable boundary. Undoubtedly, this is due to the stepwise movement of the plug combined with a conditional particle reflection back from the boundary.

One difficulty in the movableboundary condition is due to the formation of particle clusters. This takes place in the fluid-impact situation where the boundary is moving and the impinging particles are reflected back into the compressedflow region. Thus the regular procedure might place the reflected particles over the adjacent particles, or might even project them farther back into the body of the oncoming flow. Once the coordinates of two or more particles are the same or nearly so, both become inseparable from that point on. As a result, once the fluid has been "compressed" in this manner, the regular method of the analysis is unable to separate the distinct particles from one another.

Such a procedure of excessive reflection contradicts the physical behavior of the fluid in the impact situation. The obviously faulty mechanics of the technique are due to the complete freedom for the reflected particles to enter the interior of the fluid in the back. A remedial procedure should restrain the reflected particles from passing the particles of the impinging fluid. In this way, the integrity of the entire fluid body would be retained.

One possibility of correcting the procedural fault would be by devising a special reflective formulation in the fluid-impact situation. Such a formulation would seek to render the particle overlap impossible, or at least decrease the probability. Some attempts along this line have already been made without significant success. Different particle-weighting techniques also might be attempted. Another possibility might be the redistribution of particles whenever such an overlapping has taken place. This would be accomplished by subdividing the superimposed particles and 
Time $=0.6040 \mathrm{msec}$
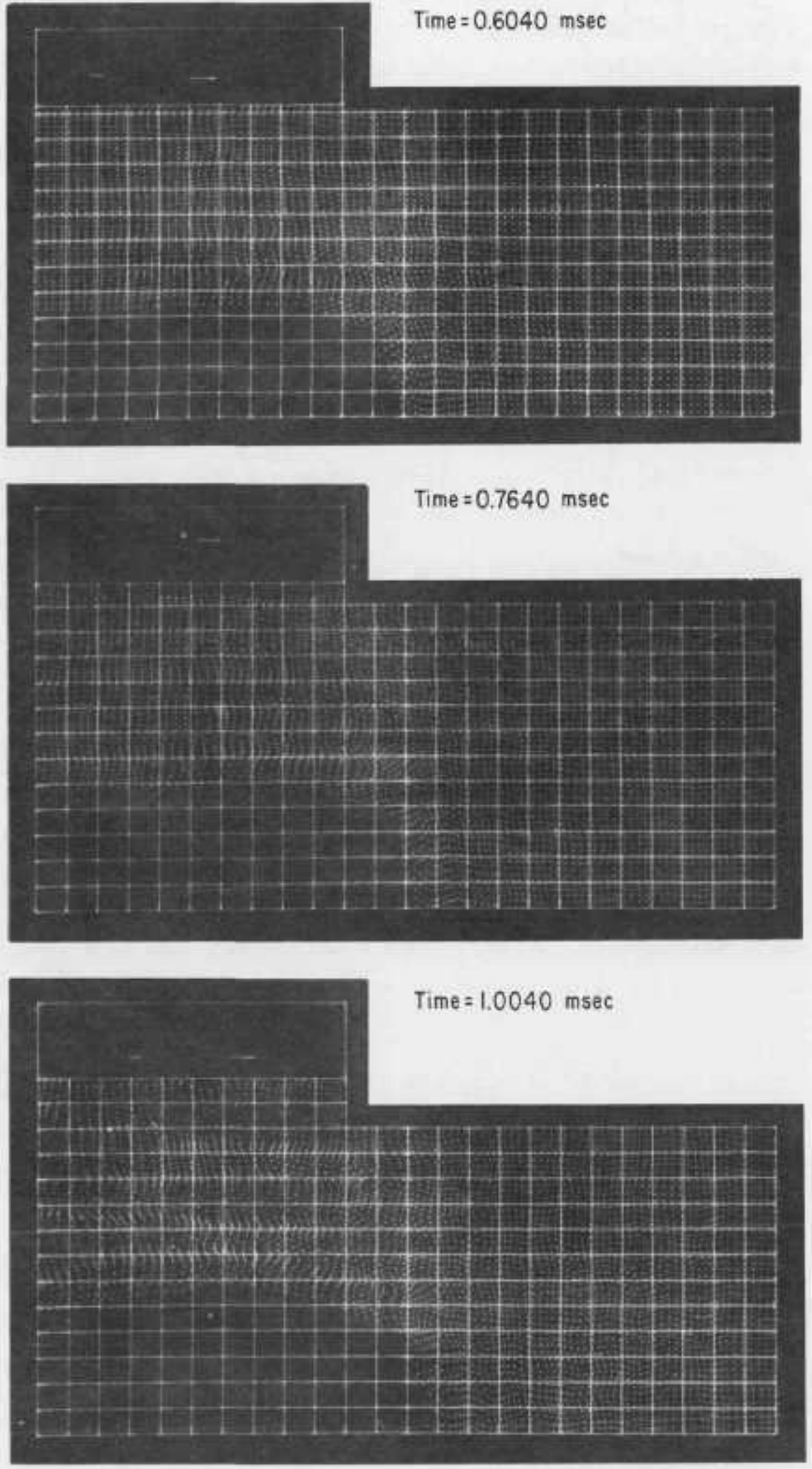

Fig. VIII.30. Motion of the Reactor Cover 
positioning the new ones in opposite directions; however, this would not, in itself, help eliminate the cause of the difficulty. Numerical techniques of the search type might be used, but they would extend the computer time.

The performance of the assumed pressure boundary condition is also shown in Fig. VIII.31. In this case, the number of particles of fluid in direct contact with the plug has been increased, while the total mass is preserved. Instead of one previous particle, five have been created to represent the given volume of fluid. The particles were staggered so that equal distances between successive rows and columns were maintained. This increase in particles should reduce the total mass transfer from cell to cell at a given time, thereby improving the stability of the solution. Figure VIII. 31 clearly indicates the overlap problem that appears as a band of particles below the plug. Further examination of this effect needs to be made to evaluate fully the consequences of the results. Remedies for the present techniques will be sought to make possible a reasonable solution of the impact problem.

Spillage of coolant to the outside of primary containment is shown by extending the plug-jump solution to a time when an assumed opening in the primary containment takes place. The results of the sample solution are shown in Fig. VIII.32. The sample solution with the magnified number of particles was chosen for illustrative purposes, but the greater the number of particles, the finer will be the resolution of coolant spillage.

The perturbation of the coolant displayed by Fig. VIII. 32 is a subject of some concern. Apparently, this part of the solution is not quite correct. Although the corresponding quantitative results are not to be relied on, the illustrations serve well in displaying coolant spillage. Continuous inventory of the fluid mass spilled can be maintained in the code by monitoring the particles crossing a given opening.

The study of fluid spillage depends on the size of the individual particles. Each particle is associated with a certain quantity of mass, so the spillage would be of quantized nature. Thus spillage calculation accuracy depends on the accuracy with which we know the mass of these individual particles.

Superficial comparison of the Eulerian and Lagrangian results shows some agreement. Pressure and velocity magnitudes at selected locations, when considered on an averaged basis, agree reasonably well when compared with results from a Lagrangian solution.

The results also indicate the difficulties involved in treating confined-fluid excursions. Instabilities of the method are detrimentally restrictive in such solutions when extended in time. This conviction is also based on many other solutions, similar to the above, where variables such 

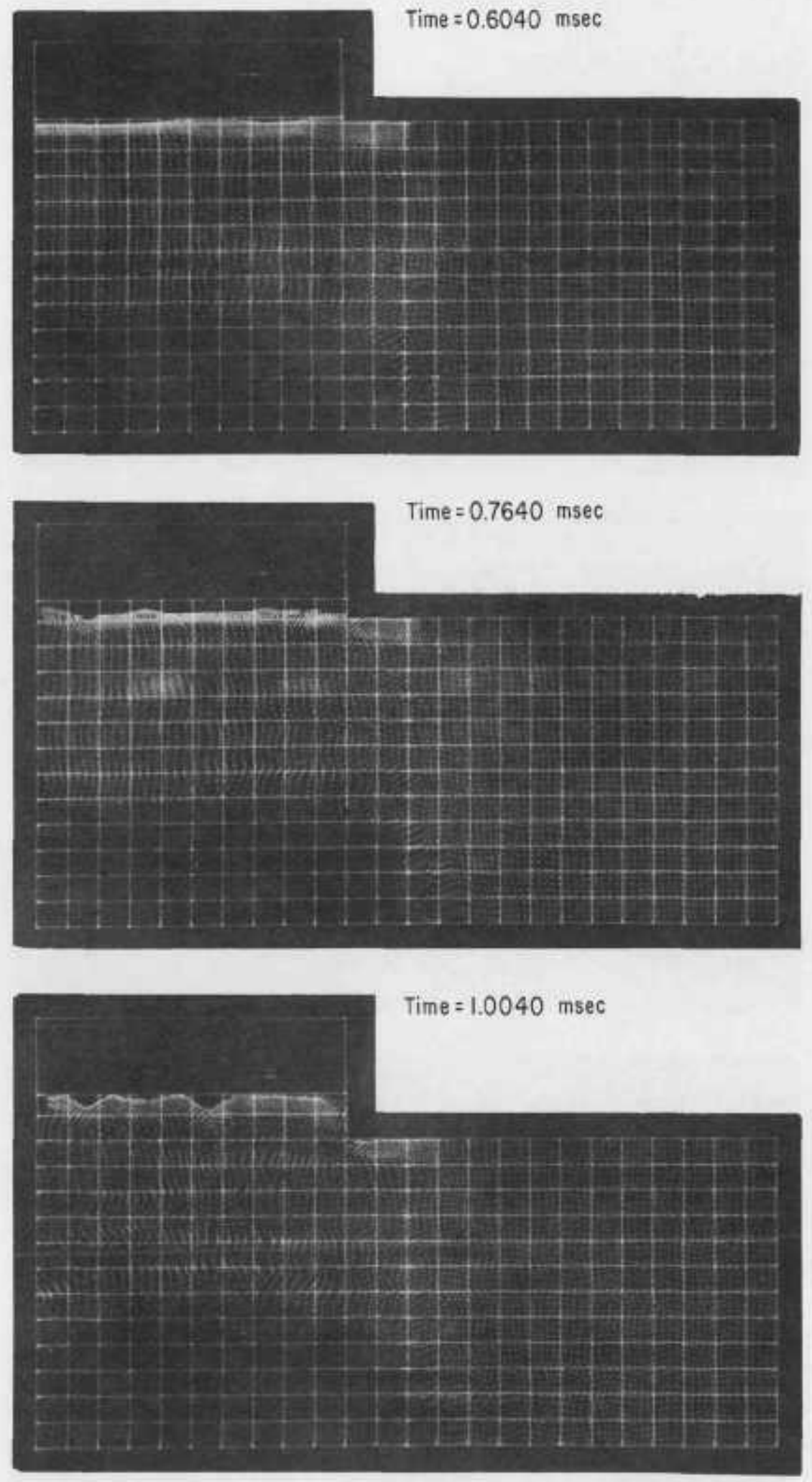

Fig. VIII.31. Effect of Cover Movement due to Increased Number of Particles 

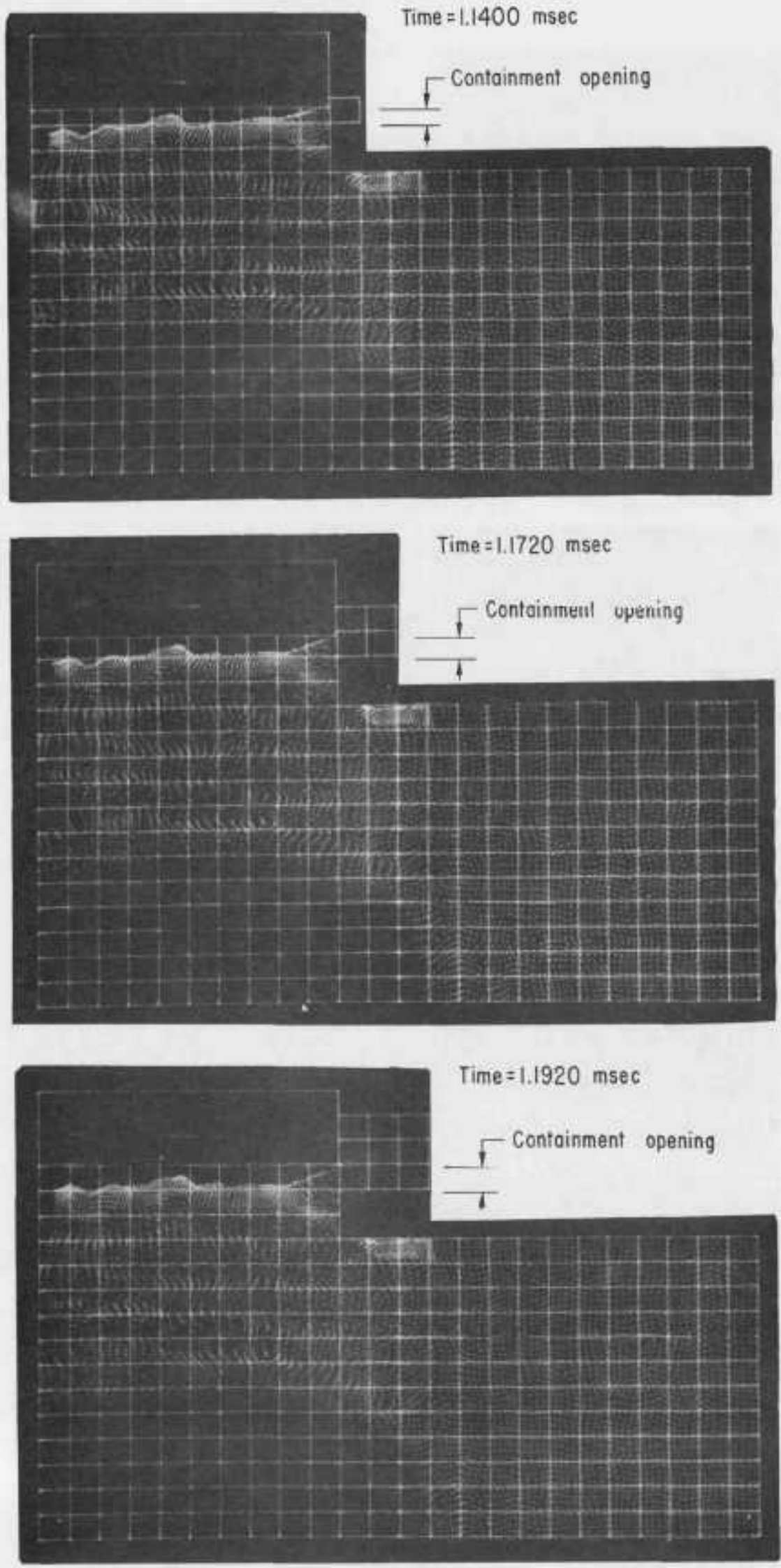

Fig. VIII.32. Display of Possible Coolant Spillage 
as the time increment have been varied. In fact, the time step was reduced to an incredibly low value without a noticeable improvement of the stability of the present example.

Correction of the particle superposition in the fluid-impact situation would also expend additional effort. Although this difficulty might not be insurmountable within the present method, the approach can be changed altogether. The problem of particle superposition is inherent in the discrete-element character of the method itself. Other hydrodynamic techniques treating the fluid as continuous should not be subject to this disadvantage.

The analysis of reactor containment using ideally rigid boundaries is not very realistic. Furthermore, flow within confined boundaries seems to yield excessive instabilities. Therefore, incorporation of a thin vessel into the code is essential.

\section{PUBLICATIONS}

DBLSCAT, A Computer Code for Double-scattering Corrections

A. K. Agrawal, S, G. Das, and F. M, Mueller ANL-7780 (Feb 1971)

Size Distribution of Bubbles Emitted from Simulated Cladding Breaks

R. P. Anderson, L. Bova, and C. J. Roop ANL-7789 (Mar 1971)

Methods of Planning Generating Unit Operation

S. W. Anderson, * R. T. Jenkins,** D. Joy, ${ }^{\dagger}$ E. T. Merril, ${ }^{+}$and

T. D. Wolsko

Proc. Am. Power Conf., Vol. 32, Ill. Inst. Technol., Am. Power Conf., Chicago, 1970, pp. 123-130

Stability of Liquid Flow Down a Heated Inclined Plane

S. G. Bankoff

Int. J. Heat Mass Transfer 14, 377-385 (1971)

SASlA, a Computer Code for the Analysis of Fast-reactor Power and Flow Transients

J. C. Carter, G. J. Fischer, T. J. Heames, D. R. MacFarlane,

N. A. McNeal, W. T. Sha, C. K. Sanathanan, and C. K. Youngdahl ANL-7607 (Oct 1970)

\footnotetext{
* Commonwealth Edison Co.

**Tennessee Valley Authority.

†ok Ridge National Laboratory.

+ Pacific Northwest Laboratory.
} 
A Study of Coolant Transients during a Rapid Fission-gas Release in a Fast-reactor Subassembly

T. C. Chawla and B. M. Hoglund ANL-7651 (Jan 1971)

Fuel Dynamics Experiments on Fast Reactor Oxide Fuel Performance under Transient Heating Conditions Using the TREAT Reactor

C. E. Dickerman, L. W. Deitrich, L. E. Robinson, A. B. Rothman, and J. C. Carter

Trans. Am. Nucl. Soc. 14(Suppl. 1), 28 (Apr 1971) Abstract

Discussion: Velocity of Sound and Critical Discharge Pressure in Annular Two-Phase Flow

H. K. Fauske and M. A. Grolmes

Fluid Mechanics and Measurements in Two-Phase Flow Systems, Inst. Mech. Eng. Proc. 184(Part 36), 235 (1971)

The Slug Expulsion of Freon-113 by Rapid Depressurization of a Vertical Tube

W. D. Ford, H. K. Fauske, and S. G. Bankoff* Int. J. Heat Mass Transfer 14, 133-140 (1971)

Discussion: Some Experiments on Sonic Velocity in Two-Phase OneComponent Mixtures and Some Thoughts on the Nature of Two-Phase Critical Flow

M. A. Grolmes and H. K. Fauske

Fluid Mechanics and Measurements in Two-Phase Flow Systems, Inst. Mech. Eng. Proc. 184(Part 36), 235 (1971)

Space-dependent Transfer-function Analysis of Large Nuclear-reactor Power Systems

L. J. Habegger and C. Hsu

ANL-7788 (Mar 1971)

Pressure-pulse Propagation in Two-phase One- and Two-component Mixtures

R. E. Henry, M. A. Grolmes, and H. K. Fauske ANL-7792 (Mar 1971)

Speed of Sound in Liquid Sodium to $1000^{\circ} \mathrm{C}$

L. Leibowitz, M. G. Chasanov, and R. A. Blomquist

J. Appl. Phys. 42, 2135-2137 (Apr 1971)

Enthalpy of Liquid Uranium Dioxide to $3500 \mathrm{~K}$

L. Leibowitz, M. G. Chasanov, L. W. Mishler, and D. F. Fischer J. Nucl. Mater. 39, 115-116 (1971) Letter

\footnotetext{
*Dept, of Chemical Engineering, Northwestern University.
} 
Instrumentation Systems to Protect LMFBR Core Integrity

W. C. Lipinski, C. E. Cohn, D. R. MacFarlane, T. P. Mulcahey,

D. Okrent, K. G. Porges, W. C. Redman, J. B. Van Erp, and

R. H. Vonderohe ANL-7793 (Mar 1971)

VENUS: A Two-dimensional Coupled Neutronics-Hydrodynamics Computer Program for Fast-reactor Power Excursions

W. T. Sha and T. H. Hughes ANL- 7701 (Oct 1970)

An Integrated Model for Analyzing Disruptive Accidents in Fast Reactors W. T. Sha and A. E. Waltar* Nucl. Sci. Eng- 44, 135-156 (May 1971)

Fuel Element Deformation Model for Fast Reactor Accident Study Code C. K. Youngdahl Nuc1. Eng. Design 15(2), 149-186 (1971)

\footnotetext{
*Hanford Engineering Development Laboratory.
} 
8.52 


\section{ENVIRONMENTAL STUDIES}

\section{A. Thermal-plume Dispersion Studies.}

B. Hoglund (02-166)

1. Sinking-plume Experiment. B. Hoglund and G. P. Romberg (Last reported: ANL-7798, p. 143)

On March 11 and 12,1971, 11 temperature recorders were placed on the bottom of Lake Michigan near the outfall from the Point Beach Nuclear Generating Plant at Point Beach, Wisconsin, to measure water temperature on the lake bottom to determine the degree to which the water might be heated as a result of a sinking thermal plume.

On May 13, 1971, the 11 temperature recorders were recovered after the positions of the recorders were determined from sightings by two surveyor's transits located on the shore. The buoys originally attached to the temperature-recorder anchors were still intact, although several of them were damaged.

While on the lake bottom, the diver described bottom conditions, visibility, anchor positions, and biological conditions. Seven of the anchors were sitting flat on the bottom; four anchors were sitting at angles up to $15^{\circ}$ in relation to the lake bottom. Several of the subsurface buoys and buoy lines were coated with periphyton. The diver recovered a sample sculpin from the bottom near temperature recorder No. 243 and a sample dead smelt from the bottom near temperature recorder No, 366.

On May 14, the temperature-recorder casings were opened and the strip charts for recording temperatures were removed. A preliminary examination of the data indicated that only five of the recorders functioned properly for the entire length of the experiment, three of the recorders functioned properly for part of the experiment, and three recorders failed to give any results. Of the six recorders that did not operate properly for the full two months, one failure was due to battery leakage while the other recorders' failures appeared to be due to faulty timing mechanisms.

\section{B. Mass/Energy Balance of the Great Lakes. B. Hoglund $(02-184)$}

1. Thermal-discharge Effect on Stratification. J. G. Asbury (Not previously reported)

The annual stratification cycle of deep lakes in the temperate zone is a well-documented phenomenon. The process is generally attributed to the interaction between turbulence and buoyancy fields, which are established in deep lakes as a result of wind mixing and surface heat exchange. 
Sundaram et al. applied three methods to estimate the effects of the proposed Bell Station discharge on the period of stratification of Cayuga Lake.* The three methods are based upon a calculated average annual increase of $0.7^{\circ} \mathrm{F}$ in lake surface temperature and upon the associated modifications in: (1) the Monin-Obukhov length, (2) the lakewide stability of stratification, and (3) the relationship between bulk Richardson Number and the vertical decay of eddy diffusivity. The authors emphasized that the three methods are equivalent, and using each method, they found that the advance of the onset of spring stratification in Cayuga Lake is from four to five days. The end of stratification in late fall was estimated to be postponed from four to five days.

Using a method slightly different from those of Sundaram et al., we have estimated the change in the period of stratification of Lake Michigan. The method is based upon the assumption that an increase in lakewide surface temperature due to thermal discharges is equivalent to a temporal advance of the annual heating cycle during the warming season and to a retardation during the cooling season. The vertical temperature distribution and, therefore, the process of stratification are assumed to "track" the surface temperature.

The advance of the stratification of Lake Michigan, therefore, can be estimated from Church's** observed rate of increase of surface temperature during May and June $\left(0.3^{\circ} \mathrm{F} /\right.$ day) and from Asbury's calculated increase in surface temperature due to thermal discharges $\left(1.4 \times 10^{-3 \circ} \mathrm{F} / \mathrm{GW}\right)$. These values lead to an advance of the onset of stratification of 6 min per gigawatt increase in thermal discharge rate. Due to the nearly symmetrical shape of the surface-temperature curve, the postponement of the end of stratification is very nearly equal to the advance of the beginning of stratification. The period of stratification, therefore, is estimated to be increased $12 \mathrm{~min}$ per gigawatt increase in thermal-discharge rate. This value is consistent with those which can be obtained using any one of the three methods of Sundaram et al.

The projected rate of discharge to Lake Michigan in the year 2000 has been estimated as $65 \mathrm{GW}^{+}$This rate of discharge would lead to an increase in the period of stratification of Lake Michigan of approximately one-half day.

*T. R, Sundaram, C. C. Easterbrook, K. R. Piech, and G. Rudinger, An Investigation of the Physical Effects of Thermal Discharges into Cayuga Lake, Cornell Aeronautical Laboratory. Inc., J'T 2616-0-2 (Nov 1969).

**P. E. Church, The Annual Temperature Cycle of Lake Michigan--Spring Warming and Summer Stationary, Petiods, 1942, The University of Chicago Misc. Report No. 18 (1954).

T. G. Asbury, Effects of Thermal Discharges on the Mass/Energy Balance of Lake Michigan, ANL/ES-1 (July 1970). 
PUBLICATION

A Phenomenological Relationship for Predicting the Surface Areas of Thermal Plumes in Lakes

J. G. A sbury and A, A. Frigo

ANL/ES-5 (Apr 1971)

PUBLICATION--General

Chemical Engineering Division Research Highlights; JanuaryDecember 1970

ANL- 7750 
